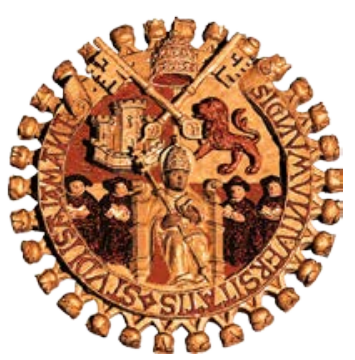

UNIVERSIDAD DE SALAMANCA

FACULTAD DE FILOLOGÍA

DEPARTAMENTO DE LENGUA ESPAÑOLA

TESIS DOCTORAL

\title{
EL DESARROLO DE LA COMPETENCIA PRAGMÁTICA: APROXIMACIÓN AL ESTUDIO DEL PROCESAMIENTO PRAGMÁTICO DEL LENGUAJE
}

\author{
Susana Verde Ruiz
}

Director: Dr. D. Emilio Prieto de los Mozos

Salamanca, 2015 



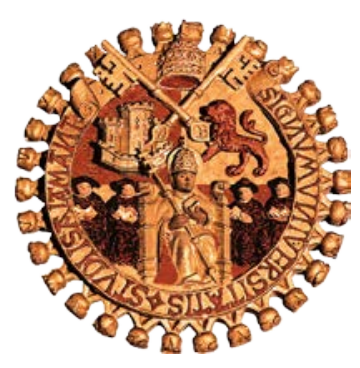

\section{UNIVERSIDAD DE SALAMANCA}

FACULTAD DE FILOLOGÍA

DEPARTAMENTO DE LENGUA ESPAÑOLA

TESIS DOCTORAL

\section{EL DESARROLO DE LA COMPETENCIA PRAGMÁTICA: APROXIMACIÓN AL ESTUDIO DEL PROCESAMIENTO PRAGMÁTICO DEL LENGUAJE}



A la memoria de Serafín Verde 



\section{AGRADECIMIENTOS}

Tras finalizar un trabajo tan arduo como es la elaboración de una tesis doctoral es el momento de echar la vista atrás y recordar a todas aquellas personas que lo han hecho posible. Me gustaría que estas líneas sirvieran para expresar mi agradecimiento por su ayuda y apoyo a lo largo de estos años.

En primer lugar, quiero expresar mi más profunda gratitud a mi director, Emilio Prieto de los Mozos, por su paciencia y confianza, su dedicación y consejos inestimables, no solo en el desarrollo de esta tesis, sino también en mi formación como docente.

Quiero agradecer también a todos los miembros del Departamento de Lengua Española de la Universidad de Salamanca sus aportaciones, su apoyo y su colaboración, muy especialmente a Noemí Domínguez García y a Carmen Fernández Juncal, por su ayuda y confianza, y a Luis Santos Río, por su dedicación y cariño.

También quisiera hacer extensiva mi gratitud a Eeva Leinonen por su amabilidad y disponibilidad durante mi estancia en la Universidad King's College de Londres, y a Soile Loukusa, de cuyo trabajo he tomado el modelo de cuestionario y los dibujos.

Un agradecimiento muy especial a los colegios C.P. José Herrero (Salamanca) y C.P. Santa $\mathrm{M}^{\mathrm{a}}$ de la Candelaria (Zamora), donde llevé a cabo el reclutamiento de la muestra infantil y donde realicé las entrevistas. A los niños y niñas de 3 a 9 años escolarizados en estos centros les agradezco que hayan participado en el estudio. De cada uno de ellos he aprendido cosas y esta experiencia ha supuesto un enriquecimiento personal incomparable al conocimiento que se encuentra en los libros.

A mi familia, principalmente a mis padres, porque han sido fuente de apoyo constante e incondicional. Sin su ayuda no hubiera sido posible esta tesis. Muchas gracias por todo lo que me habéis dado y por confiar en mí, y especialmente por enseñarme a luchar por lo que quiero y a terminar lo que he empezado.

A mis compañeros Carmela y Álvaro con quien he compartido preocupaciones y alegrías desde que empezamos la carrera. Aunque hemos emprendido distintos caminos, sé que 
siempre estáis ahí. A Pedro, Javi y Carla, por esos cafés y pinchos en los que he encontrado consejos, apoyo y ánimo en esos momentos en que no sabes por dónde seguir.

A mis amigos, los de toda la vida, los que conocí en Salamanca y ahora forman parte de mi familia y a los que he tenido la suerte de conocer estos últimos años, gracias por apoyarme con vuestro cariño.

Por último, gracias a Fer. Ha sido un camino largo y difícil, lleno de altibajos, y tú siempre has estado ahí al pie del cañón dándome apoyo y motivación para seguir adelante. Gracias por creer en mí y por estar a mi lado.

A todos,

Gracias. 


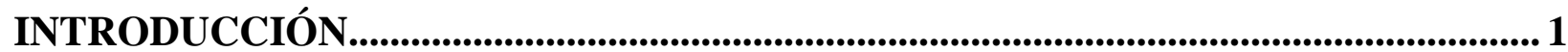

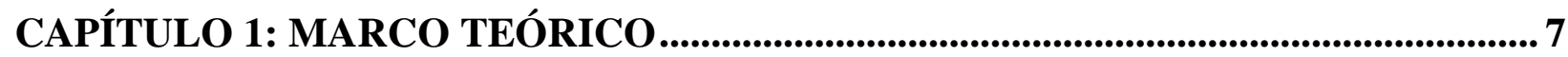

1.1 LA PRAGMÁTICA COMO PUNTO DE PARTIDA ………………………………...... 7

1.1.1 La noción de pragmática en el ámbito teórico ………………………………………..... 7

1.1.2 El objeto de estudio de la pragmática........................................................................... 14

1.2 CONTEXTO Y COMUNICACIÓN LINGÜÍSTICA ......................................................... 19

1.3 LA TEORÍA DE LA RELEVANCIA COMO INSTRUMENTO DE ANÁLISIS ........... 28

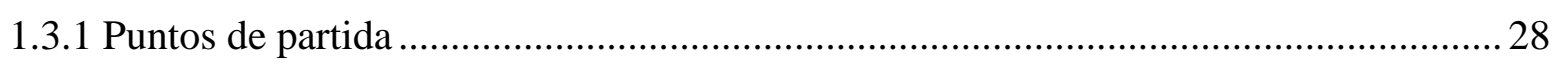

1.3.2 Los mecanismos de codificación/descodificación y de ostensión/inferencia ............... 30

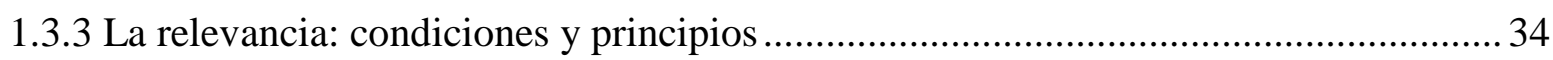

1.3.4 La aplicación de la teoría de la relevancia al estudio de la comunicación verbal......... 40

CAPÍTULO 2: HACIA LA NOCIÓN DE COMPETENCIA PRAGMÁTICA................ 47

2.1 CONOCIMIENTO Y HABILIDAD PARA EL USO DE LA LENGUA ........................... 47

2.1.1 El concepto de competencia comunicativa ..................................................................... 47

2.1.2 La distinción entre competencia y actuación ................................................................ 54

2.1.3 La competencia pragmática en los modelos de competencia comunicativa ................. 59

2.2 DISTINTAS APROXIMACIONES AL ESTUDIO DE LA COMPETENCIA

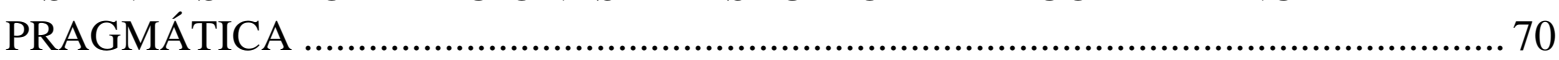

2.2.1 La competencia pragmática en el ámbito teórico …………………………………....... 70

2.2.2 La competencia pragmática y la enseñanza/aprendizaje de lenguas extranjeras .......... 74

2.2.3 La competencia pragmática y la didáctica de la lengua materna ................................... 98

CAPÍTULO 3: LA COMPETENCIA PRAGMÁTICA EN EL PROCESO DE ADQUISICIÓN DE LA LENGUA .............................................................................. 109

3.1 LA ADQUISICIÓN DEL LENGUAJE. EL ENFOQUE PRAGMÁTICO...................... 109

3.1.1 Introducción al nacimiento y desarrollo de los estudios de adquisición del lenguaje 109

3.1.2 Aproximación pragmática a la adquisición de la lengua............................................... 114

3.2 BASES PARA EL DESARROLLO DEL COMPONENTE PRAGMÁTICO................. 126

3.2.1 La importancia del contexto .............................................................................. 126

3.2.2 Factores que posibilitan el desarrollo de la competencia pragmática ..........................129

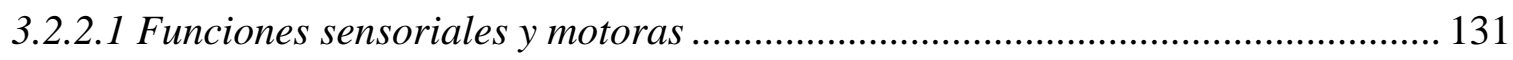

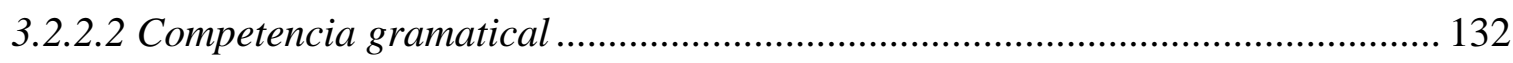

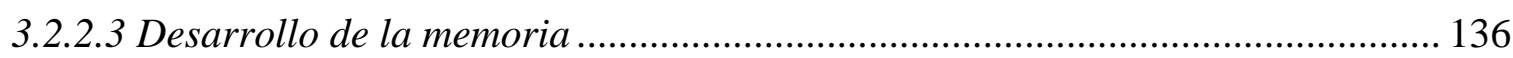

3.2.2.4 Desarrollo de la atención.................................................................................... 137 
3.2.2.5 Conocimiento del mundo y propia experiencia.................................................. 139

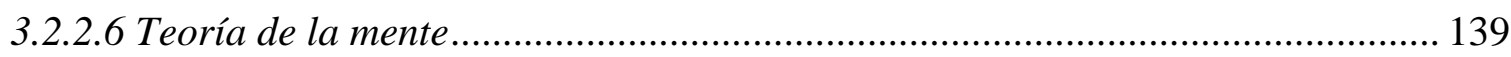

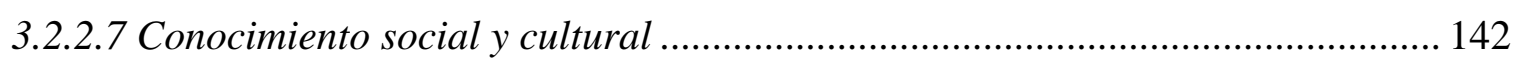

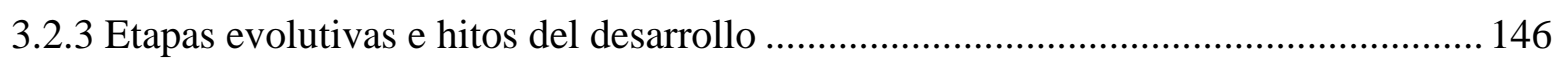

3.2.4 Procesamiento del lenguaje: la neurolingüística ..................................................... 151

3.3 APROXIMACIÓN COGNITIVA A LA COMPRENSIÓN PRAGMÁTICA DEL

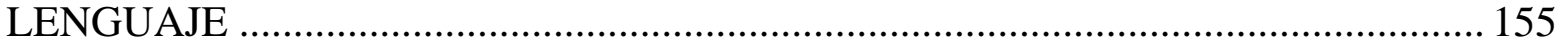

3.3.1 Relevancia: procesos cognitivos y comunicación................................................... 155

3.3.2 Tareas pragmáticas en el proceso de comprensión ................................................. 159

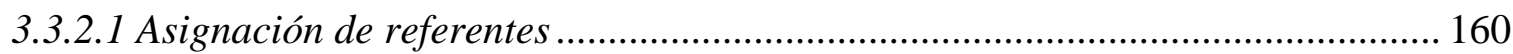

3.3.2.2 Proceso de enriquecimiento pragmático............................................................ 162

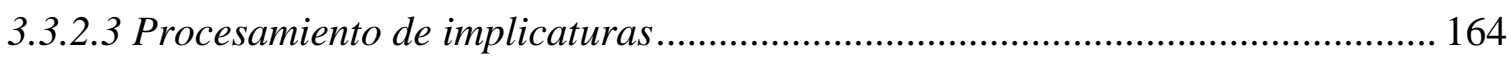

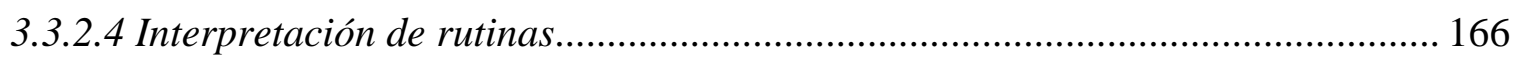

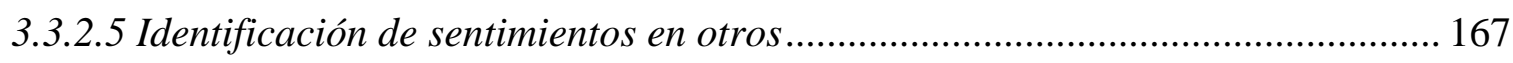

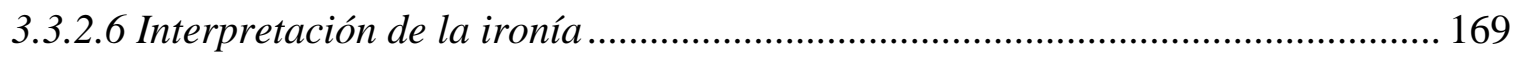

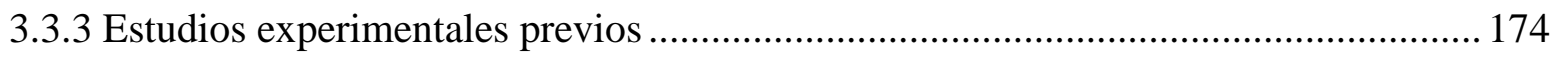

CAPÍTULO 4: DÉFICITS EN LA COMPETENCIA PRAGMÁTICA......................... 179

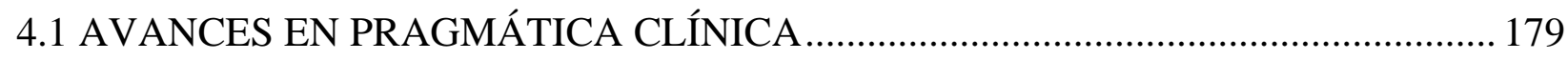

4.2 EL PAPEL DE LA PRAGMÁTICA EN LAS ALTERACIONES COMUNICATIVAS ... 184

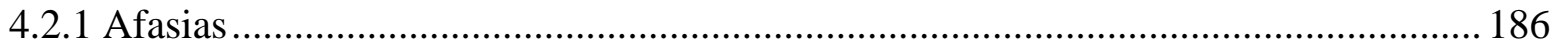

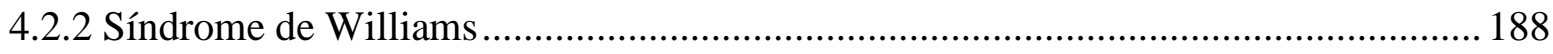

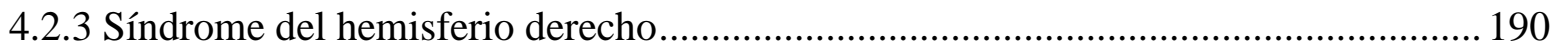

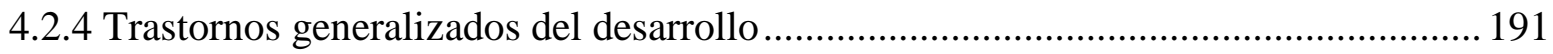

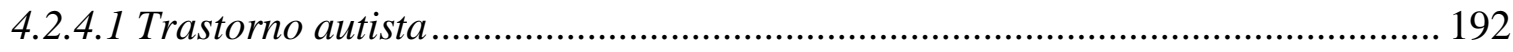

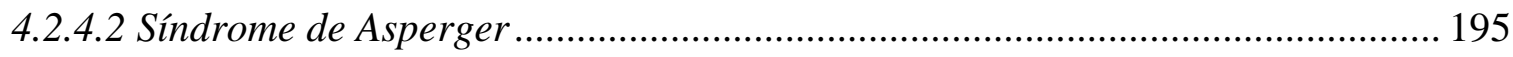

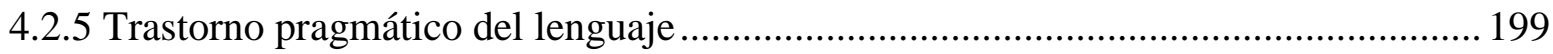

4.3 PRUEBAS PARA LA EVALUACIÓN DE LA COMPETENCIA PRAGMÁTICA.... 201

4.4 DÉFICITS EN LA ADQUISICIÓN PRAGMÁTICA Y RELEVANCIA ..................... 211

CAPÍTULO 5: ESTUDIO EXPERIMENTAL SOBRE EL DESARROLLO DE LA COMPRENSIÓN PRAGMÁTICA DEL LENGUAJE ....................................... 217

5.1 OBJETIVOS Y JUSTIFICACIÓN DE ESTE TRABAJO ......................................... 217

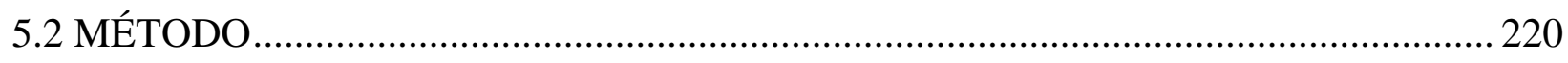

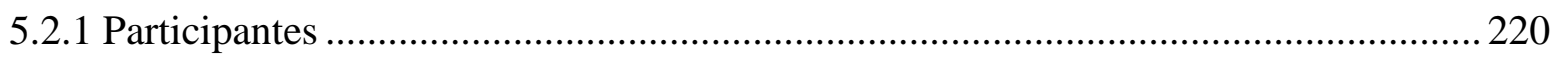

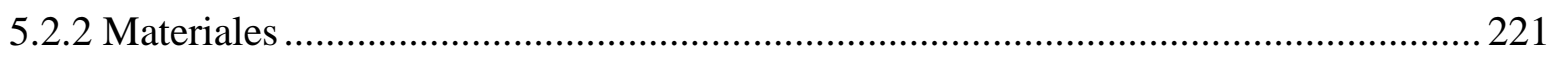

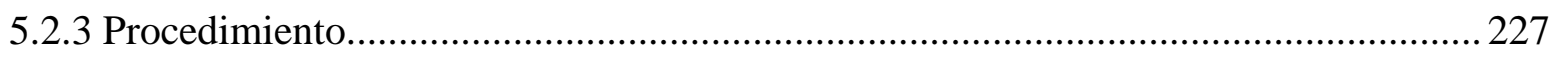

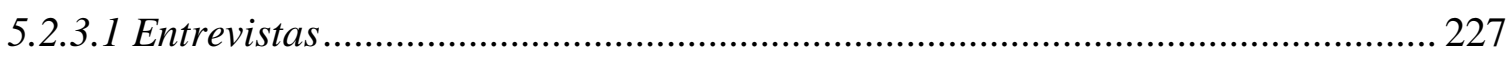




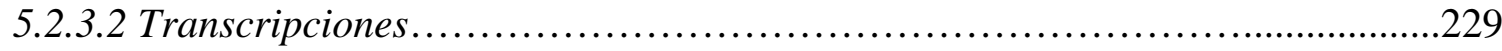

5.2.3.3 Recuento de respuestas válidas/fallidas........................................................... 232

5.3 ANÁLISIS ESTADÍSTICO DE LOS RESULTADOS............................................... 233

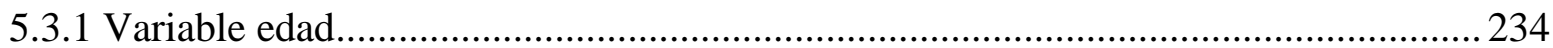

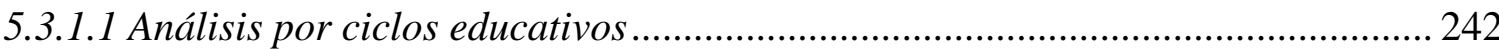

5.3.1.2 Distribución de la variable respuestas/explicaciones válidas en los distintos

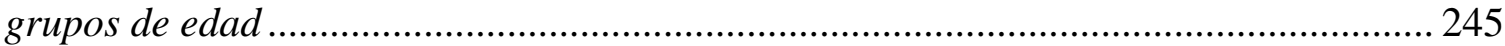

5.3.1.3 Relación entre respuestas y explicaciones válidas ............................................. 253

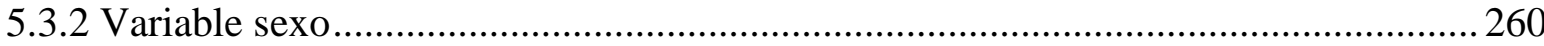

5.3.3 Variable tipo de contexto (visual/no visual) .......................................................... 262

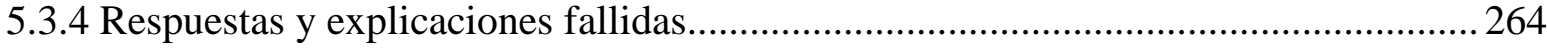

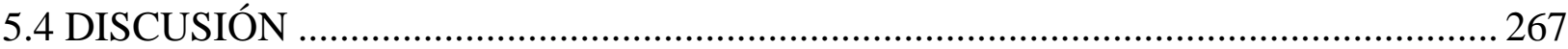

CAPÍTULO 6: CONCLUSIONES .............................................................................................. 283

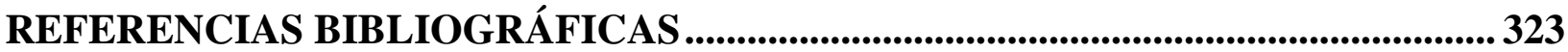

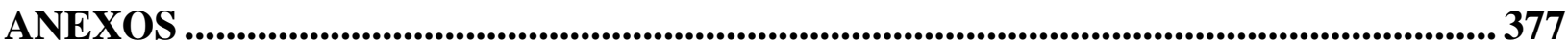

-Transcripciones completas en CD adjunto 



\section{INTRODUCCIÓN}

La competencia pragmática es uno de los componentes que integran la competencia comunicativa (Canale y Swain, 1980; Bachman, 1990; Celce-Murcia et al., 1995; Cenoz y Valencia, 1996, etc.), y se considera esencial en la comunicación intercultural y en la adquisición de lenguas extranjeras (Bouton, 1996; Kasper, 2001; Gómez Morón et al., 2009; Aquino, 2011). Sin embargo, la escasa reflexión teórica sobre el concepto de competencia pragmática ha propiciado que a menudo se use como cajón de sastre en el que se incluye el conjunto de habilidades que no encajan —o encajan mal — dentro de las denominadas competencias organizativas (la competencia gramatical y la competencia textual, según Bachman, 1990). Es en parte natural: la misma imprecisión (o desacuerdo) en torno al alcance disciplinar de la pragmática favorece la falta de limitación del propio concepto de competencia pragmática. Además, tal noción ha sido más utilizada en las aplicaciones de la lingüística (especialmente a la enseñanza/aprendizaje de lenguas extranjeras) que en la lingüística teórica. Consecuentemente, uno de los objetivos de esta tesis doctoral será profundizar en la noción de competencia pragmática y concretar sus vinculaciones con las demás subcompetencias. Para ello se realizará, en primer lugar, una revisión crítica de las ideas y contenidos aportados desde la lingüística y otras disciplinas cercanas que se han aproximado al tema. Y, en segundo lugar, se llevará a cabo la formulación motivada de propuestas teóricas para la concreción del concepto tratado.

Una vez establecida una definición coherente de competencia pragmática, constituirá nuestro siguiente objetivo la reflexión en torno a sus aplicaciones (enseñanza/aprendizaje de lenguas extranjeras, didáctica de la lengua materna, patologías del lenguaje y de la comunicación), con especial atención a su desarrollo a lo largo del proceso de adquisición de la lengua.

El enfoque pragmático ha supuesto una importante contribución al estudio de la adquisición del lenguaje y ha resultado vital a la hora de considerar aspectos de contextualización y funcionalidad lingüística que no eran abordados —o al menos no con suficiente éxito- en los modelos teóricos anteriores. Para ser hablantes 
competentes no basta con conocer una serie de reglas gramaticales, sino que también es necesario disponer de un amplio conjunto de conocimientos enciclopédicos y de principios acerca del mundo interno e intencional de las personas, así como desarrollar adecuadamente las capacidades inferenciales. Consecuentemente, el desarrollo del componente pragmático, entendido como la adquisición del conocimiento necesario para un uso apropiado y efectivo del lenguaje en las interacciones comunicativas (Ninio y Snow, 1996), constituye un elemento fundamental en la adquisición de una lengua. En efecto, para comunicarse de forma eficaz, el niño debe aprender, como hablante, a adaptar sus mensajes a la situación comunicativa y, como oyente, a interpretar el significado de los enunciados emitidos por otros interlocutores apoyándose en los factores contextuales. La dificultad radica en que no siempre se accede a la información de forma directa, ya que lo implícito desempeña un papel fundamental en la comprensión lingüística.

Así pues, la segunda parte de esta investigación se ha centrado en el análisis del desarrollo del componente pragmático dentro del estudio de la adquisición del lenguaje. Uno de los retos marcados es el análisis de datos reales sobre el desarrollo de las habilidades de comprensión pragmática en niños, desde una perspectiva lingüística y cognitiva. Para ello, se tomará como referencia básica la teoría de la relevancia de Sperber y Wilson (1986/1995), que ya ha sido utilizada con éxito como marco teórico en diferentes estudios previos relacionados con alteraciones de la comunicación (Happé, 1993; Leinonen y Kerbel, 1999) y adquisición del lenguaje (Bezuidenhout y Sroda, 1998; Foster-Cohen, 2004).

El presente trabajo se compone de cinco capítulos. El primero se dedica a establecer el marco teórico en el que se encuadra la investigación. Se ha pretendido avanzar hacia la determinación del concepto de competencia pragmática partiendo de las ideas teóricas fundamentales en torno a la noción de pragmática y su objeto de estudio. Ahora bien, hablar de pragmática implica indiscutiblemente hablar del lenguaje dentro de un contexto. Por ello, también se ha dedicado un apartado al concepto de contexto, abordado desde una perspectiva cognitiva, y con especial hincapié en la faceta sociocultural, de vital importancia en la interpretación de los enunciados. Asimismo, se han presentado los mecanismos, condiciones y principios de la teoría de la relevancia (Sperber y Wilson, 1995), tomada, a lo largo de este trabajo, 
como herramienta para analizar la comunicación lingüística, en general, y los procesos implicados en la comprensión pragmática del lenguaje, en particular. Dicha teoría constituye un modelo cognitivo de la comunicación que da cuenta de los mecanismos y estrategias que conducen desde el significado literal hasta la interpretación pragmática. Aunque tiene su origen en las ideas de Grice (1975), reinterpreta sus propuestas y es considerada, por tanto, un paradigma independiente (Pons Bordería, 2005a).

El segundo capítulo se centra en el concepto de competencia pragmática y su aplicación. Para ello se ha partido de una noción más amplia, la de competencia comunicativa, que engloba como uno de sus componentes a la competencia pragmática. Ha sido preciso, por un lado, clarificar la distinción entre los términos competencia y actuación comunicativas — que a menudo se confunden—y, por otro, establecer los conocimientos y habilidades que conforman dicha competencia. Con este objeto, se han revisado los principales modelos de competencia comunicativa ofrecidos por diferentes investigadores (Canale y Swain, 1980; Bachman, 1990; CelceMurcia, Dörnyei y Thurrell, 1995; Gutiérrez Ordóñez, 2002), así como las reflexiones que estos han suscitado. Se ha realizado un análisis comparativo y, finalmente, se ha propuesto un nuevo modelo teórico que pretende solventar las carencias de los anteriores, así como destacar sus puntos más acertados.

Conjuntamente, este capítulo recoge las ideas fundamentales de los estudios procedentes de los manuales teóricos de pragmática, de las investigaciones acerca de la enseñanza/aprendizaje de lenguas extranjeras y de los trabajos de didáctica de la lengua materna que han abordado o aplicado el concepto de competencia pragmática. En cuanto a la enseñanza/aprendizaje de lenguas extranjeras, se ha reflexionado también sobre la posibilidad de que dicha competencia sea enseñada/aprendida en las clases, así como sobre las actividades que pueden facilitar su desarrollo y las pruebas con las que podría ser evaluada. No cabe duda de la importancia que está adquiriendo la pragmática en los enfoques comunicativos que protagonizan la enseñanza de lenguas; sin embargo, los estudios en torno a la competencia pragmática —en relación con la reflexión teórica, la instrucción y la evaluación— son todavía insuficientes.

El tercer capítulo se ocupa del desarrollo del componente pragmático dentro del proceso de adquisición del lenguaje. La investigación de los últimos años reconoce 
que el aprendizaje de una lengua supone adquirir una serie de competencias comunicativas que permitan al niño entenderse con los demás, de forma que sea capaz de transmitir sus intenciones y comprender las de los otros interlocutores. En este capítulo se defiende que para estudiar el lenguaje infantil hay que partir de un prisma pragmático, ya que los usos lingüísticos se vinculan a la práctica comunicativa. No obstante, se ha constatado de nuevo la falta de acuerdo en torno al ámbito de la pragmática. Esto tiene como consecuencia que no se postule ninguna teoría de adquisición integrada, sino que se estudien por separado los distintos fenómenos pragmáticos, con lo que se conforma un campo de investigación quizá excesivamente heterogéneo. Asimismo, se ha perfilado un conjunto de factores que permiten el desarrollo del componente pragmático, tales como las funciones sensoriales y motoras, la competencia gramatical, el desarrollo de la memoria y de la atención, la propia experiencia del mundo, la teoría de la mente y el conocimiento social y cultural. Se han repasado, además, las principales etapas evolutivas del desarrollo del niño atendiendo a las facetas física, cognitiva, socioemocional y comunicativa establecidas por Owens (2003).

Finalmente, en este capítulo se ha abordado el procesamiento del lenguaje desde una perspectiva cognitiva (basada en la teoría de la relevancia), y se ha presentado un conjunto de tareas contextuales (asignación de referentes, enriquecimiento pragmático, procesamiento de implicaturas y rutinas, identificación de los sentimientos de otros e interpretación de la ironía), que forman parte de la comprensión pragmática del lenguaje y que han sido objeto de estudio de un buen número de trabajos experimentales.

En el capítulo cuatro hemos querido dar cuenta de la reciente incorporación de la pragmática al estudio de las patologías del lenguaje. Consideramos que estas investigaciones sirven como marco de comparación para el análisis del desarrollo típico del componente pragmático en la comunicación. En estas páginas se presenta una revisión de los distintos trastornos de la comunicación que incluyen deficiencias de naturaleza pragmática: síndrome de Williams, trastorno autista, síndrome de Asperger, síndrome del hemisferio derecho, trastorno pragmático del lenguaje, etc. Entre estos síntomas podemos destacar, por ejemplo, dificultades para ir más allá de la interpretación literal de los enunciados, limitaciones a la hora de reconocer las 
intenciones comunicativas de los demás, problemas generalizados con la deducción de inferencias, etc. (Monfort et al., 2004).

Asimismo, se ha reflexionado en torno a las pruebas de evaluación pragmática que han sido y son utilizadas en la pragmática clínica, y se han señalado las dificultades en la formalización y sistematización de estas debido a la falta de criterios de validez que se desprenden de la propia naturaleza subjetiva de la pragmática (Adams, 2002). El manejo simultáneo de información explícita e implícita propicia la falta de previsibilidad en las interacciones comunicativas, de ahí que las pruebas habituales de evaluación lingüística resulten ineficaces para detectar trastornos de tipo pragmático (Conti-Ramsden et al., 1997).

En el capítulo quinto se presenta nuestro estudio experimental sobre el desarrollo de la compresión pragmática del lenguaje, realizado a partir de un corpus de entrevistas a 140 niños españoles de edades comprendidas entre los 3 y los 9 años. En primer lugar, se describe y explica la metodología seguida en función de los objetivos planteados, las decisiones que han configurado el diseño de la investigación y el análisis de los datos. Nuestro propósito esencial se concreta en estudiar las respuestas e interpretaciones de los niños ante distintas categorías de preguntas que responden a diversas tareas pragmáticas con diferentes niveles de demanda contextual (referencia, enriquecimiento, rutina, implicatura, identificación de sentimientos en otros e ironía), dentro del marco de la teoría de la relevancia. Los objetivos específicos se cifran en determinar si las variables edad, sexo y tipo de contexto influyen de forma estadísticamente significativa en las respuestas y explicaciones de los niños, en analizar el contenido de estas - especialmente cuando son fallidas- y en comparar los resultados con los trabajos previos realizados con niños finlandeses (Luokusa, Leinonen y Ryder, 2007; Loukusa, 2007; Loukusa, Ryder y Leinonen, 2008).

Al final de estas páginas se recogen las conclusiones resultantes de esta investigación. Los datos obtenidos revelan que la edad es una variable claramente decisiva en el desempeño de las diferentes tareas pragmáticas estudiadas, mientras que no hemos encontrado diferencias significativas en relación con la variable sexo. El tipo de contexto dado para la resolución de la tarea (verbal o verbal y visual) sí que influye en las respuestas, pero no del mismo modo en las diferentes categorías de preguntas ni en todas las edades. Asimismo, el análisis del contenido de las respuestas o 
explicaciones fallidas ha resultado muy ilustrativo para determinar qué tipo de información no relevante han utilizado los niños, qué estrategias conversacionales han empleado o qué tipo de tareas inferenciales resultan más difíciles de procesar para ellos. Finalmente, hemos comparado nuestros resultados con los provenientes de los estudios previos con niños finlandeses y hemos concluido que, en líneas generales y salvo pequeñas excepciones puntuales, los datos coinciden. Así pues, podemos sugerir la existencia de un patrón común de actuación en el procesamiento del significado pragmático, independiente de la lengua materna.

En suma, este trabajo constituye una aportación al estudio de la competencia pragmática, cuya importancia dentro de ámbitos como el de la enseñanza/aprendizaje de lenguas extranjeras o el de la adquisición de la lengua materna es incuestionable. Nuestro propósito ha sido reflexionar sobre el concepto de competencia pragmática desde un punto de vista teórico, así como profundizar en la comprensión del proceso de interpretación pragmática en niños, desde edades tempranas, a través de un estudio experimental. 


\section{CAPÍTULO 1}

\section{MARCO TEÓRICO}

\subsection{LA PRAGMÁTICA COMO PUNTO DE PARTIDA}

Para precisar la noción de competencia pragmática (y sus aplicaciones) resulta imprescindible detenerse en el controvertido concepto de pragmática. Una de las razones que explican la imprecisión definitoria de este concepto es la diversidad de enfoques existentes en torno a la disciplina pragmática y su ámbito de estudio. La pragmática, definida a veces como "cesto de desperdicios" (Reyes, 1990) donde arrojar todo aquello que otras disciplinas no pueden explicar, ha ido evolucionando hasta convertirse en una disciplina con un puesto de honor dentro del espectro de los estudios lingüísticos (Ruiz Gurillo, 2006). De esta forma, el surgimiento del paradigma de la pragmática se hace necesario para explicar cuestiones que se escapan del ámbito de la gramática, así como aquellos aspectos para los que es necesario tener en consideración elementos externos a la lengua, pero que condicionan nuestro uso de esta.

\subsubsection{La noción de pragmática en el ámbito teórico}

La utilización especializada del término pragmática se le atribuye al filósofo Charles Morris (1938) en su intento por describir la semiótica o ciencia de signos. Dentro de esta, distinguió tres ramas: la sintaxis o 'estudio de la relación formal de los signos entre sí', la semántica o 'estudio de las relaciones entre los signos y los objetos a los que dichos signos son aplicables' y la pragmática o 'estudio de las relaciones entre los signos y los intérpretes’ (Morris, 1938). La pragmática surge, así, como parte de la reflexión filosófica, a raíz de que los autores se dieran cuenta de que hablar es hacer, esto es, de la gran cantidad de actos de habla que llevamos a cabo cuando nos comunicamos. Con el tiempo, el análisis del "lenguaje como acción" se convierte en una disciplina empírica que comienza a ofrecer teorías para explicar el uso de la lengua en relación con los hablantes, el contexto, etc. Desde entonces el término pragmática ha ampliado su extensión para referirse a un nutrido conjunto de 
fenómenos. Consecuentemente, hoy sigue siendo desconcertante la diversidad de posibles definiciones, así como la falta de límites claros ${ }^{1}$.

La primera cuestión que se plantea es cómo debemos entender la pragmática, esto es, si debemos considerarla una disciplina independiente, una disciplina dentro de la lingüística, un enfoque, una ciencia social, etc. Las opiniones en torno a esta cuestión son diversas. Levinson (1983: 28-30) defiende la necesidad de un componente pragmático dentro de una teoría lingüística general. Entre los argumentos que utiliza para defender esta postura se encuentra el que concierne al hecho de que para describir una teoría lingüística completa hay que descubrir el orden lógico de los distintos componentes o niveles. Según este investigador, la sintaxis es anterior a la fonología porque esta recurre a la utilización de categorías sintácticas. Ahora bien, si existe algún componente que necesite información de naturaleza pragmática, entonces la pragmática debe ser anterior a este componente y tendrá que ser incluida en una teoría lingüística general. Por un lado, sabemos que las informaciones contextuales son necesarias para el componente semántico, por lo tanto este sería un argumento a favor de la idea de que la pragmática es anterior a la semántica. Autores como Gazdar (1979: 164-8) apoyan esta idea recogiendo ejemplos. Entre ellos, el ejemplo tomado de Wilson (1975: 151), que se refiere a la palabra $y$, a la que solo se le puede dar la representación semántica correcta si se tiene en cuenta el significado pragmático contextual. A menudo, como ocurre en este caso, debemos interpretarla como 'y entonces': Casarse y tener un hijo es mejor que tener un hijo y casarse. Por ello, Levinson afirma que la pragmática es, en algunas ocasiones, anterior a la semántica y una teoría lingüística general debe incluirla como un componente más, equiparable, o al menos en principio, a otras disciplinas como la semántica.

Por su parte, los manuales de Leech (1983) y Gutiérrez Ordóñez (2002) comparten la consideración de la pragmática como una disciplina que no forma parte del núcleo de la lingüística, pero que a la vez se complementa con ella en el estudio general del lenguaje. No se trata, por tanto, de una disciplina al nivel de la fonología, la semántica o la morfología; aunque se interrelaciona con estas en el estudio de la

\footnotetext{
${ }^{1}$ Esto ya ocurre en sus orígenes, así lo recoge Levinson (1983) con su ya clásica revisión de las diferentes definiciones de pragmática. Algunas inciden en la importancia del contexto, otras se enfocan en la relación entre el lenguaje y los usuarios, otras equiparan la pragmática con 'significado menos semántica', etc. 
comunicación lingüística. Leech (1983) entiende que la pragmática debe integrarse como un componente más del campo de la lingüística, pero propone entender las regularidades gramaticales en forma de reglas y las de uso, en forma de principios. No hay que forzar la inclusión del estudio del uso de la lengua en la gramática propiamente dicha entendida como un sistema formal. Las teorías y modelos de explicación de la pragmática no tienen por qué ser paralelos a los de la gramática. La pragmática debe deslindarse de la gramática, pero al mismo tiempo complementarse con ella en el marco general del estudio del lenguaje. Se trata, según Leech, de dos paradigmas distintos (con dominios diferentes), pero que a su vez forman un único paradigma complejo: el de la lingüística.

En esta línea de pensamiento se sitúa también el manual de Gutiérrez Ordóñez. Según Gutiérrez Ordóñez (2002), la pragmática es una disciplina. Ahora bien, no es una disciplina que se especifique por un ámbito de estudio propio. Pragmática no se opone a fonología, morfología o sintaxis, sino a lingüística. Si bien la lingüística se centra en el código, la pragmática estudia especialmente los elementos que forman parte de la comunicación tales como el emisor, el receptor, el canal, las circunstancias, etc. El autor reconoce que aunque la lingüística está dentro de la pragmática, para simplificar la cuestión se suelen representar como disciplinas complementarias que se reparten el ámbito de estudio: la lingüística se encarga de la información codificada y, por lo tanto, del significado no contextual. Por su parte, la pragmática estudia la información no codificada (referencial e intencional), que este investigador denomina sentido.

No obstante, Gutiérrez Ordóñez (2002) advierte, acertadamente, que no podemos hacer una partición del territorio común. Si dijéramos que la pragmática se encarga del estudio de la referencia, de las modalidades, de los actos de habla, de la información implícita, entre otros, encontraríamos un problema a la hora de explicar que las presuposiciones sean informaciones implícitas pero codificadas, que haya aspectos de la denotación (como la correferencia) que están codificados, que la modalidad pueda expresarse a través de expresiones lingüísticas, etc. Por lo tanto, si separamos la lingüística de la pragmática, no podemos afirmar que dicha separación sea temática sino procedimental. No obstante, hay una gran interrelación entre el código y las inferencias. Por ello, la pragmática (con su procedimiento inferencial) se revela 
necesaria para explicar el funcionamiento comunicativo en las disciplinas de código, es decir, para entender la interpretación sintáctica, morfológica, léxica y fonológica.

Por otra parte, Reyes (1990), Verschueren (1999), Portolés (2004) y Escandell Vidal (2006) coinciden en el rechazo hacia la concepción de la pragmática como una disciplina y creen que debe entenderse como una nueva perspectiva desde donde observar los fenómenos lingüísticos. Para Verschueren (1999), la pragmática no constituye un componente adicional a la teoría lingüística general porque no puede ser identificada con una unidad de análisis específica. La considera, entonces, como una perspectiva diferente, ya que, según este autor, no hay ningún fenómeno lingüístico, a ningún nivel, que la perspectiva pragmática pueda ignorar. Asimismo, en palabras de Escandell Vidal, "la pragmática se perfila, en consecuencia, no como un nivel estructural, sino como una perspectiva de análisis, un punto de vista, una manera de acercarse al estudio de los fenómenos lingüísticos” (Escandell Vidal, 2006: 234).

Ante esta diversidad de opiniones y sin ánimo de entrar en el debate, en este trabajo vamos a considerar la pragmática como una disciplina que no está instalada en el núcleo duro de la lingüística, pero que forma parte del paradigma de la lingüística de la comunicación. Se ocupa, entonces, del estudio del uso del lenguaje en la comunicación, atendiendo a los usuarios y teniendo en cuenta factores tanto lingüísticos como extralingüísticos.

Creemos que la pragmática debe deslindarse de la gramática en líneas generales, pero al mismo tiempo complementarse con ella en el estudio general del lenguaje. Este hecho queda patente en la existencia de una interfaz gramático-pragmática que explica la existencia de aspectos gramaticales que están vinculados al lenguaje en uso. La pragmática es necesaria para las disciplinas de código, así como estas son necesarias para aquella. Muchos fenómenos gramaticales deben estudiarse con herramientas pragmáticas, ya que tienen una explicación más acertada que si se prescinde de la pragmática ${ }^{2}$. De hecho, son varios los investigadores que opinan que no hay fenómeno lingüístico a ningún nivel que le sea ajeno a la pragmática (Verschueren, 1999; Portolés, 2004). Los ejemplos son múltiples, desde la composición hasta las combinaciones de adjetivos; todos pasan por el filtro del razonamiento pragmático.

\footnotetext{
${ }^{2}$ En las últimas décadas numerosos autores han defendido una aproximación funcional a la gramática. Así, Prieto de los Mozos (1998) propugna que la pragmática es también un modo de enfocar la explicación gramatical. 
En vista de lo anterior, defendemos que el principio de autonomía de una disciplina no debe entenderse en su sentido estricto. Así lo expresan -incluso en un marco tan propicio para este principio - Eguren y Fernández Soriano (2004) en su Introducción a una sintaxis minimista para el caso de la sintaxis:

El que la sintaxis sea autónoma no implica, por tanto, que esté aislada: es incuestionable que vínculos muy fuertes unen a la forma y al significado (o a la función), y que el significado (y la función) ejercen cierta influencia sobre la forma. Lo que la tesis de la autonomía dice, es, simplemente, que las gramáticas contienen un conjunto de primitivos, de operaciones combinatorias y de principios que no se pueden derivar de nociones semánticas o discursivas (Eguren y Fernández Soriano, 2004: 47).

Del mismo modo, Chomsky (1975) reconoce que "la cuestión significativa con respecto a la tesis de la autonomía puede no ser una cuestión de 'sí' o 'no', sino más bien de 'más' o ‘menos’, o de un modo más correcto, de ‘dónde’ y 'cuánto’” (1975: 55). Por lo tanto, estas ideas pueden ser aplicadas también a la pragmática. De esta manera defenderemos su autonomía, pero sin olvidar sus vínculos con otras disciplinas como las formales o su cooperación con otras teorías del análisis de la comunicación humana.

El problema radica en que, como ya señalaba Gutiérrez Ordóñez (2002), no se trata de una disciplina que se delimite por un ámbito propio de estudio, ya que este es la totalidad del lenguaje. En consecuencia, autores como Escandell Vidal (2006) o Verschueren (1999) consideran que no es una disciplina porque no podemos asociarle unidades de análisis concretas, como ocurre con la fonología o la sintaxis. Por su parte, Reyes (1990) advierte que podríamos considerar que ha creado una unidad de estudio: el acto de habla ${ }^{3}$. Sin embargo, es difícil seguir este planteamiento, puesto que el estudio del uso del lenguaje no se limita a los actos de habla, amén de las dificultades que la teoría de los actos de habla presenta. No obstante, en este trabajo entendemos

\footnotetext{
${ }^{3}$ Tal como señalaremos en capítulos posteriores, el acto de habla, definido a partir de las propuestas clásicas de Austin $(1962)$ y Searle $(1969,1975)$ como la unidad estructural mínima de la escala de rango de unidades conversacionales, es tomado como unidad prototípica de la pragmática en los primeros estudios sobre el desarrollo (Dore, 1978; Bates et al., 1979; Ninio, 1986) y déficits en la competencia pragmática (Baron-Cohen, 1988; Shields, 1991; Smith y Leinonen, 1992). Además, los actos de habla se incorporan también a los primeros protocolos diseñados para la evaluación pragmática: el Pragmatic Protocol de Prutting y Kirchner (1983), y el Profile of Communicative Appropiateness de Penn (1985).
} 
que la pragmática no dispone de una unidad concreta de análisis porque, como apuntaba Portolés (2004), los hechos lingüísticos que se refieren al uso son difícilmente aislables y sistematizables, a diferencia a los gramaticales que sí lo son o lo son más. Pese a ello, siguen siendo relevantes para el estudio del lenguaje; de modo que no es razón justificada para que la pragmática pierda su estatus de disciplina.

No deja de ser paradójico que la pragmática, siendo ya una disciplina académica con gran cantidad de estudios publicados, no disponga de una definición unívoca ni de un alcance acordado unánimemente. Varios son los manuales que optan por hacer una revisión de las definiciones que han ido surgiendo en torno a la noción de pragmática. Así Levinson (1983) evalúa las de los demás resaltando los puntos débiles y fuertes de cada una de ellas, y concluye que:

Las más prometedoras son las definiciones que equiparan la pragmática con "significado menos semántica" o con una teoría de la comprensión del lenguaje que tiene en cuenta el contexto para completar la contribución que la semántica hace al significado (Levinson, 1983: 28).

Algunos investigadores se centran en los mecanismos de producción e interpretación de enunciados; mientras que otros insisten en las condiciones sociales y culturales que determinan el uso del lenguaje. Asimismo, Reyes (1995) extrae las ideas generales que subyacen en las definiciones tales como que la pragmática debe encargarse de la relación entre los usuarios y el lenguaje, del significado del lenguaje en uso o del significado intencional ${ }^{4}$.

Resulta indiscutible que la propia interdisciplinariedad de la pragmática propicia enfoques muy diferentes. Además de la rama formal (centrada en la delimitación respecto al componente gramatical), encontramos dos nuevas aproximaciones: la sociopragmática y la pragmática cognitiva. La sociopragmática (Leech, 1983; Brown y Levinson, 1978, 1987) parte del hecho de que el lenguaje es el medio principal por el que nos comunicamos con otros, de modo que las elecciones lingüísticas en la producción de mensajes están influidas por las reglas sociales. Así, la pragmática se entiende como "the study of the conditions of human language use as these are determined by the context of society” (Mey, 1993: 42). Por su parte, la pragmática

\footnotetext{
${ }^{4}$ El hecho de ser capaces de interpretar lo que piensa el hablante está muy relacionado con la teoría de la mente de la que hablaremos en capítulo 3.
} 
cognitiva se centra en los principios cognitivos que guían al oyente en el proceso de interpretación (Sperber y Wilson, 1986/1995). Consecuentemente, dado que el acto comunicativo envuelve los procesos tanto de producción como de interpretación, la tendencia a englobar ambos ha dado lugar a su vez a una nueva perspectiva sociocognitiva (Thomas, 1995).

Otro de los matices más interesantes de la pragmática es su estrecha relación con la retórica. Partiendo de la tradición histórica que entendía la retórica como el arte de persuadir, Leech (1983) recoge el uso del término retórico con el sentido general de 'uso eficaz del lenguaje en la comunicación'. Este autor destaca el hecho de que las situaciones verbales estén orientadas hacia un fin. En otras palabras, el hablante usa el lenguaje para conseguir algo del o en el oyente. Así lo refleja también Maingueneau (1990):

Desde la emergencia en Grecia de un pensamiento lingüístico, se ha hecho patente un gran interés por todo cuanto atañe a la eficacia del discurso en situación. La retórica, el estudio de la fuerza persuasiva del discurso, se inscribe plenamente en el dominio que acota en la actualidad la pragmática (Maingueneau, 1990: 1).

En efecto, Gutiérrez Ordóñez (2002: 140) señala que muchos de los descubrimientos que se le atribuyen a la pragmática y a la lingüística del texto ya habían sido objeto de estudio de la retórica. Según este investigador, la pragmática y la retórica comparten objetivos y características. Las figuras retóricas no son más que figuras del discurso; retórica y pragmática buscan el éxito en la enunciación frente a la gramaticalidad o corrección perseguida por la gramática; ambas han de tener en cuenta los factores externos tales como el/los oyente(s) al/ a los que se dirigen y el tema que tratan, el canal de transmisión, etc. Además, la persuasión — principal finalidad de la retórica - puede ser entendida como un objetivo dentro de la actividad perlocutiva.

No obstante, la comunicación no solo tiene como meta marcada la eficacia, sino que también utilizamos el lenguaje, por ejemplo, para mantener nuestros vínculos sociales. Si reflexionamos sobre esta aserción, podemos reconocer que hasta en una conversación de ascensor —en la que a primera vista no pretendemos informar, sino mantener las relaciones sociales - en el fondo estamos persuadiendo a nuestro interlocutor de que somos simpáticos y amistosos. 
Una vez admitida la dificultad que entraña dar una definición de lo que muchos han denominado "cajón de sastre”, pretendemos recoger de manera coherente y precisa las nociones generales en torno a este concepto. Así, concluimos que la pragmática está ubicada dentro del paradigma de la lingüística de la comunicación y es una disciplina independiente y a la vez complementaria de las disciplinas de código. Observamos, además, la unanimidad en la idea de que el entendimiento natural del lenguaje y su uso pertenecen al ámbito de la pragmática y que los aspectos sociales y cognitivos afectan a la comprensión y expresión lingüísticas. Esta disciplina se ocupa, por tanto, del estudio del uso del lenguaje en la comunicación, teniendo en cuenta los factores (tanto lingüísticos como extralingüísticos) que intervienen en la producción e interpretación de enunciados concretos en situaciones comunicativas específicas. Para ello, la pragmática toma en consideración la faceta cognitiva, social y cultural de los fenómenos lingüísticos, así como la relación entre el hablante y el lenguaje, atendiendo a las elecciones que este realiza y a los efectos que estas tienen sobre el oyente en los actos de comunicación.

\subsubsection{El objeto de estudio de la pragmática}

Con respecto al objeto de estudio, en este trabajo proponemos una distinción entre el ámbito sobre el que actúa la pragmática (la totalidad del lenguaje), los fenómenos puramente pragmáticos (aquellos que solo encuentran explicación en la pragmática), los fenómenos pragmáticos periféricos (cuya explicación es interdisciplinar) y los principios con los que la pragmática opera para explicar estos fenómenos y el uso comunicativo del lenguaje en general.

Con base en el reconocimiento de que el objetivo de la investigación pragmática es explicar la comunicación lingüística en general, si queremos delimitar su campo de estudio, lo haremos a través de la enumeración de los fenómenos que no son explicados con suficiente éxito por las disciplinas de código y que además están conectados con el acto enunciativo mismo y con las circunstancias o condiciones contextuales. La inclusión de muchos de estos fenómenos es compartida por la mayor parte de la bibliografía pragmática, mientras que otros plantean polémica. Nos detendremos en estos últimos con el fin de catalogarlos o no como fenómenos exclusivamente pragmáticos 0 , al menos, como fenómenos que precisan 
necesariamente de aspectos pragmáticos para ser abordados, aunque, obviamente, también dispongan de una parte no pragmática o puramente estructural.

Las presuposiciones constituyen uno de los fenómenos más debatidos en los manuales de pragmática. En efecto, las opiniones divergen en torno a si deben considerarse exclusivamente semánticas o también pragmáticas. El punto de vista pragmático permite entender el mecanismo inherente a las presuposiciones en el que el hablante conjetura lo que tiene en la mente su interlocutor. Podemos distinguir tres clases de presuposiciones: las presuposiciones existenciales, léxicas y focales (García Murga, 1998). Las presuposiciones existenciales están ligadas a expresiones referenciales y dan por sentada la existencia de lo denotado en una representación mental que se encuentra accesible en la memoria; por ejemplo, en La casa tiene ventanas de aluminio (Portolés, 2004: 131), la presuposición es que existe una casa definida accesible en el universo de discurso creado. Las presuposiciones léxicas son significados adicionales que están implícitos en algunos verbos; así, en Gutiérrez dejó de llamarme (Reyes, 1995: 45) encontramos la presuposición 'Gutiérrez me llamaba'. Las presuposiciones focales están relacionadas con ciertas formulaciones prosódicas o sintácticas, de forma que si alguien dice Fueron los niños los que trajeron las flores (Portolés, 2004: 132) se presupone que ‘alguien ha traído las flores’.

Ahora bien, para algunos autores las presuposiciones son implicaturas convencionales, mientras que para otros no lo son porque consideran que las implicaturas convencionales son separables (al decir algo con el mismo valor de verdad usando una expresión diferente, la implicatura desaparece), mientras que las presuposiciones son inseparables. En este debate toman partido, de una u otra manera, Karttunen y Peters (1979), Ducrot (1984), Horn (1988), Carston (2002), Portolés (2004), etc. También hay divergencia de opiniones en torno a si las presuposiciones son cancelables o no, o en cuanto al problema de la proyección. Este último aparece en algunos casos en los que las construcciones que incluyen una presuposición están subordinadas en una estructura más compleja y, en lugar de conservan sus presuposiciones, las pierden (Levinson, 1983; Verschueren, 1999).

En este trabajo vamos a abordar las presuposiciones como relaciones entre una forma lingüística y un significado implícito al que se puede llegar por un proceso de inferencia (pragmática). Asumimos que las presuposiciones son las inferencias más 
relacionadas con el uso explícito, puesto que se trata de significados con anclaje en el código lingüístico. Cabría pensar que su manejo depende del componente semántico; sin embargo, la presuposición constituye una categoría pragmática porque sirve, entre otras cosas, para que el emisor organice los distintos planos informativos según sus intereses. Por eso, López García (1989) define pertinentemente la presuposición como "proposición activada por el enunciado y que depende de su sujeto cuando al mismo se enfrenta la enunciación” (1989: 276).

El fenómeno de la deixis ${ }^{5}$ se encuentra también en el límite entre la semántica y la pragmática, ya que trabaja con elementos gramaticales, pero a su vez codifica aspectos del contexto. Supone el anclaje del uso del lenguaje en el mundo real señalando alguna de sus dimensiones, en un tiempo, espacio, sociedad y discurso particulares (Verschueren 1999: 103). Como es consabido, las expresiones deícticas establecen conexiones entre lo que se dice y las entidades del contexto, por lo que no tienen significación si no las asociamos a un contexto. Todas las lenguas tienen deícticos, esto es, formas especiales para hacer referencia a los diferentes elementos de la situación: pronombres personales de primera y segunda persona, demostrativos, posesivos, muchos adverbios de lugar y de tiempo, morfemas de tiempo de la flexión verbal, fórmulas de tratamiento y formas anafóricas y catafóricas, etc. En efecto, debemos reconocer que la interpretación de los enunciados que contienen estos elementos depende de los factores extralingüísticos que configuran el acto comunicativo. Es necesario conocer la identidad del emisor o del destinatario o las circunstancias de tiempo y lugar de la emisión para alcanzar una interpretación completa de los enunciados. En este trabajo, por tanto, partimos de que estamos, en cualquiera de las vertientes de la deixis (personal, temporal, espacial, social y discursiva), ante un fenómeno pragmático. Ahora bien, en una reflexión más profunda reconocemos que la deixis no es exclusivamente pragmática, ya que como una categoría gramatical se codifica en la gramática ${ }^{6}$. Podemos decir, entonces, que, tanto

\footnotetext{
${ }^{5}$ Para mayor información sobre las expresiones deícticas consúltese Kaplan (1989), Récanati (1993); sobre los distintos tipos de deixis, Cifuentes (1989), Vicente Mateu (1994), Levinson (2004); sobre la deíxis social, Pérez García (2007) y sobre deícticos en español, Eguren (1999) y Gutiérrez-Rexach (2002).

${ }^{6}$ Prueba de ello es que las gramáticas incluyen por regla general un capítulo en torno a los elementos deícticos. Así, Demonte y Bosque en su Gramática Descriptiva de la Lengua Española 16
} 
en el caso de las presuposiciones como en el de la deixis, nos encontramos ante fenómenos pragmáticos periféricos. Así, podemos distinguir fenómenos centrales (aquellos puramente pragmáticos) y fenómenos periféricos (que son aspectos estructurales del lenguaje dependientes del contexto, como la deixis, cuyo significado restringe las inferencias que se pueden obtener de los miembros discursivos que las unidades vinculan).

En cuanto a los fenómenos de paralenguaje, kinésica y proxémica ${ }^{7}$, que autores como Portolés (2004) incluyen en sus manuales, no vamos a considerarlos puramente pragmáticos, ya que pertenecen a la comunicación no verbal; ello no obsta, sin duda, para que reconozcamos sus aportaciones en la interpretación de los enunciados. Tampoco incluiremos el análisis de la conversación ${ }^{8}$ porque entendemos que se trata de una línea de investigación diferente (aunque relacionada con la pragmática, la sociolingüística interactiva y la psicología cognitiva), pero sobre todo porque sus objetivos son diferentes. El objetivo del análisis de la conversación es analizar cómo conseguimos crear y mantener un orden social compartido en nuestras actividades comunicativas. El análisis de la conversación describe y explica pautas de conducta, por lo que su propósito sustantivo no es el lenguaje, sino cómo se traban las relaciones humanas dentro del lenguaje, esto es, la organización social que se desarrolla a través de la interacción.

Por otro lado, consideramos oportuno que la pragmática atienda a fenómenos retóricos como la metáfora, la ironía, la hipérbole, etc., que encajan perfectamente en nuestra idea de pragmática. Cuando nos comunicamos utilizando enunciados irónicos, metáforas, etc. no pretendemos ser veraces sino pertinentes, de forma que nuestro interlocutor pueda obtener las implicaturas oportunas. Estos fenómenos son recursos rentables, ya que comunican matices que de otra manera no existirían (Sperber y Wilson, 1990; Reyes, 2002). Si una madre, después de ver el caos de la habitación de su hijo, le dice el siguiente enunciado irónico: Pues sí que eres un chico ordenado, no solo le está diciendo que es desordenado, sino que también se extrae la implicatura de

dedican un capítulo a las relaciones deícticas en los pronombres y adverbios demostrativos (Eguren, 1999).

${ }^{7}$ Para más información sobre estos fenómenos consúltese Poyatos (1994).

${ }^{8}$ El análisis de la conversación es una disciplina más dentro del paradigma de la lingüística de la comunicación (Gutiérrez Ordóñez, 2002: 86). 
que debería ser ordenado o de que no es cierta la imagen de chico ordenado que quiere dar (Portolés, 2004: 223).

Finalmente, incorporamos en esta descripción de la disciplina pragmática principios tales como el de cooperación, la teoría de la relevancia, la teoría de los actos de habla, el principio de cortesía y la teoría de la argumentación. Estos principios, aunque se presentan controvertidos y no libres de críticas $^{9}$, deben ser parte de los manuales de pragmática, ya que constituyen las herramientas de trabajo necesarias para explicar las regularidades que encontramos en el uso del lenguaje en diferentes contextos sociales y situacionales. Esta lista no está cerrada; de hecho, autores como Gutiérrez Ordóñez (2002) la amplían incluyendo principios como el de informatividad, de sinceridad o de cuantificación positiva (o negativa), algunos de los cuales son ampliaciones de las máximas de otros. No obstante, son acogidos siempre y cuando aporten nuevas explicaciones del uso lingüístico, así como también lo son las críticas y superaciones de los principios tradicionales.

El interés principal de estas líneas ha sido bosquejar brevemente un panorama de la pragmática, concluyendo que no podemos hablar de una unidad temática ni metodológica, pero sí de una gama de fenómenos pragmáticos más o menos centrales que corresponden a una visión general de esta disciplina: implicaturas, actos de habla, cortesía, fenómenos relacionados con la retórica como la metáfora o la ironía, etc., que ponen de manifiesto el carácter lingüístico, social y cognitivo de la pragmática. Al mismo tiempo, defendemos la posibilidad de entender que dentro de la pragmática hay también aspectos que no podemos considerar centrales pero sí periféricos. Estos fenómenos periféricos como las presuposiciones, la deixis, la definitud ${ }^{10}$, la deixis de la flexión de los verbos ${ }^{11}$, etc. se sitúan en una interfaz entre distintos ámbitos: la configuración estructural y la pragmática y, por tanto, requieren una explicación interdisciplinar.

\footnotetext{
${ }^{9}$ Con respecto a la teoría de los actos de habla: Franck (1981) y Haverkate (1979 y 1984); en relación con principio de cooperación: Burton-Roberts (1984), Kempson (1988) y Horn y Ward (2004); sobre la teoría de la relevancia: Mey y Talbot (1988), O’Neill (1988-89) y Walker (1989).

${ }^{10}$ Los artículos definidos, por ejemplo, tienen significado de definitud, de manera que se entiende que el referente del sintagma determinante se identifica de forma unívoca en el contexto de uso (Leonetti, 1999). Además, este significado no solo lo encontramos en la mayor parte de los sintagmas determinantes con artículo definido, sino también en las expresiones directamente referenciales como los deícticos (Portolés, 2004).

${ }^{11}$ A través de los morfemas temporales de los verbos obtenemos también implicaturas de los enunciados (véase Portolés, 2004).
} 


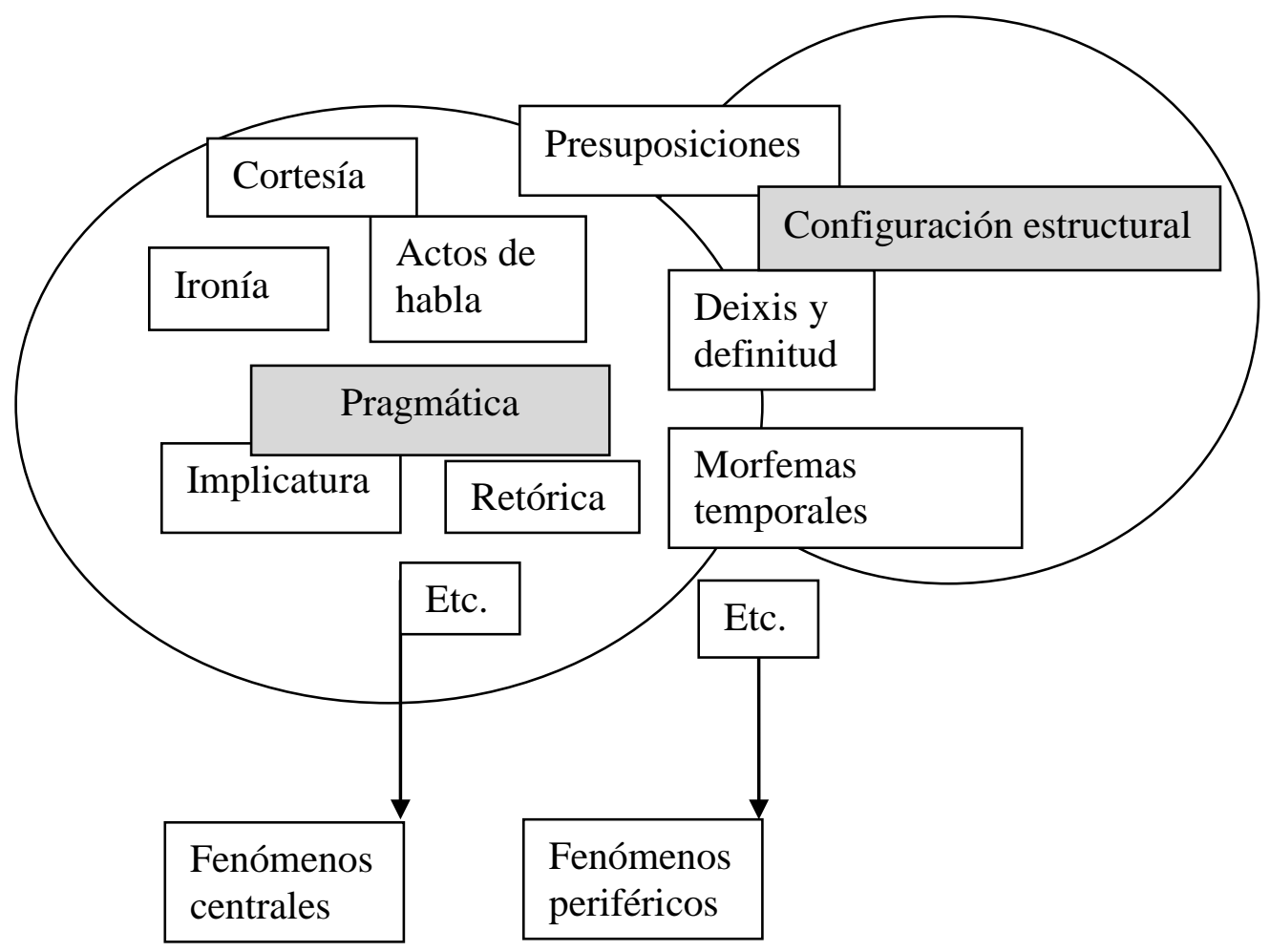

Figura 1. Fenómenos pragmáticos centrales y periféricos

\subsection{CONTEXTO Y COMUNICACIÓN LINGÜÍSTICA}

De lo anteriormente expuesto podemos derivar que la pragmática se dedica al estudio global del lenguaje en uso; en otras palabras, se ocupa del lenguaje en contexto. No obstante, tal como reconoce Berbeira Gardón (1994), existen pocos modelos o formulaciones teóricas que pretendan explicar el papel del contexto en la interpretación de la comunicación de manera sistemática. Entre nuestras empresas estarán, entonces, por un lado, la de formular una definición de la noción de contexto lo suficientemente acotada y, por otro, la de analizar cómo ese contexto afecta a la interpretación de los enunciados (Blakemore, 1992; Sperber y Wilson, 1986).

Como sabemos, a menudo la interpretación de una misma expresión lingüística varía en función del contexto o las diferentes circunstancias que rodean al acto comunicativo. Consecuentemente, en la comprensión es necesario ir más allá del código lingüístico y servirnos de los diversos factores contextuales de la situación (Donaldson, 1992; Ervin-Tripp, 1996; Verschueren, 1999). 
Son muchos especialistas de diversas disciplinas los que se han acercado a la noción de contexto: lingüistas, sociolingüistas, etnometodólogos, etc. ${ }^{12}$ Estas aproximaciones dependerán de los aspectos en los que se haga mayor hincapié: aspectos sociales, psicológicos, situacionales, etc. Así pues, se trata de un concepto considerablemente amplio y que ha sido estudiado desde múltiples enfoques, lo cual contribuye a su propia indeterminación y, naturalmente, a su riqueza.

Ahora bien, la noción de contexto es poco precisa incluso en el propio ámbito de la lingüística, en el sentido de que cada modelo teórico le otorga un significado diferente. En un principio se distinguía entre contexto verbal y extraverbal. Si nos remontamos a Coseriu (1967), vemos que este autor emplea el concepto de contexto extraverbal cultural con el que se refiere a las "circunstancias no lingüísticas que se perciben directamente o que son conocidas por el hablante” (1967: 313), esto es, todo aquello que física o culturalmente rodea al acto de enunciación. En esta línea distingue los siguientes tipos de contexto:

a) Contexto físico: las cosas que están a la vista o a las que un signo se adhiere.

b) Contexto empírico: los estados de cosas objetivos que se conocen por quienes hablan en un lugar y en un momento determinados, aunque no estén a la vista.

c) Contexto natural: totalidad de contextos empíricos posibles.

d) Contexto práctico u ocasional: particular coyuntura objetiva o subjetiva en que ocurre el discurso.

e) Contexto histórico: las circunstancias históricas conocidas por los hablantes.

f) Contexto cultural: la tradición cultural de una comunidad.

Según Varón López (2008), en esta clasificación el contexto verbal puede modificar todos los contextos extraverbales en los que podamos pensar, pero a su vez se alimenta de ellos, de ahí que se les dé preferencia a estos. No obstante, resulta poco práctico diferenciar tantos tipos de contexto. Así, las teorías actuales sobre el contexto suelen distinguir tres tipos fundamentales: el lingüístico, el situacional y el sociocultural (Reyes, 1990; Padilla, 2005a; entre otros):

${ }^{12}$ En lingüística, encontramos los trabajos clásicos sobre el contexto de la mano de Van Dijk (1977) y Halliday (1978), en psicología las aportaciones de Giles y Coupland (1991) y en etnografía de la comunicación estudios como el de Gumperz (1982a) o Duranti y Goodwin (1992). 
-el contexto lingüístico (cotexto) es el material lingüístico que rodea al enunciado;

-el situacional es el conjunto de información accesible a los interlocutores que se encuentra en el entorno físico inmediato;

-y, finalmente, el sociocultural está formado por la información procedente de condicionamientos sociales y culturales sobre el comportamiento verbal y su adecuación a las diferentes circunstancias de un grupo social concreto o de la sociedad en general.

Curiosamente, no todos los manuales de pragmática incluyen el contexto sociocultural (muy importante a la hora de determinar los marcos de referencia o frames y guiones o scripts de los que hablaremos a continuación). Este contexto influye en lo que decimos y en cómo lo decimos, generando expectativas y presuposiciones en los hablantes miembros de una misma comunidad. En efecto, los hablantes son los que, desde un marco sociocultural compartido, pueden interpretar significados en función de los contextos. Veamos el siguiente pasaje:

Ayer, al volver al trabajo después de comer encontré una carta en el suelo de mi despacho. Al principio no le di importancia. Después observé que tenía los bordes un poco quemados y la curiosidad hizo que me acercara y la recogiera. Cuál fue mi sorpresa al ver que se trataba del as de espadas, siempre había sido mi naipe preferido. Supuse que se había caído de la estantería y la coloqué con el resto de la baraja.

Al terminar de leer estas líneas, la palabra carta se interpreta en un sentido diferente al que parecía indicar el contexto inicial. Así vemos la importancia del contexto, en este caso en principio se trataba de un contexto lingüístico, pero también subyace una especie de contexto general compartido (cuando encontramos un significado que encaja dejamos de buscar otros significados posibles). Este mecanismo nos permite la economía en la comunicación, pero a la vez puede llevarnos a malinterpretar la intención comunicativa del hablante (por diferencias culturales, ideas preconcebidas o incluso prejuicios).

Consecuentemente, podemos deducir que el contexto está formado por una serie de suposiciones que posibilitan la comprensión de los enunciados. Según Portolés 
(2004), estas suposiciones se encuentran en nuestra memoria ${ }^{13}$ o se crean en nuestra mente en el momento de la comunicación. Por tanto, para explicar el uso efectivo de la lengua no solo es necesario un mecanismo que guíe las inferencias. También será imprescindible explicar el ordenamiento de nuestro contexto mental, aunque desgraciadamente, como advierte Portolés (2004), esto está lejos de conseguirse.

En su obra Expression and meaning: Studies in the theory of speech acts, J. R. Searle habla de un contexto ciertamente inconsciente denominado trasfondo (background). El trasfondo está formado por suposiciones comunes a todos los seres humanos, extremadamente generales y que a menudo olvidamos que tenemos. Asimismo, Searle distingue entre el trasfondo profundo (común a todas las culturas) y las prácticas culturales locales. Pinker (1997) entiende el trasfondo profundo como una especie de base de datos de la que disponemos de forma tácita:

Cuando, por ejemplo, Irving coloca el perro en el coche, sabemos que ya no está en el porche. Cuando Edna va a la Iglesia, acude... con su cabeza. Si Doug está en casa quiere decir que ha entrado abriendo la puerta, a menos que desde haber nacido nunca hubiera salido. Si Sheila estaba viva a las cinco de la tarde quiere decir que también estaba viva a mediodía... (Pinker, 1997: 30).

Por otro lado, las prácticas culturales locales se refieren a lo que Clark (1996) denomina fundamento compartido (common ground), que son las suposiciones que compartimos con unas personas y no con otras al formar parte de determinadas comunidades (de tipo geográfico, profesional, religioso, étnico, político o incluso por aficiones comunes a un determinado tipo de música).

Estas informaciones de trasfondo se ordenan en nuestra mente de diferentes formas. A menudo disponemos de antemano de conceptualizaciones interiorizadas sobre una determinada situación o contexto, esto es, tenemos una serie de expectativas sobre situaciones concretas que se repiten en el entorno social. Una vez identificamos esa situación, activamos un conjunto de expectativas asociadas y le asignamos una serie de características generales. Con esto pretendemos decir que a menudo las situaciones tienen elementos recurrentes fácilmente reconocibles y que son

\footnotetext{
${ }^{13}$ La memoria operativa se entiende como la "capacidad del sistema cognitivo de procesar y retener temporalmente en activo porciones limitadas de información, mientras son elaboradas e integradas con otras, como paso previo a su representación y almacenamiento en la memoria a largo plazo” (Gutiérrez Calvo, 2003: 123).
} 
compartidos por toda la comunidad. Por ejemplo, cuando vamos a comprar el pan todos tenemos una idea preconcebida de cómo será el intercambio comunicativo entre cliente y dependiente, de qué temas se va a hablar o de cuáles no, la secuencia de acontecimientos, etc., y completamos a través de la inferencia todo aquello que no se dice o a lo que no se hace referencia porque es común a los participantes. Así, cuando decimos Póngame una barra el dependiente enriquece el significado de barra y no se plantea si lo que queremos es que nos instale una barra de herramientas en nuestro navegador.

Es consabido que desde que nacemos vamos adquiriendo una serie de conocimientos y experiencias. Cabe preguntarse, entonces, cómo se almacena el conocimiento en la mente (este ha sido una de los principales objetos de estudio de la inteligencia artificial) y cómo lo usamos en las interacciones comunicativas diarias. Para referirnos a las estructuras de conocimiento organizado se utilizan conceptos como el de marco (frame) y el de guion (script). Minsky (1975) determina que los hablantes utilizamos $\operatorname{marcos}^{14}$ (frames), que son estructuras de datos tomadas de la memoria a largo plazo a partir de situaciones estereotipadas que se dan frecuentemente. Estos marcos suelen hacer referencia a esquemas visuales: cuando alguien va a entrar a una clase espera ver paredes, mesas, sillas, una mesa del profesor, una pizarra, etc. En palabras del propio Minsky:

A frame is a data-structure for representing a stereotyped situation like being in a certain kind of living room or going to a child's birthday party. Attached to each frame are several kinds of information. Some of this information is about how to use the frame. Some is about what one can expect to happen next. Some is about what to do if these expectations are not confirmed (Minsky, 1977: 355).

Un marco general, a su vez, se puede categorizar en otros más específicos, de forma que en los intercambios lingüísticos accedemos a un sistema de marcos que se van activando sucesivamente a lo largo de la conversación. Así, cuando una persona se

${ }^{14}$ Los marcos (frames), según Minsky (1975, 1977), son unidades de almacenamiento que contienen una estructura del análisis de una situación. Cada marco se caracteriza por un conjunto de campos (slots), que contienen distintas clases de información. Parte de esta información indica cómo usar el marco, otra se refiere a lo que se espera que suceda a continuación y otra parte indica qué hacer cuando no se confirman tales expectativas. En su propuesta original, más que describir con detalle un método completo, trató de dar ideas y sugerencias, por ello del planteamiento original han surgido numerosos modelos muy diferentes entre sí (véase Santamaría, 1995; Brever, 1999). 
enfrenta a una nueva situación selecciona uno de estos marcos y lo manipula para que se ajuste a la realidad. Una vez que el marco es activado, las casillas o slots de las que se compone pueden rellenarse con información concreta sobre el acontecimiento particular.

Por su parte, el concepto de guion ${ }^{15}$ (script) se emplea para hacer referencia a un conjunto de acciones estereotipadas que se llevan a cabo en una situación conocida. Schank y Abelson (1977) lo definen como:

A structure that describes an appropiate sequence of events in a particular context. A script is made up of slots and requirements about what can fill those slots. The structure is an interconnected whole, and what is in one slot affects what can be in another" (Schank y Abelson, 1977: 41)

Estos autores ponen como ejemplo típico el guion que se sigue cuando acudimos a un restaurante: desde que buscamos sitio para sentarnos hasta que pagamos.

La idea del uso de guiones y marcos, que a simple vista parece sencilla, es enormemente interesante, ya que, como reconoce Escandell Vidal (2005), explica nuestra capacidad de interaccionar de manera eficaz prediciendo estructuras de eventos y permitiéndonos completarlos vía inferencia.

Sin embargo, no es suficiente para explicar cómo el contexto afecta a la interpretación de los enunciados. Hay que poner límites al conocimiento activado en un marco, de forma que únicamente se active el conocimiento de fondo pertinente a la interpretación de un enunciado determinado.

En esta misma línea, pero dentro de lo que se ha denominado semántica de situaciones, Barwise y Perry (1983) caracterizan el contexto incluyendo, entre otros conceptos, el de situaciones recursivas. Estas se entienden como el conocimiento común a todos los hablantes partícipes de un contexto específico que les permite aportar información sobre un estado de cosas a partir de otro diferente. Siguiendo el planteamiento de Barwise y Perry (1983: 36), cuando un padre le dice a su hijo que saque al perro utiliza el hecho de que el hijo sabe que solo tienen una mascota en casa para decir algo sobre ella. No obstante, esta teoría tampoco da explicación de cómo se seleccionan los parámetros contextuales en cada situación discursiva.

\footnotetext{
${ }^{15}$ Los guiones se identifican asimismo con lo que Lakoff (1987) denominó escenarios. 
También merecen mención, a la hora de abordar la idea de contexto, las obras del sociolingüista John Gumperz (1982a, 1982b, 1992, etc.). Este autor, partiendo de la noción de contexto como un elemento dinámico que se va modificando a medida que avanza la interacción, introduce el concepto de índices de contextualización (contextualization cues). Estos índices se refieren a los elementos (ya sean lingüísticos o no lingüísticos) que nos dan pistas para construir el contexto en una situación concreta e influyen en la comprensión de los enunciados. Ahora bien, una de las condiciones para hacer uso de estos índices de contextualización es la de pertenecer a una misma cultura o grupo social. Así, podemos ver casos en los que aunque ambos interlocutores comparten una misma lengua, no utilizan los índices de contextualización del mismo modo al no ser miembros del mismo grupo social. Gumperz (1999) pone como ejemplo las diferencias en la entonación en entrevistas de trabajo entre asiáticos y británicos, que pueden ocasionar problemas debido a que los índices de contextualización se malinterpretan.

La diversidad de interpretaciones de la noción de contexto de la que estamos dejando constancia a lo largo de estas páginas ha dado lugar, frecuentemente, a la utilización de términos más específicos para referirnos a esa cantidad de conocimientos provenientes de diversas fuentes y que son tan necesarios para la interpretación de enunciados. Este es el caso del término información pragmática. Para Dik (1989) la información pragmática tiene tres componentes:

a) información general (información externa, comprende el conocimiento del mundo, sus características naturales, culturales, etc.);

b) información situacional (la que incluye el conocimiento derivado de lo que los hablantes perciben en la interacción);

c) información contextual (la que se deriva de las expresiones lingüísticas).

De esta forma, la información pragmática de un participante en un acto comunicativo viene dada por su conocimiento del mundo, por la información situacional y por la información discursiva. No es difícil darse cuenta de que, aunque cambiemos de término, el concepto se mantiene. Lo que estos tres componentes recogen no es otra cosa que la información proveniente de los diferentes tipos de 
contexto que ya hemos mencionado con anterioridad: contexto lingüístico o cotexto, contexto situacional y contexto sociocultural.

Los hablantes poseen también lo que Escandell Vidal (2006: 34-35) denomina parcelas de información. Estas parcelas incluyen los conocimientos lingüísticos de una o más lenguas, los conocimientos enciclopédicos, los estereotipos, las creencias, etc. que se comparten por el hecho de pertenecer a una misma cultura. De esta forma, los interlocutores comparten una subparcela de información pragmática y, además, cada uno construye una hipótesis sobre dicha subparcela de la información del otro.

La idea de compartir la información pragmática entre emisor y destinatario o hipótesis de conocimiento mutuo ha tenido algunos críticos, entre ellos, Sperber y Wilson (1995), quienes consideran que determinar el conocimiento mutuo que existe entre el emisor y el destinatario es una tarea de gran dificultad, ya que nunca podemos estar totalmente seguros del conocimiento del otro y viceversa. Estos autores proponen hablar de un entorno cognoscitivo compartido ${ }^{16}$. Así, el entorno cognoscitivo de un hablante está formado por los hechos mentales que le son manifiestos, esto es, por los hechos que se pueden representar en la mente y cuya representación es aceptada como verdadera o como probablemente verdadera (Sperber y Wilson, 1995: 54-55). De esta forma, para que el acto comunicativo sea eficaz, no es necesario un conocimiento total compartido, sino que los interlocutores construyan una hipótesis sobre el conocimiento pragmático y la información de la que el otro dispone. El éxito dependerá, entonces, de que la hipótesis o suposición que se construya sea la acertada.

Todo esto nos lleva a cuestionarnos de nuevo cómo se selecciona el contexto pertinente para la interpretación de un enunciado. Como es esperable, la mayor parte del conocimiento que es accesible a los interlocutores (conocimientos almacenados en la mente, conocimientos de las circunstancias espacio-temporales, de los participantes o de otros elementos de la interacción concreta) no es relevante para la interpretación de un enunciado. A la hora de interpretar un enunciado, el oyente dispone de un contexto muy extenso (la situación de enunciación, conocimiento compartido con el hablante, conocimientos de su memoria) del cual debe seleccionar los rasgos realmente

\footnotetext{
${ }^{16}$ La teoría del entorno cognoscitivo compartido tampoco está exenta de críticas. Para Escandell Vidal esta teoría es "demasiado restrictiva porque no da cabida a todo el ámbito de información pragmática que se comparte y que puede ponerse en juego en una interpretación” (2006: 34).
} 
importantes y combinarlos con la información lingüística para llevar a cabo una interpretación eficaz.

Según Sperber y Wilson (1995), el oyente presupone que el enunciado es relevante y selecciona el contexto que establecerá la pertinencia de lo que ha oído y no al contrario. Los interlocutores eligen un contexto en virtud del cual el enunciado resulta pertinente. No todos los rasgos contextuales son relevantes en el proceso de interpretación, sino solo aquellos que alteran el entorno cognitivo del oyente. Por lo tanto, para explicar cómo se selecciona el contexto adecuado de un enunciado es necesario hablar del concepto de relevancia, que revisaremos ampliamente en el siguiente apartado.

En esta misma línea cognitiva, Van Dijk (2001) defiende que los interlocutores llevan a cabo una representación mental y subjetiva de la situación comunicativa denominada modelo de contexto o simplemente contexto. Esta teoría del contexto se desarrolla dentro del marco de la teoría psicológica de los modelos mentales (JohnsonLaird, 1983) y permite explicar aspectos de la comunicación como el hecho de que los interlocutores adapten el discurso a la situación social-comunicativa. De nuevo, aquí el contexto no se entiende como algo externo, sino como una representación mental que construyen los propios hablantes. De esta forma, "no es la situación socialcomunicativa la que influye en las estructuras verbales/discursivas, sino su representación mental en cada participante” (Van Dijk, 2001: 71).

Estos modelos del contexto no incluyen todos los conocimientos extraídos de una situación comunicativa, sino que el hablante selecciona solo los aspectos que él considera relevantes en ese momento concreto. Además son personales y subjetivos (dependerán de la experiencia de cada interlocutor, aunque suelen tener bastantes aspectos en común entre los interlocutores que pertenecen a una misma comunidad), dinámicos (están en continuo cambio, se actualizan) y tienen una estructura más o menos fija (aunque las situaciones cambian sus estructuras son parecidas, esto es, podemos hablar de categorías como dominio, participantes, objetivos, escenario, acción, etc., reconocibles en todos los modelos).

Por lo tanto, los hablantes en una interacción comunicativa, antes de producir o interpretar un enunciado, construyen o actualizan un modelo de contexto. Según Van Dijk y Kintsch (1983), esta operación es estratégica. Se lleva a cabo rápidamente 
rellenando primero las categorías más relevantes (participantes, escenario, objetivos) para ese acto comunicativo concreto, y si hay algún error se adapta y se cambia en cuestión de milisegundos.

Como ya hemos ido avanzando, por lo que respecta a la teoría de la relevancia, el contexto se entiende en términos psicológicos, no socioculturales o discursivos. La información que constituye el contexto de cada interacción proviene de la percepción inmediata de la situación comunicativa concreta, de lo que se ha mencionado antes o de la memoria. Lo importante es que los interlocutores comparten o creen compartir una idea parecida de ese contexto y el éxito de la comunicación dependerá, en parte, del conocimiento mutuo: de lo que cada interlocutor sabe y de lo que cada uno sabe que el otro sabe.

Consecuentemente, en este trabajo adoptaremos una perspectiva cognitiva a la hora de acercarnos a la noción de contexto, que definiremos como el conjunto de conocimientos, saberes, supuestos y creencias que nos permiten la comprensión de un enunciado y que se encuentran en nuestra memoria, en el propio discurso previo, en el entorno físico o que proceden de condicionamientos socioculturales (que aprendemos a través de nuestra experiencia en una comunidad determinada). Estos conocimientos y creencias se elaboran y actualizan en el momento de la interacción para cada enunciado concreto.

\subsection{LA TEORÍA DE LA RELEVANCIA COMO INSTRUMENTO DE ANÁLISIS}

\subsubsection{Puntos de partida}

Gran parte de la bibliografía lingüística considera la teoría de la relevancia de Dan Sperber y Deirdre Wilson (1986/1995) como una de las teorías más influyentes en el ámbito de la pragmática (Pons Bordería, 2004). Este modelo ofrece una explicación cognitiva de todos los actos comunicativos lingüísticos, más concretamente, de los procesos que se siguen desde el significado literal hasta la interpretación pragmática. Pertenece, por tanto, a las teorías de inferencia pragmática, ya que pretende explicar cómo el oyente interpreta el significado del mensaje emitido por el hablante apoyándose en factores contextuales.

Esta teoría tiene su asiento en las ideas griceanas (Grice, 1969, 1975) de que el reconocimiento de las intenciones es un rasgo esencial de la comunicación humana y 
en la suposición de que los enunciados generan automáticamente expectativas que guían al oyente hacia el significado que ha querido expresar el hablante. Sin embargo, no debe entenderse como una mera extensión del modelo de Grice, ya que ofrece una manera diferente de explicar el proceso de la comunicación lingüística. De acuerdo con el planteamiento de Grice, los hablantes damos por sentado que en las interacciones comunicativas somos cooperativos, pero la teoría de la relevancia da un paso más y nos explica por qué. La respuesta es sencilla: porque ganamos algo a cambio, obtenemos una modificación o enriquecimiento de nuestro conocimiento del mundo o, en términos de la propia teoría, conseguimos efectos contextuales o cognoscitivos, como explicaremos más adelante.

En el apartado anterior establecimos que en la comunicación lingüística, para comprender el mensaje y entender la intención del hablante, el oyente dispone de la información comunicada directamente, la comunicada indirectamente y la que no se comunica pero se presupone como, por ejemplo, la información sobre la cultura de la que participa el interlocutor (Sperber y Wilson, 1997).

Según la teoría de la relevancia, es común que los enunciados tengan varias interpretaciones que sean compatibles con la información lingüística, pero esas interpretaciones no son igualmente accesibles en cada situación concreta. Esto significa que no todas las interpretaciones posibles se forman con la misma facilidad en la mente del oyente. Así, podemos decir que la comunicación humana busca la relevancia (también denominada comúnmente pertinencia) (Sperber y Wilson, 1982; Wilson y Sperber, 1993, 2002b, 2004). En efecto, cuando procesamos el lenguaje, utilizamos la información contextual relevante para deducir el significado de los enunciados. De esta manera, prestamos atención automáticamente a la información que es relevante para nosotros y no procesamos toda la información disponible ${ }^{17}$. No

\footnotetext{
${ }^{17}$ No solo discriminamos la información sino también los sonidos pertinentes. Este es el conocido cocktail party effect. Dicho efecto se refiere a la capacidad humana de focalizar la atención de la escucha en un solo discurso/sonido aun en medio de otros estímulos auditivos. Este fenómeno se explica como parte del procesamiento auditivo cerebral y de la capacidad de atención selectiva del ser humano. El sistema perceptual humano es muy eficiente en el sentido de que extrae la información relevante necesaria para llevar a cabo el proceso de percepción. Cherry (1957) fue el primero en estudiar de forma sistemática la atención focalizada. Así, en una situación común, como una fiesta, una persona rodeada de gran cantidad de estímulos puede seguir una sola conversación, la de la persona con quien conversa, aun cuando el resto de personas mantienen otras muchas conversaciones a la vez: "One of our most important faculties is our ability to listen
} 
obstante, aunque buscamos instintivamente la información relevante a la hora de interpretar un enunciado, en el procesamiento de la información también son factores a tener en cuenta la atención, la memoria y el razonamiento (Wilson y Sperber, 1988). En las páginas siguientes intentaremos presentar brevemente los fundamentos de esta teoría. Revisaremos los procesos que nos llevan a interpretar los mensajes de nuestros interlocutores, los principios que rigen la comunicación y, específicamente, las aplicaciones a la comunicación lingüística; y todo ello sin olvidar el papel primordial del contexto.

\subsubsection{Los mecanismos de codificación/descodificación y de ostensión/inferencia}

Según la teoría de la relevancia, dos son los procesos que se ponen en funcionamiento en la comunicación humana: el de código y el inferencial. El modelo de código (basado en la codificación y descodificación) empareja las representaciones fonéticas y semánticas de las oraciones con sus significados. De este modo, parte de una señal y desemboca en la recuperación de un mensaje que es asociado a sus premisas por un código. Por su parte, el proceso inferencial (basado en la ostención y la inferencia) parte de un conjunto de premisas y desemboca en una serie de conclusiones que derivan de forma lógica de las premisas o, por lo menos, están garantizadas por estas (Sperber y Wilson, 1995: 12-13).

Ambos mecanismos funcionan autónomamente en áreas cerebrales diferentes (Escandel Vidal, 2006). El mecanismo de codificación/descodificación, a cargo del sistema periférico del cerebro, se ocupa de establecer la proposición ${ }^{18}$ expresada (lo dicho), mientras que el mecanismo de ostensión/inferencia, a cargo del sistema central, se encarga de seleccionar el contexto que se combina con la proposición inicial para determinar la intención del hablante (lo comunicado).

Los procesos de codificación y descodificación han sido ampliamente estudiados por ser considerados la base de la comunicación humana. No obstante, las reflexiones hechas hasta ahora han puesto de relieve que no es posible explicar la complejidad de la comunicación humana basándose únicamente en la existencia de un código común

to, and floow, one speaker in the presence of others...we may call it "the cocktail party problem" (Cherry, 1957: 280).

18 Entendemos por proposiciones las representaciones mentales que construimos cuando procesamos la información del mundo que nos rodea (ya sean signos lingüísticos, conocimientos enciclopédicos, recuerdos, percepciones sensoriales, etc.). 
con una asociación convencional entre señales y mensajes. Nos detendremos, por ello, en el modelo inferencial. En él aparece el término ostensión, que hace referencia a la intención de hacer algo manifiesto. De esta manera, en la comunicación ostensivoinferencial el hablante produce un estímulo ostensivo con el que hace manifiesto al oyente que, a través de dicho estímulo, está tratando de hacer manifiesto un conjunto de hechos. Así, podemos establecer que la comunicación ostensiva consiste en crear un estímulo que atraiga la atención para comunicar que algo es de una determinada manera, con el propósito de que el oyente infiera a qué se está refiriendo el hablante y con qué intención. Consecuentemente, para que dicha comunicación se lleve a cabo con éxito es imprescindible que el oyente reconozca que se trata de un estímulo intencional, que va dirigido a él y que modifica el entorno conscientemente para atraer su atención sobre un conjunto de hechos. Asimismo, en un siguiente paso, para procesar la información de manera eficaz es necesario también que el oyente reconozca la intención comunicativa subyacente. De hecho, en algunos casos, parte de la información básica no resultaría manifiesta en absoluto si no se tomara en cuenta la intención que hay tras la ostensión. Así, en el ejemplo de Sperber y Wilson (1995: 6869), una joven que ha decidido ponerse un vestido veraniego para dar un paseo turístico sale del hotel. Un anciano local, al verla, mira hacia las nubes ostensivamente. La chica, que ya se había percatado de que había algunas nubes, entiende, entonces, que si el anciano se las señala es porque va a llover, ya que él conoce mejor el clima de la ciudad. Por ello, al atraer su atención hacia las nubes, el anciano tiene intención de manifestarle que va a llover. La chica ya era consciente del hecho de que había nubes (era en parte manifiesto para ella), pero con la intención ostensiva del anciano se hace más manifiesto todavía.

Por consiguiente, diferenciamos claramente dos niveles de información que se encuentran en todo estímulo ostensivo:

- un nivel de información básico que se refiere a los propios hechos de los que se dice algo o de los que se informa.

- un segundo nivel que consiste en que dichos hechos están siendo intencionalmente señalados. 
Podemos, entonces, establecer que la comunicación ostensivo-inferencial consiste en "making manifest to an audience one's intention to make manifest a basic layer of information” (Sperber y Wilson, 1995: 54). De modo que puede entenderse en términos de intención informativa e intención comunicativa. La teoría de la relevancia describe la intención informativa como la intención por parte del hablante de modificar el entorno cognitivo del oyente y formula esta intención a través del siguiente criterio: el emisor produce un estímulo con el que pretende hacer manifiesto o más manifiesto para el oyente un conjunto de supuestos.

Por su parte, la intención comunicativa se basa en la idea de que cuando nos comunicativos producimos un determinado estímulo con el objetivo de cumplir una intención informativa, pero, además, tenemos el propósito de hacer mutuamente manifiesto al oyente y a nosotros mismos que tenemos dicha intención comunicativa. De acuerdo con este planteamiento, los autores sugieren que la mayor parte de la comunicación humana es de tipo intencional, ya que nos ofrece beneficios: si ofrecemos pruebas directas de nuestra intención informativa podemos transmitir una gama más amplia de información que la que se transmite ofreciendo pruebas directas de la información básica en sí misma (Sperber y Wilson, 1995: 64).

El mecanismo inferencial radica, esencialmente, en la creación de un supuesto ${ }^{19}$ a partir de otro. La inferencia es, de esta forma, un proceso de razonamiento deductivo. Se parte de ciertas premisas para llegar a una conclusión que se deriva lógicamente de esas premisas, aunque no en el sentido de la lógica clásica.

Según la teoría de la relevancia, el proceso inferencial consiste en la aceptación de un supuesto como verdadero sobre la base de la verdad de otro supuesto. Ahora bien, no todos los supuestos se conciben en la mente con la misma seguridad: consideramos que algunos supuestos tienen más posibilidades de ser ciertos que otros y a la inversa. Así, entre dos supuestos, aquel que se considere con más posibilidades de ser cierto desplazará al otro. Por ejemplo, podemos estar seguros de que hemos guardado el móvil en el abrigo, pero si lo oímos sonar en el salón, el supuesto de que el móvil está en el salón tiene más posibilidades de ser cierto y desplaza al anterior.

\footnotetext{
${ }^{19}$ Por supuesto entenderemos "cada uno de los pensamientos que un individuo tiene catalogados como representaciones del mundo real, esto es, representaciones diferentes de las opiniones personales, las creencias, los deseos, etc.” (Escandell Vidal, 2006: 116-117) y que acepta como verdaderos.
} 
Con todo, Sperber y Wilson afirman que los supuestos están formados por dos representaciones: por un lado, la representación de un estado de cosas, y, por el otro, la representación del valor de confirmación de dicha representación de un estado de cosas. De esta manera, cuando aparecen pruebas nuevas, el valor de confirmación de un supuesto puede aumentar o disminuir. Además, no hay que olvidar que la fuerza de un supuesto depende también de la forma en que se ha adquirido. En orden de importancia primarán aquellos supuestos que procedan de la experiencia directa del hablante, seguidos de los transmitidos por otras personas (que a su vez dependen de la credibilidad que concedamos a dichas personas) y de aquellos a los que llegamos a través de vías deductivas (que también dependen de la fuerza de sus premisas). De todo esto se deduce que el peso de los supuestos puede variar con el tiempo y las circunstancias. Cuando el individuo dispone de nuevos datos sobre un conjunto de hechos puede modificar el supuesto que le había comunicado otro, por ejemplo.

De este modo, la fuerza de un supuesto es de vital importancia a la hora de extraer inferencias. Un supuesto cuya validez sea prácticamente absoluta derivará en una inferencia más fuerte que la que se deriva de un supuesto más dudoso.

Como hemos establecido anteriormente, el proceso inferencial es un mecanismo deductivo. Sperber y Wilson (1995: 132-133) distinguen dos tipos diferentes de reglas deductivas: las reglas analíticas y las reglas sintéticas. Las reglas analíticas toman un solo supuesto como base, y por ello la conclusión o implicación que se deriva tiene el mismo grado de validez que el supuesto del que se deduce. Por su parte, las reglas sintéticas toman como base dos supuestos diferentes, de manera que la implicación será verdadera solo si los dos supuestos lo son.

El mecanismo deductivo deriva primero las implicaciones analíticas de un supuesto y, a continuación, deriva las implicaciones sintéticas que se puedan obtener al combinar este nuevo supuesto con los supuestos ya existentes en la memoria del sujeto. Estas conclusiones se denominan efectos contextuales. Así, ante un nuevo enunciado, procesamos la información nueva junto con la que ya poseíamos en nuestra memoria a través de un mecanismo deductivo. Puede ocurrir que la información proveniente de este nuevo enunciado refuerce un supuesto ya asentado o, por el contrario, que contradiga un supuesto previo. En este caso nos decantaríamos por la implicatura derivada del supuesto con más fuerza, como vimos anteriormente. 
Ahora bien, aunque los mecanismos de codificación e inferencia son esencialmente independientes, suelen combinarse para reforzarse y favorecer la eficacia de la comunicación. Puede ocurrir que un mensaje lingüístico no codifique directamente el contenido que se quiere transmitir, pero funcione como estímulo ostensivo y alerte al oyente para que construya la inferencia necesaria; y así descubra la intención comunicativa que hay tras el mensaje. Consideremos el siguiente ejemplo:

(1) Esta cocina es una cochiquera.

Este enunciado contiene una afirmación claramente falsa una vez codificado el mensaje, pero podemos llegar al contenido que se quiso transmitir si seguimos el siguiente proceso inferencial: por nuestro conocimiento enciclopédico sabemos que las cochiqueras son establos para cerdos y, por lo tanto, están sucios y llenos de porquería. Si se dice literalmente que esa cocina es una cochiquera, se está comparando con un establo de cerdos. Si pensamos en qué pueden tener en común, llegamos a la conclusión de que se está diciendo que está muy sucio y huele mal. De esta forma, en (1) el oyente no solo debe codificar el significado lingüístico, sino que a partir de él tiene que inferir qué pretendió decir el hablante con dicho enunciado. Así, se codifica un mensaje diferente del que se transmite, que sirve de estímulo ostensivo para desencadenar un proceso de inferencia que lleva al contenido que se quiso comunicar.

\subsubsection{La relevancia: condiciones y principios}

Hasta ahora hemos sugerido que, en las interacciones comunicativas, esperamos que lo que nos comunique nuestro interlocutor contribuya a enriquecer o modificar de algún modo nuestro conocimiento del mundo o, lo que es lo mismo, esperamos recibir efectos contextuales ${ }^{20}$. Pues bien, tener efectos contextuales es una de las condiciones necesarias para la relevancia. En igualdad de condiciones, cuanto mayores sean los efectos contextuales, mayor será la relevancia. Por tanto, un supuesto que carezca de efectos contextuales en un contexto determinado es irrelevante en dicho contexto. Según Sperber y Wilson (1995: 121), existen tres tipos de casos en los que un supuesto es irrelevante en un contexto:

\footnotetext{
${ }^{20}$ Una nueva información puede tener efectos contextuales de dos maneras:

a) la información nueva refuerza información ya existente en la memoria,

b) la información nueva contradice o debilita la información que se poseía anteriormente. 
- El supuesto aporta información nueva, pero esta información no guarda conexión con ninguna información del contexto.

- El supuesto ya estaba presente en el contexto y su fuerza no se ve afectada por la información que se presenta.

- El supuesto es incoherente en el contexto y si se procesara no provocaría ningún cambio en el contexto.

Cabe resaltar que en estos tres casos solo es el supuesto explícitamente expresado el que carece de efectos contextuales. La relevancia podría lograrse, sin embargo, expresando supuestos irrelevantes, siempre y cuando esta conducta expresiva sea en sí misma relevante.

Ahora bien, el concepto de relevancia no es un concepto absoluto: puede hablarse de distintos grados de relevancia. Para determinar dichos grados, no solo debemos tener en cuenta el factor de los efectos cognoscitivos de un supuesto. Como sabemos, los efectos cognoscitivos o contextuales son ocasionados por los procesos mentales. Estos procesos mentales implican a su vez cierto esfuerzo, cierto gasto de energía. Por consiguiente, el esfuerzo de procesamiento implicado en conseguir efectos contextuales constituye la segunda condición que debe tenerse en cuenta para establecer el grado de relevancia. En este caso, se trata de un condicionante negativo, ya que, en igualdad de condiciones, cuanto mayor sea el esfuerzo de procesamiento menor será la relevancia. Así, para medir ${ }^{21}$ la relevancia de un enunciado, debe calcularse la relación entre efectos contextuales y esfuerzo de procesamiento, como queda representado en la siguiente fracción:

$$
\text { Relevancia }=\frac{\text { Efectos contextuales }}{\text { Esfuerzo de procesamiento }}
$$

Los seres humanos, según Sperber y Wilson, somos eficientes en el procesamiento de la información: tendemos a equilibrar ganancia y esfuerzo, esto es, a

\footnotetext{
${ }^{21}$ Como era esperable, no puede plantearse una definición cuantitativa de relevancia. La relevancia es una propiedad que no necesita ser calculada para poder alcanzarse. Cuando se la representa se hace en términos de juicios comparativos y de juicios absolutos aproximados, pero no en términos de juicios absolutos exactos, es decir, cuantitativos (Sperber y Wilson, 1995: 132).
} 
lograr lo propuesto con el menor coste posible. De esta forma, cuantos más efectos contextuales produzca un enunciado y menos esfuerzo de interpretación requiera, más relevante será. De ahí se deduce que con respecto a los efectos contextuales, se presupondrá que el nivel de efectos conseguibles nunca será inferior al necesario para hacer que merezca la pena procesar el estímulo; y, con respecto al esfuerzo, se presumirá que el nivel de esfuerzo requerido nunca será mayor que el preciso para obtener dichos efectos.

Una vez establecido que la relevancia deriva de la relación entre un supuesto y un contexto, la siguiente cuestión que nos planteamos es cómo se determina ese contexto respecto al cual una información resulta más o menos relevante o, en otras palabras, cómo se selecciona un determinado subconjunto dentro del conjunto total de supuestos de un individuo. Para responder a esto es necesario recordar la interpretación de la noción de contexto que produce esta teoría. Como vimos en el apartado anterior ${ }^{22}$, para Sperber y Wilson en la interpretación de un enunciado no existe un contexto inicial fijado de antemano, sino que se elige en cada momento de la interacción. Para cada uno de los elementos de la nueva información podrían seleccionarse como contexto muchos conjuntos de supuestos diferentes procedentes de fuentes como la percepción, la descodificación lingüística, la memoria enciclopédica o el propio mecanismo deductivo. Sin embargo, será el oyente el que los seleccione en cada situación concreta teniendo como meta primordial la búsqueda de la relevancia. Cabe puntualizar que la elección del contexto forma parte del proceso de interpretación en sí mismo. De esta manera, al contrario de lo que podríamos pensar, lo dado no es el contexto, sino la presunción de que lo expresado por el mensaje es relevante. El oyente que interpreta un estímulo lo hace pensando que va a ser pertinente, y por ello selecciona un contexto (dentro del conjunto total de supuestos posibles) que justifique esa expectativa, esto es, que maximice la relevancia.

En el proceso de interpretación, el oyente dispone de un conjunto de contextos más o menos accesibles. Lógicamente, acceder a un contexto supone también cierto esfuerzo, por lo que cuanto menos accesible sea un contexto mayor será el esfuerzo requerido para llegar a él y viceversa. Por consiguiente, para Sperber y Wilson (1995:

\footnotetext{
${ }^{22}$ Véase 1.2.
} 
141-142), conseguir la relevancia máxima implica seleccionar el contexto que permita conseguir el mejor equilibrio entre efecto y coste.

Aquí hay que puntualizar que el contexto inicial se puede ir ampliando en diferentes direcciones. Puede recurrirse a supuestos procesados en enunciados anteriores en el intercambio verbal, a entradas enciclopédicas de los conceptos que ya están presentes en el contexto, a información procedente del entorno inmediato, etc. No obstante, parece razonable suponer que las ampliaciones se producen solo cuando son necesarias. El oyente dejará de ampliar el contexto cuando las implicaciones contextuales le satisfagan.

En definitiva, nuestro sistema cognitivo está entrenado para seleccionar los supuestos más prominentes e interpretarlos de la manera más eficaz posible (esto es, con un coste de procesamiento mínimo y con efectos contextuales tan amplios como sea posible). Así, el oyente sigue un camino del mínimo esfuerzo de procesamiento cuando accede a la información contextual y se detiene cuando la interpretación cumple sus expectativas de relevancia (Sperber y Wilson, 1995; Wilson, 2000; Wilson y Sperber, 2004).

Esta tendencia a potenciar la eficacia cognitiva (e ir directamente a la información relevante) que hemos desarrollado a lo largo de los párrafos anteriores queda formulada en el primer principio de relevancia ${ }^{23}$ :

- First, or cognitive principle of relevance: "Human condition tends to be geared to the maximisation of relevance" (Sperber y Wilson, 1995: 260).

${ }^{23}$ En la primera edición de Relevance. Comunication \& Cognition (1986) solo aparece un principio de relevancia; sin embargo, en la segunda edición de 1995, este principio es denominado principio comunicativo de relevancia o segundo principio de relevancia y se añade el principio cognitivo de relevancia o primer principio de relevancia. Wilson justifica este cambio en un trabajo posterior: "The move from one to two Principles of Relevance was purely terminological, and was designed to draw attention to the distinction between maximal and optimal relevance, which our earlier formulation had obscured. In the first edition, we distinguished between maximal relevance (the greatest possible effects for the smallest possible effort) and optimal relevance (adequate effects for no unjustifiable effort), and argued that while cognition tends to be geared to the maximisation of relevance, communication merely creates an expectation of optimal relevance. Two generalisations were made, but only the second was singled out and called a Principle of Relevance. This led to misunderstandings. Reviewers tended to overlook the distinction between maximal and optimal relevance, and took us to be arguing for a single principle of maximal relevance, governing both communication and cognition. By distinguishing two Principles of Relevance, we hope to avoid this situation” (Higashimori y Wilson, 1996: 112). 
Asimismo, partiendo del supuesto de que para que haya comunicación tiene que haber intención comunicativa, se deriva la idea de que los estímulos producidos de manera intencional por parte del hablante crean una presunción de relevancia lo suficientemente precisa para conducir al oyente hacia la interpretación correcta, lo cual queda recogido en el segundo principio de relevancia:

- Second, or communicative principle of relevance: "Every act of ostensive communication communicates a presumption of its own optimal relevance" (Sperber y Wilson: 1995: 158).

Los hablantes asumimos que nuestro esfuerzo será recompensado con información relevante sobre las intenciones del emisor. La óptima relevancia significa que un enunciado es lo suficientemente relevante para que el oyente haga el esfuerzo de procesarlo y lo suficientemente claro de forma que el hablante manifieste su intención.

Como avanzábamos al principio de este capítulo, aunque esta teoría se asienta sobre las ideas de Grice $(1969,1975)$, existen muchos aspectos en los que difiere del enfoque griceano. Uno de ellos es que los principios de relevancia son más explícitos que el principio de cooperación y las máximas ${ }^{24}$ de Grice. Otro es que alcanzar la relevancia óptima es menos costoso que seguir las máximas de Grice. Por ejemplo, tal como reconocen Sperber y Wilson (1995: 162), es posible ser óptimamente relevante sin ser "tan informativo como lo requiera el propósito del intercambio", según postula la máxima de cantidad.

Pero, sin duda, la diferencia más importante se refiere a la explicación de la comunicación. Cuando Grice define la comunicación distingue entre lo explícito (que da por supuesto que se explica con el modelo de código) y lo que se implica (que se entiende como supuestos que el hablante deduce partiendo de que las máximas o, al menos, el principio de cooperación han sido respetados). Por su parte, el principio de relevancia explica la comunicación ostensiva en su totalidad, tanto la comunicación explícita como la implícita.

\footnotetext{
${ }^{24}$ El principio de cooperación de Grice (1975) se formula de la siguiente forma: "Haga que su contribución a la conversación sea, en cada momento, la requerida por el propósito o la dirección del intercambio comunicativo en el que está usted involucrado”. Este principio se desarrolla en otras normas de menor rango llamadas máximas: de cantidad, de cualidad, de relación y de modalidad (1975: 45-47).
} 
Las máximas de Grice resultan quizá demasiado restrictivas: el principio de relevancia parece suficiente para explicar la comunicación humana. Surge como una tendencia natural de los seres humanos a maximizar los efectos obtenidos de los estímulos ostensivos que reciben. Este principio no se ve como una máxima del tipo de las de Grice, ya que no puede ser transgredido o cumplido. Los hablantes no pueden violar el principio de relevancia aunque quieran, ni tampoco aprenderlo, de hecho, no suelen ser conscientes de su existencia. Además, se aplica a todos los actos de comunicación intencional, sin ninguna excepción. Si es cierto que el hablante podría fracasar en su intento comunicativo y no ser relevante. No obstante, es suficiente con que su enunciado transmita la presunción de óptima relevancia, puesto que dicha relevancia determina la interpretación del enunciado en cuestión. Lo que el oyente utiliza en la comprensión no es el principio general, sino "the fact that a particular presumption of relevance has been communicated by and about a particular act of communication” (Sperber y Wilson, 1995: 162).

En definitiva y recapitulando, en la comunicación ostensivo-inferencial, el éxito depende de la capacidad del oyente para inferir las intenciones del hablante. Así, para reconocer la intención informativa del hablante, el oyente debe averiguar con respecto a qué conjunto de supuestos el hablante tenía razones para creer que confirmaría la presunción de relevancia. La labor del oyente consistirá, entonces, en construir las posibles hipótesis interpretativas y elegir la pretendida por el hablante. Para ello el oyente podría elaborar una lista e ir comprobando una a una las distintas hipótesis. Sin embargo, dado el entorno cognitivo, el contexto y el estímulo ostensivo concreto, unas hipótesis resultarán más accesibles que otras, o en otras palabras, requerirán menor esfuerzo de procesamiento. Por tanto, según la teoría de la relevancia, la primera interpretación accesible y coherente con el principio de relevancia es la que el hablante pretendía transmitir.

Ahora bien, si dos interpretaciones diferentes son igualmente accesibles para el oyente y ambas son coherentes con el principio de relevancia, el oyente no será capaz de decidir cuál era la pretendida y la comunicación fallará. No obstante, normalmente se deja que el hablante se encargue de construir los supuestos sobre qué interpretación será más accesible en el proceso de comprensión. De esta forma, la responsabilidad de evitar malentendidos recae sobre el hablante, ya que el oyente confía en su interlocutor 
y supone que la interpretación pretendida es realmente la primera interpretación óptimamente relevante que viene a su mente.

\subsubsection{La aplicación de la teoría de la relevancia al estudio de la comunicación verbal}

A la vista de lo anterior, parece claro que la teoría de la relevancia se presenta como una tendencia general usada para explica cualquier tipo de comunicación ostensiva. Centrémonos ahora en la comunicación verbal y en el análisis de esta partiendo de los principios de relevancia.

Frente a denominaciones más generales como mensaje, el término enunciado ${ }^{25}$ se emplea específicamente para hacer referencia a un mensaje construido siguiendo un código lingüístico concreto. Por lo tanto, un enunciado se concibe como un estímulo ostensivo de carácter lingüístico. Así, este estímulo lingüístico, una vez identificado por la mente del oyente, desencadena automáticamente un proceso de descodificación y un proceso de tipo inferencial que llevan, finalmente, a la identificación de la intención del emisor.

Vayamos paso a paso. El oyente, al percibir el estímulo lingüístico o enunciado, pone en marcha un mecanismo automático (a menudo ni siquiera es consciente de ello) de descodificación por el que recupera su representación semántica. Ahora bien, siguiendo los postulados de la teoría de la relevancia, la interpretación correcta de un estímulo ostensivo es la primera interpretación accesible coherente con el principio de relevancia. Por lo general, esta será una interpretación basada en las propiedades semánticas, aunque en algunos casos excepcionales ${ }^{26}$, estas no proveerán una

\footnotetext{
${ }^{25}$ La mayor parte de los manuales de pragmática entienden que un enunciado corresponde a cada una de las intervenciones de un interlocutor, por lo que está delimitado por el cambio de emisor y no puede caracterizarse utilizando criterios gramaticales sino discursivos. De esta manera, puede establecerse la distinción entre enunciado y oración. Una oración es una entidad abstracta que se define y evalúa siguiendo criterios de naturaleza gramática; por el contrario, el enunciado es una secuencia lingüística emitida por un hablante concreto en una situación concreta y se evalúa según criterios pragmático-discursivos. Así, la realización de una oración puede constituir un enunciado, pero no todo enunciado es la realización de una oración (Escandell Vidal, 2006: 30-31)

${ }^{26}$ Uno de estos casos poco comunes es ejemplificado por Sperber y Wilson (1995: 178) con el siguiente diálogo:

A: Did your treatment for stammering work?

B: Peter Piper picked a peck of pickled pepper

A: How amazing!

B: Sí, b-b-but th-th-that’s not s-s-something Iv-v-very often w-w-want to say. 
interpretación adecuada y será necesario recurrir a otras propiedades que sí lo hagan, sin apartarnos con ello del principio de relevancia.

A continuación, la labor del oyente incluirá una serie de tareas inferenciales. La primera consiste en asignar al enunciado una forma proposicional única. Para ello es necesario resolver la ambigüedad de la oración transmitida en el enunciado, esto es, elegir una entre las posibles representaciones semánticas que la gramática puede asignarle. También es necesario determinar un referente a cada expresión que establezca una referencia, así como completar e enriquecer dicha representación semántica para que refleje la forma proposicional expresada por el enunciado.

Una vez construida dicha forma proposicional explícita, el oyente tiene que identificar la actitud proposicional, y para ello habrá de determinar la modalidad. Por ejemplo, si el enunciado tiene una entonación descendente, la modalidad será enunciativa (“el hablante dice que”); frente a si la entonación es ascendente, en cuyo caso la modalidad será interrogativa (“el hablante pregunta si”). Así, el modo también determina la actitud proposicional expresada. No obstante, aun conociendo la modalidad, el oyente puede seguir ignorando la actitud proposicional que quería transmitir el hablante. En el caso del modo enunciativo, el hablante puede estar diciendo que $\mathrm{X}$, o bien comunicando que cree que $\mathrm{X}$. Asimismo, con la modalidad interrogativa pueden expresarse objetivos transaccionales e interaccionales. El hablante puede estar pidiendo información como en (2a) o comunicándola como en (2b):

(2) a. ¿Este autobús va a la estación de trenes?

b. ¿ंSabes que Juan se va a casar?

Efectivamente, determinar la actitud proposicional será necesario para saber qué quería decir nuestro interlocutor con el enunciado, es decir, identificar la intención del hablante. De esta forma, junto con la información mutuamente manifiesta, el oyente va a inferir otros supuestos o implicaciones contextuales combinando la forma proposicional explícita con supuestos procedentes de la información contextual, la memoria enciclopédica, etc.

Aquí comprobamos que en este caso no son las propiedades semánticas las que proporcionan la interpretación adecuada sino las acústicas. 
Llegados a este punto es necesario diferenciar entre comunicación explícita y comunicación implícita y, consecuentemente, entre explicaturas e implicaturas. Como ya hemos avanzado, Sperber y Wilson (1995: 182) rechazan la distinción clásica que postula que el contenido explícito de un enunciado son los supuestos descodificados y el contenido implícito, los inferidos. Según el modelo de Grice (1975: 48-51), el contenido explícito de un enunciado se recupera cuando se reconoce la forma y la actitud proposicionales, de manera que cualquier otro supuesto (descodificado o inferido) se considera implícito. Las implicaturas que él denomina convencionales son las implicaturas descodificadas, y las no convencionales (dentro de las cuales se encuentran las conversacionales) son las implicaturas inferidas. Pues bien, en la teoría de la relevancia, no existen implicaturas convencionales en el sentido griceano, sino que el lado explícito de la comunicación se considera también inferencial. En otras palabras, para Sperber y Wilson, la recuperación de cualquier supuesto requiere siempre la intervención de elementos de naturaleza inferencial.

Una vez precisado este nuevo enfoque, definiremos las nociones de explicatura e implicatura dentro de la teoría de la relevancia. La explicatura de un enunciado es la forma proposicional completa que estaba en la intención del hablante. Es el resultado de la descodificación y de los procesos inferenciales de desambiguación, asignación de referencia y enriquecimiento. Así, en cada uno de estos procesos, el oyente tiene que seleccionar la opción más accesible (que implique menos esfuerzo), a menos que no produzca una interpretación coherente con el principio de relevancia en cuyo caso debería ser abandonada. Como era de esperar, la selección implica factores contextuales. Consideremos el siguiente ejemplo:

(3) El casco estaba limpio.

En este enunciado, para desambiguar el término casco no basta con conocer todas sus acepciones, esto es, no basta con un conocimiento completo del código lingüístico, es necesario también tener en cuenta la situación y el entorno en el que tiene lugar el acto comunicativo.

La desambiguación, como hemos visto en (3), consiste en averiguar a qué significado nos estamos refiriendo con el significante casco. Para ello, hemos de hacer uso de la información contextual: si estamos visitando una nueva ciudad, se referirá al 
conjunto de edificaciones de esta; si estamos en una carrera de ciclismo, se referirá a la cobertura que se usa para proteger la cabeza ante posibles caídas, y así sucesivamente.

La asignación de referentes consiste en determinar a qué ente concreto (más específicamente a su representación mental) hace referencia una determinada expresión lingüística. Veamos un ejemplo:

(4) Pásame eso.

Si seguimos el principio de relevancia, primero habría que considerar el contexto inmediato y ver si alguno de los conceptos de identidad no humana (existentes en dicho contexto) presenta una forma proposicional coherente con el principio relevantista cuando se sustituye por eso. Si no es así, habría que repetir el procedimiento ampliando el contexto.

Finalmente, el enriquecimiento es el proceso por el cual se termina de completar la información que no estaba bien especificada. Las representaciones semánticas son formas lógicas incompletas no solo porque contienen expresiones referenciales indeterminadas (como en 4), sino también porque contienen constituyentes vagos o poco definidos.

(5) La niña tiene ya cierta edad.

Aquí nos encontramos ante una nueva indeterminación. Cierta tiene un significado vago que debemos enriquecer con ayuda del contexto. En esta situación, al referirnos a una persona, puede denotar que la niña en cuestión es “ya mayor” para hacer ciertas cosas como volver sola del colegio. La interpretación cambiaría radicalmente si nos refiriéramos a una persona de avanzada edad. Es este caso significaría que es demasiado mayor para hacer algo como, por ejemplo, conducir.

$\mathrm{Al}$ igual que en la asignación de referentes, en el proceso de enriquecimiento, la elección entre las varias posibilidades se hace de forma casi inconsciente a favor de la que implica menor esfuerzo de procesamiento. Solo si la forma más accesible o evidente no funciona entramos en un proceso consciente de decisión.

Como avanzábamos antes, la explicatura de un enunciado es la proposición resultante tras estos tres mecanismos inferenciales. Este análisis ofrece, efectivamente, una explicación de cómo entendemos lo explícito, aplicando el mismo principio de relevancia que se emplea para inferir implicaturas. 
Por lo que respecta al concepto de implicatura, la teoría de la relevancia postula que las implicaturas de un enunciado se obtienen haciendo referencia a las expectativas manifiestas del hablante sobre cómo el enunciado debería lograr su óptima relevancia. Veamos un ejemplo:

(6) A.- ¿ 'Te vienes a ver el partido?

B.- Mañana tengo examen de Historia.

Ante la pregunta de A, B no contesta directamente (esto es, explícitamente), pero hace manifiesta una respuesta intencionada y contextualmente implicada. Pues bien, dicha respuesta implicada es una implicatura de su enunciado. Se trata, entonces, de un supuesto o implicación contextual que el emisor ha querido hacer manifiesto al oyente sin expresarlo explícitamente.

Ahora bien, las implicaturas pueden provenir de diferentes fuentes: pueden recuperarse de la memoria enciclopédica, tomarse del contexto o inferirse a través de un mecanismo deductivo partiendo de las explicaturas y del contexto. Hay, por tanto, dos clases diferenciadas de implicaturas: las premisas implicadas y las conclusiones implicadas. Las premisas implicadas tiene que proporcionarlas el oyente, bien recuperándolas del contenido del conocimiento enciclopédico, o bien construyéndolas a través del desarrollo de esquemas de supuestos rescatados de la memoria. De esta forma, lo que permite identificar dichas premisas como implicaturas es que conducen a una interpretación coherente con el principio de relevancia y que, por tanto, son las premisas más fácilmente accesibles para llegar a dicha interpretación.

Con respecto a las conclusiones implicadas, estas se deducen de las explicaturas y premisas implicadas del enunciado y del contexto. En este caso no debe aportarlas el oyente, sino que se obtienen como consecuencia lógica de la combinación de los supuestos conocidos previamente. Lo que permite identificar dichas conclusiones es que el hablante tiene que haber esperado que el oyente las derivara, puesto que quería que su enunciado fuera manifiestamente relevante para su interlocutor. Imaginemos el siguiente diálogo:

(7) A.- ¿'Te has comido mi Bollycao?

B.-Yo no como grasas saturadas. 
De él podemos extraer las implicaturas correspondientes:

Explicatura: "Yo no como grasas saturadas"

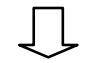

Premisa implicada: "La bollería industrial contiene muchas grasas saturadas"<smiles>[TeH]</smiles>

Conclusión: "Yo no como Bollycaos"<smiles>[TeH]</smiles>

Conclusión implicada: "Yo no me he comido tu Bollycao"

Tanto las premisas como las conclusiones implicadas se consideran supuestos plenamente determinados, por lo que el hablante es tan responsable como si los hubiera afirmado explícitamente. El emisor previamente habrá valorado los conocimientos previos, los supuestos y los recursos de los que dispone el oyente. Ahora bien, puede ocurrir que el hablante haya sobrevalorado a su interlocutor y le haya creído capaz de aportar unas premisas que desconoce, en cuyo caso la comunicación fallará. Sin embargo, este fallo no se puede atribuir al razonamiento implicado por el hablante ni a la presunción de relevancia, sino a la creencia equivocada de que el oyente seleccionará el contexto adecuado. Además, incluso en este caso, la interpretación del oyente habrá seguido el proceso inferencial que postula la teoría la relevancia.

En los ejemplos de (6) y (7) hemos visto que B opta por dar una respuesta indirecta. Cabría preguntarse, entonces, por qué lo hace pudiendo ofrecer una respuesta directa más sencilla. Del principio de relevancia se desprende que, al darle una respuesta indirecta, B espera conseguir algunos efectos contextuales adicionales que compensarían el esfuerzo de procesamiento añadido para obtener la premisa y deducir la conclusión implicada. La respuesta de B en (7) da acceso a A a los contenidos de su memoria enciclopédica sobre las grasas saturadas. Así pues, la respuesta indirecta abre una serie de posibilidades de interpretación que no se encontrarían en una respuesta negativa directa del tipo "no me he comido tu Bollycao", puesto que también se comunica un supuesto del hablante sobre las grasas saturadas: no las come. Al mismo tiempo, otros supuestos (causas, consecuencias, extensiones, etc. de las implicaturas) se insinúan: por ejemplo, que tampoco comerá 
hamburguesas ni patatas fritas, que desaprueba que su interlocutor coma muchas grasas saturadas, etc.

De lo anterior se deriva que las implicaturas de un enunciado, al igual que ocurre con los supuestos de los que hablamos al principio de este apartado, pueden variar en grados de fuerza. Las implicaturas más fuertes - tanto premisas como conclusionesson aquellas que están totalmente predeterminadas, esto es, aquellas que realmente han de proporcionarse para que la interpretación sea coherente con el principio de relevancia, de las que el hablante se hace totalmente responsable y el oyente se ve fuertemente inducido a inferirlas. Cuanto más débil sea la inducción y cuanta más cantidad posibilidades de entre las que elegir haya, más débil será la implicatura. Esto es lo que sucede con las implicaturas del tipo "B desaprueba que A coma grasas saturadas”. Cabe esperar que de esta implicatura no se pueda responsabilizar al emisor, ya que no está predeterminada y no es imprescindible para mantener la relevancia. Efectivamente, puede ocurrir que sobre la base de un mismo entorno cognitivo dos personas conciban supuestos diferentes. Así, cuanto más débiles sean las implicaturas, más dudas tendrá el oyente sobre si sus implicaturas se corresponden con la intención comunicativa del hablante.

Como avanzábamos al comienzo de este apartado, la teoría de la relevancia da una explicación exhaustiva del funcionamiento de los mecanismos mentales que intervienen en la interpretación de estímulos ostensivos. En estas líneas hemos fijado los aspectos más interesantes, así como los conceptos y principios que sirven de fundamento y que aplicaremos posteriormente en nuestro estudio. Reconocemos, no obstante, que se detecta cierta desatención hacia los mecanismos que hacen posible la producción de los enunciados, desde el momento en que el emisor tiene una intención comunicativa hasta que la verbaliza. Sin embargo, el cuerpo de este estudio está orientado también hacia la interpretación, por lo que no se ve afectado por esta carencia. Por ello hemos considerado provechoso tomar como modelo teórico de fundamentación la teoría de la relevancia. 


\section{CAPÍTULO 2}

\section{HACIA LA NOCIÓN DE COMPETENCIA PRAGMÁTICA}

\subsection{CONOCIMIENTO Y HABILIDAD PARA EL USO DE LA LENGUA}

\subsubsection{El concepto de competencia comunicativa}

Antes de profundizar en la noción de competencia pragmática, creemos oportuno partir del concepto de competencia comunicativa, que incluye como uno de sus componentes a aquella. Es consabido que la competencia comunicativa de los hablantes ha llegado a constituir el objeto fundamental para las teorías lingüísticas actuales que pretenden describir y explicar el conjunto de conocimientos y habilidades que permiten a los usuarios comunicarse de forma adecuada, apropiada y eficaz. No obstante, el concepto de competencia comunicativa es también ciertamente controvertido (Groot, 1975; Taylor, 1988). Probablemente esto se debe, entre otras cosas, a que esta noción es más utilizada en las aplicaciones de la lingüística que en la propia teoría lingüística. En efecto, creemos que generalmente no se trabaja sobre el concepto de competencia comunicativa (y su alcance) sino sobre su aplicación. En este sentido es significativo el hecho de que haya sido la lingüística aplicada (especialmente en ámbitos como la enseñanza/aprendizaje de lenguas extranjeras) la más interesada en apoyarse en el concepto de competencia comunicativa, con el fin de establecer principios y diseñar metodologías docentes y pruebas de evaluación. Así, a partir del año 1972, en la mayoría — si no todos— los manuales de enseñanza de lenguas extranjeras se utilizan constantemente términos como competencias comunicativas o comunicación con intención de señalar su distanciamiento de los modelos más formales. Sin embargo, a pesar de ser términos comúnmente recurrentes no se definen, solo se aplican.

En estos años, buena parte del trabajo sobre este concepto son aplicaciones en las que se considera que con los enfoques estructurales se desatiende el estudio de las modalidades de uso, de los actos de habla y de las normas socioculturales que rigen las interacciones. Esto lleva, consecuentemente, a deficiencias en el desarrollo de las capacidades comprensivas y expresivas de los hablantes. 
En líneas generales podemos entender la competencia comunicativa como una suma de capacidades y destrezas de interacción relacionadas con habilidades verbales y no verbales (Lomas, Osoro y Tusón, 1993; Codina, Fortanet y Otal, 1996; Portillo Mayorga, 2003; Lacorte, 2007; etc.). Estas destrezas se apoyan en conocimientos sobre patrones de actuación lingüística (los propios de los actos de habla concretos), sobre las posibles variantes lingüísticas y sobre los significados de esas variantes en situaciones de habla concretas. Las destrezas de interacción integran capacidades como la percepción de los rasgos sobresalientes de las acciones comunicativas, o la selección e interpretación de las formas apropiadas con respecto a la situación, los papeles y las relaciones en una acción comunicativa. También suponen habilidades para la organización textual y la regulación del discurso (Álvarez, 1995), conocimientos sobre las normas de interacción involucradas en la interpretación y procesamiento de los mensajes y, finalmente, capacidades estratégicas enfocadas a la consecución de objetivos (Kasper y Kellerman, 1997). Asimismo, el conocimiento cultural integrado en la competencia comunicativa incluye, ante todo, conocimientos sobre la estructura social, sobre actitudes, valores y normas y sobre el manejo adecuado de guiones o scripts y mapas o esquemas cognitivos ${ }^{27}$ (Bateson, 1972; Goffman, 1974; Fillmore, 1977; Tannen y Wallat, 1987).

La noción de competencia surge dentro del paradigma generativo con el lingüista Noam Chomsky. Chomsky (1965) postula, como una de las necesidades de una teoría lingüística general, la explicación de las capacidades mentales que permiten la adquisición del lenguaje y que posibilitan la creatividad lingüística que poseen los usuarios nativos de cualquier lengua. Este autor advierte que cada hablante desarrolla su conocimiento lingüístico (de la gramática) a partir de datos escasos e inconsistentes, de forma que es capaz de producir y comprender frases que no ha oído ni visto antes.

Chomsky establece también la conocida distinción entre competencia y actuación. Por competencia entiende el conocimiento que el hablante-oyente tiene de la lengua y por actuación, el uso real de la lengua en situaciones concretas (Chomsky, 1965). Sin embargo, este autor no se preocupa por el uso del lenguaje o su aplicación en la enseñanza de lenguas, sino que dirige sus atenciones al desarrollo de una teoría lingüística centrada en reglas, y después principios, gramaticales. Esta teoría toma

\footnotetext{
${ }^{27}$ De ellos hablamos en el capítulo 1. Véase apartado 1.2. 
como unidad de estudio los enunciados de una sola oración y se desentiende del uso y el contexto. Por tanto, su concepto de competencia será limitado, ya que solo tiene en cuenta la gramática y no se interesa por la realización del comportamiento lingüístico, ya sea de carácter comunicativo o de otro tipo. Así, en la teoría de Chomsky no cabe hablar de variación, de lo individual o de lo esporádico, de manera que el análisis lingüístico se resuelve en juicios universales.

Múltiples han sido las desviaciones de la visión chomskiana (no solo las que dejan fuera el uso de la lengua, sino incluso aquellas que se centran únicamente en la competencia gramatical ${ }^{28}$ ). Entre los autores que ofrecen una perspectiva diferente a la de Chomsky destacan lingüistas como Lyons — que reivindica el carácter social de la competencia y señala que el hablante no solo ha de saber producir enunciados gramaticalmente correctos sino también acordes a la situación social en la que se emiten (Lyons, 1970: 287) — o Campbell y Wales (1970: 247), que destacan la importancia de la adecuación al contexto.

La ampliación del concepto de competencia lingüística de Chomsky viene de la mano del etnógrafo del habla Dell Hymes. Hymes $(1968,1971,1972)$ creyó necesario para el desarrollo de la lingüística en uso ampliar la noción de competencia, de forma que no se restringiera a los parámetros de una comunidad homogénea y de un conocimiento perfecto. Si se analiza la lengua de una determinada comunidad simulando que esta sea uniforme, trabajaremos sobre una idealización que en la práctica encuentra muchos obstáculos. Por el contrario, si partimos de la diversidad, se puede observar la homogeneidad que ciertamente existe. Los niños, a lo largo del proceso de adquisición, van abstrayendo reglas tanto gramaticales como de uso de formas diferentes para situaciones distintas, pero no podemos asumir una competencia análoga entre el individuo y la lengua del grupo.

Consecuentemente, Hymes defiende que para que la comunicación lingüística se dé de una manera apropiada, el hablante tiene que conocer un sistema de reglas lingüísticas (reglas sintácticas, fonológicas y semánticas reconocidas por Chomsky), así como un sistema de principios de uso que establezca relación con el contexto de

\footnotetext{
${ }^{28}$ Widdowson (1989) pone de relieve que las reglas gramaticales no explican las expresiones lexicalizadas que son un componente importante de la competencia lingüística. Por ejemplo, no podemos sustituir la expresión lexicalizada No levanta cabeza por la oración No levanta la cabeza, que, aunque es gramaticalmente correcta, tiene un significado diferente.
} 
situación. Hymes entiende la competencia como el conocimiento subyacente general y la habilidad para el uso de la lengua que posee el hablante-oyente. Además, subraya la importancia de las reglas de uso que ya había anunciado Chomsky, aunque quedaran fuera de su campo de interés:

Hay reglas de uso sin las cuales las reglas gramaticales serían inútiles. Del mismo modo que las reglas sintácticas pueden controlar aspectos de la fonología, y las reglas semánticas quizá controlar aspectos de la sintaxis, las reglas de los actos de habla actúan como factores que controlan la forma lingüística en su totalidad (Hymes, 1972: 278).

Chomsky que, en un principio, excluye el uso relegándolo a la actuación, más tarde reconoce que algunos aspectos del uso pueden sistematizarse en reglas. Así, en 1980 admite que además de la competencia gramatical también existe una competencia pragmática:

Podemos proceder a la distinción entre "competencia gramatical” y "competencia pragmática”, restringiendo la primera al conocimiento de la forma y significado y la segunda al conocimiento de las condiciones y modo de uso apropiado, conforme a varios fines (Chomsky, 1980: 224).

En 1972 Hymes acuña el concepto de competencia comunicativa ${ }^{29}$, que incluye el significado referencial y social del lenguaje. Con el acrónimo SPEAKING recoge los principales componentes del hecho comunicativo, entre los que destaca la situación (tanto espacial como temporal o psicosocial), las características y relaciones entre los participantes, las finalidades, las secuencias de actos de interacción, el grado de formalidad, los instrumentos, las normas y los géneros.

De esta forma, el código lingüístico es desplazado por el acto de habla como foco de atención. Para Hymes (1972), la competencia comunicativa presenta cuatro dimensiones: el grado en el que algo resulta formalmente posible (gramaticalidad), el grado en el que algo resulta factible (el hecho de que las expresiones estén sintácticamente bien formadas no hace que necesariamente sean posibles), el grado en

\footnotetext{
${ }^{29}$ Este concepto ya se había ido delineando durante la segunda mitad de los años sesenta. D. Hymes data su propia formulación en manuscritos de 1967 y en su presentación titulada "On Communicative Competence” para un congreso de 1971. Un año después aparece en la colección de artículos de Pride y Colmes (eds.) de 1972. No obstante, el concepto circuló con anterioridad, ya que Savignon terminó su tesis en 1971 con el título Communicative Competence: An Experiment in Foreign Language Teaching, y no aparece ninguna referencia a Gumperz ni Hymes.
} 
el que algo resulta apropiado (adecuación respecto a las reglas sociolingüísticas del contexto) y el grado en el que algo se da en la realidad ${ }^{30}$ (no podemos inventarnos usos de la lengua). Estas dimensiones se oponen a la visión idealizante que ofrecía Chomsky en la que afirmaba que los juicios son de dos tipos: de gramaticalidad (en relación con la competencia) y de aceptabilidad (en relación con la actuación).

Ahora bien, Hymes (1972) no se queda en la identificación de los cuatro parámetros que, según hemos visto, conforman la competencia comunicativa, sino que va más allá señalando que en cada uno puede distinguirse el conocimiento de la habilidad. Esto viene a implicar que no solo disponemos de un conocimiento de lo posible, lo factible, lo adecuado y lo que ocurre en la realidad, sino también de la habilidad para conseguirlo.

A partir de las ideas expuestas por Hymes, publicaciones posteriores continúan con el desarrollo de los elementos de la definición de competencia comunicativa. Por ejemplo, Gumperz (1972) reconoce que la competencia comunicativa es lo que necesita el hablante para manejarse en contextos que son significativos culturalmente, y Saville-Troike (1989: 21) añade otros aspectos como el reconocimiento del estatus de nuestro interlocutor, de las rutinas en la alternancia de turnos y otros elementos relacionados con el uso en determinados contextos.

Desde entonces han surgido diferentes propuestas para la formulación del concepto de competencia comunicativa; en ellas destaca la incorporación del uso de la lengua para llegar a metas comunicativas concretas, el dinamismo de la comunicación, la importancia de adecuar el discurso al contexto y a la intención, etc. De esta forma, la noción de competencia comunicativa ha ido evolucionando no solo en extensión sino también de forma cualitativa. Autores como Cenoz (1996) defienden que la competencia comunicativa no es solo una extensión del concepto chomskiano de competencia, sino que supone un cambio en la naturaleza del significado de tal noción.

\footnotetext{
${ }^{30}$ En la opinión de N. H. Hornberger (1989), lo que es realmente relevante para Hymes es el hecho de tener en cuenta una dimensión que va más allá del control o la intención del hablante. Incluye lo que puede ser posible, factible, adecuado, pero no hecho, es decir, que no se da en la realidad.
} 
En efecto, según Cenoz (1996), la competencia lingüística es estática ${ }^{31}$, ya que se considera un producto, un conocimiento que es innato y tiene base biológica. Además es individual y no deja lugar a la comparación. En cambio, el concepto de competencia comunicativa es un concepto dinámico y social, ya que obedece a la negociación del significado entre dos o más hablantes-oyentes, considerándose, por tanto, un proceso y no un producto. A diferencia de la anterior, la competencia comunicativa no es absoluta sino relativa, por lo que los hablantes pueden ser competentes en distintos grados (Cenoz y Valencia, 1996: 101).

Además, en esta distinción podemos añadir que la competencia lingüística trata de explicar aquellos aspectos gramaticales que se creen comunes a todos los humanos, con independencia de los determinantes sociales. Por el contrario, la competencia comunicativa considera a los hablantes como exponentes de funciones sociales e intenta describir cómo usar el lenguaje para llevar a cabo dichas funciones. Consiguientemente, va más allá del conocimiento del código lingüístico para incluir la capacidad de saber qué decir, a quién, cuándo, cómo, etc. (Cots et al., 1990: 55).

Victoria Escandell Vidal (2004a) se propone caracterizar la competencia comunicativa de un modo más concreto, y llega a la conclusión de que un hablante competente es capaz de expresarse con propiedad, corrección y de manera adecuada a las diferentes situaciones comunicativas, así como comprender e interpretar las producciones de otros usuarios, tanto las informaciones explícitas como las implícitas. Para ello, el hablante debe, al menos, tener un buen conocimiento de las reglas gramaticales y del léxico, ser capaz de identificar los distintos tipos de situación comunicativa tomando las elecciones lingüísticas en función de estos y, por último, conocer las convenciones asociadas al tipo de medio empleado. Según la autora, el conocimiento lingüístico global se compone de distintos tipos de conocimiento y capacidades parciales y específicas (véase fig. 2).

\footnotetext{
${ }^{31}$ El concepto de competencia lingüística es estático si se atiende al carácter innato y biológico. Entendemos que no es inerte, ya que es creativo y la creatividad no puede ser calificada en ningún caso como estática. 


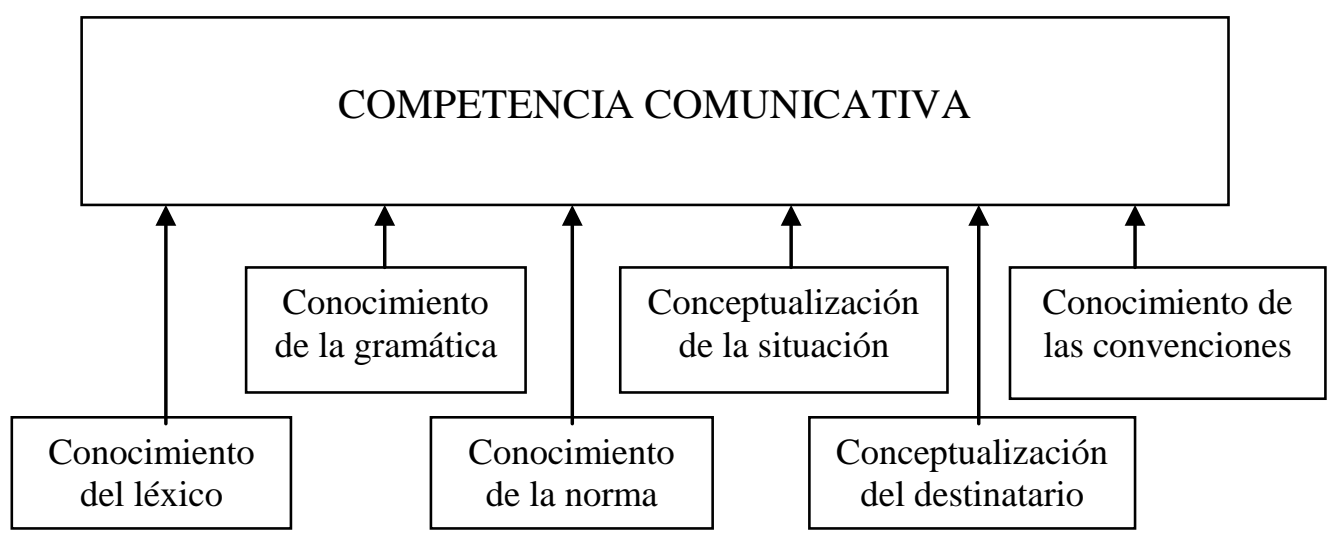

Figura 2. Conocimientos de los que se compone la competencia comunicativa Fuente: Escandel Vidal (2004a)

Escandell Vidal (2004a) propone un modelo de comunicación que sistematiza, en cierta forma, los elementos de la competencia comunicativa que hasta ahora hemos ido perfilando. Las regularidades que observamos derivan de tres fuentes: el conocimiento compartido del código, el conocimiento compartido de normas culturales específicas y el sistema cognitivo general que poseemos los seres humanos. Podemos decir, entonces, que un hablante es más o menos competente porque compartimos una serie de representaciones internas sobre lo que es culturalmente aceptable en las distintas situaciones comunicativas.

Ahora bien, ya que estas regularidades pertenecen a diferentes niveles, diferentes también serán los métodos que utilicemos para analizarlas. En primer lugar, partimos de que dichas regularidades dependen del uso compartido de un mismo sistema lingüístico. El conocimiento gramatical es un tipo de conocimiento interiorizado, puesto que aprendemos la gramática, entre otras cosas, al estar expuestos a una lengua determinada. Bosque ${ }^{32}$ define esta competencia como el "conocimiento interiorizado que el hablante tiene del sistema gramatical de su lengua, a la vez versátil y restrictivo" (1998: 28). Las reglas y principios gramaticales forman parte del conocimiento compartido por los miembros de esa comunidad lingüística. Sin

\footnotetext{
${ }^{32}$ Esta afirmación de Bosque se enmarca en el modelo chomskiano, en su versión conocida como teoría de principios y parámetros. En el modelo de principios y parámetros las nociones básicas que articulan la competencia gramatical de los hablantes no dependen de la eficacia de la comunicación, sino de principios independientes no aprendidos que poseen una realidad mental física. El lenguaje se concibe como un sistema cognoscitivo, no como un sistema comunicativo. Hoy sigue vigente el debate entre funcionalistas y formalistas (Newmeyer 1983; Droste y Joseph, 1991; Kuno y Takami, 1993).
} 
embargo, el conocimiento de estas no es consciente, ya que los hablantes usan dichas reglas en su actuación, pero normalmente son incapaces de enunciarlas explícitamente ${ }^{33}$. Además, sabemos que la adquisición del conocimiento gramatical es posible gracias a la existencia de una base cognitiva especializada en el procesamiento de los datos lingüísticos. Pues bien, algo similar ocurre con los conocimientos relativos al uso del lenguaje, con respecto a los cuales podríamos hablar de bases cognitivas de otras capacidades involucradas en el uso lingüístico.

\subsubsection{La distinción entre competencia y actuación}

En cuanto a la dicotomía competencia/actuación, observamos que a lo largo de la investigación lingüística la competencia se ha entendido, en líneas generales, como el conocimiento interiorizado que tiene todo hablante nativo del sistema implícito de su lengua, y la actuación, como el acto de producir o interpretar un enunciado ${ }^{34}$. Si bien lo más común es que se defina a modo de cajón de sastre, indicando que es todo lo que no es competencia. Se distingue, entonces, entre lo que un hablante "sabe” y la manera en la que se comporta en situaciones particulares. En toda disciplina podemos distinguir entre el conocimiento y la puesta en práctica de ese conocimiento en una actuación concreta. Por ello, desde esta perspectiva, Canale y Swain (1980) hablan de una teoría de la competencia (que equivaldría a una teoría de la gramática y recogería las reglas lingüísticas necesarias para diferenciar las oraciones de una lengua que son gramaticales de las que no lo son) y de una teoría de la actuación (que se centraría en la aceptabilidad de las frases), aunando así la teoría de la gramática con factores más periféricos e incluso extralingüísticos.

Sin embargo, esta distinción entre competencia y actuación no tiene en cuenta el grado de adecuación de los enunciados al contexto al que pertenecen. Esto ya fue señalado por Hymes (1972), que advierte que durante la adquisición de una lengua el niño no solo adquiere el conocimiento de lo que es gramatical (en el sentido

\footnotetext{
${ }^{33}$ Según Bosque (1998) es un error identificar el conocimiento con el pensamiento consciente. La disposición para adquirir la competencia gramatical en una lengua natural representa un tipo de conocimiento inconsciente e inmanente.

${ }^{34}$ Eugenio Coseriu (1988) advierte de que no hay que confundir la distinción entre competencia y actuación con la contraposición de langue y parole de Saussure (1916), ya que la lengua particular no hay que entenderla solo como competencia (saber lingüístico) sino también en la actividad del hablar mismo. 
chomskiano), sino también respecto a cuándo hablar, acerca de qué y con quién, dónde y de qué modo (Hymes, 1972) ${ }^{35}$. De ahí que proponga otra noción más amplia de competencia (aquella que engloba tanto el conocimiento tácito como la capacidad de uso) y postule una posible separación de las nociones de competencia y actuación comunicativas (entendiendo esta última como el uso práctico de la lengua).

Canale y Swain (1980) recogen la divergencia de opiniones en torno a si la competencia comunicativa debe distinguirse de la actuación comunicativa. En principio, y aunque de manera implícita, todos los investigadores defienden esta distinción. La excepción la constituyen seguidores de la corriente chomskiana como Kempson, que continúa defendiendo que "una teoría de la competencia comunicativa es sencillamente una teoría de la actuación” (1977: 54-55). Por tanto, esta autora equipara el término de competencia con el de competencia gramatical y el de actuación con el de competencia comunicativa. Por otra parte, Wiemann y Blacklund (1980) intentan construir un modelo que incluya el concepto de habilidad en una teoría de la competencia comunicativa que resulta ciertamente compleja: "a diferencia del punto de vista lingüístico sobre la competencia y la actuación, el punto de vista de la comunicación considera la actuación como parte de la competencia (no como un concepto separado)" (Wiemann y Blacklund, 1980: 188). Canale y Swain se oponen a estas consideraciones, ya que reconocen que se pueden abstraer regularidades del conocimiento que el hablante tiene tanto de la gramática como del uso lingüístico y, a su vez, de sus realizaciones concretas en la actuación. Por consiguiente, distinguen entre competencia comunicativa o conocimiento y habilidad requeridos para la comunicación (incluyendo tanto el conocimiento de las reglas gramaticales como de uso lingüístico) y actuación comunicativa ${ }^{36}$ o ejecución práctica de este conocimiento en situaciones reales de uso de la lengua y en función de propósitos comunicativos auténticos, siempre bajo las limitaciones psicológicas y ambientales como restricciones de percepción y de memoria, fatiga, nerviosismo, distracciones, etc.

\footnotetext{
${ }^{35}$ Son muchas las investigaciones que señalan cómo los niños, desde edades muy tempranas, adquieren varios aspectos de la competencia comunicativa (Ingram, 1989; Gleason, 2001) y, por ejemplo, utilizan diferentes expresiones según el estatus social de su interlocutor (Andersen, 1990). Sobre estos aspectos profundizaremos en el capítulo 3.

${ }^{36}$ En el artículo de 1983, Canale prefiere el término comunicación real ya que el término actuación comunicativa ha sido fuente de confusión en la lingüística aplicada desde que Chomsky (1965: 4) introdujera los sentidos “fuerte” y “débil” de los términos competencia y actuación.
} 
Ahora bien, como ya hemos avanzado, ante estas definiciones debemos señalar el lugar que ocupan los factores psicolingüísticos generales como la memoria o las estrategias de percepción. Para Hymes, tales factores deberían quedar incluidos en la noción de competencia comunicativa. Otros investigadores como Canale y Swain asumen que dichos factores no son específicos de la competencia comunicativa y, por tanto, deben ser tratados como aspectos de la actuación comunicativa. La razón que alegan estos autores es que en la mayoría de los casos se los considera como limitaciones psicológicas generales que afectan a la comprensión y producción de enunciados concretos ${ }^{37}$. Así las cosas, ellos mismos reconocen que estos factores serán muy significativos a la hora de diseñar un programa de enseñanza comunicativo de segundas lenguas, por ejemplo en lo que respecta a la gradación de las estructuras gramaticales (Canale y Swain, 1980).

Es importante subrayar nuevamente que la competencia comunicativa se refiere tanto al conocimiento como a la habilidad para usar ese conocimiento en situaciones reales. Así, el conocimiento engloba lo que sabemos consciente o inconscientemente sobre el lenguaje y sobre los aspectos de su uso; mientras que la habilidad es un conocimiento procedimental que se refiere a la destreza con la que se utiliza ese conocimiento en las situaciones reales. Para Canale (1983), el conocimiento y la habilidad están incluidos en la competencia comunicativa porque subyacen a la comunicación real de forma sistemática. Esta posición es coherente con la distinción entre competencia comunicativa y actuación comunicativa y, de hecho, depende de ella, puesto que, como reconoce el propio autor, "este concepto de habilidad (lo bien o mal que se utiliza este conocimiento en situaciones reales) requiere distinguir entre las capacidades subyacentes (competencia) y su manifestación en situaciones concretas (comunicación real)" (Canale, 1983: 66).

Según Alcaraz Varó (1990), el concepto de competencia comunicativa refleja la evolución de distintos paradigmas. Como anunciábamos anteriormente, Chomsky introduce la dicotomía competencia/actuación dentro del paradigma generativista. La principal limitación de este paradigma es que tiene como objetivo primordial la teorización sobre la competencia gramatical de un hablante-oyente nativo ideal desatendiendo el contexto real y las funciones del lenguaje. Esto se ha visto traspasado

\footnotetext{
${ }^{37}$ Para obtener mayor información sobre este asunto véase Bever (1970). 
con la aparición de nuevas disciplinas como la lingüística textual, el análisis del discurso, la sociolingüística, etc., que abordan el lenguaje en uso. Según Alcaraz Varó, toda investigación relacionada con el lenguaje podría englobarse en un nuevo paradigma: el de la pragmática. Sin embargo, este paradigma no ha alcanzado aún el grado de madurez sistemática y general necesario. Sobresale, así, la divergencia de opiniones y todavía no se ha consolidado como sistema, sino que se considera una nueva y necesaria perspectiva investigadora. Sus principales características son la consideración del lenguaje como medio de comunicación, la interdisciplinariedad, el funcionalismo que surge del uso del lenguaje, el empirismo al usar datos lingüísticos reales (es decir, contextualizados), la atención hacia el estudio de procesos que tienen lugar en la comunicación y la búsqueda de los universales de uso lingüístico (Alcaraz Varó, 1990).

Una de las principales metas de la investigación de este paradigma es el análisis de la competencia comunicativa, concepto que ahora nos ocupa. Van Dijk (1977) utiliza el término cognición social para hacer referencia al carácter social de nuestra capacidad cognoscitiva. Esta alcanza la percepción, la producción, la interpretación, el saber, pero también las normas y restricciones sociales inherentes a la convencionalidad de la que participan los miembros de una determinada comunidad. No podemos negar que todo sistema conceptual está ligado a una cultura, y más concretamente a una comunidad epistemológica ${ }^{38}$. Siendo esto así, las intenciones lingüísticas de los hablantes dependen del contexto cultural compartido. De esta forma, para que un enunciado pueda tener sentido y la comunicación sea exitosa, son imprescindibles no solo los conocimientos gramaticales y de uso que apuntábamos anteriormente, sino también las expectativas, los saberes, las escalas de valores y la información cultural.

Tal como hemos señalado, varias han sido las propuestas para la formulación del concepto de competencia comunicativa. Destaca la incorporación del conocimiento de cómo se usa la lengua para llegar a metas comunicativas determinadas y el reconocimiento del uso del lenguaje como un proceso dinámico. Savignon (1983: 8-9)

\footnotetext{
${ }^{38}$ Las comunidades epistemológicas son comunidades de conocimientos y de saberes. Los miembros de estas comunidades comparten gran parte de la información de dicha comunidad, de forma que pueden comunicarse fácilmente entre sí. Además, cada hablante no forma parte de una única comunidad epistemológica, normalmente pertenece a varias.
} 
recalca el dinamismo de la comunicación y pone en relieve la negociación del significado por parte de los hablantes y la importancia del contexto. En la misma línea, Kramsch (1986: 367) afirma que el hablante tiene que ser capaz de ajustar el discurso a la intención que pretende causar en el oyente, y Bachman (1990: 84) acuña el término de habilidad lingüística comunicativa, que viene a ser un sinónimo de lo que hasta ahora hemos llamado competencia comunicativa, ya que la entiende como la habilidad para usar la lengua de forma comunicativa incluyendo tanto el conocimiento de la lengua como la capacidad para ponerlo en práctica ${ }^{39}$.

Canale y Swain (1980) acentúan la aplicabilidad de la competencia comunicativa en la enseñanza y en la evaluación de una segunda lengua al realizar pruebas del dominio de la lengua en estudiantes de francés. La importancia de una teoría de la competencia comunicativa para desarrollar pruebas de una lengua es obvia, ya que antes de elaborar las pruebas debemos preguntarnos en qué consiste conocer una lengua. Y esto es lo que, en nuestra opinión, debe ser el pilar sobre el que se construya una buena teoría de la competencia comunicativa.

De este modo, se va forjando una teoría de la competencia comunicativa en la que en lugar de reglas se habla de principios ${ }^{40}$ comunicativos. Las reglas están ligadas al código lingüístico y, por tanto, son de carácter general y de obligado cumplimiento. Los principios, sin embargo, al no estar ligados al código, se presentan como normas de buena conducta comunicativa y no son tan restrictivos. Además, la violación de estos supone incoherencias, inadecuaciones o descortesía, pero nunca agramaticalidad.

A la vista de lo anterior, la competencia comunicativa puede ser definida como una suma de habilidades y destrezas que se apoyan en conocimientos sobre el código lingüístico, sobre los contextos socioculturales que nos permiten producir enunciados apropiados en relación con estos, sobre las reglas conversacionales, sobre la organización textual, sobre las normas culturales de la comunidad de habla, sobre los actos de habla en función de las metas comunicativas, etc. Y en cuanto a la dicotomía competencia/actuación consideramos, entonces, que la competencia comunicativa engloba tanto el conocimiento como la habilidad para usar dicho conocimiento, y que

\footnotetext{
39 Bachman usa los términos conocimiento y competencia prácticamente como sinónimos y habilidad para referirse a la competencia y a la capacidad para ejecutar dicha competencia.

${ }^{40}$ Curiosamente este mismo paso se da en las escuelas formalistas reconocidas. No obstante, los principios en pragmática no son de obligado cumplimiento, mientras que en gramática sí lo son. 
la actuación comunicativa consiste en la ejecución práctica de la competencia en situaciones reales de uso.

\subsubsection{La competencia pragmática en los modelos de competencia comunicativa}

Dentro del concepto de competencia comunicativa se hace necesario definir las distintas dimensiones de esta para determinar en qué consiste ser competente en una lengua. Ninguna disciplina puede por sí sola describir los componentes y procesos que configuran la competencia comunicativa. Es necesaria, por tanto, una integración adecuada y coherente de varias (Escandell Vidal, 2004a). Así, hemos tomado como referencia la revisión de las principales propuestas de modelos de competencia comunicativa: Canale y Swain (1980), Bachman (1990), Celce-Murcia, Dörnyei y Thurrell (1995), Gutiérrez Ordóñez (2002), llevada a cabo en un trabajo anterior (Verde Ruiz, 2010). En estos modelos encontramos similitudes respecto a rasgos generales de clasificación y a subcompetencias que suelen incluirse siempre (como la competencia lingüística, la competencia sociolingüística, la competencia discursiva o la competencia pragmática), pero también hallamos numerosas diferencias.

El modelo de Canale y Swain (1980) propone un marco teórico con carácter integrador (véase fig. 3). En él se distinguen tres subcompetencias dentro de la competencia comunicativa: la competencia gramatical, la competencia sociolingüística y la competencia estratégica. La competencia gramatical incluye "el conocimiento del léxico y las reglas de la morfología, la sintaxis, la semántica de la oración gramatical y la fonología” (Canale y Swain, 1980: 81); la competencia sociolingüística encierra el conocimiento sobre las normas socioculturales de uso y las normas de discurso que nos permiten interpretar el significado social de los enunciados; y la competencia estratégica está formada por "las estrategias de comunicación, tanto verbales y no verbales, que cabe poner en acción con vistas a compensar las rupturas en la comunicación debidas a factores relacionados con una actuación o con una competencia insuficiente” (Canale y Swain, 1980: 82). Los hablantes (ya sean nativos o aprendientes de una lengua) utilizan estrategias para compensar sus limitaciones a la hora de expresarse, bien porque en ese acto comunicativo concreto no son capaces de acceder a un elemento gramatical o de uso lingüístico, o bien porque lo desconocen. Estas estrategias pueden ser de dos tipos: las que se relacionan con la competencia 
gramatical (como parafrasear para evitar construcciones sintácticas que no se controlan) y las que se relacionan con la competencia sociolingüística (por ejemplo, la manera de dirigirse a extraños cuando no se conoce su estatus social).

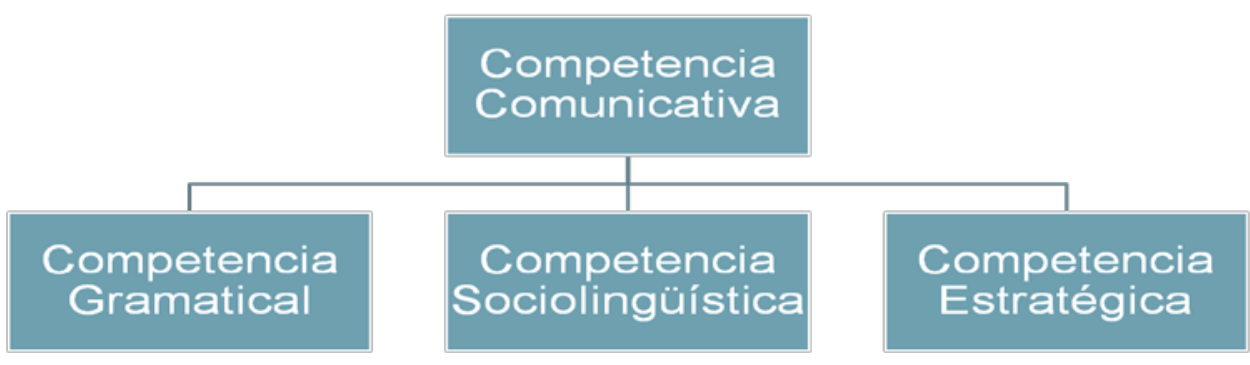

Figura 3. Modelo de Canale y Swain, 1980

Fuente: Cenoz y Valencia (1996)

Este modelo de competencia comunicativa fue revisado y modificado por Canale (1983) tres años más tarde (véase fig. 4). La innovación principal reside en el concepto de competencia sociolingüística, que fue perfeccionado y diferenciado de la competencia discursiva. Así, la competencia sociolingüística se define ahora como la capacidad para producir y comprender enunciados de "forma apropiada en distintos contextos sociolingüísticos dependiendo de factores contextuales como el estatus de los participantes, el propósito de la interacción y las normas y convenciones de la interacción” (Canale, 1983: 67) y la competencia discursiva ${ }^{41}$ comprende la capacidad de combinación de formas gramaticales y significados para elaborar textos escritos o hablados unificados, de forma que tengan "cohesión en la forma y coherencia en el significado" (Canale, 1983: 68).

Canale (1983: 69-70) también amplía el concepto de competencia estratégica incluyendo las estrategias compensatorias de comunicación debidas a la competencia insuficiente y las estrategias utilizadas para favorecer el efecto retórico de los enunciados. Se trata, entonces, del dominio de estrategias que compensen fallos en la comunicación y favorezcan su efectividad. Probablemente, Canale no supo apreciar la relevancia de su extensión del concepto de competencia estratégica. Este autor recoge

41 La escisión de la competencia discursiva como subcompetencia independiente de la sociolingüística tiene que ver con la eclosión de los trabajos en lingüística textual a partir del año 1982 y con la emergencia de conceptos como cohesión, introducido por Halliday (Halliday y Hassan, 1976) o coherencia, que tiene su origen en la retórica clásica, pero recibe un sentido nuevo en lingüística textual de la mano de autores como Smith o Van Dijk, considerado este último padre de la lingüística textual en Europa. 
las capacidades para planificar el discurso de forma que sea eficaz, por lo que realmente tendríamos que hablar de una competencia retórica, que ya no tiene que ver solo con la compensación ante posibles fallos o deficiencias. La eficacia se convierte, entonces, en la medida de lo retórico.

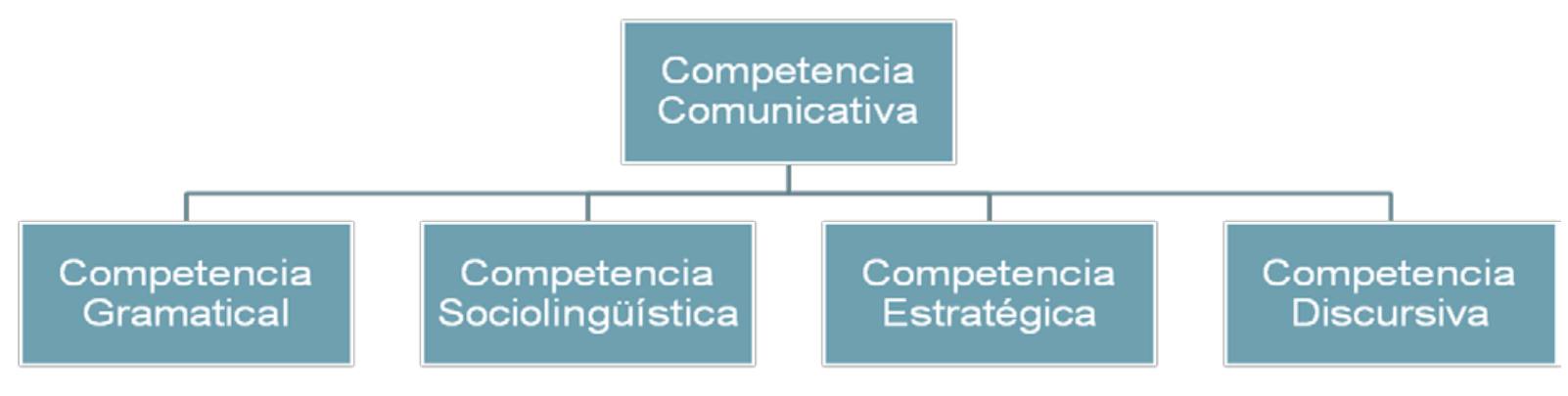

Figura 4. Modelo de Canale, 1983

Fuente: Cenoz y Valencia (1996)

En el modelo de Bachman (1990), el marco de referencia de la habilidad lingüística comunicativa está formado por tres componentes principales: las competencias lingüísticas (o competencias del lenguaje, que pueden ser clasificadas en dos tipos: competencia organizativa y competencia pragmática), la competencia estratégica (que proporciona los medios para relacionar la competencia lingüística con el contexto situacional y las estructuras de conocimiento) y los mecanismos psicológicos (procesos neurológicos y psicológicos implicados en la ejecución real del lenguaje que caracterizan el canal y el modo en que la competencia es realizada) (véase fig. 5).

En este trabajo nos vamos a centrar en la clasificación de las competencias de la lengua (véase fig. 6). Este modelo distingue entre competencia organizativa y competencia pragmática, que a su vez se dividen en competencia gramatical y competencia textual, y competencia ilocutiva y competencia sociolingüística, respectivamente.

La competencia organizativa incluye "those abilities involved in controlling the formal structure of language for producing or recognizing grammatically correct sentences, comprehending their propositional content, and ordering them to form texts” (Bachman 1990: 87). Se basa en la organización de las señales lingüísticas que se utilizan en la comunicación y en el modo en el que estas señales se usan para referirse a personas, objetos, ideas y sentimientos. Se refiere, por tanto, no solo a la 
gramática de la oración sino a la gramática del texto ${ }^{42}$. Esta competencia se divide en: competencia gramatical (que incluye la competencia en cuanto al sistema lingüístico) y competencia textual (que está formada por el conocimiento de las convenciones para enlazar enunciados de manera que formen un texto oral o escrito).

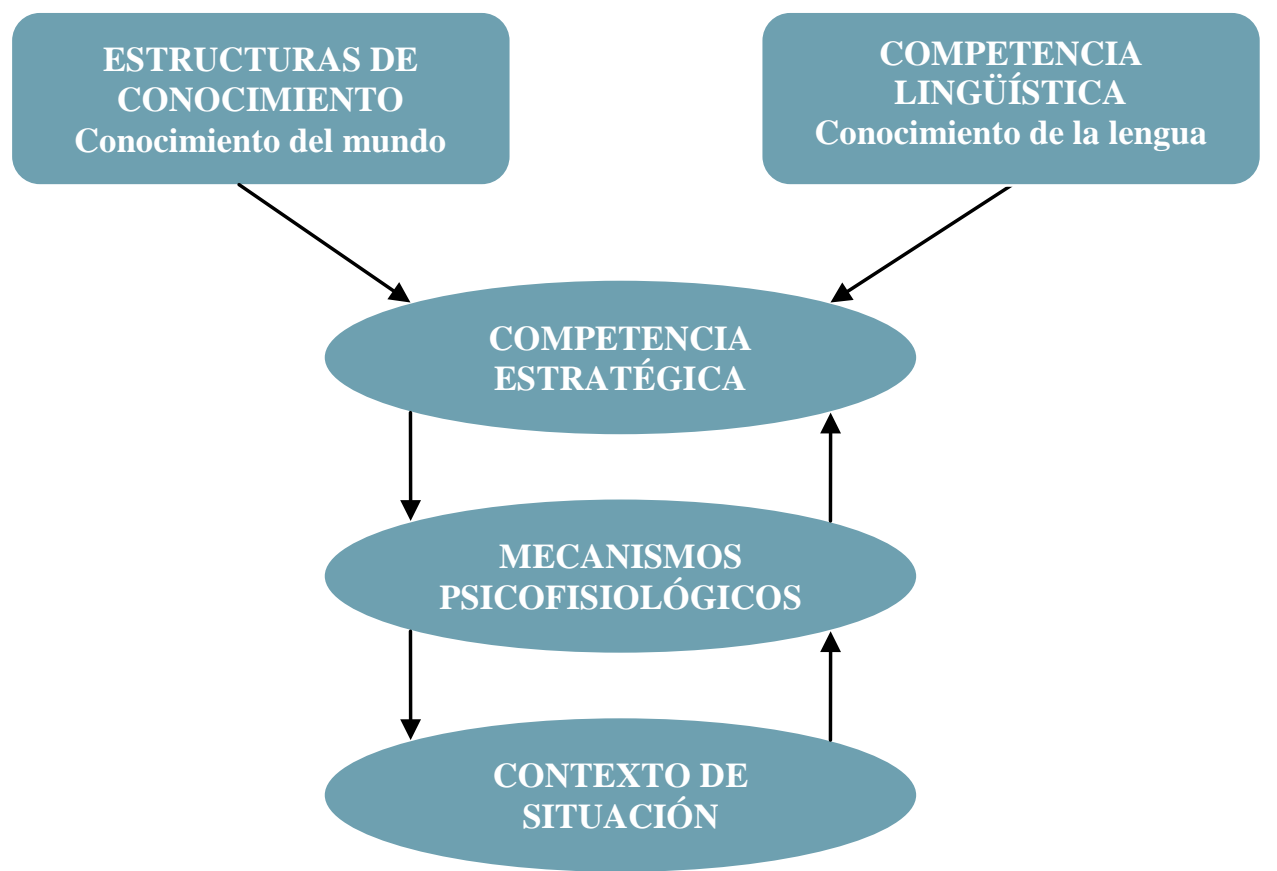

Figura 5. Marco de referencia de la habilidad lingüística comunicativa Fuente: Bachman (1990)

En el modelo de Bachman (1990), la competencia pragmática concierne a las relaciones entre signos y referentes, y a las relaciones entre usuarios de la lengua y contexto de comunicación. Por lo tanto, la competencia pragmática tiene dos ramas: la competencia ilocutiva (que se refiere a las relaciones entre enunciados y los actos de habla o funciones comunicativas que los hablantes intentan realizar con estos) y la competencia sociolingüística (que nos permite realizar funciones lingüísticas de manera que sean adecuadas al contexto de uso).

Asimismo, Bachman entiende que también la competencia estratégica ${ }^{43}$ debe situarse dentro de los elementos que constituyen la habilidad lingüística comunicativa

\footnotetext{
${ }^{42}$ Se relaciona con la idea de los funcionalistas de entender la gramática oracional como una parte de la gramática textual.

${ }^{43}$ Para explicarla utiliza el modelo de producción del habla de Faerch y Kasper (1983), aunque mientras estos autores se limitan a analizar el uso de las estrategias de comunicación en la comunicación con interlengua, Bachman ofrece una visión más general e incluye todo el uso comunicativo de la lengua. Frente a las dos fases que proponen Faerch y Kasper: planificación y 62
} 
general, pero no es considerada un componente más de la competencia de la lengua, como lo son la competencia gramatical o la sociolingüística. Es la capacidad que proporciona los medios para vincular la competencia de la lengua (con todas sus subcompetencias) con aspectos del contexto de situación y las estructuras de conocimiento (conocimiento sociocultural, conocimiento del mundo) del usuario de la lengua. Para Bachman, entonces, la competencia estratégica se iguala a la competencia comunicativa.

En 1996 Bachman y Palmer llevan a cabo una revisión de este modelo y consideran tres componentes dentro de la competencia pragmática: el conocimiento del léxico (que antes estaba dentro de la competencia gramatical), el conocimiento funcional (similar pero más ampliado que la definición de competencia ilocutiva) y el conocimiento sociolingüístico (que permanece como fue definido en la primera versión). Además, en la versión ampliada de 1996, se modifica el término para referirse a la competencia estratégica, que ahora se denomina competencia metacognitiva.

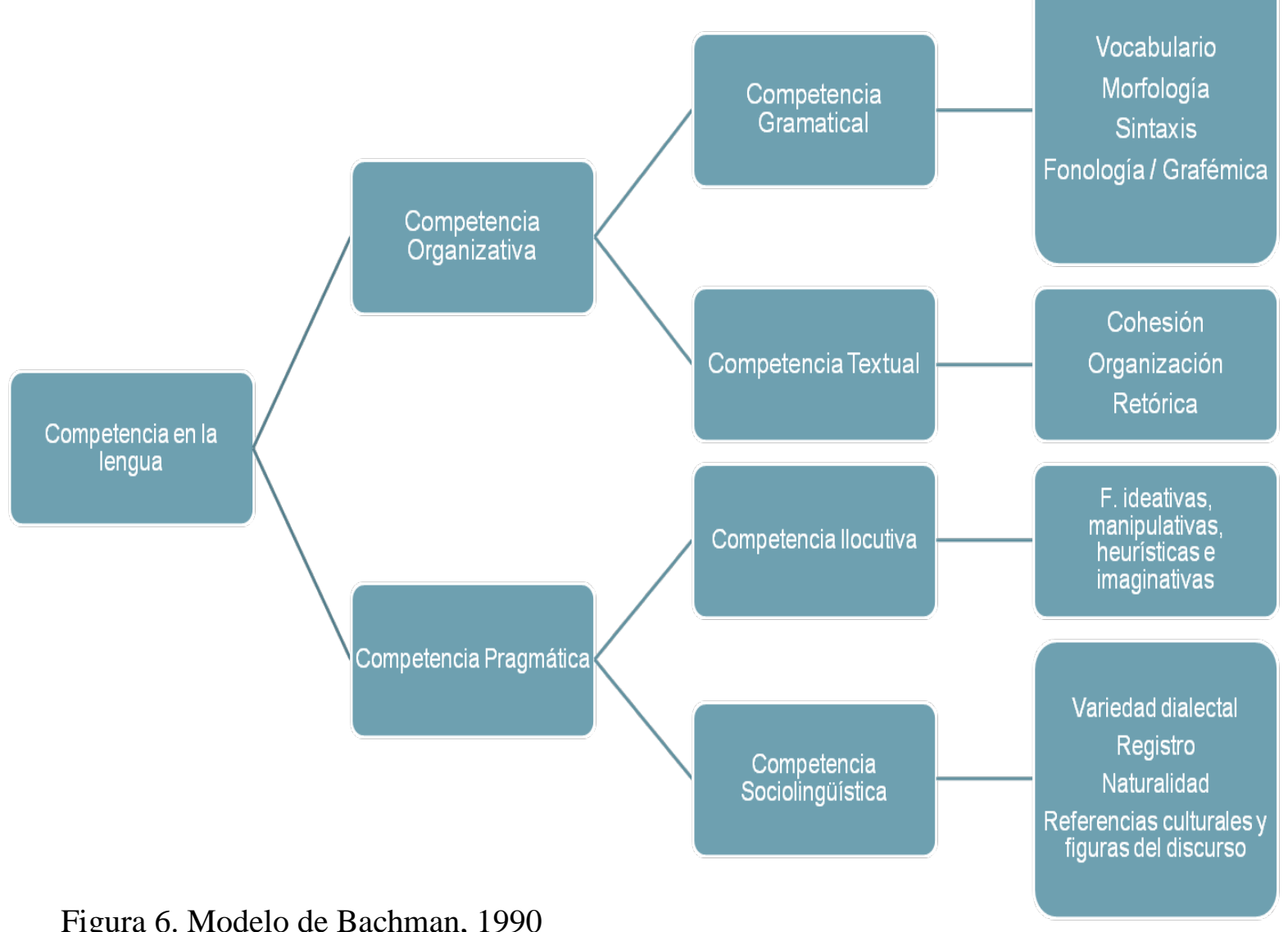

1990

Fuente: adaptado de Cenoz y Valencia (1996)

ejecución, Bachman incluirá tres: evaluación, planificación y ejecución; como veremos más adelante. 
El modelo de Celce-Murcia ${ }^{44}$, Dörnyei y Thurrell (1995) (véase fig. 7) divide la competencia comunicativa en cinco subcompetencias: competencia discursiva, competencia lingüística, competencia accional (actional), competencia sociocultural y competencia estratégica. La competencia discursiva incluye la cohesión, la deixis, la coherencia, la estructura genérica y la estructura conversacional inherente a la alternancia de turnos; la competencia lingüística ${ }^{45}$ se refiere al conocimiento del código lingüístico; la competencia accional incluye el conocimiento de las funciones comunicativas y los actos de habla; la competencia sociocultural se refiere al conocimiento que tiene el hablante de los contextos socioculturales que le permite producir enunciados apropiados en relación con estos; y, finalmente, la competencia estratégica se refiere al uso de las estrategias de comunicación, incluyendo las estrategias compensatorias.

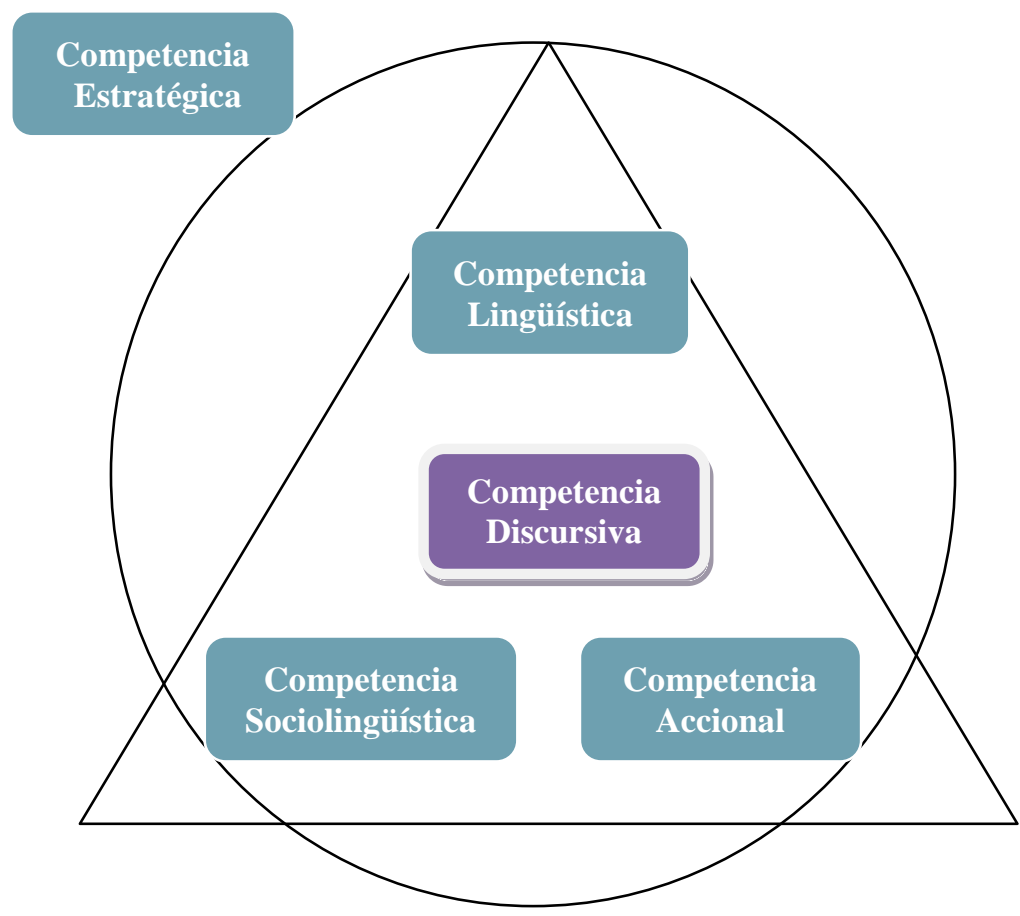

Figura 7. Modelo de Celce-Murcia, Dörnyei y Thurrell, 1995

Fuente: Cenoz y Valencia (1996)

\footnotetext{
${ }^{44}$ Toda la obra de la profesora Marianne Celce-Murcia está dedicada a la enseñanza de la lengua, lo que evidencia de nuevo que un tema como la competencia comunicativa, que debería ser importante para la lingüística teórica, no es tratado generalmente por lingüistas teóricos.

${ }^{45}$ Los autores usan el término competencia lingüística en lugar de competencia gramatical para indicar explícitamente que incluyen el componente léxico y fonológico además del gramatical. 
Además, cabe destacar que el modelo de Celce-Murcia, Dörnyei y Thurrell sitúa la competencia discursiva en una posición central con respecto a la competencia lingüística, accional y sociolingüística; y en otro nivel incluye la competencia estratégica, que sirve para compensar las deficiencias en otras competencias.

Por su parte, el modelo de Salvador Gutiérrez Ordóñez (2002: 202) establece tres niveles (véase fig. 8). En el primer nivel, ocupando una posición central, encontramos la competencia lingüística. Después, en un segundo nivel, hallamos una serie de competencias periféricas en torno a la competencia lingüística, tales como la competencia sociolingüística, la cultural, la psicolingüística (esta resulta una novedad con respecto a los anteriores modelos que no la contemplaban), la textual y la conversacional (esta última tampoco había sido tenida en cuenta de forma aislada en las anteriores propuestas). Y, finalmente, el tercer nivel lo constituye la competencia pragmática o semiótico-pragmática, que en líneas generales recoge el uso de la lengua y, por ello, envuelve a las periféricas. Estos componentes se relacionan con las disciplinas correspondientes, de forma que Gutiérrez Ordóñez mantiene las mismas denominaciones salvo la de competencia cultural, que está ligada a la etnolingüística.

\section{Competencia Pragmática}

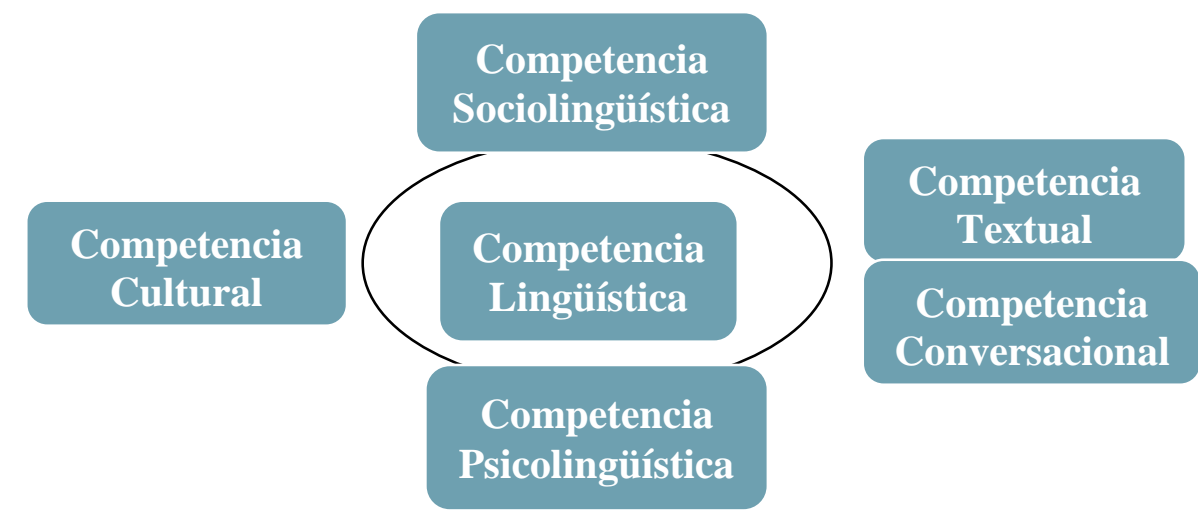

Figura 8. Modelo de Gutiérrez Ordóñez, 2002

Fuente: Gutiérrez Ordóñez (2002)

Si llevamos a cabo un análisis contrastivo de estos modelos observamos que el modelo de Bachman (1990) se asimila al de Canale y Swain (1980) y al de Canale (1983) en lo que respecta a la consideración de las competencias gramatical y sociolingüística. Asimismo, la competencia textual de Bachman se asemeja a la competencia discursiva de Canale (1983), pero se presenta de forma más elaborada. En 
cuanto a la competencia estratégica, Bachman se diferencia de Canale y Swain (1980) y Canale (1983) en que trata de describir los dispositivos por los que la competencia estratégica opera, manejando los tres componentes: valoración, planificación y ejecución. Es discutible, sin embargo, su consideración de la competencia pragmática. Las tareas de la competencia ilocutiva no se detallan con suficiente claridad y, además, son insuficientes.

Las competencias lingüística y sociolingüística de Celce-Murcia, Dörnyei y Thurrell (1995) se corresponden en términos generales con la competencia gramatical y sociolingüística de Canale y Swain (1980) —en la primera solo cambia el término para indicar que incluyen el léxico y la fonología además de la gramática, y en la competencia sociolingüística la descripción de los componentes es más completaLa competencia accional es similar a la competencia ilocutiva de Bachman (aunque utiliza otro término) y la competencia discursiva es una reelaboración que incluye la competencia discursiva y textual de los modelos previos.

Asimismo, creemos que los marcos teóricos de la competencia comunicativa de Canale (1983), Bachman (1990) y Celce-Murcia, Dörnyei y Thurrell (1995) presentan limitaciones, ya que solo se refieren a la lengua. Como apunta Ingram (1989), la competencia para comunicarse depende también de otros factores como la personalidad de los individuos y su conocimiento del mundo. Por ello, Gutiérrez Ordóñez (2002) los tiene en cuenta bajo las nociones de competencia cultural y psicolingüística.

Finalmente, una vez analizados los modelos anteriores, presentamos en la figura 9 nuestra propuesta (Verde Ruiz, 2010). En ella la competencia comunicativa se divide en una serie de componentes o subcompetencias que se refieren a distintos tipos de conocimientos, habilidades y destrezas. Nuestro modelo teórico presenta una integración de todas las subcompetencias como componentes de la competencia comunicativa. Este modelo no presenta ninguna competencia en posición central; todas ellas son necesarias para alcanzar la competencia en una lengua y se complementan entre sí, de forma que unas necesitan de las otras y viceversa. No obstante, creemos que dichas subcompetencias pueden organizarse en tres grupos. El primero de ellos estaría formado por las competencias primarias (competencia psicolingüística y competencia cultural). Las denominamos primarias en el sentido de 
que son posibilitadoras, son los prerrequisitos sobre los que se construye la comunicación (cualquier tipo de comunicación, no solo la comunicación lingüística). Es necesario que el hablante desarrolle sus capacidades cognitivas, esto es, que disponga de una serie de capacidades relacionadas con la percepción, el razonamiento, la inteligencia, la memoria, etc., que posibilitan la producción y comprensión de la comunicación; así como que conozca una serie de esquemas, representaciones mentales y valores culturales compartidos por su comunidad.

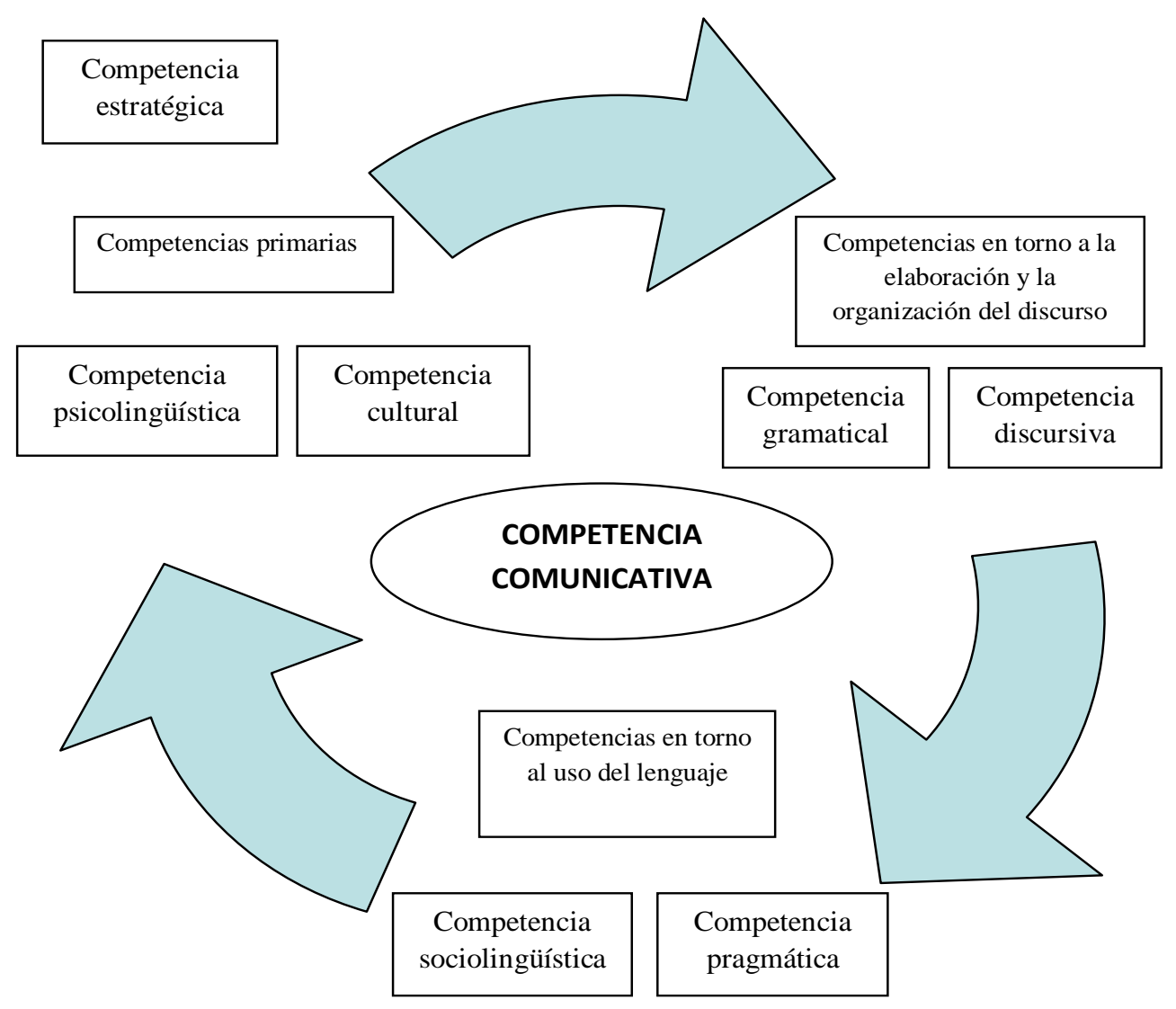

Figura 9. Nuevo modelo de competencia comunicativa

Fuente: Verde Ruiz (2010)

El segundo grupo incluiría las competencias relacionadas con la elaboración y organización del discurso (estas son: la competencia gramatical y la competencia discursiva) y el tercero agruparía las competencias en torno al uso del lenguaje en la comunicación (competencia pragmática y competencia sociolingüística). Finalmente, separamos la competencia estratégica, ya que, siguiendo el modelo de Celce-Murcia et al. (1995), consideramos que el conocimiento de dichas estrategias sirve para 
compensar los fallos o deficiencias en cualquiera de las demás. Seguidamente expondremos a qué conocimientos y habilidades se refiere cada una de ellas.

En primer lugar, consideramos la competencia gramatical como una subcompetencia fundamental de la competencia comunicativa que recoge el conocimiento lingüístico (morfología, sintaxis, léxico y fonología). Cabe destacar que el conocimiento de las reglas y principios gramaticales no es normalmente consciente, ya que los hablantes, en general, usan dichas reglas en su actuación pero son incapaces de explicarlas. Esto se debe a que se trata de un conocimiento interiorizado que aprendemos al estar expuestos a una lengua concreta.

La competencia discursiva se refiere tanto el conocimiento de los principios y convenciones utilizados para unir enunciados de manera que formen un texto ${ }^{46}$ oral o escrito (incluyendo principalmente el conocimiento de mecanismos de cohesión y coherencia), como al conocimiento del uso conversacional de la lengua (reglas conversacionales sobre cómo desarrollar un tema, alternancia de los turnos de palabra, pares de adyacencia, etc.) y su habilidad para aplicarlos.

La competencia sociolingüística incluye el conocimiento del significado social de los enunciados y de los distintos contextos sociolingüísticos así como la capacidad para construir mensajes adecuados a dichos contextos, y está condicionada por factores como el género, la edad, el nivel sociocultural, la procedencia geográfica, etc.

La competencia pragmática se refiere al conocimiento de ciertos principios pragmáticos así como a la capacidad para inferir y para lograr un uso apropiado y eficaz de la lengua que responda a nuestros propósitos comunicativos.

La competencia cultural es el conocimiento de las normas de comportamiento de una cultura determinada. Incluye la comprensión y asimilación de todos los aspectos de la cultura, los valores, las creencias y el modo en el que se espera que se hagan las cosas en una determinada comunidad de hablantes.

La competencia psicolingüística incluye los aspectos que condicionan el ambiente psicológico de las situaciones comunicativas. Recoge las habilidades naturales a la condición humana como la capacidad de procesar información, el

${ }^{46}$ En este trabajo entendemos texto y discurso como sinónimos "puesto que el enfoque pragmático actual ha acabado por vincular la Lingüística del texto con el Análisis del discurso, perspectivas de análisis antes diferenciadas según la unidad texto se considerara como producto, estático, o como proceso interactivo dinámico; es decir, según se entendiera el texto sin contexto (= texto) o con contexto (= discurso) (Van Dijk, 1977)" (Briz, 1997: 79). 
razonamiento, la inteligencia, la teoría de la mente ${ }^{47}$ así como la base común para conceptuar situaciones, eventos y actos de habla que se denomina sociocognición ${ }^{48}$. Por otra parte, también incluye la personalidad de los interlocutores, su estado de ánimo o sus motivaciones, factores que influyen en la cantidad y la calidad de las interacciones.

En último lugar vamos a considerar la competencia estratégica como la habilidad para reparar los fallos en la comunicación usando medios verbales y no verbales. Sería algo parecido a una competencia antinegativa que nos diría cómo no ser ineficaces. Basándonos en Bachman (1990), podemos definir esta competencia como la capacidad de evaluar, planear y llevar a cabo estrategias para compensar y reparar. Además, opera tanto consciente como inconscientemente. En la lengua oral desarrollamos rutinas de forma que utilizamos frecuentemente los mismos esquemas para compensar los fallos en la comunicación. En la lengua escrita ocurre lo mismo, pero disponemos de más tiempo para decidir y planear estas estrategias.

Finalmente, es necesario subrayar que, partiendo de nuestra idea de competencia (como la suma de conocimientos y habilidades para usarlos), distinguimos consecuentemente en las diversas subcompetencias dos tipos de conocimientos: declarativos y procedimentales. Por un lado, los declarativos son conocimientos almacenados que se reflejan en teorías que pueden describirse objetivamente (como es el caso del conocimiento gramatical) y por otro, los procedimentales son un tipo de conocimiento que no tiene que ver con "saber" sino con "saber hacer", como es el caso de saber inferir — relativo a la competencia pragmática — o el caso de saber adecuar nuestros enunciados a los distintos contextos sociolingüísticos —referente a la competencia sociolingüística-.

El modelo teórico que aquí ofrecemos es una propuesta más que, a nuestro parecer, podría integrar los aspectos más importantes de los modelos anteriores. Recalcamos la necesidad de la interacción de todas las subcompentencias, ya que es la suma de estas la que permite a los hablantes ser competentes desde el punto de vista de la comunicación real.

\footnotetext{
${ }^{47}$ En el capítulo 3 profundizaremos sobre la teoría de la mente.

${ }^{48}$ Para mayor información véase Van Dijk (1995).
} 
Tal como señalaba Gutiérrez Ordóñez (2002), existe una correspondencia de las distintas competencias con las disciplinas de las que toman su denominación. Así, en este trabajo entendemos que la competencia pragmática está íntimamente relacionada con la noción de pragmática. Pues bien, en el capítulo anterior definimos la pragmática como el estudio del uso del lenguaje en la comunicación, teniendo en cuenta los factores (tanto lingüísticos como extralingüísticos) que intervienen en la producción e interpretación de los enunciados. Asimismo, son objeto de estudio de la pragmática fenómenos como las implicaturas, los actos de habla, la cortesía, la ironía, la relevancia, etc. Además, consideramos que entre la retórica y la pragmática existe una relación muy estrecha, ya que en los intercambios comunicativos los hablantes intentan conseguir adecuación y eficacia para lograr el éxito comunicativo.

Por lo tanto, con base en nuestro concepto de pragmática entendemos que la competencia pragmática es una suma de conocimientos y destrezas sobre cómo usar la información lingüística y extralingüística en la producción e interpretación de enunciados, que incluye tanto la capacidad para inferir lo implícito y lo explícito, como el conocimiento de las posibles correspondencias entre formas y funciones que permiten transmitir y reconocer las intenciones comunicativas.

Estos conocimientos pragmáticos no se formulan en reglas que recogen un conjunto de conocimientos almacenados y reflejados en teorías que se pueden objetivar en una descripción. Este sería el caso de la competencia gramatical (donde el teórico puede describir el sistema fonológico, el sistema sintáctico e incluso los sistemas semánticos que configuran el léxico). Por el contrario, los conocimientos pragmáticos se vinculan a un conjunto de principios que guían nuestros intercambios y pretenden lograr el éxito comunicativo. Es, por tanto, esencial para el mantenimiento de buenas relaciones interpersonales y para conseguir la adecuación y eficacia de nuestros mensajes.

\subsection{DISTINTAS APROXIMACIONES AL ESTUDIO DE LA COMPETENCIA PRAGMÁTICA}

\subsubsection{La competencia pragmática en el ámbito teórico}

Como adelantábamos al comienzo de este capítulo, ha sido la lingüística aplicada la más interesada en el estudio de la competencia pragmática. En el ámbito teórico, 
resulta significativo que varios de los manuales clásicos de pragmática más conocidos (Levinson, 1983; Leech, 1983; Reyes, 1990; Verschueren, 1999) no aludan al concepto de competencia pragmática. Verschueren (1999) sí menciona la existencia del concepto de competencia comunicativa introducido por Hymes y hace algunas referencias a la pragmática en el área de la adquisición del lenguaje y sus patologías. Con esto, deducimos que entiende que pueden existir deficiencias en la competencia comunicativa de los hablantes que afecten solo al aspecto pragmático y, entonces, cabría hablar de una competencia pragmática autónoma con respecto al resto de competencias. Por su parte, Levinson (1983) tampoco hace alusión a la competencia pragmática (de hecho, sigue la distinción de Chomsky entre competencia y actuación) y sitúa la pragmática dentro de la actuación, aunque reconoce que está regulada en una serie de principios de la actuación en el uso. Cuando este autor expone las aplicaciones de la pragmática, incluye la teoría y la práctica del aprendizaje de una segunda lengua. Y, finalmente, también menciona la posible no universalidad de los procesos pragmáticos, que nos llevaría a concluir que existen diferencias no solo en la estructura de las lenguas sino en su uso, y la existencia de patologías esencialmente pragmáticas. En cuanto al manual de Reyes (1990), tan solo hay una referencia al concepto de competencia en la introducción a la lingüística generativa, y define aquella como el conocimiento subjetivo del lenguaje que posee el hablante.

Los manuales más recientes (Gutiérrez Ordóñez, 2002; Portolés, 2004; Escandell Vidal, 2006) sí reflexionan, en mayor o menor medida, sobre el concepto de competencia pragmática. Portolés (2004: 24-26) recoge las nociones básicas en torno al surgimiento de la competencia comunicativa y su oposición frente a la competencia lingüística. Según este investigador, el interés despertado por la competencia comunicativa en los profesores de lenguas extranjeras ha favorecido que esta se llegue a identificar con la pragmática y que, por tanto, se hable de competencia pragmática. No obstante, él mismo reconoce que si se amplía el concepto de pragmática hasta identificarla con la competencia comunicativa, antes tendremos que distinguir entre una pragmática propiamente lingüística y una que sea objeto de sociólogos, psicólogos o antropólogos, puesto que muchos fenómenos que le interesan a la competencia comunicativa están más relacionados con estos que con la propia lingüística. 
Salvador Gutiérrez Ordóñez (2002) dedica el segundo capítulo de su libro De Pragmática y Semántica a los nuevos caminos de la lingüística enfocados a los diversos aspectos de la competencia comunicativa. Considera que la competencia pragmática o semiótico-pragmática engloba las competencias nucleares lingüísticas (semántica, sintáctica, etc.) y las competencias periféricas (sociolingüística, textual, cultural, etc.), como ya vimos anteriormente.

Por su parte, Escandell Vidal (2006) se pregunta si los fenómenos que se estudian dentro de la pragmática forman parte de la competencia o de la actuación y concluye que al menos una parte del uso de la lengua es el reflejo directo del conocimiento que tenemos de este (Harnish y Farmer, 1984). Por lo tanto, varios de los fenómenos que consideramos pragmáticos no pertenecen a la actuación, sino que conciernen a la competencia. Partiendo de esta visión, hablamos de la competencia pragmática como aquella que tutela al usuario sobre cómo usar la información contextual en la producción e interpretación de los enunciados. Sin embargo, Escandell apunta que la competencia pragmática, que refleja también un conocimiento interiorizado, no se guía por los mismos instrumentos teóricos que la competencia gramatical. Es erróneo pretender que la competencia pragmática adopte un sistema de reglas como el de la competencia gramatical (así lo intenta, con dudoso éxito, Gochet en 1980), de forma que se especifiquen las condiciones de adecuación y de éxito de un conjunto infinito de enunciados, siguiendo un conjunto de reglas recursivas que asocien los enunciados y su contexto con sus interpretaciones. Como es sabido, la interpretación de los enunciados no siempre está sujeta a reglas convencionales y, a veces, su conocimiento no garantiza el éxito.

Escandell Vidal (2006) sistematiza las diferentes capacidades que integran la competencia en dos grandes grupos: el conocimiento del código y el conocimiento compartido de un conjunto de normas culturales específicas ${ }^{49}$. De esta forma reconoce que las regularidades de la comunicación se observan en diferentes niveles. En cuanto a las normas culturales, adquirimos el sistema de nuestro grupo social por abstracción a partir de las conductas que observamos y de la valoración que estas reciben. Para

\footnotetext{
${ }^{49}$ En este trabajo no contradecimos las ideas de Escandell Vidal (2006) pero reconocemos que hay otras capacidades de la comunicación como los requisitos o desarrollos cognitivos, saber cómo va a interpretar el oyente o que el hablante sabe que el oyente va a buscar la relevancia o va a ser capaz de entender la elipsis, etc. La autora reconoce, más adelante, algunos de estos aspectos cuando habla de la capacidad inferencial o de las restricciones arquitectuales.
} 
Escandell, las normas culturales se adquieren por socialización, de manera que su noción de competencia no incluye los aspectos inferenciales de la comunicación ${ }^{50}$. Según la investigadora, la inferencia no forma parte de la competencia pragmática porque no constituye un cuerpo de conocimiento que el hablante adquiere o interioriza, sino que es una capacidad común a todos los seres humanos.

Como cualquier otra clase de competencia, la competencia pragmática solo puede estar formada por aquellos aspectos que impliquen poseer o no un determinado saber, como el conocimiento de las reglas gramaticales y de las pautas sociales y culturales que determinan el comportamiento verbal; quedan necesariamente excluidos de la noción de competencia, por tanto, los sistemas generales, las capacidades comunes y los mecanismos de procesamiento (Escandell Vidal, 2006: 225).

No obstante, la autora reconoce que al no incluir dentro de la competencia los mecanismos inferenciales estamos dejando fuera una parte importante de las regularidades de la comunicación. Para entender cuál es el lugar que ocupa el fenómeno inferencial dentro del conocimiento pragmático, Escandell apunta que las regularidades que observamos en la comunicación pueden provenir de nuestros sistemas cognitivos (llamadas restricciones arquitecturales) o de un conjunto de experiencias compartidas (llamadas restricciones individuales). Las restricciones arquitecturales dan lugar a las regularidades que se reflejan en nuestra manera de procesar, independientemente de cuál sea nuestra lengua o nuestra cultura. Así, si es verdad que existe una capacidad cognitiva común que sirve de base a la gramática de las diferentes lenguas (denominada gramática universal), debemos reconocer también la existencia de una capacidad social entendida como un mecanismo universal de categorización destinado a producir representaciones sobre las relaciones sociales y la interacción comunicativa (demoninada sistema de categorización social). La capacidad inferencial es una capacidad de procesamiento común al género humano que nos permite interpretar las representaciones obtenidas de la descodificación lingüística y de las informaciones contextuales. Por ello, concluye Escandell que "no hay nada que podamos llamar competencia inferencial, ya que no hay un cuerpo de

\footnotetext{
${ }^{50}$ Los primeros debates en torno a la competencia pragmática se centraron en los aspectos inferenciales. Así, por ejemplo, Morgan (1975: 298-290) entendía la competencia como la suma de un componente lingüístico al modo de Chomsky y un componente pragmático que se ocupaba de cómo conseguir que se hicieran cosas con las palabras.
} 
conocimientos específico que sustente la capacidad inferencial” (2006: 228). En nuestra opinión, sin embargo, creemos que sí lo hay, ya que son precisamente los conocimientos que forman parte de la competencia pragmática los que sustentan grosso modo dicha capacidad inferencial. Lo que ocurre es que no se trata de conocimientos declarativos sino procedimentales.

\subsubsection{La competencia pragmática y la enseñanza/aprendizaje de lenguas} extranjeras

En la introducción del libro Pragmatics Applied to Language Teaching and Learning (2009), se reconoce el carácter central de la pragmática en el desarrollo de la competencia comunicativa en segundas lenguas ${ }^{51}$. Consiguientemente, se pone de manifiesto la necesidad de que los profesores de lenguas extranjeras conciencien a sus estudiantes en torno a:

specific aspects of particular speech acts in the target language, such as their routinised nature, the semantico-syntactic formulae frequently used to perform them, their integrant conversational moves and sequences, what motivates their performance or avoidance in specific context- i.e. when, where, how and with whom they can perform or avoid them (Gómez Morón et al., 2009: XV).

De esta forma, hoy en día se considera de vital importancia que los programas de lenguas extranjeras contribuyan a la conciencia metapragmática de los aprendientes (Vera Luján y Blanco Rodríguez, 2014), así como a desarrollar sus habilidades pragmáticas, lo que hubiera sido impensable en los antiguos métodos de enseñanza de lenguas como el método gramática-traducción, el método directo o natural o el audiolingual.

No cabe duda de que abordar la enseñanza/aprendizaje de lenguas extranjeras en cualquiera de sus aspectos supone la necesaria alusión al Marco común europeo de referencia para las lenguas: aprendizaje, enseñanza, evaluación ${ }^{52}$ (MCER, 2002). Este tiene su origen en el desarrollo de la pragmática y de los métodos comunicativos,

51 En este trabajo trataremos los conceptos de lengua extranjera y segunda lengua como sinónimos.

52 El MCER Se publicó en el año 2001, coincidiendo con la celebración del Año Europeo de las Lenguas, en cumplimiento de un compromiso llevado a cabo diez años antes por los miembros del Consejo en un congreso intergubernamental celebrado en Suiza titulado "Transparencia y coherencia en la enseñanza de idiomas en Europa: objetivos, evaluación, certificación”. 
así como en el esfuerzo por parte del Consejo de Europa -iniciado con el proyecto “lenguas vivas” (langues vivantes) (1971-1981) — de unificar las pautas para el aprendizaje y la enseñanza de lenguas dentro del contexto europeo.

Según el MCER (2002), la competencia comunicativa comprende varios componentes: el lingüístico, el sociolingüístico y el pragmático, que a su vez comprenden una serie de conocimientos, destrezas y habilidades específicas. Las competencias pragmáticas, que ocupan nuestra atención en este trabajo, son definidas de la siguiente forma:

Las competencias pragmáticas tienen que ver con el uso intencionado de los recursos lingüísticos (producción de funciones de lengua, actos de habla) sobre la base de guiones o escenarios de intercambios comunicativos. También tienen que ver con el dominio del discurso, la cohesión y la coherencia, la identificación de tipos y formas de texto, la ironía y la parodia. Respecto a este componente, incluso más que en el caso del componente lingüístico, apenas es necesario resaltar el gran impacto que ejercen las interacciones y los entornos culturales en que se desarrollan las mencionadas capacidades (MCER, 2002: 14).

Como se observa, bajo la denominación de competencias pragmáticas, el MCER incluye otros conocimientos y habilidades que van más allá de la pragmática y que podemos agrupar en distintos ámbitos: el de la lingüística textual, con los conceptos de cohesión y coherencia; el de la lingüística cognitiva, con los conceptos de guion (script) y marco (frame); el del análisis de la conversación, con los esquemas de interacción; etc.

La adaptación de las directrices del MCER a la enseñanza de español como lengua extranjera es uno de los objetivos cumplidos por el Plan curricular del Instituto Cervantes (2006). El Plan curricular ${ }^{53}$ desarrolla y fija los niveles de referencia para el español según las recomendaciones que propuso el Consejo de Europa en el año 2001.

Centrándonos en el tema que nos interesa, el Plan curricular entiende que la pragmática "tiene por objeto describir y explicar las reglas que rigen la actuación

\footnotetext{
${ }^{53}$ La serie de tres volúmenes que constituye los niveles de referencia para el español del Plan curricular se sitúa en las coordenadas de la acción institucional del Consejo de Europa en el campo de la enseñanza de lenguas y responde a un análisis actual de la lengua desde la perspectiva de la comunicación basado en el MCER y en los documentos de la serie del Nivel Umbral (Threshold level series, en su versión original).
} 
lingüística de los hablantes, así como las estrategias que estos utilizan para que los mensajes resulten adecuados y eficaces según los destinatarios a los que se dirigen y el contexto en que tiene lugar" (2006, 2007: 261). Por ello, incluye un componente pragmático-discursivo que se basa en la capacidad de los alumnos de participar eficazmente en intercambios comunicativos, lo cual implica el uso de tácticas y estrategias pragmáticas y un análisis de la correspondencia entre formas y funciones, que permiten verbalizar las intenciones del hablante de forma eficaz. Este componente pragmático-discursivo se materializa, por tanto, en tres inventarios: el de Funciones, el de Tácticas y estrategias pragmáticas y el de Géneros discursivos y productos textuales. El inventario de Funciones ${ }^{54}$ parte de la idea, que ya se defendía en el Nivel Umbral $^{55}$, de que el conocimiento de la lengua no se considera un fin, sino que el objetivo último es la capacidad de usar la lengua. Por lo tanto, nos encontramos ante un listado de funciones ${ }^{56}$ que podemos realizar mediante el uso de la lengua: preguntar, rechazar, pedir disculpas, etc. Tanto el aumento del número de funciones como la complejidad de los elementos utilizados para llevarlas a cabo se estipulan en función del desarrollo de las competencias del alumno: a medida que estas se expanden, aumenta su capacidad para intervenir de forma efectiva, adecuada y precisa en las distintas situaciones comunicativas.

En la concepción de la competencia pragmática por parte del Plan curricular podemos destacar la frecuencia con la que se alude acertadamente a la eficacia en la comunicación. Los alumnos deben alcanzar la capacidad de usar la lengua de forma efectiva y eficaz para lograr el éxito comunicativo. Sin embargo, no compartimos la idea de entender esta competencia unida a la discursiva. En nuestra opinión, se trata de habilidades diferentes, aunque evidentemente relacionadas entre sí.

54 Tal como reconoce Halliday, "la organización interna del lenguaje puede ser explicada idóneamente partiendo de las funciones sociales a las que el lenguaje en su evolución sirve” (Halliday, 1973: 34).

${ }^{55}$ El Nivel Umbral (o Threshold level series en su versión original) es una serie que se compone de tres libros de J. A. van Ek y J. L. M. Trim: Treshold 1990 (que es una actualización de la versión original del año 1975), publicado en 1991; Waystage 1990, publicado en 1991; y Vantage, publicado en 2001. El Treshold level, en sus adaptaciones a las distintas lenguas europeas, tuvo gran acogida ya que abría nuevas posibilidades de diseñar las programaciones de los cursos y se centraba en el propio alumno y sus propósitos comunicativos. La única traducción disponible en español es la de la primera versión, en 1975, que no recoge las actualizaciones de este documento realizadas posteriormente.

56 En el Plan curricular se opta por denominar funciones a lo que el MCER denomina microfunciones y el Treshold, funciones de la lengua. 
Del Instituto Cervantes proviene también el Diccionario de términos clave de $E L E$. Se trata de una obra de consulta para profesores, formadores y estudiantes de tercer ciclo, que pretende recoger los estudios que han tenido mayor repercusión en la didáctica y ayudar a la sistematización de la terminología en el ámbito de enseñanza/aprendizaje de español como lengua extranjera. El Diccionario nos remite a los análisis de Canale y Swain (1980), Van Ek (1986), Bachman (1990) y MCER (2002) y define la competencia pragmática como:

La capacidad de realizar un uso comunicativo de la lengua en el que se tengan presentes no solo las relaciones que se dan entre los signos lingüísticos y sus referentes, sino también las relaciones pragmáticas, es decir, aquellas que se dan entre el sistema de la lengua, por un lado, y los interlocutores y el contexto de comunicación, por otro (Diccionario de ELE, en la red).

Como vemos, esta explicación no aporta novedades a nuestro análisis, ya que hace referencia a la relación entre la lengua y sus usuarios presentada ya en la definición de Morris (1938) y a la capacidad de usar adecuadamente la lengua según su contexto comunicativo.

Otro punto de referencia importante son los artículos que encontramos en las publicaciones de las actas de los congresos nacionales e internacionales de la Asociación para la Enseñanza del Español como Lengua Extranjera (ASELE). Estos son un claro reflejo del trabajo que se está llevando a cabo sobre competencia pragmática en el ámbito de enseñanza/aprendizaje de ELE. El término competencia pragmática aparece con gran frecuencia en estas publicaciones; de hecho, el XV Congreso celebrado en 2005 en Oviedo recibe el nombre de La competencia pragmática y la enseñanza del español como lengua extranjera. Resulta paradójico que la mayoría —si no todos- los artículos y ponencias mencionan en algún momento la competencia pragmática, pero son muy pocos los que ofrecen una definición teórica de este concepto y, lo que es más importante, tampoco se mueven en terrenos homogéneos o bien delimitados. Esto confirma la idea, que ya veníamos anunciando anteriormente, de que no se trabaja sobre el concepto de competencia pragmática sino sobre su aplicación, lo cual a menudo lleva al desconcierto y a la desorganización. A continuación nos proponemos examinar brevemente cómo definen 
la competencia pragmática si es que lo hacen y qué líneas de trabajo se están siguiendo entorno a la aplicación de este concepto en la enseñanza/aprendizaje de ELE.

Para definir la competencia pragmática, algunos investigadores recurren a los modelos de competencia comunicativa de Canale y Swain (1980), Bachman (1990) y Celce-Murcia, Dörnyei y Thurrell (1995), que ya desarrollamos en el apartado anterior. Así, Agustín Llach (2005) siguiendo a Celce-Murcia, Dörnyei y Thurrell (1995), define la competencia pragmática tomando la cita literal de lo que estos autores denominan competencia accional: "habilidad de transmitir y comprender el intento comunicativo por medio de la ejecución e interpretación de los actos de habla y las funciones lingüísticas” (1995: 17). Del mismo modo, Bosch (1997) recurre al modelo de Canale y Swain (1980), y Garrido Rodríguez (2005) toma como punto de referencia la división de la competencia comunicativa de Canale (1983) en cuatro componentes: competencia gramatical, sociolingüística, discursiva y estratégica; y entiende que la competencia pragmática, ilocutiva o accional consiste en saber transmitir y reconocer las intenciones comunicativas.

Otros investigadores llegan a identificarla con la competencia comunicativa (AlMonami y Jáimez, 2005) y toman la definición de Rodríguez (2005, en línea):

El uso de la lengua en el contexto de la comunicación, especialmente las relaciones entre las oraciones, los hablantes, las intenciones de estos y las situaciones o contextos culturales en que estas se usan. La falta de competencia pragmática en una segunda lengua puede llevar a dos tipos de fallos: los fallos pragmáticolingüísticos y los fallos sociopragmáticos [...] El primero es un fallo en el lenguaje debido a interferencias de la lengua nativa (L1). El segundo es un fallo que tiene que ver con lo que es apropiado en la cultura de la L2 y es debido a diferentes expectativas culturales (2005: 1).

Estos autores entienden que la competencia pragmática se logra cuando el acto tiene un desenlace feliz, esto es, cuando el interlocutor logra su propósito ${ }^{57}$. Esta es una forma indirecta de definir la competencia pragmática, exponiendo cuándo se consigue o cuándo falla. Según Blum-Kulka (1996), la deficiencia de competencia pragmática significa que el aprendiente no sabe qué estructuras lingüísticas debe usar en qué contextos y con quién y, consecuentemente, se desvía de la norma sociocultural

\footnotetext{
${ }^{57}$ La idea de que los actos de habla sean felices, es decir, se logren, procede de la famosa obra de Searle (1969). 
que rige el intercambio comunicativo concreto, de forma que influirá en la propia imagen del aprendiente y, por supuesto, en la interacción.

García Mata (2005) toma la definición de pragmática de LoCastro: "Pragmatics is the study of the speaker and hearer meaning created in their joint actions that include both linguistic and non-linguistic signals in the context of socioculturally organised activities” (2003: 15) y recomienda para profundizar en un análisis exhaustivo de la materia el manual clásico — pero no actual— de Levinson (1983). Además, recoge los componentes de la competencia pragmática de Roever (2001) adaptándolos. Así pretende mostrar la complejidad cognitiva que supone el desarrollo de las capacidades pragmáticas en una segunda lengua.

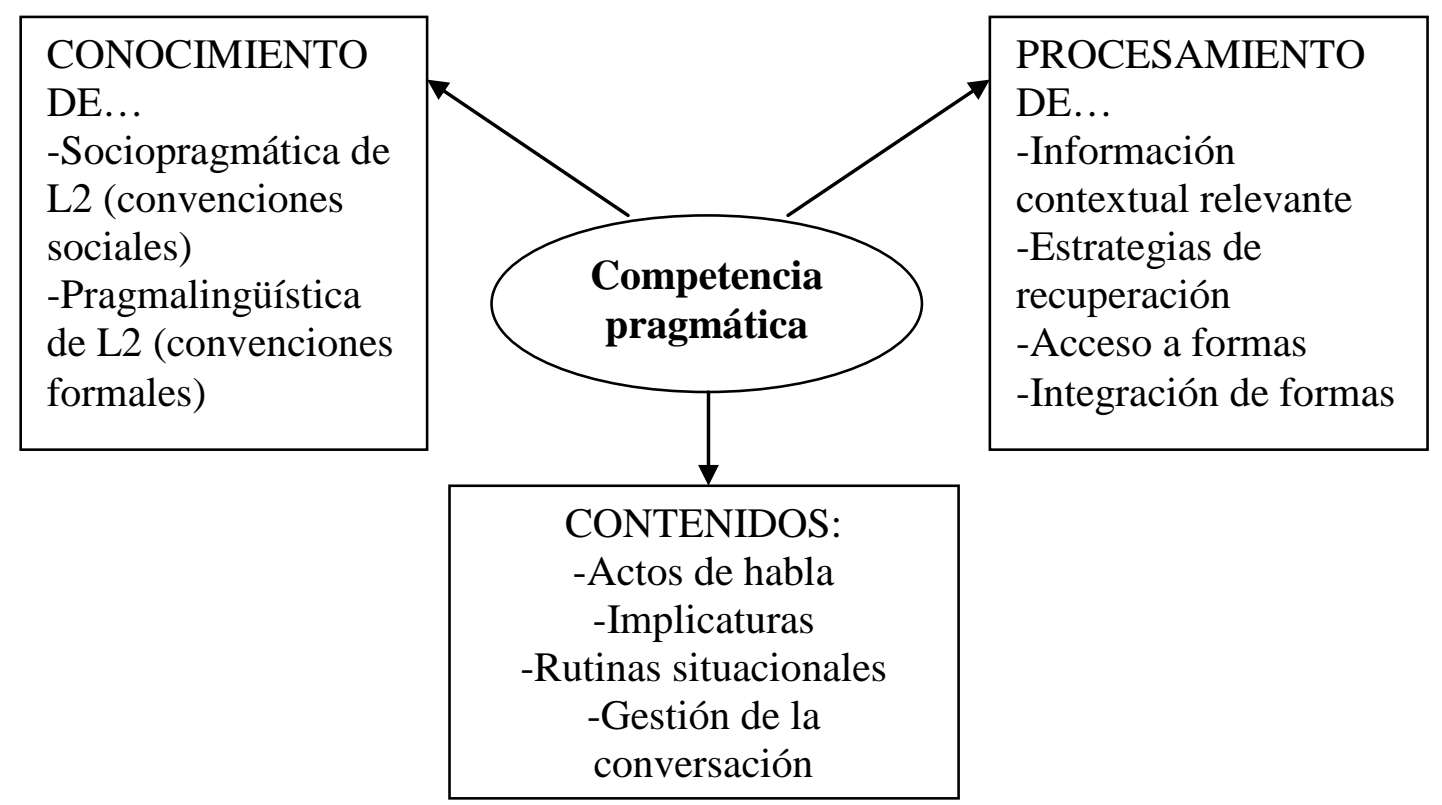

Figura 10. Componentes de la competencia pragmática (Adaptado de Roever, 2001) Fuente: García Mata (2005)

Al margen de estas pequeñas pinceladas sobre el concepto de competencia pragmática, la tónica general de estos trabajos consiste en la aplicación del concepto sin detenerse en la reflexión teórica sobre la noción misma y, lo que es peor, sobre el alcance empírico del concepto, es decir, en qué se traduce a la hora de trabajar. Esto tiene una serie de consecuencias, entre ellas que la mayoría de los profesores de L2 no saben cómo concretar en actividades específicas la competencia pragmática. La práctica que se observa hoy en día en las clases de español lengua extranjera no es la adecuada si se quieren conseguir aprendientes de ELE pragmáticamente efectivos 
(Gutiérrez Ordóñez, 2005). Por consiguiente, se hace necesario investigar cómo se enseña la competencia pragmática en las clases de L2 y qué métodos o tratamientos pedagógicos son los más adecuados para este desarrollo pragmático (Kasper, 2001; Niezgoda y Röver, 2001). Esta opinión es compartida por Baralo Ottonello (2005), que reconoce que no hay estudios suficientes en ELE que describan de forma analítica las habilidades pragmáticas específicas y que las fundamenten desde una perspectiva sociopragmática y pragmalingüística. Además, tampoco es fácil encontrar materiales didácticos específicos para facilitar su desarrollo en clase. Baralo Ottonello (2005) advierte que para elaborar materiales didácticos y reglas claras de uso es necesario un mayor desarrollo y difusión de la pragmática descriptiva del español, que todavía no ha tenido lugar. Sería necesario contar con un corpus de interacción oral del español, atendiendo a las distintas situaciones y relaciones entre los interlocutores, información compartida, etc.

No obstante, la gran mayoría de los autores reconoce la relevancia de la competencia pragmática como componente básico en los procesos de aprendizaje y enseñanza de segundas lenguas (Cenoz y Valencia, 1996; Kasper y Rose, 2001; Vera Luján y Blanco Rodríguez, 2014). El interés por la competencia pragmática en la enseñanza/aprendizaje de una L2 surge, así, debido a la creciente importancia de la comunicación intercultural, y a los efectos que una competencia pragmática deficitaria puede tener en dicha comunicación: malentendidos, imagen del hablante como poco cooperativo o maleducado, etc. (Liddicoat y Crozet, 2001; Gómez Morón, 2004).

Otra fuente de la enseñanza/aprendizaje de español lengua extranjera es el Vademécum para la formación de profesores. Enseñar español como segunda lengua (L2) / lengua extranjera (LE) (Sánchez Lobato y Santos Gargallo, 2004). Se trata de una obra de referencia obligada para aquellos que se dedican a la enseñanza de español. Pretende contribuir a un acercamiento entre los profesionales que desempeñan esta actividad docente e investigadora y ofrecer un panorama completo de lo que se está haciendo en el ámbito de la enseñanza/aprendizaje del español como segunda lengua. En la primera parte - titulada epistemología—, se presenta el estado de la cuestión de las distintas disciplinas cuyas aportaciones son imprescindibles para explicar el proceso de enseñanza/aprendizaje de segundas lenguas, entre las cuales se encuentra la pragmática. En apartados posteriores, se desglosa la competencia 
comunicativa en sus correspondientes componentes: subcompetencia lingüística o gramatical, léxico-semántica, sociocultural, pragmática, discursiva y estratégica, dedicándoles capítulos exentos. En los capítulos dedicados a las aportaciones de la pragmática y a la competencia pragmática encontramos autores que ya nos son conocidos como Cenoz, Gutiérrez Ordóñez o Escandell Vidal.

En opinión de Escandell Vidal (2004b), en los últimos años la pragmática se ha convertido en una materia obligada en la formación del profesor de una segunda lengua, ya que le ofrece las herramientas teóricas y metodológicas para descubrir el entramado interno de los principios que seguimos cuando nos comunicamos. Uno de los factores decisivos para la comunicación es la representación del entorno. Algunas de nuestras representaciones son de carácter individual, pero otras son compartidas con miembros de nuestro mismo grupo social o cultural (Janney y Arndt, 1992: 30). Estas representaciones nos facilitan la interacción con los demás y el procesamiento, puesto que contienen información sobre la manera de tipificar las situaciones y las relaciones con los demás, y a su vez, forman parte del contenido de la competencia pragmática definido como "el conjunto de representaciones interiorizadas relativas al uso de la lengua que comparten los miembros de una comunidad” (Escandell Vidal, 2004b: 185). Según Escandell, los aspectos de la pragmática que tienen especial interés para las tareas de enseñanza de una segunda lengua son los actos de habla y la cortesía, ya que, por un lado, los actos de habla clasifican las intenciones y analizan los medios lingüísticos que se emplean para expresarlas y, por otro, la cortesía estudia los parámetros que determinan la distancia social y sus manifestaciones lingüísticas. Además, es en estos dos aspectos donde se hacen más evidentes las diferencias culturales y se manifiestan los fenómenos de interferencia pragmática (Thomas, 1983; Blum-Kulka et al., 1989; Scarcella et al., 1990; Kasper, 1992; Escandell Vidal, 1996).

Gutiérrez Ordóñez es el encargado de tratar la subcompetencia pragmática en el Vademécum. En primer lugar, reconoce que el ámbito de la pragmática (teoría de los actos de habla, relevancia, cortesía, etc.) abre nuevas perspectivas para los teóricos de la lingüística aplicada ${ }^{58}$. Por ejemplo, la teoría de los actos de habla ha constituido el

\footnotetext{
58 "Lingüística teórica y lingüística aplicada son dos caras de un mismo rostro. Se hallan estrechamente relacionadas. Todo cambio, todo proceso que experimente la teoría lingüística encuentra inmediatamente repercusión en la lingüística aplicada. Y viceversa, toda aplicación que
} 
pilar sobre el que se ha desarrollado una nueva metodología para la enseñanza de lenguas extranjeras (las unidades didácticas tratan de resolver las funciones comunicativas $^{59}$ por orden de aparición: saludar, presentarse, despedirse, preguntar por la procedencia, etc.).

Asimismo, la teoría de la relevancia, que presentamos en el capítulo anterior, ha transformado la forma de entender la lengua. No solo explica cómo llegamos al sentido implícito de los mensajes, sino que también ofrece explicaciones de la comprensión fonológica, gramatical, sintáctica y léxica. Por lo tanto, la competencia pragmática es totalmente necesaria para poder explicar cómo desciframos las secuencias fónicas, cómo se articulan los enunciados en la sintaxis o cómo llegamos a identificar el sentido último de una palabra. Ahora bien, resulta complicado llevar la visión teórica de la relevancia a la realidad del aula de lenguas extranjeras.

En efecto, otro de los fenómenos de los que debe dar cuenta la competencia pragmática consiste en desvelar la parte oculta de los mensajes, lo implícito. Como veremos en el siguiente capítulo, es sorprendente la rapidez con la que los niños producen e interpretan actos de habla indirectos, esto es, mensajes con información implícita. Gutiérrez Ordóñez (2004) atestigua que a edades muy tempranas los niños dicen a sus madres lo mucho que las quieren cuando van a pedirles algo o, a la inversa, entienden que les están pidiendo un beso o un abrazo cuando les preguntan ¿Quién me quiere a mí? (2004: 542). Esto nos da una idea de lo que entendemos como cardinal dentro de la competencia pragmática $y$, por tanto, si esta es una capacidad que adquirimos cuando aprendemos la lengua materna, deberemos incorporarla también al aprendizaje de una segunda lengua. Según Celce-Murcia y Olshtain (2000):

Human communication fulfills many different goals at the personal and social levels. We communicate information, ideas, beliefs, emotions, and attitudes to one another in our daily interactions, and we construct and maintain our positions within various social contexts by employing appropriate language forms and performing speech activities to ensure solidarity, harmony, and cooperation-or to express disagreement or displeasure, when called for. The acquisition of communication skills in one's first language is a lifelong process, but the basic skills are acquires quite early in life. When learning

se acompaña de éxito práctico deberá encontrar fundamento en la dimensión teórica” (Gutiérrez Ordóñez, 2004: 549).

${ }^{59}$ El concepto de función comunicativa está profundamente relacionado con el de acto de habla. 82 
another language, we have to add to, change, and readjust our native language strategies

to fit the new language and culture (Celce-Murcia y Olshtain, 2000:3).

Así las cosas, aunque un estudiante posea un nivel avanzado y gran fluidez en la segunda lengua, no tiene garantizado el éxito en las situaciones comunicativas reales. Tal como reconoce Lamb (2005), desarrollar las habilidades conversacionales supone ser capaz de descodificar, inferir y comportarse de acuerdo con las reglas de cada sociedad (2005: 231). De este modo, la tarea del profesor de lenguas extranjeras deberá ser:

Equip the student to express her/himself in exactly the way she/he chooses to do so rudely, tactfully, or in an elaborately polite manner. What we want to prevent is her/his being unintentionally rude or subservient (Thomas, 1983: 96).

Lo que esta autora propone es, en otras palabras, que los estudiantes sean dotados con el conocimiento pragmático necesario para tomar sus propias decisiones sobre el uso apropiado de la L2.

Llegados a este punto, debemos reflexionar sobre la posibilidad de enseñanza (ya sea explícita o implícita) de la competencia pragmática, esto es, si dicha competencia necesita instrucción o si, por el contrario, se desarrolla de forma natural junto con el conocimiento gramatical y no necesita ninguna intervención pedagógica. García Mata (2005) parte de que cualquier competencia, ya sea lingüística o pragmática no puede ser enseñada; mientras que para autores como Kasper y Rose (2002), Barcelar da Silva (2003) o Martínez-Flor y Fukuya (2005), las competencias son un tipo de conocimiento que los hablantes poseen, desarrollan, adquieren o pierden, por lo que la labor del profesor consiste en facilitar la adquisición, desarrollo y uso de esa capacidad en los alumnos. Precisamente, Rose (2005), en su revisión sobre la investigación en torno a los efectos de la instrucción en pragmática en la enseñanza de segundas lenguas, defiende que "exposure alone does not account for gains in pragmatic ability" (2005: 391).

En su estudio, Bardovi-Harlig (1996) señala los factores que influyen directamente en la adquisición de la competencia pragmática. Estos son, entre otros, el input al que están expuestos los estudiantes, la instrucción por parte del profesor, el nivel lingüístico y el tiempo pasado en contacto con la cultura de la L2. En cuanto a este último factor, resulta razonable que cuanto mayor es el tiempo que el aprendiente 
interactúa con nativos o está inmerso en una comunidad de hablantes de L2, mayor conciencia adquiere de los aspectos pragmáticos, aunque esto no siempre es posible.

Investigadores de adquisición de la lengua materna como Scarcella, Andersen y Krashen (1990) llaman la atención sobre el hecho de que "while many aspect of communicative competence may be acquired quite early by young first language learners, many aspect may be late-acquired or never acquired at all” (1990: 3). Además, los expertos han corroborado cómo estos aspectos de la competencia comunicativa pueden ser adquiridos también por aprendientes de segundas lenguas. Sin embargo, tal como apunta Aquino (2011), cuando los niños adquieren este tipo de conocimiento están expuestos a la cultura de su lengua materna, mientras que los estudiantes de segundas lenguas no suelen tener contacto real con aspectos específicos de la cultura y su asimilación, por tanto, se vuelve más difícil. Es tarea del profesor favorecer en sus clases el desarrollo de este tipo de conocimiento. En esta línea, autores como Eslami-Rasekh et al. (2004) opinan que "making contextualized, pragmatically appropriate language input available to learners in an EFL context in which they don't have the chance to encounter this input outside the classroom is pedagogically necessary and politically right” (Eslami-Rasekh et al., 2004: 10). De esta forma, cuanto más se trabaja sobre la competencia pragmática en clase, los estudiantes son más conscientes de estos aspectos de la comunicación. Así, LoCastro (2006) insta a los profesores de segundas lenguas a considerar "the greater need for explicit teaching and exposure to linguistic and nonlinguistic input for learners” (2006: 329) para ampliar su competencia pragmática en la L2.

Por otra parte, cabe plantearnos también el hecho de que si la competencia pragmática se desarrolla en hablantes no nativos adultos que no han recibido instrucción es porque parte del conocimiento pragmático que poseemos es universal y otros aspectos los transferimos de nuestra lengua materna. El trabajo de Agustín Llach (2005) nos recuerda la distinción entre los principios pragmáticos universales y los específicos de cada comunidad lingüística. Los principios universales ${ }^{60}$ son generales,

60 Así como existen universales lingüísticos, también es posible hablar de universales pragmáticos o "expresiones ordenables en estructuras generales de la situación del habla, como los pronombres personales, giros para el inicio del discurso, expresiones deícticas y verbos preformativos e intencionales" (Lewandowski, 1982: 366). Habermas (1981) reconoce que la pragmática universal intenta la reconstrucción de las condiciones (que tienen lugar en toda posible situación de habla) producidas por el hablante en la ejecución lingüística, logrando la 84 
y por lo tanto, independientes de la norma cultural de cada lengua. Estos son diversas estrategias de comunicación, los distintos tipos de actos de habla (saludos, peticiones, disculpas, quejas, etc.) y fenómenos como la cortesía verbal. Los aprendientes saben que la conversación sigue unos principios, que muchos de los intercambios se hacen de forma indirecta y que para interpretarlos deben usar la información contextual y el conocimiento enciclopédico. Por ejemplo, los hablantes saben que una forma de suavizar las peticiones es haciéndolas más indirectas. Esto se ha documentado en varios estudios sobre estrategias para realizar peticiones en estudiantes de inglés que eran nativos de chino (Johnston, Kasper y Ross, 1994), de alemán (House y Kasper, 1987), de japonés (Takahashi y Dufon, 1989 apud Kasper, 1997) o de español (Rintell y Mitchell, 1989). En los niveles más bajos los aprendientes no son capaces de usar estas estrategias porque todavía no tienen conocimientos lingüísticos suficientes, pero cuando su conocimiento lingüístico se lo permite, utilizan estas tácticas de petición sin necesidad de instrucción.

Los principios específicos, sin embargo, dependen de las normas culturales de cada comunidad lingüística ${ }^{61}$ y se materializan en los diversos mecanismos verbales que se utilizan para llevar a cabo los actos de habla, así como en una serie de convenciones sociales y culturales que vienen determinadas por variables como la distancia social y psicológica, el poder, el estatus, el grado de imposición del acto en el interlocutor, etc. (Ruiz de Mendoza, 1996; Kasper y Rose, 2001). Teniendo en cuenta esto, sabemos que los aprendientes de L2 a menudo transfieren su conocimiento pragmático de la L1 a la L2. La transferencia ${ }^{62}$ de conocimientos de carácter

comprensión intersubjetiva. Por lo tanto, entendemos los universales pragmáticos como las expresiones lingüísticas existentes en todas las lenguas que posibilitan llevar a cabo las distintas situaciones comunicativas. Dentro de estos universales se encuentran, por ejemplo, las expresiones de cortesía estudiadas por Brown y Levinson (1978).

${ }^{61}$ En las actas de los congresos de ASELE encontramos numerosos trabajos en torno a diferencias de tipo pragmático entre hablantes de diferentes culturas, por ejemplo Haverkate (1996) hace un análisis intercultural de la cortesía entre españoles y holandeses y Aparecida Duarte y Nascimento Campos (1999) estudian las diferencias pragmáticas en el uso del imperativo en castellano y portugués.

${ }^{62}$ El fenómeno de la transferencia se convierte en objeto de estudio de los lingüistas tras los estudios de Charles Fries (1945), que reivindicaba la necesidad de una comparación sistemática de la lengua nativa del estudiante con la lengua que intenta aprender, buscando similitudes y diferencias que permitieran identificar las áreas de dificultad que aparecían durante el aprendizaje. Estas ideas fueron formuladas de forma más clara por Robert Lado (1957). Hoy podemos decir que se trata de un fenómeno del que existe abundante bibliografía entre la que destacan los 
pragmático desde la lengua materna del alumno a la lengua meta está frecuentemente presente en los procesos de adquisición de segundas lenguas. Este tipo de transferencia ha sido reconocida hace relativamente poco tiempo por lo que actualmente continúa en desarrollo. Uno de los primeros en hablar de transferencia pragmática (pragmatic transfer) fue M. Clyne (1977) con un estudio sobre los actos de habla de inmigrantes alemanes en Australia. Estos estudios contrastivos se han ido sucediendo dando lugar a la pragmática intercultural (cross-cultural pragmatics) ${ }^{63}$. Fernández Silva (2002) subraya que la pragmática intercultural debe entenderse como una herramienta de ayuda para el profesor de segundas lenguas y destaca la carencia de descripciones funcionales de la lengua española y de trabajos contrastivos del español con otras lenguas ${ }^{64}$.

Si los aspectos pragmáticos de L1 y L2 coinciden se habla de transferencia positiva, pero si difieren, estaríamos ante casos de transferencia negativa (Jessner, 1996; Kasper y Rose, 2001). Así, la transferencia negativa da lugar a errores pragmáticos tales como la sobreutilización, la subproducción (Jessner, 1996) o errores de tipo pragmático-léxico ${ }^{65}$ (Agustín Llach, 2005).

La transferencia positiva se da cuando la distribución de los derechos y obligaciones de los interlocutores coincide en las dos comunidades lingüísticas, de forma que los hablantes solo tienen que hacer un pequeño ajuste en su categorización social (Kasper, 1997). Desgraciadamente, los aprendientes no siempre transfieren este tipo de conocimiento y es ahí donde debe intervenir la instrucción. Según Kasper (1997), hay que enseñar a usar el conocimiento pragmático universal y transferible de L1 en los contextos de L2. La instrucción en pragmática es necesaria en los casos de

estudios de Corder (1981, 1983), Kellerman y Sharwood Smith (1986), Odlin (1989), Gass y Selinker (1992), etc.

${ }^{63}$ Para mayor información sobre pragmática intercultural consúltese Hernández Sacristán (1999), Oliveras (2000), Bravo y Briz (2004), Caballero Díaz (2005), Elizondo Azagra (2008), Barros García (2008), entre otros.

${ }^{64}$ Entre la creciente bibliografía en español sobre la transferencia y análisis contrastivos entre lenguas destacan Oliveras, 2000; Manchón Ruiz, 2001; Bosco Camón, 2004; Escandell Vidal, 2006; etc.

${ }^{65}$ Un ejemplo de error pragmático-léxico es aquel que se produce cuando se intercambian dos palabras que pertenecen a distintos registros, así nos sorprende oír en una conversación coloquial: Para mí es muy difícil discernir entre dos marcas de vino. Esto puede dar lugar a que consideremos pedante al interlocutor. Para evitar estos errores es necesario instruir a los estudiantes no solo sobre las dimensiones semántica, sintáctica o morfológica del léxico, sino también sobre la pragmática, sobre cuándo y cómo se han de utilizar ciertas palabras y realizar una práctica explícita del uso léxico en contextos comunicativos reales (Agustín Llach, 2005). 
estudiantes que tienen una competencia lingüística elevada en L2 pero cuya competencia pragmática es deficiente. Bouton (1988) examinó cómo los estudiantes entienden los diferentes tipos de respuestas indirectas o de implicaturas y detectó que en el $27 \%$ de los casos las implicaturas son entendidas de forma diferente por hablantes nativos y no nativos de una lengua, aunque las diferencias se reducen cuanto mayor es el tiempo dedicado al estudio de una lengua. Asimismo, Bardovi-Harlig (1996) descubrió, después de un periodo de observación, que los estudiantes no mitigaban sus sugerencias y rechazos apropiadamente como lo haría un nativo. En un estudio posterior, Bardovi-Harlig y Dörnyei (1998) revelaron que estudiantes húngaros e italianos de todos los niveles reconocían la incorrección gramatical más rápidamente que la inadecuación pragmática. Esto sugiere que, sin un foco pragmático, la enseñanza de L2 permite tener conciencia metalingüística, pero no contribuye al desarrollo de la conciencia metapragmática.

Como hemos visto, sin instrucción muchos aspectos de la competencia pragmática no se desarrollan lo suficiente. Algunos lingüistas recomiendan enseñar la pragmática de la L2 de forma explícita (Bouton, 1996; Meier, 1999) mientras que otros defienden que la pragmática debe enseñarse de forma implícita ${ }^{66}$ (BardoviHarlig, 1996; Kasper, 1997). Galindo Merino (2005), que aborda este tema en su conferencia del XV Congreso de ASELE en Oviedo, aboga por la enseñanza explícita, pero asimismo reconoce que no se pretende que los aprendientes se comporten como nativos, sino que "sean conscientes de los efectos comunicativos y sociales de ciertos usos lingüísticos y comportamientos asociados a una cultura” (2005: 294).

En su estudio de 2011, Gu Xiao-le se propone averiguar si la instrucción explícita e implícita de las estrategias de petición puede ser efectiva en clases de estudiantes chinos de inglés L2. El experimento se basa en un pre-test y un post-test en el que se pide a los alumnos que realicen una tarea de discurso escrito y un role play. Los resultados concluyen que todos los estudiantes mostraron mejoras después de la instrucción, pero en diferente grado. El grupo que recibió instrucción explícita mostró un mayor progreso en el nivel de formalidad y cortesía de las peticiones. Esto sugiere la necesidad de incorporar la conciencia en estos aspectos a través de actividades de

\footnotetext{
${ }^{66}$ La enseñanza explícita se basa en la descripción, explicación y discusión sobre los fenómenos pragmáticos además de la práctica y el input en relación con estos; mientras que la enseñanza implícita incluye el input y la práctica, pero sin el componente metapragmático.
} 
enseñanza pragmática en las aulas. Sin embargo, los aprendientes de ambos grupos mostraron un progreso muy limitado en las actividades orales de role play, lo cual indica que son necesarias más oportunidades de práctica, de forma que los estudiantes adquieran familiaridad en su uso. Este estudio confirma los hallazgos de numerosos estudios empíricos de enseñanza en competencia pragmática: dicha competencia, como componente indispensable de la competencia comunicativa, no puede ser plenamente adquirida sin instrucción apropiada. Este trabajo también revela que la instrucción explícita es más eficaz que la implícita en la realización de peticiones. Así, enseñar conocimiento metapragmático ayuda a los estudiantes a despertar su conciencia pragmática y a mejorar su habilidad para elegir las formas pragmáticas apropiadas y las estrategias más útiles en ciertas circunstancias comunicativas.

En la misma línea de investigación encontramos el trabajo de Koike y Pearson (2005). Estos autores probaron que el índice de adquisición de la competencia pragmática en nativos ingleses estudiantes de español era más alto si recibían instrucción explícita y feedback. Por su parte, Alcón Soler (2005) comparó dos grupos de estudiantes españoles y descubrió que el grupo que había recibido instrucción explícita mostraba una mayor velocidad en el dominio de las sugerencias en inglés. Igualmente, Bardovi-Harlig y Griffin (2005) llevaron a cabo un estudio en el que una de las tareas consistía en disculparse. Los autores concluyeron que la instrucción explícita puede beneficiar a los aprendientes de L2, si bien es cierto que en los niveles avanzados detectaron conciencia pragmática sin instrucción.

Por su parte, Norris y Ortega (2000) demostraron que la instrucción explícita resulta ser más efectiva a través de un estudio en el que analizaron 49 trabajos publicados entre 1980 y 1998 - sobre la instrucción en varios aspectos lingüísticos. No obstante, los autores reconocen que en este tipo de estudios, los resultados de aprendizaje siempre favorecen a los tratamientos explícitos, ya que suponen tareas explícitas de memoria y/o en un uso descontextualizado de la L2. Los tratamientos explícitos son típicamente más intensos y variados que los implícitos. Además, los tratamientos implícitos requieren periodos de observación más largos para ser detectados.

Asimismo, en las últimas décadas se han llevado a cabo una serie de estudios experimentales para comprobar la efectividad de la instrucción en determinados 
aspectos pragmáticos: rutinas pragmáticas ${ }^{67}$ (Tatemaya, 2001; Yoshimi, 2001), estructura conversacional (Myers-Scotton y Bernstein, 1988), fluidez pragmática (House, 1996), peticiones (Takahashi, 2001), disculpas (Olshtain y Cohen, 1990), cumplidos (Manes y Wolfson, 1981; Rose y Kwai-fun, 2001), quejas y rechazos (King y Silver, 1993), normas interaccionales (Liddicoat y Crozet, 2001), atenuaciones en escritura académica (Wishnoff, 2000), etc. Los resultados de la mayoría de estos estudios están también en consonancia con la idea del efecto positivo de la intervención pedagógica, y apoyan la idea de que la instrucción en pragmática puede facilitar el desarrollo de la competencia pragmática en los aprendientes de L2.

En su trabajo de 1997, Kasper recoge una serie de estudios enfocados a determinar qué aspectos de la pragmática pueden enseñarse y qué métodos son los más efectivos. Los estudios para comprobar el efecto de la instrucción pragmática se realizaron también sobre distintos aspectos: rutinas pragmáticas (Wildner-Bassett, 1984; Tateyama et al., 1997), implicaturas (Bouton, 1994; Kubota, 1995), determinados actos de habla como cumplidos (Billmyer, 1990), disculpas (Olshtain y Cohen, 1990), etc., a distintos niveles, con distintos objetivos y con distintos procedimientos. Los trabajos de Wildner-Bassett (1984) y Tateyama et al. (1997) demostraron que las rutinas pragmáticas pueden enseñarse a los estudiantes del nivel bajo, lo cual desmiente la idea de que la pragmática solo pueda ser instruida cuando se tiene un conocimiento sólido de la gramática y el léxico. Los estudiantes, desde el principio, pueden ir aprendiendo las rutinas pragmáticas, aunque no las analicen todavía, para poder desenvolverse en situaciones comunicativas reales.

Por otro lado, el estudio de Kubota (1995) puso de manifiesto que existen aspectos de la pragmática (por ejemplo, algunos tipos de implicaturas) que no se desarrollan mejor a través de la instrucción. Los estudiantes japoneses con los que trabajó entendían las implicaturas que manejaban en las clases, pero eran incapaces de generalizar las estrategias de inferencia a los nuevos casos de implicaturas que se les planteaban.

En los últimos años han aparecido también numerosos estudios cuyo objetivo es comprobar la importancia de la enseñanza de determinados aspectos pragmáticos de la

\footnotetext{
${ }^{67}$ Entre las rutinas pragmáticas más importantes se encuentran las llamadas fórmulas de cortesía así como las fórmulas o estrategias conversacionales.
} 
comunicación en las clases de lenguas extranjeras. Por ejemplo, Padilla Cruz (2010) recalca la falta de atención hacia las interjecciones en los materiales de inglés como segunda lengua. Según el autor, es necesario que los estudiantes reconozcan la contribución de las interjecciones a la comunicación y dónde recae su importancia interactiva, lo cual debería incluirse en la enseñanza pragmática dentro del aula. Vittoria Grossi (2009) plantea en su estudio cómo enseñar las fórmulas de cumplidos y respuestas a cumplidos en sus clases de inglés con estudiantes adultos. En efecto, la revisión de la literatura sobre el tema sugiere que la instrucción explícita tiene efectos positivos en la adquisición de estos tipos de actos de habla. Su propuesta consiste, entonces, en la elaboración de una base de datos con ejemplos naturales orales tomados de películas con hablantes de diferentes edades y en distintas situaciones comunicativas, lo cual resulta muy positivo para su uso en el aula, sobretodo en la realidad intercultural.

Por su parte, Aquino (2011) se plantea la posibilidad de ayudar a los estudiantes a desarrollar aspectos pragmático-culturales específicos a través de una metodología basada en tareas ${ }^{68}$. Los resultados ponen de relieve algunos de los aspectos positivos de la instrucción en competencia pragmática. De esta forma, dicha aproximación basada en tareas puede ayudar a los estudiantes a darse cuenta de que la forma lingüística es el resultado del significado pretendido (intended) y que los hablantes usamos diferentes formas en función de lo que queremos significar cuando hacemos uso del lenguaje. La autora resalta además la importancia de diseñar metodología más eficiente, de forma que la pragmática tenga un papel esencial en el currículo de lenguas extranjeras.

Finalmente, Fraser (2010) llama nuestra atención sobre el concepto de hedging ${ }^{69}$ como aspecto fundamental de la competencia pragmática en la enseñanza de inglés

${ }^{68}$ La autora entiende tarea comunicativa como "a piece of classroom work which involves learners in comprehending, manipulating, producing or interacting in the target language while their attention is principally focused on meaning rather than form”(Nunan, 1993: 10). Ellis (2004) añade que "a task requires participants to function primarily as 'language users' in the sense that they must employ the same kinds of communicative processes as those involved in real-word activities" (2004: 3).

${ }^{69}$ Se entiende por hedging la estrategia retórica por la cual el hablante atenúa el valor de una expresión semántica (por ejemplo "John is sort of smart") o la fuerza de un acto de habla (como en "I must ask you to stop doing that")(Fraser, 2010). El primer lingüista que habla sobre este concepto es Weinreich (1996: 163) cuando trata los operadores metalingüísticos: "for every language 'metalinguistic operators' such as in English true, real, so-called, strictly speaking, and 90 
como segunda lengua, ya que no solo nos permite alcanzar nuestras metas comunicativas, sino que si falla puede dar lugar a malentendidos y dificultades comunicativas.

La siguiente cuestión que debemos plantearnos es cómo debe ser esta instrucción en competencia pragmática. En las clases de segundas lenguas tradicionales el esquema que se sigue es el de: pregunta por parte del profesor - respuesta por parte de los alumnos - feedback del profesor (Chaudron, 1988: 37). Long et al. (1976) ya demostraron que las actividades centradas en los alumnos aumentaban su participación en clase permitiéndoles practicar un mayor número de actos de habla e interaccionar más con otros participantes.

En líneas generales, los aprendientes imitan los patrones de los hablantes nativos para poder llegar a construir su propio conocimiento pragmático con el input correcto. Se han elaborado estudios comparativos para demostrar cómo los diálogos que aparecen en los libros de texto difieren de los recogidos en situaciones comunicativas reales (Myers-Scotton y Bernstein, 1988; Bardovi-Harlig et al., 1991). Como advertimos al comienzo de este apartado, es necesario un input auténtico de L2 para el aprendizaje pragmático, aunque no se asegura el éxito. Cuando los alumnos observan una situación comunicativa real, no solo registran lo que están oyendo, sino que lo interpretan. Según la psicología cognitiva (Sanford y Garrod, 1981), cuando intentamos entender las prácticas de una comunidad lingüística que no nos es familiar, lo hacemos a través del filtro de nuestras propias costumbres, de forma que las clasificamos en función de si son familiares (y entonces no requieren reflexión o análisis) o desconocidas (en cuyo caso requieren una interpretación y explicación). La enseñanza de lenguas extranjeras tiene, entonces, la tarea de ayudar a los estudiantes a situar las prácticas comunicativas de la L2 en su contexto sociocultural y apreciar sus significados y funciones dentro de la comunidad de L2. De ahí que sea primordial que el material de las clases de segundas lenguas sea auténtico, con conversaciones y situaciones reales, tal como defienden autores como Kasper (1997), Vellenga (2004) o LoCastro (2006).

the most powerful extrapolator of all, like, function as instructions for the loose or strict interpretation of designata”. Sin embargo, será Lakoff (1972) quien lo popularice llamando la atención sobre el estudio de este terreno: "For me, some of the most interesting questions are raised by the study of words whose meaning implicitly involves fuzziness -words whose job it is to make things fuzzier or less fuzzy” (1972: 471). 
En su trabajo, Rueda (2006) defiende que la instrucción pragmática en segundas lenguas, en particular en la clase de conversación de inglés como L2, debe abordar tres funciones: (1) exponer a los aprendientes a un input adecuado de la lengua objetivo, (2) despertar su conciencia pragmática y (3) ofrecer a los alumnos oportunidades auténticas para practicar su conocimiento pragmático. Estos objetivos los reconocemos en autores como Rose (1997), que introduce actividades con material audiovisual como películas $^{70}$, de forma que los estudiantes puedan darse cuenta de cómo se llevan a cabo determinados actos de habla mediante distintos enunciados, o Silva (2003), que propone despertar la conciencia pragmática de los alumnos de L2 escuchando actos de habla de rechazo de invitaciones por parte de nativos americanos.

No obstante, creemos que la exposición a un input apropiado no es suficiente para que los estudiantes de L2 adquieran la competencia pragmática. Así lo reconoce Schmidt (1993: 36) y determina que esto se debe a la opacidad de algunas estrategias lingüísticas y la falta de prominencia (salience) de algunos factores contextuales.

Así las cosas, consideramos que la finalidad primordial de la instrucción en competencia pragmática debería ser sensibilizar a los estudiantes en cuanto a los diversos factores contextuales que dan lugar a la variación en la elección de enunciados posibles y no enseñarles grandes repertorios de diferentes actos de habla.

Kasper (1997) también examina los objetivos que la instrucción en pragmática puede conseguir. En primer lugar, hay que tener en cuenta que los hablantes nativos no son hablantes ideales, y por lo tanto, no tiene sentido exigir un nivel de competencia comunicativa a los estudiantes que los nativos no tienen. En segundo lugar, los aprendientes no tienen que imitar el modelo de los hablantes nativos ${ }^{71}$ sino crearse una

\footnotetext{
${ }^{70}$ Rose (1997) opta por el material audiovisual como una fuente alternativa al auténtico input: "in foreign language contexts, exposure to film is generally the closest that language learners will ever get to witnessing or participating in native speaker interaction” (1997: 283).

${ }^{71}$ Pensar que los estudiantes de segundas lenguas tienen que alcanzar la competencia nativa ideal ha sido cuestionado por distintos autores. Grosjean $(1989,1992)$ y Cook $(1992,1993,1995)$ critican la llamada visión monolingüe del bilingüismo, que consiste en la creencia de que los aprendices de una segunda lengua tienen que alcanzar una competencia nativa en la segunda lengua, esto es, idéntica a la de los hablantes monolingües de esa lengua. Tal como recoge Edwards (1994), resulta excepcional encontrar a un hablante bilingüe o plurilingüe que sea perfectamente equilibrado, es decir, que posea competencia nativa en todas sus lenguas. Grosjean (1992) propone una visión holística, de forma que considera que el hablante bilingüe tiene un tipo de competencia especial que refleja las interacciones que existen entre las lenguas que conoce. En esta misma línea, Cook (1992) propone el término multicompetencia para denominar a este tipo de competencia que poseen los hablantes bilingües o trilingües. Según Cook, los hablantes de L2 92
} 
nueva identidad interlingüística en el proceso de aprendizaje (Siegal, 1996). En tercer lugar, los hablantes nativos pueden considerar intrusiva la convergencia total a los mecanismos pragmáticos por parte de los estudiantes de L2; por ello, Giles, Coupland y Coupland (1991) entienden que no tiene que haber convergencia total sino óptima. La convergencia óptima es aquella en la que los significados se negocian. Por último, en cuarto lugar, tal como recoge Bonny Norton Peirce (1995), la clase de segundas lenguas debe ser un lugar donde los aprendientes puedan reflejar sus encuentros comunicativos, sus experiencias y observaciones. Se trata de generar un ambiente que los prepare para la comunicación efectiva en la L2. Así, la enseñanza de segundas lenguas "will expand its role from that of language instruction to that of language education” (Kasper, 1997: 15).

Volviendo al terreno de español lengua extranjera, Pons Bordería (2005b) examina cómo es la pragmática que ya se enseña en las clases de español para extranjeros y algunas de las líneas que pueden resultar útiles y que todavía no se tratan. Para analizar cómo es la pragmática que se emplea en la enseñanza de español utiliza varios manuales (Gente, Prisma, Avance, etc.) centrándose en los niveles iniciales. La influencia de la pragmática se hace visible en la inclusión de funciones comunicativas del tipo saludar y despedirse, preguntar e informar sobre direcciones, etc. Sin embargo, como apunta Pons Bordería, solo un pequeño número de funciones se corresponden con el concepto teórico de acto de habla. Podemos decir que son subtipos de funciones generales. Por ejemplo, un función sería preguntar y dentro de esta habría subtipos: preguntar por el nombre, preguntar por una calle, preguntar por un producto, etc., que mantienen las mismas condiciones de fortuna: conseguir la información solicitada. Sin embargo, con tantos subtipos podríamos llegar a tener una lista extremadamente larga de actos de habla en lengua española (Fernández Cinto, 1991), por lo que la solución desde la didáctica teórica consistiría en reducir el número de categorías y subcategorías de funciones comunicativas. No obstante, en el campo de ELE, las distintas subcategorías sí que son significativas, puesto que no es lo mismo preguntar por el nombre que preguntar por una dirección. Por ello, la didáctica de las lenguas

no son imitadores sino que poseen formas únicas de competencia. Finalmente, Cenoz (2004) añade que aunque todas las subcompetencias (lingüística, pragmática, sociolingüística, etc.) son necesarias para la comunicación efectiva en varias lenguas, "no es necesario desarrollar todos los componentes para todas las situaciones comunicativas en todas las lenguas” (2004: 460). 
extranjeras ha acuñado el término de situación comunicativa, que le es más propio, pero que aún carece de reflexión teórica.

Las nuevas líneas propuestas por Pons Bordería para el tratamiento de la pragmática en clase de ELE se centran en el estudio del significado implícito, de la cortesía y de la pragmática intercultural. Aunque el significado implícito es dependiente del contexto, en ocasiones se generaliza y alcanza un cierto grado de estabilidad (esto ya lo reconocía Grice en 1975). Los estudiantes que se enfrentan a una situación comunicativa en L2 realizan un proceso de ajuste inferencial continuo. Será, entonces, labor del profesor hacer que el alumno tenga consciencia de este mecanismo, así como de las diferencias entre su lengua materna y la L2. En efecto, como hemos señalado anteriormente, los estudios de pragmática intercultural, que analizan las diferencias de significado obtenidas por interlocutores de diferentes culturas, son de gran interés para la elaboración de manuales y suponen una nueva línea de investigación para la enseñanza de lenguas (Franch y Signes, 1999).

Asimismo, Gutiérrez Ordóñez (2005) nos habla además de la existencia de principios o normas de buena conducta comunicativa (principio de cooperación, principio de cortesía, principio de adecuación, etc.). La transgresión de uno de estos principios por parte del aprendiente de L2 puede ser considerada un acto de grosería o mala educación, lo cual dañaría su imagen social. El hecho de que los expertos demanden la inclusión de estos en los manuales de lenguas extranjeras pone de manifiesto que se trata también de un ámbito importante de la pragmática, ya que dichos principios rigen nuestros intercambios comunicativos.

Finalmente, la evaluación ${ }^{72}$ de la competencia comunicativa en general $-\mathrm{y}$ pragmática en particular - es otro de los temas debatidos en la enseñanza de lenguas extranjeras. Resulta significativo que dos de los modelos que más difusión han tenido en torno al marco teórico de la competencia comunicativa (Canale y Swain, 1980 y Bachman, 1990) provengan del área de evaluación de segundas lenguas. Canale y Swain (1980) reivindican que la distinción entre competencia y actuación hace que no tengamos que evaluar solo los conocimientos que el aprendiente posee sobre una

\footnotetext{
${ }^{72}$ En este trabajo vamos a entender por evaluación "la reunión sistemática de información para propósitos de toma de decisiones. La evaluación usa tanto métodos cuantitativos (exámenes) como cualitativos (observaciones, evaluaciones) y juicios de valor" (Longman Diccionary of Applied Linguistics, Richards et al.,1985: 81). 
lengua y su uso, sino también su capacidad para ponerlos en práctica en la comunicación; y Rea (1985) considera que la competencia no puede evaluarse directamente sino a través de la actuación. Weir (1988) observa, asimismo, la existencia de un problema respecto a la distinción entre competencia y actuación cuando hablamos de pruebas de evaluación y afirma que "solo la actuación puede ser evaluada” (1988: 10). Para este investigador, cualquier comportamiento lingüístico, incluso realizar un test de respuesta múltiple, implica necesariamente actuación. No obstante, en la práctica, la distinción entre competencia y actuación ${ }^{73}$ resulta difícil de mantener.

Teresa Bordón (1993), aun reconociendo que la actuación puede variar en función de factores o variables como la situación, el tipo de tarea, etc., advierte que competencia y actuación no son dos parámetros diferentes, sino que la actuación es la manifestación de la competencia. Es importante, entonces, llevar a cabo una investigación empírica que compruebe hasta qué punto las pruebas evalúan fielmente la capacidad de los estudiantes para manejarse en situaciones comunicativas reales. Según Canale y Swain (1980), es necesario elaborar criterios fiables para calificar el grado de adecuación de los enunciados en diversos contextos socioculturales y discursivos. Por otra parte, en el trabajo de Bachman (1990), que versa sobre cómo debe evaluarse o medirse el aprendizaje de lenguas: los problemas, los criterios, el uso, etc., se reconoce acertadamente que si queremos crear buenos test debemos basarlos en claras definiciones de las habilidades que vamos a evaluar.

En esta línea, Spolsky (1978) también reivindica la necesidad de integrar las diferentes habilidades que forman parte de la comunicación real en el proceso de evaluación. No obstante, en la actualidad la medición de la competencia comunicativa en la enseñanza de segundas lenguas supone dificultades. El problema radica en que en los test basados en un enfoque puramente comunicativo a menudo se mide más la inteligencia o algún tipo de especificidad cognitiva que la habilidad lingüística real del alumno examinado.

Álvarez Piñeiro (2005) presenta un modelo de evaluación para analizar la competencia pragmática. Esta autora defiende una evaluación formativa (realizada durante el proceso de enseñanza/aprendizaje) e interna (elaborada y evaluada por el

\footnotetext{
${ }^{73}$ Véase 1.1.2.
} 
profesor mismo). Un ejemplo de su propuesta de evaluación consiste en que, una vez seleccionado el grupo en función del nivel, se seleccionan una o varias funciones comunicativas (por ejemplo, ofrecer o rechazar una invitación u ofrecimiento) y se diseña la actividad que consta de una parte escrita —en la que el estudiante debe escribir un correo electrónico de agradecimiento, disculpa, felicitación, etc., en función de una serie de situaciones dadas-, y una parte oral — que consiste en un juego de rol con el profesor o con otro compañero, relativo a una situación planteada con anterioridad- L La forma de llevar a cabo la evaluación es dejando de lado las otras competencias, para así centrarse en las pragmáticas definidas por el MCER (2002), como las que se refieren al conocimiento que posee el usuario de los principios según los cuales los mensajes se organizan, se estructuran y se ordenan con el fin de llevar a cabo funciones comunicativas a través de esquemas de interacción y de transacción. Con todo, se realizan tablas en las que el profesor evalúa la habilidad del alumno para elaborar enunciados ordenados, coherentes y adecuados en cuanto al estilo y registro, así como su respeto hacia las máximas de Grice.

Por su parte, Hervás, Picó y Vilarrubias presentaron en el II Congreso de ASELE celebrado en Madrid la elaboración de un test pragmático para ELE ${ }^{74}$ centrado en los extranjeros que vienen a España a cursar estudios universitarios. El test que proponen estos autores está basado en el que realizó Farhady (1980) para el inglés. Este partía de un conjunto de cuatro respuestas de elección múltiple en donde la respuesta correcta era apropiada gramaticalmente y funcionalmente, mientras que las otras tenían desviaciones en la gramática, en la pragmática o en ambas. El problema que presenta es que no permite advertir la variabilidad, ni desde el aspecto normativo ni desde el interlingual. Además, los resultados limitan su grado de generalización a las situaciones específicas tratadas.

Este test se fundamenta en la lista de necesidades comunicativas y de nociones y funciones del Nivel Umbral del español para delimitar los elementos a evaluar, de forma que los ítems del test se basan en la relación entre funciones lingüísticas y actos de habla determinados. La selección de los actos de habla se apoya en una serie de criterios: la frecuencia de uso, la utilización en la vida académica, la relación y el estatus social de los interlocutores y la no superposición de unas funciones con otras.

\footnotetext{
${ }^{74}$ Véase anexo 1. 
A partir de estos criterios elaboran treinta situaciones, que se caracterizan en términos de situación, participantes, función, relación social y estatus, etc. y que corresponden a cada uno de los ítems del test. El test se suministró como test de respuesta abierta a veinte alumnos extranjeros del nivel intermedio y después a veinte alumnos de $\mathrm{COU}^{75}$ nativos. A partir de sus respuestas se construyó un test de respuesta múltiple, de forma que la respuesta correcta provenía de los nativos y las incorrectas de los extranjeros. A continuación se administró el test de nuevo a estudiantes nativos y extranjeros para comprobar su validez. Se tomó, por tanto, a los nativos como criterio con el que comparar la competencia de los no nativos, siguiendo a Oller $(1979)^{76}$. Los ítems en los que no había un elevado índice de acuerdo en las respuestas de los nativos o había una variación muy amplia fueron suprimidos. No obstante, los autores advirtieron que los ítems en los que fallan los nativos pueden explicarse, entre otras causas, porque en las lecturas rápidas el lector pasa por alto las palabras gramaticales (Crowder, 1982).

En su trabajo, Tordera (2014) reflexiona sobre la adecuación de los objetivos del Plan curricular del Instituto Cervantes para evaluar la competencia pragmática y examina cómo se plasman estos objetivos en los exámenes oficiales del Instituto Cervantes en el nivel B2. En opinión de Tordera para evaluar la competencia pragmática deberían tenerse en cuenta los siguientes hechos pragmáticos:

¿El hablante no nativo consigue satisfacer su objetivo comunicativo según las normas y convenciones que impone la lengua/cultura española? ¿Utiliza adecuadamente los elementos deícticos de la lengua española? ¿Sabe transmitir la información de una fuente distinta a la suya propia? ¿Sabe transmitir toda la información no explícita de su interlocutor? ¿Capta, por tanto, las ironías, los dobles sentidos, las intenciones

\footnotetext{
${ }^{75}$ El Curso de Orientación Universitaria (COU) era una enseñanza no obligatoria en España perteneciente al sistema educativo diseñado en Ley General de Educación de 1970 y constaba de un solo curso, equivalente al último de Bachillerato de la LOGSE. Era el último curso de la enseñanza media que los estudiantes debían realizar para prepararse para las Pruebas de Acceso a la Universidad (PAU).

${ }^{76}$ Oller defiende que los nativos nos pueden servir de criterio con el cual comparar la competencia de los no nativos: "native performance is a more valid criterion against which to judge the effectiveness of test items than no-native performance is [...] In a fundamental and indisputable sense, native speaker performance is the criterion against which all language proficiency can be defined. To choose non-native performance as a criterion whenever native performance can be obtained is like using an imitation when the genuine article is ready to hand. The choice of native speaker performance is the criterion against which to judge the validity of language proficiency test, and as a basic for referring and developing them, guarantees greater facility in the interpretation of test scores, and more meaningful test sensitive (i.e. variance)" (1979: 203-204).
} 
humorísticas, etc.? Al perseguir su objetivo comunicativo, ¿lo hace dañando lo menos posible la imagen de su receptor? (2014: 275).

Aunque el tratamiento del componente pragmático es adecuado en el Plan curricular, en su evaluación a través del examen DELE se detectan algunas deficiencias. Según el autor, en las pruebas 1 y 2 (comprensión de lectura y comprensión auditiva respectivamente) no se evalúa la competencia pragmática real del examinado, ya que en ambos casos se pide una respuesta escrita tras la comprensión de un discurso en el cual no hay lugar a la interacción. Por su parte, las pruebas 3 y 4 (expresión escrita y oral) en principio prestan más atención al componente pragmático, sin embargo las interacciones son también artificiales: a los examinados se les impone un tema del cual pueden no saber mucho o no estar interesados y se les permite que lo preparen de antemano. Esto hace que a menudo los alumnos memoricen un texto y lo reproduzcan literalmente. Se deberían incentivar, por tanto, conversaciones más naturales, en las que sea posible evaluar los mecanismos usados por el estudiante para satisfacer sus objetivos e intenciones comunicativas. Además, en opinión de Tordera (2014), el contexto de un examen de lengua propicia que el alumno se sienta observado y no interactúe como lo haría en una situación de habla normal, lo que pone de relieve la denominada paradoja del observador ${ }^{77}$.

\subsubsection{La competencia pragmática y la didáctica de la lengua materna}

La didáctica de la lengua se ha definido como una disciplina de acciónintervención cuya finalidad principal es el estudio de cómo se enseñan y se aprenden las lenguas para poder promover formas de uso que contribuyan al desarrollo lingüístico de los alumnos (Noguerol, 1995; Bronckart y Schneuwly, 1996; Mendoza, López y Martos, 1996). Por lo tanto, como señala Nussbaum (1996), esta concepción implica que la didáctica de la lengua tenga una doble labor: por un lado, "de comprensión de la realidad de la enseñanza y el aprendizaje de la lengua” y, por otro,

\footnotetext{
${ }^{77}$ Labov (1972), figura clave dentro del campo de la sociolingüística, fue el primero en hablar de la paradoja del observador. Labov se percató de que los informantes no interactúan de la misma manera cuando se sienten observados. Si el hablante sabe que está siendo grabado, su conversación no será espontánea. Esta paradoja se puede aplicar al ámbito de la enseñanza de lenguas, ya que aquí también nos encontramos ante el conflicto entre la imposibilidad de medir lo estrictamente espontáneo y la necesitdad de observación que se deriva de las pruebas de evaluación. 
“de intervención en ese proceso” (Nussbaum, 1996: 110). De esta manera, el cometido del profesor de lengua, según Noguerol (1995), será llevar a cabo un programa de acción que permita desarrollar la competencia comunicativa de sus alumnos y favorecer la comunicación en el centro.

El problema que surge en torno a la didáctica de la lengua es que se trata de una disciplina de creación reciente que todavía está en fase de conceptualización (Mendoza y Cantero, 2003). Al tratarse de una disciplina joven ha tenido que definir su campo de actuación, sus enfoques metodológicos, sus líneas de investigación, así como establecer sus límites en relación con otras disciplinas. No obstante, esto no quiere decir que no pueda (o más bien necesite) recibir aportaciones de otras disciplinas implicadas en el hecho lingüístico como la psicolingüística, la lingüística textual o la pragmática. Muchos autores insisten en la utilidad pedagógica de las aportaciones de estas disciplinas a la hora de abordar la planificación educativa en el aula de lengua (Lomas, Osoro y Tusón, 1993). Por ejemplo, la pragmática es importante, ya que los alumnos deben aprender que la interpretación de los enunciados depende de las expectativas del emisor y del receptor, que hay que adecuar los actos de habla a nuestras intenciones, que hay factores extralingüísticos que afectan al hecho comunicativo, etc. Ya Lyons (1983) advertía que la interpretación de las expresiones lingüísticas depende, en parte, del sistema lingüístico, pero también de los factores que rodean su emisión e interpretación, y es precisamente la pragmática la que considera conjuntamente las perspectivas del emisor y del destinatario.

Los modelos de pragmática aportan numerosos y sugerentes puntos de vista para el planteamiento de la interacción didáctica y para el desarrollo de enfoques metodológicos, así como para la definición de objetivos de aprendizajes en términos funcionales, la determinación de aquellos actos de habla que resultan más rentables y adecuados a las necesidades de formación lingüística, las estrategias de comprensión y producción que para ello habrá de desarrollar el individuo, así como la consideración de los condicionantes del contexto comunicativo (Mendoza, López y Martos, 1996: 109110).

De esta manera, la didáctica de la lengua es un área que se ha ido definiendo a partir de las contribuciones de diversas disciplinas, aunque tal como advierte Prado (2011), no supone la suma de las mismas, sino la transformación de los contenidos 
científicos aportados por estas en didácticos, de forma que puedan ser asimilados por los estudiantes y favorezcan su desarrollo lingüístico.

Como señalamos anteriormente, en el campo de la enseñanza de lenguas (incluida la lengua materna) se ha producido un giro hacia los métodos comunicativos debido a las insuficiencias que se encuentran en los enfoques gramaticales. Si lo que se pretende es la enseñanza de la lengua de forma que los estudiantes sean capaces de usarla eficazmente en situaciones reales, tendremos que partir de los usos lingüísticos. La noción de uso aparece, así, como el eje de enfoques pragmáticos, sociolingüísticos y discursivos de la lengua. Estos enfoques, señalan Lomas, Osoro y Tusón (1993), "entienden la actuación lingüística y las prácticas comunicativas en general como un conjunto de normas y estrategias de interacción social orientadas a la negociación cultural de los significados en el seno de situaciones concretas de comunicación” (1993: 13).

Durante mucho tiempo, los profesores de lengua se han ocupado de impulsar destrezas puntuales en sus alumnos tales como el reconocimiento morfológico de palabras, la ortografía, el análisis sintáctico de las oraciones, etc. Estas habilidades forman parte del conocimiento lingüístico pero son insuficientes a la hora de acercarnos al complejo proceso de la comunicación. Por tanto, en la tradición académica ligada a la teoría gramatical se olvida un factor relevante, puesto que lo que motiva la producción de un texto oral o escrito no es tanto su forma como su intención de producir un efecto determinado. En consecuencia, para hacer a los alumnos competentes en términos comunicativos habrá que plantearse la enseñanza de lenguas enfocada al desarrollo de las capacidades de expresión y comprensión, actualizando competencias discursivas adecuadas a cada contexto y situación y suministrando a los estudiantes estrategias de uso y reflexión metacomunicativa que hagan sus producciones verbales más adecuadas al uso (González Nieto, 1990).

A principios del siglo XX, autores como Lenz o Américo Castro ya se dieron cuenta de que saber gramática no era suficiente para aprender a usar la lengua y denunciaron el abuso de la enseñanza gramatical en la educación obligatoria. Así, Americo Castro expresa su opinión al respecto: 
La gramática no sirve para enseñar a hablar y escribir correctamente la lengua propia, lo mismo que el estudio de la fisiología o de la acústica no enseña a bailar, o que la mecánica no enseña a montar en bicicleta (1922 [1987:214]).

En la misma línea de reprobación de los abusos de la carga gramatical en la enseñanza obligatoria, Violeta Demonte ya apuntaba hace unos años que "el mal uso de las escuelas lingüísticas aplicadas a la gramática escolar solo conduce a un empobrecimiento del lenguaje. Lo que hace es una presentación incomprensible no solo para el alumno sino también muchas veces para el mismo pedagogo” (Demonte, 1987: 141). Asimismo, Castellà señala que la gramática no es el objetivo principal en el aprendizaje de la lengua materna pero nos recuerda que constituye un medio ineludible:

Los objetivos generales en la enseñanza de la lengua son la comprensión y la expresión escrita y oral: escuchar, hablar, leer y escribir. Los alumnos tienen que ejercitarse en la manipulación de frases y párrafos, en la planificación del texto, en la lucha por expresarse con sentido. La gramática tiene que ser una ayuda, un medio, no un fin. Enseñar, mejor dicho, acompañar al alumno en el aprendizaje del uso de la lengua no es fácil, por supuesto. Sin embargo, ese es el reto (Castellà, 1994a: 18).

Mendoza, López y Martos (1996) reconocen que el conocimiento de los contenidos gramaticales no garantiza la asimilación o dominio de las habilidades lingüísticas, por ello abogan por la atención a la diversidad de usos y a las expectativas de recepción. Según estos autores, la comunicación es un proceso que integra una serie de factores entre los que se encuentran: el dominio global de destrezas y habilidades lingüísticas, el dominio de la pragmática comunicativa, los conocimientos enciclopédicos, lingüísticos, intertextuales de cada estudiante y su propia experiencia como hablante y receptor (1996: 48).

En los enfoques comunicativos, el objetivo de la enseñanza de la lengua materna consiste en capacitar al alumno con los recursos de expresión y comprensión sobre los usos lingüísticos y comunicativos, de forma que sea capaz de emitir enunciados adecuados a las intenciones y situaciones comunicativas en diversos contextos. Consecuentemente, la atención didáctica a las capacidades de uso de la lengua implica partir del concepto aquí discutido de competencia comunicativa. 
El objetivo de la educación lingüística y literaria en la enseñanza obligatoria es, por consiguiente, favorecer el aprendizaje de los conocimientos y las habilidades que integran las diferentes competencias cuyo dominio hace posible un uso adecuado de la lengua en las variadas situaciones comunicativas. De ahí que, tal como reconoce Lomas (1997):

No baste ya con la enseñanza de un cierto saber lingüístico (fonética, fonología, morfología y sintaxis) [...] Si de lo que se trata es de ayudar a los alumnos y alumnas en el difícil y arduo aprendizaje de la comunicación entonces la educación lingüística y literaria en las aulas debe contribuir también a ayudarles a saber hacer cosas con palabras y, de esta manera, a adquirir el mayor grado posible de competencia comunicativa en las diversas situaciones y contextos de la comunicación (Lomas, 1997: $62)$.

Del mismo modo, en los trabajos de la Red Europea de Información sobre la Educación (Eurydice, 2002) se aboga por la necesidad de que los currículos y los métodos de enseñanza se basen en competencias y no en conocimientos de los hechos. La competencia supone desarrollar la capacidad de adaptarse a un contexto determinado en cada situación comunicativa, así como hacer uso de los conocimientos conceptuales y de las destrezas, actitudes y valores necesarios para tener éxito en dichas situaciones.

De esta forma, en los diversos currículos de enseñanza de las lenguas en la Educación Primaria y Secundaria se refleja ya una orientación hacia el desarrollo y afianzamiento de las capacidades de uso lingüístico y comunicativo de los alumnos. Entre los objetivos está el de favorecer su reflexión en torno a los rasgos formales, semánticos y pragmáticos implicados en los usos verbales y no verbales. Estos objetivos, al fin y al cabo, no son más que un reflejo de los que vimos en el apartado anterior relativos a la enseñanza de lenguas extranjeras. Así, investigadores especializados en didáctica de la lengua materna (Lomas, Osoro y Tusón, 1993) reconocen que toman como fuente autores y planteamientos que pertenecen al ámbito de la enseñanza de lenguas extranjeras, pero no ven inconveniente en aplicarlos al aprendizaje de la propia lengua, ya que al igual que el concepto de competencia comunicativa es universal, el enfoque didáctico también lo será. La diferencia solo radica en el diferente grado de dominio o conocimiento inicial de la lengua, esto es, en 
la distinta competencia de la que parte el alumno. Por ejemplo, el adolescente no tiene el mismo dominio de recursos de producción e interpretación en situaciones comunicativas que le son habituales que en contextos más complejos, más formales y que requieren un mayor conocimiento de la lengua y su uso. Por lo tanto, es precisamente en estos contextos donde deberá actuar el profesor ayudando a mejorar sus habilidades y destrezas comunicativas.

No obstante, el problema que surge en torno a estos enfoques comunicativos en materia de didáctica de la lengua es que hay un gran abismo entre la teoría y la práctica de lo comunicativo:

Ese abismo a menudo se observa entre lo que se dice cuando se habla de los objetivos de la enseñanza de la lengua (enseñar lengua es enseñar a usar de forma adecuada el lenguaje en diversas situaciones de comunicación) y lo que en ocasiones se hace en las clases de lengua en la educación secundaria (enseñar una de las lingüísticas y algunas destrezas ortográficas y sintácticas) (Lomas y Osoro, 1996a: 26).

Al comparar los objetivos comunicativos con lo que se lleva a cabo en las aulas Cassany, Luna y Sanz (2002) corroboran también la existencia de este gran contraste:

Si observamos las clases de lengua — sin analizar diferencias entre el tratamiento metodológico de la primera lengua o de las segundas - veremos que buena parte del tiempo que se emplea en ellos está dedicado al estudio y la práctica de la normativa. La ortografía es la parte de la gramática que se lleva más horas escolares y, a la vista de los resultados, más horas sin ningún provecho. Le siguen la morfología, la sintaxis y la lectura en voz alta; también podemos añadir algunas prácticas de redacción y muy poco trabajo o nada de expresión oral. [...] en definitiva muy pocas veces la lengua es un elemento vivo y útil para la comunicación (Cassany, Luna y Sanz, 2002: 14).

En los diversos currículos que han regulado y regulan la enseñanza de la lengua y de la literatura (MEC, 1991a, 1991b, 1992, 2007, 2011, 2012, etc.) aparece como finalidad principal el desarrollo de las capacidades de uso expresivo y comprensivo de los alumnos, haciendo referencia a los procesos cognitivos implicados en la comprensión y producción de los mensajes y a las normas socioculturales por las que se rigen. Si estamos de acuerdo en esto, la educación lingüística estará orientada a la adquisición por parte de los alumnos de los conocimientos y destrezas que configuran la competencia comunicativa. El fin de la enseñanza de la lengua será, entonces, 
conseguir en los alumnos el desarrollo de dicha competencia, esto es, el dominio de las variedades de uso que deben ponerse en juego en situaciones concretas de comunicación en función de diversas finalidades.

$\mathrm{La} \mathrm{LOE}^{78}$ (2006) y la LOMCE ${ }^{79}$ (2013) recogen entre las competencias básicas que se establecen para el currículo español la competencia en comunicación lingüística. Dicha competencia tiene como meta saber comunicar, esto es, hacer un uso efectivo de las habilidades lingüísticas y de las normas de uso en diferentes situaciones. Según Pérez Esteve (2007):

Esta competencia implica iniciar el conocimiento de las reglas de funcionamiento del sistema de la lengua, de las estrategias necesarias para interactuar lingüísticamente de una manera adecuada, para expresar e interpretar diferentes tipos de discurso acordes a la situación comunicativa en contextos sociales y culturales variados y especialmente en situación escolar (Pérez Esteve, 2007: 18).

Por ello, esta autora advierte que la deficiencia en la adquisición de la competencia en comunicación lingüística lo largo de la educación obligatoria tiene consecuencias negativas en el aprendizaje de conocimientos del resto de las áreas y en el desarrollo del propio pensamiento. De ahí la importancia vital de esta competencia en el marco curricular.

Así las cosas, hoy en día disponemos de un currículo semiabierto y flexible ${ }^{80}$ de manera que se limita a ofrecer unos objetivos generales, unos bloques de contenidos y unos criterios de evaluación. Esto da lugar a un gran abanico de posibilidades de cada programación puesto en manos del profesorado. Por consiguiente, aunque podemos reconocer cierta unanimidad en cuanto a los fines, existe una gran diversidad de criterios de selección de contenidos, de métodos pedagógicos y de uso de materiales didácticos y de evaluación (Lomas, 1994). En la selección de los contenidos de aprendizaje conviene considerar tanto los ámbitos del uso lingüístico (Castellà, 1992, 1994b) como las denominadas prácticas sociales de referencia (Bronckart y Schneuwly, 1996), es decir, los usos comunicativos más habituales en nuestras sociedades a los que tendrán que enfrentarse los alumnos en su vida adulta. Asimismo,

\footnotetext{
${ }^{78}$ Ley Orgánica 2/2006, de 3 de mayo, de Educación (BOE 4-05-06).

${ }^{79}$ Ley Orgánica 8/2013, de 9 de diciembre, para la mejora de la calidad educativa (BOE 10-122013).

${ }^{80}$ Tal como ya señalaba la LOGSE (1993) y corroboran la LOE (2006) y la LOMCE (2013). 104
} 
en la enseñanza de la comprensión (Alonso Tapia, 1995) es primordial el análisis de los diferentes tipos de textos y la adquisición de habilidades de identificación de la idea principal, de la estructura, de la estrategia textual y de la intención del autor.

Lomas y Osoro (1996b) llevaron a cabo un análisis crítico ${ }^{81}$ del currículo de lengua castellana y literatura del MEC (MEC, 1991b y MEC, 1992) de la Enseñanza Obligatoria y del Bachillerato. Los autores reconocen cierta orientación pragmática y sociolingüística en la introducción del currículo del área, pero esta no se encuentra con la misma intensidad en los distintos bloques de contenidos. Se presenta como finalidad curricular el dominio de las cuatros destrezas básicas (hablar, escuchar, leer y escribir) respetando los principios de adecuación, coherencia, cohesión y corrección que, según los autores, se relacionan con las subcompetencias del modelo de competencia comunicativa de Canale y Swain (1980) y Canale (1983). Ahora bien, aunque el currículo de lengua castellana y literatura se adscribe a un enfoque comunicativo o procesual $^{82}$, esta autodefinición no es garantía de que dicho planteamiento comunicativo se respete (Nunan, 1993). En primer lugar, los contenidos correspondientes al currículo de la Educación Secundaria deberían agruparse alrededor de dos conceptos: el uso comunicativo y la reflexión sistemática sobre esos usos. Los autores entienden que un conocimiento de estos aspectos contribuiría al desarrollo de la competencia comunicativa de los alumnos, entendida como "el aprendizaje del conjunto de procesos, habilidades y estrategias que deberán poner en juego para

${ }^{81}$ Este estudio contrastivo tiene sus antecedentes en los trabajos de Fidalgo et al. (1990), que realizan un análisis crítico del Diseño Curricular Base (MEC, 1989) de Lengua Castellana y Literatura para la Educación Secundaria Obligatoria, y el de Lomas y Osoro (1992), que analizan el ajuste pragmático, discursivo y sociolingüístico del currículo partiendo de un estudio comparado entre el Diseño Curricular Base y el decreto que regula los objetivos, contenidos y criterios de evaluación del área (MEC, 1991b).

${ }^{82}$ Breen (1987) describe las diferentes formas de abordar la programación en la enseñanza de lenguas. Frente a los clásicos programas formales y funcionales, nos habla de la aparición de un paradigma alternativo: los programas procesuales. Siguiendo a Breen (1987), los programas procesuales se caracterizan por asumir como fin explícito el desarrollo de la competencia comunicativa de los alumnos. Estos ponen énfasis sobre los procedimientos y el uso lingüístico, frente a la primacía tradicional de los conceptos, y pretenden integrar en un único proceso el conocimiento formal e instrumental de la lengua adoptando una perspectiva cognitiva. El cambio hacia los programas procesuales se ha manifestado de forma más evidente en la enseñanza de lenguas extranjeras como vimos en el apartado 3.2., pero apenas ha tenido desarrollo en el campo de la enseñanza de la lengua materna, a excepción de algunos intentos teóricos o prácticos de la mano de Lomas, Osoro y Tusón (1993), Siguán (1995) y Osoro (1996), entre otros. 
producir y comprender textos adecuados a las diversas situaciones y contextos de comunicación” (Lomas y Osoro, 1996b: 153).

Se mantiene, por tanto, el concepto de competencia comunicativa como fin esencial, pero se incluyen diferencias de grado de desarrollo de las subcompetencias. Por lo que se refiere a la competencia sociolingüística, se amplía el abanico de posibles situaciones comunicativas incluyendo los usos formales de la vida social o en relación con distintas instituciones públicas. Asimismo, la competencia discursiva se enriquece con nuevos modelos textuales, como textos de divulgación científica o cultural. Los autores interpretan los objetivos tomando como referencia, de nuevo, el modelo de Canale y Swain (1980) y el de Canale (1983). Según Lomas y Osoro (1996a), "la adquisición de tales subcompetencias, referidas tanto al saber como al saber hacer cosas con las palabras, constituye el eje en torno al cual cobra sentido un trabajo educativo en el aula de lengua orientado al desarrollo de la competencia comunicativa de las personas" (1996a: 56).

En suma, los reales decretos por los que se establecen las enseñanzas mínimas de Educación Infantil, Educación Primaria, Educación Secundaria y Bachillerato tienen como meta principal la adquisición de la competencia comunicativa, entendida como "el conjunto de habilidades, estrategias y conocimientos que son necesarios para interactuar satisfactoriamente en diferentes ámbitos sociales” (Perez Esteve, 2007:29). Reconocemos, por tanto, que los últimos currículos de lengua castellana y literatura recogen un ajuste pragmático y cognitivo en la visión del hecho lingüístico y comunicativo en general. Así, expertos en pedagogía y didáctica de la lengua castellana como Milián (1993), Sánchez Miguel (1998), Camps (2000), Prado (2001), Alonso Tapia (2005), Vilà (2005) o Pérez Esteve y Zayas (2007) han desarrollado en estos últimos años una serie de propuestas metodológicas para una puesta en práctica en el aula del desarrollo de la competencia en comunicación lingüística.

Dentro de esta concepción más integral de la educación en competencia lingüística, se sitúa el método cooperativo (Goikoetxea y Pascual, 2002), que entiende el aprendizaje en grupos organizados de forma que exista un intercambio continuo de información entre los estudiantes. Esto requiere un diseño estructurado de los programas de aprendizaje que permita que los alumnos se interrelacionen y se sientan motivados para comunicarse y ayudarse entre sí. Entre los beneficios más destacados 
de la implementación de actividades basadas en el aprendizaje colaborativo se encuentran que potencia el desarrollo de la competencia en comunicación oral y que promueve la capacidad de pensar críticamente (Naughton, 2006; Prieto Navarro, 2007).

Así las cosas, para abordar un planteamiento globalizador en la enseñanza de la lengua es necesario atender a los aspectos pragmáticos de la comunicación que relacionan los elementos lingüísticos con sus contextos de producción e interpretación. Por consiguiente, no debemos olvidar que cuando enseñamos a usar una lengua contribuimos, entre otras cosas, al desarrollo del dominio global de destrezas y habilidades que componen la competencia pragmática. Por ello, antes de finalizar este capítulo, nos gustaría plantearnos también la necesidad de la enseñanza implícita de determinados aspectos pragmáticos en el aula de lengua. Fernández Vallejo (1998) considera su tratamiento en la asignatura de Lengua Española absolutamente necesario si se quieren incorporar conceptos como uso, contexto, actos de habla, cortesía, etc., ya que, según el autor, en el caso de la pragmática, en el currículo no existe una estructuración ${ }^{83}$ o desarrollo de los temas sino imprecisiones sobre lo comunicativo, lo discursivo, implicaturas, etc. Asimismo, Lomas (1994) reclama la urgencia de incluir aspectos concretos de pragmática en la educación lingüística actual. Esto implica la programación de contenidos y actividades en función de cada nivel educativo a partir de Secundaria. Según Fernández Vallejo (1998), la enseñanza de contenidos pragmáticos se podría iniciar en el primer ciclo con una teoría básica y actividades muy sencillas centrándose en el concepto de intención comunicativa, mientras que en el segundo ciclo, se podrían introducir contenidos implícitos, casos de metáforas e ironías. Por su parte, Bulnes Jiménez (1993) proponen para el $4^{\circ}$ curso "una actividad inicial consistente en presentarles una oración descontextualizada, dotada de cierta ambigüedad, y mostrarles a continuación el texto en que adquiere su pleno desarrollo” (1993: 19). En Bachillerato se realizaría un análisis más completo y preciso de aspectos pragmáticos como la cortesía, los actos ilocutivos ${ }^{84}$, lo dicho y lo implícito,

${ }^{83}$ Es preciso aludir al hecho mencionado anteriormente de que actualmente disponemos de currículo abierto y flexible, de modo que la tarea de abordar estos contenidos esbozados en el currículo corresponde a los departamentos de cada centro, profesores y editores de manuales.

${ }^{84}$ De acuerdo con Austin (1962) todo acto de habla presenta a su vez tres actos distintos que se ejecutan de forma simultánea: acto ilocutivo (por el que se dice algo), acto ilocutivo (por el que se 
etc. Y, finalmente, podrían incluirse cuestiones de reflexión pragmática en la prueba de acceso a la universidad (Fernández Vallejo, 1998). produce un efecto en el oyente). 


\section{CAPÍTULO 3}

\section{LA COMPETENCIA PRAGMÁTICA EN EL PROCESO DE ADQUISICIÓN DE LA LENGUA}

\subsection{LA ADQUISICIÓN DEL LENGUAJE. EL ENFOQUE PRAGMÁTICO}

3.1.1 Introducción al nacimiento y desarrollo de los estudios de adquisición del lenguaje

La adquisición del lenguaje es un tema capital para las hoy denominadas ciencias cognitivas, especialmente para la psicología y la lingüística. Los primeros trabajos se basaron en las observaciones que el autor hacía sobre sus propios hijos y registraba a través de informes diarios. De entre estos primeros estudios destaca el trabajo de 1907 del matrimonio alemán Stern titulado El habla de los niños (Die Kindersprache), en el que se recoge la evolución diaria de sus hijos durante seis años, y ofrece aportaciones interesantes además de una descripción lingüística muy cuidada.

No obstante, al margen de estos trabajos aislados, la primera mitad del siglo XX en Europa se caracteriza por dos marcos psicológicos poco compatibles: la epistemología genética de Piaget (1923) y el funcionalismo sociocultural de Vygotsky (1934). Piaget planteó la evolución del conocimiento de los niños a partir de un modelo de adaptación biológica y postuló que el lenguaje estaba compuesto por formas simbólicas subordinadas al pensamiento conceptual. Sus discípulos de la escuela de Ginebra (Sinclair, 1967; Bronckart, 1977 y Karmiloff-Smith, 1979) estudiaron los requisitos cognitivos necesarios para la adquisición de las estructuras específicamente lingüísticas, así como los detalles que empleaban los niños para adquirir dichas estructuras ${ }^{85}$. Por su parte, Vygotsky defendía una adaptación funcional sociocultural, que no era el resultado de la imitación del medio ni de la maduración biológica, sino de instrumentos mentales que el niño construía paulatinamente. Por lo tanto, la adquisición del lenguaje tendría un papel fundamental en la estructuración progresiva del pensamiento.

${ }^{85}$ Estos investigadores consideraban las estructuras del lenguaje como objetos concretos que asimilar y no como una estructura general tal como proponía Piaget. 
En los Estados Unidos, en la primera mitad del siglo XX, la psicología del lenguaje se fue centrando en aspectos metodológicos y experimentales, mientras que los evolutivos quedaron, en buena parte, desatendidos. Un enfoque general que tuvo gran influencia fue el conductismo ${ }^{86}$ (Watson, 1925), que permitía explicar el comportamiento a partir de modelos asociacionistas y motivacionales y en el que casi todo era reducible a estímulos, respuestas y refuerzos. Según esta teoría, las conductas cambian a partir de los sucesos que las siguen o que son contingentes con ellas. Así, un suceso que incremente la probabilidad de aparición de una conducta se entiende como reforzador de dicha conducta, mientras que si disminuye la probabilidad de ocurrencia se denomina castigo. De esta forma, el cambio resultante en la conducta se concibe como aprendizaje o condicionamiento operante. El lenguaje se define, entonces, en términos de conducta verbal, esto es, como una conducta aprendida, sujeta a las reglas del condicionamiento operante, y se analiza también como cualquier otra conducta y no como la expresión de conocimientos.

Entre los seguidores de Watson destaca Skinner (1957), que concibe el lenguaje como un comportamiento en el que hay que estudiar los episodios verbales, entendidos como las emisiones que producen los interlocutores. De acuerdo con Skinner, los padres y cuidadores proporcionan refuerzos y modelos a los niños. De esta forma, aunque en los primeros meses de vida el niño produce sonidos que son ajenos a su lengua materna, acabará usando solo los propios debido al refuerzo proporcionado por sus padres. Así, los sonidos que son ignorados tenderán a usarse cada vez con menos frecuencia y desaparecerán.

Según Skinner (1957), se puede predecir lo que un hablante responderá o aprenderá describiendo los estímulos (que producen un abanico de respuestas) y estudiando el refuerzo que dichos estímulos pueden dar. Evidentemente, esta teoría presenta notables imperfecciones. Por ejemplo, no da una explicación lo suficientemente amplia, ya que los padres normalmente solo refuerzan directamente un pequeño porcentaje de todos los episodios verbales producidos por sus hijos. Además, esta hipótesis resulta inviable porque, entre otras cosas, es imposible estudiar en

\footnotetext{
${ }^{86}$ La influencia del conductismo, asimismo, fue mayor en la aplicación de la lingüística que en la propia lingüística, sobre todo en lo referente a la metodología de enseñanza de lenguas extranjeras, a través de los llamados métodos audiolinguales basados en la asociación de estímulos (preguntas) a reacciones (respuestas).
} 
detalle la enorme cantidad de contingencias de cada estímulo, el contexto y el refuerzo consiguiente.

Skinner fue duramente criticado por Chomsky (1959) basándose en que su perspectiva no tiene en cuenta las aportaciones del niño a la tarea de aprendizaje. Chomsky utiliza para ello argumentos como el de la creatividad: los niños producen oraciones nunca oídas previamente, mostrando que poseen reglas de producción propias. Además, los niños no pueden construir la gramática únicamente a partir del input que reciben, ya que este es mínimo e inconsistente. Por tanto, los niños deben tener una capacidad innata y específica para el lenguaje que les permite el desarrollo, esto es, una gramática universal. De este modo, la capacidad lingüística es autónoma con respecto a los mecanismos generales de la cognición y se rige por principios y reglas propias.

Chomsky estableció que las lenguas humanas solo difieren superficialmente, mientras que los principios subyacentes son más homogéneos y están basados en características universales. Chomsky, en su obra Estructuras sintácticas (1957), entiende el lenguaje, desde una aproximación psicolingüística, como la capacidad para producir y comprender una lengua. Propone para ello la existencia de dos niveles de procesamiento lingüístico. El primer nivel maneja reglas universales que establecen las relaciones básicas que subyacen a la estructura de la frase, sea cual sea la lengua. El segundo opera mediante reglas de transformación que permiten la reorganización de los elementos estructurales característicos de cada lengua concreta.

Desde sus principios, Chomsky entiende la adquisición del lenguaje como un proceso de maduración y desarrollo de unas capacidades relativamente fijadas, bajo condiciones externas apropiadas. El Mecanismo de Adquisición del Lenguaje (Language Adquisition Device o LAD) que postula tiene dos componentes: input (entrada de universales lingüísticos que aportan los datos lingüísticos primarios) y output (de salida bajo la forma de una de las posibles gramáticas o sistemas de comunicación lingüística). Autores como McNeill (1966) trabajaron con este planteamiento entendiendo que el LAD está compuesto por una serie de principios lingüísticos subyacentes de carácter universal, es decir, reglas para la estructuración de oraciones. Esto explicaría cómo los niños a partir de unas categorías iniciales podrían llegar a la gramática de los adultos. El LAD permite a cada niño procesar el lenguaje 
al que está expuesto y establecer hipótesis basadas en las regularidades que encuentra. Así, cuando contrasta dichas hipótesis, alcanza una noción adecuada de las reglas sintácticas de esa lengua. Esta propuesta fue rebatida por Pinker (1982) basándose en que se desatienden las relaciones cognitivas y comunicativas, imprescindibles para el aprendizaje. Chomsky y sus colaboradores se centran en el conocimiento sintáctico innato ignorando la existencia de otras capacidades cognitivas igualmente innatas. Esta teoría subestima, por tanto, la importancia del entorno y de las primeras experiencias sociales y cognitivas.

Otra de las debilidades de la teoría chomskiana es que ignora la aportación de la semántica, esto es, no reconoce la existencia de estructuras semánticas subyacentes de las cuales depende también la forma del lenguaje. Si nos basamos únicamente en la sintaxis encontraremos grandes limitaciones a la hora de describir las etapas de desarrollo del lenguaje de palabras aisladas y de combinaciones de palabras.

Dadas dichas carencias, Bloom presentó en su trabajo de 1970 un nuevo enfoque del estudio del lenguaje de los niños centrándose en el análisis semántico-pragmático. En él analizaba la estructura del lenguaje infantil con relación al significado que pretenden comunicar los niños ${ }^{87}$, el cual se interpretaba a partir del contexto. Así, la hipótesis semántico-cognitiva defiende que las primeras emisiones lingüísticas expresan las relaciones semánticas que perciben a su alrededor, y no relaciones sintácticas entre elementos lingüísticos. Además, dichas emisiones reflejan el conocimiento de relaciones entre las entidades y las acciones que conforman la realidad y son producto del funcionamiento cognitivo del niño (Bowerman, 1974; Rice, 1984). No obstante, el mayor inconveniente que presenta esta teoría es que no explica la relación entre las capacidades cognitivas y la adquisición del lenguaje (McLean y Snyder-McLean, 1978). Al mismo tiempo, no esclarece el hecho de que los conceptos cognitivos acaben codificándose lingüísticamente, y, efectivamente, algunos aspectos del desarrollo lingüístico no pueden explicarse sin hacer referencia al input lingüístico.

\footnotetext{
${ }^{87}$ Una línea similar sigue Halliday (1975), que formula el proceso de adquisición en tres fases. En la primera el niño domina las funciones extralingüísticas (instrumental, personal, imaginativa e informativa), en la segunda aparecen usos del lenguaje y avances en el vocabulario, la sintaxis, etc., y en la tercera se produce la adecuación del lenguaje del niño a la lengua del adulto. 
Por su parte Krashen (1981), influido por las ideas chomskianas (principalmente en lo que se refiere al LAD), desarrolló una teoría sobre la adquisición del lenguaje que incluye un input comprensivo (que sirve para la adquisición del código de manera inconsciente) y una competencia adquirida. La competencia, entonces, se desarrolla a partir de conocimientos adquiridos derivados de las distintas modalidades de input y se manifiesta en la actuación. Para Krashen, entre el input comprensivo y la competencia se sitúa un filtro afectivo, esto es, modelos lingüísticos, variedades dialectales, registros, etc., que condicionan la adquisición. Y en cuanto a la adquisición del código, Krashen señala que es necesario conocer la normativa gramatical, el léxico, los mecanismos de cohesión, la diversidad sociolingüística, los convencionalismos comunicativos de carácter pragmático, etc.

En la misma línea, autores como Wexler y Cullicover (1980) propusieron la Teoría de la Aprendibilidad (Learnability Theory), que postula que los niños proyectan los inputs lingüísticos recibidos sobre interpretaciones contextuales derivadas a partir de un conjunto de gramáticas iniciales posibles. Es decir, los niños comparan los datos lingüísticos recibidos con las gramáticas que encajan mejor y así las seleccionan, a la vez que rechazan aquellas que han resultado inconsistentes.

Igualmente, hay autores que han considerado que el lenguaje es tan solo una de las habilidades dependientes del sistema cognitivo humano (Anderson, 1983). En la línea de investigación que basa el aprendizaje de la lengua en las capacidades cognitivas generales se sitúa Slobin (1985), que considera que la cognición es la base para las adquisiciones lingüísticas. Slobin defiende la existencia de unos principios operativos de la adquisición del lenguaje, entendidos como autoinstrucciones que el niño extrae de forma implícita a partir de la práctica de comprender y producir significados. De esta manera, los niños, equipados con esta capacidad "para hacer lenguaje”, extraen, segmentan y archivan el input que reciben, de forma que una vez comprendido, pueden activarlo y producirlo.

Dentro de la línea funcionalista — que supone que aprendizaje del lenguaje se "construye" al igual que ocurre con otros conocimientos y procedimientos- Bates y MacWhinney (1989) proponen el Modelo de Competición (Competition Model), hoy replanteado como el Modelo Emergentista (MacWhinney, 1999). Este modelo apoya la hipótesis de que, a partir de componentes tanto biológicos (relativos a la percepción 
y a la motricidad) como sociales en interacción, surgen cambios que hacen emerger un nuevo sistema de soporte y representación simbólico para la comunicación.

Finalmente, cabe mencionar la aparición de los llamados modelos conexionistas, que, inspirados en el funcionamiento neuronal, suponen que la adquisición del lenguaje se puede explicar a partir de la extracción de regularidades por parte de un sistema simple pero de gran potencia computacional (Rumerlhart et al., 1986; Plunkett, 1995; etc.). Estos modelos se replantean cuáles son las bases genéticas de la adquisición del lenguaje y cuáles serían las condiciones ambientales necesarias para su desarrollo.

Con todo, hoy en día, el panorama de las tendencias actuales en torno al estudio de la adquisición del lenguaje corresponde principalmente a tres líneas de investigación (Serra et al., 2000). La primera, de raíz lingüística y centrada en el marco generativo, parte de unos principios formales y busca su contraste con los datos, de forma deductiva. La segunda, se basa en trabajos psicológicos y lingüísticos y es de tipo inductivo, esto es, parte de corpus o de datos recogidos en los experimentos para desarrollar teorías que expliquen cómo se producen los cambios y evoluciones que guían el desarrollo lingüístico en los niños. Finalmente, la tercera línea se basa en los trabajos sobre aspectos pragmáticos que se ocupan de los usos del lenguaje, la interacción, las condiciones de aprendizaje, etc. Este panorama, tal como reconocen Serra y sus colaboradores (Serra et al., 2000), resulta muy esquemático, ya que la realidad actual se caracteriza por la aparición de abundantes trabajos que estudian fenómenos muy específicos y que van incorporando nuevas lenguas. Esto permitirá, a largo plazo, la realización de análisis comparativos que determinen qué es particular de cada lengua y qué es común a todas en términos de adquisición del lenguaje.

\subsubsection{Aproximación pragmática a la adquisición de la lengua}

Como hemos defendido en este trabajo, para ser un usuario competente de un lenguaje natural no basta con conocer un conjunto de reglas o principios gramaticales $^{88}$, sino que también es necesario disponer de un amplio conjunto de conocimientos de sentido común y principios acerca del mundo interno e intencional

\footnotetext{
${ }^{88}$ Entendidas en el sentido chomskiano, que incluye reglas sintácticas, morfológicas, fonológicas, etc. (Bosque y Gutiérrez-Rexach, 2009).
}

114 
de las personas. Por ello, los niños que aprenden una lengua materna tienen que adquirir tanto una competencia lingüística, esto es, un dominio de los aspectos formales de la lengua, como una competencia comunicativa, que implica hacerse entender por los demás y ser capaces de trasmitir sus intenciones, ideas, deseos, emociones y necesidades. Así, Pinker (1995) pone de manifiesto que el lenguaje real no se reduce a las nociones gramaticales que se han analizado en los experimentos de adquisición del lenguaje durante décadas. Para poder participar eficazmente en intercambios comunicativos, los niños deben disponer de un conjunto de habilidades y conocimientos relacionados con aspectos sociales y cognitivos que van más allá de conocer el significado de las palabras o cómo deben ordenarse en una oración.

Por consiguiente, para estudiar el lenguaje infantil hay que partir de presupuestos pragmáticos, ya que los usos lingüísticos se dan en la práctica comunicativa, y los posibles trastornos o limitaciones en la habilidad lingüística se observan en relación con la interacción y la eficacia comunicativas. De ahí que muchos de estos trastornos ${ }^{89}$ se refieran a alteraciones en las habilidades de atribución intencional, a aspectos pragmáticos o a deficiencias en las capacidades de usar el lenguaje funcionalmente (Frith, 1989). Esta postura es también defendida por autores como Fernández Pérez (2000), que subraya que si queremos estudiar los fenómenos lingüísticos en su materialidad comunicativa, la perspectiva ha de ser pragmática, ya que permite la conjunción de los elementos que intervienen en los actos lingüísticos.

Sorprendentemente, durante años se profundizó poco en el desarrollo del conocimiento pragmático en los niños, con la excepción de investigaciones como la de Bates (1976a), que mostraba una idea general de la pragmática en el lenguaje infantil, o la de Halliday (1975), que supuso un precedente para los estudios de desarrollo basado en la pragmática. Este entendía que la evolución en el lenguaje infantil tiene lugar en una secuencia de funciones (instrumental, reguladora, interactiva, personal, heurística, imaginativa y representativa) y, por consiguiente, abogaba por la adopción de una perspectiva pragmática tanto para el desarrollo como para la percepción de las habilidades lingüísticas.

Sin embargo, en las últimas décadas, el área de adquisición de primeras lenguas ha prestado más interés a la adquisición y desarrollo de la competencia comunicativa,

\footnotetext{
${ }^{89}$ A ellos dedicaremos el capítulo 4.
} 
especialmente a las subcompetencias discursiva y pragmática, antes desatendidas. En cuanto a la competencia pragmática, autores como Gleason (2001) se han concentrado en el estudio de la adquisición de algunos actos de habla. Se ha observado que los niños, desde la etapa no verbal, expresan ya algunas peticiones y, cuando cumplen los 4 años, son capaces de producir la mayor parte de las peticiones, aunque a veces interpretan los enunciados literalmente y encuentran dificultad a la hora de descifrar la intención del hablante.

Según Fernández Pérez (2006), el análisis del desarrollo verbal en el periodo infantil no puede reducirse al conocimiento de las reglas gramaticales y al aprendizaje posterior del uso de esas reglas en un contexto, sino que "la dimensión pragmática se hace visible desde el principio, no hay que aguardar a que la gramática haya adquirido depósito” (2006: 593). En efecto, investigaciones como la de Prego Vázquez (2004) han detectado que los niños desarrollan funciones comunicativas aun no habiendo avanzado en la vertiente estructural, por lo que sugieren que algunas estrategias pragmáticas pueden ser el detonante para la aparición de rasgos construccionales. En la misma línea, Clark (2003) señala que en ocasiones son precisamente los recursos verbales motivados por su función comunicativa los que favorecen el asentamiento de determinados principios gramaticales.

El componente pragmático tiene gran peso en la adquisición del lenguaje debido a que, tal como advierten Hulit y Howard (2002), los cambios más espectaculares en el desarrollo del lenguaje de los niños tienen lugar en el área de la pragmática entendida como el uso efectivo del lenguaje- - A medida que el niño va creciendo, va dominando el arte de los intercambios conversacionales. Además, se vuelve más seguro al usar el lenguaje con el objetivo de manipular los comportamientos, actitudes y sentimientos de los demás. El niño aprende a manejar a otras personas indirectamente con sus palabras, de tal forma que estas apenas notan que están siendo manipuladas. Algunos niños progresan más que otros en el desarrollo de la pragmática; hay quienes se convierten en comunicadores eficaces muy pronto, mientras que otros siguen sin dominar esta habilidad en la edad adulta. No obstante, sea cual sea la competencia pragmática que adquiera cada individuo, esta empieza a desarrollarse a edades muy tempranas. 
Tal como expusimos al comienzo de este trabajo, uno de los principales problemas que se plantean en el ámbito de la pragmática es que carecemos de una definición precisa y coherente que sirva de guía para acotar la investigación. Consecuentemente, lo mismo ocurre con el estudio del desarrollo del componente pragmático: se trata de un campo enormemente heterogéneo (Galeote Moreno, 2002). Bara, Bosco y Bucciarelli (1999) reconocen que ninguna teoría cubre de manera sistemática la capacidad pragmática, y O’Neill (1996) recuerda que “las muy variadas definiciones de pragmática existentes han motivado diferentes estrategias de investigación, así como diferentes exámenes de las habilidades pragmáticas en niños y adultos. Dependiendo de la definición usada, diferentes tópicos son de interés” (1996: 253).

Por tanto, el hecho de que el ámbito de la pragmática esté poco definido tiene como consecuencia inmediata que no se postule una teoría integrada, sino que se estudien por separado los distintos constituyentes del componente pragmático (McTear y Conti-Ramsden, 1992; Ninio y Snow, 1996; etc.). No obstante, se trata de un elemento básico en la adquisición del lenguaje, ya que explica por qué fracasan las máquinas de traducción automática ${ }^{90}$ o por qué las personas con problemas de adaptación socioemocional tienen dificultades para asimilar este componente (Serra et al., 2000).

Como consecuencia de lo anteriormente expuesto, el componente pragmático incluye muchos fenómenos heterogéneos que tienen en común únicamente el hecho de que ninguno puede explicarse con independencia del uso del lenguaje. Por ejemplo, Ninio y Snow, en su obra Pragmatic Development (1996), incluyen en la investigación sobre el desarrollo de la pragmática fenómenos como:

- Adquisición de las intenciones comunicativas y el desarrollo de su expresión lingüística.

- Habilidades conversacionales: tomar el turno de palabra, interrupciones, etc.

\footnotetext{
${ }^{90}$ Asimismo, los ordenadores son capaces de producir frases correctas pero les resulta muy difícil extraer un significado con sentido. Por lo tanto, aunque podemos programar un ordenador para que produzca oraciones correctas desde el punto de vista fonológico y gramatical, no podemos hacerlo en orden a aspectos pragmáticos.
} 
- Habilidades relacionadas con la organización del discurso: cohesión, géneros, etc.

- Adquisición de las formas lingüísticas asociándolas con sus funciones comunicativas en lugar de con su significado semántico.

- Cortesía y reglas de uso del lenguaje determinadas culturalmente.

- Deixis.

- Etc.

Uno de los fenómenos en los que se ha centrado principalmente la investigación es la adquisición de las intenciones comunicativas y el desarrollo de su expresión lingüística, esto es, los actos de habla. Psicólogos como Bates, Camaioni o Volterra (Bates et al., 1979) han defendido que la adquisición de algunos actos de habla tiene lugar antes de que haya lenguaje, de forma que los bebés expresan sus intenciones a los adultos e influyen en la conducta de estos mediante determinadas vocalizaciones antes de disponer de estructuras lingüísticas organizadas. Los datos extraídos del lenguaje infantil revelan que hay alternativas pragmáticas que los niños utilizan para comunicarse antes incluso de que sean capaces de articular palabras. Por ejemplo, la referencia se lleva a cabo señalando, tocando o mirando fijamente, antes de conseguirse a través de medios lingüísticos (Bates et al., 1979). En efecto, en estas edades los niños utilizan, principalmente, el gesto y el contexto de producción para que el interlocutor entienda su petición (Bruner, 1983).

Ante estas afirmaciones, una de las primeras preguntas que surge entre los investigadores es si los niños al nacer están "preprogramados" para participar en interacciones sociales, esto es, si los llantos o gritos son simples expresiones naturales de estados físicos o manifestaciones de la habilidad para expresar sus intenciones. Según Peraita (1989), se trata de conductas preparatorias de las posteriores habilidades comunicativo-intencionales. Además, esta investigadora señala también que no debemos olvidar que es el adulto quien interpreta estas expresiones como intenciones y les da sentido (hambre, dolor, alegría, etc.).

La comunicación prelingüística puede, entonces, constituir un precursor crucial del desarrollo del lenguaje infantil. Esto ha llevado a algunos autores a defender que el sistema lingüístico desarrollado por los niños en sus primeras etapas es una 
continuidad del sistema de comunicación no verbal anterior, es decir, que los niños adquieren las primeras expresiones verbales como sustitutas de las no verbales que ya habían manifestado para expresar sus intenciones (Bates, Camaioni y Volterra, 1975; Bates, 1976a; Lock, 1980; Bruner, 1983).

Obviamente, aquellos que rechazan la existencia de esta precocidad comunicativa en los bebés niegan la hipótesis continuativa (Shatz, 1982). Otros, como Dore $(1975,1978)$, creen que los niños desde muy tempranas edades expresan sus intenciones y se comunican con otros de forma no verbal, pero defienden que los sistemas verbales y no verbales no constituyen un mismo desarrollo continuo e interrumpido. Asimismo consideran que las expresiones lingüísticas operan únicamente siguiendo dos mecanismos: referencia y predicación, que no existen en las formas no lingüísticas. Dore (1978) argumenta que los actos ilocutivos disponen de un componente gramatical del cual la comunicación no verbal carece. Por lo tanto, las habilidades comunicativas prelingüísticas son necesarias pero insuficientes para el desarrollo de la comunicación lingüística. Por sus propios medios no pueden ofrecer una explicación para el desarrollo del habla, pero sí un origen del que partir.

Como ya hemos visto, son muchos los investigadores que afirman que los orígenes de los actos de habla se sitúan en una etapa anterior a la aparición del lenguaje hablado ${ }^{91}$. No obstante, el problema reside tanto en la determinación de cuándo comienzan los niños a comunicarse intencionalmente como en las consecuencias que este hecho puede tener para posibilitar el desarrollo de la competencia lingüística propiamente dicha (Gómez et al., 1995). Este campo de investigación está abierto, ya que continúan las polémicas no solo con respecto a qué puede ser considerada una conducta comunicativa intencional, sino también en cuanto a qué tipo de intenciones comunicativas producen los niños, cómo han de evaluarse, etc. No obstante, como apunta Galeote Moreno (2002), aunque esta investigación no haya resultado del todo exitosa, ha arrojado datos que nos han permitido conocer aspectos de las capacidades sociales y comunicativas de los niños que no se dejan ver desde investigaciones puramente formales.

91 Bates (1976b) reconocía ya, en la distinción entre funciones comunicativas y medios lingüísticos para expresarlas, que las funciones se pueden realizar no solo a través del lenguaje. 
Para establecer si una determinada conducta en los niños es intencional, autores como Bates (Bates et al., 1979) o Bruner (1984) han establecido una serie de criterios. No obstante, la mayor dificultad radica en concretar qué se entiende por intencionalidad. Reddy (1999) plantea tres aproximaciones que podrían adoptarse:

1. Aproximación cognitiva (que entiende las intenciones comunicativas como concepciones o representaciones individuales y mentales de objetos específicos y, por tanto, requiere la conciencia por parte del individuo de un objetivo como algo separado de los medios para lograr dicho objetivo).

2. Aproximación del interaccionismo social (que defiende que la comunicación intencional surge de un complejo sistema de apoyo social de atribución de la intencionalidad, difiriendo de la anterior en que no es un requisito previo tener conciencia de la información que se va a transferir o de la capacidad del otro para recibir la información que se pretende comunicar).

3. Aproximación innatista (que postula que la intencionalidad comunicativa en sí misma es algo que viene dado, aunque luego se desarrolla en complejidad y no requiere representaciones mentales de objetivos y medios).

Es difícil decantarse por una de las aproximaciones, si bien es cierto que experimentos empíricos (Van der Meer et al., 1995) han descubierto acciones intencionales en neonatos que, según Reddy (1999), pondrían en entredicho tanto la aproximación cognitiva como el interaccionismo social.

Belinchón et al. (1992) afirman que en el periodo de 12-18 meses, los niños muestran ya conductas comunicativas claramente intencionadas. A través de esas conductas son capaces de crear en otros intenciones nuevas, que responden a sus objetivos de comunicación. En lo que respecta a la capacidad para captar la intencionalidad, Premack (1990) subraya el carácter temprano de las competencias infantiles de percepción de intenciones, que se desarrollan también antes de la adquisición por parte del niño de la función simbólica del lenguaje. Esta es la razón por la que los niños son capaces de entender muchas intenciones básicas antes de comprender las palabras y las oraciones que las expresan. Así, podemos concluir que los procesos de desarrollo psicolingüístico van de arriba abajo, esto es, de las 
intenciones a las palabras, y que a partir del reconocimiento de las intenciones se facilita el desciframiento del lenguaje con el que se expresan (Belinchón et al., 1992).

El habla de los niños ha sido muy investigada también en el periodo de palabras aisladas $^{92}$ (Bates et al., 1979; Camaioni y Laicardi, 1985; Griffiths, 1985; Wells, 1985; etc.). Los primeros enunciados de los niños son más bien palabras clave para algunas interacciones que actos de habla propiamente dichos. Su función social es más evidente que su función pragmática y sus metas son fundamentalmente dos: participar en situaciones sociales significativas y asegurar un estado de intersubjetividad con otros. La primera da lugar a enunciados puramente performativos (Greenfield y Smith, 1976) que consisten en sonidos lúdicos u onomatopéyicos, imitaciones, exclamaciones, etc. Estas expresiones obedecen a las preferencias idiosincrásicas de los niños y sus padres, y su significado depende del rol en contextos interactivos concretos, ya que no expresan un significado lingüístico más allá del juego en el que se utilizan.

La segunda meta consiste en establecer una atención conjunta entre el niño y los padres o cuidadores. Esta meta puede considerarse pragmática, pero en el sentido utilitario de la palabra. Los niños producen una serie de actos comunicativos específicos para establecer la atención mutua. En general, parece como si los niños empezaran adquiriendo el uso pragmático del habla estableciendo, así, un control verbal sobre otros tipos de usos del habla.

Por otra parte, Tomasello, Kruger y Ratner (1993) estudian los enunciados que no son espontáneos sino imitaciones de otros. Para ello, comienzan defendiendo que los niños experimentan un desarrollo en sus capacidades de instrucción social. El primer periodo se basa en el mecanismo de imitación como modo de aprendizaje. Por lo tanto, una gran proporción de los primeros enunciados emitidos son imitaciones de otros producidos anteriormente. Sin embargo, las imitaciones no pueden considerarse un comportamiento verbal intencional como las peticiones o las aserciones, sino que deben entenderse como una fase anterior a alcanzar la madurez intersubjetiva por parte de los niños. Ninio y Snow (1996), desde la perspectiva de la psicología cultural, se oponen a esta visión que excluye las imitaciones del repertorio comunicativo de los niños o las consideran comportamientos primitivos que reflejan la falta de

\footnotetext{
${ }^{92}$ También denominado periodo holofrástico. Véase apartado 3.2.2.2.
} 
subjetividad. Estas autoras señalan que en los niños no se puede distinguir un periodo de imitación independiente del entendimiento, ya que, aunque de forma imprecisa, repetir las palabras o acciones de otra persona significa que el niño ha comenzado un intercambio interpersonal con la persona a la que imita. De esta forma, la imitación es, simplemente, otro tipo de comportamiento comunicativo, o lo que Halliday llamó función instrumental (Halliday, 1975).

Muchos estudios empíricos sobre desarrollo pragmático han tomado como referencia la teoría de los actos de habla de Searle (1969). Sin embargo, los sistemas de codificación basados en esta propuesta poseen una gran limitación, ya que están centrados en las producciones individuales como unidad de análisis, de forma que constituyen un sistema demasiado simplista de la organización del habla y de los actos sociales (Dore y McDermott, 1982; Levinson, 1983; Ninio, 1986; etc.). Ninio y Snow (1996) creen que un análisis sistemático de los actos comunicativos debe reconocer la organización del habla en unidades más amplias así como teorías sobre la acción y el significado social. Por su parte, Levinson (1983) propuso que las descripciones de los usos del lenguaje por los niños debían basarse en conceptos como la intención comunicativa, la función de producción o el contexto interactivo, en lugar de en la noción de actos de habla, por ello abogaba por la visión intencional de Grice (1975).

De todos los actos de habla, los más estudiados en el área de adquisición del lenguaje son las peticiones, debido a que su aparición es altamente frecuente en las interacciones entre adultos y niños desde edades muy tempranas. En segundo lugar, en las últimas décadas, han aparecido numerosos trabajos que estudian los actos de habla compromisivos. En este caso se trata de actos de mayor complejidad, puesto que los niños encuentran dificultades a la hora de entender el significado de obligación moral y personal que conlleva una promesa. Los niños no entienden el compromiso implícito y la reciprocidad que implica el hecho de prometer algo a alguien, lo cual no ocurre hasta los 8 años, según el estudio realizado por Astington (1988). Además, hasta aproximadamente los 10 años de edad, los niños pueden llevar a cabo un acto de habla siguiendo las reglas pragmáticas, pero son incapaces de juzgar un acto determinado y reconocer conscientemente si se transgreden las reglas o no ${ }^{93}$.

93 Esto nos conduce a la distinción entre pragmática propiamente dicha y metapragmática, entendida como el conocimiento metalingüístico de los principios pragmáticos. 
Serra et al. (2000) recogen varios estudios sobre de la producción de peticiones en niños de 2 a 10 años. En ellos se ha estudiado la variación de los tipos de petición en función de la situación de comunicación, teniendo en cuenta el contenido de la petición, el estatus del interlocutor y la edad de los sujetos. Algunos de estos trabajos analizan las posibles diferencias entre las peticiones de acción y de información ${ }^{94}$ (Wilkinson et al., 1984; Feider y Saint-Pierre, 1987), y concluyen que las peticiones de información suelen formularse directamente ${ }^{95}$, mientras que las peticiones de acción tienden a realizarse de forma indirecta (mediante imperativas encubiertas).

Por regla general, la mayoría de los estudios realizados demuestran que la naturaleza de la petición y el estatus del interlocutor condicionan el tipo de peticiones que producen los niños, si bien no está tan claro cómo influye la edad de estos. Según Serra et al. (2000), los niños de 6 años producen menos peticiones directas y más imperativas enmascaradas que los de 7 , lo que parece demostrar que están más preocupados por producir un enunciado aceptable que los niños de 7 años, que prefieren enunciados comprensibles.

Paulatinamente, los niños ya no solo hacen peticiones, sino que las justifican y exponen sus necesidades personales. Serra et al. (2000) recogen ejemplos de niños de 4 años capaces de realizar una petición acompañada de negociación, del tipo Si me lo dejas un ratito, yo te dejo esto otro ratito (2000: 508). De igual forma, McTear y Conti-Ramsden (1992) observan el comportamiento de niños en edad preescolar. Estos no solo hacen peticiones, sino que utilizan diferentes recursos para convencer a sus interlocutores y contraargumentan las justificaciones que han recibido por parte de estos. Es en el periodo comprendido entre los 4 y los 8 años cuando los niños aprenden a desarrollar su capacidad para la argumentación, la persuasión y la modulación de los usos sociales del lenguaje.

\footnotetext{
${ }^{94}$ En un estudio longitudinal realizado con niños de 2 a 4 años a partir del corpus de Serra-Solé (Solé, 1996 apud Serra et al., 2000) se concluyó que las peticiones más frecuentes eran las de acción e información, seguidas de las peticiones de atención. Parece que en una primera fase los niños piden información para saber qué tienen que hacer, más tarde preguntan por el nombre de los objetos y un poco más tarde, sobre los 3 años, hacen peticiones de información sobre terceras personas.

${ }^{95}$ Se habla de petición directa cuando hay coincidencia entre los aspectos locutivos del enunciado y la fuerza ilocutiva que refleja la intención del hablante. Suelen estar formadas por oraciones imperativas, a diferencia de las peticiones indirectas, que incluyen interrogativas y declarativas.
} 
Por otro lado, respecto a los actos de habla indirectos, está demostrado que los niños entienden mejor las peticiones directas que las indirectas ${ }^{96}$. De esta manera, cuando se les hace una pregunta indirecta tienden a interpretarla literalmente. Así lo refleja el ejemplo tomado del trabajo de Warren y McCloskey (1997):

Conversación telefónica entre un niño de 3 años y un adulto:
A: ¿Qué haces?
B: Estoy hablando por teléfono.
A: ¿Está en casa mamá?
B: Sí (pero no va a buscarla).

Los estudios previos sugieren que los niños comienzan a entender y a usar este tipo de peticiones indirectas durante las etapas preescolar y escolar. En la etapa escolar predominan las formas directas, ya que el niño tiene dificultades para entender el lenguaje sutil (Ervin-Tripp, 1977). A los 4 años aproximadamente el niño se limitará a responder al enunciado Hace un poco de frío aquí, ¿no? diciendo que sí, sin entender que se trata de una petición indirecta para que cierre la ventana. Con el tiempo, en muchos casos a partir de los 6 años, el niño irá distinguiendo las peticiones indirectas (Cherry-Wilkinson y Dollaghan, 1979). Según Bernicot (1992), hasta los 5 años de edad lo que comprenden de una petición es la acción, mientras que a partir de los 6-7 años los niños ya son capaces de descifrar la intención del hablante.

No obstante, como era de esperar, algunas formas indirectas son más difíciles de procesar que otras (Carrell, 1981). Por ejemplo, las formas positivas son más comprensibles que las negativas. Si un día lluvioso un adulto le dice a un niño ¿ No deberías ponerte tus botas?, el niño tendrá dificultades a la hora de comprender que se trata de una acción positiva aunque su estructura contenga una forma negativa (Hulit y Howard, 2002). De hecho, tal como reconocían Clark y Chase (1972), incluso algunos adultos tienen dificultades con las peticiones indirectas con estructura negativa o interrogativa ${ }^{97}$. En general, los datos de los estudios apuntan que a la edad de 7 años es

\footnotetext{
${ }^{96}$ En la comprensión de las peticiones indirectas influyen elementos de carácter cultural y social. Por ejemplo, los niños japoneses son más precoces a la hora de entender las peticiones indirectas porque las madres japonesas utilizan más peticiones indirectas cuando se dirigen a sus hijos, además utilizan gestos y la entonación apropiada para facilitar la comprensión del mensaje (Warren y McCloskey, 1997).

${ }^{97}$ Está probado que las estructuras marcadas (como las interrogativas o las negativas) son formal, funcional y cognitivamente más complejas de procesar que las no marcadas (Givón, 1995). 
cuando podemos afirmar que el niño es competente en la producción de peticiones indirectas.

Finalmente, en el ámbito hispánico, podemos destacar el estudio de Prego Vázquez et al. (2011) sobre la adquisición de los actos de habla en el periodo de edad temprana (comprendido entre 1 y 4 años). Las autoras parten del corpus de habla infantil Koiné ${ }^{98}$ para analizar los patrones de comportamiento comunicativo y proponen la existencia de tres etapas en el desarrollo de los actos de habla: la fase deíctica (en la que las intenciones comunicativas solo se señalan y afectan a objetos o eventos contextuales), la fase ideativa ${ }^{99}$ (en la que los enunciados ya están formados por locución, ilocución y perlocución) y la fase discursiva (en la que se introduce la función textual y la adquisición de nuevas habilidades sociodiscursivas). Además, los datos reflejan el paso de lo exclusivamente contextual a lo operativo contextual y global.

En resumen, en este trabajo defendemos la necesidad de incorporar el componente pragmático dentro de las investigaciones de adquisición y desarrollo del lenguaje. Se trata de un componente de gran importancia en el que intervienen muchos aprendizajes coordinados. Sin embargo, como vimos anteriormente, solo se recurre a él cuando falla o no se aprende, como sucede por ejemplo en el caso de niños con autismo, síndrome de Asperger o síndrome de Willliams ${ }^{100}$.

La pragmática sitúa la adquisición del lenguaje en su contexto de uso, de forma que el niño debe aprender que la mayoría de las formas lingüísticas y significados vienen determinados en función del contexto en el que son usados. Además, el desarrollo de la pragmática no consiste únicamente en evitar transgredir los principios conversacionales. Antes de que los niños aprendan en qué situación social es apropiado usar una petición directa y en cuál una indirecta, deben entender qué son las peticiones y qué formas verbales se utilizan típicamente para expresarlas. Incluso antes de considerar las habilidades que están involucradas en seguir los principios

\footnotetext{
${ }^{98}$ Corpus de habla infantil realizado por el grupo de investigación de los Estudios Interdisciplinares de Comunicación, dirigido y coordinado por Milagros Fernández Pérez dentro del área de Lingüística General de la Universidad de Santiago de Compostela. Consta de un corpus de habla infantil de 166 transcripciones en formato CHAT (sistema CHILDES): http://www.usc.e/koine/adquisic_corpus-es.html.

${ }^{99}$ Esta fase coincide con la función ideativa del lenguaje según Halliday (1975).

${ }^{100}$ Hablaremos de ellos en el capítulo 4.
} 
pragmáticos, hay que tener en cuenta la adquisición del conocimiento necesario de los usos sociales del lenguaje. Los niños tienen que aprender cómo usar el lenguaje apropiadamente en la sociedad y cómo interpretar los enunciados de otros, incluyendo la información que se manifiesta de forma implícita.

\subsection{BASES PARA EL DESARROLLO DEL COMPONENTE PRAGMÁTICO}

\subsubsection{La importancia del contexto}

Si analizamos el fenómeno de la adquisición lingüística desde una perspectiva pragmática es ineludible dar cuenta del papel primordial que ejercen los factores contextuales en el desarrollo del lenguaje y su función comunicativa (Peralta, 2000):

El contexto social desempeña un rol fundamental en el aprendizaje de las locuciones tempranas, proporcionando la estructura y contenido de estas. Los factores situacionales, que a veces condicionan qué es lo que puede decir el niño, incluyen objetos, actividades y personas de la acción comunicativa, así como otras variables conversacionales. También los factores internos del niño, que incluyen su percepción de la situación, influyen en las primeras locuciones. En la etapa inicial del desarrollo lingüístico el niño comunica más de lo que puede codificar, lo cual se demuestra en la capacidad de los adultos de adivinar el mensaje que pretende enviar el niño (Peralta, 2000: 59).

Así, autores como Leinonen et al. (2000) han llegado a identifican el desarrollo de la habilidad pragmática con la habilidad progresiva de los niños para usar el contexto en la comprensión y expresión del lenguaje.

Como ya expusimos en el primer capítulo de este trabajo, el concepto de contexto es multidimensional, ya que incluye el contexto social, cognitivo, cultural, lingüístico, físico, etc. (Sperber y Wilson, 1995). De esta manera, establecimos que el contexto agrupa toda la variada información que el oyente utiliza para interpretar las expresiones lingüísticas. Según Judith Felson (1995), pueden identificarse seis tipos de contexto que tienen especial implicación en el desarrollo de las habilidades

comunicativas del niño: 1) contexto social, 2) contexto emocional ${ }^{101}$, 3) contexto

${ }^{101}$ La autora entiende la emoción como un elemento fundamental en el aprendizaje del lenguaje. Así, un estado disposicional positivo es esencial para el pleno desarrollo de las habilidades comunicativas básicas en el niño. 
funcional, 4) contexto psicológico, 5) contexto de eventos ${ }^{102}$ y 6) contexto del discurso. Estos contextos, señala Felson (1995), están presentes cuando nos comunicamos, influyen en la comunicación y a la vez la constituyen.

De forma generalizada, en los niños se puede observar una clara evolución desde la dependencia del contexto inmediato al manejo del contexto cognitivo no situacional. Al comienzo del desarrollo, los niños confían plenamente en el contexto físico en el que tienen lugar los intercambios; por ello, sus primeros intentos comunicativos están ligados al "aquí y ahora” (Milosky, 1992; Bishop, 1997). De esta manera, cuando los niños más pequeños interpretan enunciados, dan más credibilidad a lo que están viendo y a su conocimiento del mundo que al propio significado dado en la expresión lingüística (Marinac y Ozanne, 1999).

En las primeras etapas, el niño habla sobre su entorno inmediato, pero cuando va creciendo, interactúa con más personas que no comparten su experiencia del mundo. El niño tendrá que usar, entonces, lo que algunos autores denominan lenguaje descontextualizado $^{103}$ (Snow, 1991; Snow y Dickinson, 1991). Según Serra et al. (2000), uno de los requisitos indispensables para que el niño produzca un discurso organizado es que tenga en cuenta el conocimiento que tiene su interlocutor de los hechos que está narrando. Para ello, los niños deben tener un dominio del lenguaje basado en el conocimiento y la perspectiva compartida entre el hablante y el oyente. Este es uno de los logros que tienen que alcanzar para ser hablantes competentes. Así, para conseguir un lenguaje descontextualizado necesitan disponer de las habilidades pragmáticas que les permitan evaluar las expectativas del interlocutor, asumir que la información que se ofrece puede ser total o parcialmente desconocida y que, por lo tanto, debe suplirla con medios lingüísticos y, finalmente, debe evaluar la comprensión por parte del interlocutor, teniendo en cuenta su punto de vista. Todo ello supone un periodo largo de aprendizaje que empieza alrededor de los 2 años y no se completa hasta los 8 o 10 años de edad (Serra et al., 2000: 519).

Según el estudio de O’Neill (1996), los niños de 2 años ya demuestran que pueden tener en cuenta las necesidades contextuales de sus padres como interlocutores

${ }^{102}$ El contexto de eventos se relaciona con la comunicación en el sentido de que permite conceptualizar esquemas temporales, relaciones de causalidad y rutinas.

${ }^{103}$ El lenguaje descontextualizado se refiere al lenguaje que usa una persona cuando habla de cosas, eventos y conceptos que no están en su contexto personal e inmediato (Snow, 1991; Snow y Dickinson, 1991). 
cuando se enfrentan a situaciones familiares como, por ejemplo, pedir ayuda para alcanzar un juguete. Cuando los padres no localizan el juguete, los niños nombran el juguete y gesticulan hacia la dirección en la que se encuentra. Esto se considera un gran logro pragmático.

Es incuestionable que desde edades muy tempranas los niños son capaces de tener en cuenta el contexto cuando formulan o interpretan expresiones lingüísticas (O’Neill, 1996; Bezuidenhout y Sroda, 1998; Jaswal y Markman, 2001). Sin embargo, aunque los niños comienzan muy pronto a usar la información contextual, habrá que esperar a etapas más avanzadas de su desarrollo para que, en las variadas situaciones comunicativas a las que tengan que enfrentarse, sean capaces de utilizar información contextual más diversa y de un modo más flexible (Becker, 1990; Lloyd et al., 1995; Ryder y Leinonen, 2003).

En su estudio, Ryder y Leinonen (2003) examinaron a niños de edades entre 3,6 y 5,6 años utilizando preguntas dentro del contexto de un libro de cuentos. Las autoras descubrieron que la habilidad para usar información contextual cuando los niños responden a preguntas que exigen la comprensión de referentes, el enriquecimiento de enunciados incompletos y la recuperación de implicaturas depende de la edad. La habilidad para realizar inferencias contextualmente apropiadas comienza a desarrollarse después de los 3,6 años y continúa hasta los 5,6. Los niños de 3 años son capaces de utilizar el contexto cuando interpretan referencias pronominales (cerca del $55 \%$ de respuestas correctas) y muestran una habilidad creciente para responder a las preguntas de enriquecimiento (cerca del 25\% de respuestas correctas), pero todavía no han desarrollado la habilidad para responder a preguntas que requieren el procesamiento de implicaturas, en las que es necesaria la consideración del contexto previo, el conocimiento del mundo y la información verbal dada. Además, los resultados indican que la comprensión de las preguntas de enriquecimiento y las que requieren el procesamiento de implicaturas se desarrollan rápidamente solo a partir de la edad de 5 años.

En la misma línea, Karmiloff-Smith (1986) concluyó que entre las edades de 5 a 9 años los niños aprenden paulatinamente a centrarse en la información contextual relevante y perciben que no es necesario dar toda la información al oyente, ya que él puede rellenar los vacíos, esto es, enriquecer los enunciados. 
Con todo, no cabe duda de que una exitosa adquisición del lenguaje implica que los niños sean sensibles al contexto. Para ser competente, el hablante debe conocer las normas para adaptar el lenguaje a la situación comunicativa. Sin embargo, una dificultad que acarrea el contexto es que no siempre se accede a él de forma directa. El propio lenguaje es contexto; por ejemplo, la elección de un código (lengua, dialecto, registro, etc.) puede afectar a la interpretación de la intención del hablante. Así, la elección de la variante estándar en lugar de la no estándar puede interpretarse como que el hablante quiere poner distancia entre él y su interlocutor (Bloom y Gumperz, 1972).

Según Ochs y Schieffelin (1979), el análisis del habla infantil contribuye positivamente al estudio del lenguaje en contexto. Los estudios sobre el lenguaje de los niños ofrecen una investigación multidisciplinar, una metodología basada en la observación empírica y la oportunidad de observar el desarrollo paulatino de la sensibilidad al contexto en el uso del lenguaje. No obstante, hoy en día no hay trabajos sistemáticos sobre la habilidad de los niños para usar la información contextual. Es necesario que aparezcan nuevos estudios, con distribuciones de edades más amplias, que permitan analizar el curso del desarrollo del procesamiento de la información contextual por parte de niños de diferentes lenguas con diferentes culturas, puesto que hasta ahora la mayoría de los estudios se han hecho con niños ingleses y no podemos saber con certeza si los resultados podrían generalizarse (Adams, 2002).

\subsubsection{Factores que posibilitan el desarrollo de la competencia pragmática}

Tal como defendimos en nuestro modelo de competencia comunicativa presentado en el segundo capítulo de este trabajo ${ }^{104}$, aunque no consideramos que deba establecerse una jerarquía estricta entre los componentes que conforman dicha competencia, creemos que sí puede hablarse de un primer grupo de subcompetencias primarias. Este grupo está formado por aquellas competencias que posibilitan la comunicación en el sentido más amplio de la palabra. Para que el niño pueda dominar la producción y la comprensión de enunciados es necesario que desarrolle sus capacidades cognitivas, esto es, aquellas relacionadas con la percepción, la atención, la memoria, el razonamiento, la teoría de la mente, etc. (competencia psicolingüística).

\footnotetext{
${ }^{104}$ Véase figura 9.
} 
Igualmente, debe también conocer una serie de esquemas y valores compartidos por la sociedad en general y por su comunidad en particular (competencia cultural).

Así, de forma análoga, en el desarrollo de la competencia pragmática podemos también establecer una serie de factores influyentes o posibilitadores. Según Loukusa (2007), la habilidad pragmática por parte de los niños depende de múltiples factores entre los que se encuentran: el desarrollo de las funciones sensoriales y motoras, la habilidad lingüística, la memoria, la capacidad de atención, el conocimiento del mundo y sus propias creencias y la habilidad para leer la mente. Todas estas capacidades están recogidas en lo que hemos denominado competencia psicolingüística, con excepción de la capacidad lingüística, que se corresponde, siguiendo nuestra terminología, con la competencia gramatical.

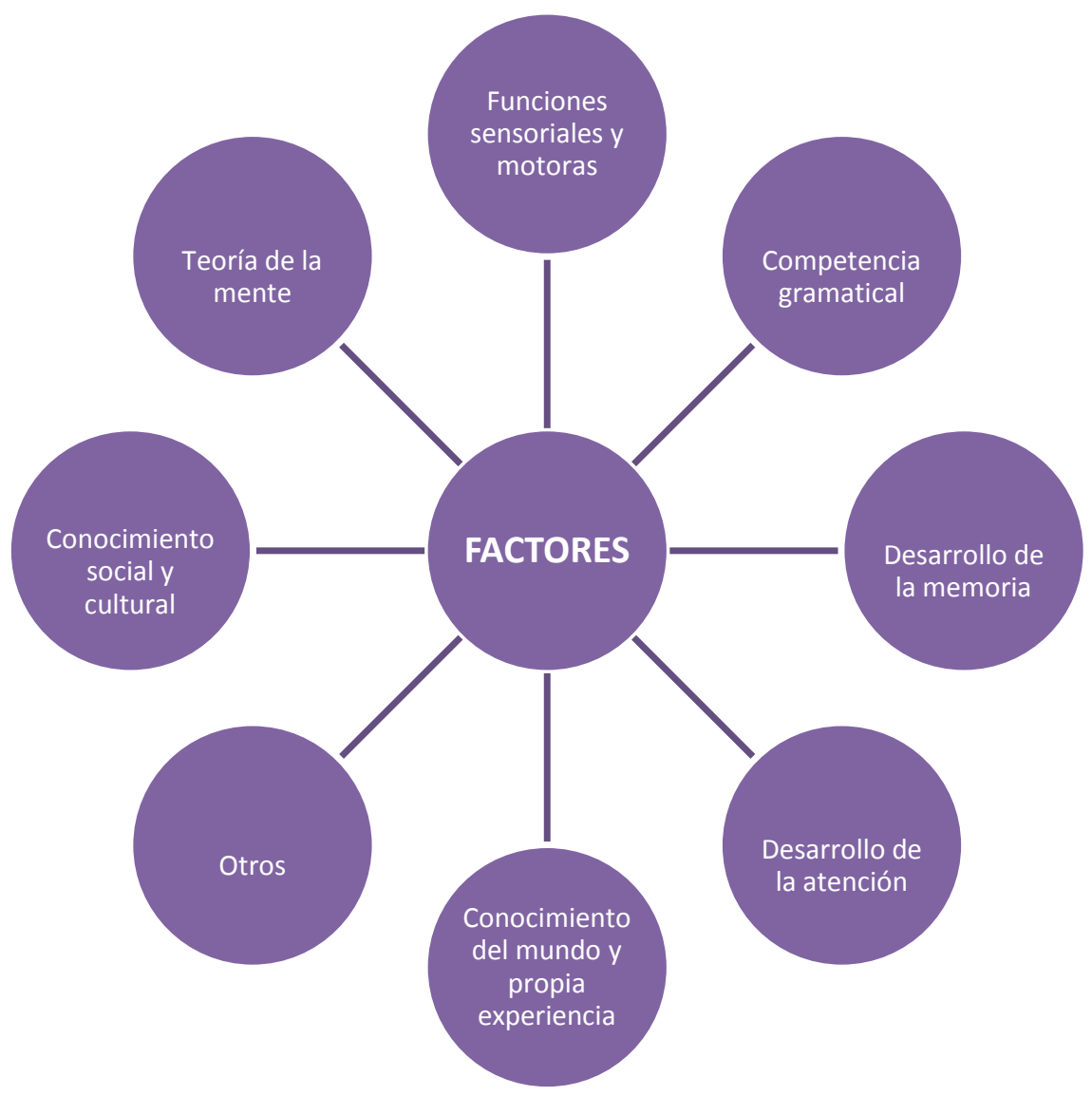

Figura 11. Factores que posibilitan el desarrollo de la competencia pragmática

Fuente: adaptado de Luokusa (2007: 33)

Ahora bien, como ya hemos anunciado anteriormente, en este trabajo también creemos oportuno incluir en estos factores la importancia del conocimiento sociocultural, esto es, de aquellos conocimientos sobre los aspectos de la cultura, 
valores y creencias de cada sociedad recogidos en el concepto de competencia cultural (que forma parte, a su vez, de las competencias primarias). Este tipo de conocimientos facilitarán que el niño se convierta en un ser social, esto es, que llegue a ser miembro de la sociedad en la que está inmerso.

Aunque no es el objetivo de este trabajo hacer una exposición exhaustiva del desarrollo de cada una de estas capacidades, es conveniente mencionar algunos datos destacables acerca de estos factores básicos que afectan a la comunicación y, en particular, a la habilidad pragmática.

\subsubsection{Funciones sensoriales y motoras}

En primer lugar, las funciones sensoriales - como la percepción auditiva y visual - y las motoras — como la habilidad articulatoria — son consideradas un requisito previo de la comunicación. Las capacidades sensoriales son las primeras funciones que se desarrollan en el niño, pues son la base del desarrollo perceptivo y cognitivo. A través de los sentidos se reciben las primeras informaciones del entorno y se elaboran las sensaciones y percepciones.

Según Bower (1984), desde el nacimiento, el cerebro del niño desarrolla determinadas capacidades perceptivas importantes, y aunque tenga limitaciones en el procesamiento de la información, con el tiempo las va superando a través de la ejercitación y la estimulación sensorial. Así, un recién nacido, por ejemplo, solo está capacitado para reaccionar al sonido y, a medida que va creciendo y familiarizándose con sonidos específicos, podrá discriminar hasta los más complejos, como son los del lenguaje.

En general, los sistemas sensoriales están constituidos por el órgano sensorial, las células receptoras y los nervios transmisores que conectan con el cuerpo celular neuronal en el córtex. Los sistemas sensoriales que más influyen en el desarrollo cognitivo-motor son el sistema visual, el sistema auditivo y el sistema somatosensorial o táctil-quinestésico ${ }^{105}$. Las percepciones visuales y auditivas son directas y se reciben en áreas identificadas del cerebro, mientras que el sistema somatosensorial o táctil-

${ }^{105}$ El sistema somatosensorial o táctil-quinestésico está relacionado con la sensibilidad táctil, con la sensibilidad relativa al movimiento, y con las posturas que puede adoptar el cuerpo. 
quinestésico no dispone de un nervio sensorial directo y recibe estimulación proveniente de diversas fuentes (McBurney y Collins, 1977).

A través de los sentidos, los mensajes son enviados por los nervios sensoriales hasta el cerebro, donde reciben un significado. De esta forma se inicia el proceso perceptivo en cuya fase final las percepciones sensoriales comienzan a agruparse, son asimiladas y se incluyen en el repertorio de conocimiento almacenado para posteriormente ser aplicadas a nuevas situaciones.

La integración motora, por su parte, tiene lugar cuando el niño emplea el sistema motor para responder a la estimulación sensorial. Paulatinamente, gracias al movimiento, el niño va adquiriendo una experiencia de cuanto le rodea, al tiempo que desarrolla comportamientos que suponen una relación inteligente con el entorno. Al nacer los movimientos son bruscos e involuntarios, al igual que ocurre con los sonidos, que son de carácter reflejo como el llanto. Gradualmente, el niño comienza a controlar su cuerpo desarrollando así sus capacidades motrices y articulatorias.

\subsubsection{Competencia gramatical}

En segundo lugar, la competencia gramatical es la que posibilita la comprensión de la información lingüística de un enunciado. En efecto, la capacidad de los niños para la comprensión pragmática de los enunciados está condicionada por su habilidad para manejar estructuras lingüísticas y por su conocimiento del significado de las palabras. Esta competencia recoge el conocimiento del uso lingüístico (morfología, sintaxis, fonología y léxico-semántica).

Los inicios de la adquisición del lenguaje en cuanto al desarrollo de la morfología y la sintaxis se describen en función de la cantidad de palabras en las emisiones lingüísticas de los niños. Así, en líneas generales se distinguen varias etapas primarias o básicas: etapa prelingüística (caracterizada por la emisión de vocalizaciones y balbuceos), etapa holofrástica (o etapa de una palabra), etapa de las dos palabras y etapa telegráfica ${ }^{106}$ (Yule, 2007). Más allá de estos periodos iniciales, el

\footnotetext{
${ }^{106}$ La denominación de esta etapa como etapa telegráfica procede de la obra de Brown y Fraser (1963). Sin embargo, a pesar de emplear la misma terminología, algunos autores se refieren a esta etapa como al periodo de entre los 2 y los 3 años en el que los niños producen cadenas de morfemas léxicos, mientras que para otros se refiere a la etapa que abarca de los 18 a los 27 meses en la que, de forma general, los niños comienzan a combinar dos o más palabras.
} 
uso de la lengua por parte de los niños se torna más complejo y para su descripción es necesario recurrir a la secuenciación de la adquisición gramatical.

Tras las primeras manifestaciones de conocimiento morfosintáctico, los niños paulatinamente se vuelven sensibles a las estructuras gramaticales de su lengua. Este fenómeno se denomina comúnmente proceso de gramaticalización y contempla varias fases cuya descripción depende de los autores. Tomasello y Brooks (1999) distinguen cuatro periodos a través de los cuales se produce la adquisición morfosintáctica. El primer periodo (de 12 a 18 meses) se considera pregramatical, ya que se caracteriza por la utilización de palabras aisladas o amalgamas de palabras. El segundo (de 18 a 24 meses) se define por la combinación de dos o más símbolos lingüísticos relacionados con la predicación y se relaciona con la etapa telegráfica. El tercer periodo (de 24 a 36 meses) se caracteriza por el desarrollo de recursos morfológicos y sintácticos y en él ya se aprecia cierta productividad ${ }^{107}$. Finalmente, en el cuarto periodo (36 meses en adelante) encontramos el uso de mecanismos y recursos gramaticales propios de la competencia adulta.

Ahora bien, otros autores han considerado que el estudio de las fases del desarrollo morfosintáctico atendiendo estrictamente a la edad es inadecuado. En esta línea cabe mencionar la propuesta de Brown (1973) de establecer las etapas del desarrollo en función de la longitud media de las emisiones ${ }^{108}$ (LME) de los niños, medidas en morfemas. La LME se ha utilizado como índice evolutivo del desarrollo del lenguaje, especialmente de su complejidad (Blake, Quartaro y Onorati, 1993). Los incrementos en la LME se corresponden con progresos en la complejidad sintáctica hasta que se alcanza una LME de 4,0. No obstante, por encima de 4, la complejidad está más relacionada con el contexto que con la sintaxis (D’Odorico y Franco, 1985). Los autores que han utilizado esta medida han señalado también numerosas limitaciones entre las que destaca que solo es sensible a aquellos aspectos del lenguaje que provocan incrementos en la longitud de las emisiones. De esta forma, cambiar el

\footnotetext{
${ }^{107}$ Una de las características más acertadas de la clasificación por etapas de Tomasello y Brooks (1999) es que toman en cuenta tanto los aspectos formales de las emisiones lingüísticas de los niños como la productividad que se observa en ellas.

${ }^{108}$ Para calcular la LME de un hablante se parte de una muestra de entre 50 a 100 enunciados. Una vez transcrito, cada enunciado se descompone en morfemas, y se calcula el promedio de longitud de los enunciados de ese hablante. Se trata, por tanto, de un valor promedio y no se refiere a la emisión más larga de los niños.
} 
orden de los elementos de una emisión no supone un aumento de la LME, pero puede originar oraciones mejor formadas desde el punto de vista sintáctico. Además, tal como señalan Dromi y Berman (1982), la LME se diseñó para analizar la longitud de los enunciados de niños ingleses y, por tanto, debe modificarse para adaptarse a otras lenguas ${ }^{109}$ como, por ejemplo, el español, donde la complejidad lingüística no se refleja necesariamente en enunciados de mayor longitud.

Principalmente, podemos determinar que el desarrollo morfosintáctico empieza a producirse entre los 18 y los 36 meses, y evoluciona de forma gradual hasta alcanzar la competencia gramatical adulta. No obstante, los conocimientos no se adquieren uno tras otro, sino que hay aspectos que evolucionan de forma conjunta y otros de forma condicional, de tal manera que es necesario que se adquieran otros previamente para que puedan aparecer estos. En opinión de algunos autores, el rigor del estudio de la adquisición morfosintáctica se consigue únicamente basándose en un aspecto gramatical concreto. Así, a lo largo de las últimas décadas encontramos numerosos estudios centrados en aspectos morfológicos y sintácticos, tales como el morfema de plural (Pérez-Pereira, 1989), los aumentativos y diminutivos (Snow et al., 1980), la morfología temporal del verbo (Pérez-Leroux y Liceras, 2002), las oraciones interrogativas (Bloom, 1991; Serrat y Capdevila, 2001), las oraciones negativas (Déprez y Pierce, 1993; López-Ornat et al., 1994), las oraciones compuestas (Sebastián y Slobin, 1994; Zorriqueta, 1996; Serra et al., 2000), etc.

Muchos de los cambios sintácticos y morfológicos propios de los años preescolares son un reflejo del desarrollo del sistema fonológico subyacente del niño. Así, parte de la producción morfológica de los niños dependerá de su capacidad para percibir y producir unidades fonológicas (Owens, 2003). En efecto, los distintos niveles de la adquisición lingüística están relacionados entre sí, de forma que, por ejemplo, en torno a los 2 años, la precisión de la producción de fonemas disminuye como resultado del inicio de la etapa morfosintáctica en la que los niños comienzan a combinar palabras (Nelson y Bauer, 1991). Los niños en edad preescolar siguen una serie de reglas fonológicas, lo que permite predecir sus vocalizaciones. Después, a medida que desarrollan sus capacidades de producción, dichas reglas se van

\footnotetext{
${ }^{109}$ La utilización de la LME en el estudio del desarrollo del lenguaje en niños españoles ha sido llevada a cabo por Clemente (1989, 1995), que presenta una propuesta sobre la revisión y aplicación de esta metodología adaptada a la lengua castellana. 
actualizando (Kuczaj, 1982). Además, no todos los fonemas se asimilan igual: algunos sonidos son más fáciles de percibir y producir que otros, lo que supone un proceso de adquisición más extendido. En general, se considera que los niños no dominan plenamente todos los sonidos del habla hasta aproximadamente los 7 años de edad, si bien es cierto que adquieren gran parte de su almacén fonético en la etapa preescolar. En este primer periodo probablemente no perciben los fonemas como unidades en las que puedan descomponer el lenguaje, pero sí son conscientes de que las palabras son similares o diferentes. De hecho, aunque desconozcan las razones de estas similitudes, ya las intuyen (Hakes, 1982).

En cuanto al desarrollo del léxico, la mayoría de las primeras palabras de los niños solo contienen una o dos sílabas y los fonemas más frecuentes son /p/, /t/, /m/ y /n/, junto con /g/ y /k/ (Jackson-Maldonado et al., 1993). Además, el léxico inicial suele incluir el nombre de animales, comida y juguetes; y desde el principio se hallan palabras ligadas a contextos y funciones. Hacia los 18 meses de edad, los niños ya disponen de un léxico compuesto de unas 50 palabras (Gentner, 1982). Después, entre los 18 y los 24 meses, se produce lo que se conoce como explosión del léxico (lexical spurt) (Dromi, 1987; Mervis y Bertrand, 1995). Se trata de un cambio repentino y notable en el procedimiento de aprendizaje de palabras una vez que han llegado a un nivel mínimo.

Al comienzo del desarrollo del léxico, la categoría gramatical predominante es la de los nombres. Una de las muchas explicaciones de esto es que se trata de referentes más concretos y tangibles (Tomasello, 1992). A partir de las 100 palabras los verbos comienzan a aumentar, mientras que otras categorías como las preposiciones no aparecen hasta que el niño no dispone de un vocabulario de en torno a 400 palabras (Ochs y Schieffelin, 1984).

En cuanto al desarrollo de la sofisticación semántica, este depende en gran medida del nivel educativo, del estatus socioeconómico, de la cultura, etc. (Kurland y Snow, 1997). Durante los años escolares los niños añaden rasgos a las definiciones de las palabras que ya conocen y unifican todas las definiciones que puedan ajustarse a una palabra determinada. Asimismo, autores como Johnson y Anglin (1995) consideran que la adquisición del contenido semántico de una palabra aparece en los niños antes que la capacidad de utilizar una sintaxis correcta para definirla. 


\subsubsection{Desarrollo de la memoria}

En tercer lugar, también es necesaria una habilidad para almacenar la información, por lo que el desarrollo de la memoria a corto y largo plazo constituye otro de los factores relevantes en el desarrollo de la comprensión pragmática de los enunciados (Cohen, 1989; Baddley, 1996). Desde la psicología educativa, la memoria se entiende como una capacidad plástica que varía en función de las necesidades y de las experiencias de cada etapa del desarrollo.

Tal como señala López García (2014), en la actualidad la neuropsicología reconoce la existencia de tres clases de memoria (declarativa, procedimental y emotiva) ligadas a tres órganos concretos del sistema límbico: córtex-hipocampo, núcleo caudano (estriado) y amígdala, respectivamente. Como parece lógico, ya que las redes neuronales no están aisladas, no deben entenderse de forma aislada; cualquier comportamiento relativo a uno de estos tipos de mecanismo memorístico combina necesariamente con los otros dos. Ahora bien, López García (2014: 99) sugiere un interesante paralelismo entre las tres ramas clásicas de la semiótica (Morris, 1938) y los tres tipos de memoria. Así, considera que la memoria estriatal (procedimental) se relaciona con la fonética, la memoria hipocampal (declarativa) con la sintaxis, y la memoria amigadaliana (emotiva) con la pragmática. En relación con el componente pragmático, este se vincula al sistema de emociones centrado en la amígdala, así como a los demás circuitos neuronales que transitan por el sistema amigdalinano y son responsables de la dependencia del contexto extralingüístico (Gläscher y Adolplas, 2003), significados connotativos y metáforas (Brownell et al., 1984), actos de habla indirectos (Stemmer et al., 1994), etc.

En general, la memoria en la etapa infantil se define por su carácter involuntario, es un resultado indirecto y complementario de las acciones de percepción y de pensamiento llevadas a cabo por el niño. Por su parte, el dominio de las formas voluntarias de memoria se desarrolla a lo largo de las diversas etapas de crecimiento y comienza por distinguir las tareas de retención mental y recordación-reproducción. A lo largo de la niñez y la adolescencia se produce un aumento en la capacidad para recordar información a corto y largo plazo (Meyers y Meyers, 2000; Roselli et al., 2001), así como en el desarrollo del uso de estrategias que facilitan tanto el 
almacenamiento como la evocación de la información almacenada (Gathercole y Hitch, 1993; Roodenrys, Hulme y Brown, 1993; Siegel, 1994).

Durante mucho tiempo se creyó que la memoria no podía desarrollarse hasta que no tuviera lugar la adquisición del lenguaje. Sin embargo, investigaciones posteriores demostraron el desarrollo de la memoria incluso en bebés de 3 a 6 meses. En uno de estos estudios (Bower, 1989) se demostró que los niños de un año tenían capacidad para reconocer si los protagonistas de los vídeos que se les presentaban eran niños o niñas con independencia de la ropa que vistieran. Se descubrió que identificaban diferentes pautas de movimiento a la hora de andar o agacharse a por un juguete porque las recordaban.

Por su parte, en los niños de 2 a 6 años se puede observar una capacidad extraordinaria para almacenar ciertas representaciones de acontecimientos, de forma que crean marcos dentro de los cuales recuerdan experiencias concretas. Por ejemplo, un niño de 3 años puede explicar la secuencia de un restaurante ${ }^{110}$ : se pide la comida, se come y se paga (Nelson, 1986). Además, en esta etapa recuerdan experiencias del pasado y pueden reconstruir acontecimientos del día (Hudson, 1990).

Más adelante, entre los 6 y 14 años, los niños ya utilizan diferentes estrategias de almacenamiento así como estrategias de recuperación. El procesamiento de la información se hace más rápido y los niños son capaces de pensar más ágilmente y sobre más cosas al mismo tiempo. Se trata del periodo en el que más se desarrolla la memoria.

Asimismo, varios estudios concluyen que la memoria, y en concreto la memoria a corto plazo, es también un factor importante cuando derivamos un significado implicado de un enunciado, como muestran los estudios sobre la comprensión de textos por parte de niños (Oakhill y Yuill, 1986; Cain et al., 2001).

\subsubsection{Desarrollo de la atención}

En cuarto lugar, también debemos considerar el desarrollo de la atención. Los estudios demuestran que la capacidad para elegir los estímulos pertinentes para una tarea y evitar la distracción por estímulos irrelevantes también mejora con la edad. Así,

\footnotetext{
${ }^{110}$ Este hecho está relacionado con el uso de guiones y marcos conceptuales de los que hablamos en el primer capítulo. Véase apartado 1.2.
} 
a lo largo de la niñez podemos observar cómo se desarrolla la habilidad para cambiar el foco de atención de un estímulo a otro, o de responder simultáneamente a tareas múltiples.

Según Ruiz-Contreras y Cansino (2005), la atención es un proceso paralelo y estrechamente relacionado al desarrollo de la memoria. El desarrollo de la atención se hace evidente también a edades tempranas, cuando el niño refleja su interés por los objetos de su entorno y las acciones realizadas con ellos. Ahora bien, el niño de corta edad se concentra solo mientras tenga interés. De esta forma, a medida que va creciendo, la atención se vuelve más centrada y estable.

De acuerdo con Gupta y Kar (2009), el desarrollo de los procesos de atención es rápido durante los primeros años. La atención voluntaria del niño hacia un estímulo evoluciona de manera gradual, de modo que en torno a los 4 años ya puede explorar el medio, dirigir su atención a los estímulos que encuentra e interactuar con ellos; mientras que a los 5 y 6 años, el niño dirige su atención internamente de forma voluntaria y consciente hacia los estímulos que le interesan (Goswani y Brown, 1998).

A medida que la atención mejora, los niños se centran en los aspectos relevantes de la tarea que están realizando e ignoran otras fuentes de información. Así, en su estudio, Lane y Pearson (1982) analizan el desarrollo de la atención introduciendo estímulos irrelevantes en distintas tareas y concluyen que la edad en la que mejora notablemente la capacidad de mantener la atención en los rasgos centrales de una tarea es entre los 6 y los 9 años.

Colombo (2001) entiende que la atención incluye cuatro componentes interrelacionados: 1) estado de alerta, 2) orientación espacial, 3) atención a las características de los objetos y 4) atención controlada o endógena. Así, aunque estos mecanismos están presentes de forma primaria desde el nacimiento, todos ellos muestran un rápido desarrollo durante los primeros meses y la maduración se observa a lo largo de la vida escolar (Gómez-Pérez et al., 2003) y la adolescencia. Se ha comprobado, por ejemplo, que la atención auditiva y visual se desarrolla especialmente entre los 5 y los 8 años (Korkman, Kemp y Kirk, 2001; Rosselli et al., 2004), si bien es cierto que pueden observarse cambios todavía entre los 14 y 16 años (Rosselli et al., 2001). 


\subsubsection{Conocimiento del mundo y propia experiencia}

El quinto factor influyente en la interpretación pragmática en los niños lo constituyen su propio conocimiento del mundo y sus creencias. Los niños aprenden mientras juegan, observan o escuchan, esto es, a través de su propia interacción con el mundo que les rodea; de ahí la importancia del papel del entorno como fuente de experiencia y de conocimiento.

Según Acuña y Sentis (2004), el niño construye su conocimiento a partir de la relación que establece con el medio (entendido no solamente como un medio físico sino también afectivo, cultural, social, histórico, etc.). De esta forma, a partir de la interacción con los demás y con el medio que le rodea adquiere una visión del mundo.

Ahora bien, el niño no absorbe toda la información, sino que la transforma, para poder asimilarla, conforme a los esquemas y conocimientos que se ha formado previamente. Desde edades muy tempranas el niño se va forjando un conjunto de ideas sobre su entorno, pero esta visión puede no coincidir con la visión de los adultos ni con la realidad, ya que suele tener ingredientes propios o ideas distorsionadas de la realidad o de su propio medio. Así, a lo largo del desarrollo, los niños van construyendo gradualmente un complejo sistema de creencias, que utilizarán en el futuro (Donaldson, 1992). Este sistema de creencias es flexible y se amplía o actualiza a medida que los niños van experimentando nuevas vivencias (Milosky, 1992; Sperber y Wilson, 1995; Nelson, 1996).

\subsubsection{Teoría de la mente}

En sexto lugar, constituye uno de los factores más destacados por los autores la habilidad para leer la mente (mind reading ability), también conocida como teoría de la mente ${ }^{111}$. Según los expertos, el uso funcional del lenguaje supone una adaptación de los hablantes a los estados mentales de sus interlocutores. Cabe suponer, entonces, que la evolución de la comprensión de la mente en el niño va relacionada con su desarrollo neuronal, que a su vez progresa en paralelo con la socialización, factor que veremos a continuación.

${ }^{111}$ El término teoría de la mente fue utilizado por primera vez por Premack y Woodruff (1978) para explicar la capacidad de ciertos chimpancés de engañar intencionadamente. Premack y Woodruff propusieron que dicha capacidad se llamara teoría de la mente puesto que lo que se hace es leer en las acciones de los demás las intenciones subyacentes que explican esas acciones y predecir qué conductas realizará esa persona con esas intenciones (Gómez y Núñez, 1998). 
La teoría de la mente puede considerarse "una elaboración compleja de la estrategia intencional, que implica la capacidad de diferenciar los estados mentales propios de los ajenos” (Belinchón et al., 1992: 198). Esta teoría presupone la habilidad de atribuir estados mentales a otros y se manifiesta, por ejemplo, a través del engaño intencionado. Según Galeote Moreno (2002), la teoría de la mente penetra en la investigación de diversos fenómenos que tienen que ver con la distinción entre el significado literal y el significado que se pretende comunicar.

Los niños desarrollan rápidamente su capacidad de teoría de la mente. A los 2 años de edad, varios de sus juegos consisten en engañar y ser engañados, y muy precozmente pueden demostrar, en situaciones experimentales, pautas de engaño sirviéndose de personajes (Chandler et al., 1989). En la bibliografía destacan dos experimentos de falsa creencia con diferente grado de complejidad. En primer lugar, Baron-Cohen y sus colaboradores (Baron-Cohen, Leslie y Frith, 1986) elaboraron el experimento Sally-Anne, que se describe habitualmente como la tarea de falsa creencia de primer orden. En el experimento, el niño mira cómo el experimentador representa una historia con dos niñas: Sally, que tiene una cesta, y Anne, que tiene una caja. Sally coloca una canica en su cesta antes de salir de la habitación. Anne —cuando Sally está fuera - saca la canica de la cesta y la coloca en su caja. Cuando Sally regresa a la habitación, se le pregunta al niño dónde buscará Sally su canica. La investigación demuestra que los niños con desarrollo normal en torno a los 3 años y medio ya son capaces de atribuir la falsa creencia al personaje y predecir que Sally buscará en la cesta porque no sabe que Anne ha cambiado la canica y la ha puesto en su caja. Sin embargo, como veremos en el siguiente capítulo dedicado a los trastornos del lenguaje, aproximadamente el 80\% de los niños con autismo suponen que el personaje buscará en la caja porque no entienden que Sally no ha sido testigo del cambio, esto es, no comprenden que los demás tienen sus estados mentales que pueden ser diferentes de la realidad y que pueden diferir de los propios.

La falsa creencia de primer orden consistirá, entonces, en entender que la representación del personaje es falsa con respecto a una situación real, y entrará en juego una capacidad que podemos denominar metarrepresentacional. Comprender que alguien ha sido engañado presupone tanto la conciencia de que los otros tienen estados de creencia como la diferenciación entre los estados mentales propios y los ajenos. 
Además, podemos afirmar que es en torno a los 4 y 5 años cuando los niños ya son plenamente capaces de reconocer cuándo un personaje tiene una creencia falsa que no se corresponde con un estado de hechos, ni con sus propias creencias sobre estos hechos (Wimmer y Perner, 1983).

Por otro lado, la falsa creencia de segundo orden se refiere a la capacidad de los niños para atribuir a los demás falsas creencias del tipo María piensa que su madre cree (Sullivan et al., 1994). Esta tarea tiene una serie de requerimientos representacionales en su ejecución, ya que no solo hay que representar los estados mentales de los personajes, sino también el estado mental que tienen los personajes de los estados mentales de los demás personajes de la historia. Al igual que en la prueba de falsa creencia de primer orden, se parte del relato de una historia; sin embargo, se intercalan preguntas, de las cuales las cuatro primeras son de control (para saber si el niño comprende el relato) y las dos últimas son sobre el estado mental que tiene un personaje acerca del estado mental de otro personaje de la historia. El relato es el que sigue: María es una niña que quiere un gato para su cumpleaños. Su madre le dice que no es posible tenerlo, pero que le comprará una muñeca. En realidad, la madre de María le compra el gato en una tienda de mascotas y lo guarda en un baúl que hay en la casa. A continuación el experimentador hace dos preguntas: (1) ¿Realmente la madre le ha comprado a María una muñeca para su cumpleaños? (2) ¿Le dijo la madre a María que le iba a comprar una muñeca para su cumpleaños? El experimentador continúa con el relato: luego, sin que su madre lo sepa, María encuentra el gato cuando va a buscar sus patines en el baúl que hay en la casa. El experimentador nuevamente le plantea dos preguntas: (3) ¿Sabe María que su madre le ha comprado un gato para su cumpleaños? (4) ¿Sabe la madre que María ha visto el gato en el baúl? Finalmente el experimentador cuenta la última parte de la historia: la madre y la abuela de María están hablando sobre el regalo del cumpleaños de María. La abuela le pregunta a la madre ¿Sabe María que le vas a regalar realmente para su cumpleaños? El experimentador le pregunta al niño (5) ¿Qué le dirá la madre a la abuela? Luego, la abuela le pregunta a la madre ¿Qué cree María que le vas a comprar en su cumpleaños? Nuevamente el experimentador le pregunta al niño (6) ¿Qué le contesta la madre a la abuela? 
En este caso se precisa que el niño tenga en cuenta lo que los demás conocen de los pensamientos de otras personas y que comprenda la naturaleza recursiva de los estados mentales. Los resultados experimentales parecen indicar que hay una etapa del desarrollo - en torno a los 6 y los 7 años- en la que los niños desarrollan estas tareas de falsa creencia de segundo orden.

Poco a poco, los niños van realizando inferencias cada vez más complejas acerca de los estados mentales de otros (Perner, 1991). En general, la bibliografía sobre el tema coincide en que el desarrollo de la teoría de la mente en los niños se produce entre las edades de 3 y 5 años (Siegal y Beattie, 1991; Wellman et al., 2001), franja de edad en la que se desarrollan activamente los procesos de comprensión pragmática (Bucciarelli et al., 2003). Según Abe e Izard (1999), en este rango de edad se dan también importantes desarrollos evolutivos:

- Creciente sentido de autoconciencia, que se refleja a través de la expresión de emociones como el enfado, la ira o conductas desafiantes.

- Desarrollo de la capacidad de comprender a los demás y de distinguir entre su propio yo y los demás.

- Aumento de la sensibilidad hacia las normas morales.

- Surgimiento de emociones autoevaluativas como la culpa, la vergüenza, etc.

En suma, decimos que el niño ha desarrollado la teoría de la mente cuando es capaz de generar expectativas sobre las creencias de otros, diferenciándolas de las propias y, consiguientemente, puede hacer o predecir algo en función de estas creencias atribuidas.

\subsubsection{Conocimiento social y cultural}

Finalmente, el último factor que vamos a analizar es el conocimiento social y cultural. Los estudios demuestran que, a medida que los niños están adquiriendo el lenguaje, están construyendo también su conocimiento sobre la sociedad. De esta forma aprenden que el estatus social está ligado a una serie de derechos y obligaciones que se ponen de manifiesto en el comportamiento verbal (Ochs y Schieffelin, 1979). Según Shantz (1982), el conocimiento social incluye el conocimiento de los otros como individuos, de las relaciones sociales entre individuos, de las relaciones sociales diádicas, de las relaciones y el funcionamiento de los grupos sociales más extensos; y, 
finalmente, del funcionamiento de las instituciones sociales tales como la familia, la escuela, el mundo empresarial, etc.

Cada sociedad ha desarrollado sus propias formas de pensar, normas de actuación, etc. Estas formas están organizadas como representaciones colectivas, de manera que la sociedad ejerce presión sobre el individuo para que las adopte si quiere ser aceptado en el grupo. Así, el proceso de socialización supone que el individuo asume dichas representaciones a través de la participación activa en la familia y otras instituciones involucradas en la transmisión de normas y valores. Según Emler, Ohana y Dickinson (1990), esto no significa que el niño tenga un papel pasivo en la construcción del conocimiento, ya que participa activamente mediante la comunicación y la interacción con otros en su comunidad.

Como ya hemos señalado, la adquisición del lenguaje es un proceso muy complejo que implica el uso de estrategias de aprendizaje. Ahora bien, estas estrategias pueden variar en función de las diversas culturas. En nuestra cultura, a menudo las madres intentan establecer una conversación con sus hijos a raíz de que estos hayan señalado o nombrado un objeto con la intención de promover el desarrollo del lenguaje. Esto no ocurre en otras culturas como, por ejemplo, entre los kipsigis de Kenia o los afroamericanos de la Luisiana rural, que valoran más la comprensión que la producción y se dirigen a sus hijos casi siempre con imperativos sencillos. Así, los padres kakuli de Nueva Guinea tampoco suelen seguir la dirección conversacional que establecen sus hijos (Ochs y Schieffelin, 1984). Por su parte, algunas madres mexicanas proporcionan modelos de lenguaje apropiado en situaciones específicas y estimulan a sus hijos para que imiten el modelo de habla que escuchan a su alrededor, de forma que cuando están con otros adultos les orientan para que den respuestas verbales apropiadas (Briggs, 1984). Todo esto indica que el input lingüístico que reciben los niños también depende de la cultura. Los estudios señalan que las madres norteamericanas tienden a dar más información que las madres japonesas, utilizan más preguntas y enunciados gramaticalmente correctos. Por el contrario, las madres japonesas usan frases más sencillas, sonidos sin sentido y onomatopéyicos (Shand y Kosawa, 1985). Owens (2003) sugiere que estas diferencias pueden reflejar diferentes estilos culturales de conversación. En la cultura americana los hablantes son más 
directos y se centran en la expresión de la individualidad; mientras que en la cultura japonesa son más indirectos y destaca la empatía y la conformidad.

Actualmente, la cognición social constituye un campo de estudio de gran interés dentro de la psicología (Garfield, Peterson y Perry, 2001; Repacholi y Slaughter, 2003; Flavell, 2004), ya que se considera primordial para predecir y explicar el comportamiento en sociedad tanto en el plano de la acción (Mitchell, 1997) como en el comunicativo (Bishop, 1997). Asimismo, se ha demostrado que los niños con una mayor habilidad lingüística presentan también una elevada capacidad sociocognitiva (Astington y Jenkins, 1999).

Autores como Ninio y Snow (1996) advierten de la existencia de una interfaz entre el sistema pragmático y la cognición social que es crucial para el desarrollo de ambos: "whereas developments in the social-conceptual system drive pragmatic development, the mastery of verbal communicative acts also drives the social cognitive system” (1996: 105). Un concepto como dar permiso o hacer una promesa no existe fuera del sistema de actos de habla, por lo tanto, si el niño aprende este acto de habla, estos conceptos son asimilados en su aparato cognitivo.

En los niños se observa, por tanto, una expansión del conocimiento de las convenciones que conllevan determinados actos de habla. Este conocimiento implica no solo las estructuras lingüísticas, sino también las condiciones bajo las cuales estos actos son apropiados en la comunidad (Ochs y Schieffelin, 1979). Además, para describir fenómenos como la cortesía o para analizar cómo los niños utilizan estas reglas, debemos estudiar cómo se socializan en el uso de estas, es decir, debemos considerar la totalidad de una cultura. La mayoría de los estudios sobre cómo los niños aprenden a hablar de una forma pragmáticamente apropiada incluyen información sobre el background en el que han sido educados. Ninio y Snow (1996) reconocen que es muy difícil trazar la línea que separa la pragmática lingüística de la efectividad social. Por consiguiente, podemos concluir que las habilidades pragmáticas no son fácilmente separables de las habilidades sociales cognitivas, ya que la acumulación de este tipo de conocimientos es necesaria también para el éxito en los intercambios interpersonales.

Un estudio ya lejano (Flavell et al., 1968) señaló que al pedirles a niños de distintas edades que explicaran un texto primero a un adulto y luego a un niño de 4 
años no presentes, sus explicaciones no mostraban grandes diferencias, ni siquiera en los niños de 8 años de edad. Estos niños no eran capaces de adaptar el texto a las características del interlocutor, de modo que Flavell lo interpretaba como resultado de su conducta egocéntrica. Sin embargo, estudios posteriores centrados en el paradigma sociolingüístico (Shatz y Gelman, 1973) demostraron que los niños de 4 años utilizaban un lenguaje más simple cuando hablaban con niños más pequeños. Esto demostraría que los niños desde edades tempranas sí tienen en cuenta las capacidades comunicativas de su interlocutor y adaptan su mensaje en función de ellas. Este enfrentamiento de opiniones tiene su origen en la famosa polémica - ya mencionada - sostenida en torno al lenguaje egocéntrico y al lenguaje socializado. Para Piaget (1923), el lenguaje infantil es básicamente egocéntrico hasta los 7 años, mientras que, para Vygotsky (1934), es de carácter socializado. Según Piaget (1923), el lenguaje es un reflejo del pensamiento y el pensamiento infantil se basa en el egocentrismo, esto es, los niños son incapaces de situarse en un punto de vista distinto del suyo ${ }^{112}$. A partir de la edad de 7 años el lenguaje adquiere su carácter socializador, es decir, poco a poco se descentraliza y tiene en cuenta el punto de vista de los demás. En ello influyen las interacciones con el adulto y con sus compañeros de edad ${ }^{113}$. Además, Piaget entiende que el lenguaje es el resultado de la organización cognitiva de los esquemas de acción y su representación mental, por lo tanto, la dirección evolutiva es de dentro hacia fuera.

Por su parte, Vygotsky (1934) defiende que la función primaria del lenguaje es la comunicación. Este autor considera que, puesto que el lenguaje surge de la interacción con los demás, es socializado. En los primeros años el lenguaje es más egocéntrico, ya que, aunque tiene sus orígenes en la comunicación, también desempeña otras funciones como la de acompañar la actividad infantil, planificar tareas o evaluarlas. De esta forma, el niño expresa con antelación la acción que va a llevar a cabo o, una vez terminada, habla de los resultados que observa en voz alta. A partir de los 7 años este

\footnotetext{
112 Sería interesante comparar el concepto de egocentrismo con la actual teoría de la mente. El primero hace hincapié en la función "hablar para” y la segunda en "hablar teniendo en cuenta" el estado mental del interlocutor.

${ }^{113}$ Para apoyar estas afirmaciones Piaget se basó en el análisis de las conversaciones de niños menores de 6 años, en las que observó un predominio de mensajes que no iban dirigidos a nadie en particular sino que eran repeticiones ecolálicas, monólogos o monólogos colectivos. Con todo, concluyó que la finalidad del lenguaje no era la comunicación con los demás (Piaget, 1923).
} 
lenguaje egocéntrico se vuelve interiorizado dando lugar al pensamiento como habla interior. De esta manera, el lenguaje se convierte en un medio para la reflexión acerca de las actividades desarrolladas, por lo que la evolución es del exterior al interior, a la inversa de la propuesta de Piaget.

Finalmente, una vez admitida la importancia del desarrollo social, nos planteamos la relación entre el lenguaje individual y la sociedad. Francescato (1986) reconoce que la socialización del sistema lingüístico infantil supone la entrada del niño en la tradición y la garantía de continuidad lingüística para la comunidad, aunque ello no implica que sus producciones concretas no estén inmersas en la subjetividad.

\subsubsection{Etapas evolutivas e hitos del desarrollo}

Como hemos visto hasta ahora, para comprender y analizar el desarrollo del lenguaje es necesario conocer también las bases del desarrollo general del niño. Dicho desarrollo tiene un carácter predecible, ya que "aunque existe cierta variación individual, los niños suelen alcanzar los hitos del desarrollo más o menos a la misma edad” (Owens, 2003: 68). Asimismo, de acuerdo con Owens (2003: 70-103), distinguimos diferentes etapas del desarrollo infantil destacando cuatro áreas evolutivas diferentes pero relacionadas: física, cognitiva, socioemocional y comunicativa:

- El recién nacido (desde el nacimiento hasta el primer mes de vida)

- El observador (de 1 a 6 meses)

- El experimentador (de 7 a 12 meses)

- El explorador (de 12 a 24 meses)

- El exhibidor (de los 3 a los 5 años)

- El experto (de 6 a 12 años)

El recién nacido o neonato (Owens, 2003: 72-78) no es capaz de controlar de manera voluntaria sus músculos. Sus movimientos son bruscos, aleatorios y están formados por patrones involuntarios conocidos como reflejos. Gracias a estos reflejos, el niño reacciona de forma apropiada ante determinados estímulos antes de ser capaz de controlar su conducta. Así, con el tiempo los reflejos son reemplazados por habilidades motrices más sofisticadas. En cuanto a los sonidos que produce, también son de carácter reflejo, como los gorjeos y el llanto. En concreto el llanto ha sido 
estudiado como el primer intento comunicativo. Además, los neonatos también disponen de ciertas capacidades perceptivas de audición y de visión y dan señales de poseer una memoria visual a corto plazo. Sin embargo, la inmadurez del cerebro y el hecho de que no existe coordinación entre los dos hemisferios cerebrales dificultan su capacidad para integrar señales sonoras y visuales.

La etapa del observador (Owens, 2003: 78-83) es aquella en la que los niños alcanzan rápidamente cierto control motor, se produce la maduración del cerebro y el campo visual se amplía. Esto les permite examinar objetos y personas de su entorno, y supone, por tanto, un progreso en el desarrollo social. Asimismo, el aumento de la memoria visual hace que el niño pueda reconocer personas y familiarizarse con los estímulos visuales. A los 6 meses se les considera seres sociales, puesto que responden a la interacción con sonrisas y vocalizaciones. Durante este periodo, los niños experimentan con los sonidos que producen y paulatinamente aparecen secuencias de sonidos más largas con consonantes posteriores y vocales medias y posteriores.

La etapa del experimentador (Owens, 2003: 83-89) finaliza con el desarrollo de múltiples capacidades: los niños empiezan a hablar, a andar y a utilizar herramientas, como resultado de la evolución de las capacidades motrices y cognitivas. Durante este periodo los niños comienzan a usar la estrategia de solución de problemas basada en el ensayo/error. Además, la imitación juega un papel importante como estrategia de aprendizaje así como en la interacción social. Los niños comienzan a mirar los objetos que se nombran y a reconocer palabras familiares. Hacia los 7 meses el balbuceo también empieza a cambiar, se convierte en balbuceo duplicado, que consiste en secuencias de sílabas repetidas, y después en balbuceo variado, donde las sílabas que lo componen ya no son iguales. Asimismo, en torno al primer año, los niños producen su primera palabra real.

El periodo del explorador (Owens, 2003: 89-93) se caracteriza por el desarrollo de nuevas capacidades locomotrices, comunicativas y de atención. Todo ello unido a la mayor capacidad de memoria permite a los niños de esta edad modificar la idea que tienen de la realidad que les rodea y de ellos mismos. Además, también demuestran una mejoría en sus capacidades para resolver problemas físicos. Cabe destacar que a esta edad a los niños les encantan las rutinas, predecir sucesos habituales o la localización de un objeto familiar y, sobre todo, ser el centro de atención, como parte 
de su interacción social. En esta etapa cada niño tiene un lexicón o diccionario propio, compuesto por palabras que reflejan su entorno y cuya expansión convive con la persistencia del balbuceo (Whitehurst et al., 1991).

El periodo del exhibidor (Owens, 2003: 94-100) se caracteriza por la independencia, ya que es en esta etapa en la que los niños adquieren muchas capacidades de autonomía. Además, el desarrollo de las habilidades lingüísticas y de la memoria les faculta para solucionar problemas, comprender conceptos temporales y recordar sucesos. Podemos distinguir 3 edades: los 3, los 4 y los 5 años.

A los 3 años las capacidades motrices finas continúan desarrollándose. En esta edad es muy importante el papel de la imaginación: los niños elaboran dibujos más representativos, de hecho es frecuente que un mismo dibujo represente cosas diferentes. Y lo mismo sucede en los juegos, ya que un mismo juguete puede representar algo distinto. En el lenguaje se observa un gran crecimiento en el vocabulario (en torno a unas 1000 palabras), el predominio absoluto de oraciones simples en las que se omiten preposiciones o conjunciones con el formato SUJETOVERBO-OBJETO, y el empleo de modificadores nominales, artículos y plurales.

Los niños de 4 años han desarrollado ya el control de los movimientos independientes de ambos lados del cuerpo. Gracias a sus capacidades lingüísticas y de memoria pueden recuperar información mediante estrategias más sutiles, construyen oraciones más complejas de una media de cuatro o cinco palabras, utilizan formas negativas, interrogativas e imperativas y poseen un vocabulario de unas 1600 palabras. Además, en esta edad son buenos conversadores, aunque su conversación está llena de preguntas.

A los 5 años, los niños tienen un gran conocimiento y control de su cuerpo y pueden realizar tareas y juegos complicados. El aumento de la capacidad de memoria les permite, asimismo, organizar juegos de reglas sencillas. Además, en este periodo destaca el desarrollo del sentido del tiempo, que facilita la comprensión de las explicaciones basadas en causas y efectos. En cuanto a las habilidades lingüísticas, los niños de esta edad utilizan un lenguaje muy cercano al habla adulta, aunque todavía no dominan estructuras sintácticas complejas. Su vocabulario alcanza las 2200 palabras, pueden contar historias, tienen cierto sentido del humor y pueden hablar sobre emociones. 


\begin{tabular}{|c|c|c|c|c|}
\hline $\begin{array}{c}\text { Edad } \\
\text { (años) }\end{array}$ & MOTRICIDAD & COGNICIÓN & SOCIALIZACIÓN & COMUNICACIÓN \\
\hline 3 & $\begin{array}{l}\text {-Sube y baja las } \\
\text { escaleras sin ayuda } \\
\text {-Camina sin mirarse } \\
\text { los pies } \\
\text {-Anda } 5 \text { metros de } \\
\text { puntillas } \\
\text {-Monta en triciclo } \\
\text {-Utiliza el cuchillo } \\
\text { para extender } \\
\text {-Explora, } \\
\text { desmantela y } \\
\text { desarma } \\
\text {-Toca instrumentos } \\
\text { musicales sencillos }\end{array}$ & $\begin{array}{l}\text {-Crea un tipo de arte } \\
\text { representativo } \\
\text {-Empareja colores y } \\
\text { formas } \\
\text {-Comprende el } \\
\text { concepto de dos } \\
\text {-Disfruta con los } \\
\text { juegos de fantasía y } \\
\text { simulación } \\
\text {-No sabe cuánto } \\
\text { dura un año }\end{array}$ & $\begin{array}{l}\text {-Juega en grupo, } \\
\text { hablando mientras } \\
\text { lo hace y elige a sus } \\
\text { compañeros de } \\
\text { juego } \\
\text {-Comparte juguetes } \\
\text { durante breves } \\
\text { momentos } \\
\text {-Adopta turnos } \\
\text {-Le encanta ser el } \\
\text { centro de atención }\end{array}$ & $\begin{array}{l}\text {-Vocabulario productivo } \\
\text { de unas } 1000 \text { palabras } \\
\text {-Construye oraciones de } \\
3 \text { o } 4 \text { palabras } \\
\text {-Sus frases son sencillas } \\
\text { pero compuestas de } \\
\text { sujeto y verbo } \\
\text {-Juega con las palabras y } \\
\text { los sonidos } \\
\text {-Sigue instrucciones de } \\
\text { dos pasos } \\
\text {-Habla sobre el presente } \\
\text {-Dice "palabrotas" }\end{array}$ \\
\hline 4 & $\begin{array}{l}\text {-Sube y baja las } \\
\text { escaleras alternando } \\
\text { los pies } \\
\text {-Salta sobre objetos } \\
\text {-Salta a la pata coja } \\
\text {-Puede copiar } \\
\text { grupos de letras }\end{array}$ & $\begin{array}{l}\text {-Clasifica objetos } \\
\text {-Cuenta } \\
\text { mecánicamente } \\
\text { hasta 5, pero } \\
\text { comprende el } \\
\text { concepto de tres } \\
\text {-Conoce los colores } \\
\text { primarios }\end{array}$ & $\begin{array}{l}\text {-Juega y coopera } \\
\text { con los demás } \\
\text {-Se divierte con } \\
\text { juegos de papeles }\end{array}$ & $\begin{array}{l}\text {-Vocabulario productivo } \\
\text { de unas } 1600 \text { palabras } \\
\text {-Sus oraciones son cada } \\
\text { vez más complejas } \\
\text {-Recuerda historias y el } \\
\text { pasado inmediato } \\
\text {-Comprende la mayoría } \\
\text { de preguntas sobre su } \\
\text { entorno inmediato } \\
\text {-Se basa en el orden de } \\
\text { las palabras para } \\
\text { interpretar las oraciones }\end{array}$ \\
\hline 5 & $\begin{array}{l}\text {-Buen control motor } \\
\text { y buen } \\
\text { conocimiento de su } \\
\text { cuerpo } \\
\text {-Corta la carne con } \\
\text { el cuchillo } \\
\text {-Colorea sin salirse } \\
\text { de las líneas y sus } \\
\text { dibujos son más } \\
\text { fáciles de reconocer } \\
\text {-Escribe palabras } \\
\text { sencillas } \\
\text {-Lateralidad manual } \\
\text { bien establecida }\end{array}$ & $\begin{array}{l}\text {-Observa el } \\
\text { seguimiento de una } \\
\text { regla a lo largo de } \\
\text { una actividad } \\
\text {-Identifica su } \\
\text { izquierda y derecha } \\
\text {-Cuenta hasta 13, } \\
\text { comprende el } \\
\text { concepto de más de } \\
\text { tres } \\
\text {-Acepta la magia } \\
\text { como explicación } \\
\text {-Adquiere los } \\
\text { conceptos } \\
\text { temporales } \\
\text {-Reconoce la } \\
\text { relación entre la } \\
\text { parte y el todo }\end{array}$ & $\begin{array}{l}\text {-Se entretiene con } \\
\text { juegos sencillos } \\
\text {-Selecciona a } \\
\text { compañeros de su } \\
\text { mismo sexo } \\
\text {-Disfruta haciendo } \\
\text { teatro y en } \\
\text { actividades de grupo } \\
\text {-Juega de manera } \\
\text { constructiva y con } \\
\text { un objetivo }\end{array}$ & $\begin{array}{l}\text {-Vocabulario productivo } \\
\text { de unas } 2200 \text { palabras } \\
\text {-Discute sobre los } \\
\text { sentimientos } \\
\text {-Comprende los } \\
\text { términos antes y } \\
\text { después, } \\
\text { independientemente del } \\
\text { orden en que aparezcan } \\
\text { en la oración } \\
\text {-Obedece instrucciones } \\
\text { de tres pasos } \\
\text {-Ha adquirido el } 90 \% \text { de } \\
\text { la gramática }\end{array}$ \\
\hline
\end{tabular}

Tabla 1. Etapa del exhibidor (3-5 años)

Fuente: adaptado de Owens (2003: 94-95) 
Finalmente, la etapa del experto (Owens, 2003: 100-103) se caracteriza por una gran maduración motriz y coordinación de todo tipo de movimientos, así como por la evolución de las capacidades cognitivas. En este sentido, los grandes avances tienen que ver con la capacidad de inferir de la realidad, la descentración y el pensamiento transformacional ${ }^{114}$. Asimismo, el incremento de la atención selectiva y de las capacidades de memoria permiten a los niños procesar y organizar la información de una forma más eficaz, y el desarrollo de las habilidades lingüísticas facilita el uso de estructuras subordinadas y la utilización y comprensión del lenguaje figurado (metáforas, símiles, frases hechas, refranes, etc.). En cuanto al vocabulario, este alcanza las 50000 palabras y refleja el manejo de las reglas para la formación de palabras. Además, en esta etapa los niños aprenden a manipular e influir a los demás a través del uso del lenguaje y se convierten paulatinamente en conversadores eficaces (son, por ejemplo, capaces de introducir nuevos temas, mantenerlos o darlos por terminados). Cuando finaliza esta etapa puede decirse que los niños han adquirido la mayor parte de las habilidades cognitivas y lingüísticas de un adulto.

\begin{tabular}{|c|c|c|c|c|}
\hline $\begin{array}{c}\text { Edad } \\
\text { (años) }\end{array}$ & MOTRICIDAD & COGNICIÓN & SOCIALIZACIÓN & COMUNICACIÓN \\
\hline 6 & $\begin{array}{l}\text {-Tiene una mejor } \\
\text { coordinación motriz } \\
\text {-Lanza pelotas con } \\
\text { habilidad } \\
\text {-Comienzan a salir } \\
\text { los dientes } \\
\text { permanentes }\end{array}$ & $\begin{array}{l}\text {-Se incrementa su } \\
\text { amplitud intencional } \\
\text {-Se distrae menos } \\
\text { con la información } \\
\text { irrelevante de un } \\
\text { problema } \\
\text {-Recuerda y repite } \\
\text { tres dígitos }\end{array}$ & $\begin{array}{l}\text {-Disfruta con los } \\
\text { juegos activos } \\
\text {-Es competitivo } \\
\text {-Se identifica con } \\
\text { los compañeros del } \\
\text { mismo sexo } \\
\text {-Va superando el } \\
\text { egocentrismo }\end{array}$ & $\begin{array}{l}\text {-Vocabulario productivo } \\
\text { de unas } 2600 \text { palabras y } \\
\text { comprensivo de entre } \\
\text { unas } 20000 \text { y } 24000 \\
\text { palabras } \\
\text {-Sus oraciones pueden } \\
\text { ser complejas y suelen } \\
\text { estar correctamente } \\
\text { construidas }\end{array}$ \\
\hline 8 & $\begin{array}{l}\text {-Sus brazos y manos } \\
\text { son muy largos } \\
\text {-Buenas capacidades } \\
\text { manipulativas } \\
\text {-El tamaño de su } \\
\text { cerebro está casi } \\
\text { completo } \\
\text {-Aumenta el número } \\
\text { de dientes } \\
\text { permanentes }\end{array}$ & $\begin{array}{l}\text {-Conoce la } \\
\text { izquierda y la } \\
\text { derecha de los } \\
\text { demás } \\
\text {-Comprende la } \\
\text { conservación } \\
\text {-Detecta diferencias } \\
\text { y similitudes } \\
\text {-Lee de forma } \\
\text { espontánea }\end{array}$ & $\begin{array}{l}\text {-Disfruta teniendo } \\
\text { una audiencia } \\
\text {-Se da cuenta de que } \\
\text { los demás tienen } \\
\text { perspectivas } \\
\text { diferentes } \\
\text {-Muestra lealtad } \\
\text { hacia su pandilla, } \\
\text { pero necesita el } \\
\text { apoyo de los adultos }\end{array}$ & $\begin{array}{l}\text {-Habla mucho } \\
\text {-Hace bromas y } \\
\text { fanfarronea } \\
\text {-Verbaliza ideas y } \\
\text { problemas con facilidad } \\
\text {-Comunica sus } \\
\text { pensamientos } \\
\text {-Tiene pocas dificultades } \\
\text { en las relaciones } \\
\text { comparativas }\end{array}$ \\
\hline
\end{tabular}

114 La descentración se refiere a "la capacidad de tener en cuenta simultáneamente diversos aspectos de un problema en vez de centrarse en uno solo" (Owens, 2003: 100) y el pensamiento transformacional a "la capacidad para considerar un problema físico como algo que tiene lugar en el tiempo, y anticipar de manera eficaz sus consecuencias” (Owens, 2003: 100) 


\begin{tabular}{|l|l|l|l|l|}
\hline $\begin{array}{l}\text { Edad } \\
\text { (años) }\end{array}$ & \multicolumn{1}{|c|}{ MOTRICIDAD } & COGNICIÓN & SOCIALIZACIÓN & COMUNICACIÓN \\
\hline 10 & $\begin{array}{l}\text {-Sus ojos tienen casi } \\
\text { el tamaño adulto } \\
\text {-Sus pulmones y sus } \\
\text { sistemas digestivo y } \\
\text { circulatorio están casi } \\
\text { desarrollados }\end{array}$ & $\begin{array}{l}\text {-Planifica acciones } \\
\text { futuras } \\
\text {-Soluciona } \\
\text { problemas a partir } \\
\text { de escaso apoyo } \\
\text { concreto }\end{array}$ & $\begin{array}{l}\text {-Disfruta con los } \\
\text { juegos, los deportes } \\
\text { y los pasatiempos } \\
\text {-Descubre que } \\
\text { puede ser el objeto } \\
\text { de la perspectiva de } \\
\text { otra persona }\end{array}$ & $\begin{array}{l}\text {-Sigue hablando mucho } \\
\text {-Tiene una excelente } \\
\text { comprensión }\end{array}$ \\
\hline 12 & $\begin{array}{l}\text {-Experimenta un } \\
\text { descanso en el } \\
\text { crecimiento antes del } \\
\text { estirón } \\
\text {-Rápido crecimiento } \\
\text { muscular en cuanto } \\
\text { empieza la pubertad }\end{array}$ & $\begin{array}{l}\text {-Pensamiento } \\
\text { abstracto }\end{array}$ & $\begin{array}{l}\text {-Tiene intereses } \\
\text { diferentes a los del } \\
\text { sexo opuesto }\end{array}$ & $\begin{array}{l}\text {-Vocabulario } \\
\text { comprensivo de unas } \\
50 \text { ono palabras } \\
\text {-Construye definiciones } \\
\text { adultas }\end{array}$ \\
\hline
\end{tabular}

Tabla 2. Etapa del experto (6-12 años)

Fuente: adaptado de Owens (2003: 101)

\subsubsection{Procesamiento del lenguaje: la neurolingüística}

Como hemos visto anteriormente, el desarrollo del lenguaje está íntimamente relacionado con la maduración y la especialización cerebral. El cerebro se compone de dos mitades conocidas como hemisferio izquierdo y hemisferio derecho, divididas a su vez en cuatro lóbulos, cada uno de los cuales desempeña funciones específicas (Kandel, Schwartz y Jessell, 1997):

- El frontal (encargado especialmente de planificar acciones y controlar movimientos).

- El parietal (especializado en el sentido del tacto y la imagen corporal).

- El occipital (se encarga de la visión).

- El temporal (esencial para la audición, la memoria, el aprendizaje y las emociones).

Las diferentes funciones especializadas, como el lenguaje, se distribuyen de manera distinta en ambos hemisferios, de tal forma que se habla de asimetría hemisférica. De manera sintética podemos señalar que el procesamiento del hemisferio derecho es de tipo holístico y en paralelo, mientras que el procesamiento del hemisferio izquierdo es de tipo analítico y a través de secuencias (Witelson, 1987).

Suele decirse que el hemisferio izquierdo es mejor en tareas intelectuales, racionales, verbales, para el procesamiento del ritmo y para el pensamiento analítico o 
matemático. El derecho, en cambio, respondería mejor ante estímulos sensoriales, emocionales, de orientación espacial y para respuestas intuitivas, en las que son esenciales el reconocimiento y la asociación, con procesamiento simultáneo de la información (Marrero Aguiar, 2009: 315).

Las capacidades del hemisferio derecho relacionadas con el lenguaje parecen estar enfocadas a los aspectos receptivos del lenguaje. Incluyen la comprensión y la producción de la prosodia, el lenguaje metafórico, la semántica, entre otros (Shapiro y Danley, 1985). A su vez, el hemisferio izquierdo está especializado en todas las modalidades del lenguaje (oral, visual y escrito) y en el razonamiento lógico ${ }^{115}$ (Mateer, 1983).

Es consabido que el procesamiento del lenguaje comienza con la comprensión. Las señales auditivas se reciben por el tálamo y se remiten al área de la corteza auditiva denominada circunvolución de Heschl. Allí se diferencia entre información lingüística y sonidos irrelevantes, sobre la base del conocimiento adquirido mediante la propia experiencia del individuo. De esta forma, el input lingüístico codificado se envía al lóbulo temporal izquierdo mientras que el input paralingüístico (entonación, énfasis, etc.) se envía al derecho (Gow y Gordon, 1993). En el lóbulo temporal izquierdo se encuentra el área de Wernicke ${ }^{116}$, que procesa la información lingüística con la ayuda de las circunvoluciones angular y supramarginal. Asimismo, la comprensión dependerá de las palabras y los conceptos almacenados en la memoria de cada individuo.

En cuanto al proceso de producción, se parte del área de Wernicke donde se organiza la estructura del mensaje y se transmite a través del fascículo arqueado ${ }^{117}$ hasta el área de Broca ${ }^{118}$, situada en el lóbulo frontal. Desde allí se envían impulsos

\footnotetext{
${ }^{115}$ La organización por hemisferios descrita es la general, pero no todos los cerebros humanos la comparten. Por ejemplo, algunas personas zurdas tienen un predominio del hemisferio derecho para el lenguaje y un reducido porcentaje de la población presenta una actuación lingüística bilateral.

${ }^{116}$ El área de Wernicke se encuentra en la región cortical donde se procesan todos los sonidos (córtex auditivo primario). Debe su nombre al médico alemán Carl Wernicke que descubrió en la década de los setenta del siglo XIX que varios de los pacientes que tenían dificultades para comprender el lenguaje presentaban una lesión en esta parte del cerebro.

${ }^{117}$ El fascículo arqueado lo constituye un haz de fibras blancas que se encuentra situado debajo de la circunvolución angular.

${ }^{118}$ El área de Broca o área motora del lenguaje se encuentra próxima a la zona de la corteza que controla los movimientos de la cara, la lengua y la laringe. Debe su nombre al cirujano francés Paul Broca que descubrió en la década de los sesenta del siglo XIX que las lesiones en esta parte 152
} 
nerviosos a las zonas de la corteza motriz que activan los músculos responsables de la respiración, la fonación, la resonancia y la articulación.

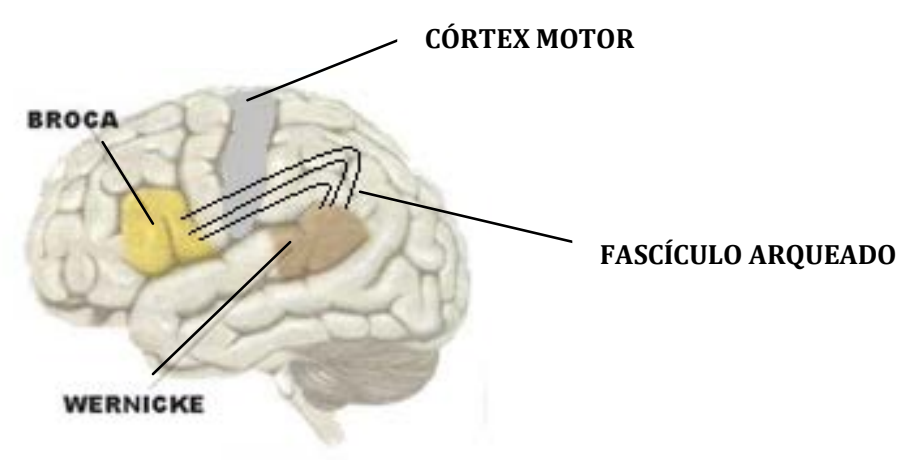

Figura 12. Partes del cerebro

Fuente: adaptado de Geschwind (1991)

Obviamente, dichos procesos son mucho más complejos y hoy en día todavía se desconoce con exactitud cómo se realizan estas funciones múltiples. No obstante, podemos hacernos una idea de cómo los niños no solo aprenden a controlar sus músculos, sino también a manejar su cerebro. A media que los niños adquieren más experiencia y más información, deben organizarla para tener un acceso eficaz a ella.

Según Igoa et al. (2011), la comprensión pragmática de enunciados abarca circuitos neuronales ampliamente distribuidos por la corteza cerebral (lóbulos frontal, temporal y parietal). Dichos circuitos comprenden las áreas asociadas clásicamente al procesamiento del lenguaje en el hemisferio izquierdo, pero también regiones homólogas en el hemisferio derecho, cuyas funciones son todavía objeto de debate.

Tal como señalan León y Escudero (2010), las investigaciones de neuroimagen $^{119}$ sobre el procesamiento del discurso han supuesto un avance primordial en el estudio del lenguaje. De estos estudios se desprende que:

No existe una sola área del cerebro dedicada específicamente al lenguaje, sino que todas estas áreas también están implicadas en otras funciones no lingüísticas

concreta del cerebro estaban relacionadas con una dificultad en la producción del habla. Posteriormente, estas evidencias se han interpretado en el sentido de que el área de Broca desempeña un papel crucial en la producción.

${ }^{119}$ La neuroimagen es una técnica que permite explorar el cerebro humano analizando las variaciones de la actividad funcional de las neuronas en los procesos mentales específicos del ser humano pudiendo relacionar las áreas cerebrales con cualquier pensamiento, emoción, proceso de razonamiento, etc. La actividad neuronal se registra a través de cambios en el flujo sanguíneo o en el metabolismo, y a partir de los datos de la actividad neuronal se dibuja un mapa del cerebro. 
relacionadas con el control cognitivo, memoria, atención, percepción o acción. Estos dos puntos proporcionan un cambio principal en la investigación neurolingüística, reconociendo la necesidad de ir más allá de crear un mapa de funciones cognitivas dentro de la neuroanatomía (mapa cerebral) más hacia una comprensión sistemática del procesamiento de la información neuronal que subyace al lenguaje (León y Escudero, 2010: 112).

En la última década se han realizado numerosos estudios neuropsicológicos en poblaciones de niños (Taga et al., 2003; Thierry et al., 2003; Mills et al., 2005). Mills y sus colaboradores (Mills et al., 1993, 1997) demuestran que, cuando los niños de 1 a 1'5 años se exponen a palabras familiares o nuevas, las diferencias de amplitud de la señal eléctrica en el cerebro son similares en ambos hemisferios. Por el contrario, a los 20 meses de edad, estas diferencias se manifiestan en las regiones temporal y parietal del hemisferio izquierdo, lo cual indica que es alrededor de los 20 meses cuando existe una considerable especialización cerebral en el procesamiento del lenguaje. En un estudio posterior, Mills et al. (2005) sugieren que la familiaridad de cada niño con las palabras es un factor importante en la actividad cerebral durante el procesamiento lingüístico. De esta forma, a mayor vocabulario, mayor incremento en la especialización cerebral frente a palabras familiares.

Asimismo, el daño en cualquiera de las áreas mencionadas (área de Broca, área de Wernicke, fascículo arqueado, etc.) provoca diferentes tipos de trastornos, como los conocidos habitualmente como afasias ${ }^{120}$, que conllevan dificultades para entender o producir formas lingüísticas. Sorprende el hecho de que las lesiones cerebrales causantes de afasia o pérdida del habla en los niños presenten una capacidad de recuperación mucho mayor que la observada en jóvenes o adultos. Los terapeutas del lenguaje han comprobado repetidamente la mejora en los resultados con una intervención temprana, si bien todo ello parece relacionado con el momento de la especialización hemisférica.

120 Para más información sobre las afasias véase Caplan, 1987; Ardilla y Roselli, 1990; Goodglass, 1993; Rondal y Serón, 1995; Cuetos Vega, 1998; Van Hout, 2001, etc. No obstante, de ellas y de otros trastornos de la comunicación hablaremos en el capítulo 4. 


\subsection{APROXIMACIÓN COGNITIVA A LA COMPRENSIÓN PRAGMÁTICA DEL}

\section{LENGUAJE}

En los últimos años, han surgido diversos trabajos sobre trastornos lingüísticos que parten de teorías pragmáticas con orientación cognitiva (Surian et al., 1996; Leinonen y Kerbel, 1999; Leinonen et al., 2003). En particular, la teoría de la relevancia ha sido utilizada con éxito en estudios sobre desórdenes pragmáticos del lenguaje entre los que podemos destacar los trabajos de Happé (1993), Leinonen y Kerbel (1999), Leinonen et al. (2003) y Loukusa (2007). Por ello, tal como señalamos anteriormente, en este estudio hemos decidido tomar la teoría de la relevancia de Sperber y Wilson como marco teórico en el estudio de la compresión pragmática del lenguaje, ya que consideramos sumamente acertada su orientación hacia el plano cognitivo.

\subsubsection{Relevancia: procesos cognitivos y comunicación}

En el primer capítulo de este trabajo ${ }^{121}$ establecimos los principios de la teoría de la relevancia (Sperber y Wilson, 1986/1995). De forma simplificada, la relevancia ha de entenderse en términos de coste y beneficio. El coste viene del esfuerzo de procesamiento requerido y el beneficio de los efectos cognitivos alcanzados. Así, dada la tendencia cognitiva universal de maximizar la relevancia en la comunicación, podemos predecir qué información se activará más fácilmente en la mente del oyente. Esta teoría pragmática ofrece, por tanto, una explicación de cómo el oyente, usando la información contextual disponible, alcanza el significado pretendido por el hablante.

La psicolingüística demuestra que esta propensión del oyente a la búsqueda de la relevancia se produce de forma espontánea también en los niños. En la comunicación diaria estos eligen la interpretación más accesible de los enunciados, aquella que supone menor esfuerzo de procesamiento. De esta manera, podríamos afirmar que el proceso de comprensión pragmática es manifiestamente inferencial y puede definirse, entonces, como "a metapsychological process involving the construction and evaluation of a hypothesis about the communicator's meaning on the basis of evidence she has provided for this purpose” (Sperber y Wilson, 2002: 8).

\footnotetext{
${ }^{121}$ Véase apartado 1.3.
} 
Según la teoría de Fodor (1983) sobre el desarrollo de la mente, se distinguen dos tipos de procesos o sistemas cognitivos: los módulos de entrada y los sistemas centrales ${ }^{122}$. Así pues, la capacidad gramatical se considera un sistema de entrada modular y específico, puesto que opera sobre un tipo de estímulos específicos (los lingüísticos) y su procesamiento sigue pautas específicas y exclusivas que no encontramos en otros subsistemas. Por el contrario, la interpretación pragmática se entiende como un proceso inferencial y, por lo tanto, central, ya que el resultado depende de factores globales como, por ejemplo, el acceso a la información almacenada en la memoria. En efecto, esta segregación entre competencias gramaticales y pragmáticas puede comprobarse en individuos autistas o con síndrome de Asperger ${ }^{123}$, los cuales disponen de una capacidad sintáctica aparentemente normal, pero fallan a la hora de comprender los actos de habla indirectos o las ironías (Escandell Vidal, 2006: 231). En consecuencia, el hecho de que las competencias del ámbito gramatical y las capacidades pragmáticas puedan darse disociadas apoyaría la idea de que constituyen sistemas diferentes.

Ahora bien, Grice $(1957,1969,1989)$ fue el primero en señalar que la interpretación pragmática puede entenderse como un ejercicio de capacidad de lectura de la mente ${ }^{124}$. En términos de atribución de estados mentales, reconocer el significado del hablante equivale a reconocer la intención detrás del comportamiento comunicativo de este. En la misma línea, Sperber y Wilson (2002) también advierten que las habilidades pragmáticas que implican la asignación inferencial de las intenciones del hablante están intrínsecamente relacionadas con las habilidades de lectura de la mente usadas para interpretar las acciones cotidianas. No obstante, en contra de la teoría clásica de Fodor, los autores consideran que ambas habilidades constituyen sistemas cognitivos modulares.

\footnotetext{
${ }^{122}$ Los sistemas de entrada de información se realizan a través de unos procesos cognitivos que están encapsulados, son específicos y se denominan módulos. Estos módulos están localizados en zonas neuronales concretas, tienen un dominio específico y son automáticos. Un módulo reúne, al menos, dos características: opera solo sobre un tipo de información determinado y posee principios de funcionamiento propios. Por su parte, el sistema central tiene carácter global y es el encargado de realizar los procesos cognitivos básicos que permiten almacenar e interpretar la información. Se trata de mecanismos computacionales que procesan la información de forma lenta y voluntaria (Fodor, 1983).

${ }^{123}$ De estos casos hablaremos en el apartado 3.4.

${ }^{124}$ También denominada teoría de la mente y de la cual hemos hablado en el apartado 3.2.2.6. 156
} 
Desde una perspectiva más evolucionada de las propiedades de los módulos de Fodor, Wilson (2003) establece que lo que caracteriza un módulo no son las propiedades que Fodor atribuye a los mecanismos de los sistemas de entrada (rápidos, locales, encapsulados), sino "the presence of dedicated mechanism (typically biological adaptations to regularities in some domain) which cannot be seen as special cases of more general mechanisms operating in broader domains" (Wilson, 2003: 108). Si seguimos la versión clásica de Fodor, la capacidad de lectura de la mente sería catalogada como sistema central, ya que la información que utilizamos para predecir y explicar los estados mentales de otros puede provenir de diversas fuentes y depende de factores globales. Sin embargo, para Wilson (2003), lo importante no es si se trata de procesos globales o locales, sino si son llevados a cabo por mecanismos de uso general o por mecanismos autónomos con un propósito y un dominio específico. Desde este enfoque, la capacidad de lectura de la mente sería un sistema modular, ya que posee un mecanismo inferencial de uso específico y un dominio concreto: el comportamiento intencional. Además, Wilson (2003) refuerza la visión de la lectura de la mente como un sistema modular -en lugar de central - argumentando que hay claras disociaciones entre la capacidad de lectura de la mente y las habilidades generales de razonamiento. Para ello se basa, por ejemplo, en casos proporcionados por pacientes con síndrome de Williams, que tienen buenas capacidades para leer la mente y para la comunicación, pero habilidades de razonamiento muy pobres. O en sentido opuesto: las personas con síndrome de Asperger, que disponen de buenas habilidades de razonamiento, combinadas con serias dificultades para la teoría de la mente.

Dicha argumentación puede aplicarse también a las habilidades pragmáticas, que en este caso son consideradas un submódulo del sistema modular de lectura de la mente, con sus propios propósitos y mecanismos. Así, dada la tendencia cognitiva de maximizar la relevancia, el hablante es capaz de predecir, al menos en cierta medida, cuál es la información que se activará más fácilmente. Desde esta visión, las regularidades descritas en los principios cognitivo y comunicativo ${ }^{125}$ de la relevancia proporcionarán una base adecuada para comprender el mecanismo de la interpretación pragmática como un submódulo dentro del módulo de la teoría de la mente.

${ }^{125}$ Véase apartado 1.3.2. 
En las últimas décadas, numerosos estudios neuropsicológicos respaldan la concepción de la comunicación inferencial como una variedad de la teoría de la mente y ofrecen evidencias de la unión entre ambas (Leslie, 1991; Baldwin, 1991, 1993; Happé, 1993, 1994; Baron-Cohen, 1995; Bloom, 2000, 2002). Del mismo modo, también se han detectado paralelismos entre fallos de las habilidades de lectura de la mente y fallos en las habilidades de interpretación inferencial. Por ejemplo, en su estudio Sigman y Kasari (1995) muestran cómo los niños autistas presentan dificultades en el desarrollo de la teoría de la mente, así como en los actos de comunicación no verbal, como el acto de señalar. De este modo, estos niños confían automáticamente en las asociaciones fijas entre objetos y palabras, en lugar de prestar atención a las intenciones referenciales del hablante o a su mirada.

En su estudio sobre la competencia comunicativa y la teoría de la mente, Happé (1993) realiza un análisis comparativo de la interpretación de metáforas e ironías en niños con desarrollo normal y personas autistas. Los resultados muestran una clara relación entre la comprensión de las metáforas y la habilidad de lectura de la mente de primer orden, así como entre la interpretación de ironías y la habilidad de lectura de la mente de segundo orden. Igualmente, conclusiones similares han sido obtenidas por Langdon, Davies y Coltheart (2002) en su estudio sobre el procesamiento de metáforas e ironías en personas con daños en el hemisferio derecho.

Sperber (1994) propone un marco teórico sobre el cual puede estudiarse la relación entre las habilidades pragmáticas y la capacidad de lectura de la mente. Para ello describe tres estrategias usadas a la hora de interpretar un enunciado, con diferentes niveles de teoría de la mente: el optimismo naíf o ingenuo, el optimismo cauto y el entendimiento sofisticado.

-El optimismo naíf o ingenuo (naïve optimism) es la estrategia más simple. Un oyente de este tipo busca la primera interpretación que parezca lo suficientemente relevante y asume que es la pretendida por el hablante. Además da por hecho que el hablante es competente y benevolente.

-El optimismo cauto (cautious optimism) es una estrategia más compleja. Un oyente de este tipo asume que el hablante es benevolente pero no necesariamente competente. En lugar de conformarse con la primera interpretación aceptable, se cuestiona qué interpretación habrá pensado el hablante para que el enunciado sea lo 158 
suficientemente relevante para el oyente. Así, este nivel superior de teoría de la mente le permite evitar los casos de relevancia accidental (cuando la primera interpretación a pesar de poder ser relevante no es la pretendida) y de irrelevancia accidental (como, por ejemplo, lapsus linguae o errores simples que el optimista cauto puede reinterpretar).

-El entendimiento sofisticado (sophisticated understanding) permite al oyente desenvolverse con la idea de que el hablante puede ser engañoso. En este caso, para identificar la interpretación pretendida, el oyente considera la interpretación que el hablante habrá supuesto que él podría pensar que es la más relevante.

Estas tres estrategias tienen implicaciones en el desarrollo de la comprensión inferencial. Así, los niños parten del optimismo naíf o ingenuo, de forma que en los primeros años cometen errores simples, como, por ejemplo, de desambiguación. A continuación, la evolución de optimismo naíf al cauto coincide, a grandes rasgos, con la adquisición del primer orden de la teoría de la mente, que como vimos al comienzo de este capítulo aparece entre los 3 y los 5 años. Finalmente, el desarrollo de la comprensión sofisticada se relaciona con la aparición de la teoría de la mente de segundo orden y con la habilidad para desenvolverse ante diferentes tipos de engaños, situándose entre los 6 y 7 años. Según Wilson (2003), este desarrollo es particularmente interesante, ya que ofrece evidencias sobre cómo se articula el mecanismo de compresión pragmática en relación con otros submódulos del mecanismo de lectura de la mente.

\subsubsection{Tareas pragmáticas en el proceso de comprensión}

Dado que el lenguaje es a menudo indeterminado, a lo largo del proceso de comprensión de enunciados, el oyente debe llevar a cabo una serie de tareas contextuales o pragmáticas para alcanzar el significado pretendido por el hablante (Luokusa, 2007). Dichas tareas pragmáticas no pueden ordenarse secuencialmente, ya que su procesamiento ocurre en paralelo (Wilson y Sperber, 2004). Sin embargo, sí pueden categorizarse en términos de complejidad contextual (Ryder y Leinonen, 2003). Así, desde el punto de vista de la demanda contextual, la asignación de referentes o el proceso de enriquecimiento de enunciados son procesos considerablemente más sencillos que la interpretación de implicaturas o ironías. A 
continuación expondremos algunas de las tareas pragmáticas que forman parte de la comprensión pragmática del lenguaje.

\subsubsection{Asignación de referentes}

En las teorías semánticas, la referencia se define como "la relación que se establece entre una expresión nominal y el objeto, real o conceptual, al que alude en una situación concreta de habla” (Alcaraz Varó y Martínez Linares, 1997: 491). De esta forma "comprender una frase no consiste simplemente en recuperar significados, sino también en identificar referentes” (Escandel Vidal, 2006: 22). Así, la asignación de referentes de basa en determinar a qué ente concreto (o mejor dicho, a su representación mental) hace referencia una determinada expresión lingüística.

Tal como establecimos en el primer capítulo ${ }^{126}$ de este trabajo, el fenómeno de la deixis constituye la manifestación más clara de la relación entre el lenguaje y el contexto en la estructura de la lengua. Se trata de un fenómeno pragmático que conecta el enunciado con las entidades del contexto (Levinson, 2004). Los deícticos son, por consiguiente, aquellos términos (pronombres, demostrativos, posesivos, muchos adverbios de lugar, tiempo y modo, los morfemas verbales de tiempo y persona, las formas de tratamiento, los elementos anafóricos y catafóricos, etc.) que hacen referencia a los diferentes elementos de la situación. Lo que permite, entonces, comprender dichos términos es el conocimiento compartido de la situación o contexto en que se usan o al que se refieren, junto con el concepto referido (posición, persona o tiempo). Algunas expresiones o términos deícticos señalan aspectos contingentes del acto de habla, dado que también se refieren a elementos de persona, lugar o tiempo dentro del contexto del discurso en el que son empleados. Así, habitualmente se distingue entre deixis endofórica y exofórica. La deixis endofórica remite a la relación de un elemento del texto con otro mencionado en el propio texto, esto es, en el cotexto. Por el contrario, la deixis exofórica se refiere a la relación de un elemento del texto con entidades de su entorno inmediato (tiempo, participantes, lugar,...) o compartido por los interlocutores, es decir, el contexto discursivo.

Con todo, la interpretación de enunciados con elementos deícticos depende de factores extralingüísticos como conocer la identidad del emisor y el receptor, las

\footnotetext{
${ }^{126}$ Véase apartado 1.1.2. 
circunstancias de lugar y tiempo, etc.; de manera que solo a través de una perspectiva pragmática se puede llevar a cabo la interpretación adecuada.

En este sentido, podemos establecer que la deixis es un fenómeno inherente al uso comunicativo de la lengua. Desde muy temprano, los niños comienzan a utilizar gestos que permiten indicar lo que les interesa, dirigir la conducta y la atención de los otros, o señalar objetos o eventos en el espacio. Así, en términos de demanda contextual, la tarea de asignación de referentes es considerada una de las más sencillas dentro del proceso de comprensión pragmática, puesto que, de forma simplificada, la misión del oyente se reduce a localizar el objeto o la persona de referencia dentro del contexto dado. La información contextual es vital, ya que, como hemos señalado, deícticos muy frecuentes en la comunicación como los pronombres no pueden ser interpretados sin tener en cuenta el contexto (Leinonen et al., 2000).

Ahora bien, la adquisición de los elementos deícticos conlleva una serie de dificultades $^{127}$. El aprendizaje de las expresiones deícticas relaciona la adquisición del lenguaje con el desarrollo cognoscitivo, puesto que el niño debe ser capaz de establecer relaciones entre diversas referencias en el espacio o en el tiempo y ser capaz de ponerse en el punto de vista del otro. Son numerosos los estudios sobre la adquisición de las expresiones deícticas. Los trabajos acerca de la situación espacial en lengua inglesa demuestran que los niños de edad preescolar entienden los términos deícticos aquí (here) y allí (there) en relación tanto con la proximidad como con la distancia de la persona que está hablando, y cuando dudan siempre escogen un espacio próximo al locutor (Forrester, 1996). Charney (1979) defiende que los niños saben que allí (there) se refiere a un lugar alejado del locutor y de los otros interlocutores, mientras que aquí (here) se refiere a algo que está cerca de uno mismo o cerca de otras personas $^{128}$.

${ }^{127}$ A pesar de que el aprendizaje de estos elementos se inicia a edades muy tempranas, algunos estudios demuestran que a los 8 o 9 años de edad todavía se observan dificultades con algunas expresiones deícticas más complejas (Karmiloff-Smith, 1983).

${ }^{128}$ Como sabemos, este sistema no es común a todas las lenguas. Feuillet (2006) distingue tipológicamente tres tipos lenguas según la estructura de su deixis espacial:

1. de orientación única (según el hablante)

2. de orientación doble (según el hablante y el oyente)

3. de orientación múltiple (más complejos, tienen en cuenta parámetros como posición, verticalidad, visibilidad y extensión) 
También encontramos estudios centrados en la deixis personal, más concretamente en la reversibilidad pronominal, esto es, la capacidad de pasar del yo al tú. Para que el niño use correctamente los deícticos personales, tiene que llegar a comprender que se refieren a los roles de hablante y oyente. Pine (1995) descubrió que los niños que tienen un hermano mayor utilizan muchos más pronombres personales en sus primeras 100 palabras que los primogénitos. Esto se debe, según Pine (1995), a que oyen con más frecuencia los intercambios de pronombres en su entorno familiar, de forma que se demuestra que la frecuencia por medio de la participación facilita el aprendizaje de la inversión de los pronombres yo y tú.

Por regla general, los elementos personales y espaciales aparecen más tempranamente que los temporales. Es en torno a los 7 y 9 años cuando podemos decir que los niños (que ya usan apropiadamente pronombres y preposiciones) utilizan de forma adecuada y regular términos específicos acerca del tiempo (Clemente, 1995).

\subsubsection{Proceso de enriquecimiento pragmático}

El enriquecimiento pragmático es el proceso que lleva a cabo el oyente, a menudo de forma automática e inconsciente, cuando completa, usando el contexto, la información que no aparece bien especificada en el enunciado. Por ejemplo, si antes de cruzar la carretera una madre les dice a sus hijos "recordad mirar a los dos lados”, los niños tendrán que enriquecer dicho enunciado transformándolo en algo como "cuando vosotros vayáis a cruzar la carretera tenéis que recordar mirar a ambos lados de esta para comprobar que no viene ningún coche” (Loukusa, 2007: 44). Si los oyentes no hicieran esta expansión, no les sería posible entender que tienen que mirar a ambos lados de la carretera.

Parece obvio que la mayoría de los enunciados del lenguaje natural no presentan toda la información necesaria para derivar una representación proposicional. A menudo nos enfrentamos, en palabras de Igoa et al. (2011), al problema de la infradeterminación semántica, lo cual indica que el significado lingüístico de un enunciado escasas veces coincide con su significado proposicional, lo que hace necesario un enriquecimiento adicional. De esta forma, el proceso de enriquecimiento pragmático permite descubrir la forma proposicional, esto es, permite al oyente acceder al significado semántico de la expresión (Sperber y Wilson, 1995). 
A esta proposición enriquecida contextualmente la teoría de Grice $(1957,1975)$ la denomina lo dicho y la teoría de la relevancia de Wilson y Sperber (2002a) — como ya vimos en el primer capítulo-explicatura ${ }^{129}$ :

By 'explicitly communicated content' (or EXPLICATURE), we mean a communicated proposition recovered by a combination of decoding and inference, which provides a premise for the derivation of contextual implications and other cognitive effects (Wilson y Sperber, 2002a: 261).

En el marco de la teoría de la relevancia, el nivel de explicatura no incluye solo lo estrictamente semántico y objeto de descodificación, sino también aspectos pragmáticos del significado que se obtienen por medio de procesos de inferencia a partir del contexto.

Según Portolés (2004), en un enunciado podemos distinguir, entonces, el significado lingüístico o significado codificado, lo explicitado y lo implicado. El significado lingüístico es convencional e independiente del contexto por lo que no puede por sí mismo constituir una proposición. Por el contrario, lo explicitado y lo implicitado son dependientes del contexto y, al menos, proposicionales (Récanati, 2001:76).

Con todo, si nos centramos en la obtención de las explicaturas, se distinguen tres grandes subtareas $^{130}$ :

-la desambiguación (el proceso que nos permite seleccionar el significado apropiado de una palabra o de una construcción gramatical que podría tener más de una interpretación, haciendo uso de la información contextual), -la asignación de referentes (de la cual ya nos hemos ocupado en el apartado anterior),

- y el proceso de enriquecimiento.

Estas tres tareas generalmente se activan automáticamente en nuestro cerebro, de forma que parece que los oyentes no seamos conscientes de la existencia de las otras posibilidades de interpretación que descartamos de manera inconsciente. Estos

${ }^{129}$ El concepto de explicatura ha sido ampliamente desarrollado por autores como Blakemore (1992) o Carston $(1988,2002)$ desde que fuera esbozado en la obra clásica de Sperber y Wilson (1986). También, en el mismo sentido encontramos conceptos semejantes como el de significado enunciativo (Garrido Medina, 1990) o contenido del enunciado (Kaplan 1989).

${ }^{130}$ Esto ya fue tratado en el apartado 1.3.2 de este trabajo. 
procesos responden, por tanto, al principio cognitivo de relevancia ${ }^{131}$. Así, el oyente elige la primera interpretación contextualmente relevante, esto es, la opción que implica menor esfuerzo y da lugar a mayores efectos contextuales, y, a su vez, la más coherente con el supuesto de que el emisor está siendo óptimamente relevante.

\subsubsection{Procesamiento de implicaturas}

En la comunicación diaria, a menudo suele ocurrir que la forma proposicional de un enunciado no es suficiente para alcanzar el significado pretendido por el hablante. En estos casos se requiere un procesamiento extra para recuperar el significado implicado. El oyente ha de recurrir al contexto físico, al conocimiento del mundo, a la información contextual previa, etc. Así, siguiendo el ejemplo de Luokusa (2007: 45), si un hombre está cortando el césped y su mujer le dice "hay flores creciendo en el centro así que recuerda tener cuidado”, el hombre ha de llegar al significado pretendido por su mujer de que no debe cortar las flores. Para ello tiene que combinar su conocimiento del mundo (las flores alegran el jardín y huelen bien, y si pasas el cortacésped por ellas las cortas y mueren) con el contexto físico y verbal ("hay flores en el centro" y "recuerda tener cuidado").

En el primer capítulo ${ }^{132}$ defendimos que en el estudio de la comunicación verbal es preferible adoptar la perspectiva del modelo inferencial de Sperber y Wilson (1995) frente al modelo griceano y expusimos cómo estos autores afinan los conceptos de explicatura e implicatura. La teoría de la relevancia postula que la implicatura de un enunciado es el supuesto o implicación contextual que el emisor ha querido hacer manifiesto al oyente sin expresarlo explícitamente. Las implicaturas, por tanto, requieren un esfuerzo de procesamiento complementario respecto de las explicaturas. Sin embargo, para entenderlas basta con el principio de relevancia: si el procesamiento de un enunciado conlleva un esfuerzo mayor, se espera también una compensación mediante el incremento de los efectos contextuales relevantes que produce. En el proceso de interpretación de implicaturas, el oyente combina la información recibida con los supuestos presentes en su memoria y, como resultado, obtiene una serie de

\footnotetext{
${ }^{131}$ De hecho, aunque en este trabajo hemos presentado por separado las tareas de enriquecimiento y asignación de referentes, también encontramos autores que consideran esta última un subtipo de enriquecimiento pragmático (Récanati, 2002; Portolés, 2004).

${ }^{132}$ Véase apartado 1.3.4. 
efectos contextuales. Asimismo, estos máximos efectos contextuales deben ir acompañados de un esfuerzo de procesamiento mínimo. Consecuentemente, para que el procesamiento sea rápido y fácil, el oyente debe seleccionar entre los supuestos accesibles en su memoria aquellos que constituyan un contexto que, al combinarse con la información recibida, le lleve a la interpretación más relevante.

Con todo, la teoría de la relevancia ofrece un modelo explícito en la construcción de implicaturas, entendidas sencillamente como las premisas y conclusiones contextuales que el oyente incluye en el proceso interpretativo. Como ya señalamos en el primer capítulo ${ }^{133}$, hay dos clases diferenciadas de implicaturas: las premisas implicadas y las conclusiones implicadas. Las premisas implicadas las elabora el oyente, mediante la recuperación del contenido de la memoria enciclopédica o mediante la construcción a través del desarrollo de esquemas de supuestos rescatados de la memoria. Por el contrario, las conclusiones implicadas se deducen como consecuencia lógica de las explicaturas y premisas implicadas del enunciado y del contexto.

Entre las investigaciones más recientes sobre la construcción de implicaturas, cabe mencionar el de autores como Papafragou y Tantalou (2004), que analizan el procesamiento por parte de niños (entre 4 y 6 años) de implicaturas extraídas de enunciados con elementos que hacen referencia a un valor escalar ${ }^{134}$. Los resultados de su estudio ponen de manifiesto la habilidad temprana de los niños para procesar aspectos inferenciales del significado del hablante. De hecho, cuando la información aportada por el hablante no coincide con las expectativas informativas del intercambio conversacional, los niños son capaces de extraer las implicaturas relevantes. Así, si el hablante utiliza un elemento cuantificador como algunos cuando se espera que diga todos, el niño infiere que significa 'no todos’ aunque no se diga explícitamente.

Por su parte, el estudio de Cain et al. (2001) demuestra que los niños que manifiestan problemas en la comprensión de textos encuentran también dificultades a la hora de extraer inferencias que requieren la integración de premisas contextuales y

\footnotetext{
${ }^{133}$ Véase apartado 1.3.4.

${ }^{134}$ Un ejemplo de este tipo de implicaturas se observa en la siguiente interacción:

A: ¿ ¿Te gustan los vinos de California?

B: Me gustan algunos.

De ella se extrae la implicatura: a B no le gustan todos los vinos californianos (Papafragou y Tantalou, 2004: 71).
} 
del conocimiento general. Además, este trabajo concluye que dichas dificultades a la hora de derivar implicaturas no aparecen solo en la comprensión de lectura, sino también en la comprensión auditiva. Los diferentes errores pueden darse a la hora de recordar un ítem del conocimiento base, la premisa correcta del texto o por un fallo a la hora de integrar ambos. No obstante, el error más frecuente viene derivado de la dificultad para elegir la información más relevante.

Finalmente, también es necesario tener en cuenta que la fuerza de las implicaturas puede variar en función del aspecto inferencial y de la familiaridad del enunciado (Wilson, 2000; Wilson y Sperber, 2002b), de ahí que vayamos a diferenciar el procesamiento de implicaturas frente al de rutinas, tarea que veremos a continuación.

\subsubsection{Interpretación de rutinas}

Son numerosos los autores que reconocen que cuando una situación comunicativa es familiar para el niño, la carga inferencial de los enunciados que procesa es menor, ya que tiene la posibilidad de recurrir a rutinas que ya ha interiorizado (Strohner y Nelson, 1974; Hudson y Slackman, 1990; Gillam y Bedore, 2000). Consecuentemente, cuando un niño adquiere la suficiente experiencia en el uso de determinados enunciados en situaciones habituales para él, ya no necesita derivar el significado pretendido por el hablante mediante el proceso contextual, sino que el entendimiento surge de forma rutinaria (Wilson y Sperber, 2002b). Según Loukusa (2007: 45), una de estas situaciones rutinarias podría tener lugar, por ejemplo, cuando una madre llama a sus hijos para que vengan a cenar diciendo: "La cena está lista”. En este ejemplo, los niños no tienen que enriquecer el enunciado ni inferir después, mediante la ayuda del contexto, que si la cena está lista deben dejar lo que están haciendo e ir a la cocina porque si no se enfría. Se trata de un enunciado que oyen frecuentemente, por ello lo han interiorizado y saben que el significado pretendido es que tienen que ir a cenar porque siempre es así.

En su estudio, Nelson (1978) sugiere que la conciencia de las rutinas se desarrolla muy tempranamente. Todos los niños de 4 años que formaron parte de dicho estudio fueron capaces de describir sin dificultad estructuras secuenciales de eventos familiares (comer en casa, en el colegio, en McDonald's) demostrando un buen control 
del conocimiento de rutinas. De esta forma, este estudio entiende el uso de guiones (scripts) ${ }^{135}$ como un factor influyente en la representación mental del conocimiento del mundo en los niños. Por su parte, Hudson y Slackman (1990) descubrieron que niños de 4 y 5 años entendían mejor preguntas basadas en el conocimiento de eventos organizados esquemáticamente que preguntas que requerían inferencias puntuales respecto a la historia que se les iba narrando. Concluyeron, además, que para los niños de 4 y 5 años el conocimiento tiende a ser esquemático, mientras que para los niños de 6 y 7 años este se vuelve más flexible.

En la misma línea, Hudson y Nelson (1986) defienden también que el factor de la familiaridad de las situaciones tiene un gran efecto en los relatos de los niños, tanto en los generales como en los más específicos. Hay una evidencia de que a medida que los niños repiten un evento o experiencia, esta se generaliza. Las conclusiones de este trabajo dan cuenta, además, de una transición desde la memoria episódica a la semántica a medida que aumenta la familiaridad de los eventos ${ }^{136}$.

\subsubsection{Identificación de sentimientos en otros}

Cuando la tarea a la que el oyente se enfrenta es la identificación de los sentimientos de otra persona, también se lleva a cabo un procesamiento contextual a través de la recuperación e integración de información proveniente de diferentes fuentes (Loukusa, 2007). Como ya anunciamos, según Sperber y Wilson (2002), la tendencia cognitiva universal de búsqueda de la relevancia encaja con la idea de anticipar o predecir los estados mentales de los demás. Para Wilson (2000), la habilidad de leer la mente enriquece el proceso de comprensión de tal modo que, por ejemplo, la información sobre el estado de ánimo de las personas influye en la interpretación de sus enunciados.

135 Tal como vimos en el capítulo 1, el concepto de guion (script) se refiere al conjunto de acciones estereotipadas llevadas a cabo en una situación conocida. Consecuentemente, el uso de guiones explica la habilidad de los niños para predecir la estructura de eventos familiares como, en este caso, comer en el comedor del colegio.

${ }^{136}$ Este cambio de la memoria episódica a la memoria semántica ya fue anunciado por Linton (1975, 1982). Linton sugiere que, conforme avanza el tiempo y los episodios de un mismo tipo son experimentados una y otra vez, se construye una representación típica para ese tipo de acontecimientos de forma que se recuerda lo general, pero cualquier especificación precisa de un episodio particular es difícil de recuperar. 
Durante las últimas décadas se ha mostrado mucho interés por el desarrollo en los niños del entendimiento del mundo mental, a menudo relacionado con la teoría de la mente (Flavell y Miller, 1998). Los estudios muestran que ya en los bebés suele aparecer un interés muy precoz por los estímulos relacionados con la expresión de sentimientos. Según Rivière (1996), hacia los 2 o 3 meses los niños comienzan a fijarse en los matices expresivos de los rasgos faciales, y comparten e intercambian expresiones emocionales. A partir del segundo año, el desarrollo emocional alcanza una nueva evolución. A esta edad los niños ya utilizan el lenguaje para inventar emociones que no son verídicas como parte de sus juegos. Sin embargo, no es hasta más tarde (en torno a los 3 y 5 años ${ }^{137}$ ) cuando la habilidad para reflejar emociones se vuelve más precisa y compleja, ya que es en este periodo cuando los niños comienzan a ser conscientes de que las emociones también se pueden controlar o fingir. No obstante, los trabajos sobre adquisición de términos emocionales no han reunido los datos suficientes para definir un patrón de evolución común (Monfort y Monfort Juárez, 2001).

En su estudio, Flavell et al. (2001) examinan las habilidades introspectivas de los niños. Los autores parten de la idea de que hasta los niños más pequeños son capaces de identificar sentimientos cuando hay un estímulo externo, pero tienen muchas dificultades cuando no lo hay. En general, los niños de 4 y 5 años entienden lo que son los sentimientos y que los sentimientos vienen desencadenados por un input externo dado por el contexto de la situación (Saarni, 1999). Por ejemplo, saben que si una persona le hace algo malo a otra, esta se sentirá mal como resultado. Sin embargo, lo que interesa en este estudio es investigar si los niños son conscientes de que los sentimientos pueden ser provocados no solo por circunstancias externas, sino también por pensamientos internos, que un sentimiento generalmente va acompañado de pensamientos acordes o relevantes a ese sentimiento y que las personas pueden modificar sus sentimientos cambiando su estado mental. Los resultados de este trabajo sugieren que el desarrollo de estos aspectos se da en tres etapas de desarrollo. Primero, los niños descubren que los hechos y situaciones provocan sentimientos relacionados con dichos hechos. Por ejemplo, incluso los niños preescolares saben que un hecho

\footnotetext{
${ }^{137}$ Esta franja de edad coincide con el momento en el que los niños son capaces de resolver las tareas de falsa creencia de primer orden, como vimos al comienzo de este capítulo (véase 3.2.2.6). 168
} 
triste provoca un sentimiento triste. Después, los niños aprenden que solo recordando una situación triste del pasado podemos tener un sentimiento triste ${ }^{138}$, reconociendo así una conexión casual entre pensamientos y sentimientos. Y, finalmente, los niños se vuelven sensibles al hecho de que los pensamientos espontáneos pueden generar o venir acompañados de sentimientos. Así, a lo largo de esta evolución, los niños aprenden que los demás también tienen sentimientos y este aprendizaje influye, asimismo, en la tarea de monitorizar y regular sus propios sentimientos.

\subsubsection{Interpretación de la ironía}

Es consabido que la ironía verbal es una forma de crítica encubierta que se utiliza con la intención de provocar un efecto pragmático en el oyente. No obstante, los enunciados irónicos no se caracterizan por contener una estructura lingüística particular. La peculiaridad de la ironía verbal se basa, entonces, en que depende profundamente del contexto en el que se emite y de ciertas señales ostensivas que pueden acompañarla, como por ejemplo una caracterización prosódica determinada ${ }^{139}$ (Padilla, 2005b). Asimismo, los investigadores coindicen en que la ironía es un fenómeno esencialmente pragmático y no semántico —ya que pertenece al ámbito de lo "implicado" por el hablante— y que está relacionado con las normas y expectativas sociales. Dichas expectativas proporcionan la base para evaluar hechos $\mathrm{y}$ comportamientos, por lo general negativos, que justifican el uso de comentarios irónicos (Belinchón, 1999).

Otro aspecto que merece la pena subrayar respecto al fenómeno de la ironía, es su estrecha relación con la teoría de la mente (Happé, 1993) ${ }^{140}$. Como ya

${ }^{138}$ En la misma línea, las investigaciones de Lagattuta (Lagattuta, Wellman y Flavell, 1997; Lagattuta y Wellman, 2001) muestran que los niños preescolares son a veces capaces de detectar vínculos entre pensamientos y sentimientos. Así, entienden que algo que previamente hemos asociado con un suceso triste puede traernos recuerdos y reinstaurar sentimientos de tristeza.

${ }^{139}$ Según Padilla (2005b) la entonación de los enunciados irónicos tiene un carácter enfático en la inflexión final de la curva entonativa, esto es, se caracteriza por un aumento de los hercios del rango característico del hablante. Así, estos rasgos paralingüísticos parecen facilitar la identificación de los enunciados irónicos, aunque dicho rol ha sido debatido por diferentes investigadores del tema (Creusere 1999). Para Keenan y Quigley (1999) este es solo uno de los muchos elementos que permiten el reconocimiento e interpretación de los enunciados irónicos, por lo que no debe entenderse como el rasgo primordial.

${ }^{140}$ Tal como mencionamos al comienzo de este capítulo, en su estudio, Happé (1993) demuestra que los niños autistas que fallan en la tarea de lectura de la mente de segundo orden tienen 
adelantábamos, se ha observado que el rendimiento en la comprensión de ironías depende, entre otras cosas, de la habilidad de lectura de la mente y, en particular, de la capacidad de atribuir estados mentales de segundo orden, así como del control metacognitivo (Champagne-Lavau y Joanette, 2009). En su estudio Creusere (1999) muestra que los niños de 5 y 6 años confunden las ironías con las mentiras piadosas, probablemente porque esta capacidad de metarrepresentar está todavía estableciéndose. Y, en la misma línea, Sullivan et al. (1995) concluyen que la teoría de la mente de segundo orden es un prerrequisito para que los niños discriminen entre bromas irónicas y mentiras.

Ahora bien, para entender el proceso de comprensión de los enunciados irónicos es necesario considerar las diferentes posturas teóricas que dan cuenta de ello. La respuesta tradicional a este interrogante fue presentada por Grice $(1978,1989)$. Grice defiende que la intención irónica se detecta cuando la interpretación literal no encaja en el contexto. Así, consecuentemente, el oyente asigna un significado opuesto a lo expresado literalmente por el hablante. Sin embargo, en la realidad existen muchos ejemplos de ironía que caen fuera de este ámbito de la definición clásica en el que la ironía equivale a decir una cosa y querer decir o implicar lo contrario. Como señala el ejemplo de Belinchón (1999), un oyente podría atacar irónicamente a un pedante que da mucha más información de la solicitada diciendo: “Tú sí que sabes de este tema”. En este caso, el emisor no comunica lo contrario de lo que dice, sino que intenta hacer manifiesto que les está aburriendo con su charla carente de interés. No obstante, el mayor déficit de esta teoría es que no explica por qué el hablante, que teóricamente podría haber expresado directamente el mensaje, opta por decir lo contrario de lo que piensa.

Desde una perspectiva diferente, Sperber y Wilson (1981) defienden que la ironía incluye la habilidad de crear una metarrepresentación ${ }^{141}$. Según la teoría de la relevancia (Wilson, 2006), los enunciados irónicos son interpretaciones de segundo

también más dificultades a la hora de escoger la interpretación no literal de un enunciado irónico en el contexto de una historia.

${ }^{141}$ Sperber y Wilson (1981) explican el fenómeno de la ironía a través de la teoría del usomención. Las expresiones lingüísticas se pueden usar o mencionar. El uso es la representación lingüística de la realidad extralingüística, mientras que la mención es la metarrepresentación de otra representación. Así, el hablante irónico no expresa su actitud hacia el contenido de la expresión lingüística sino hacia la enunciación misma. 
grado del pensamiento de otra persona. Estas interpretaciones alcanzan la relevancia informando al oyente del hecho de que el hablante tiene en mente lo que tal persona dijo o algo que sucedió, y tiene una determinada actitud hacia ello. Así, la interpretación del hablante del pensamiento de esa persona es en sí misma relevante y se considera un caso de interpretación de eco (Sperber y Wilson, 1995: 238). Consecuentemente, para estos autores, la ironía verbal supone la expresión implícita de una actitud y, por tanto, la relevancia de un enunciado irónico dependerá de la información que transmite sobre la actitud del hablante respecto a la opinión de la que se hace eco. La actitud que se expresa en un enunciado irónico es de rechazo o desaprobación, de forma que el hablante se separa de la opinión a la que alude indicando que no la respalda (Jorgensen, Miller y Sperber, 1984). En el ejemplo propuesto por Sperber y Wilson (1995:239), un hombre dice que hace un día precioso para ir de excursión, van y llueve. Consecuentemente, la mujer le dice: "Sí, es verdad, hace un día precioso para ir de excursión”. En este ejemplo la mujer cree, obviamente, que no es un buen día para ir de excursión, pero además de su enunciado pueden extraerse implicaturas como que el hombre ha cometido un error, que su juicio ha sido equivocado y que no deberían haber salido de casa. En resumen, esta teoría sostiene que en el procesamiento de los enunciados irónicos, lo característico es la mención, por parte del hablante, de un hecho del que pretende tomar distancia para expresar una actitud crítica hacia él. Por tanto, con el empleo de la ironía, el hablante se sitúa en un plano metalingüístico.

Según Sperber y Wilson (1998), además del enunciado ajeno inmediato (eco explícito), el hablante puede ecoizar deseos, normas generales y pensamientos anteriores en el tiempo (eco implícito). Por lo tanto, puede ocurrir que el enunciado no tenga una fuente de eco obvia, sino que esta sea un pensamiento imaginado, una norma social, expectativas o deseos positivos generales ${ }^{142}$.

Ahora bien, aunque esta teoría es una de las más plausibles ${ }^{143}$ a la hora de explicar el procesamiento de la ironía, también ha sido criticada por ser demasiado

\footnotetext{
${ }^{142}$ En el trabajo de 1981, Sperber y Wilson defienden que todos los enunciados irónicos son casos de mención ecoica. Sin embargo, en la obra de 1986/1995, sustituyen este término por el de interpretación ecoica, que incluye las fuentes explícitas e implícitas del eco.

${ }^{143}$ En el ámbito de la psicología, han surgido también teorías que intentan explicar el fenómeno de la ironía desde diferentes perspectivas. La teoría de la pretensión (Clark y Gerrig, 1984) sostiene que la ironía es una forma de acto comunicativo en el que el hablante pretende ser una
} 
restrictiva. Autores como Berrendonner (1987) consideran que es insuficiente, ya que no distingue entre las diversas formas de mención y, por lo tanto, no representa la especifidad de la ironía, y Ruiz Gurillo et al. (2004) señalan que hay casos en los que el recordatorio ecoico no es tan evidente. En efecto, la noción de eco implícito es problemática, ya que su fuente es abstracta, de ahí que diferentes autores propongan solucionar este problema sustituyendo el término eco por otros más precisos como recuerdo (reminder) o alusión (allusion) (Kreuz y Glucksberg, 1989; KumonNakamura et al., 1995; Utsumi, 2000).

Asimismo, cabe resaltar que, a pesar de que estas teorías intentan explicar el proceso de interpretación de los enunciados irónicos, no profundizan en cómo adquieren los niños esta capacidad ni tampoco en qué periodo de la adquisición lingüística son capaces de comprender la ironía. Según Pexman y Glenwright (2007), la habilidad para comprender la ironía comienza a los 6 años, y continúa desarrollándose hasta los 12 o 13 años. Para Nippold (1998), dicha capacidad se desarrolla durante la edad escolar y la adolescencia (entre los 6 y los 18 años), por lo que puede considerarse parte del desarrollo tardío del lenguaje. Para otros autores como Ackerman (1986) y Capelli et al. (1990) en los primeros años de la edad escolar ya existen evidencias de comprensión de enunciados irónicos. Estas divergencias, en opinión de Creusere (1999), se deben al uso de diferentes materiales y diferentes métodos en los estudios experimentales.

Nakassis y Snedeker (2002) consideran que los niños de 10 años en adelante pueden procesar formas más sutiles de ironía, mientras que los más pequeños (de 5 o 6 años) tienen un entendimiento más limitado, pero aun así son capaces de comprender algunos enunciados irónicos más sencillos, de forma que no estamos ante un fenómeno de todo o nada, sino ante un continuum.

En su estudio, Bara, Bosco y Bucciarelli (1999) defienden que la capacidad para comprender y producir expresiones irónicas pasa por dos estadios. En el primero, los niños dominan las expresiones irónicas del tipo “una persona dice $p$ para intentar decir

persona invisible que se dirige a una audiencia desconocida. Cuando el oyente reconoce la pretensión del hablante, entiende su actitud negativa sin procesar el significado literal del enunciado. Otro planteamiento es defendido por Kumon- Nakamura et al. (1995), que sugieren que el recordatorio ecoico es solo un tipo de alusión. Según esta teoría, la ironía puede ser comunicada en cuatro modos además de los asertivo-contrafacturales: aserveraciones verdaderas, preguntas, ofrecimientos y solicitudes exageradamente amables.

172 
no-p” y en el segundo, los niños manejan inferencias más sutiles en las que está involucrada una habilidad metarrepresentacional.

Por su parte, Crespo et al. (2007) analizan el desarrollo de la comprensión oral de enunciados irónicos en niños de 5 a 13 años, con el objetivo de describir el grado de comprensión de las ironías en las diferentes edades, así como descubrir qué tipo de enunciados irónicos son más fáciles o más difíciles de comprender. Los resultados demuestran que, como era esperable, a medida que se incrementa la edad, aumenta la capacidad de comprender ironías, aunque esta comienza a desarrollarse en la edad escolar y no antes. Además, en lugar de hablar de periodos o edades críticas bien diferenciadas, los autores proponen fases de desarrollo que se solapan unas con otras. Finalmente, en cuanto al tipo de enunciado, los más fáciles de comprender por los niños participantes en el estudio son los enunciados contrafactuales (en los cuales lo que se expresa es lo contrario de lo que se quiere decir o se espera que sea dicho en un contexto concreto) y los más difíciles las preguntas irónicas, ya que lo más probable es que los niños las confundan con peticiones indirectas (Escandell Vidal, 1998; Belinchón, 1999).

Pexman y Glenwright (2007) señalan que existen tres aspectos de un enunciado que el niño debe entender para poder reconocerlo como irónico: la actitud del emisor, su intención de hacer bromas y la incertidumbre de si el emisor cree en lo que dice. Esto lo adquiere el niño a través de su socialización. Por ejemplo, cuando el niño escucha un enunciado irónico (no literal) y sus padres le dicen algo como "estaba bromeando, no iba en serio”, el niño aprenderá a reconocer la ironía siguiendo el modelo de los adultos.

Los estudios experimentales sobre el procesamiento de ironías muestran que el acceso al significado implicado en los enunciados irónicos supone un tiempo adicional de procesamiento en comparación con el significado literal (Bottini et al., 1994). Giora (1995) defiende que la comprensión inferencial del significado irónico requiere el procesamiento previo del significado literal, es decir, este se mantiene para que el desajuste entre el sentido literal y el sentido implícito pueda generar la implicatura final. Consecuentemente, este hecho tiene repercusiones en el tiempo que se necesita para entender la ironía, que tiende a ser más largo. Así, la comprensión de la ironía “se apoya en procesos más lentos y controlados de inferencia pragmática que son, además, 
dependientes del contexto y ponen en juego habilidades cognitivas de índole más compleja” (Igoa et al., 2011: 127). Giora y Fein (1999) demostraron que los sujetos de su experimento activaban el significado literal en torno a 150 milisegundos antes que el significado irónico cuando se trataba de ironías no familiares. Por el contrario, en el caso de las ironías familiares el tiempo era el mismo, ya que se trataba de ironías estereotipadas.

Finalmente, por lo que respecta a la evidencia neurolingüística del procesamiento de la ironía, el estudio de Wakusawa et al. (2007) muestra que los juicios sobre la adecuación de la ironía a situaciones sociales están correlacionados con la activación del córtex frontal medial del hemisferio izquierdo, mientras que los juicios relativos al significado literal de los enunciados se asocian a la activación del polo temporal del hemisferio derecho y el córtex órbito frontal medial. Estas regiones intervienen también en las tareas relacionadas con la teoría de la mente, lo cual apoyaría la idea de que la comprensión de los enunciados irónicos está relacionada con la habilidad de lectura de la mente.

En su investigación, Shamay-Tsoory et al. (2005) advierten que el procesamiento de la ironía está condicionado por el aprendizaje social. Así, los pacientes que poseen dañados los lóbulos frontales (responsables de la cognición social) no solo tienen problemas en el comportamiento social, sino que también son incapaces de llevar a cabo funciones cognitivas como predecir el significado no literal.

\subsubsection{Estudios experimentales previos}

A lo largo de este último apartado hemos hecho referencia a estudios realizados sobre diferentes aspectos del desarrollo de la comprensión pragmática. Todos estos trabajos tienen en común que analizan el uso por parte de los niños de la información contextual en el procesamiento del lenguaje a través de diversas habilidades pragmáticas. A estos podríamos añadir también, por ejemplo, el desarrollo de rutinas a través de guiones (Nelson, 1978), el desarrollo de inferencias (Eson y Sapiro, 1982; Hudson y Slackman, 1990), el desarrollo de la teoría de la mente (O’Neill, 1996; Bezuidenhout y Sroda, 1998), el desarrollo de las estrategias de comprensión (Marinac y Ozanne, 1999), etc. 


\begin{tabular}{|c|c|c|}
\hline $\begin{array}{l}\text { CONDUCTAS } \\
\text { PRAGMÁTICAS }\end{array}$ & $\begin{array}{l}\text { EDAD APROXIMADA } \\
\text { DE EMERGENCIA }\end{array}$ & FUENTE \\
\hline $\begin{array}{l}\text { Mantener el tema en la } \\
\text { interacción con un adulto }\end{array}$ & Desde 2 años & Ervin-Tripp, 1979 \\
\hline Hacer aclaraciones & Desde 2 años & $\begin{array}{l}\text { Gallagher, 1977; Ferrier et } \\
\text { al., } 2000\end{array}$ \\
\hline $\begin{array}{l}\text { Adaptarse al estilo de habla } \\
\text { del interlocutor }\end{array}$ & Desde 2 años & Dunn y Kendrick, 1982 \\
\hline $\begin{array}{l}\text { Utilizar formas corteses } \\
\text { tempranas }\end{array}$ & Desde 2 años & Bates et al., 1979 \\
\hline $\begin{array}{l}\text { Responder a peticiones de } \\
\text { información no específicas }\end{array}$ & 2 años & Yont et al., 2000 \\
\hline $\begin{array}{l}\text { Inventario de actos } \\
\text { comunicativos básicos } \\
\text { consolidado }\end{array}$ & 3-4 años & $\begin{array}{l}\text { McTear y Conti-Ramsden, } \\
1992\end{array}$ \\
\hline $\begin{array}{l}\text { Inferir información de una } \\
\text { historia }\end{array}$ & 3-4 años & Paris y Upton, 1976 \\
\hline Inferir significados indirectos & 4-6 años & Eson y Shapiro, 1982 \\
\hline $\begin{array}{l}\text { Disminución de los lapsos en } \\
\text { la interacción }\end{array}$ & 5 años & Dewart y Summers, 1995 \\
\hline $\begin{array}{l}\text { Habilidades metapragmáticas } \\
\text { presentes }\end{array}$ & 6-7 años & $\begin{array}{l}\text { Andersen-Wood y Smith, } \\
1997\end{array}$ \\
\hline $\begin{array}{l}\text { Uso adecuado de la referencia } \\
\text { anafórica }\end{array}$ & 6-7 años & Karmiloff-Smith, 1985 \\
\hline $\begin{array}{l}\text { Relevancia informativa } \\
\text { consolidada }\end{array}$ & 9 años & Lloyd et al., 1995 \\
\hline $\begin{array}{l}\text { Formas corteses desarrolladas } \\
\text { por completo }\end{array}$ & Desde 9 años & $\begin{array}{l}\text { McTear y Conti-Ramsden, } \\
1992\end{array}$ \\
\hline $\begin{array}{l}\text { Disminución de los errores de } \\
\text { cohesión y referencia }\end{array}$ & 9-12 años & Ripich y Griffin, 1988 \\
\hline Explicación de modismos & Hasta los 17 años & Spector, 1996 \\
\hline
\end{tabular}

Tabla 3. Desarrollo de conductas pragmáticas por edades aproximadas

Fuente: adaptado de Adams (2002: 975)

En el campo de la evaluación pragmática y los trastornos de la comunicación, a los cuales dedicaremos el siguiente capítulo, Adams (2002) recoge una interesante selección de estudios dedicados al desarrollo de diversos aspectos de naturaleza 
pragmática que señalan la edad aproximada de adquisición. No obstante, la propia investigadora advierte que las edades deben entenderse con cierta flexibilidad (véase tabla 3).

La mayoría de los trabajos recopilados en esta tabla provienen del área de investigación sobre las patologías del lenguaje o de estudios contrastivos entre niños con desarrollo normal y niños con algún déficit de la comunicación. Además, cada estudio utiliza sus propios métodos, por lo que es difícil establecer conclusiones generalizables.

Ahora bien, además de estas fructíferas investigaciones sobre diferentes aspectos pragmáticos de la comprensión del lenguaje, tal como expusimos en el primer capítulo, es necesario hacer referencia también a los estudios sobre los actos de habla, uno de los fenómenos pragmáticos más analizados en la bibliografía clásica. No obstante, la investigación en torno a la adquisición de los actos de habla comunicativos presenta varios problemas. Algunos de ellos son metodológicos como, por ejemplo, los relacionados con la trascripción del lenguaje y el análisis pragmático. Entre otras dificultades destaca que la mayoría de los estudios utilizan muestras pequeñas de informantes, lo que no hace del todo fiable su generalización. Asimismo, algunos fueron diseñados para niños muy pequeños (Dore, 1974; Halliday, 1975; Bates et al., 1979; McShane, 1980) de tal manera que su comparación con otros que utilizan niños de mayor edad y sistemas comunicativos más complejos se hace difícil. Además, aquellas investigaciones mejor fundamentadas teóricamente se suelen centrar en un subconjunto (Keenan en 1977 estudió solo las repeticiones; Garvey en 1975, solo peticiones de acción; Ninio y Bruner en 1978, solo las rutinas de lectura, etc.), por lo que no pueden tomarse como referencia para extraer conclusiones de las habilidades pragmáticas generales de los niños.

Por lo común, los datos sobre el desarrollo del lenguaje infantil suelen recogerse a través de dos vías: la observación natural de conversaciones espontáneas o la manipulación experimental en situaciones estructuradas de antemano (Owens, 2003). Así, las características y limitaciones de cada una influirán en cómo se describe el lenguaje. Los resultados de los estudios con test y experimentos son más fiables, pero no pueden generalizarse y su validez es limitada, ya que están restringidos a la tarea específica que se ha diseñado para provocar determinadas conductas lingüísticas. 
Por el contrario, el estudio de conversaciones espontáneas es más fiable, aunque presenta otros problemas, como la gran dificultad a la hora de controlar todas las posibles variables que pueden influir en la actuación de los niños. Según Wells (1985), lo idóneo sería, entonces, emplear ambos procedimientos para obtener más información y de una forma menos sesgada.

Por lo que respecta a la recogida de datos, existen diversas técnicas con listas de palabras, informes de los padres o tutores, grabaciones de voz o de vídeo, etc. Algunas pueden ser más útiles para el estudio del desarrollo semántico o morfológico, como las listas de palabras o los diarios de los padres (Marchman y Bates, 1994); pero si queremos un análisis más profundo es necesario recurrir a tecnología más avanzada con las grabadoras de vídeo o de voz. Si bien es cierto que ambas ofrecen la ventaja de que las interacciones pueden observarse las veces que sea necesario, el vídeo puede resultar más completo que solo el audio, ya que recoge también aspectos del lenguaje no verbal y del contexto de la situación comunicativa.

Asimismo, las nuevas tecnologías facilitan la clasificación de los datos en soportes electrónicos, con nuevos métodos para tratarlos y describirlos. Hoy en día es posible obtener datos sobre el lenguaje infantil a través del sistema CHILDES ${ }^{144}$ (Child Language Data Exchange System), que almacena transcripciones e incluye programas informáticos y herramientas para vincular la transcripción a un sistema multimedia. Según Fernández Pérez (2011), el nuevo paradigma de la lingüística basada en los usos reales ha llevado al cambio en las técnicas y los modos analíticos. Las interacciones infantiles se han convertido en la fuente principal de datos de cómo hablan los niños. Así, para llevar a cabo el análisis de estos datos, señala Fernández Pérez (2011), se han desarrollado métodos referentes a la creación y gestión de corpus. Dichos corpus ofrecen grandes ventajas, ya que constituyen un inventario de emisiones lingüísticas producidas por niños transcritas y etiquetadas según los rasgos relevantes. Consecuentemente, los corpus de lenguaje infantil han propiciado el desarrollo de numerosas investigaciones empíricas sobre la adquisición de lenguas.

Finalmente, en cuanto a las bases teóricas, son varios los estudios que han confirmado en la práctica los postulados de la teoría de la relevancia (Van der Henst et

${ }^{144}$ CHILDES (http://childes.psy.cmu.edu/dat) ofrece datos de adquisición de 33 lenguas así como datos de desarrollo bilingüe en 20 corpus. En español hay 18 bancos, entre ellos el corpus Koiné (véase nota 95). 
al., 2002; Leinonen et al., 2003; Van der Henst y Sperber, 2004). La teoría de la relevancia se ha tomado como base en diferentes estudios pragmáticos referidos a la adquisición del lenguaje (Bezuidenhout y Sroda, 1998; Foster-Cohen, 2000, 2004), a la enseñanza de segundas lenguas (Wolf, 1999; Zegarac, 2004) o a los déficits lingüísticos (Leinonen y Kerbel, 1999; Happé, 1993). Asimismo, los estudios relacionados con el desarrollo o los déficits de la competencia pragmática muestran que dichas habilidades pragmáticas están conectadas con funciones cognitivas como la inferencia (Leinonen et al., 2003) y la teoría de la mente (Happé, 1993; Papp, 2006), y que el conocimiento del mundo y las experiencias desempeñan un papel fundamental en la interpretación de los enunciados. 


\section{CAPÍTULO 4}

\section{DÉFICITS EN LA COMPETENCIA PRAGMÁTICA}

\subsection{AVANCES EN PRAGMÁTICA CLÍNICA}

En este capítulo no pretendemos profundizar en aspectos técnicos clínicos, sino dar cuenta de la importancia de la pragmática en el estudio de los trastornos lingüísticos. Somos conscientes de que el ámbito de las patologías del lenguaje es claramente multidisciplinar, lo que hace necesario la conjugación del enfoque neuropsicológico, logopédico y lingüístico (con especial hincapié en las aportaciones de la disciplina pragmática).

En general, el interés lingüístico de las limitaciones en la habilidad del lenguaje no se ha reconocido en toda su pertinencia hasta hace pocos años. Tal como señala Fernández Pérez (1999), en el caso concreto de España:

Los problemas lingüísticos reales como los trastornos y déficits en la habilidad del lenguaje no han sido tratados con rigor y precisión en su pertinencia desde el prisma lingüístico. Urge, pues, empezar a ocuparse de las deficiencias comunicativas desde la perspectiva lingüística (Fernández Pérez, 1999: 633).

Actualmente se hace necesario que las teorías lingüísticas se legitimen a través de sus posibilidades de aplicación. Consecuentemente, la lingüística aplicada no debe volcarse únicamente en la enseñanza de lenguas extranjeras ${ }^{145}$, ya que posee un campo de estudio mucho más rico y extenso. Tal aplicación supone, según Gallardo Paúls (2002a), la interdisciplinariedad entre la lingüística y otros discursos científicos. De hecho, dentro de esta interdisciplinariedad, uno de los campos más interesantes es el ámbito de los trastornos del lenguaje, en el que convergen, como ya hemos avanzado, áreas como la lingüística, la neurología y la logopedia.

Ahora bien, como era de esperar, la descripción del déficit lingüístico no puede limitarse a la competencia gramatical, sino que también deben tenerse en cuenta otros

\footnotetext{
${ }^{145}$ Es consabido que la eclosión de la disciplina pragmática influyó notablemente en el modo de concebir la enseñanza de segundas lenguas, poniendo el énfasis en las actividades comunicativas y el uso del lenguaje en contexto, y desplazando así al enfoque gramatical.
} 
aspectos. Los trabajos de neurología y neuropsicología analizan algunos casos clínicos y llegan a concluir que el paciente posee una habilidad lingüística normal pero presenta déficits en otros ámbitos como las inferencias (esto es, problemas para interpretar chistes, captar ironías o indirectas, etc.), la gestión de la conversación, el establecimiento de relaciones sociales en la interacción comunicativa. Aunque en principio esto parezca una contradicción, se puede explicar debido a la tradicional equiparación de la capacidad lingüística con la capacidad gramatical. Según Gallardo Paúls (2007), esta identificación se debe, entre otras causas:

a. al desarrollo de la afasiología a partir de las clásicas distinciones de lesiones del hemisferio izquierdo;

b. al hecho de que la propia lingüística, dominada por el generativismo, ignora el componente pragmático hasta década de los 60;

c. a la radicalización de la interpretación modularista fodoriana.

Efectivamente, estos motivos están recogidos en la bibliografía clínica que intenta explicar por qué la disciplina pragmática no ha alcanzado el estatus de aceptabilidad propio de otras disciplinas (Manochiopining, Sheard y Reed, 1992; Penn, 1999). Así, tal como reconoce Moreno Campos (2010), los enfoques clásicos localizacionistas han defendido durante mucho tiempo la relación del lenguaje con el hemisferio izquierdo, dejando de lado la importancia del hemisferio derecho ${ }^{146}$, cuyas lesiones identificadas con el déficit pragmático han sido estudiadas con cierta imprecisión. Además, en cuanto al proceso de evaluación pragmática, este ha supuesto mayores obstáculos debido a que las categorías pragmáticas son más difíciles de identificar y clasificar. Penn (1999) defiende que la evaluación pragmática debe ser multidimensional para poder explicar la variación de la comunicación en diversos contextos. Consecuentemente, esto supone un obstáculo extra a la hora de establecer objetivos y diseñar pruebas de evaluación.

Hoy se sabe que, aunque la habilidad gramatical no esté visiblemente dañada, puede haber un déficit lingüístico debido a alteraciones de la capacidad pragmática. Aunque la incorporación de la pragmática al ámbito de la logopedia y los trastornos

\footnotetext{
${ }^{146}$ Chantraine, Joanette y Ska (1998) atestiguan también la escasez de publicaciones en torno al estudio del hemisferio derecho y las habilidades conversacionales. 
del lenguaje puede verse ya en trabajos como los de Carol Prutting y Diane Kirchner (1983), Ginnie Green (1984), Dorothy Bishop y Catherine Adams (1989) o Audrey Holland (1980), habrá que esperar hasta la década de los 90 para poder hablar de la eclosión de la pragmática clínica ${ }^{147}$. En este momento los autores comienzan a identificar el hemisferio derecho con la competencia pragmática $-\mathrm{y}$ comunicativa en sentido amplio— - y a asociar las dificultades en la interpretación adecuada del lenguaje no literal con las lesiones en dicho hemisferio.

De nuevo, surge el problema en torno a la definición del concepto de pragmática. Si entendemos la pragmática como una disciplina al mismo nivel que la semántica y la sintaxis, se adopta la postura denominada por Gallardo Paúls (2007) pragmática cognitiva, que incluye la teoría de la relevancia de Sperber y Wilson (1986/1995). Como vimos, esta teoría da una importancia primordial a los procesos inferenciales, que no se consideran exclusivos del sistema lingüístico y se apoyan en la teoría de Fodor (1983) sobre la modularidad de los procesos cognitivos. Como ya establecimos, el problema es que la teoría de Fodor a veces se aplica de forma muy radical, entendiendo que entre los módulos hay una independencia absoluta, lo que supone que los sistemas de entrada no intercambian información entre ellos ni con los procesos centrales. La neuropsicología cognitiva reinterpreta esta concepción entendiendo que la gramática constituye un módulo que a su vez tiene su propia organización modular interna, de forma que los distintos componentes son módulos independientes. Según Monfort et al. (2004), la pragmática es menos modular que la fonología o la sintaxis y, por tanto, puede resultar más influida por otros dominios del desarrollo, sobre todo a nivel cognitivo y emocional.

En el proceso de difusión de la pragmática clínica, cabe señalar también el hecho de que en los últimos años hayan proliferado revistas científicas en las que la presencia de la pragmática tiene un papel esencial, tales como Brain and Language, Clinical linguistics \& Phonetics y Seminars in Speech Language. En ellas se encuentran trabajos que parten de planteamientos lingüísticos o que formulan iniciativas terapéuticas o pruebas de evaluación basadas en elementos pragmáticos. Asimismo, la

\footnotetext{
${ }^{147}$ Entre la bibliografía centrada en el enfoque pragmático de las patologías del lenguaje destacan Clinical Pragmatics, de Smith y Leinonen publicado en 1992; Pragmatics: theoretical and clinical issues, editado en 1999 por Stemmer y el artículo de Conti-Ramsdem y McTear (1989) titulado "La investigación pragmática” dentro de la miscelánea Linguistics in clinical practice.
} 
pragmática clínica ya aparece como entrada en enciclopedias lingüísticas como Handbook of Pragmatics (Verschueren y Östman, 2006) o The Pragmatics Encyclopedia (Cummings, 2009a).

Frente al protagonismo clásico del hemisferio izquierdo en las patologías del lenguaje, autores como Barroso y Nieto (1996) recogen las observaciones de varios especialistas en torno a la importancia del hemisferio derecho en la actividad verbal y concluyen que es fundamental "para el procesamiento léxico-semántico y para una adecuada relación lenguaje-contexto" (1996: 285). Estos autores, partiendo de la bibliografía existente sobre el tema, enumeran una lista de tareas en las que interviene el hemisferio derecho tales como la interpretación de actos de habla indirectos, la inferencia de implicaturas, la interpretación correcta de ironías, metáforas y sentidos no literales y la organización e interpretación de un texto. En definitiva, los pacientes con lesiones en el hemisferio derecho presentan factores afectados propios de diferentes niveles pragmáticos: actos de habla directos e indirectos, implicaturas conversacionales, deixis, dominio de las aperturas y cierres conversacionales, etc. En concreto, el subnivel pragmático denominado por Gallardo Paúls (1996) pragmática receptiva surge de la concepción del acto enunciativo como reacción a otro acto enunciativo previo emitido por otro interlocutor y, según la autora, es compatible con la teoría de la mente. Así, Obler y Gjerlow (2001) señalan que "los niños, después de una determinada edad, desarrollan una sensibilidad a propósito de lo que sus interlocutores conocen y lo que no" (2001: 114).

Recientemente, el aumento progresivo de la bibliografía que estudia las lesiones del hemisferio derecho ha llevado a considerar que ambos hemisferios participan de manera igualmente relevante en el procesamiento del lenguaje (Obler y Gjerlow, 2001). Por su parte, autores como Zaidel, Kasher, Soroker y Batori (2002) concluyen que el hemisferio izquierdo interviene también en el procesamiento de ciertas categorías pragmáticas. En esta línea, Gallardo Paúls (2002b) defiende la utilidad del uso de categorías pragmáticas en las ramas de neuropsicología o logopedia que analizan las alteraciones comunicativas, ya que, por un lado, las lesiones en el hemisferio derecho pueden suponer alteraciones en las categorías pragmáticas y solo a través del estudio global y la sistematización pueden diagnosticarse las patologías. Y, 
por otro lado, la rehabilitación de lesiones en el hemisferio izquierdo se mejora con la potenciación de capacidades verbales pragmáticas, propias del hemisferio derecho.

Ahora bien, aunque la incorporación de la pragmática en las patologías del lenguaje ha supuesto un gran avance, los estudios presentan grandes discrepancias en los resultados, debido, en su mayor parte, a una serie de problemas en la investigación. En algunos trabajos no queda claro si se están estudiando actos de habla —en el sentido pragmático - o habilidades sociales; la selección de sujetos y tareas varía sustancialmente de unas investigaciones a otras; en general no se controla el grado de comprensión del lenguaje ni la cognición social —variables que, según Johnson (1988), deben constituir el control más pertinente—; etc. No obstante, en estudios posteriores se está tratando de resolver estos problemas. Para ello, la pragmática se concibe desde modelos teóricos de mayor alcance, se intentan integrar las distintas dimensiones del lenguaje superando la estricta modularidad inicial y se pretende dar solución a algunos problemas metodológicos (Mendoza Lara, 2001).

Asimismo, una de las críticas más frecuentes sobre los estudios de pragmática clínica es su difícil cuantificación y, por consiguiente, la escasez de datos concretos que se puedan contrastar o analizar a través de un análisis estadístico. Sin embargo, en los últimos años han surgido buena parte de estudios experimentales de base pragmática que dan muestra de su gran potencial para un futuro desarrollo, tal como reconocen Noveck y Sperber (2007):

Although a few pioneers in psycholinguistics had, for more than twenty years, approached various pragmatic issues experimentally, it is only in recent years than investigators have begun employing experimental methods in order to test pragmatics hypotheses. We see this emergence of a proper experimental pragmatics as an important advance with a great potential for further development (Noveck y Sperber, 2007: 184).

No obstante, aunque los estudios teóricos sobre déficits pragmáticos han aumentado sustancialmente en los últimos años, lamentablemente los profesionales todavía no incorporan dicho conocimiento en las sesiones de rehabilitación debido a la falta de consenso: "approaches to pragmatic therapy currently in use tend to be eclectic and a 'method' of intervention would currently be difficult to identify" (Adams, 2001:301). 
En resumen, en este trabajo defendemos la necesidad e importancia del estudio del déficit pragmático en los trastornos relacionados con el lenguaje, ya que, como reconoce Cummings (2005), "disorders at the pragmatic level of languaje constitute a considerable and frustating barrier to effective communication” (2005: 253). Creemos, por tanto, que el avance en el estudio de adquisición del componente pragmático supondrá mejoras en la evaluación para detectar este tipo de deficiencias y en la presentación de líneas de rehabilitación. Como hemos señalado, en los últimos 30 años la pragmática clínica ha evolucionado visiblemente y de forma paralela a los avances teóricos en lingüística, lo que ha permitido la creación de una base conceptual de la pragmática en ámbitos patológicos. Sin embargo, compartimos la opinión de Gallardo Paúls acerca de la necesidad de que las distintas categorías pragmáticas sean definidas y delimitadas por el lingüista antes de que el neurólogo o el logopeda las analicen dentro de los trastornos comunicativos correspondientes (Gallardo Paúls, 2002b).

\subsection{EL PAPEL DE LA PRAGMÁTICA EN LAS ALTERACIONES COMUNICATIVAS}

En este apartado nos proponemos hacer un repaso de las diversas alteraciones comunicativas que pueden incluir déficits pragmáticos. Con ello pretendemos demostrar que las deficiencias pragmáticas pueden surgir al margen de las gramaticales, aunque, como ya hemos indicado, no en sentido estricto. De hecho, en la literatura, la identificación del déficit pragmático surge por oposición al concepto de déficit gramatical, normalmente usado en el ámbito del lenguaje infantil. Bajo el término de déficit pragmático se describen una serie de características que varían en función del investigador, aunque la tónica general es, de nuevo, la falta de acuerdo en la definición:

Pragmatic impairment is a complex and elusive concept that encompasses several scientific areas. It is a concept hard to pin down, without clear defining features and sufficiently constrained inclusion criteria (Holck et al., 2009: 943).

En los capítulos anteriores señalamos que la competencia pragmática se refleja en la comprensión del lenguaje en su contexto de uso y en el conocimiento de las reglas socioculturales; por ello, las alteraciones pragmáticas del lenguaje se manifiestan, en primer lugar, en déficits en el procesamiento de la información externa. Así, los pacientes con dificultades pragmáticas para comunicarse con los 
demás tienen también dificultades para entender las intenciones de otros. Y lo mismo sucede de forma recíproca: si un niño no es capaz de comprender las intenciones de los demás, de tener en cuenta el contexto, de organizar la información conocida y la nueva, etc., su comportamiento desorientará a su interlocutor, que, probablemente, tampoco será capaz de entenderle o deducir su intención.

Monfort et al. (2004: 38-52) recogen una lista de síntomas registrados en niños con trastornos pragmáticos de la comunicación clasificándolos en dos vertientes: la receptiva (relacionada con la recepción y comprensión del lenguaje, con la comunicación y la interacción social) y la expresiva (relacionada con la expresión oral y con las actividades lúdicas y sociales). En cuanto a la vertiente receptiva destacan síntomas como la interpretación literal de los mensajes debido a que los niños no tienen en cuenta la intención implícita del hablante, la información previa o el contexto. Entre los ejemplos que presentan los autores respecto a este síntoma podemos destacar el de un adulto que quiere que el niño corrija su pronunciación y le dice "repite cinco veces dibujo" y el niño contesta "cinco veces dibujo" (Monfort et al., 2004: 38). Además, dentro de esta vertiente receptiva también encontramos alteraciones relacionadas con la falta de interés por las actividades de los otros, falta de sensibilidad para las emociones de los demás, adquisición inadecuada de las normas sociales, dificultad en la resolución de tareas de teoría de la mente, dificultad para entender las ironías y el uso metafórico de las palabras, etc. En cuanto a este último síntoma podemos destacar el ejemplo en el que un adulto le dice a un niño: "Mira este bebé, está para comérselo", y el niño de 6 años responde: "Los bebés no se comen" (Monfort et al., 2004: 40).

Por lo que respecta a la vertiente expresiva, los autores reúnen síntomas relacionados con dificultades que se detectan en la conducta activa de los niños. Entre estos podemos destacar trastornos relacionados con la pobreza de registros, la dificultad para ajustar las fórmulas verbales al contexto o a las normas sociales, dificultades para reparar los malentendidos, el exceso de información o la información inadecuada, entre otros. Un ejemplo registrado de este último se recoge en un niño de 7 años que dice: “Quiero este juego”, sin señalar nada y en un despacho donde no hay juegos a la vista (Monfort et. al, 2004: 43). 
Estos y otros síntomas de carácter pragmático pueden encontrarse en una serie de síndromes que incluyen trastornos de la comunicación. A continuación haremos una breve revisión a través de los más importantes.

\subsubsection{Afasias}

Habitualmente las afasias se describen como deficiencias en fonética, fonología, estructuras morfosintácticas y léxico, elementos en principio localizados en el hemisferio izquierdo del cerebro, aunque esta idea se ha ido matizando desde hace tiempo (Delis y Bihrle, 1989).

Los modelos de clasificación de las afasias son asombrosamente numerosos. Según Love y Webb (1996), esto se debe a que han sido cuantiosos los estudiosos que han dado un enfoque personal a estos síndromes, basándose únicamente en la ejecución del lenguaje sin especificar la localización de las lesiones. En nuestra opinión, otra de las explicaciones plausibles de tal disparidad de modelos es que estas clasificaciones suelen depender fuertemente de las múltiples concepciones del lenguaje por parte de los autores que las realizan.

Una de las distinciones más generalizada es la que parte de las zonas en las que se localiza la recepción y la producción del lenguaje, para distinguir, de forma general, la afasia de Broca y la afasia de Wernicke (Peña-Casanova et al., 1995). Esta perspectiva localizacionista la encontramos en Güell y Olivé (2001), que dividen las afasias en afasia global, de Wernicke, sensorial transcortical, de conducción, de Broca, anómica y motora transcortical; y en Love y Webb (1996), que también basan su clasificación en la localización de las áreas neurológicas afectadas. No obstante, la tendencia de los estudios cognitivos que han surgido tras el desarrollo de las tecnologías de diagnóstico por imagen defiende que las relaciones entre los síntomas afásicos y las zonas específicas del cerebro no son tan estrictas. De esta forma, un mismo síntoma puede provenir de lesiones en diferentes puntos del hemisferio derecho o en otra zona cerebral (Cardebat, 1999).

Asimismo, también es habitual encontrar clasificaciones basadas en destrezas (hablar, escuchar, escribir, leer) y las anomalías asociadas a ellas (Serón y Feyereisen, 1982). Junto a estas suelen incluirse también dos afasias consideradas por Cuetos Vega 
(1998) como cajones de sastre. Se trata de la afasia mixta y la afasia global ${ }^{148}$, en las que se incluyen los pacientes cuyos síntomas no se ajustan a los demás tipos.

En este trabajo vamos a partir de una clasificación mucho más simple, esto es, aquella que divide las afasias en afasias motoras y afasias sensitivas. Las afasias motoras o no fluentes, en general, se caracterizan por un déficit en la capacidad expresiva y una relativamente buena conservación de las categorías pragmáticas. Así lo expresa Holland:

It appears to differ from other components by being relatively less vulnerable to destruction by the focal lesions that disrupt lexicon, syntax, phonology, etc., in aphasia. This is not meant to imply that pragmatic skills remain unaffected by focal brain damage. Language structure and its use are clearly not doubly dissociated, and the words 'relatively less vulnerable' must be emphasized. Nevertheless, there is a substantial body of information to support the notion that pragmatic skills are relatively well preserved in aphasia (Holland, 1991: 198-199).

En general, los pacientes afásicos manifiestan deficiencias gramaticales: la afasia motora trae consigo agramatismo ${ }^{149}$, mientras que las afasias sensitivas se caracterizan por el paragramatismo ${ }^{150}$.

Ahora bien, aunque en principio en las afasias la competencia pragmática no parece alterada, si aparecen ciertos efectos pragmáticos causados por el agramatismo y el paragramatismo; por ejemplo, aquellos que se plasman en la construcción formal de los actos de habla. Según Gallardo Paúls y Moreno Campos (2006), uno de los rasgos

\footnotetext{
${ }^{148}$ La afasia mixta se identifica con un trastorno grave del lenguaje caracterizado por la alteración tanto de la comprensión como de la expresión verbal. Las lesiones que la causan suelen ser múltiples y afectar a zonas corticales y subcorticales alrededor de las áreas del lenguaje, de ahí que también se denomine a este síndrome aislamiento del área del lenguaje. Asimismo, el término de afasia global se utiliza cuando también están gravemente afectadas tanto las funciones expresivas como las receptivas. Es consecuencia de lesiones extensas en el territorio de la arteria cerebral media izquierda, con afectación de las áreas frontoparietales y temporoparietales. Además, suele presentar trastornos neurológicos asociados, que, unidos a la enorme dificultad para comunicarse, suele dar lugar a la asociación con un cuadro depresivo (Vendrell, 2001).

${ }^{149}$ El agramatismo consiste en un habla telegráfica, yuxtaponiendo morfos léxicos y omitiendo los funcionales (Goodglass y Kaplan, 1983) o también en el empleo de estrategias como dar siempre el papel de agente a un elemento animado y que sea compatible con la acción (Pérez Pamies, Manero y Bertrán Serra, 1988).

${ }^{150}$ El paragramatismo consiste en sustituciones u omisiones asistemáticas de morfos funcionales y palabras del léxico, en una organización gramatical confusa con un discurso hiperfluido, rápido y resistente a interrupciones (Goodglass y Kaplan, 1983) o en disintaxis, que se caracteriza por transgresiones sintácticas de carácter totalmente impredecible (Pérez Pamies, Manero y Bertrán Serra, 1988).
} 
que caracteriza la afasia motora es que los actos de habla locutivos pueden perder su valor proposicional, es decir, su valor de trasmitir un significado. Además, las afasias motoras suelen ir acompañadas de limitaciones en la movilidad del hablante, y por lo tanto, de limitaciones en sus posibilidades de expresión gestual (Helm-Estabrooks y Martin, 1991).

Por el contrario, los hablantes con afasias sensitivas muestran la situación opuesta: son capaces de encadenar actos proposicionales, pero sin atender a su coherencia interna, dando lugar a lo que Ardila (2006) define como habla vacía. En estos casos, las expresiones formales seleccionadas por los hablantes no son las adecuadas al acto ilocutivo que pretenden realizar, esto es, a su intención comunicativa.

Según Gallardo Paúls (2002b), dentro del campo de investigación teórica sobre las afasias han surgido numerosas propuestas de incorporación de la pragmática. Entre ellas podemos citar el trabajo de Joanette y Ansaldo (1999), que defienden una afasia pragmática con especial interés en la descripción teórica de las alteraciones comunicativas de los pacientes y en el uso de planteamientos teóricos pragmáticos en el diseño de las pruebas de evaluación. También merece mención el estudio de Dennis et al. (2001), que parte de una perspectiva psicopragmática para analizar elementos como la ironía, la broma, la indirección, etc. No obstante, no existe un déficit pragmático específico que pueda vincularse a la afasia, ya que las categorías pragmáticas más afectadas en estos pacientes son las que pueden considerarse de base gramatical (Moreno Campos, 2011).

\subsubsection{Síndrome de Williams}

Otra alteración comunicativa es el llamado síndrome de Williams. Se trata de un tipo de deficiencia mental de base genética. El patrón clásico lingüístico de los años 80 de este síndrome sostenía que el lenguaje estaba intacto, así como las habilidades pragmáticas (Udwin, Yule y Martin, 1987; Bellugi et al., 1988; Bihrle et al., 1989, etc.), en comparación con otras habilidades cognitivas. Por ello, en un principio, dicho síndrome se caracterizó por su riqueza léxica y expresiva y por una gran habilidad comunicativa, a pesar de que la adquisición llevaba un proceso más lento de lo normal. Sin embargo, tras la incorporación de los estudios pragmáticos desde finales de los 
años 90, se puso de manifiesto que los hablantes con síndrome de Williams poseían grandes déficits pragmáticos (Rondal, 1995; Losh et al., 2000; Bellugi y St. George, 2001; Garayzábal 2004, 2005). Garayzábal (2005) señala que el componente pragmático resulta muy problemático, ya que estos hablantes muestran una sobredependencia del contexto, hablan de temas que no tienen interés para el interlocutor, pierden el sentido de las bromas o ironías, se extrañan cuando una palabra se usa con un sentido menos convencional, etc.

Por su parte, Gallardo Paúls (2007) reconoce que los que padecen síndrome de Williams muestran déficit en el respeto del principio de cooperación y las máximas conversacionales que de él se derivan, así como en la interpretación de las implicaturas ${ }^{151}$ generalizadas (basadas en el significado literal) y anómalas (que exigen el recurso a la indirección):

Los datos analizados de hablantes con síndrome de Williams muestran un desajuste generalizado con el principio de cooperación que en el ámbito enunciativo puede explicar los fallos en la deducción de implicaturas ${ }^{152}$ (temas no pertinentes, exceso de información, inadecuación léxica) (Gallardo Paúls, 2007: 128).

En el ámbito pragmático se ha subrayado también que las personas con síndrome de Williams presentan importantes dificultades a la hora de aportar información relevante y de contextualizar los significados de las palabras y enunciados en situaciones concretas. Esto repercute en la comunicación referencial, que resulta poco precisa o inadecuada (John, Bowe y Mervis, 2009). Además, este síndrome afecta al ámbito textual e interactivo, ya que los hablantes muestran escasa topicalización de los temas ajenos, ausencia de actos de habla proyectivos, escasez de actos de habla

${ }^{151}$ La evaluación de las implicaturas generalizadas y anómalas se ha incluido en algunas de las pruebas de evaluación pragmática como el Profile of Pragmatic Impairment in Communication de Linscott, Knight y Godfrey (1996), la Pragmatic Battery de Kasher et al. (1999), la Right Hemisphere Communication Battery de Zaidel et al. (2002) o, en español, la Batería de Lenguaje Objetiva y Criterial de Puyuelo et al. (1997). No obstante, de la evaluación hablaremos en el siguiente apartado.

${ }^{152}$ Como consecuencia de los problemas con el principio de cooperación se ve implicada la deducción de las implicaturas condicionadas por las máximas conversacionales. En lo que respecta a la máxima de pertinencia, aparecen problemas para apreciar por qué es pertinente lo que dice el interlocutor; con respecto a la máxima de manera, hay problemas para adecuar la selección léxica y estilística al contexto; y con respecto a la máxima de cantidad, se aprecia un exceso verborreico, con informaciones innecesarias e irrelevantes (Gallardo Paúls, 2007: 131). 
dinámicos o de enlace, escasez de turnos predictivos, frecuencia de turnos sueltos, desarrollo de turnos largos de apariencia fonológica, etc.

En su estudio, Bernicot, Lacrois y Reilly (2003) comparan las respuestas de un grupo de niños y adolescentes con síndrome de Williams, un grupo con síndrome de Down y un grupo de control en una prueba basada en una historia narrada con apoyo visual de dibujos. Los resultados destacan que el grupo con síndrome de Williams demuestra hipersociabilidad en las interacciones durante la narración de la historia. Sin embargo, tanto este grupo como el de pacientes con síndrome de Down fallan o muestran grandes dificultades a la hora de entender la historia y mantener el tema de esta.

Por su parte, Udwin y Jule (1990) resaltan que lo que se observa en los niños con síndrome de Williams es una notable disarmonía entre una aparente facilidad para imitar a los adultos y asimilar formas verbales complejas y una gran dificultad para incorporar su contenido. A menudo no entienden bien dicho contenido y no son capaces de interpretar las mismas expresiones sintácticas cuando se usan en otros contextos.

\subsubsection{Síndrome del hemisferio derecho}

A lo largo de las últimas décadas han surgido numerosos términos para referirse al lenguaje de los hablantes con lesión de hemisferio derecho: afasia discursiva, disipoia, apragmatismo, etc. En este trabajo hemos tomado la denominación sugerida por Blake (2005) de síndrome del hemisferio derecho. De forma generalizada, los pacientes con lesiones en el hemisferio derecho presentan dificultades para ir más allá del significado referencial, problemas inferenciales, dificultades para elegir las soluciones plausibles, cierta rigidez cognitiva, hacen a menudo comentarios irrelevantes, prestan poca atención al interlocutor, etc.

Más concretamente, la bibliografía sobre pacientes con síndrome del hemisferio derecho se ha centrado en las dificultades en la interpretación de actos de habla indirectos (Zaidel et al., 2002), problemas generalizados con la deducción de inferencias (Brownell et al., 1984 ${ }^{153}$; Huber, $1990^{154}$; Joanette et al., 2008), tendencia

\footnotetext{
${ }^{153}$ En el trabajo de Brownell et al. (1984) se presenta un estudio comparativo sobre la actuación de pacientes con lesiones en el hemisferio izquierdo (LHI) y pacientes con lesiones en el 190
} 
a conversaciones autocentradas con escasa atención al interlocutor y con abundancia de información poco relevante (Blake, 2009), entre otros. En este trabajo consideramos de especial interés las investigaciones sobre pacientes con síndrome del hemisferio derecho que analizan cómo estos hablantes interpretan fenómenos como la ironía, el humor, las peticiones indirectas o las implicaturas (Bihrle et al., 1986; Molloy et al., 1990; Kasher et al., 1999; Surian y Siegal, 2001). En su estudio, Surian y Siegal (2001) comparan el procesamiento de las implicaturas en pacientes con lesión en el hemisferio derecho e izquierdo y concluyen que las dificultades en esta tarea pueden estar más relacionadas con problemas de atención y memoria que con un déficit en el conocimiento y uso de las restricciones pragmáticas. Los resultados muestran que no hay diferencias especialmente relevantes en la actuación de pacientes afásicos y pacientes con lesión en el hemisferio derecho. En ambos grupos se observa mayor cantidad de errores en comparación con el grupo de control. Además, dichos errores, en su mayoría, están relacionados con la cantidad de información aportada (a menudo excesiva e irrelevante) y con la cortesía.

Surian y Siegal (2001) también llevan a cabo distintas tareas de falsa creencia (relacionadas con la teoría de la mente) en pacientes con lesiones en el hemisferio izquierdo y en el derecho. La primera tarea se compone de una descripción verbal acompañada de dibujos. Los resultados (Surial y Siegal, 2001: 229-230) sugieren que los dos grupos de pacientes son capaces de resolver las tareas de falsa creencia de primer orden, pero los pacientes con lesiones en el hemisferio derecho fallan en estas tareas si no disponen de apoyo visual.

\subsubsection{Trastornos generalizados del desarrollo}

El déficit pragmático también se encuentra en hablantes con autismo o síndrome de Asperger, que generalmente fallan en la interpretación de inferencias surgidas por la trasgresión de las máximas conversacionales, sobre todo ante los actos de habla

hemisferio derecho (LHD) en la interpretación de connotaciones. El estudio concluye que los pacientes con LHD presentan problemas con los usos connotativos, pero no con los denotativos, mientras que los pacientes con LHI interpretan bien las connotaciones, pero presentan dificultades en el uso denotativo.

${ }^{154}$ En su estudio Huber (1990) concluye que los pacientes con LHD presentan dificultades para captar el significado figurado en situaciones descontextualizadas, si bien es cierto que mejoran cuando el uso es contextual. 
indirectos. Estos hablantes muestran también dificultades en la descodificación de sentidos figurados, humor, metáforas, etc. Tanto el síndrome de Asperger como el autismo son denominados trastornos generalizados del desarrollo. Este concepto se utiliza en el ámbito clínico para designar un conjunto de trastornos con una alteración cualitativa del desarrollo, que comparten las alteraciones generales del autismo, con distintos grados de frecuencia e intensidad de sus síntomas (De la Iglesia y Olivar, 2008). Los trastornos generalizados del desarrollo forman parten de los trastornos de inicio en la infancia, la niñez o la adolescencia, aunque también se diagnostican algunos casos en la edad adulta.

Estos trastornos se caracterizan por presentar alteraciones en tres componentes: alteraciones del comportamiento social, alteraciones de la función simbólica y alteraciones de la comunicación en toda su extensión (Monfort et al., 2004). En estos pacientes, la fonología o la morfosintaxis rara vez están afectadas, mientras que son los elementos pragmáticos los que sufren mayor alteración. En general las personas con algún trastorno generalizado del desarrollo, aun siendo inteligentes, no comprenden el mundo que les rodea y la interacción con los demás se vuelve muy compleja para ellas (Attwood, 2009). A menudo presentan grandes dificultades para atribuir estados mentales a otros y a sí mismos de forma diferenciada. Consecuentemente, estas dificultades pragmáticas se reflejan en la interacción y comprensión social, puesto que no entienden la variedad de emociones e intenciones que subyace al comportamiento de las personas.

\subsubsection{Trastorno autista}

Con respecto al trastorno autista, cabe señalar, en primer lugar, que no todos los pacientes muestran una sintomatología idéntica. De forma generalizada, se distinguen tres grupos: niños autistas que no adquieren el lenguaje (Aarons y Gitten, 1992), niños que aprenden algunas palabras pero no las usan para comunicarse (Messer, 1994) y niños autistas de alto funcionamiento, que adquieren los aspectos formales del lenguaje, pero fallan en el componente funcional $y$, en consecuencia, en el comunicativo (Baron- Cohen, 1988; Martos, 2001).

El trastorno autista se caracteriza por alteraciones en todos los niveles lingüísticos (fonético-fonológico, morfológico, sintáctico, semántico y pragmático), 
con especial hincapié en la interfaz semántico-pragmática (dificultad en la atribución de significado a la realidad, así como en la expresión espontánea de intenciones comunicativas y en el aprendizaje de actos de habla complejos) (Rivière, 1997). No obstante, también surgen casos en los que la persona con autismo parece disponer de una competencia gramatical perfecta — sin déficits evidentes en los niveles lingüísticos tales como el fonológico, morfosintáctico o semántico (Tamarit, 1992)—, pero incluso en estos casos persisten las dificultades pragmáticas. Así lo considera Frith (1989), que opina que las dificultades de carácter pragmático constituyen uno de los rasgos universales del autismo. Según este investigador, cualquiera que sea el nivel de destrezas gramaticales de los pacientes autistas, su competencia pragmática será siempre mucho menor.

En la bibliografía clásica encontramos fundamentalmente dos teorías sociocognitivas que intentan explicar el autismo: la teoría de la mente y la teoría afectiva (Tamarit, 1990; Belinchón et al., 1992). La teoría de la mente, como ya vimos, se refiere a la capacidad para atribuir estados mentales a los demás y, subsiguientemente, para inferir lo que otro cree. Esta habilidad está ligada al reconocimiento de intenciones del emisor y, por tanto, a la capacidad de inferencia. Partiendo de esta idea, podemos establecer que los niños autistas presentan un déficit cognitivo que les inhabilita para reconocer lo que los demás saben, creen o conocen y, consecuentemente, para inferir sus intenciones. De esta forma, debido a la incapacidad para reconocer la intención de comunicar, muchos sujetos autistas son incapaces de distinguir el conocimiento ostensivo del no ostensivo (Mundy, Sigman y Kasari, 1993).

Con todo, la investigación acerca de la teoría de la mente en niños autistas (Happé, 1993) ha detectado que algunos sujetos autistas a veces sí son capaces de atribuir estados mentales y de resolver las tareas de falsa creencia de primer orden ${ }^{155}$. Autores como Frith, Morton y Leslie (1991) señalan que esto se explica no porque tengan teoría de la mente, sino porque están usando una estrategia compensatoria, mientras que Happé (1993) defiende que no debemos descartar que hayan desarrollado algún tipo de habilidad metarrepresentacional. No obstante, esta autora reconoce que, aunque una minoría de sujetos autistas entiende las intenciones de primer orden, falla

${ }^{155}$ Véase apartado 3.2.2.6. 
en las tareas de reconocimiento de intenciones acerca de los estados mentales de otros, de tal forma que son capaces de reconocer la intención informativa del hablante pero no la intención comunicativa, que corresponde, como ya vimos, a una intención de segundo orden.

Numerosas investigaciones han defendido que el déficit comunicativo en el trastorno autista se debe primordialmente a las dificultades a la hora de comprender los estados mentales (Frith, 1989; Perner et al., 1989; Baron-Cohen, 1995). En su estudio, Hadwin et al. (1997) examinan si la enseñanza de la comprensión de los estados mentales a niños con autismo tiene efectos positivos en su habilidad comunicativa. Lamentablemente, los resultados sugieren que no hay una mejoría perceptible. Aunque se les enseñó a resolver diferentes tareas, los niños que realizaron el experimento no fueron capaces de trasladar lo aprendido a sus capacidades comunicativas en contextos reales.

Por otro lado, la teoría afectiva (Hobson, 1993) explica el autismo como la incapacidad para el contacto socioafectivo. De esta forma, los niños autistas no saben interactuar adecuadamente con los demás, por lo que su conocimiento parte únicamente de sus propias experiencias y no de las ajenas. Esto conlleva además la incapacidad del reconocimiento de los sentimientos de otros, así como la dificultad en la abstracción y simbolización que se deriva (Tordera, 2007).

Dentro de las peculiaridades de los rasgos formales del lenguaje de los niños autistas podemos destacar déficits en el plano prosódico ${ }^{156}$ tanto en la percepción como en la producción, retraso en la inversión de los pronombres tú y yo (Belinchón et al., 1992), problemas en el uso de elementos deícticos (Martos y Ayuda, 2002), dificultades con las palabras polisémicas y homonímicas ${ }^{157}$ (Monsalve, 2001), problemas con el uso de vocabulario abstracto (Martos y Ayuda, 2002) y problemas en

\footnotetext{
${ }^{156}$ Por regla general los niños con autismo no saben interpretar los cambios de tono o intensidad de sus interlocutores. Además, en su discurso oral no acentúan correctamente las palabras tónicas y átonas, por lo que a menudo es difícil darle sentido a su entonación (Belinchón et al., 1992).

${ }^{157}$ Muchos de estos déficits están ligados al componente pragmático. En el caso de los elementos deícticos, estos adquieren significado al situarlos en un contexto. Además, para poder usarlos correctamente, el niño autista debe tener el cuenta el contexto visual y cognitivo de su interlocutor, lo que implica tener teoría de la mente y capacidad metarrepresentacional (Tordera, 2007). En cuanto a la comprensión de palabras con más de un significado, nuevamente está relacionada con la capacidad pragmática de resolver ambigüedades, para lo cual es necesario buscar el significado relevante de acuerdo al contexto (Sperber y Wilson, 1995).
} 
la utilización del conocimiento semántico para facilitar el procesamiento del léxico (Belinchón et al., 1992).

No obstante, tal como señalamos al comienzo de este apartado, podemos afirmar que el verdadero déficit en cuanto al desarrollo lingüístico se halla en el componente pragmático (Tager-Flusberg, 1981; Ramberg et al., 1996). Uno de los rasgos caracterizadores del trastorno autista es la dificultad para mostrar intenciones comunicativas, así como para reconocerlas en el interlocutor (Martos, 2001). De ahí se derivan otras alteraciones como la violación de las máximas conversacionales de Grice (Belinchón et al., 1992) y la incapacidad de entender los actos de habla indirectos, las metáforas o las ironías ${ }^{158}$ (Martos y Ayuda, 2002).

\subsubsection{Síndrome de Asperger}

Algunos autores consideran que el síndrome de Asperger es una variante del autismo, sin embargo, reconocen que tiene sus propios rasgos distintivos, en particular, buena inteligencia verbal y mejores habilidades sociales, que diferencian su cuadro clínico del autismo clásico (Frith, 1991). A día de hoy el síndrome de Asperger todavía constituye una categoría de diagnóstico controvertida, aunque la sintomatología ha sido ampliamente estudiada y definida.

El síndrome de Asperger se caracteriza, según Rivière y Núñez (2001), por una capacidad intelectual normal o superior en la que la adquisición de los elementos formales del lenguaje (fonología, sintaxis, léxico, etc.) sigue por regla general un orden adecuado, mientras que el uso pragmático es deficitario e inapropiado al contexto, a la vez que se presentan problemas para interpretar o usar el lenguaje en situaciones sociales comunicativas (Landa, 2000).

En un análisis más exhaustivo, Martín Borreguero (2005) hace un repaso por los diferentes niveles lingüísticos y señala que:

a) en el ámbito fonológico, los niños con síndrome de Asperger presentan un desarrollo adecuado, aunque se advierten algunas alteraciones relacionadas con la prosodia;

\footnotetext{
${ }^{158}$ Como vimos en el capítulo anterior, en su estudio, Happé (1993) demuestra que los niños autistas que fallan en la tarea de lectura de la mente de segundo orden presentan también grandes dificultades a la hora de escoger la interpretación no literal propia de la ironía.
} 
b) semánticamente, presentan mayor facilidad para reconocer y definir términos formales e inusuales, no así con conceptos mucho más comunes y coloquiales $^{159}$;

c) y, finalmente, son las competencias pragmáticas las más afectadas llevando a estos niños a una interpretación literal de los enunciados y dificultando, por tanto, la comprensión del lenguaje figurado (como son las ironías, los sarcasmos o las metáforas).

Así, estas deficiencias en la flexibilidad cognitiva han dado lugar a que autores como Martín Borreguero (2005) concluyan que este síndrome puede estar relacionado con un déficit cognitivo-social y no con la comprensión misma del lenguaje.

Freire et al. (2004) señalan que los individuos con síndrome de Asperger manifiestan también dificultades para interactuar con otras personas, tanto para comprender los estados mentales del otro (teoría de la mente) como para reconocer sus intenciones comunicativas, lo que limita la comprensión de los deseos y necesidades de los demás. De este modo, la interacción se ve alterada, ya que, por un lado, el sujeto con Asperger no comprende las señales implícitas y, por otro, el interlocutor se extraña ante su egocentrismo y falta de empatía.

En cuanto a la teoría de la mente, mientras que los niños con autismo fallan en las tareas de falsa creencia, los afectados por el síndrome de Asperger a menudo las superan. No obstante, los investigadores sugieren que el hecho de que controlen este tipo de tareas no implica necesariamente que comprendan los estados mentales. Según Frith (1991), lo más probable es que desarrollen una teoría alternativa, adquirida tarde y con esfuerzo, que les permite solucionar estas tareas a través de la lógica, aunque su habilidad para leer la mente siga siendo pobre. Esta teoría sería, entonces, de tipo científico, ya que los pacientes que la desarrollan siguen sin disponer del soporte intuitivo, propio del desarrollo normal, que permite entender las situaciones sociales

159 Rattazzi (2009) corrobora esto señalando que el vocabulario adquirido por los niños con síndrome de Asperger puede parecer inusual, debido a que aprenden palabras complejas o preferentemente utilizadas por adultos. Además los niños las utilizan en contextos informales donde el vocabulario esperado sería de carácter más sencillo o familiar. Quizá una posible explicación sea que las palabras comunes necesiten de un contexto para ser comprendidas mientras que las más inusuales solo tengan un significado asociado. Esto apoyaría la idea de que el componente pragmático está más dañado que el semántico, ya que es el uso de las palabras en su contexto el que nos permite desambiguar las palabras polisémicas.

196 
nuevas a partir de las experiencias personales previas. Así, en estudios más exhaustivos puede verse que personas con síndrome de Asperger que solucionan tareas de falsa creencia en experimentos controlados presentan problemas para aplicar la teoría de la mente en situaciones de la vida real (Frith, 1991).

Al margen de las similitudes entre el síndrome de Asperger y el autismo relacionadas con alteraciones en las habilidades cognitivas, pragmáticas y sociales, podemos encontrar numerosas diferencias entre ambos diagnósticos. En primer lugar, los aspergerianos destacan por ser más capaces intelectualmente y, en especial, por tener mayor destreza en el uso del lenguaje, con una aparición de este en tiempo normal y una gramática y vocabulario a menudo por encima del promedio. Por el contrario, los autistas suelen tener un coeficiente intelectual generalmente por debajo de la media, presentan retraso en la aparición del lenguaje y una gramática y vocabulario limitados. En segundo lugar, mientras que el autismo se diagnostica en los primeros años de vida, en el caso del síndrome de Asperger en muchas ocasiones el diagnóstico se realiza más tarde, a menudo en la etapa escolar o en la adolescencia. Finalmente, los niños con síndrome de Asperger muestran interés por las relaciones sociales, desean tener amigos y se sienten frustrados por sus dificultades sociales, mientras que, por el contrario, los niños autistas poseen un desinterés general hacia las relaciones sociales.

Ahora bien, existe un tipo de autismo que se aproxima más al diagnóstico del síndrome de Asperger: el autismo de alto funcionamiento (Attwood, 2009). Se trata de un grupo minoritario de autistas que tienen una inteligencia media o alta y obtienen buenos resultados en las pruebas de nivel cognoscitivo. No obstante, estos niños comparten con el autismo clásico la falta de interés y motivación hacia los demás. Según Bloch-Rosen (1999), un rasgo diferenciador de este tipo de autismo y el síndrome de Asperger está relacionado con la forma de acercamiento a los demás. En el autismo de alto funcionamiento se observa un mayor autoaislamiento y unas relaciones sociales muy rígidas; en cambio, en el síndrome de Asperger, tal como hemos señalado, hay motivación por acercarse al otro, aunque se trata de un acercamiento excéntrico, sin flexibilidad ni muestra de empatía.

En la misma línea, Martín Borreguero (2008) diferencia ambos trastornos señalando que en el autismo de alto funcionamiento el lenguaje expresivo está muy 
desarrollado y la ecolalia ${ }^{160}$ es muy frecuente, mientras que en el síndrome de Asperger, el paciente expresa ideas con facilidad y utiliza un vocabulario sofisticado e idiosincrático. Además, en cuanto a las habilidades cognitivas y las conductas adaptativas, señala Martín Borreguero (2008: 121) que en el autismo de alto funcionamiento hay una actuación avanzada en las capacidades espaciales, de razonamiento no verbal, de formación de conceptos no verbales y memoria visual, en contraposición al sujeto con síndrome de Asperger, que tiene una actuación avanzada en el razonamiento verbal, la comprensión verbal, el vocabulario y la memoria auditiva.

En los últimos años han surgido numerosos estudios realizados con sujetos con autismo de alto funcionamiento y con síndrome de Asperger basados en las dificultades que estos grupos comparten para ir más allá de la interpretación literal (Rapin y Dunn, 2003; Bogdashina, 2005; Pijnacker et al., 2009) y realizar inferencias contextuales (Dennis, Lazenby y Lockyer, 2001; Norbury y Bishop, 2002). Loukusa y Moilanen (2009) llevan a cabo una revisión de 20 trabajos publicados entre 1996 y 2009 en torno a la comprensión pragmática y las habilidades inferenciales en individuos con autismo de alto funcionamiento y síndrome de Asperger. En concreto, nos interesa destacar el estudio llevado a cabo por Loukusa y sus colaboradores (recogido en Loukusa, 2007), en el que, basándose en la teoría de la relevancia, analizan la habilidad de niños (de 7 a 9 años) y preadolescentes (de 10 a 12 años) con síndrome de Asperger y autismo de alto funcionamiento para responder a preguntas que requieren diferente grado de procesamiento pragmático. Los resultados demuestran los principios de la teoría de la relevancia, ya que ponen en evidencia que la habilidad gramatical no es suficiente para entender el significado de los enunciados: es necesario ir más allá de la información literal usando la información contextual relevante (Sperber y Wilson, 1995; Wilson, 2000). Los datos indican que tanto los grupos de adolescentes y los niños con síndrome de Asperger o autismo de alto funcionamiento fallan más respuestas que el grupo de control (en este caso el índice de respuestas acertadas es más alto en los adolescentes que en los niños con estos

\footnotetext{
${ }^{160}$ La ecolalia se define como la repetición mecánica del habla de otros. Los niños autistas repiten con un análisis muy limitado de lo que están memorizando y reproducen frases con un nivel morfosintáctico que contrasta muy marcadamente con el nivel de competencia lingüística real (Prizant, 1983).
} 
diagnósticos). De esta forma, los resultados apoyan la hipótesis de que las dificultades de comprensión pragmática son evidentes en niños y adolescentes con síndrome de Asperger o autismo de alto funcionamiento, incluso cuando el resto de sus habilidades lingüísticas tienen un desarrollo normal, tal como proponen Norbury y Bishop (2002).

\subsubsection{Trastorno pragmático del lenguaje}

Finalmente, haremos mención a una alteración en la que los pacientes no suelen encontrar dificultades a la hora de aprender el código en sí, sino en aprender "lo que pretenden hacer los demás con él y, a continuación, cómo usarlo ellos mismos adecuadamente" (Monfort et al., 2004: 62). Este es el denominado trastorno pragmático-semántico o trastorno pragmático del lenguaje. Rapin y Allen, en 1983, reagruparon bajo el nombre de síndrome semántico-pragmático una combinación de síntomas que Rapin revisó en 1996. Entre ellos destacan: verbosidad, dificultad para interpretar el lenguaje en función del contexto, elección atípica de las palabras (lenguaje pedante), destrezas conversacionales inadecuadas, presencia de habla no dirigida a un interlocutor, frecuentes preguntas fuera de contexto, etc.

Bishop y Rosenbloom, en 1987, utilizaron la misma denominación (semánticopragmática) pero asociándola a la palabra trastorno, y consideraron entonces que se refería únicamente a un subtipo del trastorno específico del lenguaje (TEL ${ }^{161}$ ). Recientemente, se prefiere utilizar la denominación trastorno pragmático del lenguaje ${ }^{162}$, partiendo de la clásica distinción entre lo que se refiere a semántica (significado en abstracto de las construcciones lingüísticas) y a pragmática (significado que dan los hablantes a las construcciones lingüísticas que usan).

${ }^{161}$ El trastorno específico del lenguaje (TEL) afecta a un 5-7\% de la población infantil y se caracteriza por una limitación significativa de las habilidades lingüísticas junto con unas aptitudes intelectuales no-verbales adecuadas para la edad (Leonard, 1998). No obstante, los autores consideran que parte de los impedimentos lingüísticos que presenta esta población están relacionados con una dificultad en los recursos de procesamiento, más que con una limitación específica de la información verbal (Bishop, 1992; Johnston et al., 2001). Los déficits se relacionan con su capacidad y velocidad para procesar la información verbal (Bishop, 1992), con la habilidad para retener las representaciones fonológicas (Conti-Ramsden et al., 2001; Weismer y Evans, 2002) y, en general, con la atención, la memoria, la inhibición y la flexibilidad mental (ImBolter et al., 2006).

162 En este trabajo trataremos estas denominaciones como sinónimas y las usaremos indistintamente en función del autor. 
Los niños con este tipo de trastorno se diferencian del resto de niños con trastorno específico del lenguaje por la importancia de sus dificultades pragmáticas. Sin embargo, son todavía un grupo muy heterogéneo. Por ello, Conti-Ramsden (2000) propone ocho subgrupos en los que distingue dos tipos de dificultades pragmáticas: trastorno pragmático "puro" del lenguaje (que se refiere a dificultades cognitivas y lingüísticas) y trastorno pragmático "plus" del lenguaje (que incluye también alteraciones mentalistas y sociales). No obstante, cabe preguntarse si se trata de distintos niveles de afectación dentro de un mismo síndrome o de distintos niveles que se producen a lo largo de la evolución (Monfort et al., 2004).

La pregunta de si existe realmente el trastorno pragmático del lenguaje ha dado lugar a un debate interesante ${ }^{163}$ que todavía no está cerrado. Hay tres posturas respecto a este tipo de trastorno. Autores como Shields et al. (1996) consideran que el síndrome semántico-pragmático es la expresión más leve de los trastornos generales del desarrollo, como lo son también el síndrome de Asperger y el autismo de alto funcionamiento. Por el contrario, Rapin (1996) o Gérard y Brun (2003) lo incluyen en el grupo de los trastornos específicos del lenguaje; y, finalmente, Boucher (Boucher y Carmthers, 1998) defiende que los niños con trastorno semántico-pragmático resultan difíciles de incluir en cualquiera de los dos grupos anteriores, por lo que propone que se considere como una entidad diagnóstica independiente, situada entre ambos grupos formando un continuum.

Monfort et al. (2004) coinciden en esta última idea, que describe un continuum con zonas de solapamiento. No obstante, a su vez defienden una clara diferenciación del trastorno pragmático del lenguaje con el trastorno autista y con respecto al síndrome de Asperger, basándose en los criterios propuestos por Bishop (2000). Según esta autora, la distinción puede hacerse en torno a tres factores: la estructura del lenguaje, el uso social del lenguaje y los intereses reducidos. De esta forma, los niños autistas son los que presentan mayores alteraciones en los tres aspectos. Los niños con síndrome de Asperger no tienen dificultades con la estructura del lenguaje pero sí con su uso social y sus intereses. Y, finalmente, los niños con trastorno pragmático del lenguaje presentan alteraciones tanto en la estructura del lenguaje como en su uso

\footnotetext{
${ }^{163}$ Véase la discusión entre Boucher, Rapin, Allen, Botting, Bowler y Brooks en el $n^{\circ} 1$ del vol. 33 del Journal of Language and Communication Disorders (pp. 71-108) o su análisis en castellano en Mendoza Lara (2001, capítulo 10). 
social, pero son menores las alteraciones en los intereses sociales y la tendencia a la invariabilidad. Además, tras realizar estudios para comprobar la respuesta de estos niños a diferentes propuestas educativas, Monfort et al. (2004) encuentran diferencias significativas respecto a la evolución mostrada por los diferentes grupos:

En los niños que presentan TPL (Trastorno Pragmático del Lenguaje), los progresos lingüísticos y sociales se producen de una forma más o menos paralela mientras que en los niños del grupo TGD (Trastorno General del Desarrollo), se produce una fuerte disociación entre ambos aspectos: las adquisiciones de habilidades lingüísticas no se reflejan en la misma proporción en su comportamiento social en general (Monfort et al., 2004: 72).

En su estudio Leinonen y Letts (1997) comparan la actuación de niños con desarrollo normal y con trastorno pragmático del lenguaje y advierten que la diferencia más significativa se manifiesta en que los niños con desarrollo normal se dan cuenta cuando la información aportada por el interlocutor es insuficiente y piden más, mientras que los niños con trastorno pragmático del lenguaje intentan resolver la tarea con la información de la que disponen sea o no suficiente.

En definitiva, con esta revisión de los diversos tipos de trastornos que incluyen deficiencias pragmáticas severas pretendemos defender que el déficit pragmático debe tenerse en cuenta en el estudio de las alteraciones de la comunicación, ya que, como reconoce Gallardo Paúls, “proporciona información importantísima sobre el estadio de competencia lingüística y pragmática de un sujeto, y constituye, por tal motivo, un punto de partida inmejorable para la planificación de los procesos de intervención pedagógica” (2007: 179). Como hemos señalado, puede ocurrir que el individuo no sufra, a simple vista, limitaciones en su habilidad lingüística (formal), pero falle, sin embargo, en la comunicación debido a trastornos de tipo pragmático.

\subsection{PRUEBAS PARA LA EVALUACIÓN DE LA COMPETENCIA PRAGMÁTICA}

En el ámbito de la evaluación, las pruebas habituales de lenguaje son, por regla general, ineficaces a la hora de detectar o describir dificultades pragmáticas (ContiRamsden et al., 1997), incluso cuando contienen una sección con ese objetivo. A menudo, los especialistas que realizan las pruebas carecen de una formación pragmática específica, que en la práctica se traduce en una valoración poco precisa que 
evalúa la pragmática de forma general y con base en criterios personales (Moreno Campos, 2010).

Las pruebas de evaluación utilizadas para diagnosticar las afasias, por ejemplo, miden distintos componentes gramaticales descuidando el conocimiento pragmático (Smith y Leinonen, 1992). Además, el hecho de evaluar cada aspecto del lenguaje por separado hace que los resultados reflejen un uso descontextualizado, esto es, alejado del uso real del lenguaje. En consecuencia, es frecuente que algunos estudios (Vanhalle et al., 2000) obtengan resultados distintos en las pruebas de test y en acciones similares en contextos naturales.

A pesar de que muchos estudios han demostrado la importancia y eficacia de la evaluación pragmática (Penn, 1985; Lomas et al., 1989), la práctica no está aún suficientemente extendida. Según Crockford y Lesser (1994), esto se debe, entre otras razones, a la naturaleza subjetiva de la pragmática, que no admite los métodos usados en el análisis de los aspectos gramaticales y al mayor coste que suponen los métodos cualitativos ${ }^{164}$ propios de los protocolos pragmáticos, en los que los especialistas deben invertir mucho más tiempo en su realización y seguimiento.

La dificultad que supone la evaluación de la competencia pragmática deriva también de la no previsibilidad de las interacciones comunicativas debido al manejo simultáneo de significados implícitos y explícitos. A diferencia de lo que ocurre con la gramática (donde hay puntos de referencia fijos para evaluar la formación de plurales o la conjugación verbal, por ejemplo), en pragmática un estímulo puede desencadenar una pluralidad de respuestas y podría ocurrir que todas ellas fueran válidas o correctas. Como apunta Fernández Pérez (2001), en la teoría esta pluralidad cuestiona lo que vamos a entender por "normalidad” y enfrenta al investigador a una consideración realista de la lengua y su uso.

Es consabido que las habilidades pragmáticas varían en función del contexto y de la audiencia (Perkins, Crisp y Walshaw, 1999). Por ello, la evaluación pragmática no encaja en los métodos típicos de evaluación del lenguaje en los que las normas pueden

\footnotetext{
${ }^{164}$ En los métodos cualitativos se estudian procesos generales y no aspectos concretos. A menudo se realizan grabaciones de los pacientes en contextos familiares y los resultados tienen validez interna, pero no pueden ser generalizados. Por el contrario, los métodos cuantitativos permiten comparar los datos obtenidos con otros pacientes, observar la evolución y estimar el grado de desviación respecto a la media (Moreno Campos, 2010: 167). De ellos hablaremos a lo largo de este capítulo.
}

202 
derivarse de test estandarizados (Adams, 2002). Como hemos visto a lo largo del capítulo anterior, los estudios sobre el desarrollo de la competencia pragmática se han centrado en el estudio de aspectos concretos cuyos patrones de desarrollo se conocen de forma limitada, ya que las investigaciones solo ofrecen una edad aproximada de aparición del fenómeno. Así, los estudios indican que entre los 3 y los 4 años se desarrolla prácticamente todo el abanico de actos de habla, con la excepción de los más sofisticados, como los compromisorios, los persuasivos o las formas de cortesía, que no se desarrollan de forma completa hasta los 9 años (McTear y Conti-Ramsden, 1992). En lo que respecta a las habilidades metapragmáticas, las investigaciones señalan que aparecen en torno a los 7 años (Andersen-Wood y Smith, 1997); asimismo, se cree que entre los 4 y los 6 años se produce el cambio de las interpretaciones literales a las no literales. A esto hay que añadir el hecho de que la competencia pragmática se ve afectada por los estilos individuales de comunicación (Hewitt, 2000) y que todavía no se ha llegado a un consenso sobre cómo trasladar esto a la evaluación (Adams, 2002).

Como ya señalamos al comienzo de este capítulo, en nuestra opinión, el mayor problema al que nos enfrentamos es que las pruebas de evaluación pragmática carecen de criterios de fiabilidad y de validez. Entre los intentos para formalizar y sistematizar la evaluación pragmática podemos destacar el Test of Pragmatic Skills ${ }^{165}$ de Shulman (1985) (que utiliza breves situaciones de juego para obtener diagnósticos) y el Test of Pragmatic Language ${ }^{166}$ de Phelps-Terasaky y Phelps-Gunn (1992) (que incluye situaciones prototípicas que el niño debe solucionar verbalmente ${ }^{167}$ ). No obstante, estos trastornos se prestan mal a los juicios cuantitativos y normativos.

${ }^{165}$ En este test se intenta que el niño lleve a cabo ciertos actos ilocucionales mediante actividades de juego con muñecos, lápiz y papel, etc. Las reacciones se codifican en una escala de 6 niveles: 1) ausencia de respuesta, 2) respuesta contextualmente inapropiada, 3) propiedad contextual solo en lo no verbal, 4) respuesta apropiada de una sola palabra, 5) respuesta apropiada de dos o tres palabras y 6) respuesta apropiada de más de tres palabras.

${ }^{166}$ Este es un test más complejo que evalúa la competencia comunicativa, incorporando léxico complejo y razonamiento verbal. Generalmente se usa con adolescentes con déficits comunicativos. En la actualidad, ha sido usado para diferenciar desórdenes pragmáticos del lenguaje en niños con autismo comparándolos con el grupo de control (Young et al., 2005).

${ }_{167}$ A menudo, la validez de estas pruebas queda en entredicho, ya que los niños de mayor edad pueden resolver intelectualmente las situaciones presentadas en los test, pero luego son incapaces de resolverlas en la vida real (Monfort et al., 2004). 
Otros investigadores han optado por diseñar registros de observación o cuestionarios elaborados partiendo de comportamientos prototípicos y listas de habilidades pragmáticas ${ }^{168}$ (Bishop y Adams, 1989; Hilton, 1990; Dewart y Summers, 1995). Estos cuestionarios deben ser completados por las personas del entorno del niño, bien sean padres, profesores o especialistas. A menudo acarrean el problema de imprecisión acerca de lo que debe hacer el examinador para contestar a las preguntas. Entre estos cuestionarios destaca el Children's Communication Checklist, propuesto por Bishop y su equipo (creado en 1998, pero en constante renovación: Nathan, 2002; Bishop y Norbury, 2002). Este cuestionario se compone de 70 ítems ${ }^{169}$ cuyos resultados ofrecen al final una puntuación global. Se utiliza, principalmente, para establecer diagnósticos diferenciales entre niños con trastorno generalizado del desarrollo, niños con trastorno específico del lenguaje y niños con trastorno pragmático del lenguaje, a una edad en torno a los 7-9 años. En opinión de especialistas como Monfort et al. (2004), el Children's Communication Checklist es actualmente la propuesta más elaborada ${ }^{170}$ en la evaluación clínica de los trastornos pragmáticos de los niños y aporta una referencia muy importante en el debate, ya comentado, sobre el lugar del trastorno pragmático del lenguaje respecto a los trastornos generalizados de desarrollo y los trastornos específicos del lenguaje.

Los estudios de Gallardo Paúls (2002a y 2006), que recogen las principales pruebas de evaluación con un enfoque pragmático, destacan, entre otros:

- el Pragmatic Protocol de Prutting y Kirchner (1983), considerado una de las primeras pruebas que se ocuparon de aspectos pragmáticos. Se compone de 30 parámetros ${ }^{171}$ organizados en tres secciones que reflejan la estructura triple de la interacción (Poyatos, 1980): lenguaje, paralenguaje y comunicación no verbal. Los datos de análisis son conversaciones grabadas del sujeto con dos interlocutores: uno de confianza y otro no familiar. A

\footnotetext{
${ }^{168}$ Véase anexo 2.

${ }^{169}$ Véase anexo 3.

${ }^{170}$ El Children's Communication Checklist ha sido usado en estudios con diferentes pacientes clínicos: niños con autismo (Bishop et al., 2006), niños con autismo de alto funcionamiento y síndrome de Asperger (Verté et al., 2006), niños diagnosticados de autismo, síndrome de Asperger y otros tipos de déficits lingüísticos (Farmer y Oliver, 2005), niños con dificultades pragmáticas (Spanoudis et al., 2007), etc.

${ }^{171}$ Véase anexo 4. 
partir de estos datos, se observa el dominio de diversas categorías pragmáticas.

- el Test of Pragmatic Skills, propuesto por B. Shulman en 1985, para la evaluación de niños con algún tipo de dificultad conversacional referida a las intenciones comunicativas, del que hemos hablado anteriormente.

- el Pragmatic Screening Test, de P. Prinz y F. Weiner (1987), diseñado también para la evaluación infantil. Este test amplía el marco de investigación, incluye las habilidades de los niños de teoría de la mente y, además, se incorpora también la información de un observador (el maestro del niño), que valora su conducta verbal general (Comti-Rasdem y McTear, 1989: 226).

- el PPECS (The Pragmatic Profile of Early Communication Skills, de Hazel Dewart y Susie Summers, 1988), que se basa en un cuestionario sobre la conducta del habla en niños administrado a los padres u otros cuidadores ${ }^{172}$. Se evalúan cuatro elementos: intenciones comunicativas, respuestas, interacción conversacional y variación contextual. Conti-Ramsdem y McTear (1989: 214) advierten de que una de sus debilidades es la validez que pueda tener una información indirecta, proporcionada además por personas que generalmente carecen de formación metalingüística.

- El TOPL (Test of Pragmatic Language, de Diana Phelps-Terasaki y Trisha Phelps-Gunn, 1992), diseñado para niños de 5 a 13 años. Sus objetivos son: identificar a los niños que puedan tener problemas pragmáticos respecto a los niños de su edad, determinar los aspectos fuertes y débiles en el plano pragmático y dar cuenta del desarrollo pragmático del lenguaje. Al niño se le enseña una imagen y se le proporciona un estímulo verbal que desencadenará cierto tipo de respuesta. La principal crítica (Adams, 2002: 976) es que es una prueba muy amplia, ya que no solo abarca elementos pragmáticos, sino también semánticos y cognitivos, y puede resultar excesiva si la meta es la evaluación únicamente pragmática.

\footnotetext{
${ }^{172}$ Véase anexo 5.
} 
- La Pragmatic Battery de Kasher, Batori, Soroker, Graves y Zaidel (1999), que analiza dos categorías pragmáticas básicas: los actos de habla y las implicaturas, y no solo se centra en la comunicación verbal, sino también en la no verbal o icónica. Para ello se sirve de implicaturas dobles: verbales (a través de diálogos) y visuales (a través de cuadros famosos con gran valor simbólico). Esta prueba se presenta a pacientes con lesiones en ambos hemisferios.

A esta lista se pueden añadir otras pruebas como el Test of Language Competence (Wiig y Secord, 1989), el Clinical Evaluation of Language Fundamentals (Semel, Wiig y Secord, 2000) o el Assessment of Comprehension and Expression (Adams et al., 2001). En la tabla 4 puede verse un resumen de los test que actualmente se usan, el rango de edades que cubren y el objetivo a evaluar. Igualmente, en lo referente a los cuestionarios, protocolos y listas de capacidades pragmáticas, además del Children's Communication Checklist, podemos mencionar los recogidos en la tabla 5.

\begin{tabular}{|l|l|l|l|l|}
\hline \multicolumn{1}{|c|}{ Nombre del test } & \multicolumn{1}{|c|}{ Autor/es } & Edad & \multicolumn{1}{|c|}{ Metodología } & \multicolumn{1}{|c|}{$\begin{array}{c}\text { Aspectos } \\
\text { pragmáticos } \\
\text { estudiados }\end{array}$} \\
\hline $\begin{array}{l}\text { Assessment of } \\
\begin{array}{l}\text { Comprehension and } \\
\text { Expression }\end{array}\end{array}$ & $\begin{array}{l}\text { Adams } \text { et al., } \\
2001\end{array}$ & $6-11$ & Historia y dibujos & $\begin{array}{l}\text { Comprensión no } \\
\text { literal } \\
\text { Comprensión } \\
\text { inferencial, } \\
\text { Narrativa }\end{array}$ \\
\hline $\begin{array}{l}\text { The Listening Skills } \\
\text { Test }\end{array}$ & $\begin{array}{l}\text { Lloyd } \text { et al., } \\
2001\end{array}$ & $\begin{array}{l}3-6 \\
6-11\end{array}$ & $\begin{array}{l}\text { Tareas comunicativas y y } \\
\text { dibujos }\end{array}$ & $\begin{array}{l}\text { Ambigüedad } \\
\text { Evaluación del } \\
\text { mensaje verbal } \\
\text { Comprensión de } \\
\text { direcciones }\end{array}$ \\
\hline $\begin{array}{l}\text { Test of Language } \\
\text { Competence } \\
\text { Expanded }\end{array}$ & $\begin{array}{l}\text { Wiig y Secord, } \\
1989\end{array}$ & $5-18$ & $\begin{array}{l}\text { Interpretación de } \\
\text { enunciados orales e } \\
\text { inferencias }\end{array}$ & $\begin{array}{l}\text { Ambigüedad } \\
\text { Inferencias } \\
\text { Metáforas }\end{array}$ \\
\hline $\begin{array}{l}\text { Test of Pragmatic } \\
\text { Language }\end{array}$ & $\begin{array}{l}\text { Phelps- } \\
\text { Terasaki y } \\
\text { Phelps-Gunn, } \\
1992\end{array}$ & $5-13$ & $\begin{array}{l}\text { Contexto social } \\
\text { Dibujos }\end{array}$ & $\begin{array}{l}\text { Audiencia } \\
\text { Tópico } \\
\text { Actos de habla }\end{array}$ \\
\hline $\begin{array}{l}\text { Understanding } \\
\text { Ambiguity }\end{array}$ & Rinaldi, 1996 & $8-13$ & $\begin{array}{l}\text { Identificación de } \\
\text { dibujos, mensajes y } \\
\text { expresiones faciales }\end{array}$ & $\begin{array}{l}\text { Significados } \\
\text { múltiples en } \\
\text { contexto } \\
\text { Emoción }\end{array}$ \\
\hline
\end{tabular}

Tabla 4. Lista de test de contenido pragmático

Fuente: adaptado de Adams (2002) 


\begin{tabular}{|c|c|c|}
\hline Nombre & Autor/es & Propósito/Método \\
\hline $\begin{array}{l}\text { Assesment of Language } \\
\text { Impaired Children's } \\
\text { Conversations }\end{array}$ & $\begin{array}{l}\text { Bishop y Adams, } 1989 \\
\text { Bishop et al., } 2000\end{array}$ & $\begin{array}{l}\text { Clasificación del comportamiento } \\
\text { conversacional en categorías } \\
\text { Cuantitativo }\end{array}$ \\
\hline $\begin{array}{l}\text { Children's Communication } \\
\text { Checklist }\end{array}$ & Bishop, 1998 & $\begin{array}{l}\text { Presencia de déficits pragmáticos del } \\
\text { lenguaje }\end{array}$ \\
\hline $\begin{array}{l}\text { Directing Discourse } \\
\text { Checklist of Linguistic } \\
\text { Processes }\end{array}$ & Blank y Marquis, 1992 & $\begin{array}{l}\text { Información sobre la habilidad para } \\
\text { formular explicaciones }\end{array}$ \\
\hline $\begin{array}{l}\text { Pragmatic Profile of } \\
\text { Everyday Communication } \\
\text { Skills in Children }\end{array}$ & $\begin{array}{l}\text { Dewart y Summers, } \\
1995\end{array}$ & $\begin{array}{l}\text { Cuestionario entregado a los padres o } \\
\text { cuidadores, requiere interpretación }\end{array}$ \\
\hline Pragmatic Protocol & Prutting y Kirchner,1983 & 30 ítems en una escala de 3 puntos \\
\hline $\begin{array}{l}\text { Social Interactive Coding } \\
\text { System }\end{array}$ & $\begin{array}{l}\text { Rice, Sell y Hadley, } \\
1990\end{array}$ & $\begin{array}{l}\text { Observación de un interacción } \\
\text { grabada en vídeo }\end{array}$ \\
\hline $\begin{array}{l}\text { Social Use of Language } \\
\text { Programme }\end{array}$ & Rinaldi, 2001 & $\begin{array}{l}\text { Uso de la comunicación en contextos } \\
\text { sociales }\end{array}$ \\
\hline
\end{tabular}

Tabla 5. Lista de cuestionarios y protocolos de contenido pragmático Fuente: adaptado de Adams (2002)

En nuestro país, un intento notable de incorporación de la pragmática a las pruebas de evaluación del lenguaje lo constituye la BLOC: Batería de Lenguaje Objetiva y Criterial, diseñada por Miguel Puyuelo, Elisabeth H. Wiig, Jordi Renom y Antoni Solanas $(1997)^{173}$. La batería de pruebas se organiza en tres secciones: 1) morfología, 2) sintaxis, 3) semántica y pragmática. En el módulo destinado a la pragmática, se sitúa al individuo en el papel de emisor dentro de un contexto de comunicación en forma de diálogo. Se basa en escenas ("la clase”, "el recreo”, "el zoo”, "la consulta del veterinario”, “el restaurante de comida rápida” y subescenas A, $\mathrm{B}, \mathrm{C} \mathrm{y} \mathrm{D)} \mathrm{en} \mathrm{las} \mathrm{que} \mathrm{aparecen} \mathrm{distintos} \mathrm{personajes} \mathrm{en} \mathrm{diferentes} \mathrm{situaciones} \mathrm{o}$ contextos comunicativos. El individuo, entonces, debe ponerse en la situación comunicativa del personaje que se le indique y expresar, en estilo directo, lo que diría tal personaje en esa situación concreta ${ }^{174}$.

\footnotetext{
${ }^{173}$ Estas pruebas están inspiradas en el CRIL (Criterion Referenced Inventory of Language) de E.H. Wiig de 1990.

${ }^{174}$ Los actos de habla que se intentan provocar en el sujeto son:

-saludos y despedidas

-reclamar la atención

-peticiones/concesiones-negativas

-peticiones de información
} 
En las pruebas de evaluación de la pragmática de este método es fácil encontrar las huellas de las máximas de Grice ${ }^{175}$. Sin embargo, autores como Gallardo Paúls (2002a) creen que el desarrollo concreto de esta batería falla en algunos presupuestos importantes como es la selección de actos de habla analizados, la presentación de las pruebas al sujeto, o la información que se da al evaluador acerca de lo que debe esperar y analizar en cada ítem.

Al margen de estos tipos de pruebas de evaluación, también podemos citar diferentes sistemas para analizar la interacción en contextos naturales elaborados en torno a diferentes aspectos pragmáticos como los actos de habla, la gestión del tópico, etc. En lo que respecta al análisis de los actos de habla, a menudo se utiliza para perfilar el empleo de las funciones comunicativas en los niños en términos de variedad y para indicar cómo usan los diferentes tipos de actos de habla en diferentes contextos (Adams, 2002). Fey (1986) plantea un sistema de codificación en el que los actos de habla se subdividen en directivos (especialmente peticiones), asertivos y realizativos. Este sistema tiene la ventaja de que permite caracterizar al niño como, por ejemplo, comunicador asertivo (Adams et al., 2002).

En cuanto a la gestión del tópico, podemos citar el trabajo de Brinton y Fujiki (1989), que ofrece una explicación de su desarrollo y variabilidad. Sin embargo, los test formales no son viables debido a que el gran número de variables (contextuales y personales) que afectan al desarrollo y mantenimiento de un tópico son imposibles de controlar en un escenario natural (Brinton, Fujiki y Powell, 1997).

De esta forma, la evaluación a través de la observación natural es preferible para algunos investigadores porque refleja el comportamiento típicamente contextual

\footnotetext{
-peticiones de confirmación o negación -preguntas con pronombres interrogativos -comentarios de aprobación/desaprobación -solicitudes de acción directas

-solicitudes de acción indirectas

-protestas y disconformidades

175 "El estudio de los principios que regulan la interpretación de los enunciados ha contribuido a definir el ámbito de la pragmática tal como se concibe actualmente. Esta considera que los participantes en un intercambio comunicativo deben adaptar su participación en la conversación a la dirección que adopte en cada momento el intercambio comunicativo, teniendo en cuenta aspectos como: 1) que la cantidad de información que se dé sea la necesaria, esto es, ni excesiva ni escasa, 2) a nivel cualitativo, que la información sea verdadera, 3) que la información se relacione con lo que se está hablando y que sea relevante, y 4) El modo de decirlas cosas debe ser claro y ordenado" (Puyuelo et al., 1997: 40).

208
} 
(Ninio et al., 1994). El estudio de la conversación permite a los evaluadores comprobar el conocimiento del mundo y las habilidades cognitivas del niño. En esta línea, Cummings (2009b) defiende la utilidad del análisis del discurso de niños a los que se les induce a la producción de un monólogo preguntándoles por un juego que les es familiar o pidiéndoles que describan un dibujo. Sin embargo, tal como comentamos anteriormente, requiere mucho más tiempo y recursos.

Finalmente, queremos hacer especial hincapié en la evaluación de la comprensión pragmática del lenguaje, esto es, cómo el niño lleva a cabo la tarea de comprender el lenguaje en contexto, especialmente cuando presenta limitaciones lingüísticas (Leinonen y Letts, 1997) o limitaciones en la cognición social como, por ejemplo, problemas para establecer el conocimiento compartido (Happé, 1993) o para usar su conocimiento del mundo (Milosky, 1992), etc. En este sentido la tarea inferencial ha sido uno de los aspectos pragmáticos que ha experimentado más avances en los métodos de evaluación y que ha despertado más interés, ya que es través de la inferencia como se completa la información que no se ofrece explícitamente para llegar a la compresión del texto o del discurso. Tal como vimos anteriormente, los niños que comprenden adecuadamente las oraciones desde el punto de vista gramatical pueden fallar a la hora de hacer inferencias (Bishop y Adams, 1991; Letts y Leinonen, 2001).

Las inferencias verbales suelen evaluarse a través de estudios experimentales que utilizan una historia o un contexto representado a través de dibujos. A partir de esa historia o contextos al niño se le hacen una serie de preguntas para descubrir lo que es capaz de inferir (Bishop y Adams, 1992; Leinonen y Letts, 1997). Este formato también es usado por el Test of Language Competence (Wiig y Secord, 1989), por el Test of Problem Solving (Bowers et al., 1994) y por un subtest de compresión inferencial dentro del Assessment of Comprehension and Expression (Adams et al., 2001). En estas pruebas, el control sobre las variables como el contexto y el input lingüístico permiten al investigador comparar la comprensión inferencial de los pacientes con los datos del grupo de control. Sin embargo, no puede asegurarse que este tipo de evaluación refleje la verdadera capacidad inferencial en contextos reales; por ello, es necesaria una investigación más exhaustiva sobre el fenómeno de la 
inferencia y la naturaleza de los fallos en este nivel de la comprensión del lenguaje (Harley, 2001).

La preferencia en los criterios para la elección del método de evaluación apropiado ha cambiado a lo largo de los años. Igualmente, la edad del niño puede determinar que se seleccione uno u otro método. Así, en niños de edad preescolar son preferibles métodos de observación a través de juegos con familiares o compañeros y el uso de listas o cuestionarios que deben ser completados por los padres o tutores.

Como hemos ido perfilando en este apartado, en rasgos generales, la evaluación puede hacerse de forma cualitativa o cuantitativa. Los métodos cuantitativos han sido criticados por prestar poca atención a la interacción y concentrarse en la actuación del niño de forma aislada. Por el contrario, el análisis cualitativo ha permitido a los investigadores un acercamiento más individualizado y una mejor planificación de las terapias en niños que presentan deficiencias en el lenguaje (Radford y Tarplee, 2000) o autismo (Dobbinson et al., 1998), pero con el inconveniente de que implica emplear mucho más tiempo en el análisis y un alto nivel de conocimiento lingüístico por parte del investigador.

Muchos autores defienden que la competencia pragmática debe ser analizada en situaciones naturales y que el hecho de establecer de antemano los contextos comunicativos puede tener un impacto significativo en la interacción resultante, de forma que estos sistemas de evaluación no reflejarían habilidades reales de los hablantes. Sin embargo, la evaluación en contextos naturales proporciona menos oportunidades para observar determinados actos de habla (Brinton y Fujiki, 1989; Iacono, Waring y Chan, 1996). Además, el hecho de que no se observe una determinada respuesta no significa que el niño no tenga capacidad para producirla (Prutting y Kirchner, 1987).

Según Adams (2002), los estudios evidencian que las técnicas enfocadas a la evaluación de determinadas tareas planeadas previamente pueden ser un método complementario efectivo para medir la habilidad pragmática. De esta forma, la evaluación más completa sería aquella que combinara la observación natural y las tareas conversacionales estructuradas de antemano llevadas a cabo mediante el uso de juguetes o dibujos y mediante la interacción (Bishop y Adams, 1989). 
Con todo, tras esta revisión de los diferentes modelos de evaluación de la comprensión pragmática cabe preguntarse, de nuevo, por su validez. Como ya hemos reiterado, a diferencia de otros aspectos lingüísticos, la pragmática depende inevitablemente del contexto y, por lo tanto, no ofrece el mismo nivel de fiabilidad (Cummings, 2009b). Ervin-Tripp (2000) señala una serie de elementos contextuales que pueden influir en los métodos de evaluación pragmática: la familiaridad con el interlocutor, el estilo del investigador a la hora de hacer preguntas, el modelo de lenguaje del examinador, etc. En la práctica es difícil controlar estos factores, pero si las pruebas se utilizan con fines clínicos las influencias contextuales deben ser especialmente consideradas y analizadas.

Ahora bien, al igual que con los déficits gramaticales al profesional se le exige un conocimiento mínimo de las categorías estructurales, con la inclusión del componente pragmático creemos que también será necesaria la formación referente a los fenómenos pragmáticos pertinentes, para la cual es necesaria una reflexión teórica de base. Además, las pruebas de evaluación deben orientarse a la competencia comunicativa, por lo que necesitan incorporar el contexto, el conocimiento enciclopédico, la relevancia, la inferencia, etc. En este sentido, apoyamos la opinión de Gallardo Paúls (2002b), que defiende que estos test deben concentrarse en la eficacia sociocomunicativa del paciente y, consecuentemente, ha de asumirse una perspectiva pragmática.

\subsection{DÉFICITS EN LA ADQUISICIÓN PRAGMÁTICA Y RELEVANCIA}

Como ya hemos mencionado a lo largo de este trabajo, la teoría de la relevancia proporciona una explicación de los procesos cognitivo-lingüísticos, por lo que ha sido tomada como marco teórico en numerosos estudios centrados en el desarrollo normal o deficitario de habilidades pragmáticas. Así, Happé (1993) parte de ella en la investigación de la capacidad de teoría de la mente en niños autistas, Leinonen y Kerbel (1999) en el estudio de los fallos pragmáticos en la conversación en niños con problemas en la comprensión lingüística, Dipper et al. (1997) para analizar por qué los pacientes con daños en el hemisferio derecho poseen deficiencias en su conocimiento semántico y pragmático, Loukusa (2007) para comparar la actuación pragmática de 
niños con desarrollo normal y niños diagnosticados con síndrome de Asperger y autismo de alto funcionamiento, etc.

Tal como señalamos en el capítulo anterior, los estudios sobre el desarrollo lingüístico en los niños sugieren que hasta los 3 años el lenguaje se centra en eventos concretos de su mundo (aquello que pueden ver y tocar) y, a medida que van creciendo, son capaces de comprender eventos más abstractos, de pensar en las intenciones del interlocutor y de entender el lenguaje en contexto (Bishop, 1997). Con ello, la teoría de la relevancia sugiere que el desarrollo de la compresión pragmática es gradual, de forma que los niños comienzan a ser capaces de utilizar el contexto para asignar referentes, resolver ambigüedades o enriquecer los enunciados hasta llegar a la capacidad para deducir implicaturas. En su estudio con niños de 3 a 5 años, Ryder y Leinonen (2003) descubrieron la existencia de un patrón de desarrollo en el uso del contexto: los niños de 3 años fueron incapaces de resolver las implicaturas planteadas, mientras que los niños de 5 años, que dominaban a la perfección la asignación de referentes y el enriquecimiento de los enunciados, demostraron evidencias de que estaban empezando a desarrollar dicha habilidad para inferir implicaturas.

Por el contrario, los niños con déficits lingüísticos a menudo muestran dificultades para tener en cuenta el contexto (tanto en la producción como en la comprensión del lenguaje), para seleccionar las palabras adecuadas, o para expresar determinadas ideas. En definitiva, presentan dificultades en la comunicación. En un estudio posterior, Leinonen y Ryder (2008) señalaron que niños de 8 años diagnosticados con trastorno específico del lenguaje respondían al nivel de niños de 4 años con desarrollo normal, mostrando un retraso en el patrón de desarrollo.

Según Leinonen y Ryder (2008), la teoría de la relevancia nos permite hacer predicciones sobre los niveles de competencia comunicativa en niños y adultos que 1) no disponen de teoría de la mente, 2) solo disponen de teoría de la mente de primer orden o 3) poseen habilidades de segundo orden. Así, se ha sugerido que la habilidad para entender el lenguaje figurado (como el sarcasmo, la metáfora o la ironía), que se desarrolla gradualmente en los niños a partir de los 5 años (Laval y Bert-Erboul, 2005), está relacionada directamente con la capacidad para atribuir estados mentales a los demás. De esta forma, los niños de 3 años tienen grandes dificultades con 
fenómenos como el sarcasmo o las metáforas al igual que los niños y adultos con autismo.

Ahora bien, la teoría de la relevancia puntualiza que hay distintos niveles a la hora de entender el lenguaje figurado, por ejemplo, la metáfora supone un procesamiento más sencillo que el sarcasmo ${ }^{176}$. En este sentido, el sarcasmo implica un esfuerzo extra, ya que es necesario reconocer las emociones o intenciones del hablante. En su trabajo, McDonald (1999) investiga la comprensión del sarcasmo en pacientes con daño cerebral traumático y toma como base teórica los principios de la relevancia para examinar la naturaleza de las dificultades que muestran dichos pacientes, que interpretan los enunciados sarcásticos de forma literal (siempre que una interpretación literal es posible). La teoría de la relevancia sugiere que la compresión del sarcasmo implica la capacidad de hacer inferencias sobre la situación contextual, así como sobre el estado mental del hablante (actitud, intenciones, conocimientos). Además, como ya vimos, los comentarios sarcásticos suelen hacer eco de una aserción anterior, lo que supone una pista para entender la actitud despectiva del hablante frente a esta. No obstante, tras su estudio McDonald (1999) concluye que la habilidad de los pacientes para entender el sarcasmo es independiente de su capacidad para comprender el tono emocional y que, sin embargo, la dificultad recae en la habilidad para razonar una inferencia a partir de la información verbal. Así, los pacientes que participan en este estudio, por regla general, son capaces de usar la información visual relevante, pero no la verbal, donde encuentran más dificultades.

La teoría de la relevancia también permite explicar los resultados de los estudios con pacientes con lesiones en el hemisferio derecho, que a menudo se relacionan con dificultades lingüísticas de tipo pragmático, como ya adelantamos en este capítulo. En su estudio basado en preguntas a través de una historia, Dipper et al. (1997) estudiaron las dificultades pragmáticas de 6 pacientes con daño unilateral en el hemisferio derecho en comparación con un grupo de control compuesto por 12 personas. Los datos resultantes demostraron que los pacientes con daño cerebral en el hemisferio derecho no usaban el contexto de la historia para responder a las preguntas, pero aun

\footnotetext{
${ }^{176}$ A menudo sarcasmo se utiliza como sinónimo de ironía o como un tipo o grado de esta. Son muchos los autores que identifican el sarcasmo con la ironía crítica (Gibbs y O’Brien, 1991; Giora, 1995; Kotthoff, 2003; Shamay-Tsoory et al., 2005) o como una variante negativa de la ironía (Jorgensen, 1996). En este trabajo consideraremos el sarcasmo como un tipo de ironía llevada al extremo: fuerte, mordaz y, en algunos casos, cruel.
} 
así eran capaces de justificar sus respuestas. Dichas justificaciones revelaban que los sujetos no eran conscientes de la información contextual, pero hacían uso de su conocimiento del mundo para generar las inferencias. Los participantes de este estudio respondían a tres tipos de preguntas: las primeras requerían el uso del input lingüístico dado en la historia; las segundas, la información derivada del discurso y del contexto vía inferencial; y las terceras, el conocimiento del mundo del tipo "cuando pelas cebollas te lloran los ojos”. El estudio concluyó que los pacientes con daño cerebral en el hemisferio derecho mostraban resultados peores que el grupo de control en todos los tipos de preguntas, especialmente en las dos primeras, debido a que la información enciclopédica era la que más confianza les suscitaba. Según el modelo de comprensión del lenguaje de la teoría de la relevancia, sobre el input lingüístico opera un sistema deductivo. El daño sufrido por estos pacientes afecta a dicho sistema, de modo que el uso del contexto lingüístico para inferir el significado pretendido se ve, consecuentemente, alterado. Los autores sugieren que esta incapacidad para usar la información contextual en el sistema deductivo se relaciona con una dependencia excesiva en la información enciclopédica almacenada en la memoria.

Leinonen y Ryder (2008) llaman nuestra atención sobre el hecho de que esta tendencia a usar el propio conocimiento que procede de la experiencia se encuentra también en niños con desarrollo normal entre 4 y 5 años cuando responden a preguntas en las que se espera que se sirvan de la información relevante para el contexto dado.

Como vimos, en la teoría de la relevancia, el mayor esfuerzo cognitivo se relaciona con un aumento de los efectos contextuales. De esta forma, el procesamiento de un enunciado que requiera la inferencia de un referente o la desambiguación de una expresión supone menos esfuerzo cognitivo que aquel que suponga la recuperación de una implicatura. Consecuentemente, la teoría de la relevancia se presta a la investigación empírica de los procesos involucrados en la comprensión del lenguaje, así como al estudio de la noción de esfuerzo cognitivo o de competencia comunicativa y, consiguientemente, a la investigación en torno a la naturaleza del desarrollo de la comprensión pragmática del lenguaje.

Los estudios sobre déficits lingüísticos que han usado como punto de partida la teoría de la relevancia han corroborado las predicciones de dicha teoría en cuanto a los diferentes niveles de complejidad pragmática en los diferentes fenómenos que se dan 
en el procesamiento del lenguaje. Además, a menudo, determinados casos de déficits pragmáticos se pueden comprender mejor si se adopta el prisma de los supuestos de la teoría de la relevancia. Leinonen y Ryder (2008) señalan las ventajas de trabajar con esta teoría:

Working within a theoretical framework enables one to make testable predictions about the nature of language disorders and the kinds of behaviors that children and adults with impaired language production and comprehension are likely to exhibit. We have found that working with RT [Relevance Theory] has enable us to move from description of surface behaviors to a deeper understanding of why pragmatic language difficulties may come about and why they have the impact that they do on the quality of conversational interactions (Leinonen y Ryder, 2008: 58).

Con todo, la teoría de la relevancia nos ofrece un marco teórico sobre el que investigar la comprensión del lenguaje en pacientes con déficits lingüísticos, así como predecir el esfuerzo cognitivo implicado en los diferentes enunciados. Además, nos permite no solo describir los comportamientos comunicativos, sino explicar las dificultades pragmáticas, incluyendo aquellas que afectan a la calidad de las interacciones comunicativas. 



\section{CAPÍTULO 5}

\section{ESTUDIO EXPERIMENTAL SOBRE EL DESARROLLO DE LA COMPRENSIÓN PRAGMÁTICA DEL LENGUAJE}

\subsection{OBJETIVOS Y JUSTIFICACIÓN DE ESTE TRABAJO}

A lo largo de los capítulos anteriores hemos repasado teorías lingüísticas y cognitivas, así como factores, fenómenos y principios relativos a la competencia pragmática. Creemos ahora conveniente dar un paso más allá de la reflexión teórica y de la revisión de los estudios elaborados hasta el momento, y realizar una investigación experimental en la que podamos trabajar sobre el desarrollo de la competencia pragmática con datos reales. La investigación en este campo mantiene un buen número de interrogantes sobre los que pretendemos indagar con el fin de despertar el interés hacia futuras investigaciones más ambiciosas.

En este trabajo se incluyen las transcripciones de 140 entrevistas realizadas a niños de 3 a 9 años. Consideramos que la recopilación de corpus que recojan interacciones del habla de los niños es imprescindible para poder trazar las líneas generales del desarrollo verbal (Slobin, 1997). En efecto, disponer de datos representativos del habla infantil en las distintas fases del desarrollo es vital para la delimitación de perfiles y etapas evolutivas, así como para detectar posibles desviaciones o déficits. Tal como advierte Fernández Pérez (2006):

El habla de los niños tiene interés por sí misma. Es posible explorar su pertinencia en su eficacia comunicativa, no hay por qué recurrir a la lengua adulta. Prueba de su relevancia intrínseca es su función indicadora de sospecha en casos especiales o deficitarios de desarrollo verbal. Curiosamente, estas situaciones se detectan porque no encajan en la cadencia habitual del patrón adquisitivo (Fernández Pérez, 2006: 587).

De acuerdo con este planteamiento, el propósito principal de nuestro estudio experimental es llevar a cabo una aproximación al desarrollo de la comprensión pragmática del lenguaje en niños españoles dentro del marco de la teoría de la relevancia (Sperber y Wilson, 1986/1995). Para ello se analiza cómo los niños responden e interpretan distintos tipos de preguntas que comportan el procesamiento 
de implicaturas, referencias, rutinas, sentimientos, enriquecimiento e ironías y que requieren, por consiguiente, la recuperación tanto de la información contextual como del conocimiento enciclopédico. El diseño de la metodología de esta investigación ha sido tomado de los trabajos de Loukusa, Leinonen y Ryder (2007) y Loukusa, Ryder y Leinonen (2008) que demostraron que niños finlandeses entre 3 y 9 años desarrollaban la habilidad para usar la información contextual relevante cuando respondían a preguntas relacionadas con historias situadas en contextos familiares y previamente fijados por el interlocutor. Estos trabajos forman parte de la tesis doctoral de Soile Luokusa (2007) —investigadora del área de Pragmática y Psicolingüísticadesarrollada en el Departamento de Finés, Estudios de la Información y Logopedia y el Departamento de Pediatría de la Universidad de Oulu (Finlandia) y en cooperación con el Departamento de Psicología de la Universidad de Hertfordshire (Reino Unido). La Universidad de Oulu dispone también de un centro especializado: The Child Language Research Center (CLRC) (http://www.ouluclrc.fi/), cuya investigación se centra en áreas como el desarrollo del lenguaje en los niños, los trastornos del lenguaje, las bases neurobiológicas de la adquisición del lenguaje, etc.

La decisión de elaborar una réplica de este estudio (previo consentimiento y comunicaciones con las autoras) con niños españoles responde principalmente a dos razones. En primer lugar, entendemos que al tratarse de un estudio diseñado, revisado y ya probado por expertas en psicología del desarrollo infantil, logopedia y lingüística es una garantía de su validez. Además, hemos preferido centrarnos en el desarrollo de la comprensión pragmática frente a la producción porque creemos que es más proclive al análisis. Resulta más factible saber si el niño, como receptor, ha comprendido algo que se le ha dicho, que esperar a que él mismo produzca un enunciado que implique alguno de los fenómenos pragmáticos que queremos analizar.

Al mismo tiempo, consideramos que es de sumo interés mantener la misma estructura del estudio, en la medida de lo posible, para poder elaborar una comparación intercultural entre niños españoles y finlandeses y comprobar, así, si se repiten patrones en el desarrollo de la comprensión pragmática en ambas lenguas.

Dentro de los objetivos específicos de este trabajo se encuentra, por un lado, determinar cómo influye la variable edad y si influye la variable sexo en el número de 
respuestas válidas ${ }^{177}$ de los niños y en su habilidad para explicar de forma razonada sus conclusiones. Nos interesa especialmente indagar en qué momento del desarrollo el niño va adquiriendo la capacidad de comprensión de fenómenos pragmáticos tales como las implicaturas, las ironías o la asignación de referentes en el contexto, así como cuándo puede determinarse que los domina por completo. También nos ha parecido conveniente, como novedad frente a los estudios previos, clasificar a los niños no solo por edades sino por ciclos escolares ${ }^{178}$. Así, comprobaremos igualmente si hay diferencias significativas entre los niños de Educación Infantil y los de primer y segundo ciclo de Educación Primaria.

Por otra parte, en este estudio se analizan las respuestas y las explicaciones que son catalogadas como irrelevantes ${ }^{179} /$ fallidas basándonos en la teoría de la relevancia. Los datos de las respuestas y explicaciones fallidas se clasifican usando categorías que reflejan el modo en el que el niño ha utilizado la información contextual disponible. De esta forma, será nuestro siguiente objetivo, entonces, estudiar tanto el contenido de las contestaciones fallidas como las estrategias usadas por los niños cuando responden erróneamente o cuando ofrecen una explicación inapropiada a una respuesta válida. Basándonos en los primeros estudios relacionados (Marinac y Ozanne, 1999; Letts y Leinonen, 2001; Ryder y Leinonen, 2003), intuimos que el tipo de respuesta inapropiada variará en función de la edad, de forma que a mayor edad las respuestas fallidas serán más sofisticadas, esto es, más cercanas a la interpretación acertada.

${ }^{177}$ En este estudio hemos preferido la terminología respuesta válida y repuesta fallida frente a correcta e incorrecta utilizada en los trabajos anteriores. Esta decisión se debe a que queremos dejar claro que no juzgamos cuestiones de norma lingüística, lo que ocupa nuestro interés es la validez pragmática de las respuestas y explicaciones ofrecidas por los niños.

178 En el sistema educativo español establecido por el MECD (http://www.mecd.gob.es/educacion-mecd/areas-educacion/sistema-educativo/ensenanzas.html) se distinguen cinco grandes tipos de enseñanzas: la Educación Infantil, la Educación Primaria, la Educación Secundaria, la Educación Superior y las Enseñanzas de Régimen Especial. Los niños participantes en este estudio pertenecen a las etapas de Educación Infantil (segundo ciclo: de los 3 a los 6 años) y Educación Primaria: primer ciclo (cursos $1^{\circ}$ y $2^{\circ}$, de 6 a 8 años) y segundo ciclo (cursos $3^{\circ}$ y $4^{\circ}$, de 8 a 10 años). La referencia legislativa la constituye la Ley Orgánica Educativa (http://www.boe.es/boe/dias/2006/05/04/pdfs/A17158-17207.pdf), ya que aunque la Ley Orgánica para la Mejora de la Calidad Educativa (LOMCE) es posterior, no establece cambios a estos niveles educativos, salvo la novedad de realización de una evaluación individualizada de cada niño al finalizar $3^{\circ}$ de Primaria con el objeto de realizar una detección precoz de dificultades del lenguaje (http://www.boe.es/boe/dias/2013/12/10/pdfs/BOE-A-2013-12886.pdf).

${ }^{179}$ En este trabajo, relevante no solo significa que la respuesta se encuadra dentro del tópico, sino que además se espera que el niño haya utilizado la parte del contexto que era pertimente en relación con la pregunta. 
También se observará si en los resultados influye que el contexto dado —previo a las preguntas - sea únicamente verbal o tenga apoyo visual. Como veremos más adelante, en la descripción del material, algunas de las preguntas no solo son introducidas por la entrevistadora verbalmente, sino que además se sirven del apoyo de un dibujo que refleja lo que la entrevistadora describe oralmente. Analizaremos, por tanto, la influencia de la variable tipo de contexto en el número de respuestas y explicaciones válidas por parte de los niños.

Finalmente, constituye nuestro último objetivo la comparación de los resultados de este estudio realizado con niños españoles con los trabajos previos (Loukusa, Leinonen y Ryder, 2007; Loukusa, 2007; Loukusa, Ryder y Leinonen, 2008), que tienen como protagonistas a niños finlandeses. De esta forma, podremos determinar si la comprensión del significado pragmático puede entenderse como un proceso asociado a una lengua particular o si, por el contrario, existe un patrón adquisitivo común.

Este trabajo constituye, ante todo, una aproximación al estudio de este tipo de fenómenos pragmáticos dentro del desarrollo comunicativo y lingüístico de los niños españoles. No pretendemos llegar a conclusiones generales, sino dar algunas pinceladas, apoyadas en datos reales, que, en todo caso, deberán ser contrastadas con futuros análisis más amplios.

\subsection{MÉTODO}

\subsubsection{Participantes}

Los participantes en este estudio han sido niños españoles de edades entre 3 y 9 años. Fueron entrevistados en sus respectivos colegios (C.P. José Herrero en la localidad de Salamanca y C.P. Santa $\mathrm{M}^{\mathrm{a}}$ de la Candelaria en la localidad de Zamora). Solo se han tenido en cuenta los datos de los niños con desarrollo normal. Para ello se ha preguntado a padres y a profesores sobre su historial médico y pedagógico, haciendo hincapié en lo concerniente al desarrollo del lenguaje. De esta forma, el niño se excluye si sus tutores o profesores han percibido algún problema en su desarrollo. Este es el caso de dos niños de 2 y 5 años que mostraron problemas de atención y lingüísticos respectivamente y, por ello, sus datos no han sido tenidos en cuenta en este trabajo. 
La petición para llevar a cabo este estudio se hizo en primer lugar mediante entrevistas personales con los directores de ambos centros. Una vez obtenida su aprobación y la del equipo docente, los padres fueron informados y se les entregó una hoja de consentimiento (véase anexo 6) que los niños trajeron firmada a clase al cabo de unos días. La participación de unos niños y no de otros dependió de si tenían dicha autorización firmada.

Los padres de 174 niños dieron su aprobación para que sus hijos fueran entrevistados. De ellos, 168 realizaron la entrevista y los datos de un total de 140 (elegidos aleatoriamente teniendo en cuenta únicamente la edad y el sexo) se analizan en este estudio. Los niños se dividen en 7 grupos en función de sus edades. Asimismo, se ha intentado entrevistar a un número equitativo de niñas y niños. En general, cada grupo está formado por 10 niñas y 10 niños, con algunas excepciones que pueden verse en la siguiente tabla:

\begin{tabular}{|llllllll|}
\hline & $\mathbf{3}$ años & $\mathbf{4}$ años & $\mathbf{5}$ años & $\mathbf{6}$ años & $\mathbf{7}$ años & $\mathbf{8}$ años & $\mathbf{9}$ años \\
Número & 20 & 20 & 20 & 20 & 20 & 20 & 20 \\
Niños/ Niñas & $9 / 11$ & $9 / 11$ & $12 / 8$ & $10 / 10$ & $10 / 10$ & $10 / 10$ & $10 / 10$ \\
Edad (meses) & & & & & & & \\
MEDIA & 42.65 & 53.05 & 65.2 & 78.75 & 90.4 & 101.8 & 114.4 \\
DE & 2.94 & 3.35 & 3.94 & 3.45 & 2.54 & 3.86 & 3.38 \\
Media (años) & 3.55 & $\mathbf{4 . 4 2}$ & $\mathbf{5 . 4 3}$ & $\mathbf{6 . 5 6}$ & $\mathbf{7 . 5 3}$ & $\mathbf{8 . 4 8}$ & $\mathbf{9 . 5 3}$ \\
\hline
\end{tabular}

Tabla 6. Características de los participantes en función de la edad

\subsubsection{Materiales}

Como mencionamos anteriormente, la metodología de este estudio está basada en los trabajos pioneros de Loukusa, Leinonen y Ryder (2007), Loukusa (2007) y Loukusa, Ryder y Leinonen (2008). Las autoras realizaron entrevistas individuales a niños finlandeses de las citadas edades. Las entrevistas se componían de preguntas breves sobre variadas historias, algunas con el apoyo visual de un dibujo y otras no. Dichas preguntas fueron construidas para investigar las habilidades de comprensión pragmática que postula la teoría de la relevancia de Sperber y Wilson (1995). 
En consecuencia, gran parte del material utilizado está tomado de los estudios mencionados anteriormente. Los dibujos se han conservado intactos (véase anexo 7), pero con respecto a las preguntas, que naturalmente han sido traducidas al español, hemos introducido algunos cambios que hemos considerado convenientes, hemos añadido algunas (las incluidas en el nuevo apartado referente a la ironía) y hemos eliminado otras debido a su estrecha relación con motivos culturales fineses (como, por ejemplo, la costumbre sistemática de que los niños coman caramelos los sábados).

El contexto dado consiste en dibujos, pequeños escenarios y una breve historia que es presentada en pequeñas secciones con el fin de minimizar los esfuerzos de memoria. Asimismo, la gramática y el vocabulario de las preguntas se han simplificado lo máximo posible para facilitar su comprensión.

Antes de realizar el estudio, el material fue probado en un estudio piloto con cuatro niños de 3, 5, 6 y 9 años. De esta forma, fue excluida una pregunta de asignación de referencia porque no funcionó bien con ninguno de ellos: los cuatro niños la interpretaron mal. Igualmente, se desambiguaron algunas expresiones y se simplificó el contexto verbal de dos historias. En este análisis preliminar se observó que el niño de 9 años respondía acertadamente al 90\% de las preguntas. Por ello, basándonos en este resultado y en los estudios de Loukusa, Leinonen y Ryder (2007) y Loukusa, Ryder y Leinonen (2008), que también trabajaron con niños de una edad máxima de 9 años, decidimos establecer en esa edad el corte y no entrevistar a niños que la superaran.

El material que finalmente compone este estudio está formado por 42 preguntas, que se clasifican en seis tipos: de asignar referencias (8), de enriquecimiento (8), implicaturas (10), rutinas (6), de sentimientos (5) e ironías (5). Todas las preguntas se construyen de una forma similar, de manera que se espera que los niños conecten su conocimiento del mundo con el contexto visual o verbal dado y lleguen a una conclusión. No todas las preguntas disponen de apoyo visual, en algunas solo se presenta verbalmente una historia (véase fig. 13).

Tras enunciar las preguntas (con excepción de las de referencia y enriquecimiento), si el niño proporciona una repuesta válida se le pide que dé una explicación preguntándole ¿cómo sabes eso? o ¿por qué piensas eso? Una de las implicaturas (la número 21) no requiere explicación. En ella, después de oír la historia 
de un perro que se escapa y no obedece a su dueña, a los niños se les pregunta qué creen que pasará después en la historia. En sus respuestas es frecuente que los niños se refieran a una parte anterior de la historia, por lo que preguntar por una explicación no tendría sentido. Igualmente, no se pide a los niños que justifiquen sus respuestas de asignación de referentes y de enriquecimiento. En consecuencia, en estos dos tipos de preguntas solo se codifican los datos de respuestas válidas/fallidas.

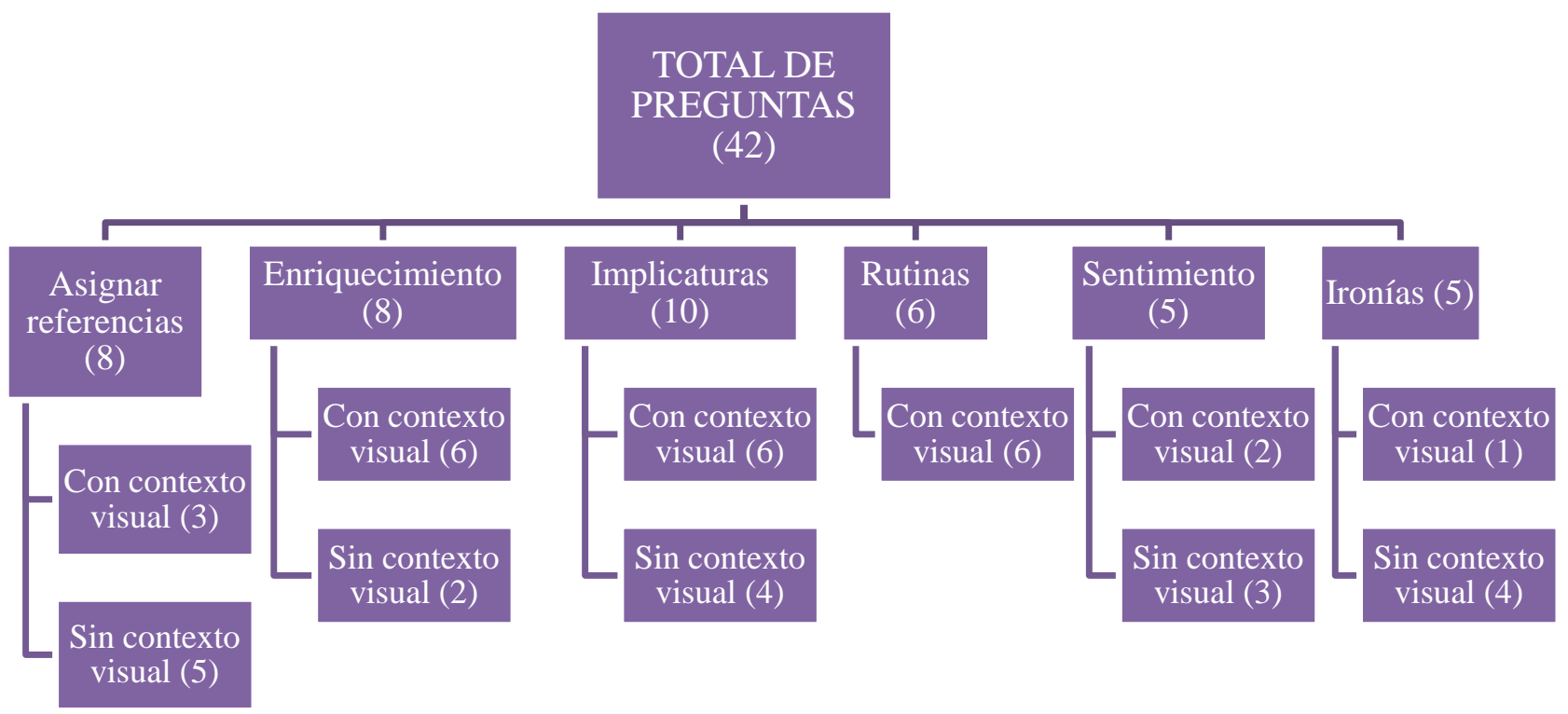

Figura 13. Clasificación de las preguntas

En las preguntas de referencia, el niño debe asignar el referente de un objeto o una persona mencionados antes en la historia (a veces reforzados por el soporte visual). A nuestro juicio estas serán las preguntas más fáciles desde el punto de vista de la demanda contextual, ya que el niño solo tiene que encontrar el elemento previamente mencionado en el contexto verbal, $y$ no es necesario ningún procesamiento más allá de la información dada. El test se ha centrado, por tanto, en referencias endofóricas, si bien es cierto que también se dan procesos de deixis exofórica cuando los niños se ayudan de los dibujos para reconocer la referencia. Además, en todos los casos se trata de referencias anafóricas, en las que un elemento remite a otro que ha aparecido anteriormente, de forma que se establece una relación entre dos unidades lingüísticas en la que la segunda adquiere sentido por su relación con la que se ha mencionado antes en el contexto.

Para responder a las preguntas de enriquecimiento el niño debe enriquecer la información semántica incompleta basándose en el contexto verbal (y/o visual) y en su 
propio conocimiento del mundo. Se trata de un proceso a menudo inconsciente en el que el oyente termina de completar la información que no queda especificada en el enunciado. Para ello elige la forma más accesible o evidente en el contexto de acuerdo con la teoría de la relevancia.

Las preguntas con implicaturas requieren que el niño conecte su conocimiento del mundo con el contexto verbal (y/o visual) para llegar a la inferencia, esto es, para recuperar el significado pretendido (intended). Para hacerlo más fácil, las preguntas de implicaturas se basan en temas corrientes como, por ejemplo, mojarse cuando llueve.

De igual manera, las preguntas de rutinas están orientadas a que el niño procese una pregunta relacionada con el contexto familiar de cada día, lo que lleva normalmente al acceso automático de la respuesta. La diferencia entre las preguntas con implicaturas y las preguntas de rutinas es únicamente la familiaridad del contexto. Como ya hemos mencionado antes, las preguntas con implicaturas tratan temas que les son cercanos a los niños; mientras que las rutinas utilizan un contexto que forma parte del día a día y les es sumamente familiar, como ir a cenar cuando se les dice que la cena está lista.

En las preguntas de sentimiento los niños deben reconocer los sentimientos de algún personaje de la historia. En estas preguntas el niño tiene que conectar su conocimiento del mundo con la información dada (por ejemplo, saber que es embarazoso salir a la calle con la camiseta del revés sin darse cuenta) y, por lo tanto, requieren también un procesamiento inferencial.

Finalmente, en las preguntas de ironía (creadas como novedad para este estudio $^{180}$ ) el niño debe ser capaz de captar el tono con el que se emiten los enunciados de las historias y utilizar el contexto dado (verbal o visual) para saber que los protagonistas de estas se refieren a lo contrario de lo que dicen. En todos los casos se trata de expresiones contrafactuales del tipo "una persona dice $p$ para intentar decir no$p^{\text {"181. }}$.

A continuación presentamos ejemplos de los diferentes tipos de preguntas:

\footnotetext{
${ }^{180}$ Las preguntas de ironía han sido creadas con base en un ejemplo proporcionado por la investigadora Soile Loukusa, que finalmente no utilizó en su investigación doctoral. Por tanto, se han diseñado en la misma línea del resto de preguntas, con vocabulario y gramática sencillos y situaciones contextuales familiares.

${ }^{181}$ Para una descripción más completa de estas tareas pragmáticas véase capítulo 3 apartado 3.3.2. 224
} 


\section{-Pregunta de referencia}

Escenario: una mujer llega a casa después del trabajo. Su perro la está esperando en casa. Ha estado solo todo el día y necesita hacer pipí. La mujer saca al perro a la calle.

Pregunta: ¿quién ha estado solo todo el día?

Contexto dado (verbal): el perro está esperando en casa. Ha estado solo todo el día y necesita salir a hacer pis.

Conocimiento general: quién se refiere al perro mencionado en la frase anterior.

Respuesta: el perro.

\section{-Pregunta de enriquecimiento}

Escenario: una niña y un niño están en un quiosco. Le piden a la dependienta una bolsa de gusanitos y un chupachús. La dependienta les pregunta: “¿algo más?”

Pregunta: ¿qué les está preguntando la dependienta?

Contexto dado (verbal y visual): en el dibujo los niños están en un quiosco donde venden chucherías y helados. Los niños le piden a la dependienta una bolsa de gusanitos y dos chupachús.

Conocimiento general: en las tiendas es frecuente ir pidiendo por orden al dependiente los artículos que queremos y que este nos pregunte si queremos alguna cosa más antes de decirnos lo que le debemos.

Respuesta: que si quieren alguna cosa más

\section{-Pregunta de implicatura}

Escenario: es el dibujo de un pueblo en un día de lluvia. Hay coches circulando por la carretera y un chico cruzando por el paso de cebra.

Pregunta: ¿ ¿por qué el niño está sujetando un libro por encima de la cabeza?

Contexto dado (verbal y visual): está lloviendo. El niño no tiene paraguas ni chubasquero.

Conocimiento general: a la gente no le gusta mojarse cuando llueve. Sujetar algo por encima de la cabeza puede evitar que nos mojemos mucho.

Respuesta: el niño lleva el libro por encima de la cabeza para no mojarse.

\section{-Pregunta de rutina}

Escenario: los niños están jugando en el jardín. Un niño tiene un balón en las manos. La madre dice a los niños: "la cena está lista".

Pregunta: ¿qué quiere decir la madre?

Contexto dado (verbal y visual): los niños están jugando en el jardín. La madre se asoma para decirles que la cena está lista. 
Conocimiento general: lista significa que debe ser comida pronto porque si no se enfría.

Respuesta: los niños tienen que dejar de jugar y entrar dentro para cenar.

\section{-Pregunta de sentimiento}

Escenario: un chico se ha puesto la camiseta del revés por error. Sus compañeros de clase se ríen de él.

Pregunta: ¿cómo se siente el chico?

Contexto dado (verbal): un chico se ha puesto la camiseta del revés y sus compañeros se ríen de él.

Conocimiento general: si te pones la camiseta del revés es gracioso, pero que tus compañeros se rían de ti en clase cuando no has hecho ninguna broma es embarazoso, y saber que te has puesto la camiseta del revés también lo es. Además a nadie le gusta que se rían de él de esta manera.

Respuesta: el niño se siente mal, avergonzado.

\section{-Pregunta de ironía}

Escenario: está lloviendo fuera. La madre mira por la ventana y dice (de forma sarcástica): “iqué día tan bonito!”.

Pregunta: ¿qué quiere decir la madre?

Contexto dado (verbal y visual): la madre está mirando por la ventana. Fuera llueve mucho. Dice la frase con tono sarcástico.

Conocimiento general: en general a la gente no le gusta que llueva. A veces decimos lo contrario de lo que queremos decir sabiendo que nuestro interlocutor entenderá que estamos siendo irónicos.

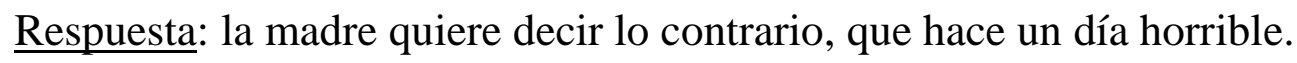

Como comentamos anteriormente, además de responder a las preguntas planteadas, a los niños se les pide que expliquen sus repuestas para así comprobar cómo las han derivado del contexto. Solo se les solicita una explicación si su respuesta es válida.

En cuanto a las respuestas fallidas, estas se clasifican en función de la información dada en las respuestas. Lo mismo se hace con las explicaciones fallidas de respuestas válidas. Las categorías ${ }^{182}$ (siguiendo el modelo de Loukusa, 2007: 60-61) son las siguientes:

${ }^{182}$ En estas categorías vemos un reflejo de los casos en los que un supuesto se considera irrelevante en un contexto (Sperber y Wilson, 1995): 
1. Foco incorrecto: la respuesta muestra entendimiento de lo que ocurre en el escenario pero falla a la hora de señalar el foco con precisión, de forma que la respuesta es imprecisa y no se puede aceptar como válida. Aunque el niño no es capaz de responder a la pregunta con precisión, la respuesta no muestra ninguna utilización de parte irrelevante del contexto. Estas respuestas son las más cercanas a las respuestas válidas si las comparamos con el resto de categorías.

2. Conocimiento del mundo: el niño ofrece una información general o habla de su propia experiencia, las cuales están vagamente vinculadas semánticamente con la pregunta, pero no encajan en el contexto particular de esta. Consecuentemente, la respuesta muestra que el niño ha usado su conocimiento del mundo de un modo incorrecto sin valerse de la información contextual específica relevante para la pregunta en cuestión.

3. Información dada: el niño utiliza la información visual y verbal dada inapropiadamente. La respuesta hace referencia a algún aspecto del dibujo o del escenario verbal, pero dicho aspecto no es relevante para la pregunta.

4. No sé: el niño responde "no sé”.

5. Irrelevante: la respuesta no contiene nada que pueda conectarse con el contexto de la pregunta.

6. Tautológica o ecoica: el niño repite la pregunta o parte de ella.

7. Turno de palabra: el niño usa una frase rutinaria para contestar. Por ejemplo, cuando se le pregunta "¿por qué?" el niño responde "porque”, y cuando se le pregunta “¿cómo?”, el niño responde “así”.

8. No hay respuesta

9. Otras: por ejemplo, las relacionadas con el mundo de la fantasía.

\subsubsection{Procedimiento}

\subsubsection{Entrevistas}

En general los niños han sido encuestados de forma individual en una clase tranquila durante el horario escolar. A veces ha sido difícil encontrar aulas vacías o informar a todos los profesores de las aulas en las que van llevarse a cabo las entrevistas en cada momento. Por ello, en algunas sesiones aparece un profesor que

-El supuesto aporta información nueva que no guarda conexión en contexto.

-El supuesto ya estaba presente en el contexto.

-El supuesto es incoherente en el contexto y si se procesara no proporcionaría ningún cambio. 
entra en ese momento, saluda y se va. Otras veces es necesario interrumpir la entrevista porque esa clase va a ser ocupada por algún grupo de niños y se continúa en una clase diferente. En este caso las entrevistas tienen dos partes, o incluso tres. Esto queda reflejado en la numeración de las grabaciones, que cuentan con dos números consecutivos, por ejemplo: A24-25.

Por otro lado, algunas entrevistas de los alumnos del colegio Santa $\mathrm{M}^{\mathrm{a}}$ de la Candelaria tienen lugar en la sala de profesores. El mayor problema en esta sala es que se encuentra situada en el primer piso, justo encima del gimnasio, y este no está insonorizado, por lo que en algunas entrevistas se oye música, gritos de niños o la voz del profesor o profesora de educación física. Si esto supone la desconcentración del niño, la entrevista se interrumpe también. Esto no suele ocurrir porque los niños entrevistados allí fueron los de edades superiores y el ruido fuera de la sala no supuso un motivo para perder la concentración. En el caso de los niños del colegio José Herrero, no se presentan estas complicaciones, ya que las entrevistas tuvieron lugar en la hora de madrugadores, esto es, una hora antes de que empiecen las clases, por lo que dispusimos de clases vacías en todo momento.

Los materiales se presentan directamente en una mesa en frente del niño. A los niños se les dice que la investigadora les va a hacer unas preguntas sobre unos dibujos e historias y se les pide que escuchen atentamente. En el caso de los niños más pequeños de 3 y 4 años, la entrevistadora pasó algún tiempo en clase y en el recreo con ellos para que se sintieran cómodos y pudieran responder sin timidez a las preguntas. En la mayoría de las sesiones, al inicio o al final de la entrevista se les pregunta a los niños cuándo es su cumpleaños para calcular su edad con exactitud en función del día en el que se realizó la entrevista y su fecha de nacimiento. En el caso de los niños más pequeños, tras comprobar que la mayoría no recuerda la fecha, se decide que esa información se le consultará más tarde a los tutores para no perder tiempo.

Cada sesión tiene una duración media de 10 a 13 minutos, si bien es cierto que las de los niños más mayores pueden ser más breves, ya que responden con mayor rapidez y son más concisos. En algunas entrevistas, en ocasiones puntuales, a los niños se les repite una pregunta si por algún motivo se cree que se han distraído, pero lo normal es que se realicen las preguntas todas seguidas, sin pausas y siguiendo siempre 
el mismo orden en el que se combinan aquellas que tienen dibujos con las que no los tienen.

Las sesiones fueron registradas con una grabadora de voz. Inmediatamente después, fueron escuchadas atentamente y transcritas siguiendo un sistema de convenciones (que veremos a continuación) diseñado para este estudio. Las transcripciones han sido revisadas en 3 ocasiones con un lapso de tiempo intermedio de 6 a 10 meses, con el propósito de obtener la mayor objetividad y precisión posibles.

Para mantener el anonimato de los niños, a las grabaciones y transcripciones correspondientes se les asigna una letra inicial (de la $\mathrm{A}$ a la D) y un número. Este sistema corresponde a la propia división de cada uno de los archivos que realiza la grabadora empleada.

\subsubsection{Transcripciones}

Como se ha expuesto desde el comienzo, el propósito de este trabajo no es el análisis del discurso. Al tratarse de entrevistas con preguntas estructuradas de antemano, las interacciones grabadas siguen el esquema de pregunta-respuesta, el cual es generalmente respetado presentando escasos solapamientos. En las ocasiones en las que la entrevistadora es interrumpida por el niño o la niña, no intenta mantener el turno, sino que le deja expresar lo que quiera decir en ese momento, incluso cuando a primera vista no es relevante para la pregunta en cuestión. Somos conscientes de que transcribir datos es una tarea laboriosa que implica tomar una serie de decisiones que manifiestamente afectan y forman parte del propio análisis. Se ha asumido como criterio de partida que la transcripción debe servir para facilitar la lectura, no para dificultarla, por lo que no colmamos los textos de símbolos, sino que usamos los que únicamente creemos motivados, familiares y transparentes. Así, partiendo de las múltiples propuestas a nuestro alcance sobre métodos de transcripción (Sacks, Schegloff y Jefferson, 1974; Du Bois, 1991; Gumperz y Berenz, 1993; Poyatos, 1994; Payrató, 1995; Tusón Valls, 1997; Calsamiglia et al., 1997; Briz y grupo Val.Es.Co, 2002) y dados nuestros objetivos de análisis, hemos optado por unas convenciones simplificadas y reducidas que aparecen reflejadas en la tabla 7.

En la línea de los procesamientos habituales en análisis de la conversación (Calsamiglia et al., 1997: 52-53) hemos utilizado la ortografía estándar del español. 
No obstante, se han representado las maneras particulares de hablar si algún participante utiliza una variedad lingüística muy marcada. Por ejemplo, se reflejan algunos rasgos característicos de la pronunciación espontánea usando signos gráficos normales en la escritura del español y otros fácilmente incorporables como el apóstrofo, que señala las elisiones de vocales en la juntura entre palabras (s'han divertido, qu'hace, s'ha caído, s'han portado, etc.) ${ }^{183}$. Sin embargo, damos por supuestas pronunciaciones habituales en las realizaciones no esmeradas; por ejemplo, transcribimos con ' $\mathrm{x}$ ' respetando la ortografía palabras como exactamente que son pronunciadas casi sistemáticamente con [s]. Tampoco alteramos la grafía 'd' en

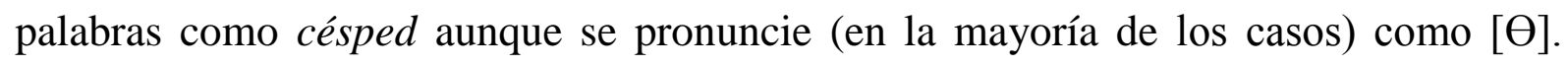
Con el fin de facilitar las operaciones informáticas no se utilizan mayúsculas, salvo el caso de nombres propios ${ }^{184}$. Y representamos la pronunciación real del hablante reflejando procesos fonéticos consolidados como casos de omisión de la 'd' en participios, contracciones, etc.; por ejemplo: pa no mojarse la cabeza, hemos terminao, mu tonto, pos, etc.

\begin{tabular}{|c|c|}
\hline \multicolumn{2}{|c|}{ Símbolos } \\
\hline$[\mathrm{xxx}]>$ & Segmento solapado con otro posterior \\
\hline$<[\mathrm{xxx}]$ & Segmento solapado con otro anterior \\
\hline$:$ & Segmento fónico alargado \\
\hline 1 & Pausa breve \\
\hline$/ /$ & Pausa media (de hasta dos segundos) \\
\hline$/ / /$ & Pausa larga (de más de dos segundos ) \\
\hline$\{x x x\}$ & Aclaraciones y acotaciones \\
\hline $\mathrm{XXX}-$ & Segmento inconcluso \\
\hline “XXX” & Discurso referido \\
\hline$(\mathrm{xx}) \mathrm{xx}$ & $\begin{array}{l}\text { Reconstrucción de una unidad léxica que se ha pronunciado errónea o } \\
\text { incompleta, cuando pueda perturbar la comprensión }\end{array}$ \\
\hline Pa'l & Fenómenos de fonética sintáctica entre palabras, especialmente marcados \\
\hline${ }^{\circ}(\mathrm{xxx})^{\mathrm{o}}$ & Fragmento pronunciado en un tono de voz más bajo, próximo al susurro \\
\hline ¿'? & Interrogaciones \\
\hline ¡! & Exclamaciones \\
\hline O: & Turno de palabra de un participante masculino \\
\hline A: & Turno de palabra de una participante femenina \\
\hline S: & Turno de palabra de la entrevistadora: Susana \\
\hline P: & Turno de palabra de algún profesor que interrumpe la entrevista \\
\hline
\end{tabular}

Tabla 7. Sistema de convenciones para la transcripción

\footnotetext{
${ }^{183}$ Renunciamos, por tanto, a las precisiones de un sistema de transcripción fonética especializado como el Alfabeto Fonético Internacional o el usado en la Revista de Filología Española, ya que este trabajo no se centra en el estudio del plano fónico.

${ }^{184}$ Cuando se trata del nombre propio del niño entrevistado se transcribe con la inicial seguida de un punto para mantener el anonimato.

230
} 
Asimismo, utilizamos los paréntesis para restaurar segmentos de palabras o unidades no emitidos o emitidos incorrectamente, pero que son perfectamente recuperables: (v)amos, e(s d)ecir, po(r)que, $t(r) e s$, (b)ueno, e(s)te, etc. Igualmente, empleamos las llaves y la letra cursiva para algunas acotaciones imprescindibles de contenido paralingüístico vocal y para todo tipo de situaciones metalingüísticas o situacionales: \{ininteligible $\},\{$ risas $\},\{$ ruido externo\}, \{alguien entra en la sala $\},\{e l$ niño tose\}, \{la niña señala algo en un dibujo\}, \{el niño niega con la cabeza\}, etc. Mientras que para favorecer la lectura y comprensión del corpus renunciamos a las precisiones de un sistema de transcripción fonética y corregimos las pronunciaciones erróneas o restauramos las no emitidas (sustituimos güeno por (b)ueno, tolo por to(d)o, fores por $f(l)$ ores, ect.), sí que mantenemos las desviaciones de la norma en el plano léxico (cocretas por croquetas, almóndigas por albóndigas, asín por así, etc.) y en el morfológico-sintáctico ( dijistes por dijiste, ponido por puesto, sabo por sé, rompido por roto, daros prisa por daos prisa, etc.), ya que aportan rasgos interesantes del habla infantil que no podemos pasar por alto y que pueden ser útiles para análisis posteriores de otra naturaleza.

No hemos reflejado algunos rasgos prosódicos (tono ascendente, tono descendente, tono agudo, tono grave, ritmo acelerado, ritmo lento, etc.) que suelen utilizarse en los estudios de textos conversacionales, ya que nuestro trabajo no está centrado en lo prosódico y tampoco disponemos de medios electrónicos o informáticos con los que analizar las grabaciones. No obstante, incluimos símbolos correspondientes a entonación interrogativa (i?), entonación exclamativa (i!), pronunciación cercana al susurro $\left({ }^{\circ}(\mathrm{xxx})^{\circ}\right)$ y corte o segmento inconcluso (xxx-). Empleamos los signos tradicionales de admiración e interrogación en aquellos enunciados que claramente se emiten como admiraciones o interrogaciones, pero no en aquellos que, siendo entendidos como tales, corresponden a declaraciones. En algunas ocasiones se emplea únicamente el signo de cierre de interrogación o admiración. Se trata de aquellos casos en los que el enunciado cobra carácter interrogativo o exclamativo a medida que va siendo producido y no desde el principio de su emisión.

Los corchetes se utilizan para indicar los solapamientos de turnos. El signo [xxx]> indica que lo contenido entre corchetes se solapa con lo contenido entre los siguientes corchetes. De igual manera, el signo $<[\mathrm{xxx}]$ indica que lo contenido entre 
corchetes se solapa con lo incluido entre los anteriores corchetes. Renunciamos, por tanto, a la costumbre en los trabajos de análisis de la conversación de hacer coincidir verticalmente los solapamientos de turnos, ya que consideramos que dificulta la consulta de las transcripciones y que cualquier cambio en la disposición de márgenes o sangrados puede acabar con las columnas de elementos solapados.

Con relación a las pausas, hemos elegido un sistema simple. Utilizamos el símbolo / para representar pausas breves o indicios claros de transcripción tonal, cuando tales pausas coinciden con las que se señalan en las transcripciones ortográficas habituales o en cualquier otro contexto ${ }^{185}$; el símbolo // se usa para una pausa media (de hasta dos segundos) y el símbolo /// refleja una pausa larga (de más de dos segundos) y pueden señalar, por ejemplo, un cambio de tópico o la reformulación del anterior. De esta manera, si no se señala otra cosa y cuando no hay solapamientos, se entiende que los turnos se enlazan sin pausas relevantes. De hecho, no hemos marcado las pausas breves al inicio de un turno porque consideramos que depende del propio ritmo de la entrevista, de esta forma solo marcamos la pausa media y la larga para indicar que el niño se lo piensa o tarda en dar una respuesta más tiempo de lo esperado en función de la propia dinámica conversacional.

\subsubsection{Recuento de respuestas válidas/fallidas}

Finalmente, una vez realizadas las transcripciones, se han analizado y contabilizado los datos. La teoría de la relevancia ha sido la base para decidir qué respuestas se consideraban válidas (apropiadas) y cuáles no. Cada respuesta ha sido estudiada minuciosamente antes de calcular los resultados de cada niño. Lo normal es que muchas respuestas y explicaciones se repitan de forma idéntica, lo que ha permitido elaborar un esquema de posibles respuestas válidas, y de esta forma se ha agilizado la tarea de analizar y contabilizar preguntas válidas y fallidas.

Así, podemos resumir el procedimiento de este estudio en la siguiente figura:

\footnotetext{
${ }^{185}$ Muchas veces los hablantes no hacemos pausas donde la norma las supone y, paralelamente, es habitual hacerlas en los lugares más insospechados. 


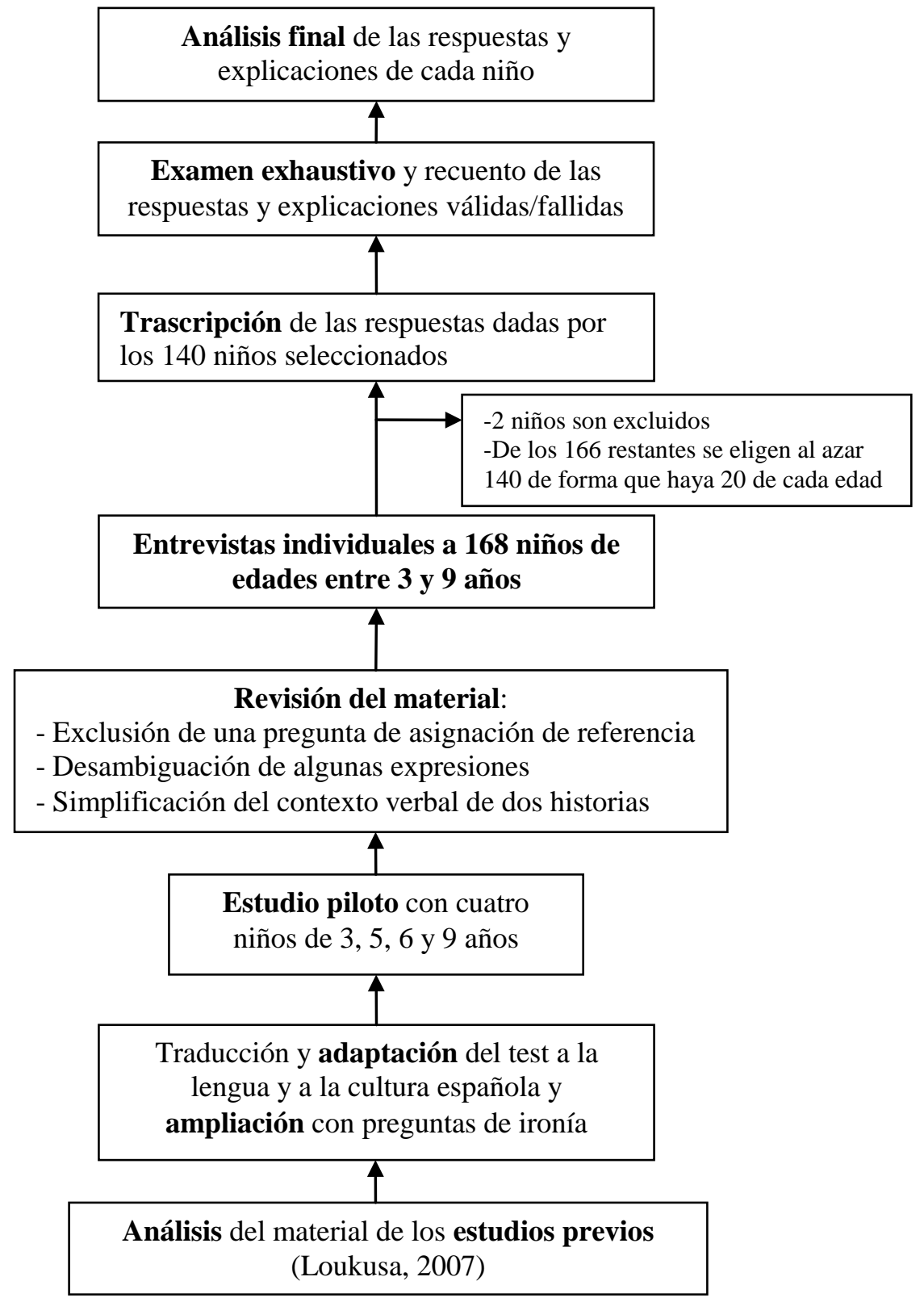

Figura 14. Esquema del desarrollo del estudio

\subsection{ANÁLISIS ESTADÍSTICO DE LOS RESULTADOS}

El análisis de los datos obtenidos se ha realizado con el paquete estadístico SPSS 20.0 para Windows y se ha centrado en el estudio de tres variables fundamentales: variable sexo, variable edad y variable tipo de contexto (visual/no visual). Antes de comenzar el análisis, se ha comprobado la distribución de la variable dependiente número de respuestas válidas (Respval)/número de explicaciones válidas (Explval) mediante la prueba de contraste Kolmogorov-Smirnov (que plantea como hipótesis nula que los datos se distribuyen de manera normal). De forma general, los valores de $p$ han resultado significativos, por lo que en los análisis hemos aplicado pruebas no 
paramétricas (Mann-Whitney o Kruskal-Wallis). Las veces en las que el supuesto de normalidad se cumple hemos aplicado pruebas paramétricas como T-Student o ANOVA. No obstante, al tratarse de muestras no muy extensas, hemos considerado oportuno repetir el análisis aplicando también pruebas no paramétricas. En estos casos, los resultados provenientes de las pruebas paramétricas y no paramétricas coinciden o son muy próximos entre sí y, por ello, hemos decidido reflejar los datos de las no paramétricas de forma que el trabajo sea homogéneo.

Por otro lado, en aquellas pruebas en las que hemos obtenido significación asintótica (bilateral) y significación exacta ${ }^{186}$, hemos optado por el valor de $p$ exacto, ya que la aproximación normal funciona bien si el tamaño de la muestra es grande, pero en tamaños muestrales limitados como el nuestro, en los que se usan métodos no paramétricos, en general, se prefiere el valor de $p$ exacto siempre que sea posible obtenerlo.

En cuanto al recuento de las respuestas y explicaciones fallidas, los porcentajes de cada categoría o tipo de respuesta fallida en cada grupo de edad han sido convertidos en frecuencias relativas (porcentaje de respuestas válidas de cada categoría en relación con el número total de respuestas fallidas en ese intervalo de edad). De esta forma, las comparaciones no se ven afectadas por el diferente número de respuestas y explicaciones fallidas entre las diferentes edades, lo cual permite que se realicen comparaciones de las distribuciones de frecuencias relativas entre los diferentes grupos.

\subsubsection{Variable edad}

Para analizar la posible dependencia del número de respuestas/explicaciones válidas respecto a la edad del niño se ha empleado el test no paramétrico de KruskalWallis. Como ya hemos mencionado anteriormente, dicha prueba es equivalente a un ANOVA, pero sin el supuesto de normalidad para la población en estudio. El objetivo del mismo es determinar si los datos sometidos a contraste proceden o no de poblaciones diferentes, es decir, si la variable independiente (edad) condiciona el comportamiento de la variable dependiente (número de respuestas/explicaciones

\footnotetext{
${ }^{186}$ La sig. asintótica bilateral es el valor $p$ bilateral aproximado 0,045 y proviene de las tablas de la distribución normal; la sig. exacta 0,052 es el valor $p$ para el test exacto que propuso Wilcoxon originalmente.

234
} 
válidas). En todos los casos, tras obtener un estadístico significativo en Kruskal Wallis se ha empleado el test no paramétrico de Mann-Whitney para efectuar múltiples comparaciones entre las distintas edades. De esta forma, se han llevado a cabo contrastes para cada tipo de pregunta, confrontando cada grupo de edad con los tres consecutivos. Cuando no se ha podido demostrar la existencia de diferencias estadísticamente significativas entre dos niveles de edad, estos han sido reagrupados y se ha repetido el análisis. En todos los casos el nivel de significación empleado es de 0,05, es decir, para rechazar la hipótesis nula en el contraste (el número medio de respuestas/explicaciones válidas es igual en ambos grupos de edad) es necesario que el Error de Tipo I (probabilidad de rechazar la hipótesis nula) sea inferior a 0,05.

Los resultados se muestran en tablas que recogen los valores de $p$ correspondientes a cada uno de los contrastes realizados. Diremos que existen diferencias estadísticamente significativas cuando el valor de $p$ es inferior a 0,05 , esto es, cuando la hipótesis nula viene rechazada y, por tanto, queda evidenciado que la edad influye en el número de respuestas/explicaciones válidas. Cuando no se detecten diferencias estadísticamente significativas tomaremos por cierto que en esos niveles de edad la variable de respuestas/explicaciones tiene un comportamiento similar y, consecuentemente, la edad no influye en el mismo.

- Preguntas de ENRIQUECIMIENTO

Tabla 8.Valores de $p$ (U de Mann-Whitney) Respuestas Válidas

\begin{tabular}{|ll|}
\hline $\begin{array}{l}\text { Comparación } \\
\text { por edades }\end{array}$ & $\begin{array}{l}\text { Respval } \\
\text { Sig. }\end{array}$ \\
\hline 3 y 4 & $.006^{*}$ \\
\hline 3 y 5 & $.000^{*}$ \\
\hline 3 y 6 & $.000^{*}$ \\
\hline 4 y 5 & .063 \\
\hline 4 y 6 & $.000^{*}$ \\
\hline 4 y 7 & $.000^{*}$ \\
\hline 5 y 6 & $.017^{*}$ \\
\hline 5 y 7 & $.003^{*}$ \\
\hline 5 y 8 & $.000^{*}$ \\
\hline 6 y 7 & .398 \\
\hline 6 y 8 & $.000^{*}$ \\
\hline 6 y 9 & $.000^{*}$ \\
\hline 7 y 8 & $.004^{*}$ \\
\hline 7 y 9 & $.001^{*}$ \\
\hline 8 y 9 & .738 \\
\hline
\end{tabular}

Nivel de significación $\mathrm{p}<.05$ 
Tabla 9. Valores de $p$ (U de Mann-Whitney) Respuestas Válidas

\begin{tabular}{|ll|}
\hline $\begin{array}{l}\text { Comparación } \\
\text { por grupos de } \\
\text { edad }\end{array}$ & $\begin{array}{l}\text { Respval } \\
\text { Sig. }\end{array}$ \\
\hline 3-4y5 & $.000^{*}$ \\
\hline 4y5- 6y7 & $.000^{*}$ \\
\hline 6y7 - 8y9 & $.000^{*}$ \\
\hline
\end{tabular}

Nivel de significación $\mathrm{p}<.05$

Atendiendo a los valores de $p$ que se muestran en la tabla 8, el resultado es que se rechaza la hipótesis nula en todos los casos salvo cuando se compara el grupo de 4 con el de 5 años, el de 6 con el de 7 y el de 8 con el de 9, dentro de los cuales el comportamiento de la variable respuesta es similar. Esto justifica la formación de tres nuevos grupos y la repetición de los contrastes, cuyos resultados, mostrados en la tabla 9, evidencian que el número de respuestas válidas para las preguntas de enriquecimiento depende de manera directamente proporcional de la variable edad siempre que los sujetos vengan agrupados del siguiente modo: 3 años, 4 y 5 años, 6 y 7 años, 8 y 9 años. Nótese que dichos grupos guardan una estrecha correspondencia con los ciclos de estudio establecidos en la Educación Infantil y Primaria del sistema de enseñanza español, que veremos en el siguiente apartado.

\section{- Preguntas de IRONÍA}

Tabla 10. Valores de $p$ (U de Mann-Whitney) Respuestas y Explicaciones Válidas

\begin{tabular}{|lll|}
\hline $\begin{array}{l}\text { Comparación } \\
\text { por edades }\end{array}$ & $\begin{array}{l}\text { Respval } \\
\text { Sig. }\end{array}$ & $\begin{array}{l}\text { Explval } \\
\text { Sig. }\end{array}$ \\
\hline 3 y 4 & $.000^{*}$ & .779 \\
\hline 3 y 5 & $.001^{*}$ & .429 \\
\hline 3 y 6 & $.000^{*}$ & $.011^{*}$ \\
\hline 4 y 5 & .565 & .678 \\
\hline 4 y 6 & $.001^{*}$ & $.028^{*}$ \\
\hline 4 y 7 & $.000^{*}$ & $.000^{*}$ \\
\hline 5 y 6 & $.013^{*}$ & .052 \\
\hline 5 y 7 & $.000^{*}$ & $.001^{*}$ \\
\hline 5 y 8 & $.000^{*}$ & $.000^{*}$ \\
\hline 6 y 7 & $.004^{*}$ & .096 \\
\hline 6 y 8 & $.001^{*}$ & $.002^{*}$ \\
\hline 6 y 9 & $.001^{*}$ & $.001^{*}$ \\
\hline 7 y 8 & .565 & .253 \\
\hline 7 y 9 & .620 & .108 \\
\hline 8 y 9 & .968 & .640 \\
\hline
\end{tabular}

Nivel de significación $\mathrm{p}^{>} .05$ 
Tabla 11. Valores de $p$ (U de Mann-Whitney) Respuestas Válidas

\begin{tabular}{|ll|}
\hline $\begin{array}{ll}\text { Comparación } \\
\text { por grupos de } \\
\text { edad }\end{array}$ & $\begin{array}{l}\text { Respval } \\
\text { Sig. }\end{array}$ \\
\hline $3-4 y 5$ & $.000^{*}$ \\
\hline $4 y 5-6$ & $.001^{*}$ \\
\hline $6-7,8 y 9$ & $.000^{*}$ \\
\hline
\end{tabular}

Nivel de significación p>.05

Tabla 12. Valores de $p$ (U de Mann-Whitney) Explicaciones Válidas

\begin{tabular}{|ll|}
\hline $\begin{array}{l}\text { Comparación } \\
\text { por grupos de } \\
\text { edad }\end{array}$ & $\begin{array}{l}\text { Explval } \\
\text { Sig. }\end{array}$ \\
\hline $3,4 y 5-6$ & $.000^{*}$ \\
\hline $6-7,8$ y9 & $.001^{*}$ \\
\hline $3 y 4-5 y 6$ & $.003^{*}$ \\
\hline $5 y 6-7,8 y 9$ & $.000^{*}$ \\
\hline $3,4 y 5-6 y 7$ & $.000^{*}$ \\
\hline $6 y 7-8 y 9$ & $.001^{*}$ \\
\hline
\end{tabular}

Nivel de significación p>.05

Al observar la tabla 10 se aprecia que para las preguntas de ironía, en el caso de las respuestas se detectan más diferencias estadísticamente significativas que en el caso de las explicaciones, es decir, la influencia de la edad es más evidente. No obstante, es cierto que en este caso la diferenciación de los grupos no es inmediata y se aprecian superposiciones. Haciendo un análisis global de los valores de $p$ de los contrastes correspondientes a las respuestas y explicaciones (tablas 10, 11 y 12), se puede justificar que la edad influye en el número de respuestas/explicaciones válidas si se agrupan los sujetos de un modo similar al de las preguntas de enriquecimiento: 3 años, 4 y 5 años, 6 y 7 años, 8 y 9 años, con algunas oscilaciones en el grupo de 6 años y en el de 7.

Es decir, en la medida que el niño pasa de un ciclo a otro, aumenta su capacidad de contestar apropiadamente a preguntas de enriquecimiento e ironía. Los niños de 3 años quedan aislados en la parte inferior de la tabla, lo cual puede tener su explicación en el hecho de que estos, además de ser pequeños y tener un nivel de madurez inferior, aún no están inmersos en el sistema educativo y conservan remanentes de la educación y atención recibidas en el contexto familiar antes de su ingreso en la escuela. 


\section{- Preguntas de SENTIMIENTO}

Tabla 13. Valores de $p$ (U de Mann-Whitney) Respuestas y Explicaciones Válidas

\begin{tabular}{|lll|}
\hline $\begin{array}{l}\text { Comparación } \\
\text { por edades }\end{array}$ & $\begin{array}{l}\text { Respval } \\
\text { Sig. }\end{array}$ & $\begin{array}{l}\text { Explval } \\
\text { Sig. }\end{array}$ \\
\hline 3 y 4 & .174 & .056 \\
\hline 3 y 5 & $.001^{*}$ & $.000^{*}$ \\
\hline 3 y 6 & $.002^{*}$ & $.000^{*}$ \\
\hline 4 y 5 & $.014^{*}$ & $.007^{*}$ \\
\hline 4 y 6 & $.028^{*}$ & $.000^{*}$ \\
\hline 4 y 7 & $.028^{*}$ & $.000^{*}$ \\
\hline 5 y 6 & .799 & $.026^{*}$ \\
\hline 5 y 7 & .799 & $.001^{*}$ \\
\hline 5 y 8 & 1.00 & $.000^{*}$ \\
\hline 6 y 7 & 1.00 & .086 \\
\hline 6 y 8 & .799 & .060 \\
\hline 6 y 9 & .799 & $.014^{*}$ \\
\hline 7 y 8 & .799 & .947 \\
\hline 7 y 9 & .799 & .565 \\
\hline 8 y 9 & 1.00 & .602 \\
\hline
\end{tabular}

Nivel de significación p>.05

Tabla 14. Valores de $p$ (U de Mann-Whitney) Respuestas Válidas

\begin{tabular}{|ll|}
\hline $\begin{array}{l}\text { Comparación por } \\
\text { grupos de edad }\end{array}$ & $\begin{array}{l}\text { Respval } \\
\text { Sig. }\end{array}$ \\
\hline $\mathbf{3 y 4} \mathbf{- 5 , 6 , 7 , 8 y 9}$ & $.000^{*}$ \\
\hline \multicolumn{2}{|c|}{ Nivel de significación $\mathrm{p}>05$} \\
\hline
\end{tabular}

Nivel de significación $\mathrm{p}>.05$

Tabla 15. Valores de $p$ (U de Mann-Whitney) Explicaciones Válidas

\begin{tabular}{|ll|}
\hline $\begin{array}{l}\text { Comparación } \\
\text { por grupos de } \\
\text { edad }\end{array}$ & $\begin{array}{l}\text { Explval } \\
\text { Sig. }\end{array}$ \\
\hline $\mathbf{3 y 4 - 5}$ & $.000^{*}$ \\
\hline $\mathbf{5 - 6 , 7 , 8 y 9}$ & $.000^{*}$ \\
\hline $\mathbf{5 - 6}$ & $.026^{*}$ \\
\hline $\mathbf{6 - 7 , 8 y 9}$ & $.002^{*}$ \\
\hline $\mathbf{5 - 6 , 7 y 8}$ & $.000^{*}$ \\
\hline $\mathbf{6 , 7 y 8 - 9}$ & .070 \\
\hline
\end{tabular}

Nivel de significación $\mathrm{p}^{>} .05$

En contraposición con las preguntas de ironía, en las de sentimiento la influencia de la edad se hace más patente en las explicaciones, no así en las respuestas. Sobre estas últimas se puede decir que quedan diferenciados dos grupos claros de edad: 3 y 4 años, y de 5 a 9 años. Sin embargo, cuando atendemos a las explicaciones, los grupos que se distinguen grosso modo son: de 3 a 5 años, y de 6 a 9 años. Nótese que si bien 238 
para las respuestas el grupo de 5 años se comporta como "los mayores", a la hora de las explicaciones su comportamiento se acerca más al de “los pequeños”. Evidentemente la madurez para responder a preguntas de sentimiento no va completamente de la mano con las antes analizadas.

\section{- Preguntas de IMPLICATURAS}

Tabla 16. Valores de $p$ (U de Mann-Whitney) Respuestas y Explicaciones Válidas

\begin{tabular}{|lll|}
\hline $\begin{array}{l}\text { Comparación } \\
\text { por edades }\end{array}$ & $\begin{array}{l}\text { Respval } \\
\text { Sig. }\end{array}$ & $\begin{array}{l}\text { Explval } \\
\text { Sig. }\end{array}$ \\
\hline 3 y 4 & $.000^{*}$ & .056 \\
\hline 3 y 5 & $.000^{*}$ & $.000^{*}$ \\
\hline 3 y 6 & $.000^{*}$ & $.000^{*}$ \\
\hline 4 y 5 & $.000^{*}$ & $.000^{*}$ \\
\hline 4 y 6 & $.000^{*}$ & $.000^{*}$ \\
\hline 4 y 7 & $.000^{*}$ & $.000^{*}$ \\
\hline 5 y 6 & .355 & $.000^{*}$ \\
\hline 5 y 7 & $.010^{*}$ & $.000^{*}$ \\
\hline 5 y 8 & $.002^{*}$ & $.000^{*}$ \\
\hline 6 y 7 & $.002^{*}$ & .738 \\
\hline 6 y 8 & $.000^{*}$ & .277 \\
\hline 6 y 9 & $.000^{*}$ & $.011^{*}$ \\
\hline 7 y 8 & .565 & .134 \\
\hline 7 y 9 & $.023^{*}$ & $.004^{*}$ \\
\hline 8 y 9 & .096 & .076 \\
\hline
\end{tabular}

Nivel de significación p>.05

Tabla 17. Valores de $p$ (U de Mann-Whitney) Respuestas Válidas

\begin{tabular}{|ll|}
\hline $\begin{array}{l}\text { Comparación } \\
\text { por grupos de } \\
\text { edad }\end{array}$ & $\begin{array}{l}\text { Respval } \\
\text { Sig. }\end{array}$ \\
\hline $\mathbf{3 - 4}$ & $.000^{*}$ \\
\hline $\mathbf{4 - 5 y 6}$ & $.000^{*}$ \\
\hline $\mathbf{5 y 6 - 7 y 8}$ & $.000^{*}$ \\
\hline $\mathbf{7 y 8 - 9}$ & $.009^{*}$ \\
\hline $\mathbf{5 y 6 - 7}$ & $.001^{*}$ \\
\hline $\mathbf{7 - 8 y 9}$ & .057 \\
\hline
\end{tabular}

Nivel de significación $\mathrm{p}>.05$ 
Tabla 18. Valores de $p$ (U de Mann-Whitney) Explicaciones Válidas

\begin{tabular}{|ll|}
\hline $\begin{array}{l}\text { Comparación } \\
\text { por grupos de } \\
\text { edad }\end{array}$ & $\begin{array}{l}\text { Explval } \\
\text { Sig. }\end{array}$ \\
\hline $\mathbf{3 y 4 - 5}$ & $.000^{*}$ \\
\hline $\mathbf{5 - 6 , 7 y 8}$ & $.000^{*}$ \\
\hline $\mathbf{6 , 7 y 8 - 9}$ & $.002^{*}$ \\
\hline $\mathbf{3 y 4 - 5}$ & $.000^{*}$ \\
\hline $\mathbf{5 - 6 y 7}$ & $.000^{*}$ \\
\hline $\mathbf{6 y 7 - 8 y 9}$ & $.003^{*}$ \\
\hline
\end{tabular}

Nivel de significación p>.05

Para las preguntas de implicaturas también la edad resulta una variable influyente, de un modo muy claro, en el número de respuestas/explicaciones válidas y se encuentran diferencias significativas entre casi todos los grupos de edad. Para las respuestas, los grupos a tener en cuenta son: 3 años, 4 años, 5 y 6 años, 7, 8 y 9 años. En el caso de las explicaciones hay solapamientos. Queda así patente que la edad condiciona el número de respuestas/explicaciones válidas, aunque esta influencia es menos importante hacia las edades más maduras dentro de la muestra estudiada.

\section{- Preguntas de REFERENCIA}

Tabla 19. Valores de $p$ (U de Mann-Whitney) Respuestas Válidas

\begin{tabular}{|ll|}
\hline $\begin{array}{l}\text { Comparación } \\
\text { por edades }\end{array}$ & $\begin{array}{l}\text { Respval } \\
\text { Sig }\end{array}$ \\
\hline 3 y 4 & .134 \\
\hline 3 y 5 & $.006^{*}$ \\
\hline 3 y 6 & $.000^{*}$ \\
\hline 4 y 5 & .142 \\
\hline 4 y 6 & $.015^{*}$ \\
\hline 4 y 7 & $.000^{*}$ \\
\hline 5 y 6 & .369 \\
\hline 5 y 7 & $.023^{*}$ \\
\hline 5 y 8 & $.001^{*}$ \\
\hline 6 y 7 & .102 \\
\hline 6 y 8 & $.005^{*}$ \\
\hline 6 y 9 & $.002^{*}$ \\
\hline 7 y 8 & .231 \\
\hline 7 y 9 & .114 \\
\hline 8 y 9 & .640 \\
\hline
\end{tabular}

Nivel de significación $\mathrm{p}>.05$ 
Tabla 20. Valores de $p$ (U de Mann-Whitney) Respuestas Válidas

\begin{tabular}{|ll|}
\hline $\begin{array}{l}\text { Comparación } \\
\text { por grupos de } \\
\text { edad }\end{array}$ & $\begin{array}{l}\text { Respval } \\
\text { Sig. }\end{array}$ \\
\hline 3y4-5y 6 & $.000^{*}$ \\
\hline $5 y 6-7,8 y 9$ & $.000^{*}$ \\
\hline $3-4 y 5$ & $.013^{*}$ \\
\hline $\mathbf{4 y 5 - 6}$ & $.047^{*}$ \\
\hline $\mathbf{6 - 7 , 8 y 9}$ & $.000^{*}$ \\
\hline $\mathbf{3 - 4 y 5}$ & $.013^{*}$ \\
\hline $\mathbf{4 y 5}-\mathbf{6 y 7}$ & $.001^{*}$ \\
\hline $\mathbf{6 y 7 - 8 y 9}$ & $.000^{*}$ \\
\hline $\mathbf{3 y 4 - 5}$ & $.013^{*}$ \\
\hline $\mathbf{5 - 6 y 7}$ & .052 \\
\hline
\end{tabular}

Nivel de significación p>.05

En el caso de las preguntas de asignación de referentes, podemos ver que no se detectan diferencias entre un grupo y el consecutivo, pero si con todos los siguientes. Esto evidencia que la edad sí que tiene una gran influencia en este tipo de respuestas, pero entre niveles lejanos de edad. En este caso conviene agrupar a los niños por ciclos de estudio —como haremos posteriormente— para obtener un análisis más transparente.

\section{- Preguntas de RUTINAS}

Tabla 21. Valores de $p$ (U de Mann-Whitney) Respuestas y Explicaciones Válidas

\begin{tabular}{|lll|}
\hline $\begin{array}{l}\text { Comparación } \\
\text { por edades }\end{array}$ & $\begin{array}{l}\text { Respval } \\
\text { Sig. }\end{array}$ & $\begin{array}{l}\text { Explval } \\
\text { Sig. }\end{array}$ \\
\hline 3 y 4 & .052 & $.007^{*}$ \\
\hline 3 y 5 & $.002^{*}$ & $.000^{*}$ \\
\hline 3 y 6 & $.000^{*}$ & $.000^{*}$ \\
\hline 4 y 5 & .121 & $.003^{*}$ \\
\hline 4 y 6 & $.033^{*}$ & $.000^{*}$ \\
\hline 4 y 7 & $.006^{*}$ & $.000^{*}$ \\
\hline 5 y 6 & .640 & $.009^{*}$ \\
\hline 5 y 7 & .121 & $.000^{*}$ \\
\hline 5 y 8 & .014 & $.000^{*}$ \\
\hline 6 y 7 & .231 & .142 \\
\hline 6 y 8 & $.030^{*}$ & $.003^{*}$ \\
\hline 6 y 9 & $.007^{*}$ & $.000^{*}$ \\
\hline 7 y 8 & .429 & .183 \\
\hline 7 y 9 & .201 & $.006^{*}$ \\
\hline 8 y 9 & .602 & .108 \\
\hline
\end{tabular}

Nivel de significación p>.05 
Tabla 22. Valores de $p$ (U de Mann-Whitney) Respuestas Válidas

\begin{tabular}{|ll|}
\hline $\begin{array}{l}\text { Comparación } \\
\text { por grupos de } \\
\text { edad }\end{array}$ & $\begin{array}{l}\text { Respval } \\
\text { Sig. }\end{array}$ \\
\hline 3y4-5,6y7 & $.000^{*}$ \\
\hline $\mathbf{5 , 6 y 7 - 8 y 9}$ & $.000^{*}$ \\
\hline $\mathbf{3 - 4 y 5}$ & $.002^{*}$ \\
\hline $\mathbf{4 y 5 - 6}$ & .091 \\
\hline $\mathbf{6 - 7 , 8 y 9}$ & $.005^{*}$ \\
\hline
\end{tabular}

Nivel de significación $\mathrm{p}>.05$

Tabla 23. Valores de $p$ (U de Mann-Whitney) Explicaciones Válidas

\begin{tabular}{|ll|}
\hline $\begin{array}{l}\text { Comparación } \\
\text { por grupos de } \\
\text { edad }\end{array}$ & $\begin{array}{l}\text { Explval } \\
\text { Sig. }\end{array}$ \\
\hline $\mathbf{5 - 6 y 7}$ & $.000^{*}$ \\
\hline $\mathbf{6 y 7 - 8 y 9}$ & $.000^{*}$ \\
\hline $\mathbf{6 - 7 , 8 y 9}$ & $.007^{*}$ \\
\hline $\mathbf{7 y 8 - 9}$ & $.007^{*}$ \\
\hline
\end{tabular}

Nivel de significación $\mathrm{p}>.05$

En el caso de las preguntas de rutina también se evidencia la influencia de la edad en el número de respuestas/explicaciones válidas, fundamentalmente en las explicaciones y, en especial, en los niños de 3 a 6 años. Estas diferencias, sin embargo, son menos patentes entre los niños de 7 a 9 años.

En general es posible concluir que la edad influye en el número de respuestas/explicaciones válidas de los niños, pero no con la misma relevancia en todos los tipos de preguntas ni en relación con todos los grupos de edad, tal como hemos especificado a lo largo de este apartado.

\subsubsection{Análisis por ciclos educativos}

A medida que nos adentrábamos en el análisis de la variable edad, hemos considerado necesaria la creación de grupos y, consecuentemente, nos ha parecido también sumamente relevante para este estudio la clasificación de los niños por ciclos educativos $^{187}$. Intuimos que entre ellos es donde hallaremos las diferencias más notables. Así pues, hemos comprobado también la influencia de la variable ciclo educativo (evidentemente ligada a la variable edad) en el número de respuestas y

\footnotetext{
${ }^{187}$ Véase nota 176.
} 
explicaciones válidas en los 6 tipos de preguntas. Para realizar este análisis hemos aplicado de nuevo pruebas no paramétricas (puesto que en ninguna de las agrupaciones se cumplía el supuesto de normalidad) de Kruskal-Wallis y Mann-Whitney.

Si comenzamos por el análisis de las preguntas de enriquecimiento, tal como esperábamos, hay diferencias significativas en el número de respuestas válidas de los niños pertenecientes a Educación Infantil, Educación Primaria $1^{\circ}$ ciclo y Educación Primaria $2^{\circ}$ ciclo.

\begin{tabular}{|r|l|r|r|}
\hline \multicolumn{1}{|c|}{ Prueba de Kruskal Wallis } & \multicolumn{1}{c|}{ Rangos } \\
\hline \multirow{3}{*}{ Resplo_educativo } & $\mathrm{N}$ & \multicolumn{1}{c|}{$\begin{array}{c}\text { Rango } \\
\text { promedio }\end{array}$} \\
\cline { 2 - 3 } & Educación infantil & 61 & 37,83 \\
& Educación primaria 1ciclo & 43 & 83,13 \\
& Educación primaria 2ciclo & 36 & 110,78 \\
& Total & 140 & \\
\hline
\end{tabular}

\section{Estadísticos de contraste ${ }^{a, b}$}

\begin{tabular}{|l|r|}
\hline & \multicolumn{1}{|c|}{ Respval } \\
\hline Chi-cuadrado & 82,175 \\
GI & 2 \\
Sig. asintót. &, 000 \\
\hline
\end{tabular}

a. Prueba de Kruskal-Wallis

b. Variable de agrupación: Ciclo_educativo

Siguiendo el sistema de análisis realizado para la variable edad, a continuación hemos aplicado la prueba de Mann-Whitney para descubrir si hay diferencias significativas, por un lado, entre las respuestas válidas de los niños de Educación Infantil y los de Primaria de $1^{\circ}$ ciclo y, por otro, entre los de Primaria de $1^{\circ}$ y $2^{\circ}$ ciclo. Como se observa en las siguientes tablas, en ambos casos el resultado es estadísticamente significativo.

\begin{tabular}{|l|l|r|r|r|}
\hline \multirow{2}{*}{} & Ciclo_educativo & $\mathrm{N}$ & \multicolumn{1}{c|}{$\begin{array}{c}\text { Rango } \\
\text { promedio }\end{array}$} & $\begin{array}{c}\text { Suma de } \\
\text { rangos }\end{array}$ \\
\hline \multirow{3}{*}{ Respval } & Educación infantil & 61 & 37,02 & 2258,50 \\
& Educación primaria 1ciclo & 43 & 74,45 & 3201,50 \\
& Total & 104 & & \\
\hline
\end{tabular}


Estadísticos de contraste ${ }^{\mathrm{a}}$

\begin{tabular}{|l|r|}
\hline \multicolumn{2}{|c|}{ Estadísticos de contraste } \\
\hline U de Mann-Whitney & \multicolumn{1}{|c|}{ Respval } \\
W de Wilcoxon & 367,500 \\
Z & 2258,500 \\
Sig. asintót. (bilateral) & $-6,321$ \\
\hline
\end{tabular}

a. Variable de agrupación: Ciclo_educativo

\begin{tabular}{|r|l|r|r|r|}
\hline \multirow{2}{*}{} & Ciclo_educativo & $\mathrm{N}$ & \multicolumn{1}{c|}{$\begin{array}{c}\text { Rango } \\
\text { promedio }\end{array}$} & \multicolumn{1}{c|}{$\begin{array}{c}\text { Suma de } \\
\text { rangos }\end{array}$} \\
\hline \multirow{3}{*}{ Respval } & Educación primaria 1ciclo & 43 & 30,67 & 1319,00 \\
& Educación primaria 2ciclo & 36 & 51,14 & 1841,00 \\
& Total & 79 & & \\
\hline
\end{tabular}

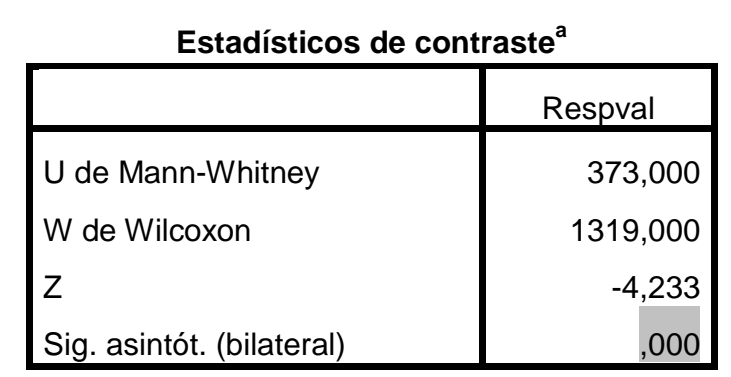

a. Variable de agrupación: Ciclo_educativo

Una vez reflejado el procedimiento de análisis en el caso de las preguntas de enriquecimiento, para el resto de tipos de pregunta se ha procedido de la misma forma $^{188}$. Los resultados generales del análisis estadístico de la variable ciclo educativo se recogen en la tabla 24.

Como se observa, en prácticamente todos los casos se detectan diferencias estadísticamente significativas; esto quiere decir que la pertenencia a un ciclo u otro determina en gran medida la capacidad del niño para realizar con éxito las tareas planteadas. Las excepciones se localizan en las preguntas de sentimiento, en las que no podemos afirmar que haya diferencias significativas entre el número de respuestas ni de explicaciones válidas de los niños de los dos primeros ciclos de Educación Primaria. Esto evidencia que el comportamiento de estos dos grupos en relación con las preguntas de identificación de sentimientos es muy similar.

\footnotetext{
${ }^{188}$ Consúltese anexo 8 para ver la aplicación de estas pruebas a las distintas categorías de preguntas. 


\begin{tabular}{|c|c|c|c|}
\hline Tipo de pregunta & Respval/Explval & Ciclos Educativos comparados & Sig. \\
\hline \multirow[t]{2}{*}{ ENRIQUECIMIENTO } & Respval & Infantil - Primaria $1^{\circ}$ ciclo & $.000^{*}$ \\
\hline & & Primaria $1^{\circ}$ ciclo - Primaria $2^{\circ}$ ciclo & $.000^{*}$ \\
\hline \multirow[t]{4}{*}{ IMPLICATURA } & Respval & Infantil - Primaria $1^{\circ}$ ciclo & $.000^{*}$ \\
\hline & & Primaria $1^{\circ}$ ciclo - Primaria $2^{\circ}$ ciclo & $.000^{*}$ \\
\hline & Explval & Infantil - Primaria $1^{\circ}$ ciclo & $.000 *$ \\
\hline & & Primaria $1^{\circ}$ ciclo - Primaria $2^{\circ}$ ciclo & $.014 *$ \\
\hline \multirow[t]{4}{*}{ IRONÍA } & Respval & Infantil - Primaria $1^{\circ}$ ciclo & $.000 *$ \\
\hline & & Primaria $1^{\circ}$ ciclo - Primaria $2^{\circ}$ ciclo & $.003 *$ \\
\hline & Explval & Infantil - Primaria $1^{\circ}$ ciclo & $.000^{*}$ \\
\hline & & Primaria $1^{\circ}$ ciclo - Primaria $2^{\circ}$ ciclo & $.005 *$ \\
\hline \multirow[t]{2}{*}{ REFERENCIA } & Respval & Infantil - Primaria $1^{\circ}$ ciclo & $.000^{*}$ \\
\hline & & Primaria $1^{\circ}$ ciclo - Primaria $2^{\circ}$ ciclo & $.000^{*}$ \\
\hline \multirow[t]{4}{*}{ RUTINA } & Respval & Infantil - Primaria $1^{\circ}$ ciclo & $.000 *$ \\
\hline & & Primaria $1^{\circ}$ ciclo - Primaria $2^{\circ}$ ciclo & $.001 *$ \\
\hline & Explval & Infantil - Primaria $1^{\circ}$ ciclo & $.000 *$ \\
\hline & & Primaria $1^{\circ}$ ciclo - Primaria $2^{\circ}$ ciclo & $.000 *$ \\
\hline \multirow[t]{4}{*}{ SENTIMIENTO } & Respval & Infantil - Primaria $1^{\circ}$ ciclo & $.000 *$ \\
\hline & & Primaria $1^{\circ}$ ciclo - Primaria $2^{\circ}$ ciclo & .193 \\
\hline & Explval & Infantil - Primaria $1^{\circ}$ ciclo & $.000 *$ \\
\hline & & Primaria $1^{\circ}$ ciclo - Primaria $2^{\circ}$ ciclo & .139 \\
\hline
\end{tabular}

Tabla 24. Variable ciclo educativo/ U de Mann-Whitney

5.3.1.2 Distribución de la variable respuestas/explicaciones válidas en los distintos grupos de edad

A continuación, para comparar gráficamente el comportamiento de la variable número de respuestas/explicaciones válidas en los distintos grupos de edad, hemos utilizado el diagrama de caja o blox-plot. Este nos permite visualizar la distribución del 
conjunto de datos (mediana, percentiles, valores extremos, dispersión) para cada tipo de pregunta en las distintas edades.

Figura 15. Preguntas de enriquecimiento (máx.8). Distribución RespuestasVálidas/Edad

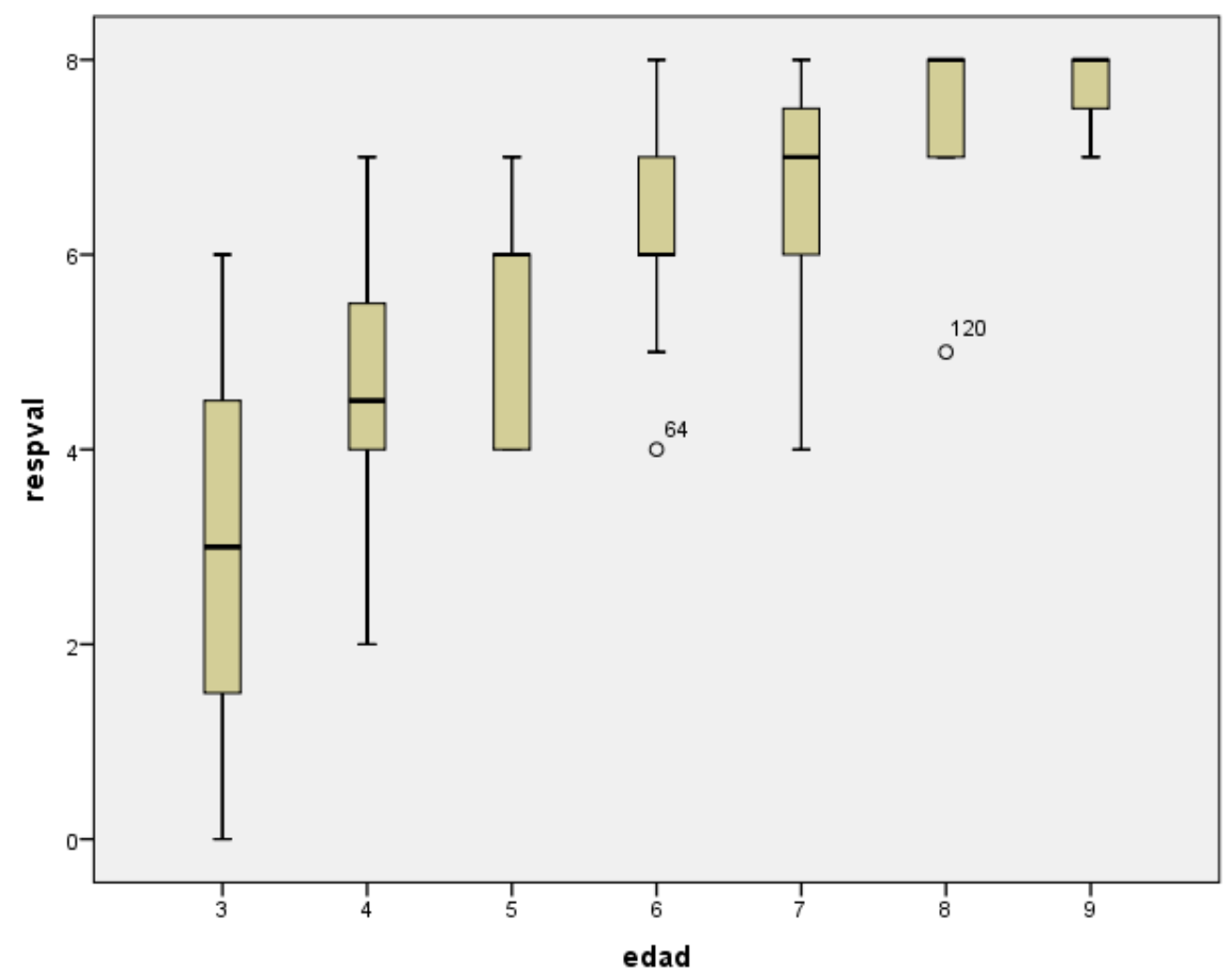

De forma general, este tipo de gráfico está compuesto por cajas (que contienen al 50\% central de los casos, esto es, el límite superior es el percentil 75 y el inferior el 25), una línea central más oscura (que representa la mediana ${ }^{189}$ de cada grupo de edad), los brazos o bigotes (que se desplazan en función de la variabilidad de las respuestas) y los valores extremos o atípicos (que no encajan con la mayoría del conjunto de datos). Asimismo, el eje vertical representa el número total de preguntas de cada tipo y el horizontal los intervalos de edad estudiados.

En el caso de las respuestas válidas a preguntas de enriquecimiento (véase fig. 15), podemos observar una dispersión mayor en los grupos de 3 y 4 años (aunque, por otro lado, la distribución es ciertamente simétrica) y, sorprendentemente, en los niños de 7 años. En este grupo el número de respuestas válidas oscila entre 4 y 8 sobre 8 , distribución que no era esperable, ya que la mediana se halla en el valor 7.

\footnotetext{
${ }^{189}$ La mediana es el valor que se encuentra en el centro de los datos. Nos indica que la mitad de los datos se encuentran por debajo de ese valor y la otra mitad por encima. 
Igualmente, encontramos dos valores atípicos; estos corresponden a la niña $\mathrm{n}^{\circ} 120$ de 8 años, que responde solo a 5 preguntas apropiadamente, valor que se aleja del comportamiento general de su grupo que oscila entre 7 y 8; y el niño nº6 de 6 años, que responde bien a 4 preguntas, valor por debajo del percentil 25 de su grupo.

Figura 16. Preguntas de ironía (máx.5). Distribución Respuestas Válidas/Edad

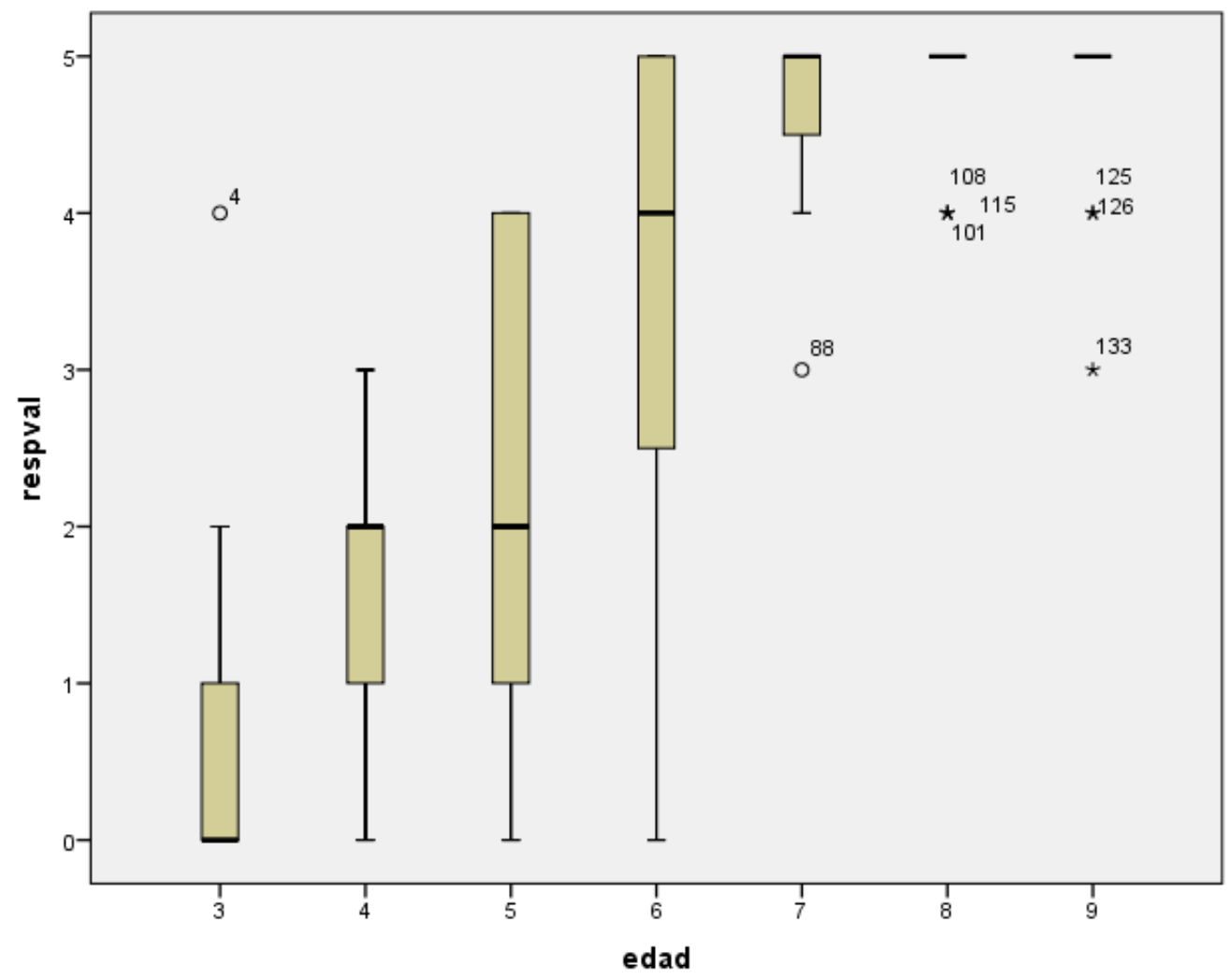

Figura 17. Preguntas de ironía (máx.5). Distribución Explicaciones Válidas/Edad

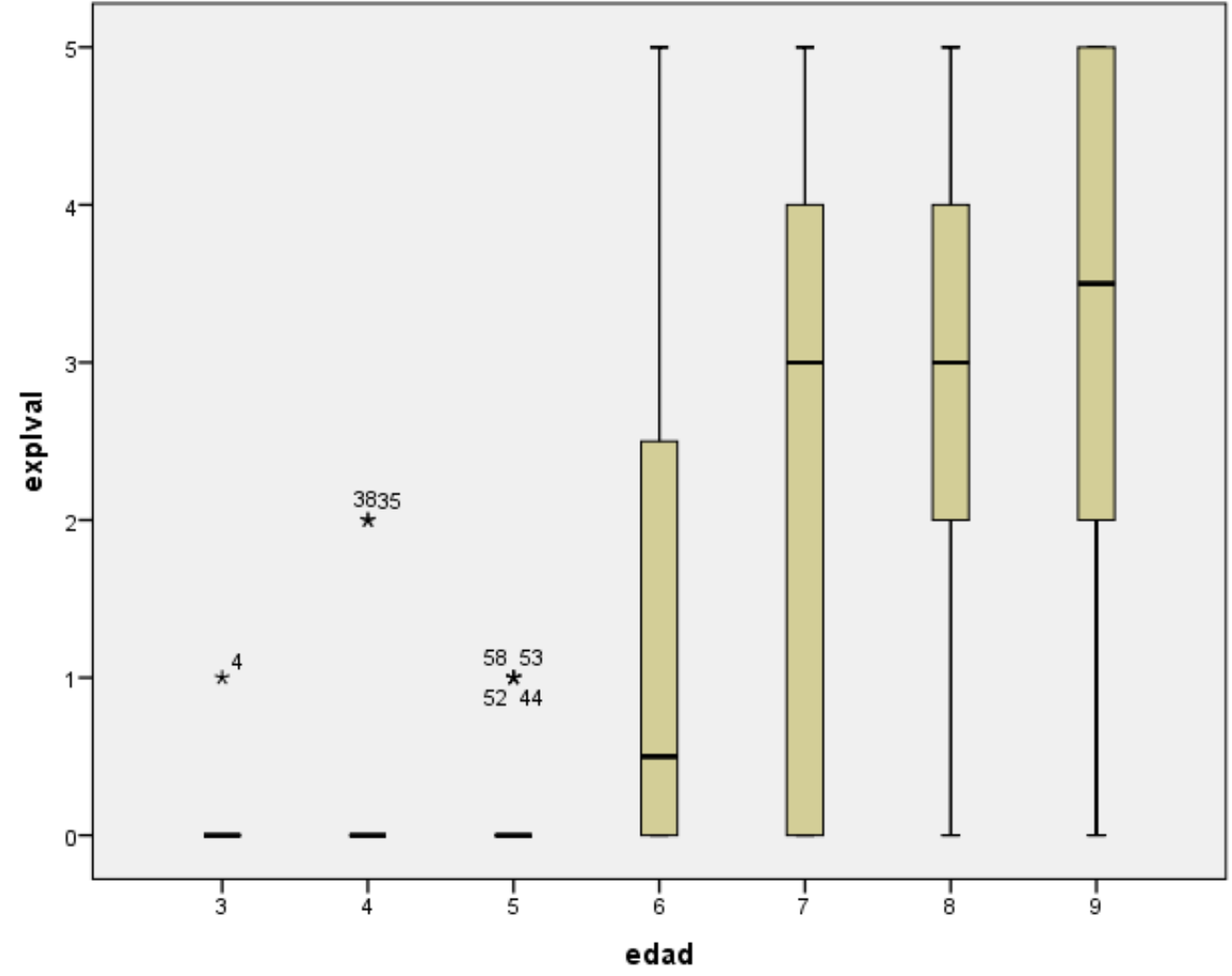


En cuanto a la distribución del número de respuestas y explicaciones válidas en las preguntas de ironía, tal como se observa en las figuras 16 y 17, encontramos gran dispersión y asimetría. En las respuestas válidas, a los 6 años sorprendentemente la dispersión alcanza la totalidad de los valores, esto es, de 0 a 5; y la mediana se sitúa en 4. Por lo que respecta a las explicaciones válidas, en los grupos de 6, 7, 8 y 9 años, la dispersión también es la máxima posible. Esto podría indicar que a estas edades nos encontramos ante casos extremos: hay niños que identifican las ironías con facilidad y de forma inmediata en todas las preguntas, mientras que otros no tienen asimilado el mecanismo y fallan en la comprensión en todos los casos.

Figura 18. Preguntas de sentimiento (máx.5). Distribución Respuestas Válidas/Edad

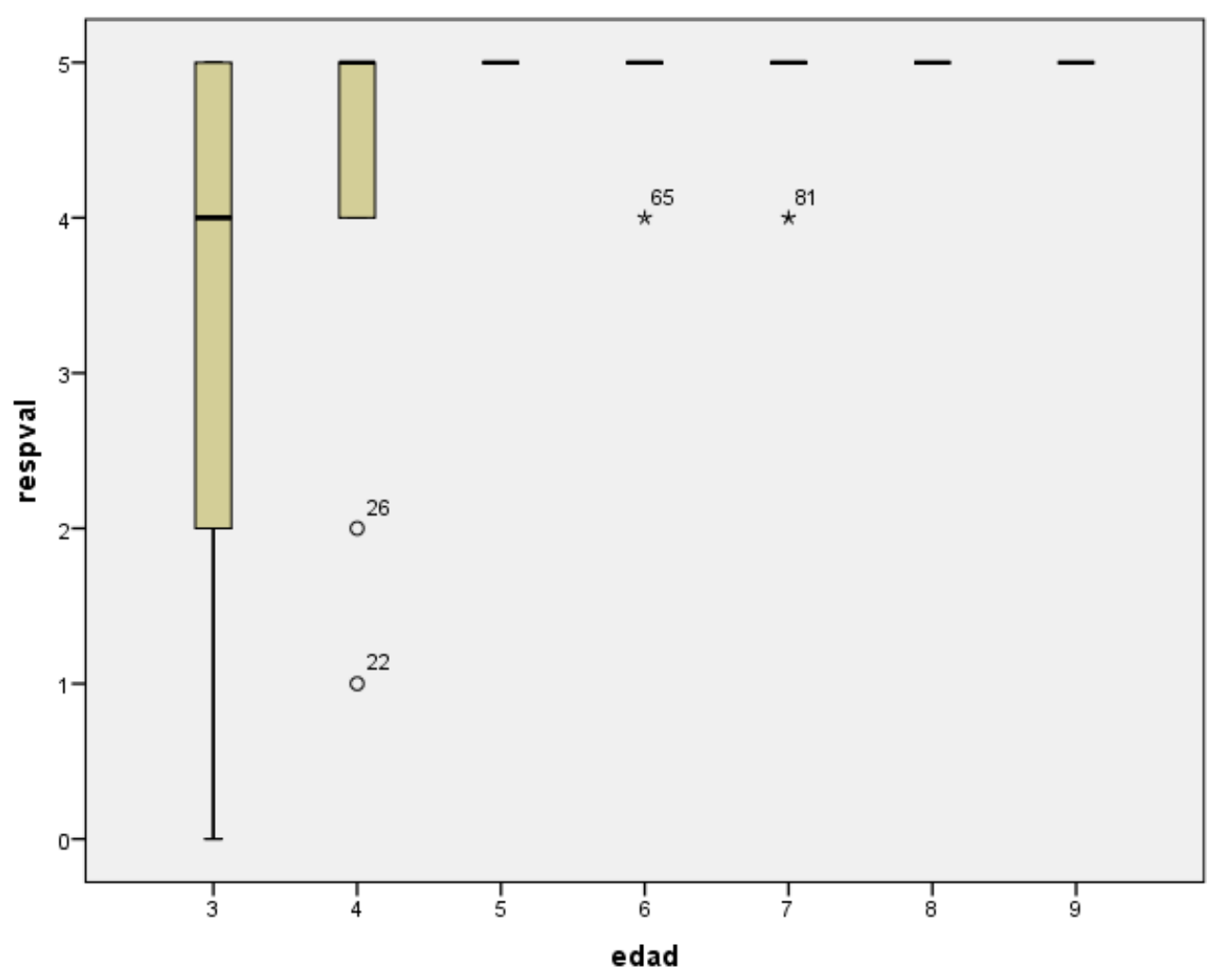

Como se observa en la figura 18, encontramos también una distribución irregular en las respuestas válidas a preguntas de sentimiento. Así, en el grupo de 3 años la dispersión abarca todos los valores posibles (de 0 a 5) y a partir de los 5 años la variación es inexistente, ya que la mediana en todos los casos es el valor máximo (5). Esto nos indica que a partir de los 5 años dichas preguntas no suponen ninguna dificultad para los niños. 
Este comportamiento varía ciertamente en las explicaciones válidas (véase fig. 19). Aquí, los grupos de 3 y 4 años presentan más dispersión frente a los de mayor edad (6, 7 y 8), cuya dispersión se reduce a dos valores: 4 y 5.

Figura 19. Preguntas de sentimiento (máx.5). Distribución Explicaciones Válidas/Edad

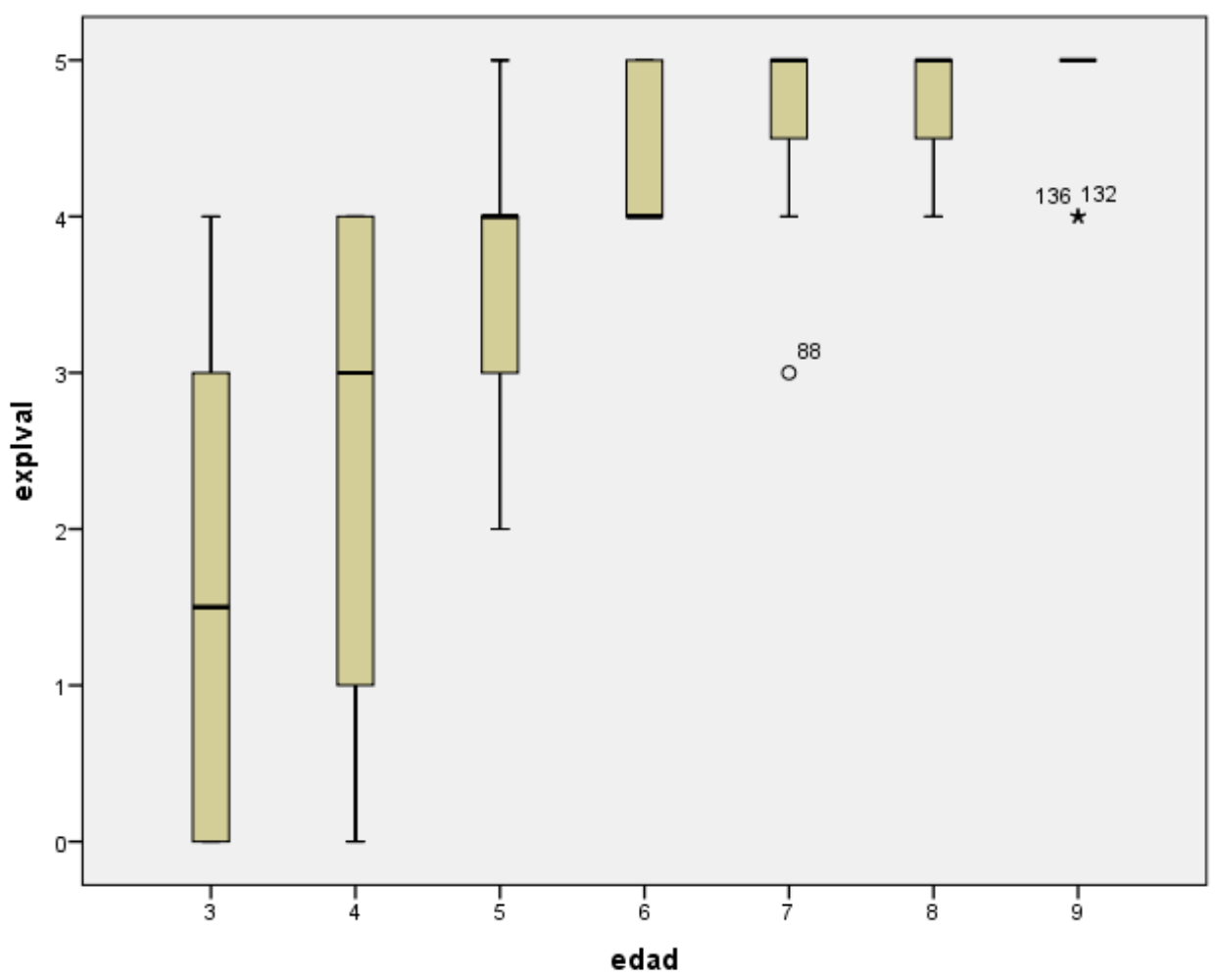

Figura 20. Preguntas de implicatura (máx.10). Distribución Respuestas Válidas/Edad

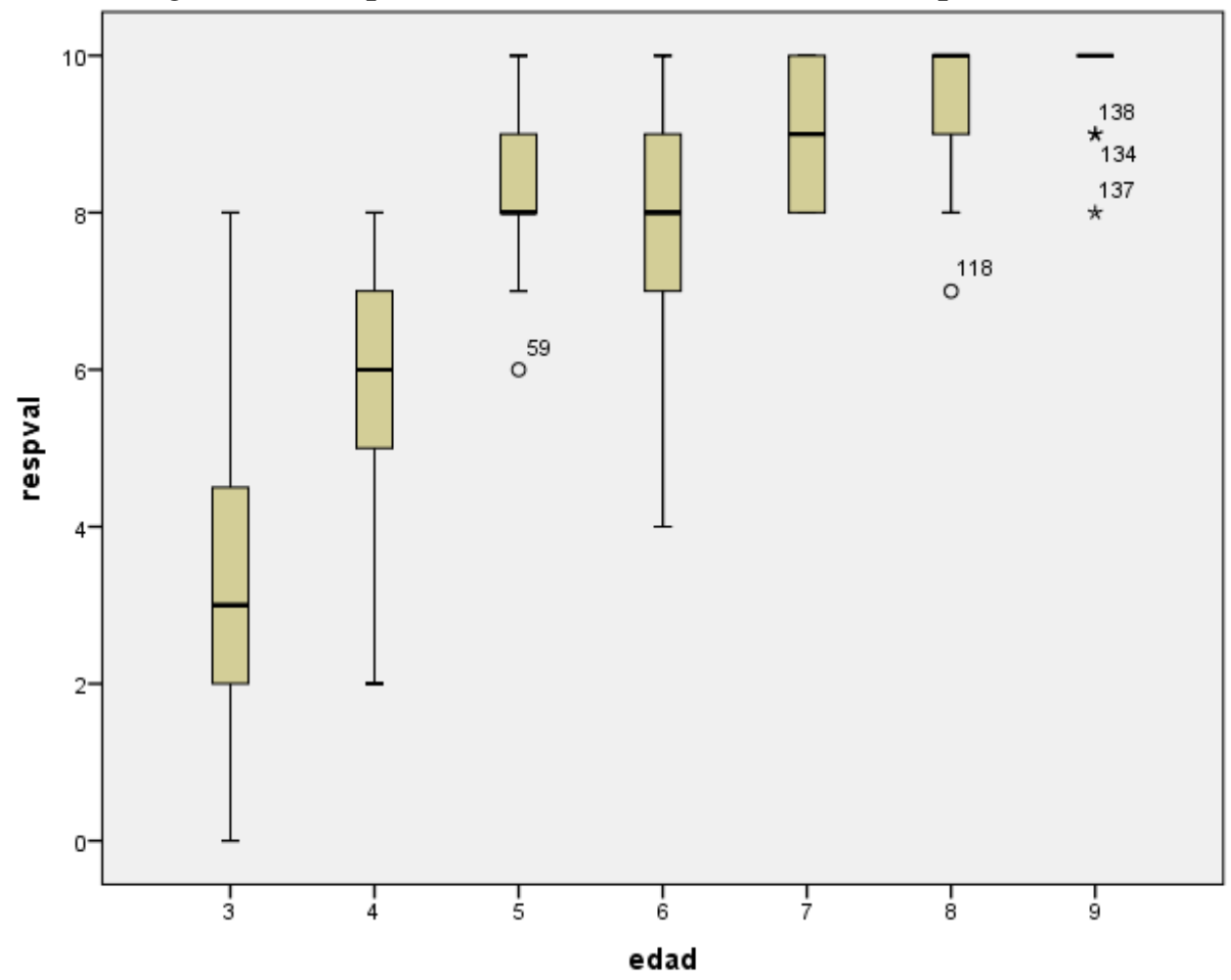


Figura 21. Preguntas de implicatura (máx.10). Distribución Explicaciones Válidas/Edad

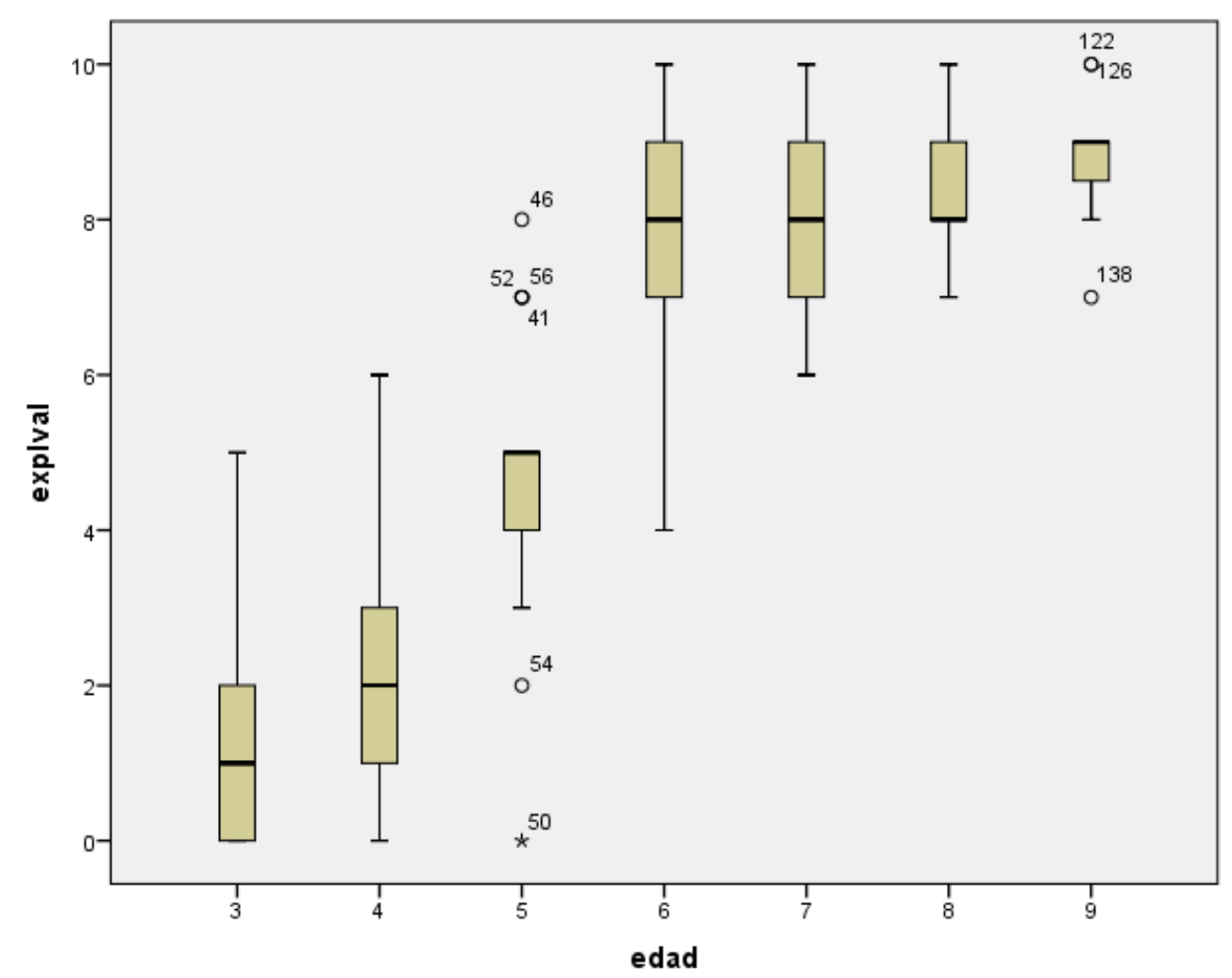

Siguiendo nuestro análisis de distribución de datos, en las respuestas válidas a preguntas de implicaturas (véase fig. 20) encontramos el mayor grado de dispersión de nuevo en las edades inferiores. Esto corrobora la idea, que ya apuntábamos en el estudio estadístico previo de la variable edad, de que a los 3 años es donde se registran las mayores diferencias entre los individuos, puesto que acaban de incorporarse al sistema educativo y cada uno procede de un entorno familiar diferente. Podemos decir, entonces, que con la escolarización se regula el desarrollo cognitivo-comunicativo del niño, o al menos en parte, ya que para cada nivel se establecen una serie de competencias mínimas que el niño debe dominar.

En el gráfico de valores de respuestas válidas encontramos también distribuciones simétricas a los 4, 6 y 7 años y algunos valores dispersos, sobre todo a los 9 años. Así, en este intervalo de edad, aunque la inmensa mayoría responde apropiadamente a todas las preguntas, hay 3 casos que se desvían, ya que fallan en una o dos preguntas.

En relación con los resultados de las explicaciones válidas en las preguntas que suponen el procesamiento de implicaturas (véase fig. 21), las distribuciones son, por regla general, simétricas. No obstante, llama nuestra atención el comportamiento del 
grupo de 5 años debido a la gran cantidad de valores atípicos que presenta (valores puntuales que van desde 0 a 8 pero que no se repiten).

Figura 22. Preguntas de referencia (máx.8). Distribución Respuestas Válidas/Edad

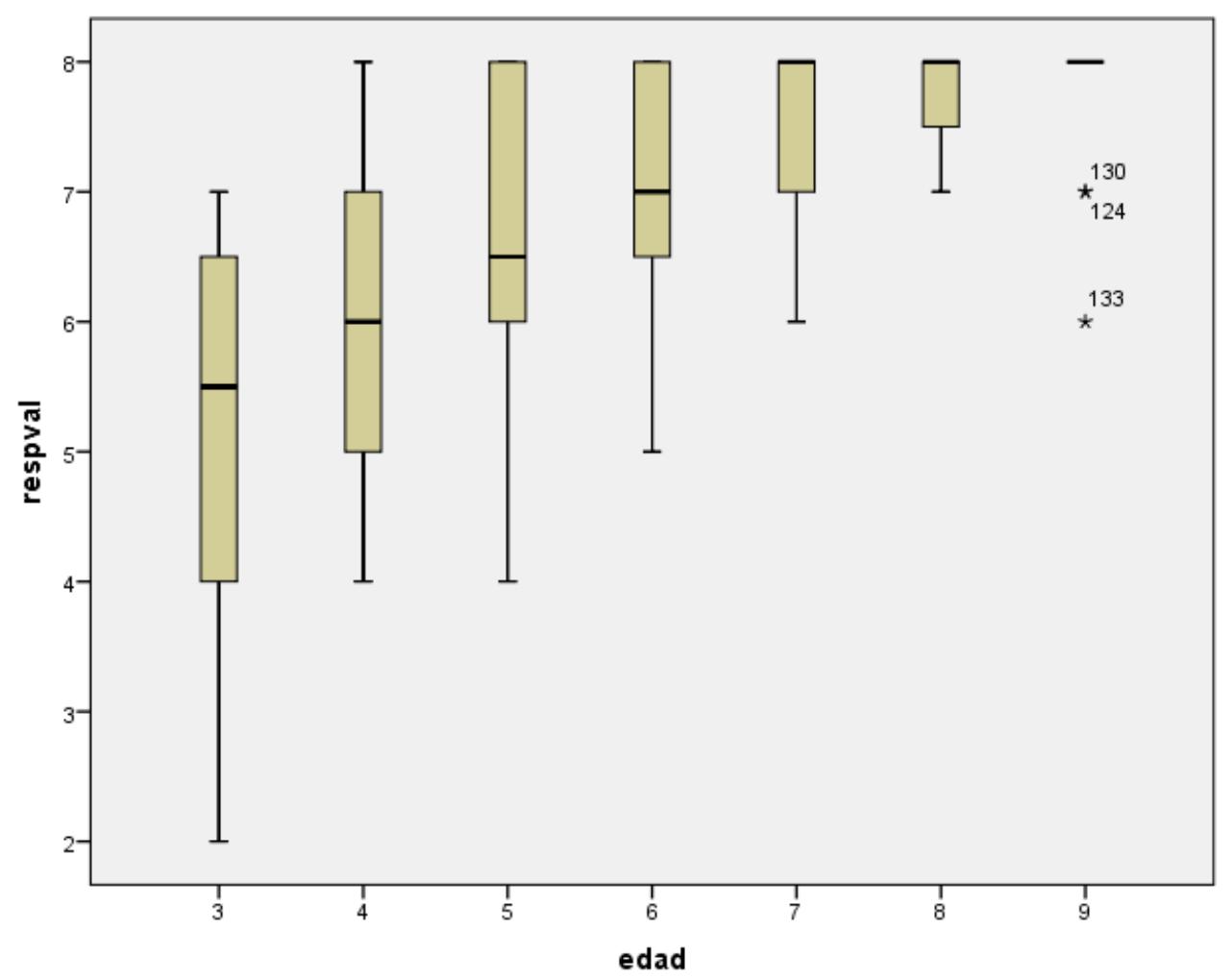

Figura 23. Preguntas de rutina (máx.6). Distribución Respuestas Válidas/Edad

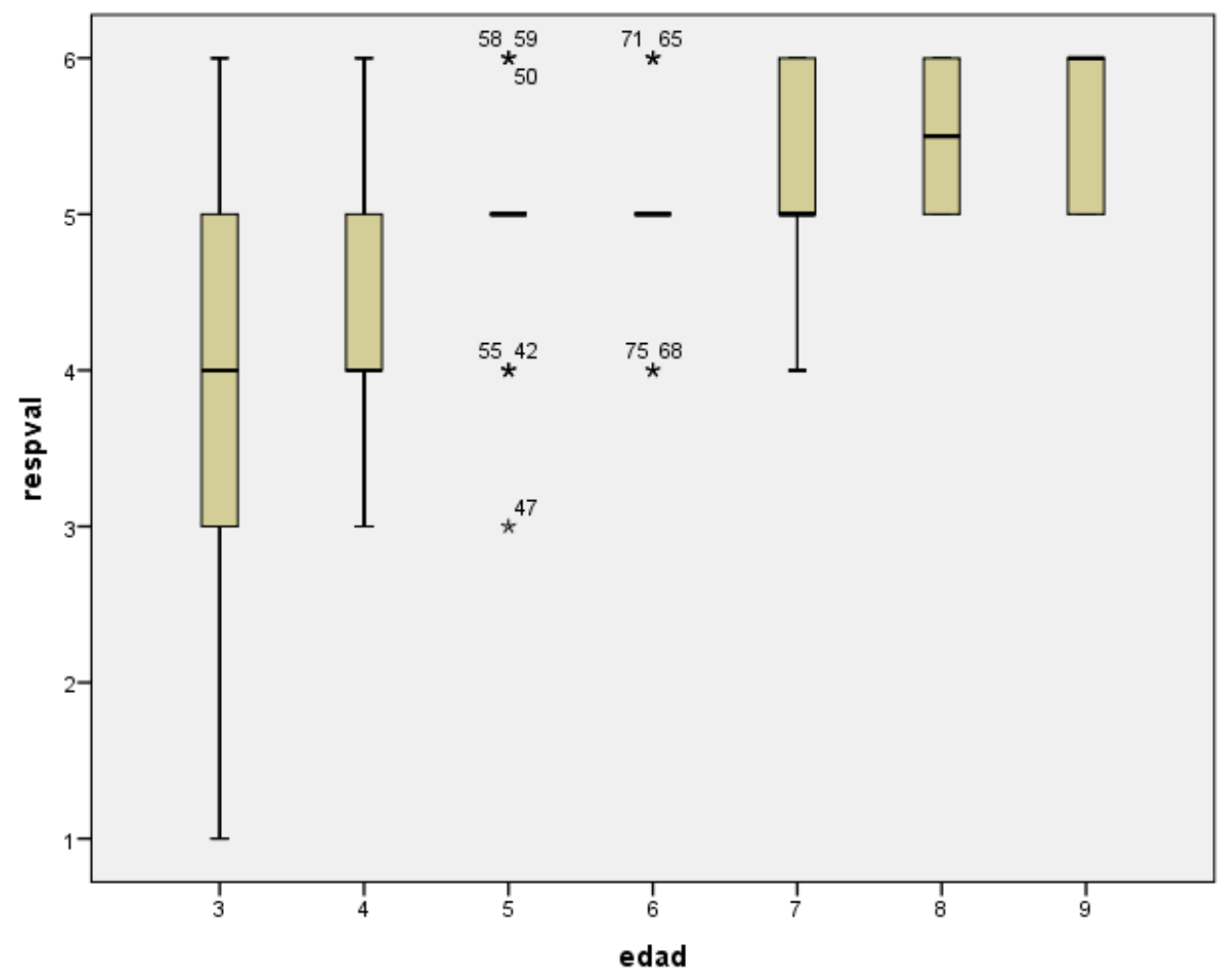


Figura 24. Preguntas de rutina (máx.6). Distribución Explicaciones Válidas/Edad

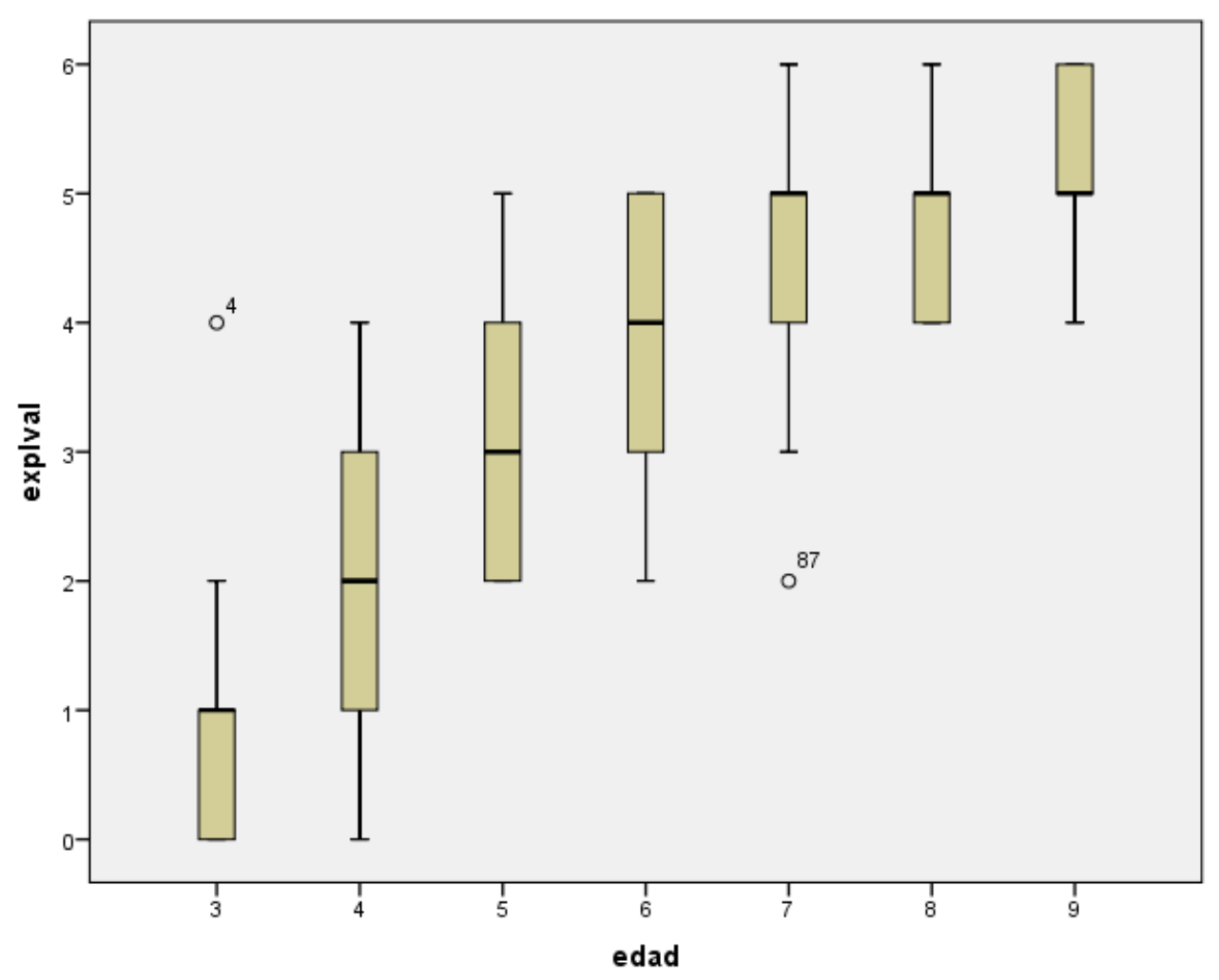

Si comparamos gráficamente el comportamiento del número de respuestas válidas en los distintos grupos con relación a las preguntas de referencia (véase fig. 22), observamos que hay similitudes entre los grupos 3-4, 5-6 y 7-8 con la evolución correspondiente. Este hecho va en línea con los resultados estadísticos iniciales en los que no detectamos diferencias significativas entre un grupo y el consecutivo, pero sí con el siguiente.

Finalmente, en cuanto a las preguntas de rutina, se advierten comportamientos muy dispares en el número de respuestas válidas (véase fig. 23). Sorprende que a los 5 y 6 años no sea posible representar al 50\% central de los casos en una caja y solo podamos obtener la mediana del grupo (que en ambos grupos coincide en el valor 5) y valores externos. Para profundizar en estos datos sería preciso realizar un estudio con una muestra más amplia y con un mayor número de preguntas de rutinas.

Por el contrario, en el número de explicaciones válidas (véase fig. 24), las distribuciones son mucho más simétricas con una dispersión media de 3 valores. Además puede verse una evolución distinta en los grupos en función de las edades. Las distribuciones menos homogéneas se encuentran en los grupos de menor y mayor 
edad (3 y 9 años). Así, a los 3 años el brazo inferior coincide con el percentil 25 y a los

9 años el brazo superior coincide con el percentil 75.

\subsubsection{Relación entre respuestas y explicaciones válidas}

Para analizar la relación entre respuestas y explicaciones válidas en cada grupo de edad, se ha calculado la media (M), la mediana (Mdn) y la desviación estándar (DE) ${ }^{190}$ de cada tipo de pregunta. Dichas medidas estadísticas descriptivas, en primer lugar referentes a las respuestas válidas, se recogen en la siguiente tabla:

Tabla 25. Media/ Mediana/ Desviación Estándar en Respuestas Válidas

\begin{tabular}{|c|c|c|c|c|c|c|}
\hline \multirow[b]{2}{*}{$\begin{array}{l}\text { Grupo de } \\
\text { edad }\end{array}$} & \multicolumn{6}{|c|}{ RESPUESTAS VÁLIDAS } \\
\hline & $\begin{array}{l}\text { Rutina } \\
\text { (6) }\end{array}$ & $\begin{array}{l}\text { Implicatura } \\
\text { (10) }\end{array}$ & $\begin{array}{l}\text { Sentimiento } \\
\text { (5) }\end{array}$ & Ironía (5) & $\begin{array}{l}\text { Referencia } \\
\text { (8) }\end{array}$ & $\begin{array}{c}\text { Enriquecimiento } \\
\text { (8) }\end{array}$ \\
\hline \multicolumn{7}{|l|}{3 AÑOS } \\
\hline M & 3.7 & 3.3 & 3.6 & 0.55 & 5.2 & 2.9 \\
\hline Mdn & 4 & 3 & 4 & 0 & 5.5 & 3 \\
\hline $\mathrm{DE}$ & 1.30 & 2.20 & 1.61 & 1.05 & 1.56 & 1.86 \\
\hline \multicolumn{7}{|l|}{4 AÑOS } \\
\hline M & 4.5 & 5.85 & 4.3 & 1.75 & 6 & 4.6 \\
\hline Mdn & 4 & 6 & 5 & 2 & 6 & 4.5 \\
\hline $\mathrm{DE}$ & 0.88 & 1.50 & 1.08 & 0.79 & 1.21 & 1.35 \\
\hline \multicolumn{7}{|l|}{5 AÑOS } \\
\hline M & 4.9 & 8.25 & 5 & 2.1 & 6.6 & 5.4 \\
\hline Mdn & 5 & 8 & 5 & 2 & 6.5 & 6 \\
\hline $\mathrm{DE}$ & 0.72 & 1.02 & 0 & 1.59 & 1.19 & 1.09 \\
\hline
\end{tabular}

${ }^{190}$ La media es la medida de posición central más utilizada. Se define como la suma de todos los valores observados, dividido por el número total de observaciones. Su principal desventaja radica en su sensibilidad al cambio de uno de sus valores o a los valores extremos demasiado grandes o pequeños. Por su parte, la mediana, tal como vimos en el apartado anterior, nos permite identificar el valor que se encuentra en el centro de los datos, es decir, nos indica que la mitad de los datos se encuentran por debajo de este valor y la otra mitad por encima del mismo. Finalmente, la desviación estándar es una medida de dispersión que nos permiten reconocer cuánto se diversifican los datos alrededor del punto central; es decir, nos indica cuanto se desvían las observaciones alrededor de su media. Así nos da como resultado un valor numérico que representa el promedio de diferencia que hay entre los datos y la media. 


\begin{tabular}{|c|c|c|c|c|c|c|}
\hline \multirow[b]{2}{*}{$\begin{array}{l}\text { Grupo de } \\
\text { edad }\end{array}$} & \multicolumn{6}{|c|}{ RESPUESTAS VÁLIDAS } \\
\hline & $\begin{array}{l}\text { Rutina } \\
(6)\end{array}$ & $\begin{array}{c}\text { Implicatura } \\
(10)\end{array}$ & $\begin{array}{c}\text { Sentimiento } \\
\text { (5) }\end{array}$ & Ironía (5) & $\begin{array}{l}\text { Referencia } \\
\text { (8) }\end{array}$ & $\begin{array}{c}\text { Enriquecimiento } \\
\text { (8) }\end{array}$ \\
\hline \multicolumn{7}{|l|}{6 AÑOS } \\
\hline M & 5.05 & 7.8 & 4.95 & 3.4 & 6.95 & 6.35 \\
\hline Mdn & 5 & 8 & 5 & 4 & 7 & 6 \\
\hline $\mathrm{DE}$ & 0.51 & 1.44 & 0.22 & 1.60 & 0.94 & 1.09 \\
\hline \multicolumn{7}{|l|}{7 AÑOS } \\
\hline $\mathrm{M}$ & 5.3 & 9.15 & 4.95 & 4.7 & 7.45 & 6.6 \\
\hline Mdn & 5 & 9 & 5 & 5 & 8 & 7 \\
\hline DE & 0.66 & 0.87 & 0.22 & 0.57 & 0.69 & 1.23 \\
\hline \multicolumn{7}{|l|}{8 AÑOS } \\
\hline M & 5.5 & 9.3 & 5 & 4.85 & 7.75 & 7.6 \\
\hline Mdn & 5.5 & 10 & 5 & 5 & 8 & 8 \\
\hline $\mathrm{DE}$ & 0.51 & 0.92 & 0 & 0.37 & 0.44 & 0.75 \\
\hline \multicolumn{7}{|l|}{9 AÑOS } \\
\hline $\mathrm{M}$ & 5.6 & 9.8 & 5 & 4.8 & 7.8 & 7.75 \\
\hline Mdn & 6 & 10 & 5 & 5 & 8 & 8 \\
\hline $\mathrm{DE}$ & 0.50 & 0.52 & 0 & 0.52 & 0.52 & 0.44 \\
\hline
\end{tabular}

Como podemos observar, la media más alta de acierto en las primeras edades se corresponde con las preguntas de sentimiento (3.6 sobre 5 en los niños de 3 años y 4.3 sobre 5 en los de 4 años), de referencia (5.2 sobre 8 para el grupo de 3 años y 6 sobre 8 para el de 4 años) y de rutina (3.7 sobre 6 en los niños de 3 años y 4.5 sobre 6 en los de 4 años). Esto indicaría que, en este tipo de preguntas, la comprensión entraña menor dificultad para los niños. Por el contrario, el menor porcentaje medio de aciertos a los 3 años se encuentra en las preguntas de ironía (0.55 sobre 5) y de implicatura (3.3 sobre 10), lo cual revelaría, como parecía esperable, que estas son las preguntas que implican una mayor complejidad, al menos en los niños de menor edad.

Al comienzo de este estudio planteamos las preguntas de rutinas e implicaturas como muy próximas. No obstante, presuponíamos que las rutinas serían más fáciles de procesar debido a su temática totalmente familiar para los niños. Los datos muestran que esto es así hasta los 7 años, edad a partir de la que se iguala la media de aciertos.

En cuanto a los grupos de edades superiores (7, 8 y 9 años), los porcentajes medios de acierto rozan el 100\% en las preguntas de sentimiento. Le siguen las de 254 
referencia, rutina, implicaturas e ironía, y en el caso de las preguntas de enriquecimiento estos valores se alcanzan solo en los niños de 8 y 9 años. Consecuentemente, podríamos deducir que, de nuevo, las preguntas que requieren menos esfuerzo serían las de referencia y sentimiento (también con altas medias de acierto en los grupos menores), seguidas de las de enriquecimiento, rutina, implicatura e ironía. Los valores de este último tipo de pregunta llaman la atención, ya que en principio pensamos que sería una de las más difíciles en la comprensión. No obstante, será necesario tener en cuenta también el análisis de las explicaciones válidas, puesto que una respuesta válida no siempre indica que el niño haya comprendido perfectamente la pregunta.

En general, se observa una evolución ascendente en la media y la mediana de cada grupo de edad en los distintos tipos de preguntas. Cabe destacar la única excepción constituida por la actuación media de los niños de 5 años cuando responden a preguntas que requieren el procesamiento de una implicatura (8.25 sobre 10), superior a la de los niños de 6 años (7.8 sobre 10). En principio podría tratarse de un hecho puntualmente casual, ya que la mediana en ambos grupos coincide (8 sobre 10). Puede resultar sorprendente también el alto porcentaje de aciertos en todas las edades en este tipo de preguntas con implicaturas, que en principio supusimos de mayor dificultad en su procesamiento. No obstante, como ya hemos apuntado, se debe analizar también el porcentaje de acierto en las explicaciones válidas, lo cual nos dará una visión más transparente y fiable de la comprensión de estas y de las demás clases de preguntas.

Seguidamente, en la tabla 26 se recogen las medidas estadísticas descriptivas correspondientes a las explicaciones válidas (recuérdese que se piden únicamente cuando la respuesta es válida y solo en los cuatro primeros tipos de pregunta: rutina, implicatura, sentimiento e ironía): 
Tabla 26. Media/ Mediana/ Desviación Estándar en Respuestas Válidas

\begin{tabular}{|c|c|c|c|c|}
\hline \multirow[b]{2}{*}{ Grupo de edad } & \multicolumn{4}{|c|}{ EXPLICACIONES VÁLIDAS } \\
\hline & $\begin{array}{c}\text { Rutina } \\
\text { (6) }\end{array}$ & $\begin{array}{l}\text { Implicatura } \\
\text { (10) }\end{array}$ & $\begin{array}{l}\text { Sentimiento } \\
\text { (5) }\end{array}$ & $\begin{array}{c}\text { Ironía } \\
(5)\end{array}$ \\
\hline \multicolumn{5}{|l|}{3 AÑOS } \\
\hline $\mathrm{M}$ & 0.8 & 1.15 & 1.6 & 0.05 \\
\hline Mdn & 1 & 1 & 1.5 & 0 \\
\hline $\mathrm{DE}$ & 0.95 & 1.35 & 1.46 & 0.22 \\
\hline \multicolumn{5}{|l|}{4 AÑOS } \\
\hline M & 1.8 & 2 & 2.5 & 0.2 \\
\hline Mdn & 2 & 2 & 3 & 0 \\
\hline $\mathrm{DE}$ & 1.24 & 1.52 & 1.43 & 0.61 \\
\hline \multicolumn{5}{|l|}{5 AÑOS } \\
\hline $\mathrm{M}$ & 3 & 4.75 & 3.75 & 0.2 \\
\hline Mdn & 3 & 5 & 4 & 0 \\
\hline $\mathrm{DE}$ & 0.92 & 1.80 & 0.91 & 0.41 \\
\hline \multicolumn{5}{|l|}{6 AÑOS } \\
\hline $\mathrm{M}$ & 3.9 & 7.8 & 4.4 & 1.25 \\
\hline Mdn & 4 & 8 & 4 & 0.5 \\
\hline $\mathrm{DE}$ & 0.97 & 1.44 & 0.50 & 1.65 \\
\hline \multicolumn{5}{|l|}{7 AÑOS } \\
\hline $\mathrm{M}$ & 4.4 & 7.75 & 4.7 & 2.3 \\
\hline Mdn & 5 & 8 & 5 & 3 \\
\hline $\mathrm{DE}$ & 1.05 & 1.16 & 0.57 & 1.87 \\
\hline \multicolumn{5}{|l|}{8 AÑOS } \\
\hline $\mathrm{M}$ & 4.9 & 8.3 & 4.75 & 3 \\
\hline Mdn & 5 & 8 & 5 & 3 \\
\hline $\mathrm{DE}$ & 0.72 & 0.86 & 0.44 & 1.62 \\
\hline \multicolumn{5}{|l|}{9 AÑOS } \\
\hline $\mathrm{M}$ & 5.3 & 8.8 & 4.85 & 3.25 \\
\hline Mdn & 5 & 9 & 5 & 3.5 \\
\hline $\mathrm{DE}$ & 0.66 & 0.69 & 0.37 & 1.58 \\
\hline
\end{tabular}

En el caso de las explicaciones válidas, como era esperable, los porcentajes de acierto son bastante inferiores a los de respuestas válidas. Las medias y medianas más bajas, tanto en edades inferiores como superiores, corresponden a las de las preguntas 
de ironía. Esto significa que este tipo de pregunta es la que supone mayor dificultad a la hora de proporcionar una explicación razonada por parte de los niños a cualquier edad. De hecho, hasta los 6 años no se alcanza el 25\% de aciertos y a los 9 años solo son capaces de explicar adecuadamente las respuestas que han dado en torno a un 65\% de las veces, esto es, 3.25 sobre 5 .

Por lo que respecta a las preguntas de rutinas e implicaturas, las medias de explicaciones válidas evolucionan paralelamente, con cierta ventaja a favor de las rutinas hasta los 5 años, entre los 6 y los 8 a favor de las implicaturas y a los 9 años con un idéntico porcentaje de acierto, un 88\% (8.8 sobre 10 para las implicaturas y 5.3 sobre 6 para las rutinas). Estos resultados se acercan a nuestras hipótesis iniciales, en las que establecimos que este tipo de preguntas eran muy similares y esperábamos que su comportamiento en cuanto al procesamiento metapragmático también lo fuera.

Finalmente, con relación a las explicaciones de preguntas de sentimiento, su desarrollo es ligeramente superior al de las de rutinas. En todos los grupos la media es ciertamente superior a la resultante para las preguntas de rutinas.

A continuación se muestran los diagramas que permiten comparar gráficamente la evolución del número de respuestas válidas y explicaciones válidas en función de la edad en cada tipo de pregunta.

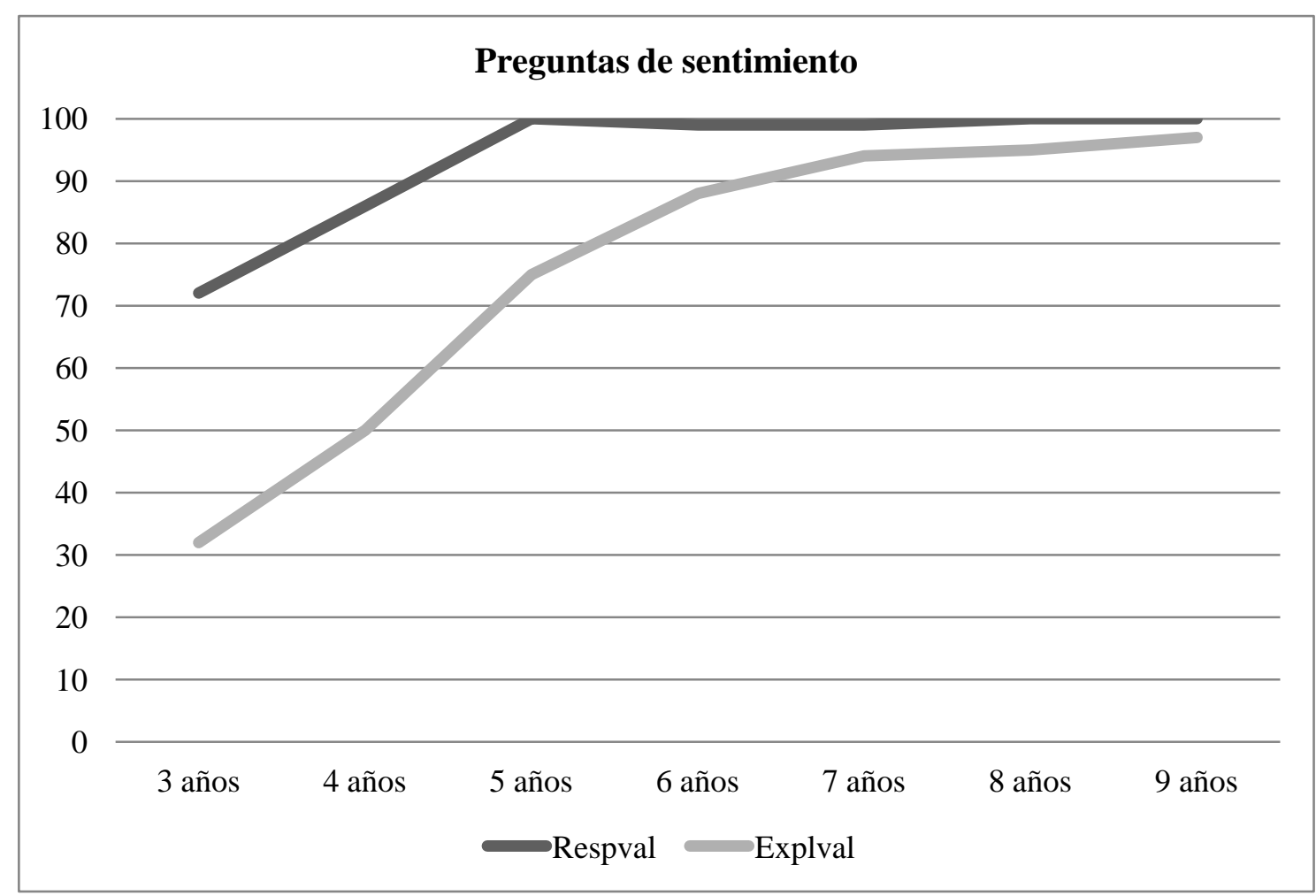

Figura 25. Respuestas/Explicaciones válidas en preguntas de sentimiento 
En las preguntas de sentimiento (véase fig. 25) se observa claramente una evolución ascendente a medida que avanza la edad. Como ya hemos visto, se trata de preguntas que no entrañan gran dificultad en la comprensión por parte de los niños. Así, en las respuestas válidas se advierte una progresión desde los 3 a los 5 años, edad a la que se logra un $100 \%$ generalizado de aciertos, que se mantiene hasta los 9 años. Las explicaciones, por su parte, repiten el esquema, pero en este caso el dominio se alcanza sobre todo a partir de la edad de 7 años.

Las preguntas de rutina (véase fig. 26) también han resultado ciertamente fáciles para los niños. En este caso, aunque el gráfico de respuestas parte de una media de acierto en torno al $60 \%$ en los niños de 3 años y el de explicaciones en torno al $10 \%$, ambas líneas de progresión convergen a los 9 años en torno al 80\% de dominio. Si bien es cierto que el crecimiento es más lineal en las respuestas y más pronunciado en las explicaciones, en ambos casos se puede observar una evolución del número de aciertos que se corresponde con la progresión de edad.

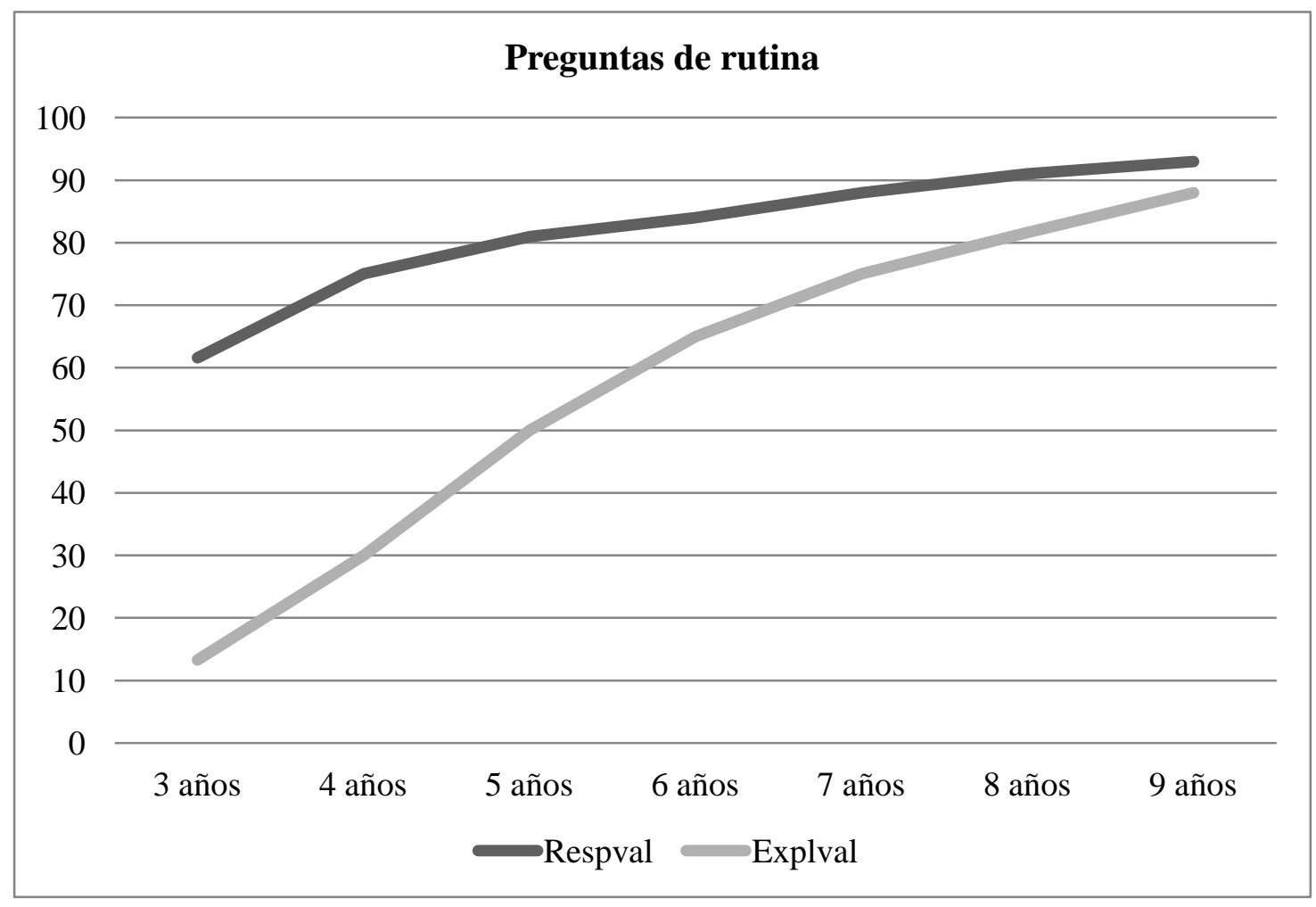

Figura 26. Respuestas/Explicaciones válidas en preguntas de rutina 


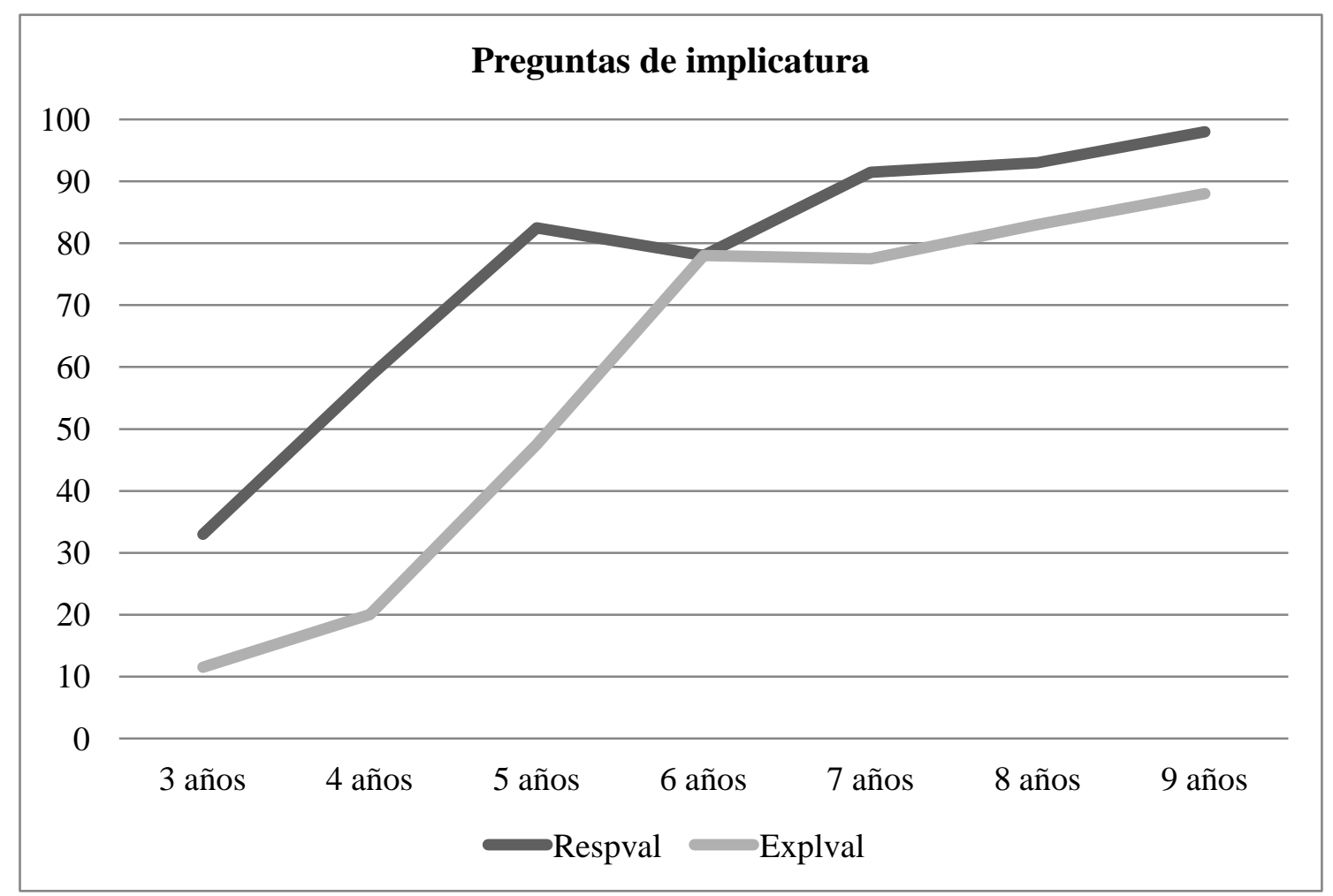

Figura 27. Respuestas/ Explicaciones válidas en preguntas de implicatura

Mientras que en las preguntas de sentimiento y rutina la evolución de preguntas y respuestas válidas en función de la edad era lineal y progresiva, el comportamiento de las preguntas de implicatura (véase fig. 27) presenta un punto de intersección localizado a los 6 años. Esto quiere decir que a esta edad el porcentaje de respuestas y explicaciones válidas coincide. A continuación, a los 7 años de nuevo se distancian y a los 8 y 9 años discurren paralelamente con una diferencia de un 10\% aproximadamente. Insistimos en que sería conveniente ampliar la muestra de niños de estas edades y con distintos tipos de implicaturas para comprobar si se mantienen estos resultados a los 6 años o si se trata de un dato casual de esta muestra. 


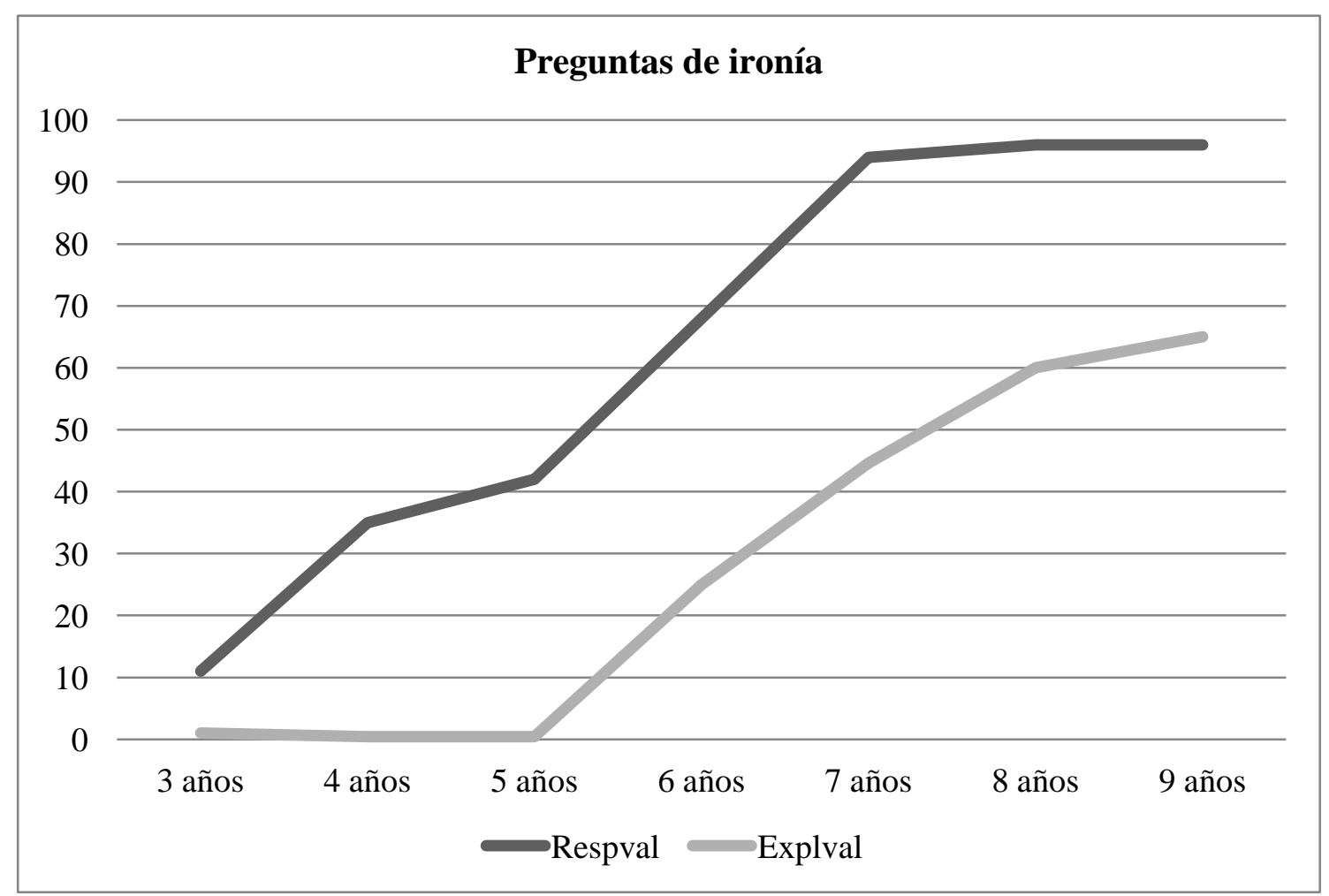

Figura 28. Respuestas/Explicaciones válidas en preguntas de ironía

Finalmente, como ya avanzábamos, las preguntas de ironía (véase fig. 28) son las que han supuesto mayor dificultad para los niños. En el gráfico se observan 2 puntos claros de inflexión en la evolución de las respuestas válidas: uno a partir de los 5 años y otro a partir de los 7. Dicho cambio contrastado también se repite a los 5 años para el número de explicaciones válidas. De hecho, es a partir de esta edad cuando los niños comienzan a ser capaces de justificar puntualmente sus respuestas relacionadas con el procesamiento de ironías.

\subsubsection{Variable sexo}

Como adelantábamos al comienzo del capítulo, para esta investigación hemos intentado seleccionar una muestra equilibrada de niños y niñas. Una vez recogidos los datos, nos plateamos ahora la posible influencia del sexo en el número de respuestas/explicaciones válidas. Para este análisis se ha empleado de forma generalizada el test no paramétrico de Mann-Whitney. Como ya hemos mencionado anteriormente, dicha prueba es equivalente a una T-Student, pero sin el supuesto de normalidad en la distribución de los datos. De esta forma, se han llevado a cabo contrastes para cada tipo de pregunta, confrontando en cada grupo de edad las 
respuestas y explicaciones de niños y niñas. Los resultados se muestran en la siguiente tabla:

Tabla 27. Variable sexo por edad y tipo de pregunta (U de Mann-Whitney)

\begin{tabular}{|c|c|c|c|c|c|c|c|}
\hline \multirow{3}{*}{$\begin{array}{l}\text { Grupo } \\
\text { Edad }\end{array}$} & \multirow{3}{*}{$\begin{array}{c}\text { Respuestas/ } \\
\text { Explicaciones }\end{array}$} & \multicolumn{6}{|c|}{ DISTINTAS CATEGORÍAS DE PREGUNTAS } \\
\hline & & Ironía & Referencia & Rutina & Enriquecimiento & Sentimiento & Implicatura \\
\hline & & Sig. & Sig. & Sig. & Sig. & Sig. & Sig. \\
\hline \multirow[t]{2}{*}{3 años } & Respval & .656 & .656 & .656 & .710 & .882 & .766 \\
\hline & Explval & .710 & - & .882 & - & .656 & .331 \\
\hline \multirow[t]{2}{*}{4 años } & Respval & .201 & .766 & .552 & .710 & .331 & .090 \\
\hline & Explval & .503 & - & .295 & - & .201 & .112 \\
\hline \multirow[t]{2}{*}{5 años } & Respval & .521 & .135 & .384 & .343 & $\mathrm{X}_{1}$ & .734 \\
\hline & Explval & .792 & - & .181 & - & .473 & .115 \\
\hline \multirow[t]{2}{*}{6 años } & Respval & .912 & .912 & .739 & .481 & .739 & .971 \\
\hline & Explval & .796 & - & .436 & - & 1.000 & .971 \\
\hline \multirow[t]{2}{*}{7 años } & Respval & .796 & $.043 *$ & $.011^{*}$ & .218 & .739 & .796 \\
\hline & Explval & .579 & - & .123 & - & .063 & .796 \\
\hline \multirow[t]{2}{*}{8 años } & Respval & .739 & .739 & .481 & .436 & $\mathrm{X}_{1}$ & .631 \\
\hline & Explval & .796 & - & .579 & - & .739 & .739 \\
\hline \multirow[t]{2}{*}{9 años } & Respval & .796 & .796 & 1.000 & .739 & $\mathrm{X}_{1}$ & .280 \\
\hline & Explval & .684 & - & .280 & - & .280 & .353 \\
\hline
\end{tabular}

$\imath$ En estos casos, el análisis no es necesario porque la distribución no tiene varianza para esta variable. Esto es, todos los niños y niñas responden al mismo número de preguntas adecuadamente.

Como se observa, de forma generalizada los valores de $p$ no son estadísticamente significativos. Curiosamente, es a la edad de 7 años donde obtenemos las excepciones. Concretamente en las respuestas a preguntas de referencia y rutina se observan diferencias entre niños y niñas, a favor de estas últimas. Podemos sugerir, por tanto, un estudio más profundo con una muestra más amplia de niños de 7 años que permitiría verificar las posibles diferencias a esta edad. 
No obstante, en este estudio las escasas diferencias estadísticamente significativas no son importantes, entre otras cosas porque el valor de $p$ es muy cercano a 0,05 y, por tanto, se pueden considerar casuales. Podemos concluir, así, que el sexo no influye en el número de respuestas/explicaciones válidas de los sujetos.

\subsubsection{Variable tipo de contexto (visual/no visual)}

En el análisis de esta variable, dado que el número de preguntas con contexto visual y no visual es diferente en todos los tipos de preguntas (véase fig. 13), se han utilizado porcentajes para hacer las comparaciones. Por ejemplo, en las preguntas con implicaturas, del total de 10 preguntas 6 tienen apoyo visual y 4 no. Así, si el niño responde a 6 preguntas con contexto visual acertadamente se anota un 100\%, mientras que si responde a 3 se anota un 50\%. De la misma forma, por lo que respecta a las preguntas sin apoyo visual, si responde a 4 apropiadamente se contabiliza como un 100\% y si, por ejemplo, responde 1 se contabiliza un 25\%. Asimismo, las pruebas utilizadas para los contrates han sido también las no paramétricas de Mann-Whitney. Los valores de $p$ obtenidos en cada caso se recogen en la siguiente tabla:

Tabla 28. Variable tipo de contexto por edad y tipo de pregunta (U de Mann-Whitney)

\begin{tabular}{|c|c|c|c|c|c|c|}
\hline $\begin{array}{c}\text { Grupo } \\
\text { Edad }\end{array}$ & $\begin{array}{c}\text { Respuestas/ } \\
\text { Explicaciones }\end{array}$ & $\begin{array}{c}\text { Ironía } \\
\text { Sig. }\end{array}$ & $\begin{array}{c}\text { Referencia } \\
\text { Sig. }\end{array}$ & $\begin{array}{c}\text { Enriquecimiento } \\
\text { Sig. }\end{array}$ & $\begin{array}{c}\text { Sentimiento } \\
\text { Sig. }\end{array}$ & $\begin{array}{c}\text { Implicatura } \\
\text { Sig. }\end{array}$ \\
\hline \multirow[t]{2}{*}{3 años } & Respval & .072 & $.000 *$ & .068 & .925 & $.038 *$ \\
\hline & Explval & .799 & - & - & .738 & $.035 *$ \\
\hline \multirow[t]{2}{*}{4 años } & Respval & $.000 *$ & $.000 *$ & .072 & .242 & $.000 *$ \\
\hline & Explval & .779 & - & - & .445 & $.000 *$ \\
\hline \multirow[t]{2}{*}{5 años } & Respval & .081 & $.000 *$ & .231 & $\mathrm{X}_{1}$ & $.000 *$ \\
\hline & Explval & .289 & - & - & .445 & $.020 *$ \\
\hline \multirow[t]{2}{*}{6 años } & Respval & .718 & $.004 *$ & .314 & .799 & $.000 *$ \\
\hline & Explval & .289 & - & - & .904 & $.000 *$ \\
\hline \multirow[t]{2}{*}{7 años } & Respval & .108 & $.014 *$ & .355 & .799 & .429 \\
\hline & Explval & .602 & - & - & .738 & $.013 *$ \\
\hline
\end{tabular}




\begin{tabular}{|cccccccc|}
\hline $\begin{array}{c}\text { Grupo } \\
\text { Edad }\end{array}$ & $\begin{array}{c}\text { Respuestas/ } \\
\text { Explicaciones }\end{array}$ & $\begin{array}{c}\text { Ironía } \\
\text { Sig. }\end{array}$ & $\begin{array}{c}\text { Referencia } \\
\text { Sig. }\end{array}$ & $\begin{array}{c}\text { Enriquecimiento } \\
\text { Sig. }\end{array}$ & $\begin{array}{c}\text { Sentimiento } \\
\text { Sig. }\end{array}$ & Implicatura \\
\hline $\mathbf{8}$ años & Respval & .820 & .183 & .678 & Xi & .833 \\
\cline { 2 - 7 } & Explval & .529 & - & - & .398 & .289 \\
\hline \multirow{2}{*}{ años } & Respval & .738 & .602 & .738 & Xi & .602 \\
\cline { 2 - 7 } & Explval & .429 & - & - & .820 & .134 \\
\hline
\end{tabular}

ŁEn estos casos, el análisis no es necesario porque la distribución no tiene varianza para esta variable. Esto es, todos los niños y niñas responden al mismo número de preguntas adecuadamente.

Según los resultados que se observan tras el análisis estadístico, el tipo de contexto no influye en el número de respuestas ni de explicaciones válidas en las preguntas de sentimiento ni de enriquecimiento (en este caso solo se contabiliza el número de respuestas, ya que en estas preguntas no se requiere explicación posterior). Asimismo, el hecho de que haya apoyo visual no influye tampoco en el número de respuestas/explicaciones válidas para preguntas de ironía, salvo en las respuestas de los niños de 4 años. Para explicar este hecho habría que indagar en la bibliografía referente al desarrollo cognitivo y comunicativo de los niños en esa edad concreta. No obstante, creemos que estos resultados son esperables: en las preguntas de sentimiento y enriquecimiento el apoyo visual no influye porque son preguntas relacionadas con contextos familiares para los niños y, por ello, no es necesaria la imagen, ya que los niños tienen interiorizadas las situaciones. En las preguntas con ironías, los resultados señalan que el apoyo visual tampoco es relevante y, en este caso, se debe a que el número de errores es muy alto, esto es, estas preguntas suponen grandes dificultades en sí mismas, con o sin apoyo visual.

En cuanto a las preguntas de referencia e implicatura, los resultados sí reflejan la importancia positiva del refuerzo visual. En este tipo de preguntas, en torno a los 7 años, deja de influir el tipo de contexto, esto es, los niños responden de forma similar haya o no apoyo visual. Concretamente, en las preguntas de implicaturas, para los niños de 3 a 6 años el tipo de contexto condiciona el número de respuestas/explicaciones válidas. Ahora bien, para los niños de 7 años el tipo de contexto influye en el número de explicaciones válidas, pero no así para las respuestas. $\mathrm{Y}$, finalmente, en los niños de 8 y 9 años que el contexto sea verbal o verbal y visual 
no determina el número de respuestas/explicaciones válidas. En estos casos, todo parece indicar que cuando los niños son mayores el apoyo visual deja de ser relevante.

\subsubsection{Respuestas y explicaciones fallidas}

Como ya hemos reiterado en numerosas ocasiones, en este estudio consideramos que las respuestas y explicaciones fallidas pueden ofrecer también valiosa información sobre la comprensión pragmática de las diferentes preguntas por parte de los niños. Si el niño falla en su respuesta podremos plantearnos qué tipo de información errónea ha usado (información contextual, de su experiencia, contenida en la propia pregunta, etc.). Las respuestas y explicaciones fallidas se clasifican en torno a 9 categorías: foco incorrecto, conocimiento del mundo, información dada, no sé, irrelevante, tautológica, no hay respuesta, turno de palabra y otras ${ }^{191}$. Esta clasificación puede indicarnos qué falla con más frecuencia en cada grupo de edad en el proceso de comprensión pragmática.

Los resultados constatan, como era esperable, que el número de respuestas y explicaciones fallidas disminuye a medida que aumenta la edad. Para poder comparar el número de respuestas y explicaciones fallidas entre las distintas edades, las cifras se han convertido en frecuencias relativas (véanse tablas 29 y 30). En cuanto a las respuestas fallidas, no se han tenido en cuenta los datos ofrecidos los niños de 9 años, puesto que en la mayoría de los casos sus respuestas válidas alcanzan más del 90\%.

En cuanto a las respuestas fallidas (véase tabla 29), no sé es una de las respuestas más comunes en todas las categorías y es la más frecuente en niños de 3, 4, 5 y 6 años, aunque en este último grupo el porcentaje es muy cercano a foco incorrecto, que será la más frecuente en los grupos de edades más avanzadas (7 y 8 años). A los 3 y 4 años también es muy habitual el tipo de respuesta irrelevante, y en el caso de los más pequeños —el grupo de 3 años - la respuesta tautológica. A partir de los 5 años, sin embargo, la frecuencia de este tipo de respuestas menos sofisticadas va decreciendo en favor de conocimiento del mundo o información dada, si bien es cierto que los 5 años es la edad a caballo entre las menos sofisticadas y las más sofisticadas. Así, a partir de los 6 años en adelante aparecen como prioritarias foco incorrecto y conocimiento del mundo. Un dato curioso lo constituye el hecho de que la respuesta más frecuente para

\footnotetext{
${ }^{191}$ Para una explicación detallada de cada una de las categorías véase apartado 5.2.2. 264
} 
el grupo de 6 años sea no sé, con un 31\%. Finalmente, como era esperable, las respuestas del tipo tautológica, no hay respuesta o turno de palabra son casi inexistentes en edades avanzadas.

Tabla 29. Frecuencias absolutas y relativas de respuestas fallidas

\begin{tabular}{|c|c|c|c|c|c|c|c|c|c|c|c|c|}
\hline \multirow{2}{*}{$\begin{array}{l}\text { Categoría de } \\
\text { respuesta }\end{array}$} & \multicolumn{2}{|c|}{3 años } & \multicolumn{2}{|c|}{4 años } & \multicolumn{2}{|c|}{5 años } & \multicolumn{2}{|c|}{6 años } & \multicolumn{2}{|c|}{7 años } & \multicolumn{2}{|c|}{8 años } \\
\hline & $\begin{array}{l}F . \\
\text { Abs. }\end{array}$ & $\begin{array}{l}\text { F. } \\
\text { Rel. }\end{array}$ & $\begin{array}{l}F . \\
\text { Abs. }\end{array}$ & $\begin{array}{l}\text { F. } \\
\text { Rel. }\end{array}$ & $\begin{array}{l}F . \\
\text { Abs. }\end{array}$ & $\begin{array}{l}\text { F. } \\
\text { Rel. }\end{array}$ & $\begin{array}{l}F . \\
\text { Abs. }\end{array}$ & $\begin{array}{l}\text { F. } \\
\text { Rel. }\end{array}$ & $\begin{array}{l}F . \\
\text { Abs. }\end{array}$ & $\begin{array}{l}\text { F. } \\
\text { Rel. }\end{array}$ & $\begin{array}{l}F . \\
\text { Abs. }\end{array}$ & $\begin{array}{l}\text { F. } \\
\text { Rel. }\end{array}$ \\
\hline $\begin{array}{l}\text { Foco } \\
\text { incorrecto }\end{array}$ & 12 & 2,7 & 33 & 11 & 20 & 10,8 & 38 & 26,8 & 23 & 32 & 17 & 42,5 \\
\hline $\begin{array}{l}\text { Conocimiento } \\
\text { del mundo }\end{array}$ & 45 & 10,1 & 38 & 12,6 & 36 & 19,5 & 15 & 10,6 & 25 & 34,7 & 10 & 25 \\
\hline $\begin{array}{l}\text { Información } \\
\text { dada }\end{array}$ & 50 & 11,2 & 36 & 12 & 25 & 13,5 & 15 & 10,6 & 5 & 6,9 & 0 & 0 \\
\hline No sé & 118 & 26,6 & 100 & 33,2 & 48 & 25,9 & 44 & 31 & 8 & 11,1 & 8 & 20 \\
\hline Irrelevante & 61 & 13,7 & 46 & 15,3 & 21 & 11,4 & 14 & 9,8 & 8 & 11,1 & 2 & 5 \\
\hline Tautológica & 55 & 12,4 & 13 & 4,3 & 23 & 12,4 & 12 & 8,4 & 2 & 2,8 & 1 & 2,5 \\
\hline $\begin{array}{l}\text { No hay } \\
\text { respuesta }\end{array}$ & 30 & 6,7 & 21 & 7 & 6 & 3,3 & 2 & 1,4 & 0 & 0 & 1 & 2,5 \\
\hline Otra (opuesta) & 30 & 6,7 & 8 & 2,6 & 5 & 2,7 & 2 & 1,4 & 1 & 1,4 & 1 & 2,5 \\
\hline $\begin{array}{l}\text { Turno de } \\
\text { palabra }\end{array}$ & 44 & 9,9 & 6 & 2 & 1 & 0,5 & 0 & 0 & 0 & 0 & 0 & 0 \\
\hline TOTAL & 445 & 100 & 301 & 100 & 185 & 100 & 142 & 100 & 72 & 100 & 40 & 100 \\
\hline
\end{tabular}

$\mathrm{N}=20$ por cada grupo de edad. $\mathrm{F}$. Abs.=Frecuencia absoluta de respuestas fallidas del total de respuestas fallidas de cada grupo en cada categoría (f). F. Rel.= Frecuencia relativa (f/y) x100\%= porcentaje sobre 100 del número de respuestas fallidas para cada categoría en cada intervalo de edad.

Los niños que inicialmente dan una respuesta válida no siempre son capaces de ofrecer una explicación adecuada. De esta forma, hemos analizado también las explicaciones fallidas dadas a respuestas válidas (véase tabla 30). Recordemos que si el niño da una respuesta fallida no se le pide ninguna explicación. Consecuentemente, el número total de explicaciones fallidas será menor que el de respuestas, ya que, por un lado, algunos tipos de preguntas no requieren explicación (las de referencia y las de enriquecimiento) y, por lo tanto, partimos de un total de 26 preguntas (frente a las 42 
totales). Y, por otro lado, si el niño responde inapropiadamente tampoco se le pregunta por una explicación.

En este estudio sí se han incluido las explicaciones fallidas de los niños de 9 años, ya que el porcentaje de acierto no es tan alto como ocurría en las respuestas.

Como se observa en la tabla 30, las explicaciones fallidas más frecuentes en los niños de 3 años y una de las más comunes en los de 4 es la de turno de palabra. Este hecho no nos sorprende, ya que en este tipo de respuesta el niño usa un par adyacente para contestar, por ejemplo, si le preguntan “¿por qué?” él responde “porque”.

Tabla 30. Frecuencias absolutas y relativas de explicaciones fallidas

\begin{tabular}{|c|c|c|c|c|c|c|c|c|c|c|c|c|c|c|}
\hline \multirow{2}{*}{$\begin{array}{c}\text { Categoría de } \\
\text { respuesta }\end{array}$} & \multicolumn{2}{|c|}{3 años } & \multicolumn{2}{|c|}{4 años } & \multicolumn{2}{|c|}{5 años } & \multicolumn{2}{|c|}{6 años } & \multicolumn{2}{|c|}{7 años } & \multicolumn{2}{|c|}{8 años } & \multicolumn{2}{|c|}{9 años } \\
\hline & $\begin{array}{l}F . \\
\text { Abs. }\end{array}$ & $\begin{array}{l}\text { F. } \\
\text { Rel. }\end{array}$ & $\begin{array}{l}\text { F. } \\
\text { Abs. }\end{array}$ & $\begin{array}{c}\text { F. } \\
\text { Rel. }\end{array}$ & $\begin{array}{l}\text { F. } \\
\text { Abs. }\end{array}$ & $\begin{array}{l}\text { F. } \\
\text { Rel. }\end{array}$ & $\begin{array}{c}F . \\
\text { Abs. }\end{array}$ & $\begin{array}{l}\text { F. } \\
\text { Rel. }\end{array}$ & $\begin{array}{l}F . \\
\text { Abs. }\end{array}$ & $\begin{array}{l}\text { F. } \\
\text { Rel. }\end{array}$ & $\begin{array}{l}F . \\
\text { Abs. }\end{array}$ & $\begin{array}{l}\text { F. } \\
\text { Rel. }\end{array}$ & $\begin{array}{l}F . \\
\text { Abs. }\end{array}$ & $\begin{array}{c}\text { F. } \\
\text { Rel. }\end{array}$ \\
\hline $\begin{array}{l}\text { Foco } \\
\text { incorrecto }\end{array}$ & 9 & 6 & 43 & 21,6 & 39 & 22,4 & 22 & 19,5 & 20 & 20,4 & 24 & 32,4 & 16 & 27,1 \\
\hline $\begin{array}{l}\text { Conocimiento } \\
\text { del mundo }\end{array}$ & 39 & 26 & 52 & 26,1 & 53 & 30,5 & 53 & 47 & 27 & 27,5 & 10 & 13,5 & 13 & 22 \\
\hline $\begin{array}{l}\text { Información } \\
\text { dada }\end{array}$ & 11 & 7,3 & 18 & 9,1 & 25 & 14,4 & 23 & 20,3 & 28 & 28,6 & 25 & 33,8 & 24 & 40,7 \\
\hline No sé & 25 & 16,7 & 23 & 11,6 & 24 & 13,8 & 7 & 6,1 & 14 & 14,3 & 13 & 17,7 & 3 & 5,1 \\
\hline Irrelevante & 6 & 4 & 9 & 4,5 & 3 & 1,7 & 0 & 0 & 0 & 0 & 0 & 0 & 0 & 0 \\
\hline Tautológica & 1 & 0,7 & 5 & 2,5 & 8 & 4,6 & 4 & 3,5 & 5 & 5,1 & 1 & 1,3 & 3 & 5,1 \\
\hline $\begin{array}{l}\text { No hay } \\
\text { respuesta }\end{array}$ & 14 & 9,3 & 10 & 5 & 9 & 5,2 & 2 & 1,8 & 4 & 4,1 & 1 & 1,3 & 0 & 0 \\
\hline $\begin{array}{l}\text { Otra } \\
\text { (opuesta) }\end{array}$ & 1 & 0,7 & 0 & 0 & 1 & 0,5 & 0 & 0 & 0 & 0 & 0 & 0 & 0 & 0 \\
\hline $\begin{array}{l}\text { Turno de } \\
\text { palabra }\end{array}$ & 44 & 29,3 & 39 & 19,6 & 12 & 6,9 & 2 & 1,8 & 0 & 0 & 0 & 0 & 0 & 0 \\
\hline Total & 150 & 100 & 199 & 100 & 174 & 100 & 113 & 100 & 98 & 100 & 74 & 100 & 59 & 100 \\
\hline
\end{tabular}

$\mathrm{N}=20$ por cada grupo de edad. $\mathrm{F}$. Abs.=Frecuencia absoluta de respuestas fallidas del total de respuestas fallidas de cada grupo en cada categoría (f). F. Rel.= Frecuencia relativa (f/y) x100\%= porcentaje sobre 100 del número de respuestas fallidas para cada categoría en cada intervalo de edad. 
Para los niños de 4, 5 y 6 años, el tipo de explicación fallida más frecuente es la de conocimiento del mundo y para los de 7, 8 y 9 años, información dada. No obstante, en el grupo de 9 años el 75\% de las explicaciones fallidas son las más cercanas a las acertadas, esto es, las de foco incorrecto.

Cabe subrayar también que, como ocurría con las respuestas, a partir de los 6 años en adelante son escasas o inexistentes las explicaciones fallidas clasificadas como tautológica, no hay respuesta, turno de palabra y otras.

Asimismo, podemos destacar el hecho de que el tipo de respuesta no sé está representado en todos los grupos de edad aproximadamente por un 15\% de frecuencia relativa, constituyendo una excepción los niños de 9 años —que, como ya comentamos anteriormente, responden erróneamente pocas veces-y los de 6 años. En el grupo de 6 años este porcentaje bajo en las explicaciones es cuanto menos sorprendente, puesto que la misma categoría no sé era la más frecuente en las respuestas fallidas. Esto podría deberse a que a esta edad hay cierta tendencia por parte de los niños a responder que no lo saben si no están convencidos de la respuesta, pero si dan una respuesta no vacilan a la hora de explicarla.

\subsection{DISCUSIÓN}

Esta investigación ha sido motivada por el hecho de que en la bibliografía en español hemos detectado una patente escasez de estudios experimentales que exploren la comprensión contextual o pragmática en niños con desarrollo normal. Afortunadamente, sí hemos observado que, en los últimos años, psicólogos y logopedas son cada vez más conscientes de la importancia del componente pragmático en la comunicación y así lo reflejan en sus trabajos.

En este estudio hemos seleccionado como marco teórico para el análisis pragmático la teoría de la relevancia. Esta elección se debe, en primer lugar, a que ya ha sido utilizada por estudios pioneros relacionados con el desarrollo y las dificultades de la comprensión pragmática (Happé, 1993; Leinonen y Kerbel, 1999), y, en segundo lugar, porque está orientada hacia un modelo cognitivo y, tal como sugiere gran parte de la bibliografía tratada, las dificultades pragmáticas podrían estar relacionadas íntimamente con fallos en las funciones cognitivas (Shields et al., 1996). 
Del mismo modo, el material de referencia tomado de los estudios de Loukusa, Leinonen y Ryder (2007), Loukusa (2007) y Loukusa, Ryder y Leinonen (2008) fue diseñado usando como marco de referencia la teoría de la relevancia. Cabe reconocer el mérito que supone la elaboración de un test con preguntas que permitan analizar el desarrollo del procesamiento pragmático y que sean válidas para niños de un rango de edades entre 3 y 9 años. La minuciosidad en la creación del material puede verse en la selección de los escenarios verbales simples, así como en el vocabulario empleado. Se ha intentado que las historias fueran breves para evitar que los niños tuvieran que memorizar mucha información. Con todo, es probable que en los grupos de 3 y 4 años haya niños que no entiendan alguna palabra, lo cual ha podido influir en el número de respuestas válidas. Asimismo puede ocurrir que en alguna pregunta se requiera un mayor esfuerzo de memoria y esto afecte a la capacidad de comprensión. Además, la falta de familiaridad con la entrevistadora también ha podido alterar la actuación de los niños, debido a una posible timidez o rechazo hacia alguien desconocido. En cualquier caso, las entrevistas han sido realizadas por la misma persona, a la que ninguno de los niños conocía previamente.

Nos gustaría señalar también que las entrevistas han sido percibidas por los niños como una tarea escolar más. Han tenido lugar en una atmósfera cotidiana, de forma que el contexto es más natural de lo que a simple vista pueda parecer. Hemos intentado, por tanto, que la entrevista reproduzca una tarea habitual en su experiencia curricular, para que no resulte una actividad extraña para ellos y se sientan cómodos con la propia dinámica del estudio.

Parece claro que la teoría de Sperber y Wilson (1986/1995) ha constituido una buena herramienta para identificar los factores que afectan a la relevancia. En efecto, la relevancia de un enunciado puede disminuir, por ejemplo, debido a la utilización de factores contextuales irrelevantes, fallo a la hora de fijar el foco de la pregunta o falta de habilidad para detener el procesamiento una vez localizada la respuesta válida. No obstante, tal como reconoce Luokusa (2007), cuando se utiliza la teoría de la relevancia en estudios sobre el desarrollo lingüístico o desórdenes del lenguaje, no hay que olvidar que se trata de una teoría orientada hacia lo cognitivo y que no soslaya la dimensión social del lenguaje, o al menos no tanto como nos gustaría. 
Como se ha dicho, el material ha sido tomado de estudios pioneros con niños finlandeses (Luokusa, Leinonen y Ryder, 2007; Loukusa, 2007; Luokusa, Ryder y Leinonen, 2008). Se trata, entonces, de un test aprobado por expertos en la materia, por lo que no dudamos de su fiabilidad. No obstante, somos conscientes de sus limitaciones. Entre ellas cabe señalar que el material utilizado parte de situaciones familiares y de factores contextuales establecidos de antemano para cada pregunta. Esto supone una ventaja, ya que facilita la categorización y el recuento de las respuestas de los niños. Sin embargo, reconocemos que la demanda contextual no refleja la dificultad propia de las situaciones comunicativas espontáneas. Por ello, tal como advierte Luokusa (2007), es posible que el material de este experimento no permita detectar pequeñas diferencias entre los grupos que sí estarían patentes en un análisis de las interacciones naturales. Además, consideramos que el hecho de que no haya el mismo número de preguntas de cada categoría ni tampoco el mismo número de preguntas con apoyo visual y sin él puede influir de algún modo en el recuento por porcentajes de los resultados.

Asimismo, somos también conscientes de las limitaciones de nuestra muestra compuesta por 140 niños. Se trata, como ya señalamos al comienzo de este capítulo, de un estudio experimental que debería desarrollarse en futuras investigaciones con una muestra más amplia.

A continuación, en las páginas que siguen, comentaremos la significatividad de los resultados más relevantes contrastando nuestra interpretación con los estudios previos y la bibliografía relacionada.

En este estudio se ha pretendido analizar la capacidad de comprensión pragmática en niños de 3 a 9 años en relación con seis clases de preguntas derivadas de la teoría de la relevancia (Sperber y Wilson, 1995). Los resultados han corroborado que los distintos tipos de pregunta responden a distintos grados de complejidad pragmática, de forma que pueden categorizarse como más simples o dificultosas en términos de demanda contextual. Así, a partir de la edad de 4 años los niños han alcanzado en torno a un $80-85 \%$ de aciertos en las preguntas de sentimientos; a partir de los 5 años en adelante este nivel de acierto se ha obtenido en las preguntas de asignación de referentes; a partir de los 6 años en las preguntas de enriquecimiento y rutina, y a partir de los 7 años en las de implicaturas e ironías. A la vista de estos 
resultados, sorprende el hecho de que las preguntas de identificación de sentimientos hayan sido las que menos problema han supuesto para los niños, por encima de las asignación de referentes, que en nuestras primeras hipótesis pensamos que serían las más sencillas. Quizá las respuestas fallidas en asignación de referentes puedan deberse más a dificultades de memoria que al propio fenómeno de la deixis. Como ya dijimos, en todos los casos se trata de referencias anafóricas y, consecuentemente, es necesario que el niño recuerde un elemento mencionado al principio de la historia. Aunque las historias son muy breves, en los niños más pequeños puede ocurrir que no hayan retenido dicho elemento, y de ahí que fallen en estas respuestas ${ }^{192}$. No obstante, el índice de acierto en asignación de referentes es muy alto, incluso en los niños de 3 años. Con respecto al resto de preguntas, puede verse el aumento progresivo esperable de la habilidad de los niños en el acceso a la información relevante para llevar a cabo el proceso de comprensión de cada pregunta. De esta forma, siguiendo a las preguntas de sentimientos y asignación de referentes, suponen una dificultad media las preguntas de enriquecimiento y rutina $\mathrm{y}$, finalmente, las más complejas han sido las de implicaturas e ironías.

El grupo más joven (compuesto por niños de 3 años) ha demostrado ser competente en las preguntas de menor dificultad pragmática, pero, además, en algunos casos hemos podido observar muestras del desarrollo de su capacidad para procesar preguntas más complejas. En relación con las preguntas de implicaturas, los niños de 3 años tienen una media de acierto del $33 \%$ y en el caso de las rutinas del $60 \%$, si bien es indudable que se trata del grupo con la desviación estándar más amplia. Este resultado está en línea con los experimentos iniciales que sugerían que los niños más pequeños poseen la capacidad para usar la información contextual siempre y cuando la comprensión no requiera un procesamiento complejo y el contexto sea familiar (O’Neill, 1996; Ryder y Leinonen, 2003). Así, por ejemplo, en una de las escenas de nuestro test se presenta a un niño que está llorando en el patio delante de un columpio.

\footnotetext{
192 Sorprendentemente, cuando los niños más pequeños no recuerdan el elemento mencionado al que hace referencia la expresión, usan como estrategia su propia lógica. Por ejemplo, en una de las historias los niños han ido a ver a Papá Noel al centro comercial y al día siguiente le cuentan a su profesora que había muchos otros niños. Inmediatamente se les pregunta: “¿Dónde había muchos niños?”. La mayoría entiende que el pronombre interrogativo se refiere al centro comercial. Los que no lo recuerdan, sí que entienden que se refiere a un lugar y, por lo tanto, responden: "En el cole", "En la otra clase", "En el parque", porque saben que en estos lugares normalmente hay muchos niños.
} 
A los niños se les pregunta que qué creen que ha pasado y una niña de 3 años responde: "Se ha caído del columpio/ porque el columpio se va moviendo" (entrevista A23). Por el contrario, si el procesamiento contextual les supera, el resultado es la ruptura del mecanismo de comprensión (Bezuidenhout y Sroda, 1998) y, por lo tanto, el fallo a la hora de responder a las preguntas relacionadas. En efecto, en las preguntas de ironía, los niños más pequeños no son capaces de deducir el significado irónico de la contradicción entre el significado literal y el contexto y ofrecen su propia explicación para dar respuesta a la situación planteada. Por ejemplo, en la historia en la que la madre está mirando por la ventana mientras llueve y dice en tono sarcástico que qué día tan bonito, algunos niños responden: "Porque se ha confundido" (niña 4 años A2), “Qué día tan bonito porque así crecen las plantas” (niño 5 años B36-37) o "Porque riega las flores" (niño 5 años C3). Con los años, los niños se vuelven capaces de integrar y manipular la información relevante en cada contexto (información previa dada, conocimiento del mundo, etc.), de forma que se torna la balanza y el número de aciertos supera al de errores.

En cuanto a la variable tipo de contexto, en este estudio se ha demostrado que en el caso de las preguntas de implicaturas (hasta los 6 años), de las de referencia (hasta los 7 años) y en las de ironías (solo para el grupo de 4 años) el porcentaje de aciertos mejora cuando las preguntas tienen apoyo visual. Probablemente, la información visual en estas preguntas ayuda a los niños a dirigir su atención hacia la parte relevante del contexto y concentrarse en el elemento por el que se les pregunta. Así, los resultados obtenidos por trabajos previos con niños finlandeses (Luokusa, 2007) indican también que el apoyo visual influye determinantemente en las preguntas de referencia (hasta los 6 años), de enriquecimiento (hasta los 5 años) y de implicaturas (a los 4 y a los 6 años).

Como ya mencionamos en el tercer capítulo, la bibliografía especializada señala que, en la evolución normal del niño, las habilidades cognitivas se desarrollan paralelamente a las habilidades lingüísticas (McTear y Conti-Ramsden, 1992; Buckley 2003). Oakhill y Yuill (1986) y Umstead y Leonard (1983) demostraron que las capacidades de razonamiento e inferencia están relacionadas con las habilidades de comprensión. En efecto, los estudios sobre la comprensión de textos sugieren que los fallos en la habilidad para inferir dan lugar a una comprensión pobre y viceversa (Cain 
et al., 2001). Estos estudios demuestran que incluso los niños que poseen los conocimientos necesarios pueden fallar en la comprensión debido a una falta de habilidad para usar e integrar el conocimiento de forma relevante en cada situación comunicativa.

En nuestra investigación, la evolución de respuestas válidas en función de la edad reproduce, en líneas generales, los patrones hallados por Ryder y Leinonen (2003) en su trabajo con niños ingleses, y también el de Loukusa (2007) con niños finlandeses. Sin embargo, de forma similar a la investigación con niños finlandeses (en la que en torno al 20\% de los niños de 3 años fueron capaces de responder algunas preguntas de implicaturas adecuadamente) en nuestro estudio, los niños de 3 años aciertan una media del 33\% de estas preguntas. Por el contrario, en el estudio de Ryder y Leinonen (2003) ningún niño de 3 años fue capaz de responder bien a preguntas de implicaturas. Esto puede deberse a que los materiales utilizados fueron diferentes, sobre todo en lo que respecta a la capacidad de memoria requerida en estas preguntas. En el estudio con niños españoles se ha seguido el modelo de preguntas de la investigación realizada con niños finlandeses (Loukusa, 2007), en la que dichas preguntas se basan en pequeños escenarios y el contexto es muy familiar. En cambio, en el estudio de Ryder y Leinonen (2003), los niños ingleses debían conectar las preguntas con información presentada mucho antes en la historia.

De igual forma, otra explicación puede ser que los factores culturales influyen en algunas áreas de la comprensión pragmática (Lloyd et al., 1995). Tanto en inglés como en finlandés o en español es frecuente el uso de enunciados indirectos, de modo que estas lenguas suponen constantemente demandas pragmáticas. Sin embargo, el aprendizaje del lenguaje tiene lugar en culturas y comunidades lingüísticas diferentes. Esto puede ocasionar pequeñas diferencias entre estas lenguas con relación a la etapa en la que los niños desarrollan la comprensión y manejo de diferentes tipos de información contextual (Luokusa, 2007). En este sentido, sería necesaria una futura investigación comparativa con lenguas distintas para determinar si efectivamente estos contrastes pueden deberse a aspectos culturales.

En este estudio también se ha analizado el contenido de las respuestas fallidas dadas por los niños. Los resultados demuestran que la respuesta categorizada como no sé es la más común en los niños de 3 a 6 años ( 30\% de las respuestas fallidas de 
estos grupos). Las siguientes respuestas fallidas más frecuentes en las edades de 5 a 8 años son las que hemos denominado foco incorrecto y conocimiento del mundo. Así, en la pregunta de implicatura que describe un pueblo un día de lluvia y se pregunta por qué el niño lleva un libro por encima de la cabeza, hemos recogido respuestas del tipo “Porque lo va a llevar a su casa” (niña 3 años A26), "Porque lo va a leer en el cole” (niño 3 años B17), "Porque lo va a llevar a la biblioteca” (niña 4 años CII5), "Porque lo quiere leer” (niña 3 años C40). Todas estas respuestas son ejemplos del uso del propio conocimiento del mundo que posee el niño: los libros se asocian a la lectura, al colegio o a la biblioteca, y de ahí que fallen al seleccionar la información contextual relevante para la pregunta en cuestión, esto es, que está lloviendo y no tiene paraguas. Este hecho sugiere que la sobregeneralización del propio conocimiento es un fenómeno especialmente habitual en los niños.

Del mismo modo, la respuesta fallida característicamente repetida en los niños de 7 y 8 años es la de foco incorrecto, que es la más se aproxima a la respuesta válida. Así, en la historia en la que una niña estrena un vestido, va corriendo por un camino lleno de charcos y su madre le dice que recuerde que lleva su vestido nuevo, un niño de 7 años responde que lo que quiere decir la madre es: “Que no manche su vestido nuevo porque no le va a comprar otro" (A50). Claramente esta respuesta evidencia que el niño ha entendido lo que ocurre en el escenario, pero no es capaz de señalar el foco con precisión. Lo relevante es el hecho de que se va a manchar el vestido con el barro de los charcos, no si le va a comprar otro vestido su madre.

$\mathrm{Y}$, finalmente, las respuestas menos refinadas como irrelevante o tautológica se reducen a medida que aumenta la edad y son poco frecuentes a partir de los 5 años. Cuando los niños dan una respuesta irrelevante, parece que están diciendo lo primero que les viene a la mente, lo cual sugiere que los niños más pequeños podrían estar usando la estrategia de optimismo naíf o ingenuo ${ }^{193}$, donde se da por supuesto que lo primero que viene a la mente es lo que el oyente espera oír (Sperber, 1994).

La mayor parte de los resultados relativos a las respuestas fallidas están en línea con los datos obtenidos en la investigación de Luokusa (2007). En el estudio con niños finlandeses, la respuesta no sé también resultó ser una de las más comunes entre los

${ }^{193}$ De las estrategias usadas en la interpretación de los enunciados descritas por Sperber (1994) hablamos en el apartado 3.3.1. 
niños de 3 a 7 años. Sin embargo, se repite especialmente en la edad de 7 años (>38\% de las respuestas fallidas), lo que difiere de los niños españoles de este grupo, que solo responden no sé en torno a un $11 \%$. Esto sugiere que los niños finlandeses a esta edad prefieren decir que no lo saben antes que dar una respuesta de la que no están seguros. Este hecho ya fue observado con anterioridad en el trabajo de Letts y Leinonen (2001), por lo que podría tratarse de un fenómeno cultural.

De igual forma y fuera de lo esperable si tenemos en cuenta los estudios previos con niños finlandeses (Loukusa, 2007), la respuesta no hay respuesta se observa en los niños españoles solo a los 3 y 4 años, y resulta poco frecuente en los demás grupos. Tal como sugiere Loukusa (2007) —en cuyo estudio la respuesta no hay respuesta desciende solo a partir de los 7 años-, este resultado también podría explicarse por razones culturales. Parece ser que para los niños finlandeses es típico quedarse en silencio si no se conoce la respuesta, mientras que los españoles prefieren arriesgarse. No obstante, sería necesaria una investigación más exhaustiva, ya que los estudios con niños ingleses (Ryder y Leinonen, 2003) tampoco hacen referencia a esta estrategia de permanecer en silencio.

Por otra parte, como ya advertimos, los niños que responden acertadamente no siempre son capaces de explicar sus respuestas. Ser consciente del proceso que implica dar una explicación supone habilidades metacognitivas y metapragmáticas, que demuestran, una vez más, que las habilidades cognitivas están relacionadas con el desarrollo de la comprensión pragmática. Autores como Gombert (1992) y Verschueren (2000) entienden la habilidad metapragmática como la conciencia y autocontrol de la comprensión y producción lingüísticas teniendo en cuenta las relaciones entre el contexto y el mensaje lingüístico en una determinada situación comunicativa. Así, Gombert (1992) considera que pueden establecerse tres fases en el desarrollo de la conciencia metapragmática en los niños: la fase de adquisición inicial, la fase epipragmática y la fase metapragmática. La primera fase se caracteriza por el uso de las primeras formas lingüísticas en determinados contextos. En la segunda, el niño lleva a cabo un control inconsciente sobre su producción y comprensión del lenguaje oral en relación con ciertos contextos extralingüísticos, pero no distingue explícitamente entre la información verbal y la no verbal. Por ello, pueden registrarse errores en la comprensión de enunciados cuya relación con el contexto no es 
plenamente evidente, como en las metáforas o las ironías. Finalmente, la tercera fase (iniciada, según el autor, en torno a los 6 años) implica la conciencia verbalizable de la diferencia entre lo lingüístico y lo contextual, así como un control reflexivo de esta en cada situación comunicativa, lo que permite al niño comenzar a procesar enunciados metafóricos o irónicos.

En la misma línea, Flavell et al. (2000) y Eisbach (2004) sostienen que, en los primeros años, los niños no son conscientes de su propio pensamiento. De ahí la incapacidad o las dificultades de estos niños a la hora de razonar sus respuestas. No obstante, aunque los niños de corta edad tienen problemas para ofrecer explicaciones, en ocasiones son capaces de explicar algunas de sus respuestas acertadamente. Por ejemplo, en la historia en la que se presenta a un chico subido en un árbol y un lobo debajo, una de las preguntas es quién podría ayudar al chico y algunos niños responden razonadamente: "Un señor que está ahí/ porque tiene una escopeta” (niña CII13 3 años), "El cazador/ porque él tiene una escopeta y le puede matar" (A20-21 niño 4 años). Y en el ejemplo del niño que lleva el libro por encima de la cabeza un día de lluvia, encontramos explicaciones del tipo: "Para no mojarse/ porque lo tiene arriba” (niño 3 años A30), "Para que no se moje/ porque cuando llueve pues hay que utilizar algo para que no se moje la gente" (niña 4 años A8) o "Porque no ha llevado su paraguas y por eso se ha puesto el libro para que no le caiga el agua encima de la cabeza” (niño 4 años CII 14). Los resultados indican que en algunos niños el desarrollo de la conciencia metapragmática es ya evidente a la edad de 3 y 4 años, aunque esta habilidad es todavía muy limitada.

Este hallazgo está en consonancia con las investigaciones de Bartsch y Wellman (1995), que descubrieron que un poco antes de la edad de 3 años, los niños ocasionalmente usaban el verbo pensar cuando se referían espontáneamente a estados mentales. En nuestro estudio también hemos recogido el uso del verbo pensar para referirse al estado mental de un personaje. Así, en uno de los dibujos se ve a un hombre cortando la hierba con una cortadora de césped. Una mujer, que está a su lado, le dice que hay flores creciendo en el centro, así que debe recordar tener cuidado. A los niños se les pregunta que por qué le dice eso la mujer al hombre y una niña de 3 años responde: "Porque piensa que quiere cortar las flores” (entrevista C40). Tal como señalan Letts y Leinonen (2001), aunque el desarrollo de la conciencia del 
pensamiento se inicia con bastante premura, es necesario el transcurso de los años para que el niño sea consciente de la información contextual que utiliza en la comprensión de los enunciados, y sea capaz de verbalizar esa información. Por regla general, en este trabajo hemos observado que la capacidad de explicar razonadamente las respuestas evoluciona con la edad. En efecto, en los niños de mayor edad, al preguntarles por qué un gato que está siendo perseguido por un perro se sube a un árbol, se dan explicaciones como la siguiente: "Porque ahí el perro no puede subir y está seguro/ porque los perros no pueden trepar a los árboles” (niña 8 años A48). No obstante, en todos los casos, el porcentaje de explicaciones válidas está por debajo del de respuestas válidas. Esto sugiere que el desarrollo de la habilidad para razonar las respuestas (y, por tanto, la capacidad metapragmática) tiene lugar gradualmente en el tiempo, pero es más tardío en relación con la capacidad de responder adecuadamente.

Así pues, al comparar respuestas y explicaciones válidas, se advierte que la relación entre las preguntas de implicaturas y las explicaciones correspondientes es diferente de la relación entre respuestas y explicaciones en el resto de categorías de preguntas, cuya evolución es paralela y progresiva. En el caso de las preguntas con implicaturas, a la edad de 6 años la media de respuestas y explicaciones válidas coincide en torno al 80\% de aciertos, se distancia de nuevo a los 7 años y evoluciona después en paralelo con una diferencia de un 10\% aproximadamente. Podemos sugerir, por tanto, un estudio más profundo con una muestra más amplia de niños de 6 años, que permitiría comprobar este resultado en relación con el procesamiento de implicaturas, y así determinar por qué el razonamiento de esta tarea pragmática difiere de las demás.

Por regla general, los niños de 4 años en adelante dan más explicaciones adecuadas para preguntas de sentimientos que para preguntas de rutinas, implicaturas e ironías. Esto significa que, por alguna razón, los niños son más conscientes de la información que han usado para responder a preguntas de sentimientos, por lo que podemos concluir que es más prominente (salience). Estos datos también coinciden con los del estudio de Luokusa (2007), en el que los niños finlandeses de 5 años en adelante dan más explicaciones válidas para preguntas de sentimientos que para preguntas de rutina. Según Loukusa (2007), una explicación para esto podría ser que en la vida cotidiana los niños tienen más experiencia a la hora de explicar sentimientos 
porque a menudo, cuando lloran o se enfadan, se les pregunta cómo se sienten y por qué. En nuestro estudio, hemos constatado que, con relación al reconocimiento de los sentimientos, desde los 3 años los niños suelen identificar bien y mal como estados de ánimo, a partir de los 4 años aparecen adjetivos como triste y contento, entre los 5 y los 6 aparecen también asustado, alegre y feliz, y de los 7 a los 9 años se produce un mayor desarrollo semántico con calificativos del tipo aterrorizado, avergonzado, dolorido, ridículo, decepcionado, satisfecho, preocupado, etc. Igualmente, los razonamientos para explicar estos sentimientos varían mucho con la edad. Por ejemplo, una de las preguntas de sentimientos relata la historia en la que un niño se pone la camiseta del revés sin darse cuenta y sus compañeros de clase se ríen de él. A los niños se les pregunta cómo se siente el niño y por qué. Las respuestas recogidas reflejan un desarrollo acorde con la edad: "Mal/ porque se están riendo los otros niños y eso está muy mal” (niña 4 años CII4), “Triste/ porque no quiere que se rían de él (niña 5 años B4), “Mal/ porque a nadie le gusta que se rían de él” (niño 7 años C29), "Ridículo/ porque se ha puesto la camiseta del revés y no se la puede quitar en clase" (niño 8 años C27), "Decepcionado por sus compañeros/ porque se están riendo de él” (niña 8 años D5), “Avergonzado/ porque cuando se ríen de ti, te avergüenzas” (niña 9 años CII19).

Por su parte, el contenido de las explicaciones fallidas muestra que, a medida que los niños crecen, se vuelven más conscientes de la información que han usado en sus respuestas, lo cual puede comprobarse en el incremento del número de explicaciones fallidas categorizadas como foco incorrecto y en el descenso del uso de explicaciones poco sofisticadas (irrelevante o tautológica). La explicación catalogada como turno de palabra en la que los niños contestan con un par adyacente del tipo “¿Cómo lo sabes?”/ “Así/ bien” es especialmente frecuente en los grupos de 3 y 4 años. Por el contrario, en el estudio con niños finlandeses (Luokusa, 2007) esta explicación se repite no solo en los niños de 3 y 4 años, sino que es muy frecuente en todos los grupos de edad. Tal como reconoce la autora, en estos casos no se puede saber con certeza si los niños conocen realmente la explicación o si asumen que han dado una respuesta razonable y que la entrevistadora debería ser capaz de entender o recuperar la información relevante. Una idea similar se desprende de una serie de explicaciones dadas por los niños de nuestro estudio al preguntarles “¿Cómo lo sabes?” o “¿Por qué 
lo sabes?”: "Porque tengo tres años” (niño 3 años A24-25), "Desde que voy a la guardería” (niño 3 años A35), "Es que yo sé todo porque soy muy lista” (niña 4 años CII1), "Es que mi abuelo me lo ha enseñado" (niño 4 años C19-20), "Porque me he acordado yo solito" (niño 5 años CII5), "Me lo dice mi cerebro" (niño 5 años C3), "Porque lo cuenta en la historia" (niña 7 años C41). En estos casos, los niños entienden que se les está solicitando la razón por la que han sido capaces de dar una respuesta válida, y no la explicación de cómo han llegado a dicha respuesta o qué información han utilizado para acceder a ella.

Con respecto a la variable sexo, no se han observado diferencias significativas entre las respuestas de niños y niñas, salvo en el grupo de 7 años y únicamente en las preguntas de referencia y rutina. En estos casos excepcionales los datos obtenidos pueden considerarse casuales, puesto que el valor de $p$ es muy cercano a 0.05. Este resultado coincide con el estudio de niños finlandeses (Loukusa, 2007), que concluye que el sexo no influye en el número de respuestas y explicaciones válidas en estas edades. En contra de la convicción tradicional que identifica a las mujeres con un mejor manejo del lenguaje oral (Hampson y Kimura, 1992), algunos estudios en torno a destrezas lingüísticas y comunicativas han registrado diferencias entre sexos también a favor de los niños, en las tareas que implican el manejo sintáctico completo (tanto a nivel de expresión como de comprensión). En efecto, en el trabajo de Hyde y Linn (1988) se observa que en la tarea de encontrar analogías, los niños lo hacen significativamente mejor que las niñas. Sin embargo, en los estudios relacionados con la productividad verbal y el vocabulario, las niñas superan a los niños (Huttenlocher $e t$ al., 1991; Morriset et al., 1995).

Por su parte Inozemtseva et al. (2010), en su estudio sobre el desarrollo del lenguaje oral (dividido en expresión, comprensión y repetición) en edad escolar (de 5 a 16 años), señalan que el efecto del sexo solo se manifiesta en la tarea de comprensión del discurso. Estos datos corroboran los resultados de un trabajo anterior (Rosselli et al., 2004) que determinó que había diferencias significativas entre niños y niñas de la misma franja de edad, a favor de los varones, en el mismo tipo de tarea. No obstante, tal como advierten Inozemtseva et al. (2010), el propio tópico del texto o discurso de las pruebas puede resultar más interesante para los niños que para las niñas y esto puede incidir en los resultados. Con todo, los estudios en este campo son escasos, por 
lo que sería conveniente profundizar más antes de establecer conclusiones precipitadas.

Entre las novedades de nuestro trabajo — respecto a los pioneros que han sido tomados como modelo - se encuentran la inclusión de las preguntas de ironía y las agrupaciones por ciclos educativos. Si bien es cierto que el análisis estadístico a partir de los ciclos educativos no fue contemplado previamente, los resultados obtenidos en relación con la variable edad nos orientaron a considerar oportuna la agrupación de los niños por ciclos de estudio. De esta forma, se han detectado diferencias significativas entre los niños pertenecientes a Educación Infantil, $1^{\circ}$ ciclo de Educación Primaria y $2^{\circ}$ ciclo de Educación Primaria, lo que indica que en función del nivel educativo en el que se encuentre el niño podemos estimar las preguntas que será capaz de responder y las que no. Asimismo, nos permite reflexionar acerca de la influencia de la escolaridad en el desarrollo de la comprensión pragmática del lenguaje. Mientras que a los 3 años hemos observado gran dispersión en los resultados, a medida que avanza el proceso educativo las diferencias dentro de un mismo grupo se reducen hasta obtener resultados muy similares (salvo algunas excepciones en función del tipo de tarea). La incorporación generalizada de los niños a la vida escolar a los 3 años implica un gran cambio para ellos (Palacios et al., 1998), especialmente para aquellos que no han estado en guarderías o escuelas infantiles, sino que han permanecido al cuidado de sus familiares u otras personas del entorno. En estos casos la adaptación puede ser más crítica (Clemente y Blasi, 1996) y podrían darse algunos bloqueos emocionales que afecten a la comunicación y al lenguaje, aunque a menudo suelen ser transitorios. Además, el propio contexto familiar del que proceden (con sus peculiaridades socioeconómicas y socioculturales) puede también influir en su comportamiento verbal.

Por lo que respecta a las preguntas de ironía, su inclusión en este trabajo ha sido fruto de nuestro interés hacia este fenómeno pragmático tan frecuente en la lengua. Los estudios experimentales previos advierten de la estrecha relación del fenómeno de la ironía con la habilidad de lectura de la mente de segundo orden (Happé, 1993; Surian et al., 1996; Champagne-Lavau y Joanette, 2009) y, por lo tanto, con la capacidad metacognitiva. Sin embargo, las estimaciones sobre el periodo del desarrollo lingüístico en el que se puede decir que los niños comprenden la ironía 
difieren de unos estudios a otros. Como ya señalamos, buena parte de estas discrepancias puede deberse a los diferentes métodos de análisis y pruebas utilizados. En nuestra investigación, para el diseño de estas preguntas hemos seguido el esquema del resto de categorías, empleando vocabulario sencillo y situaciones familiares. Y, en todos los casos, las expresiones irónicas utilizadas han sido contrafactuales del tipo "una persona dice $p$ para intentar decir no-p". Si bien es cierto que nos hubiera gustado utilizar algunas más complejas y sutiles, no lo hicimos teniendo en cuenta que íbamos a trabajar con niños de 3 a 9 años.

En el ya mencionado estudio, Crespo et al. (2007) analizan la comprensión oral de la ironía en niños de 5 a 13 años y concluyen que los enunciados irónicos más fáciles de comprender son aquellos en los que se expresa lo contrario de lo que se quiere decir y los más complejos, las preguntas irónicas. Sería oportuno, por tanto, realizar un futuro estudio basado en expresiones irónicas más complejas y con niños de edades más avanzadas. De hecho, los estudios previos sobre ironía consultados señalan que se trata de un fenómeno tardío que continúa desarrollándose hasta la adolescencia. Así, Nakassis y Snedeker (2002) determinan que es a la edad de 10 años cuando los niños pueden procesar formas sutiles de ironía, mientras que los niños de 5 y 6 años solo son capaces de comprender algunas expresiones irónicas simples. Los resultados de nuestro estudio muestran una gran dispersión y asimetría en la distribución del número de respuestas y explicaciones válidas en las preguntas de ironía. Nos encontramos, a menudo, ante casos extremos: hay niños que identifican las ironías y contestan apropiadamente a todas las preguntas y otros que no han asimilado el fenómeno y fallan en la compresión de estos enunciados. No obstante, de los 5 a los 7 años es cuando hemos constatado que se desarrolla más rápidamente la capacidad de comprensión de enunciados irónicos sencillos, hasta los 9 años, edad en la que estas expresiones suelen ser identificadas sin dificultad, aunque no siempre razonadas.

Efectivamente, en las preguntas de ironía, a los 3 y 4 años, los casos en los que los niños ofrecen una respuesta acertada son muy escasos o prácticamente inexistentes. Lo más frecuente son las respuestas del tipo no sé y tautológica. En esta última, cuando a los niños se les pregunta qué han querido decir los personajes, estos repiten el enunciado exacto o la parte de este que son capaces de recordar. Sorprendentemente, algunos niños de estas edades (tan solo 3 de 40) sí son capaces de 
identificar que lo que dice el personaje implica lo contrario, pero no saben explicar por qué. Cabe mencionar la respuesta de un niño de 3 años (entrevista A27) que responde "Eso no vale” en todas las preguntas que contienen ironías, por lo que parece que está detectando que existe una contradicción entre lo que dice el personaje y el propio contexto de la historia, aunque no es capaz de explicarla.

A los 5 años, el número de respuestas válidas a preguntas de ironía aumenta, aunque las explicaciones siguen siendo muy escasas. Podemos destacar la respuesta de una niña de 5 años (entrevista A3) que para razonar su respuesta pone un ejemplo similar: "Porque a veces Gloria dice que le tenéis muy contenta y significa que se enfada”. Igualmente, otros tres niños de 5 años explican que el personaje dice lo que dice y no lo que la lógica les dicta que debería ser "Porque les está engañando" (entrevista B6-7), "Porque les está gastando una broma” (entrevista D2) o "Porque si dice que es un buen día muy despacio es un mal día” (entrevista A9)

Es a la edad de 6 años cuando se observa un mayor aumento en la media de respuestas válidas, si bien es cierto que todavía algunos niños no son capaces de detectar la ironía de algún enunciado concreto. La mayoría de los niños de esta edad comprenden que significa lo contrario, pero les resulta difícil dar una explicación. Los que lo hacen recurren a la idea de broma o mentira, mientras que otros se acercan más al concepto de ironía: “Porque si dice mal es bien” (entrevista B38), "Porque se lo dice el profesor con la voz como si no se lo hubiera estudiado nada” (entrevista A19).

Finalmente, de los 7 a los 9 años, por regla general, todos los niños infieren que los personajes de la historia se están refiriendo a lo contrario de lo que dicen, ya que la interpretación literal no encaja en el contexto dado. Además, sus explicaciones se vuelven también más refinadas. Así, en los niños de 7 años encontramos razonamientos como "Porque es una manera de expresión de decirlo" (entrevista A53), "Porque es al revés” (C36), "Porque a veces mi padre me dice una cosa y significa lo contrario" (entrevista C42); en los niños de 8 años: "Porque lo dice en tono pillín” (entrevista C14), "Para cambiar el sentido” (entrevista C39); y en los de 9: "Porque si te dicen eso, y tu sabes que lo has hecho muy mal, sabes que es mentira" (entrevista CII20), "Porque los padres siempre que dicen eso, quieren decir lo contrario" (entrevista CII33-34). Asimismo, cabe destacar tres casos en los que efectivamente los niños identifican este fenómeno: "Porque lo ha dicho con ironía" (niño 8 años 
entrevista A43), "Es una ironía, quería decir lo contrario" (niña 9 años entrevista CII17), "Porque quería ser sarcástico" (niño 9 años entrevista CII40).

En definitiva, este estudio aporta información relevante sobre el desarrollo de la comprensión pragmática en niños españoles. Como se ha señalado, los resultados coinciden, en general, con los observados en experimentos similares con niños ingleses (Ryder y Leinonen, 2003) y finlandeses (Loukusa, Leinonen y Ryder, 2007; Loukusa, 2007; Loukusa, Ryder y Leinonen, 2008). Esto sugiere que la comprensión del significado pragmático no es un proceso relacionado con una lengua concreta, ya que el esquema se repite, con la excepción de pequeñas diferencias. En consecuencia, esta investigación apoya la idea de que hay un patrón de adquisición de la comprensión pragmática que puede relacionarse con el desarrollo de una habilidad para usar la información contextual relevante en el proceso de comprensión de enunciados en distintas situaciones comunicativas.

En futuras investigaciones sería interesante plantear otros estudios centrados, por ejemplo, en preguntas con implicaturas con diferentes demandas contextuales. Como ya se ha advertido, en este estudio el material está compuesto por preguntas simples divididas en función de las diferentes tareas pragmáticas. Por ello sería conveniente diseñar nuevas pruebas con diferentes tareas que incluyan no solo la comprensión sino también la producción. Asimismo, sería provechoso estudiar con más detalle la habilidad de los niños para explicar sus respuestas. En efecto, los resultados de este trabajo indican que los niños explican adecuadamente las preguntas de sentimientos en comparación con las de rutinas e implicaturas, por lo que convendría llevar a cabo una investigación más profunda para dar una explicación razonada a este hecho.

Tras una revisión de la bibliografía hemos detectado la falta de estudios experimentales en diferentes comunidades lingüísticas. Sería conveniente, entonces, plantear investigaciones en otras lenguas, o incluso estudios simultáneos con niños nativos de diferentes lenguas. De esta forma podríamos obtener más información sobre las diferencias y similitudes en el proceso de adquisición de la competencia pragmática. 


\section{CAPÍTULO 6}

\section{CONCLUSIONES}

El objetivo principal de esta tesis doctoral ha sido profundizar en la naturaleza del concepto de competencia pragmática y sus aplicaciones, así como reflexionar sobre su desarrollo dentro del proceso de adquisición de la lengua. Parte esencial de este trabajo ha consistido en la realización de un estudio experimental sobre la evolución del procesamiento pragmático del lenguaje en niños de edad preescolar y escolar (en el rango de 3 a 9 años). Hemos encontrado en la teoría de la relevancia de Sperber y Wilson (1986/1995) un marco propicio para aproximarnos al estudio del desarrollo de la comprensión pragmática y, por consiguiente, para llevar a cabo esta investigación.

En el primer capítulo de este trabajo se ha establecido un marco teórico previo para contextualizar nuestro estudio. Así, hemos considerado oportuno partir del propio concepto de pragmática para entender la competencia pragmática. Creemos que la misma indefinición — debido a la falta de acuerdo entre los autores - del alcance disciplinar de la pragmática propicia la dificultad de limitación del concepto de competencia pragmática. En efecto, el hecho de que la pragmática no tenga definidas con precisión sus fronteras obstaculiza el trabajo de delimitación de los componentes de la competencia pragmática y su relación con otras competencias como la sociolingüística, la discursiva, la cultural y, desde luego, la gramatical.

Frente a la diversidad de opiniones y enfoques que han surgido en torno a la disciplina pragmática en el ámbito teórico, en este trabajo hemos pretendido adoptar una perspectiva que armonice de forma coherente las ideas fundamentales con respecto al concepto de pragmática y su ámbito de estudio. En líneas generales, es consabido que la pragmática se ocupa del estudio del lenguaje en su uso. La entenderemos, entonces, como una disciplina que no forma parte del núcleo duro de la lingüística, pero que se encuentra dentro del paradigma de la lingüística de la comunicación. Creemos, por tanto, que la pragmática debe desmarcarse de la gramática, y a su vez complementarse con ella en el estudio general del lenguaje, ya 
que reconocemos la existencia de una interfaz gramático-pragmática que permite explicar un conjunto de aspectos y mecanismos gramaticales vinculados al uso del lenguaje en la comunicación.

Del mismo modo que Eguren y Fernández Soriano (2004), desde una perspectiva matizada pero esencialmente formalista, defienden que la autonomía de la sintaxis no significa que esta se encuentre aislada, con la pragmática ocurre algo similar: aunque es independiente mantiene lazos con otras disciplinas de orientación más formal y coopera con otros modelos para el análisis de la comunicación humana. Asimismo, la propia interdisciplinariedad de la pragmática ha dado lugar al surgimiento de nuevos enfoques como la aproximación sociopragmática o la pragmática cognitiva.

Una de las ideas fundamentales defendidas en este trabajo concierne a la vinculación entre la pragmática y la retórica, en el sentido del uso eficaz del lenguaje en las interacciones comunicativas. En efecto, siguiendo a Gutiérrez Ordóñez (2002), advertimos que ambas buscan el éxito de la comunicación —y no tanto determinar la gramaticalidad de los enunciados - y que la persuasión, entendida como última meta de la retórica, se vincula directamente a los actos perlocutivos estudiados por la pragmática.

La pragmática se ocupa del estudio del uso del lenguaje en la comunicación, teniendo en cuenta los factores lingüísticos y extralingüísticos que intervienen en la producción e interpretación de enunciados concretos en las distintas situaciones comunicativas. Con este objeto, estudia la perspectiva cognitiva, social y cultural de los fenómenos lingüísticos, así como la relación entre el hablante y el lenguaje, atendiendo a las elecciones que este realiza y a los efectos que aquellas tienen sobre el oyente en los intercambios lingüísticos.

Con respecto a su objeto de estudio, hemos constatado que la pragmática no tiene las fronteras bien definidas, como, por otra parte, era esperable. Se trata de un panorama no solo complejo sino también poco trabado internamente. En efecto, el problema radica en que no se trata de una disciplina a la que podamos asociarle una unidad de análisis concreta que pueda aislarse y sistematizarse. Así las cosas, en este trabajo hemos repasado brevemente los fenómenos pragmáticos, centrándonos en aquellos que suscitan más polémica, como son las presuposiciones, la deixis o los aspectos relacionados con el análisis de la conversación, entre otros. Aunque 
defendemos que el ámbito sobre el que actúa la pragmática es la totalidad del lenguaje (como competencia y como actividad), consideramos que hay una serie de fenómenos prototípicamente pragmáticos (de los que solo da cuenta la pragmática) y otros pragmáticos periféricos (cuya explicación es interdisciplinar, ya que se sitúan en una interfaz pragmático-estructural). Entre los primeros se encuentran los actos de habla, las implicaturas, la cortesía, la ironía, fenómenos relacionados con la retórica, etc. Y, entre los segundos, las presuposiciones, la deixis o la definitud, entre otros.

Asimismo, consideramos que tanto los fenómenos de paralenguaje, kinésica y proxémica, así como los relacionados con el análisis de la conversación no son objeto prioritario de estudio de la pragmática. Los primeros deben adscribirse a la comunicación no verbal y los segundos constituyen una línea de estudio diferente, ya que reflejan pautas de conducta lingüística y social, de forma que su análisis no se centra tanto en el lenguaje como en las relaciones humanas y la organización social que se manifiestan en el uso lingüístico.

Finalmente, forma parte del estudio de la pragmática un conjunto de principios tales como el principio de cooperación, la teoría de la relevancia, la teoría de los actos de habla, el principio de cortesía, etc., que constituyen una herramienta fundamental que permite al lingüista describir y explicar las regularidades que se encuentran en el uso del lenguaje en la comunicación.

A la vista de lo anterior, parece claro que señalar que la pragmática se ocupa del uso del lenguaje en la comunicación es afirmar que estudia el lenguaje en su contexto. Cuando nos comunicamos, el significado de nuestros enunciados está condicionado por las circunstancias en que se producen. Por consiguiente, hemos considerado oportuno dedicar un apartado al concepto de contexto dada su importancia en la comunicación verbal.

No obstante, como era de esperar, la noción de contexto varía también en función de las distintas perspectivas teóricas (lingüísticas, psicológicas o sociolingüísticas) que se sirven de él. En la pragmática actual distinguimos principalmente tres tipos de contexto: lingüístico (o cotexto), situacional y sociocultural, aunque sorprendentemente no todos los autores reconocen este último. En este trabajo, por el contrario, hemos defendido que el contexto sociocultural es fundamental, ya que es el responsable de generar expectativas y presuposiciones que compartimos al ser 
miembros de una determinada comunidad lingüística y facilita, por tanto, la interpretación de los enunciados. A menudo disponemos de una serie de conceptualizaciones interiorizadas sobre determinadas situaciones que se repiten en el contexto social, lo que nos permite activar un conjunto de expectativas y elementos asociados a estas situaciones. A lo largo de los años numerosas teorías han acotado este contexto sociocultural y se han referido a él con términos como trasfondo o background (Searle, 1979), fundamento compartido o common ground (Clark, 1996), situaciones recursivas (Barwise y Perry, 1983), entorno cognoscitivo compartido (Sperber y Wilson, 1995), parcelas de información (Escandell Vidal, 2006), etc.

En nuestra investigación experimental (recogida en el capítulo quinto) hemos tenido en cuenta el contexto sociocultural a la hora de adaptar el cuestionario (inicialmente creado para niños finlandeses) a la cultura española. Esto ha hecho que, por ejemplo, hayamos tenido que eliminar una pregunta relacionada con la asociación sistemática de comer caramelos los sábados. En este caso se trata de un aspecto cultural que, al parecer, comparten los miembros de la comunidad finlandesa, mientras que en España no encontramos arraigada esta costumbre.

Asimismo, consideramos que el contexto sociocultural es decisivo a la hora de determinar los denominados marcos de referencia (frames) y guiones (scripts). Como hemos advertido, tanto los marcos (estructuras de datos almacenados en nuestra memoria a partir de situaciones estereotipadas) como los guiones (secuencia de acciones que por defecto se lleva a cabo en una situación conocida) se activan en los intercambios lingüísticos de manera que nos permiten predecir estructuras de eventos y acciones que completamos a través de inferencias. Desafortunadamente, las diversas teorías no han llegado a explicar el modo en el que se limita el conocimiento activado en un marco, de forma que sea relevante en cada enunciado y situación comunicativa. Esto ha hecho que nos planteemos cómo se selecciona el contexto pertinente para la interpretación de un enunciado concreto. Según Sperber y Wilson (1995), para que la comunicación sea eficaz no es necesario que los interlocutores dispongan de un conocimiento total compartido, sino que basta con que construyan una hipótesis acertada sobre el conocimiento pragmático y la información de la que el otro dispone. De entre todos los contextos de los que el oyente dispone a la hora de interpretar un enunciado, debe seleccionar aquellos rasgos contextuales relevantes para ese 
enunciado y esa situación, y combinarlos con la información lingüística para alcanzar el significado pretendido por el hablante.

En nuestro trabajo se ha optado por una aproximación cognitiva a la noción de contexto. Consecuentemente, lo hemos definido como el conjunto de conocimientos, saberes, supuestos y creencias que nos permiten el procesamiento lingüístico y que se encuentran en nuestra memoria, en el discurso previo, en el entorno físico, o proceden de condicionamientos socioculturales (que aprendemos a través de nuestra experiencia en una comunidad determinada). Estos conocimientos y creencias se elaboran y actualizan en los intercambios lingüísticos para cada enunciado concreto.

Finalmente, en este primer capítulo se han presentado los mecanismos y principios de la teoría de la relevancia de Sperber y Wilson (1995), que ha sido utilizada, a lo largo de esta tesis doctoral, como base teórica y herramienta de análisis. La elección de esta teoría como marco de referencia se fundamenta en dos razones principales. En primer lugar, creemos que su precisión y utilidad ha sido afianzada por el hecho de que otras investigaciones relacionadas con el desarrollo y las dificultades en las habilidades pragmáticas se hayan servido de ella (Happé, 1993; Dipper et al., 1997; Leinonen y Kerbel, 1999; Leinonen et al., 2003; Foster-Cohen, 2004; Loukusa et al., 2007). En efecto, consideramos que la teoría de la relevancia se presta a la investigación empírica de los procesos implicados en la comprensión del lenguaje (son numerosos los estudios que han confirmado en la práctica sus postulados). Además, esta teoría permite explicar las dificultades pragmáticas, incluyendo aquellas que afectan a la calidad de las interacciones, y es también de gran utilidad en el diseño de intervenciones clínicas en pacientes con déficits pragmáticos del lenguaje.

La segunda razón, de carácter más teórico, es que ofrece una explicación de los procesos implicados en la interacción comunicativa desde una perspectiva cognitiva. Dicho de otro modo, explica cómo el oyente es capaz de inferir o deducir la intención comunicativa del hablante y seleccionar la interpretación adecuada de entre todas las interpretaciones posibles de acuerdo con el contexto. Esta teoría propone, por tanto, que para analizar la complejidad de los mecanismos que tienen lugar en la comunicación humana no basta con el proceso de codificación y descodificación, sino que es necesario recurrir al mecanismo de ostensión e inferencia. Aunque ambos mecanismos son esencialmente independientes, suelen combinarse para reforzar la 
eficacia de la comunicación. De hecho, a menudo, los mensajes lingüísticos no codifican directamente el contenido que el hablante quiere transmitir, pero funcionan como estímulo ostensivo que alerta al oyente para que infiera la verdadera intención comunicativa.

De esta forma, para procesar de manera eficaz la información que hay detrás de un enunciado es necesario reconocer la intención que se halla tras la ostensión. En efecto, el mecanismo inferencial se basa en la creación de un supuesto a partir de otro mediante un razonamiento deductivo. Ahora bien, tal como hemos advertido, la fuerza de los supuestos puede variar dependiendo de la forma en que se hayan conseguido. Según Sperber y Wilson (1995), los supuestos están formados por la representación de un estado de cosas y la representación del valor de afirmación de esta representación de un estado de cosas. Así, el peso de los supuestos puede variar con el tiempo y las circunstancias. Cuando aparecen pruebas o nuevos datos sobre un conjunto de hechos, el valor de afirmación de un supuesto puede aumentar o disminuir. Además, no tendrá la misma fuerza un supuesto adquirido a través de la propia experiencia del hablante que otros que hayan sido transmitidos por otra persona o deducidos a partir de ciertas premisas.

Una de las ideas más sencillas pero a la vez más interesantes de la teoría de Sperber y Wilson (1995) es que los seres humanos somos eficientes en el procesamiento de la información, es decir, tendemos a equilibrar ganancia y esfuerzo. De este modo, la relevancia de un enunciado dependerá de la relación entre los efectos contextuales y el esfuerzo de procesamiento. Cuando interpretamos un enunciado lo hacemos con la expectativa de que va a ser relevante; por ello seleccionamos un contexto (dentro del conjunto total de supuestos posibles) que justifique dicha expectativa, esto es, que maximice la relevancia. Esta idea se recoge en el primer principio de relevancia. Asimismo, todo acto ostensivo de comunicación crea una presunción de relevancia lo suficientemente precisa para conducir al oyente hacia la interpretación pretendida, fundamento a su vez incluido en el segundo principio de relevancia.

La aplicación de estos postulados teóricos al estudio de la comunicación lingüística permite a Sperber y Wilson la distinción de una serie de tareas inferenciales como la desambiguación, la asignación de referencia y el enriquecimiento pragmático. 
Así, en cada uno de estos procesos, el oyente debe seleccionar la interpretación más accesible - en función de los factores contextuales - acorde con el principio de relevancia. Las proposiciones resultantes de estos tres mecanismos inferenciales son lo que en la teoría de la relevancia y, en consecuencia, en este trabajo, se entiende como explicaturas.

Por su parte, todo supuesto no explícitamente comunicado está implícitamente comunicado y es una implicatura (Sperber y Wilson, 1995). En el proceso de interpretación de las implicaturas, el oyente combina la información recibida con los supuestos presentes en la memoria obteniendo una serie de efectos contextuales (que no son otra cosa que los supuestos o implicaciones contextuales que el hablante ha querido hacer manifiestos sin expresarlos explícitamente). En el caso de las implicaturas, distinguimos a su vez dos tipos: las premisas implicadas y las conclusiones implicadas. Las primeras las elabora el oyente mediante el desarrollo de supuestos presentes en la memoria, mientras que las segundas las deduce como consecuencia lógica de las explicaturas y las premisas implicadas del enunciado y del contexto. Asimismo, para entender las implicaturas basta con el principio de relevancia: si el procesamiento de estos enunciados requiere un mayor esfuerzo, consecuentemente se espera una compensación a través del aumento de los efectos contextuales relevantes a los que dan lugar.

Con todo, aunque en este estudio hemos seleccionado la teoría de la relevancia como marco de referencia debido a su detallada explicación de los mecanismos cognitivos que intervienen en la interpretación de estímulos lingüísticos ostensivos, reconocemos también como una de sus debilidades la limitación a la hora de describir y explicar los mecanismos de producción. No obstante, esto no ha supuesto un problema, ya que nuestra investigación se ha enfocado en el estudio de los procesos involucrados en la comprensión pragmática del lenguaje.

En el segundo capítulo de este trabajo hemos pretendido delimitar el concepto de competencia pragmática, así como sus posibles aplicaciones. Para ello, en primer lugar, hemos partido de un concepto más general: el de competencia comunicativa. Esta asocia, en una red de relaciones complejas, un conjunto de subcompetencias entre las cuales se encuentra la competencia pragmática (también llamada accional o 
ilocutiva), en ocasiones definida de forma independiente y otras veces asociada a otras subcompetencias (como la discursiva, la sociolingüística o la cultural).

Hemos constatado que desde el ámbito de la lingüística teórica se ha trabajado más sobre las aplicaciones del concepto de competencia comunicativa que sobre la propia noción. Tras revisar los manuales especializados, en los que esperábamos encontrar una definición del ámbito disciplinar y del conjunto de objetos de estudio, hemos atestiguado la mayoritaria ausencia de reflexión acerca del alcance de la competencia comunicativa en general y de la pragmática en particular. Esto resulta sorprendente, ya que una de las finalidades de la lingüística es describir y explicar el conjunto de conocimientos que permite a los hablantes de una lengua comunicarse y realizar un amplio inventario de funciones lingüísticas, y son precisamente esos conocimientos los que constituyen la competencia comunicativa.

De acuerdo con este planteamiento, hemos revisado el desarrollo del concepto de competencia comunicativa desde sus inicios (Chomsky, 1965; Lyons, 1970; Campbell y Wales, 1970; Hymes, 1972; Gumperz, 1972) hasta las propuestas más actuales (Cenoz y Valencia, 1996; Escandell Vidal, 2004a) y hemos constatado que la noción de competencia comunicativa ha ido evolucionando no solo en extensión sino también de forma cualitativa. Así, autores como Cenoz (1996) la entienden como un concepto dinámico y social —ya que obedece a la negociación del significado entre los interlocutores—, relativa —ya que los hablantes pueden ser competentes en distintos grados - y referente al habla — ya que incluye la capacidad de saber qué decir, a quién, cómo y cuándo-.

Hemos creído necesario también hacer hincapié en la distinción entre competencia y actuación comunicativas, conceptos que habitualmente se confunden. Entendemos que la competencia comunicativa engloba tanto el conocimiento como la habilidad para usar dicho conocimiento, y que la actuación comunicativa consiste, entonces, en la ejecución práctica de la competencia en situaciones reales de uso. Asimismo, cuando hablamos de conocimiento nos referimos a lo que el hablante sabe consciente o inconscientemente sobre el lenguaje y sobre los aspectos de su uso; por su parte la habilidad es un conocimiento procedimental que alude a la destreza con la que se utiliza dicho conocimiento en los intercambios lingüísticos. 
En resumen, en este trabajo hemos definido la competencia comunicativa como una suma de habilidades y destrezas que se apoyan en conocimientos (explícitos e implícitos) sobre el código lingüístico, sobre los contextos socioculturales que nos permiten producir enunciados apropiados en relación con estos, sobre las reglas conversacionales, sobre la organización textual, sobre las normas culturales de la comunidad de habla, sobre los actos de habla en función de unas metas comunicativas, etc. Igualmente, hemos concluido que hay dos tipos de conocimientos: los que se refieren a "saber" (conocimientos declarativos) y los que se refieren a "saber hacer" (conocimientos procedimentales).

De este modo, hemos ido fraguando las bases sobre las que creemos que una buena teoría de la competencia comunicativa debería asentarse. La pregunta clave es, entonces, en qué consiste “conocer” una lengua, qué conocimientos y habilidades son necesarios. Sin embargo, ninguna disciplina lingüística puede por sí sola describirlos, y es ineludible, por lo tanto, la colaboración e integración de varias. En consecuencia, en las últimas décadas han surgido diferentes modelos que presentan la distribución de los distintos componentes o subcompetencias que integran la competencia comunicativa. Así, hemos expuesto y analizado el modelo de Canale y Swain (1980), que fue revisado y modificado por Canale (1983), el modelo de Bachman (1990), el modelo de Celce-Murcia, Dörnyei y Thurrell (1995), y el de Gutiérrez Ordóñez (2002). Cabe resaltar que la mayoría de los modelos consultados (con la excepción del de Gutiérrez Ordóñez) provienen directamente del área de enseñanza de lenguas, lo que evidencia que, como ya anunciábamos anteriormente, un concepto como el de competencia comunicativa no recibe tantas atenciones como debería por parte de la lingüística teórica.

Estos modelos comparten similitudes respecto a rasgos generales de clasificación y a la inclusión de determinadas competencias como la competencia lingüística, la sociolingüística, la discursiva o la pragmática, que en casi todos suelen estar presentes. Por su parte, las diferencias se encuentran en distintos niveles. Por un lado, hay diferencias terminológicas reflejadas en las denominaciones de competencia gramatical y competencia lingüística (que se refieren al mismo tipo de conocimientos, aunque la segunda deja claro que también se incluyen, además de la gramática, el léxico y la fonología) o entre competencia pragmática, accional o ilocutiva (que en 
muchos casos son términos distintos para expresar nociones muy semejantes). Otras diferencias son de tipo jerárquico y radican en la consideración, por parte algunos modelos, de la competencia pragmática como una macrocompetencia que engloba las competencias sociolingüística, discursiva y estratégica, o en la localización de la competencia lingüística y la discursiva en posición central en relación con las demás. Encontramos también discrepancias en los conocimientos y habilidades incluidos en cada uno de los componentes (a menudo no están bien definidos los límites entre las habilidades y los conocimientos pragmáticos con respecto a los discursivos y sociolingüísticos, de forma que se confunden e intercambian). Y, por último, también existen diferencias en torno a la competencia estratégica. Algunos autores la consideran una competencia marginal, mientras que para otros se puede equiparar a la competencia comunicativa general, debido a su identificación con la capacidad para resolver problemas y compensar deficiencias, así como para incrementar la eficacia en todas las demás competencias.

La mayoría de los modelos presentados están limitados en cuanto a que solo se refieren a la lengua. Con la excepción de Gutiérrez Ordóñez (2002), el resto de los autores desatienden, en mayor o menor medida, factores como la personalidad de los individuos, los esquemas mentales o el conocimiento cultural, entre otros. Asimismo, a menudo las clasificaciones solo tienen en cuenta los conocimientos y no las habilidades para usar dichos conocimientos ni los procesos que subyacen. En consecuencia, hemos presentado nuestra propia propuesta de modelo teórico de la competencia comunicativa, que aboga, en primer lugar, por la integración e interrelación de todas las subcompetencias. En nuestro modelo ninguna de ellas queda situada en posición central, puesto que consideramos que todas son necesarias para alcanzar la competencia en una lengua y se complementan entre sí. Ahora bien, consideramos que pueden distribuirse en tres grupos: el de las competencias primarias (formado por la competencia cultural y la psicolingüística), el de las competencias que giran en torno a la elaboración y organización del discurso (compuesto por la competencia gramatical y la discursiva), y el de las competencias relacionadas con el uso del lenguaje (que incluye la competencia pragmática y sociolingüística). Finalmente, fuera de estos grupos se encuentra la competencia estratégica, que incluye 
el conocimiento de mecanismos de compensación de fallos o deficiencias en cualquiera de las demás.

Con todo, nuestra pretensión ha sido formular motivadamente una propuesta teórica para la concreción del concepto de competencia pragmática. Así, dentro de nuestro modelo, la competencia pragmática se refiere a la suma de conocimientos y habilidades sobre la utilización de la información lingüística y contextual en la producción e interpretación de enunciados, que incluye la capacidad para llevar a cabo inferencias, tanto de lo dicho como de lo implícito, y el conocimiento de las posibles correspondencias entre formas y funciones. Todo ello para conseguir que nuestros mensajes sean al mismo tiempo apropiados, adecuados y eficaces.

Ahora bien, dichos conocimientos pragmáticos no han de entenderse como reglas (conocimientos almacenados, objetivados en descripciones y reflejados en modelos teóricos propios de la competencia gramatical). No podemos especificar las condiciones de adecuación y de éxito de un conjunto infinito de enunciados con base en una serie de reglas que relacionen dichos enunciados con su contexto y posibles interpretaciones. Por ello, hemos de considerarlos como principios que guían nuestros intercambios comunicativos.

A continuación, en este capítulo hemos recogido las aportaciones de los manuales teóricos de pragmática, de las investigaciones en torno a la enseñanza/aprendizaje de segundas lenguas y de los estudios sobre didáctica de la lengua materna que han abordado o aplicado la noción de competencia pragmática.

En primer lugar, resulta significativo, como ya advertíamos al comienzo de este trabajo, que gran parte de los manuales clásicos de pragmática consultados (Levinson, 1983; Leech, 1983; Reyes, 1990; Verschueren, 1999; entre otros) no mencionen el concepto de competencia pragmática. Dentro de los que sí reflexionan en torno a esta noción se encuentran las obras de Gutiérrez Ordóñez (2002), Portolés (2004) y Escandell Vidal (2006). Ahora bien, Portolés (2004) identifica la competencia pragmática con la competencia comunicativa, aunque él mismo reconoce que esta concepción da lugar a numerosos problemas difíciles de resolver. Y, por su parte, Escandell Vidal (2006) considera que el fenómeno inferencial queda fuera de la competencia pragmática, ya que se trata de una capacidad de procesamiento común al género humano y porque, consecuentemente, no hay un conjunto específico de 
conocimientos que la sustente. Nuestra postura, sin embargo, es que dichos conocimientos forman parte del grupo de conocimientos de "saber hacer” y son los que, precisamente, constituyen el núcleo de la competencia pragmática.

En el campo de enseñanza/aprendizaje de lenguas extranjeras, tanto el MCER (2002) como su adaptación a la enseñanza de español llevada a cabo por el Instituto Cervantes en el Plan curricular del Instituto Cervantes (2006) ofrecen su propia concepción de competencia pragmática. El MCER incluye bajo la denominación de competencias pragmáticas conocimientos y habilidades que van más allá del ámbito de la pragmática, como son la cohesión y la coherencia (objeto de estudio de la lingüística textual), o los esquemas de interacción y organización de turnos de palabra (propios del análisis de la conversación). Consecuentemente, lo mismo ocurre con el Plan curricular, ya que da por supuesto que la competencia pragmática está unida a la discursiva. Sin embargo, cabe destacar la acertada insistencia en la inclusión de la capacidad para lograr la eficacia en la comunicación dentro de la noción de competencia pragmática.

Además de estas obras de referencia, hemos analizado las publicaciones de las actas de los congresos nacionales e internacionales de la ASELE, puesto que consideramos que son un claro ejemplo del tipo de investigación que se está llevando a cabo en la enseñanza de español como lengua extranjera. Nos hemos centrado en las Actas del XV Congreso que llevó por título La competencia pragmática y la enseñanza de español como lengua extranjera. Resulta significativo que la mayoría de los artículos trabajan sobre distintos aspectos de la competencia pragmática, pero son muy pocos los que se ocupan de definir o precisar su ámbito. Además, no se mueven en terrenos homogéneos ni delimitados. Los que reflexionan sobre el concepto recurren a las definiciones ofrecidas por los creadores de modelos de competencia (Canale y Swain, 1980; Bachman, 1990; Celce-Murcia, Dörnyei y Thurrell, 1995) o por el MCER (2002), la identifican con la competencia comunicativa o la definen de forma indirecta: exponiendo cuándo se logra o cuándo fracasa. Consecuentemente, esta falta de reflexión teórica sobre la noción de competencia pragmática tiene como resultado que los profesores de segundas lenguas no sepan cómo evaluar la competencia pragmática o cómo concretar en actividades específicas su desarrollo. 
El Vademécum para la formación de profesores. Enseñar español como segunda lengua reconoce la importancia de la pragmática en la formación de profesores de segundas lenguas y destaca los actos de habla, la cortesía, la relevancia y la interpretación de los mensajes implícitos como aspectos de especial interés en las tareas de enseñanza de lenguas extranjeras. La pragmática tiene mucho que decir en la comunicación intercultural, ya que una competencia pragmática deficitaria puede causar malentendidos o una imagen del hablante como grosero o poco cooperativo (Liddicoat y Crozet, 2001; Gómez Morón, 2004), que suelen resultar más problemáticos que la incorrección provocada por un fallo relativo a la competencia gramatical.

Sin embargo, a pesar de la reconocida importancia que la pragmática está adquiriendo en los métodos de orientación comunicativa y de aprendizaje por tareas, el panorama que hemos recogido muestra la necesidad de estudios más amplios sobre competencia pragmática en el ámbito de enseñanza de ELE. En este trabajo defendemos, por tanto, la elaboración de materiales didácticos centrados en la competencia pragmática, para lo cual se hace necesario una difusión de la pragmática descriptiva del español, así como un mayor conocimiento teórico de los principios pragmáticos.

Una de las primeras cuestiones que ha suscitado la incorporación de la competencia pragmática en el ámbito de segundas lenguas es la posibilidad de llevar a cabo una enseñanza —explícita o implícita - de dicha competencia. Diversas investigaciones señalan que es posible hablar de universales pragmáticos, pero también existen principios específicos que dependen de los esquemas culturales de cada comunidad lingüística y sobre los que habría que reflexionar, ya que dan lugar a casos de transferencia negativa. Esto ha desencadenado el desarrollo, en los últimos años, de la pragmática intercultural, que sirve como herramienta de ayuda y también como base conceptual para el profesor de segundas lenguas (Fernandez Silva, 2002).

Frente a aquellas opiniones que defienden que las competencias no se enseñan porque son destrezas o habilidades y sostienen que el profesor es un mero facilitador de su adquisición y desarrollo, los estudios analizados demuestran los beneficios de enseñar a usar e incrementar el conocimiento pragmático. Sin instrucción, muchos aspectos de la competencia pragmática no evolucionan apropiadamente. Además, se ha 
comprobado que el método explícito es más efectivo que el implícito y que las rutinas pragmáticas, algunas inferencias y determinados actos de habla pueden enseñarse incluso cuando todavía no se tiene un conocimiento sólido de la gramática. No obstante, existen aspectos de la pragmática — como algunos tipos de implicaturasque no mejoran a través de la instrucción, tal como demuestran los estudios recogidos por Kasper (1997).

Ahora bien, una vez asumida la necesidad de instrucción en competencia pragmática, nos hemos planteado cómo debe ser esta, comparando la práctica actual en las clases de L2 con las propuestas acerca de los aspectos pragmáticos que pueden desarrollarse a través de actividades en el aula. En primer lugar, consideramos que las tareas deben llevarse a cabo en grupos pequeños, interactivos y centrados en los alumnos, de tal manera que los aprendientes intercambien los roles de hablante y oyente en distintos tipos de eventos comunicativos y en situaciones comunicativas reales (Vellenga, 2004; LoCastro, 2006). Por otro lado, el tratamiento de la materia pragmática en clase podría centrarse en aspectos como el estudio del significado implícito - ya que en ocasiones es dependiente del contexto, se generaliza y alcanza cierta estabilidad—, de los actos de habla — puesto que hay fórmulas reconocibles y recurrentes que están ligadas típicamente a determinados actos de habla—, de la cortesía y de la pragmática intercultural —el profesor debe hacer consciente al alumno del proceso de ajuste inferencial continuo en la comunicación y de las diferencias entre su lengua materna y la L2-, etc. Finalmente, creemos que sería también recomendable que los manuales incluyeran los principios pragmáticos que normalmente se aprenden de forma implícita a través de la observación directa (Gutiérrez Ordóñez, 2005).

Por último, tras un análisis del área de evaluación de segundas lenguas, hemos concluido que la competencia pragmática acarrea grandes dificultades a la hora de ser medida, y por ello es olvidada, en la mayoría de las ocasiones, en el proceso evaluativo. Hemos defendido que cualquier competencia no puede evaluarse directamente sino a través de la actuación (Rea, 1985) y que para elaborar un buen test nos hemos de basar en definiciones exhaustivas y precisas de las competencias que vamos a analizar (Bachman, 1990). Los modelos de test de la competencia pragmática que hemos presentado están basados en preguntas con respuestas de elección múltiple 
que tienen, o bien algún tipo de desviación pragmática, o bien gramatical, o bien de ambas, de forma que solo una respuesta de entre todas las ofrecidas es correcta gramatical y funcionalmente. Además, aunque se fundamentan en las funciones del Nivel Umbral del español, dejan escapar carencias: a menudo suele medirse más la inteligencia o algún tipo de habilidad cognitiva que la capacidad pragmática real del alumno que ha realizado el test.

Otro ámbito de estudio que aborda el tratamiento de la competencia pragmática es la didáctica de la lengua y la literatura para hablantes nativos. En este campo hemos asistido también al desarrollo de enfoques comunicativos que pretenden dejar atrás la enseñanza puramente gramatical y que dan lugar a aspectos relativos al uso de la lengua en situaciones comunicativas reales. Los currículos de didáctica de la lengua presentan una serie de objetivos que son, en mayor o menor medida, un reflejo de los propios de la enseñanza de lenguas extranjeras: que los estudiantes sean capaces de usar la lengua apropiada, adecuada y eficazmente en situaciones comunicativas reales con el fin de alcanzar sus propósitos comunicativos. Sin embargo, hemos constatado que en la materia de didáctica de la lengua existe un abismo entre la teoría y la práctica de lo comunicativo (Lomas y Osoro, 1996a). Mientras que en la enseñanza de lenguas extranjeras los objetivos comunicativos tienen su aplicación en las actividades del aula, en las clases de lengua materna en las últimas décadas los docentes se han centrado básicamente en enseñar la gramática y quizá algunas destrezas ortográficas. Pocas veces la lengua ha sido entendida como un instrumento útil para la comunicación real (Cassany, Luna y Sanz, 2002). Además, cuando se intenta, se trata de un acercamiento taxonómico de identificación y clasificación de tipos o géneros de textos más que verdaderamente comunicativo. Por ello, son muchos los expertos en didáctica que abogan por que los materiales y el trabajo por parte del profesor se base ciertamente en lo comunicativo, de forma que los alumnos se enfrenten a situaciones reales de uso lingüístico.

Los diversos currículos de la lengua castellana y literatura de los últimos años (MEC, 1989, 1991a, 1991b, 1992, 2007, 2011, 2012) presentan como objetivo primordial la adquisición por parte de los alumnos de los conocimientos y destrezas que componen la competencia comunicativa. El problema es que dichos currículos son abiertos, de forma que ofrecen unos bloques de objetivos, contenidos y criterios de 
evaluación generales, y dejan la programación en manos del profesorado, encargado de decidir también sobre los métodos pedagógicos, criterios de selección, uso de materiales didácticos y formas de evaluación. No obstante, hemos observado cómo aparentemente dichos currículos recogen ya un ajuste pragmático y discursivo, de manera que la enseñanza lingüística no se limita al marco oracional y se atiende, entonces, a aspectos pragmáticos que relacionan los elementos lingüísticos con sus contextos de producción e interpretación. Asimismo, hemos podido comprobar la relación entre los objetivos de la educación lingüística y las distintas subcompetencias que constituyen la competencia comunicativa. Es, entonces, tarea de la didáctica establecer qué competencias deben desarrollar los alumnos en función del nivel en el que se hallen y conseguirlo de la forma más efectiva posible. Además, creemos que en las clases de lengua los contenidos deben seleccionarse en función de los usos comunicativos más habituales en nuestras sociedades porque son a los que tendrán que enfrentarse los alumnos en su vida adulta. En definitiva, lo que se pretende conseguir es que los alumnos mejoren sus capacidades de uso así como la adquisición de las normas, destrezas y estrategias, e incorporen mecanismos pragmáticos que consolidarán su competencia comunicativa.

En el tercer capítulo de este trabajo se ha abordado el estudio de la competencia pragmática dentro del proceso de adquisición de la lengua. Tal como hemos constatado, la investigación en torno a la adquisición del lenguaje a lo largo del siglo $\mathrm{XX}$ se ha centrado principalmente en aspectos referentes al desarrollo de las habilidades fonológicas, léxicas, morfológicas y sintácticas. Por fortuna, en los últimos años la tendencia hacia enfoques comunicativos también se ha filtrado en el campo de estudio de la adquisición. Así, se ha demostrado que aprender la lengua materna supone adquirir una serie de competencias comunicativas que van más allá de conocer y manejar un conjunto de reglas fonológicas, gramaticales, semánticas, etc. Los niños deben aprender a ser competentes en su lengua, utilizando las estructuras correctas, apropiadas al contexto y a la situación, y acordes a sus intenciones comunicativas; y todo ello de manera eficaz.

Asimismo, se ha reconocido que el componente pragmático es fundamental en la adquisición del lenguaje, ya que los cambios más llamativos, desde el punto de vista cognitivo, tienen lugar en el ámbito de la pragmática (Halliday, 1975; Hulit y Howard, 
2002). A medida que el niño va creciendo, va aprendiendo a interpretar la fuerza ilocutiva de los enunciados de sus interlocutores y va adquiriendo la capacidad de saber qué decir, cómo y a quién para conseguir sus objetivos.

Sin embargo, uno de los problemas en el tratamiento de la adquisición de la competencia pragmática es nuevamente la falta de delimitación (O’Neill, 1996; Bara, Bosco y Bucciarelli, 1999; Galeote Moreno, 2002). El hecho de que no exista una teoría que cubra de manera sistemática y global las capacidades pragmáticas ha propiciado la proliferación de trabajos que estudian por separado distintos elementos del componente pragmático (McTear y Consti-Ramsden, 1992; Ninio y Snow, 1996). Así, dentro de este heterogéneo campo de estudio, uno de los fenómenos más estudiados lo constituyen los actos de habla. En efecto, numerosos investigadores han intentado establecer qué actos de habla producen los niños, a qué edades y en qué orden de aparición. No obstante, el problema reside, precisamente, en la ausencia de una clasificación homogénea de tales actos de habla fruto de la divergencia en la concepción teórica de lo que constituye el uso comunicativo del habla.

Los actos de habla más analizados por la bibliografía son las peticiones, ya que son los más frecuentes en las interacciones en las que intervienen niños. También han interesado especialmente las promesas (en este caso más complejas debido al significado de obligación moral y personal que conllevan). Además, los estudios demuestran que la naturaleza de la petición y el estatus del interlocutor influyen en el tipo de peticiones que producen los niños: se ha advertido que las peticiones de información suelen formularse de forma directa, mientras que las de acción, de forma indirecta, o que las peticiones convencionales se usan para pedir un favor, mientras que las no convencionales se usan cuando se exige un derecho (Serra et al., 2000).

A continuación, se ha destacado la importancia de ciertos elementos que, en nuestra opinión, son la base del desarrollo del componente pragmático. Ante todo, nos hemos referido a la importancia del contexto, que desempeña un papel esencial en las etapas iniciales del desarrollo lingüístico (Peralta, 2000). Consideramos que una exitosa adquisición del lenguaje implica, ante todo, que los niños sean sensibles al contexto. En efecto, los niños comienzan usando el lenguaje en su contexto personal e inmediato, de forma que sus primeras locuciones están ligadas al "aquí y ahora”. Con el paso de los años, se observa un desarrollo progresivo de la sensibilidad al contexto 
en el uso del lenguaje, que conduce paulatinamente al dominio del contexto cognitivo no situacional. Consecuentemente, el niño va aprendiendo a utilizar un lenguaje descontextualizado, basado en el conocimiento y en la evaluación de la perspectiva que comparte con su interlocutor, de modo que su manejo del contexto se vuelve más flexible y complejo (Lloyd et al., 1995; Ryder y Leinonen, 2003).

Después, hemos presentado un conjunto de factores íntimamente ligados al primer grupo de subcompetencias primarias que integra nuestro modelo de competencia comunicativa (expuesto en el segundo capítulo). Dichos factores, según Luokusa (2007), hacen posible la comunicación y, por tanto, el desarrollo de la competencia pragmática. Entre ellos se encuentran: el desarrollo de funciones sensoriales y motoras, la memoria, las capacidades de atención, el conocimiento del mundo y las propias creencias, la habilidad para leer la mente y la competencia lingüística. Estas capacidades están englobadas en nuestro modelo bajo el epígrafe de competencia psicolingüística, con excepción de la habilidad lingüística, que, de acuerdo con nuestra terminología, integra la competencia gramatical. Ahora bien, bajo nuestro punto de vista, es necesario añadir también a esta lista de factores propuesta por Loukusa (2007) el conocimiento social y cultural, recogido en lo que hemos denominado competencia cultural.

Así, hemos expuesto brevemente en qué consisten esos factores básicos que afectan a la habilidad pragmática. En primer lugar, es consabido que las funciones sensoriales y motoras son consideradas la base del desarrollo perceptivo y cognitivo del niño y el requisito previo de la comunicación. Por su parte, la habilidad lingüística o gramatical es también necesaria, ya que para poder comprender los enunciados es necesario un manejo de las unidades y estructuras lingüísticas, esto es, el conocimiento del uso lingüístico que implica el desarrollo de la morfología, la sintaxis, la fonología y la semántica. En cuanto al desarrollo morfosintáctico, encontramos varias etapas cuya descripción varía según los autores. Los trabajos de Tomasello y Brooks (1999) estudian el proceso de gramaticalización atendiendo a cuatro etapas en función de la edad; otros autores, como Brown (1973) o Blake et al. (1993), consideran que la evolución morfosintáctica ha de medirse en función de la longitud media de las emisiones (LME) de los niños. Lo que sí es evidente es que la competencia morfosintáctica se desarrolla gradualmente y que hay aspectos que evolucionan de 
forma conjunta y otros de manera condicional, esto es, que necesitan de la adquisición previa de otros. Asimismo, autores como Owens (2003) consideran que muchos cambios morfosintácticos son un reflejo del desarrollo del sistema fonológico subyacente en el niño de edad preescolar, de forma que su habilidad para desarrollar el componente morfológico dependerá de su capacidad para percibir y producir unidades fonológicas. Y, en relación con el desarrollo del léxico, los autores coinciden en que entre los 18 y los 24 meses se produce un cambio súbito y notable en el aprendizaje de palabras conocido como explosión del léxico (lexical spurt) (Mervis y Bertrand, 1995); además, durante los años escolares los niños adquieren mayor refinamiento semántico, es decir, añaden rasgos a las definiciones de las palabras ya conocidas adaptándolas a las de los adultos.

En tercer lugar, el desarrollo de la memoria constituye otro de los factores posibilitadores de la competencia pragmática, ya que, por ejemplo, para derivar un significado implícito es necesario el desarrollo de la memoria a corto plazo. Según Nelson (1986), en los niños de 2 a 6 años podemos observar la capacidad para recordar representaciones de acontecimientos a través del desarrollo de marcos, dentro de los cuales se recuerdan situaciones concretas como ir a comer a un restaurante. En cualquier caso, a lo largo de la etapa infantil y preadolescente tiene lugar un incremento de la habilidad para almacenar información (Meyers y Meyers, 2000; Roselli et al., 2001), así como para desarrollar estrategias que facilitan las tareas de retención y evocación de la información almacenada (Siegel, 1994).

En cuarto lugar hemos presentado la capacidad de atención (Ruiz-Contreras y Cansino, 2005), ligada también al desarrollo de la memoria. Aunque el desarrollo de la atención es evidente a edades muy tempranas, se ha comprobado que la atención auditiva y visual evolucionan especialmente entre los 5 y los 8 años (Korkman et al., 2001). Asimismo, el quinto factor influyente es el propio conocimiento que los niños tienen del mundo a través de su experiencia personal. Desde el nacimiento, los niños se van formando un sistema de ideas sobre su entorno y sobre el mundo que se amplia, modifica y actualiza a medida que experimentan nuevas vivencias (Milosky, 1992).

En sexto lugar, hemos constatado que la habilidad para leer la mente (también denominada teoría de la mente) es —entre los factores relacionados con la habilidad pragmática- uno de los más destacados por los autores. La teoría de la mente se 
entiende como la capacidad de diferenciar los estados mentales propios de los ajenos. Esa capacidad se manifiesta, por ejemplo, a través del engaño intencionado. Así, en la bibliografía destacan dos experimentos de falsa creencia (de primer y segundo orden) para evaluar la teoría de la mente (Baron-Cohen et al., 1986; Sullivan et al., 1994). La falsa creencia de primer orden se basa en comprender que la representación mental de un personaje puede ser diferente de la realidad y diferir de la propia. Por su parte, la de segundo orden requiere la capacidad de representar no solo el estado mental de los personajes sino también de la idea que tienen los personajes de los estados mentales de los demás personajes de la historia. Autores como Wellman et al. (2001) determinan que el desarrollo de la teoría de la mente se produce entre los 3 y 5 años, edad en la que también evoluciona sustancialmente el procesamiento pragmático (Bucciarelli et al., 2003), así como la sensibilidad hacia las normas morales y las emociones autoevaluativas, como la vergüenza o la culpa (Abe e Izard, 1999).

En último lugar, el conocimiento social y cultural está relacionado con el concepto de contexto sociocultural que defendimos en el primer capítulo. Los niños crecen dentro de una comunidad lingüística determinada por lo que tienen que desarrollar su capacidad para adaptarse a ella, esto es, deben ser sensibles al contexto sociocultural en el que se encuentran. Para ello será necesario que incorporen los condicionamientos sociales y culturales sobre el comportamiento verbal y su adecuación a las diferentes circunstancias, así como una serie de conocimientos y supuestos compartidos por su comunidad lingüística, que a su vez les permitirán seleccionar el contexto relevante en cada situación para conseguir el éxito en la comunicación.

Conjuntamente, en este capítulo también hemos querido presentar brevemente las distintas etapas del desarrollo infantil haciendo hincapié en las cuatro áreas evolutivas principales: física, cognitiva, socioemocional y comunicativa (Owens, 2003). Consideramos que el conocimiento de lo que ocurre en cada etapa nos permitirá establecer relaciones con los cambios en el procesamiento pragmático. Según Owens (2003), pueden distinguirse las siguientes fases: el recién nacido (del nacimiento al primer mes de vida), el observador (de 1 a 6 meses), el experimentador (de 7 a 12 meses), el explorador (de 12 a 24 meses), el exhibidor (de los 3 a los 5 años) y el experto (de los 6 a los 12 años). Nos interesan especialmente estas dos últimas etapas, 
ya que engloban la franja de edades que hemos seleccionado para nuestro estudio experimental (de 3 a 9 años). A la edad de 3 años destaca un desarrollo notable de la imaginación, así como un gran crecimiento del vocabulario productivo (en torno a 1000 palabras). Asimismo, Owens (2003) destaca a la edad de 4 años una evolución de las estrategias de memoria junto con un desarrollo de oraciones más complejas desde el punto de vista sintáctico. Por su parte, a los 5 años se establece el desarrollo de las explicaciones de causas y efectos, así como de las emociones y de cierto sentido del humor. Y, finalmente, en la fase que Owens (2003) denomina etapa del experto destaca la evolución de la capacidad para inferir, de la atención selectiva, de las capacidades de memoria, etc., que permiten a los niños procesar la información de forma más eficaz, aprendiendo a manipular e influir en los demás a través del lenguaje.

Tal como anunciábamos al comienzo de este trabajo, hemos adoptado un enfoque cognitivo para acercarnos al procesamiento pragmático en el estudio de la adquisición del lenguaje. De hecho, dentro de las teorías pragmáticas nos hemos ajustado al marco teórico de la relevancia por su acertada orientación hacia el plano cognitivo. Ahora bien, según el modelo clásico de Fodor (1983), existen dos procesos o sistemas cognitivos: los módulos de entrada (como, por ejemplo, la habilidad gramatical que opera sobre un tipo de estímulos concretos cuyo procesamiento sigue pautas específicas) y los sistemas centrales (como la interpretación pragmática cuyo procesamiento depende de factores globales). Wilson (2003) sostiene que lo que debe primar en esta clasificación no es si se trata de procesos globales o locales, sino el hecho de que sean llevados a cabo por mecanismos de uso general o autónomos y específicos. Si partimos de esta perspectiva, la teoría de la mente sería un sistema modular, puesto que posee un mecanismo inferencial de uso específico. En efecto, hay diferencias claras entre la capacidad de lectura de la mente y las habilidades generales de razonamiento (prueba de ello son los ejemplos de pacientes con síndrome de Williams, que poseen una buena teoría de la mente pero habilidades de razonamiento muy pobres). Sin embargo, observamos el fenómeno opuesto con la comunicación inferencial, que en este caso se considera una variedad de la teoría de la mente. Los estudios sobre competencia comunicativa y teoría de la mente muestran evidencias de la estrecha relación entre ambas (Baron-Cohen, 1995; Bloom, 2000; Langdon, Davies y Coltheart, 2002). Así, Happé (1993) descubre —en su estudio con niños de 
desarrollo típico y con personas autistas - una clara relación entre la comprensión de metáforas y la habilidad de lectura de la mente de primer orden, así como entre la interpretación de ironías y la habilidad de lectura de la mente de segundo orden.

Por consiguiente, sobre la base de estas evidencias, Wilson (2003) considera que las habilidades pragmáticas son un submódulo del sistema modular de teoría de la mente. No obstante, tal como reconocen Igoa et al. (2011), esta interpretación modular de los procesos inferenciales tiene que superar un obstáculo, y es que debe explicar por qué un sistema cognitivo especializado en la inducción de estados mentales está encapsulado y a la vez accede a diferentes fuentes para realizar el proceso inferencial.

Asimismo, Sperber (1994) muestra la relación entre las habilidades pragmáticas y la teoría de la mente a través de tres estrategias empleadas a la hora de interpretar una expresión lingüística: el optimismo ingenuo (naïve), el optimismo cauto y el entendimiento sofisticado. En el optimismo ingenuo, el oyente asume que el hablante es competente y benevolente; en el optimismo cauto, entiende que es benevolente pero no necesariamente competente; en el entendimiento sofisticado, es consciente además de que puede ser engañoso. Así, estas estrategias pueden verse reflejadas en la evolución natural de la comprensión inferencial de los niños, que parten de un optimismo ingenuo y pasan al optimismo cauto coincidiendo con la adquisición de la habilidad de lectura de la mente de primer orden y, más tarde, a la comprensión sofisticada, ligada a la aparición de la habilidad de lectura de la mente de segundo orden. En efecto, en nuestro estudio hemos encontrado evidencias del optimismo ingenuo en los niños de 3 y 4 años cuando, por ejemplo, responden de manera irrelevante o fantasiosa creyendo que lo primero que se les ocurre es lo que el oyente espera oír. Por su parte, la estrategia del optimismo cauto se ha visto reflejada en las respuestas de niños de 4 y 5 años, ya que, en lugar de conformarse con la primera interpretación que les viene a la mente, razonan una respuesta coherente con la información contextual que han recibido. Y, finalmente, los niños de 8 y 9 años han dado muestras de entendimiento sofisticado al interpretar las ironías, puesto que han sido capaces de comprender que el hablante hace manifiesto implícitamente lo contrario de lo que dice.

Por último, en este capítulo hemos advertido que la tarea global de inferir el significado del hablante puede descomponerse en una serie de subtareas pragmáticas, 
que, Según Ryder y Leinonen (2003), pueden categorizarse en términos de complejidad contextual en función del esfuerzo requerido para su procesamiento. Así distinguimos las siguientes tareas: asignación de referentes, proceso de enriquecimiento pragmático, procesamiento de implicaturas, interpretación de rutinas, identificación de sentimientos en otros e interpretación de la ironía. Estas tareas han sido utilizadas en el diseño de la prueba de nuestro estudio experimental. Por ello, hemos considerado necesario describirlas antes desde un punto de vista teórico, así como presentar algunos de los estudios que ya se han realizado en torno a su desarrollo. En primer lugar, hablar de asignación de referentes supone aludir al fenómeno de la deixis. Tal como postulamos en el primer capítulo, la deixis es la manifestación más evidente de la relación entre el lenguaje y el contexto en la estructura de la lengua. De este modo, para interpretar de forma adecuada mensajes lingüísticos que contienen elementos deícticos es necesario tener en cuenta factores extralingüísticos como conocer la identidad de emisor y el receptor, las circunstancias de lugar y de tiempo, etc. Entendemos, entonces, que la identificación de referentes es un fenómeno inherente al uso comunicativo de la lengua, por lo que constituye una de las tareas más sencillas y básicas dentro del proceso de comprensión pragmática. Asimismo, el enriquecimiento pragmático es también considerado un proceso simple, ya que frecuentemente se realiza de forma automática e inconsciente cuando completamos la información que no aparece especificada en los enunciados usando el contexto, nuestro conocimiento enciclopédico, etc.

En cuanto a las implicaturas, estas requieren un esfuerzo de procesamiento extra. Así, el oyente ha de combinar la información recibida con los supuestos presentes en su memoria para deducir el significado pretendido por el hablante a través de un proceso inferencial. Ahora bien, según Wilson (2000), la fuerza de las implicaturas puede variar en función de la familiaridad del enunciado, de ahí que distingamos el procesamiento de las implicaturas frente al de rutinas. En el caso de las rutinas, el esfuerzo requerido para su interpretación es menor. En efecto, cuando la situación comunicativa es familiar, la carga inferencial de los enunciados se reduce, puesto que se puede recurrir a rutinas interiorizadas (Gillam y Bedore, 2000).

Respecto a la tarea de identificación de sentimientos en otras personas, también se lleva a cabo un procesamiento contextual a través de la recuperación de información 
de diferentes fuentes (Luokusa, 2007). En las últimas décadas se ha mostrado un gran interés por el desarrollo de la capacidad de identificar sentimientos, relacionada con el entendimiento del mundo mental y, por consiguiente, con la teoría de la mente (Flavell y Miller, 1998).

Finalmente, hemos presentado la interpretación de ironías, debido, en primer lugar, a su estrecha relación con la teoría de la mente (Happé, 1993; Martin y McDonald, 2004; Champagne-Lavau y Joanette, 2009) y también porque en nuestra opinión, es una de las tareas pragmáticas más interesantes desde un punto de vista lingüístico y metacognitivo. Según Bara, Bosco y Bucciarelli (1999), la capacidad de interpretación de enunciados irónicos tiene dos fases. La primera supone el dominio de expresiones irónicas del tipo "una persona dice una cosa queriendo implicar lo contrario” y la segunda requiere el manejo de inferencias más sutiles en las que se hace necesaria una capacidad metarrepresentacional.

Muchas de las investigaciones en torno a la adquisición del componente pragmático que hemos revisado han sido motivadas por la necesidad de creación de parámetros de desarrollo normal con los que comparar los casos de niños en los que se sospecha de la existencia de algún déficit comunicativo de naturaleza pragmática. Por ello, hemos considerado oportuno dedicar el cuarto capítulo a la investigación de los trastornos pragmáticos que aparecen en las alteraciones del lenguaje, con el objeto de reflejar qué ocurre cuando la competencia pragmática falla. Con ello pretendemos destacar la importancia de la pragmática en la descripción y análisis de los déficits en la habilidad comunicativa, entendiendo que la lingüística aplicada es mucho más rica y no debe relegarse únicamente a la enseñanza de segundas lenguas.

Hoy sabemos, gracias al avance de la investigación, que hay alteraciones de la comunicación en las que se reconoce un déficit lingüístico debido a fallos en la capacidad pragmática, aunque la habilidad gramatical no esté dañada, o al menos no lo esté significativamente. Así, por ejemplo, los niños con síndrome de Williams presentan alteraciones en la capacidad pragmática (sobredependencia del contexto, dificultades para interpretar el significado figurado de bromas, metáforas o ironías, etc.), mientras que la adquisición del componente formal del lenguaje parece seguir un orden adecuado. También puede ocurrir lo contrario: que el componente pragmático 
no esté dañado, pero que haya déficits gramaticales severos, como en el caso de algunas afasias.

Consecuentemente, el surgimiento de la pragmática clínica (que no tuvo lugar hasta los años 90) ha permitido la identificación de lesiones en el hemisferio derecho con déficits en tareas pragmáticas como la interpretación de actos indirectos, la inferencia de implicaturas, la interpretación de ironías, metáforas, sentidos no literales, etc. (Barroso y Nieto, 1996). Así, se ha llegado a reconocer que ambos hemisferios toman parte de manera igualmente relevante en el procesamiento del lenguaje (Obler y Gjerlow, 2001).

No obstante, a pesar del gran avance que ha supuesto la incorporación del componente pragmático en la investigación de las patologías del lenguaje, en la práctica han surgido ciertos problemas metodológicos debido a su difícil cuantificación (Mendoza Lara, 2001). Con todo, en los últimos años los autores han comenzado a realizar estudios experimentales que integran las categorías pragmáticas y que dan cuenta de su potencial para futuras investigaciones (Noveck y Sperber, 2007).

Consiguientemente, en este capítulo hemos querido revisar los principales trastornos de la comunicación que incluyen síntomas de carácter pragmático. En primer lugar, hemos hecho referencia a las afasias. En contra de la convicción generalizada de que las afasias se relacionan únicamente con deficiencias gramaticales, en la bibliografía también encontramos propuestas que señalan la existencia de ciertos efectos pragmáticos y que defienden la existencia de una afasia pragmática (Joanette y Ansaldo, 1999). No obstante, de acuerdo con la investigación de Moreno Campos (2011), concluimos que no puede hablarse de un déficit pragmático específico asociado a la afasia, ya que las posibles categorías pragmáticas alteradas son realmente periféricas, de base gramatical.

Dentro de las alteraciones que incluyen claros trastornos en el componente pragmático se encuentra el síndrome de Williams y el síndrome del hemisferio derecho. Los que padecen síndrome de Williams demuestran, entre otros síntomas, una sobredependencia del contexto y una gran incapacidad para entender el significado de bromas e ironías, así como un claro déficit en la interpretación de implicaturas generalizadas (Gallardo Paúls, 2007). Por su parte, los pacientes con síndrome del 
hemisferio derecho presentan dificultades para ir más allá del significado referencial, problemas en la interpretación de actos de habla indirectos, tendencia a conversaciones con abundante información poco relevante, etc. (Blake, 2009).

Asimismo, los trastornos generalizados del desarrollo se caracterizan por presentar alteraciones pragmáticas que se reflejan en dificultades en la interacción y la comprensión social. Dentro de estos trastornos se incluyen, principalmente, el síndrome de Asperger y el trastorno autista. En relación con el autismo, no existe una sintomatología establecida, ya que podemos encontrar diferentes tipos. En cualquier caso, los investigadores coinciden en que uno de los rasgos generalizados del autismo son las dificultades de carácter pragmático. Según Martos (2001), la característica universal del trastorno autista es la dificultad a la hora de mostrar o reconocer intenciones comunicativas; y de ahí que a menudo se asocie el autismo con el déficit en la comprensión de los estados mentales, esto es, ausencia de teoría de la mente (Happé, 1993).

Por su parte, lo que caracteriza al síndrome de Asperger son las dificultades pragmáticas que se reflejan en la interpretación literal de los enunciados, en la incapacidad de entender las ironías, las metáforas, etc. (Martín Borreguero, 2005), y en los problemas a la hora de interpretar el lenguaje en su contexto, esto es, en las diferentes situaciones sociales comunicativas (Landa, 2000). No obstante, a diferencia de los pacientes autistas, los que sufren este trastorno tienen una capacidad intelectual superior y una mayor destreza en el uso del lenguaje. Además, a menudo superan las tareas de falsa creencia, aunque, según autores como Frith (1991), esto no significa que posean teoría de la mente, sino que la suplen a través de deducciones lógicas a partir de su conocimiento del mundo previo. Con todo, existe un tipo de autismo, el autismo de alto funcionamiento, cuyo diagnóstico se aproxima más al síndrome de Asperger (Attwood, 2009), aunque comparte con el autismo clásico la falta de interés hacia la interacción social. En efecto, la relación entre ambos trastornos ha despertado el interés de numerosos investigadores, lo que ha llevado a la realización de estudios en los que se analizan las habilidades de estos grupos para realizar inferencias contextuales e ir más allá del significado literal (Dennis et al., 2001; Rapin y Dunn, 2003; Bogdashina, 2005). Así, el estudio de Luokusa et al. (2007) pone de manifiesto que tanto en niños como en adolescentes con síndrome de Asperger y autismo de alto 
funcionamiento sobresalen las dificultades de comprensión pragmática, incluso cuando el resto de habilidades lingüísticas muestran un desarrollo normal.

Finalmente, hemos presentado el denominado trastorno pragmático del lenguaje. Se trata de una alteración difícil de catalogar, ya que su definición sigue siendo heterogénea (Mendoza Lara, 2001). De acuerdo con Bishop (2000), este trastorno se caracteriza por alteraciones en la estructura del lenguaje y en su uso social, y presenta menos problemas en los intereses sociales.

Con respecto a la evaluación clínica, los test habituales no son útiles, por lo general, para detectar y analizar los trastornos pragmáticos (Conti-Ramsden et al., 1997). La dificultad radica en la imprecisión definitoria de la pragmática a la que ya nos hemos referido en el segundo capítulo cuando hemos presentado los problemas de la evaluación pragmática en la enseñanza de segundas lenguas. Estos trastornos también se prestan mal a los juicios cuantitativos y normativos (o prescriptivos) debido a la imprevisibilidad de las respuestas —al usar simultáneamente significados explícitos e implícitos-, a la dependencia del contexto, etc., por lo que se aboga por el análisis a través de métodos cualitativos, cuyo inconveniente más notorio es que suponen emplear más tiempo y recursos.

El mayor obstáculo en las pruebas de evaluación pragmática es que carecen de criterios de fiabilidad y de validez. No obstante, se han llevado a cabo varios intentos para sistematizar la evaluación pragmática (Shulman, 1985; Phelps-Terasaky y PhelpsGunn, 1992; Prutting y Kirchner, 1983; y en español Puyuelo et al., 1997), si bien es cierto que presentan carencias que todavía no se han subsanado.

Asimismo, ha surgido también otra modalidad de evaluación basada en cuestionarios elaborados a partir de comportamientos prototípicos y de listas de habilidades pragmáticas que son completados por personas del entorno de los niños (Hilton, 1990; Dewart y Summers, 1995; Bishop, 1998), y otros tipos de pruebas centradas en la observación de la interacción en contextos naturales (Ninio et al., 1994; Adams et al., 2002).

Ante esta gama de métodos de evaluación pragmática, a menudo la elección de uno u otro se lleva a cabo teniendo en cuenta criterios como la edad de los niños o si se trata de niños con desarrollo normal o con alguna deficiencia del lenguaje ya diagnosticada. En la teoría se aboga por un análisis pragmático en situaciones 
naturales, pero en la práctica se ha demostrado que establecer de antemano los contextos comunicativos permite observar un mayor número de actos de habla y tareas pragmáticas.

La teoría de la relevancia también ha sido empleada como marco teórico para el análisis en numerosos estudios en torno a trastornos pragmáticos del lenguaje (Happé, 1993; Leinonen y Kerbel, 1999; Dipper et al., 1997; Luokusa, 2007). En opinión de investigadores como Leinonen y Ryder (2008), dicha teoría permite predecir el grado de competencia comunicativa en función de si los sujetos poseen teoría de la mente o no y de qué orden. Además se ha puesto de relieve, de nuevo, la relación entre la habilidad para entender el lenguaje figurado y la capacidad para atribuir estados mentales a los demás. En suma, los estudios sobre alteraciones pragmáticas del lenguaje que han tomado como base la teoría de la relevancia han comprobado sus supuestos en cuanto a los diferentes niveles de complejidad en las distintas tareas pragmáticas, teniendo en cuenta el esfuerzo cognitivo implicado en los diferentes enunciados. Esto permite explicar las dificultades pragmáticas y también puede ser muy útil en el diseño de métodos de evaluación e intervenciones clínicas.

En el último capítulo hemos presentado nuestro estudio experimental sobre el desarrollo de la comprensión pragmática del lenguaje, para el cual hemos entrevistado a 140 niños españoles de edades entre 3 y 9 años. El propósito principal de este estudio ha sido el análisis de las respuestas e interpretaciones de los niños ante 6 distintos tipos de preguntas con diferentes niveles de demanda pragmática (referencia, enriquecimiento, rutina, implicatura, sentimiento e ironía), dentro del marco de la teoría de la relevancia (Sperber y Wilson, 1986/1995). El diseño de esta investigación es una adaptación de los trabajos con niños finlandeses de Loukusa, Leinonen y Ryder (2007) y Loukusa, Ryder y Leinonen (2008), recogidos a su vez en la tesis doctoral de Loukusa (2007), cuyo material está compuesto por preguntas breves en torno a variadas historias situadas en contextos familiares, de las cuales algunas cuentan con el apoyo visual de un dibujo y otras se presentan solo de forma verbal. En las preguntas (en total 42) se espera que el niño conecte su conocimiento del mundo con la información contextual relevante para llegar a la conclusión esperada. Asimismo, si el niño proporciona una respuesta válida se le pide que razone su respuesta. De esta forma, tanto las respuestas como las explicaciones que son consideradas fallidas se 
clasifican en distintas categorías (con base en la clasificación de Luokusa, 2007) que reflejan el modo en el que el niño ha fracasado en la utilización de la información contextual relevante para la pregunta en cuestión.

Los objetivos específicos que nos hemos planteado en este estudio han sido: determinar si las variables edad, sexo y tipo de contexto (visual/no visual) influyen en el número de respuestas y explicaciones válidas de los niños, analizar el contenido de las respuestas y explicaciones fallidas usadas por los niños cuando responden inapropiadamente y, finalmente, comparar nuestros resultados con los de los trabajos previos (Loukusa, Leinonen y Ryder, 2007; Loukusa, 2007; Loukusa, Ryder y Leinonen, 2008) para comprobar si se repiten patrones de actuación en el desarrollo de la comprensión pragmática en niños finlandeses y españoles.

Tras el estudio estadístico de los datos obtenidos hemos confirmado, como era esperable, que la edad es un factor claramente influyente en la comprensión pragmática de los niños. En un primer análisis los participantes han sido clasificados por años, pero al detectar la formación de grupos con comportamientos similares hemos considerado oportuno realizar también un análisis que agrupe a los niños por ciclos de estudio. Así, los datos demuestran, por ejemplo, que tanto en las preguntas de ironía como en las de enriquecimiento la edad influye significativamente en el número de respuestas y explicaciones válidas, pero además hemos podido agrupar a los participantes en cuatro grupos: el primero formado por los niños de 3 años, el segundo por los de 4 y 5 , el tercero por los de 6 y 7 y el último por los de 8 y 9 años. Esto sugiere que a medida que el niño pasa de formar parte de un grupo a otro, aumenta su capacidad para realizar con éxito estas tareas inferenciales. Los niños de 3 años forman un grupo aislado, ya que aún no están plenamente inmersos en el sistema educativo con el que se pauta el desarrollo, de forma que para cada nivel se establecen una serie de competencias mínimas que el niño debe adquirir. En efecto, intuimos que las diferencias halladas en los niños que cursan el primer año de escolarización respecto al resto pueden deberse a los distintos entornos familiares y sociales de los que provienen.

Asimismo, en las preguntas de asignación de referentes, la edad también constituye un factor relevante, pero las diferencias no se detectan entre grupos 
consecutivos de edad, sino con los siguientes. Esto demuestra que la edad sí que influye significativamente, pero entre grupos de edad distanciados.

Consecuentemente, como ya hemos anunciado, una de las novedades frente a los estudios previos se basa en la clasificación de los niños en función del ciclo escolar al que pertenecen. De esta forma, se han dividido en tres grupos: Educación Infantil, primer ciclo de Educación Primaria y segundo ciclo de Educación Primaria, según el sistema educativo español establecido por el MECD. El análisis estadístico ha revelado que, en prácticamente todas las categorías de pregunta, el ciclo educativo influye en el número de respuestas y explicaciones válidas dadas por los niños. La excepción la constituyen las preguntas de sentimiento, en las cuales no se han detectado diferencias estadísticamente significativas en las respuestas ni en las explicaciones válidas de los niños de primer y segundo ciclo de Primaria. Este resultado no nos sorprende, ya que se trata de preguntas que pronto dominan y por ello el comportamiento de estos dos grupos es muy similar. Asimismo hemos constatado que el ciclo educativo influye por encima de la edad, esto es, los datos señalan que los comportamientos más similares se encuentran entre niños que son del mismo curso y no necesariamente de la misma edad. De acuerdo con las diferencias entre el calendario natural y el académico, puede ocurrir que, por ejemplo, en $2^{\circ}$ de Primaria haya niños que tengan 7 años y otros que ya hayan cumplido los 8 . Pues bien, los resultados de los niños de 8 años de $2^{\circ}$ de Primaria se aproximan más a los de sus compañeros de pupitre de 7 años que a los niños de 8 años que cursan $3^{\circ}$ de Primaria; como, por otra parte, era previsible debido a la influencia de la escolarización, que presenta objetivos y currículos específicos diseñados para cada etapa.

A continuación, hemos analizado la distribución de las respuestas y explicaciones válidas dentro de los distintos grupos de edad para comprobar si hay diferencias entre los niños de un mismo grupo o si, por el contrario, su media de aciertos es similar en las distintas tareas pragmáticas. En primer lugar, en las preguntas de referencia y enriquecimiento, la distribución es en general homogénea, aunque se observa una dispersión mayor en el número de respuestas válidas en los grupos de 3 y 4 años. Esto era esperable, ya que, tal como anticipamos, los niños más pequeños están adaptándose al sistema educativo y conservan remanentes de la educación recibida en casa, que influye en ellos y los diferencia entre sí. 
Por lo que respecta a las preguntas de implicaturas y rutinas, las explicaciones válidas siguen un patrón similar de distribución simétrica en el que puede verse además la evolución a medida que aumenta la edad. No obstante, en las respuestas válidas a las preguntas de rutinas se observan comportamientos dispares, sobre todo a las edades de 5 y 6 años. Por el contrario, en las preguntas de implicaturas, las respuestas siguen el patrón esperable con mayor dispersión en las edades inferiores y curiosamente a los 6 años. En estos casos sería interesante realizar un estudio profundo con una muestra más amplia de niños de estas edades.

El comportamiento en las preguntas de sentimiento es diferente, ya que en las respuestas válidas la dispersión pasa de ser la totalidad de los valores en el grupo de 3 años a ser inexistente a partir de los 5 años. Esto se debe a que a partir de esa edad todos los niños responden acertadamente, de forma que la media es la totalidad de la puntuación. En cambio, por lo que respecta a la distribución de las explicaciones válidas de estas preguntas, encontramos mayor dispersión en los grupos de edades inferiores y, a continuación, una evolución natural hasta los 9 años.

En último lugar, las preguntas de ironía muestran una gran dispersión en la distribución del número de respuestas válidas, pero sobre todo en las explicaciones, donde se alcanza la totalidad de los valores. Estos datos se explican debido a la complejidad inherente al procesamiento de este tipo de preguntas. En efecto, hay niños que son capaces de identificar el fenómeno de la ironía y responden acertadamente a las preguntas, mientras que otros no lo comprenden y fallan en todas las ocasiones. Tal como advierten Sperber y Wilson (1995), reconocer la ironía supone un tipo de habilidades metarrepresentacionales mayor que el mero reconocimiento de la proposición expresada en un enunciado, ya sea literal o metafórica.

La inclusión de esta categoría de preguntas en el cuestionario es fruto de nuestro interés hacia este fenómeno pragmático y supone una novedad respecto a los trabajos previos con niños finlandeses. No obstante, al tratarse de una muestra de niños de 3 a 9 años, hemos diseñado enunciados irónicos sencillos del tipo "alguien dice $p$ para intentar decir no-p". Por lo tanto, nuestras conclusiones no pueden compararse con investigaciones más complejas con niños de edades superiores como, por ejemplo, el estudio de Crespo et al. (2007), que analiza la comprensión oral de la ironía en niños de 5 a 13 años. No obstante, nuestros datos coinciden con los resultados obtenidos por 
Nakassis y Snedeker (2002), que determinan que a los 5 y 6 años los niños son capaces de procesar formas simples de ironía, mientras que hay que esperar a los 10 en adelante para observar el entendimiento de ironías más sutiles. En nuestra investigación hemos advertido que la edad en la que se desarrolla más visiblemente la capacidad para detectar las ironías se sitúa entre los 5 y los 7 años, y que a partir de los 9 años estos enunciados son procesados sin grandes dificultades, aunque los niños no siempre son capaces de razonar sus respuestas. En efecto, según las fases del desarrollo metalingüístico establecidas por Gombert (1992), la fase metapragmática se iniciaría alrededor de los 6 años y estaría muy relacionada con el aumento de la capacidad en la memoria operativa. Asimismo, Bara, Bosco y Bucciarelli (1999) concluyen que la capacidad para producir enunciados irónicos se desarrolla en dos etapas. En la primera, los niños empiezan a dominar la ironía simple ( $p$ para decir no$p$ ), mientras que en la segunda los niños comienzan a manejar inferencias más refinadas hasta que alcanzan los niveles más complejos de ironía indirecta. No obstante, estos autores entienden que solo podríamos hablar del desarrollo de habilidades metarrepresentacionales en el segundo nivel.

En línea con los datos obtenidos en los trabajos con niños finlandeses (que determinan que la edad en la que puede observarse un rápido incremento en el número de respuestas válidas es entre los 3 y los 4 años, y se prolonga hasta los 5 en las preguntas de sentimientos), en este estudio, la edad en la que se observa un mayor desarrollo en las preguntas de rutina y enriquecimiento se sitúa también entre los 3 y los 4 años, y en las preguntas de sentimientos e implicaturas, entre los 4 y 5 años. Tal como recogimos en el tercer capítulo, la franja de edades entre 3 y 5 años es denominada por Owens (2003) el periodo del exhibidor y se caracteriza por el desarrollo de la autonomía en los niños. Concretamente, según el autor, a los 5 años se puede decir que los niños tienen cierto sentido del humor y pueden discutir sobre emociones, dato que se corrobora también en este estudio en el paso de los 4 a los 5 años.

Además, estas fases de desarrollo en la compresión del significado contextual pueden deberse a la evolución en esas edades de otras funciones cognitivas tales como el desarrollo de la memoria (Oakhill, 1984; Gathercole y Baddeley, 1993), la atención (Buckley, 2003) y la teoría de la mente (Wellman, Cross y Watson, 2001), que son la 
base del desarrollo de las habilidades pragmáticas, tal como argumentamos en el tercer capítulo.

Concretamente, entre los 3 y 4 años, los niños van adquiriendo más experiencias, y su conocimiento del mundo que les rodea crece, lo que afecta directamente a su capacidad para derivar significados del contexto (Milosky, 1992). Las diferencias en el nivel de experiencias pueden ser la razón que justifique la variación hallada entre estos grupos. Además, aunque los niños estudian en los mismos colegios, sus entornos familiares, culturales y lingüísticos no son idénticos (Donaldson, 1992; Robinson, 1994). Hemos observado también que las variaciones dentro de los grupos disminuyen con la edad, de forma que en los grupos de 8 y 9 años la desviación estándar se sitúa alrededor de 0.5. De hecho, a la edad de 9 años apenas hay variación, puesto que las respuestas de los niños rozan el total de aciertos. No obstante, debemos recordar que el desarrollo de la comprensión pragmática continúa en la adolescencia (Vieiro y GarcíaMadruga, 1997) y que el hecho de que hayan respondido adecuadamente a las preguntas de este estudio con contextos previamente fijados no significa que sean igualmente competentes en el habla natural.

Tras la descripción estadística obtenida en este estudio, y sobre la base de las medias y medianas de respuestas válidas de cada grupo, hemos podido establecer un orden de menor a mayor complejidad pragmática de los tipos de preguntas en términos de demanda contextual. Así, las preguntas de sentimiento, referencia, enriquecimiento y rutina han sido en las que se ha alcanzado un porcentaje más alto de aciertos. Por el contrario, las preguntas de implicaturas y, sobre todo, las de ironía han obtenido las medias de acierto más bajas. Estos resultados son coherentes con nuestras hipótesis de partida, salvo en lo relativo a las preguntas de sentimientos, que han quedado muy próximas o, en algunos grupos, por encima de las de asignación de referentes, que en un principio supusimos que serían las que obtendrían un mayor número de aciertos. Asimismo, en cuanto a las preguntas de rutinas e implicaturas, en el inicio de este estudio las entendimos como próximas entre sí, si bien es cierto que conjeturamos que las rutinas serían más fáciles de procesar dada su temática más cotidiana. En este caso los datos efectivamente han corroborado esta hipótesis, pero solo hasta los 7 años, edad en la que las implicaturas dejan de suponer mayor dificultad y sus resultados se igualan. 
En relación con la variable sexo, en línea con los trabajos con niños finlandeses, no hemos hallado diferencias estadísticamente significativas entre niños y niñas. La única excepción se encuentra en el grupo de 7 años, y únicamente para las preguntas de referencia y rutina. No obstante, como ya mencionamos, estos datos pueden considerarse casuales, ya que el valor de $p$ es muy cercano a 0.05 . Por su parte, algunos estudios de neuropsicología han registrado diferencias significativas entre los sexos en el desarrollo del lenguaje. Así, en los trabajos de Huttenlocher et al. (1991) y Morriset et al. (1995) se observan diferencias entre los niños y niñas de edades tempranas, a favor de las últimas, en tareas relacionadas con la productividad verbal y el vocabulario; mientras que investigaciones posteriores (en edades de 5 a 16 años) determinan que los niños superan a las niñas en tareas de comprensión del discurso (Rosselli et al., 2004; Inozemtseva et al., 2010). Ahora bien, no podemos extraer conclusiones generales, ya que los estudios en esta línea de investigación son escasos y de diversa naturaleza. Sería necesario, por tanto, profundizar en el análisis de las diferencias entre niños y niñas en una amplia franja de edades y con distintos tipos de tareas comunicativas, tanto a nivel expresivo como receptivo.

De igual modo, aunque tradicionalmente se ha defendido que la aparición y el desarrollo del lenguaje suele manifestarse antes en las niñas que en los niños, las investigaciones en lingüística clínica detectan que cuando el lenguaje está alterado afecta a menos niñas que niños, si bien el grado de afectación tiende a ser mayor en estas (Garayzábal, 2006). En este caso, también sería interesante realizar investigaciones más completas y con pacientes con diferentes alteraciones de la comunicación para poder respaldar estas afirmaciones.

Con respecto a la variable tipo de contexto (visual/no visual), los datos obtenidos sugieren que el hecho de tener apoyo visual influye solo en las preguntas de implicaturas (hasta los 6 años), en las de referencia (hasta los 7 años) y en las de ironía (solo en el grupo de niños de 4 años), pero no en las demás. Así, los datos obtenidos en los trabajos previos con niños finlandeses (Luokusa, 2007) coinciden en que esta variable es determinante en las preguntas de referencia (hasta los 6 años) y en las de implicaturas (a los 4 y a los 6 años). Sin embargo, en contra de nuestros resultados, en los niños finlandeses también influye el tipo de contexto en las preguntas de enriquecimiento hasta los 5 años. 
Como ya hemos señalado, el hecho de que el niño responda acertadamente no siempre significa que haya comprendido la pregunta o que pueda razonar su respuesta. Por ello, se han estudiado también los datos obtenidos tras el análisis de las explicaciones proporcionadas por los niños. En estos casos, como era esperable, el porcentaje de aciertos es menor que en las respuestas válidas. Ser capaz de explicar razonadamente una respuesta requiere habilidades metacognitivas. Así, encontramos casos en los que determinados niños de 3 y 4 años son capaces de razonar alguna de sus respuestas, lo cual indicaría que están comenzando a desarrollar su conciencia metapragmática (Gombert, 1992; Verschueren, 2000). Además, esto apoyaría la teoría planteada en trabajos anteriores (O’Neill, 1996; Ryder y Leinonen, 2003) que sugiere que los niños de menor edad ya son capaces de usar la información contextual adecuadamente siempre que el contexto sea familiar y la pregunta sencilla.

Al comparar gráficamente la evolución de preguntas y respuestas válidas para cada categoría de pregunta, hemos detectado que tanto en las preguntas de sentimiento como en las de ironía y rutina hay una progresión ascendente a medida que aumenta la edad. Sin embargo, en las preguntas de implicaturas hemos localizado un punto de intersección en los 6 años: a esa edad el número de respuestas y explicaciones válidas coincide. Además, sorprendentemente, a los 6 años, el número de respuestas válidas es un poco inferior al de los niños de 5 años. Probablemente sea un dato casual, pero sería interesante analizar lo que ocurre con este tipo de preguntas en esa franja de edad en estudios posteriores.

Nuestro segundo objetivo ha consistido en analizar el contenido de las respuestas y explicaciones fallidas. Desde el comienzo de este estudio hemos considerado que las respuestas y explicaciones erróneas son de gran utilidad a la hora de determinar qué tipo de información no pertinente ha utilizado el niño o de qué estrategia conversacional se ha servido. Como ya hemos mencionado, hemos partido de la clasificación de respuestas incorrectas del trabajo de Loukusa (2007) que utiliza las siguientes categorías: foco incorrecto, conocimiento del mundo, información dada, no sé, irrelevante, tautológica, turno de palabra, no hay respuesta y otras. Hemos considerado las tres primeras como las más refinadas, ya que son las que más se aproximan a una respuesta válida. En ellas los niños no han localizado el foco de la pregunta con precisión o bien han sobregeneralizado su conocimiento del mundo y 
experiencias personales o, por el contrario, han dado excesiva importancia a la información adicional proporcionada en el contexto de la pregunta. En cuanto a las categorías como irrelevante, tautológica o turno de palabra, son más simples y propias de los niños de menor edad. Los niños son conscientes de que tienen que dar una respuesta, de forma que dicen lo primero que se les viene a la cabeza, repiten la pregunta o parte de ella, o bien utilizan un par adyacente del tipo como/así para contestar. Finalmente, con respecto a las respuestas no sé o no hay respuesta, puede ocurrir que el niño sea sincero porque realmente no lo sabe, o que prefiera el silencio o señalar que no lo sabe antes que dar una respuesta errónea.

En nuestro estudio la respuesta fallida más frecuente en los niños de 3 a 6 años es no sé, seguida de la de conocimiento del mundo en las edades de 4 a 8 años. Por su parte, entre los grupos de 7 y 8 años la más frecuente es foco incorrecto, que, como ya advertimos, es la que más se aproxima a una respuesta válida. Estos resultados coinciden en su mayoría con los hallados en los trabajos con niños finlandeses; sin embargo, en estos la respuesta no sé sorprendentemente se repite con alta frecuencia en el grupo de 7 años. Esto puede deberse a un fenómeno cultural, como apuntan Letts y Leinonen (2001), que hallaron resultados similares en esta edad en trabajos anteriores con niños finlandeses. Parece ser que los niños finlandeses en torno a la edad de 7 años prefieren decir que no lo saben antes que dar una respuesta de la que no están totalmente seguros. No obstante, en el caso de los niños españoles, a la edad de 6 años la respuesta no sé es también la más frecuente con un 31\%, con lo que podríamos relacionar las causas al tratarse de edades muy próximas.

En cuanto al contenido de las explicaciones fallidas, se repite a grandes rasgos el patrón hallado en las respuestas fallidas. Los niños de menor edad utilizan frecuentemente respuestas más simples (tautológica, irrelevante, turno de palabra), que apenas aparecen en los niños de mayor edad, en los que son más comunes las categorizadas como foco incorrecto, conocimiento del mundo o información dada. En relación con el estudio con niños finlandeses, destaca que la respuesta turno de palabra no solo es común en los niños de 3 y 4 años (así ocurre con los españoles de nuestro estudio), sino que es también frecuente en todos los demás grupos de edad. Además, con relación a la capacidad para razonar las respuestas, un dato relevante es que tanto los resultados de niños españoles como los de niños finlandeses coinciden en 
que las preguntas que mejor saben explicar son las de sentimiento, por encima de las rutinas. La posible razón de este hecho es que quizá forme parte de su vida cotidiana, de modo que los niños estén bastante familiarizados con la expresión o el reconocimiento de sentimientos en otros, tal como advierte Loukusa (2007).

Finalmente, el último objetivo ha consistido en comparar, en la medida de lo posible, nuestros datos con los ofrecidos por las investigaciones anteriores con niños finlandeses (Luokusa, Leinonen y Ryder, 2007; Luokusa, 2007; Loukusa, Ryder y Leinonen, 2008). Con todo, podemos concluir que los resultados coinciden en su mayoría, salvo por las pequeñas excepciones que hemos mencionado en cada apartado. Por ello sugerimos que el procesamiento del lenguaje sigue un patrón en su desarrollo con independencia de la lengua materna. Además, en nuestro estudio hemos observado un incremento paulatino a medida que aumenta la edad en la capacidad de los niños para acceder a la información relevante que permite llevar a cabo el proceso de comprensión. Así pues, coincidimos con las investigaciones pioneras en que la habilidad de comprensión pragmática puede identificarse con la capacidad para usar la información contextual relevante en cada enunciado y para cada situación comunicativa.

Tal como vimos en el capítulo cuatro, en la investigación clínica es importante disponer de un patrón evolutivo normal para así poder detectar si el desarrollo del niño está dentro de los parámetros típicos o bien hay desviaciones o retrasos. Bara, Bosco y Bucciarelli (1999) reconocen que ninguna teoría cubre sistemáticamente el desarrollo de la capacidad pragmática, ni tampoco existe un protocolo que evalúe las etapas normales en las que se espera que un niño produzca o interprete diferentes actos de habla. De este modo, sin una base con datos sobre el desarrollo normal con los que poder comparar no es posible estudiar los déficits pragmáticos de forma sistemática. A la vista de lo anterior, parece obvia la utilidad y relevancia de los estudios sobre el desarrollo infantil de habilidades como la comprensión pragmática.

Según Loukusa (2007), los niños se enfrentan cada día a situaciones que constituyen un reto comunicativo. Así, la habilidad para procesar información contextual es muy importante en la vida del individuo, ya que los errores pragmáticos pueden dar lugar a discriminaciones o a otros problemas sociales como los observados en pacientes con síndrome de Asperger o autismo (Landa, 2000). Los niños que 
padecen algún déficit pragmático a menudo tienen dificultades para entender el significado contextual, por lo que puede ser muy útil explicarles cuál es el significado pretendido y cómo acceder a él. Asimismo, también será beneficioso hacer comprender a estos niños que el conocimiento del mundo de otras personas a menudo no coindice con el propio, lo que ayudaría a su desarrollo de la teoría de la mente.

En cuanto al método de evaluación elegido para desarrollar esta investigación, somos conscientes de que al tratarse de un test cuantitativo con carácter categórico tiene una validez ciertamente limitada, ya que está restringido a una tarea específica. Además, asumimos que la estructura de entrevista utilizada podría condicionar las emisiones de los participantes. Tal como reconoce Gallardo Paúls (2002b), sería recomendable evaluar la pragmática mediante un sistema de turno más libre, o bien mediante la observación natural de conversaciones espontáneas. Sin embargo, este método también presenta dificultades como el tiempo necesario invertido en su realización y seguimiento, y la dificultad a la hora de controlar todas las variables que pueden influir en la actuación lingüística (Ervin-Tripp, 2000). Asimismo, la evaluación en contextos naturales ofrece menos oportunidades para observar determinados actos de habla, ya que el hecho de que el niño no los produzca cuando está siendo observado no significa que no formen parte de su repertorio (Prutting y Kirchner, 1987; Iacono et al., 1996). La evaluación pragmática más conveniente sería, por tanto, la que combinara la observación natural con las tareas conversacionales estructuradas de antemano y la interacción pautada (Bishop y Adams, 1989).

De igual manera, consideramos que uno de los puntos fuertes de este estudio es el uso de situaciones familiares para los niños, y de contextos accesibles y verosímiles establecidos de antemano para cada pregunta. Aunque estos no reflejan la dificultad propia de las interacciones naturales, se aproximan en gran medida a las situaciones comunicativas a las que los niños se enfrentan a diario tanto en la vida escolar como familiar. Además facilitan la categorización y el análisis de las respuestas, pues permiten observar si los niños han sobregeneralizado su conocimiento del mundo, si se han basado en supuestos que no guardan conexión con el contexto, en información ya existente, etc.

El segundo punto fuerte de esta investigación es que está basada en un soporte teórico ampliamente desarrollado: la teoría de la relevancia. Esta combina la reflexión 
teórica con posibilidades de comprobación empírica, en línea con los trabajos experimentales de la psicología cognitiva. Tal como advierten Leinonen y Kerbel (1999), la teoría de la relevancia explica, por ejemplo, por qué en un contexto dado una expresión concreta es problemática o la razón por la que se produce un determinado fallo en el procesamiento pragmático (escaso conocimiento del mundo, dificultades a la hora de acceder a la información relevante, dificultades en el proceso cognitivo de inferencia, dificultades para determinar lo que otra persona sabe, etc.).

Sperber y Wilson (1995) entienden la comunicación inferencial como un proceso incierto, ya que se asienta en la construcción, por parte del oyente, de suposiciones basadas en una serie de evidencias contextuales. A veces los niños no son capaces de sopesar la información disponible para construir premisas o para acceder a la información relevante, de forma que, inevitablemente, seleccionan una interpretación inapropiada. Esto implica que el niño puede tener problemas a la hora de valorar las habilidades cognitivas del hablante, lo cual se puede identificar también con la falta de desarrollo de teoría de la mente, tal como ha sido sugerido por numerosos estudios experimentales (Happé, 1993; Shields et al., 1996). No debe olvidarse que la teoría de la relevancia es una teoría cognitiva de la comunicación, que otorga gran importancia a la atribución de estados mentales entre los interlocutores, a la capacidad de inferir y a la de crear metarrepresentaciones. En efecto, el conocimiento metacognitivo (conocimiento de los propios procesos mentales) constituye un factor esencial para el desarrollo de la capacidad infantil para adquirir y utilizar de forma efectiva el lenguaje en las interacciones comunicativas, tal como hemos comprobado en el análisis de las explicaciones ofrecidas por los niños de nuestro estudio experimental.

En este trabajo hemos defendido la importancia de la perspectiva pragmática para el estudio del intercambio verbal en el habla infantil, a pesar de que, como advierte Fernández Pérez (2006), en la investigación no se han analizado aún, con la profundidad deseable, los rasgos de eficacia comunicativa propios de los niños. Será necesario, por tanto, un estudio de la adquisición de la lengua haciendo énfasis en las estrategias y recursos que los niños emplean para comunicarse.

Durante el proceso de adquisición del lenguaje, los niños deben desarrollar un conjunto de mecanismos cognitivos necesarios para la comunicación: un dispositivo 
lingüístico encargado de codificar y descodificar el mensaje, una habilidad pragmática que les proporcione las herramientas para inferir o deducir la intención comunicativa del hablante y elegir la interpretación adecuada (de todas la interpretaciones posibles), y un desarrollo de la teoría de la mente que sirva de puente entre el dispositivo lingüístico y el pragmático, al suministrar los instrumentos para seleccionar la información relevante de acuerdo con el contexto discursivo (Camacho Toboada, 2005). Por tanto, para que los niños sean comunicadores eficaces deben ser capaces de asignar estados o representaciones mentales a los demás interlocutores (Bara, Bosco y Buciarelli, 1999), así como de juzgar los hechos aplicando el propio conocimiento y experiencia que tienen de la realidad y del mundo que les rodea.

En futuras investigaciones sería conveniente diseñar nuevas pruebas de carácter cualitativo que incluyan tareas pragmáticas no solo de comprensión, sino también de producción, así como realizar trabajos centrados en el estudio de las explicaciones de los niños a sus primeras respuestas. Además, sería provechoso diseñar experimentos para niños con diferentes lenguas maternas y culturas para obtener así, con una muestra más amplia, un mayor aporte de información sobre el proceso de adquisición y desarrollo de la competencia pragmática.

Ahora bien, una de las ideas que hemos destacado a lo largo de este trabajo es que la competencia pragmática no se puede evaluar en términos de corrección o incorrección basándonos en referencias del tipo de las que proporciona la gramática. Ante un mismo estímulo, pueden surgir diversas respuestas que a su vez contengan significados implícitos y explícitos, y que sean todas válidas; por ello, la evaluación se torna necesariamente más compleja.

Finalmente, muchos estudios han defendido la conexión entre la habilidad para leer la mente y las habilidades pragmáticas (Happé, 1993; Baron-Cohen, 1995; Surian et al., 1996; Happé y Loth, 2002). Sería interesante, por tanto, estudiar con más profundidad la relación entre las funciones cognitivas, pragmáticas y sociales del lenguaje en el proceso de adquisición, y, especialmente, con relación a la ironía. 


\section{REFERENCIAS BIBLIOGRÁFICAS}

AARONS, M. y T. GITTEN 1992: The handbook of autism. London: Routledge.

ABE, J. A. y C. E. IZARD 1999: "The developmental function of emotions: An analysis in terms of differential emotions theory”, en Cognition and Emotion, 13, pp. 523549.

ACKERMAN, B. 1986: "Children's Sensitivity to Comprehension Failure in Interpreting a Non-literal Use of an Utterance”, en Child Development, 57, pp. 458-497.

ACUÑA, X. y F. SENTIS 2004: "Desarrollo pragmático en el habla infantil”, en Onomázein, 10, pp. 33-56.

ADAMS, C. 2001: "Clinical diagnostic and intervention studies of children with semanticpragmatic language disorder", en International Journal of Language Communication Disorders, 36 (3), pp. 289-305.

ADAMS, C. 2002: "Practitioner review: The assessment of language pragmatics", en Journal of Child Psychology and Psychiatry, 43 (8), pp. 973-987.

ADAMS, C., COOKE, R., CRUTCHLEY, A., HESKETH, A. y D. REEVES 2001: Assessment of comprehension and expression 6-11 (ACE 6-11). Windsor: NFERNelson.

ADAMS, C., GREEN, J., GILCHRIST, A. y A. COX 2002: "Conversational behavior of children with Asperger syndrome and conduct disorder", en Journal of Child Psychology and Psychiatry, 43, pp. 679-690.

AGUSTÍN LLACH, M. P. 2005: "La competencia pragmática y los errores pragmáticoléxicos en la clase de ELE”, en Actas del XV Congreso ASELE. Oviedo: Universidad de Oviedo, Servicio de Publicaciones, 2006, pp. 96-102.

ALCARAZ VARÓ, E. 1990: Tres paradigmas de investigación lingüística. Alcoy: Marfil.

ALCARAZ VARÓ, E. y M. A. MARTÍNEZ LINARES 1997: Diccionario de lingüística moderna. Barcelona: Ariel.

ALCÓN SOLER, E. 2005: "Does instruction work for learning pragmatics in the EFL context?”, en System, 33, pp. 417-435.

AL-MONAMI, R. y R. JÁIMEZ 2005: "La enseñanza de la competencia pragmática en cibercursos de ELE", en Actas del XV Congreso ASELE. Oviedo: Universidad de Oviedo, Servicio de Publicaciones, 2006, pp. 115-124.

ALONSO TAPIA, J. 1995: "La evaluación de la comprensión lectora", en Textos de Didáctica de la Lengua y la Literatura, 5, pp. 63-78. 
ALONSO TAPIA, J. 2005: “Claves para la enseñanza de la comprensión lectora”, en Revista de Educación, número extraordinario, [http://www.revistaeducacion.mes.es/re2005_06.htm] (último acceso: enero 2015).

ÁLVAREZ, G. 1995: “Competencia discursiva y textual del hablante nativo”, en RLA: Revista de Lingüística Teórica y Aplicada, 33, pp. 5-14.

ÁLVAREZ PIÑEIRO, M. 2005: “El componente pragmático en la evaluación”, en Actas del XV Congreso ASELE. Oviedo: Universidad de Oviedo, Servicio de Publicaciones, 2006, pp. 142-150.

ANDERSEN, E. 1990: "Acquiring communicative competence: knowledge of register variation”, en SCARCELLA, R. C., ANDERSEN, E. y S. D. KRASHEN (eds.) 1990: Developing Communicative Competence in a Second Language. New York: Newbury House, pp. 5-25.

ANDERSEN-WOOD, L. y B. R. SMITH 1997: Working with pragmatics. London: Winslow Press.

ANDERSON, M. 1983: “Prenominal genitive NP's”, en The Linguistic Review, 3, pp. 124.

APARECIDA DUARTE, C. y S. NASCIMIENTO CAMPOS 1999: "Pídeme lo que quieras, pero... dime ipor favor! Las dificultades pragmáticas de los aprendices brasileños en el uso del imperativo en español”, en Actas del X Congreso ASELE. Cádiz: Universidad de Cádiz, Servicio de Publicaciones, 2000, pp. 73-78.

AQUINO, C. 2011: "Pragmatic Competence: How can it be developed in the foreign language classroom?”, en BELT-Brazilian English Language Teaching Journal, 2 (2), pp. 140-153.

ARDILA, A. 2006: Las afasias, en [http://www.aphasia.org/libroespañol.php] (último acceso: diciembre 2014).

ARDILA, A. y M. ROSELLI 1990: “Conduction aphasia and verbal apraxia”, en Journal of Neurolinguistics, 5, pp. 1-14.

ASTINGTON, J. W. 1988: “Children's understanding of the speech act of promising”, en Journal of Child Language, 15 (1), pp. 157-173.

ASTINGTON, J. W. y J. M. JENKINS 1999: “A Longitudinal Study of the Relation between Language and Theory-of-Mind Development”, en Developmental Psychology, 53 (5), pp. 1311-1320.

ATTWOOD, T. 2009: Guía del síndrome de Asperger. Barcelona: Paidós.

AUSTIN, J. 1962: How to do things with words. London: Oxford University Press.

BACHMAN, L. 1990: “Communicative language ability", en BACHMAN, L. 1990: Fundamental consideration in language testing. Oxford: Oxford University Press, pp. 82-111.

BACHMAN, L. y A. S. PALMER 1996: Language Testing in Practice. Oxford: Oxford University Press. 
BADDELEY, A. D. 1996: “The concept of working memory”, en GATHERCOLE, S. E. (ed.) 1996: Models of Short-Term Memory. Hove, UK: Psychology Press, pp. 1-27.

BALDWIN, D. 1991: “Infants' contribution to the achievement of joint reference”, en Child Development, 62, pp. 875-890.

BALDWIN, D. 1993: “Infants' ability to consult the speaker for clues to word reference”, en Journal of Child Language, 20, pp. 395-418.

BARA, B. G., BOSCO, F. M. y M. BUCCIARELLI 1999: "Developmental pragmatics in normal and abnormal children”, en Brain and Language, 68, pp. 507-528.

BARALO OTTONELLO, M. 2005: “Competencia pragmática en el ámbito empresarial: qué y por qué, anteriores al cómo”, en Actas del XV Congreso ASELE. Oviedo: Universidad de Oviedo, Servicio de Publicaciones, 2006, pp. 169-177.

BARCELAR DA SILVA, A. J. 2003: "The effect of instruction on pragmatic development: Teaching polite refusal in English”, en Second Language Studies, 22 (1), pp. 55-106.

BARDOVI-HARLIG, K. 1996: "Pragmatics and language teaching: Bringing pragmatics and pedagogy together”, en BOUTON, L. F. y Y. KACHRU (eds.) 1996: Pragmatic and Language Learning. Urbana, IL: University of Illinois, Division of English as an International Language, pp. 21-39.

BARDOVI-HARLIG, K., HARTFORD, B. A. S., MAHAN-TAYLOR, R., MORGAN, M. J. y D. W. REYNOLDS 1991: "Developing pragmatic awareness: Closing the conversation”, en ELT Journal, 45, pp. 4-15.

BARDOVI-HARLIG, K. y Z. DÖRNYEI 1998: "Do language learners recognize pragmatic violations? Pragmatic versus grammatical awareness in instructed L2 learning”, en TESOL Quarterly, 32, pp. 223-262.

BARDOVI-HARLIG, K. y R. GRIFFIN 2005: "L2 pragmatic awareness: Evidence from the ESL classroom”, en System, 33, pp. 401-415.

BARON-COHEN, S. 1988: "Social and pragmatic deficits in autism: cognitive or affective?”, en Journal of Autism and Developmental Disorders, 18, pp. 379-401.

BARON-COHEN, S. 1995: Mindblindness: An Essay on Autism and Theory of Mind. Cambridge, MA: MIT Press.

BARON-COHEN, S., LESLIE, A. M. y U. FRITH 1986: "Mechanical, behavioral and intentional understanding of Picture stories in autistic children”, en British Journal of Developmental Psychology, 4, pp. 113-125.

BARROS GARCÍA, M. J. 2008: “Comunicación e interculturalidad: Análisis de usos (des)corteses en los medios de comunicación y su aplicación práctica”, en RedELE, 9, [http://www.educacion.es/redele/Biblioteca2008/MJesusBarros.shtml] (último acceso: enero 2015).

BARROSO, J. y A. NIETO 1996: “Asimetría cerebral: hemisferio derecho y lenguaje”, en Psicología Conductual, 4-3, pp. 285-305. 
BARTSCH, K. y H. M. WELLMAN 1995: Children Talk about the Mind. New York: Oxford University Press.

BARWISE, J. y J. PERRY 1983: Situations and Attitude. Cambridge, Mass: MIT Press.

BATES, E. 1976a: Language and context: Studies in the acquisition of pragmatics. New York: Academic Press.

BATES, E. 1976b: "Pragmatics and sociolinguistics in child language", en MOREHEAD, D. y A. MOREHEAD (eds.) 1976: Normal and deficient child language. Baltimore, MD: University Park Press, pp. 411-463.

BATES, E., CAMAIONI, L. y V. VOLTERRA 1975: “The acquisition of performatives prior to speech”, en Merrill-Palmer Quarterly, 21, pp. 205-226.

BATES, E., BENIGNI, L., BRETHERTON, L., CAMAIONI, L. y V. VOLTERRA (eds.) 1979: The emergence of symbols: Cognition and communication in infancy. New York: New York Academic Press.

BATES, E. y B. MACWHINNEY (eds.) 1989: The crosslinguistic study of sentence processing. New York: Cambridge University Press.

BATESON, G. 1972: Steps to an ecology of mind. New York: Balantine Books.

BECKER, J. A. 1990: "Processes in the acquisition of pragmatic competence", en CONTI-RAMSDEN, G. y C. E. SNOW (eds.) 1990: Children's Language. Volume 7. Hillsdale, NJ: Lawrence Erlbaum Associates, pp. 7-24.

BELINCHÓN, M. 1999: "Lenguaje no literal y aspectos pragmáticos de la comprensión”, en DE VEGA, M. y F. CUETOS (eds.) 1999: Psicolingüística del español. Madrid: Trotta, pp. 307-373.

BELINCHÓN, M., RIVIÈRE, A. y J. M. IGOA 1992: Psicología del lenguaje: investigación y teoría. Madrid: Trotta.

BELLUGI, U., MARKS, S., BIHRLE, A. y H. SABO 1988: "Dissociation between language and cognitive function in Williams Syndrome”, en BISHOP, D. y K. MOGFORD (eds.) 1988: Language Development in Exceptional Circumstances. Edimburg: Churchill Livingstone, pp. 177-189.

BELLUGI, U. y M. ST. GEORGE (eds.) 2001: Journey from cognition to brain to gene: Perspectives from William syndrome. Cambridge, MA: MIT Press.

BERBEIRA GARDÓN, J. L. 1994: "El contexto: su naturaleza y su papel en el proceso de interpretación de enunciados”, en Pragmalingüística, 2, pp. 9-35.

BERNICOT, J. 1992: Les actes de langage chez l'enfant. Paris: Pressers Universitaires de France.

BERNICOT, J., LACROIS, A. y J. REILLY 2003: "La narration chez les enfants attaint du syndrome de Williams: Aspects structuraux et pragmatiques”, en Enfance, 55 (3), pp. 265-281.

BERRENDONNER, A. 1987: Elementos de pragmática lingüística. Barcelona: Gedisa. 
BEVER, T. G. 1970: “The cognitive basis for linguistic structures”, en HAYES, J. R. (ed.) 1970: Cognition and the development of language. New York: Wiley, pp. 277-360.

BEZUIDENHOUT, A. y M. S. SRODA 1998: “Children's use of contextual cues to resolve referential ambiguity: An application of relevance theory”, en Pragmatics and Cognition, 6, pp. 265-299.

BIHRLE, A., BROWNELL, H. H., POWELSON, J. A. y H. GARDNER 1986: "Comprehension of humorous and non-humorous materials by left and right brain damaged patients”, en Brain Cognition, 5, pp. 399-411.

BIHRLE, A., BELLUGI, U., DELIS, D. y S. MARKS 1989: "Seeing either the forest or the trees: Dissociation in visuospatial processing”, en Brain and Cognition, 11, pp. 37-49.

BILLMYER, K. 1990: "I really like your lifestyle: ESL learners learning how to compliment”, en Penn Working Papers in Educational Linguistics, 6 (2), pp. 31-48.

BISHOP, D. V. M. 1992: “The underlying nature of specific language impairment”, en Journal of Child Psychology and Psychiatry, 33, pp. 2-66.

BISHOP, D. V. M. 1997: Uncommon Understanding: Development and Disorders of Language Comprehension in Children. Hove, Sussex: Psychology Press.

BISHOP, D. V. M. 1998: "Development of the Children's Communication Checklist (CCC): A method of assessment in children”, en Journal of Child Psychology and Psychiatry, 39, pp. 879-891.

BISHOP, D. V. M. 2000: "Pragmatic language impairment: A correlate of SLI, a distinct subgroup, or part of the continuum?”, en BISHOP, D. M. V. y L. B. LEONARD (eds.) 2000: Speech and Language Impairments in Children: Causes, Characteristics, Intervention and Outcome. Hove, UK: Psychology Press, pp. 99114.

BISHOP, D. V. M. y L. ROSENBLOOM 1987: "Classification of childhood language disorders”, en YULE, W. y M. RUTTER (eds.) 1987: Language Development and Disorders. Double issue $(101,102)$ of Clinics in Developmental Medicine. London: Mac Keith Press, pp. 16-41.

BISHOP, D. V. M. y C. ADAMS 1989: “Conversational characteristics of children with semantic-pragmatic disorder. II: What features lead to a judgement of innappropriacy?”, en British Journal of Disorders of Communication, 24, pp. 241263.

BISHOP, D. V. M. y C. ADAMS 1991: "What do referential communication tasks measure? A study of children with specific language impairment”, en Applied Psycholinguistics, 12, pp. 199-215.

BISHOP, D. V. M. y C. ADAMS 1992: “Comprehension problems in children with specific language impairment: Literal and inferential meaning”, en Journal of Speech and Hearing Research, 35, pp. 119-129.

BISHOP, D. V. M., CHAN, J., ADAMS, C., HARTLEY, J. y F. WEIR 2000: "Conversational responsiveness in specific language impairment: Evidence of 
disproportionate pragmatic difficulties in a subset of children”, en Development and Psychopathology, 12, pp. 177-199.

BISHOP, D .V. M. y C. F. NORBURY 2002: "Inferential processing and story recall in children with communication problems: a comparison of specific language impairment, pragmatic language impairment and high-functioning autism”, en International Journal of Language and Communication Disorders, 37 (3), pp. 227251.

BISHOP, D. V. M., MAYBERY, M., WONG, D., MALEY, A. y J. HALLMAYER 2006: "Characteristics of the broader phenotype in autism: a study of siblings using the children's communication checklist-2”, en American Journal of Medical Genetics. Part B, Neuropsychiatric Genetics, 141 (2), pp. 117-122.

BLAKE, J., QUARTARO, G. y S. ONORATI 1993: “Evaluating quantitative measures of grammatical complexity in spontaneous speech samples”, en Journal of Child Language, 20, pp. 139-152.

BLAKE, M. L. 2005: “Right Hemisphere Syndrome”, en LAPOINTE, L. L. (ed.) 2005: Aphasia and Related Neurogenic Language Disorders. New York: Thieme, pp. 213224.

BLAKE, M. L. 2009: "Inferencing processes after right hemisphere brain damage: Maintenance of inferences”, en Journal of Speech, Language and Hearing Research, 52, pp. 359-372.

BLAKEMORE, D. 1992: Understanding Utterances: An Introduction to Pragmatics. Oxford, UK: Blackwell.

BLANK, M. y M. MARQUIS 1992: Directing discourse. Arizona: Communication Skills Builders.

BLOCH-ROSEN, S. 1999: "Síndrome de Asperger, Autismo de Alto Funcionamiento y Desórdenes del Espectro Autista”, en [http://es.geocities.com/sindromede asperger/Informa/articulos/casa.html] (último acceso febrero 2015).

BLOOM, L. 1970: Language development: Form and Function in emerging grammar. Cambridge, MA: MIT Press.

BLOOM, L. 1991: Language Development from two to three. Cambridge: Cambridge University Press.

BLOOM, L. y J. J. GUMPERZ 1972: "Social meaning in linguistic structures: Codeswitching in Norway”, en GUMPERZ, J. J. y D. HYMES (eds.) 1972: Directions in sociolinguistics. The ethnography of communication. New York: Basil Blackwell, pp. 407-435.

BLOOM, P. 2000: How Children Learn the Meanings of Words. Cambridge, MA: MIT Press.

BLOOM, P. 2002: "Mindreading, communication and the learning of names for things", en Mind \& Language, 17, pp. 1-2. 
BLUM-KULKA, S. 1996: “Introducción a la pragmática del interlenguaje”, en CENOZ, J. y J. F. VALENCIA (eds.) 1996: La competencia pragmática: elementos lingüísticos y psicosociales. Bilbao: Universidad del País Vasco, pp. 195-224.

BLUM-KULKA, S., HOUSE, J. y G. KASPER 1989: Cross-Cultural Pragmatics: Requests and Apologies. Norwood, New Jersey: Ablex.

BOGDASHINA, O. 2005: Communication issues in autism and Asperger syndrome: do we speak the same language? Londres: Jessica Kingsley Publishers.

BORDÓN, T. 1993: "Evaluación y niveles de competencia comunicativa”, en MIQUEL, L. y N. SANS (coords.) 1993: Didáctica del español como lengua extranjera. Madrid: Colección Expolingua. Fundación Actilibre, D. L., pp. 37-60.

BOSCO CAMÓN, J. 2004: "La competencia intercultural y las interferencias lingüísticas en ELE”, en Frecuencia L, 25, pp. 32-35.

BOSCH, E. 1997: “Análisis de un texto persuasivo desde los principios de la pragmática y la retórica”, en Actas del VIII Congreso ASELE. Alcalá de Henares: Universidad de Alcalá de Henares, Servicio de Publicaciones, 1998, pp. 181-194.

BOSQUE, I. 1998: “La competencia gramatical”, en ACERO, J. J. (ed.) 1998: Filosofía del lenguaje I. Semántica. Madrid: Trotta, pp. 27-56.

BOSQUE, I. y J. GUTIÉRREZ-REXARCH 2009: Fundamentos de sintaxis formal. Madrid: Akal.

BOTTINI, G., CORCORAN, R., STERZI, R., PAULESU, E., SCHENONE, P., SCARPA, P., FRACOWIAK, R. S. y C. D. FRITH 1994: “The role of the right hemisphere in the interpretation of figure aspects of language”, en Brain, 117, pp. 1241-1253.

BOUCHER, J. y P. CARMTHERS 1998: Language and thought: interdisciplinary themes. Cambridge: Cambridge University Press.

BOUTON, L. F. 1988: “A cross-cultural study of ability to interpret implicatures in English”, en World Englishes, 17, pp. 183-196.

BOUTON, L. F. 1994: “Conversational implicature in the second language: Learned slowly when not deliberately taught”, en Journal of Pragmatics, 22, pp. 157-167.

BOUTON, L. F. 1996: "Pragmatics and language learning”, en BOUTON, L. y Y. KACHRU (eds.) 1996: Pragmatic and Language Learning. Urbana, IL: University of Illinois, Division of English as an International Language, pp. 1-20.

BOWER, T. G. R. 1984: El mundo perceptivo del niño. Madrid: Morata.

BOWER, T. G. R. 1989: The rational infant: Learning in infancy. New York: Freeman.

BOWERMAN, M. 1974: "Discussion summary-Development of concepts underlying language”, en SCHIEFELBUSCH, R. y L. LLOYD (eds.) 1974: Language perspectives-Acquisition, retardation, and intervention. Baltimore: University Park Press, pp. 191-210. 
BOWERS, L., HUISINGH, R., BARRET, M., ORMAN, J. y C. LOGUIDICE 1994: Test of problem solving-elementary (revised). East Moline, IL: Linguisystems.

BRAVO, D. y A. BRIZ 2004: Pragmática sociocultural: estudios sobre el discurso de cortesía en español. Barcelona: Ariel Lingüística.

BREEN, M. 1987: "Paradigmas contemporáneos en el diseño de programas de lenguas I”, en Signos. Teoría y práctica de la educación, 19, pp. 50-64.

BREVER, W. F. 1999: “Esquemas”, en WILSON, R. A. y F. C. KEIL (eds.) 1999: Enciclopedia MIT de ciencias cognitivas, vol. I. Madrid: Síntesis, pp. 491-493.

BRIGGS, C. L. 1984: "Learning how to ask: Native metacommunicative competence and incompetence of fieldworkers”, en Language and Society, 13, pp. 1-28.

BRINTON, B. y M. FUJIKI 1989: Conversational management with language-impaired children: Pragmatic assessment and intervention. Gaithersburg, MD: Aspen.

BRINTON, B., FUJIKI, M. y J. M. POWELL 1997: "The ability of children with language impairment to manipulate topic in a structured task”, en Language, Speech and Hearing Services in Schools, 28, pp. 3-11.

BRIZ, A. 1997: "Comentario lingüístico”, en ECHENIQUE, M. T., ALONSO, C., BRIZ, A., GÓMEZ MOLINA, J. R. y A. LÓPEZ-CASANOVA 1997: El análisis textual, comentario filológico, literario, lingüístico, sociolingüístico, crítico. Salamanca: Ediciones del Colegio de España, pp. 77-130.

BRIZ, A. y Grupo Val.Es.Co (eds.) 2002: Corpus de conversaciones coloquiales. Madrid: Arco Libros.

BRONCKART, J. P. 1977: Théories du langage. Une introduction critique. Bruxelles: Mardaga.

BRONCKART, J. P. y B. SCHNEUWLY 1996: "La didáctica de la lengua materna: el nacimiento de una utopía indispensable”, en Textos de Didáctica de la Lengua y la Literatura, 9, pp. 61-78.

BROWN, P. y S. LEVINSON 1978: "Universals in language usage: politeness phenomena”, en GOODY, E. (ed.) 1978: Questions and politeness: strategies in social interaction. Cambridge: Cambridge University Press, pp. 56-311.

BROWN, P. y S. LEVINSON 1987: Politeness: Some universals in language usage. Cambridge: Cambridge University Press.

BROWN, R. 1973: A first language: The early stages. Cambridge: Harvard University Press.

BROWN, R. y C. FRASER 1963: “The acquisition of syntax”, en COFER, C. y B. MUSGRAVE (eds.) 1963: Verbal behavior and learning: Problems and processes. New York: McGraw-Hill, pp. 31-44.

BROWNELL, H., POTTER, H., MICHELOW, D. y H. GARDNER 1984: “Sensitivity to lexical denotation and connotation in brain-damaged patients", en Brain and Language, 22, pp. 253-265. 
BRUNER, J. S. 1983: Child's talk. Learning to use language. New York: Norton.

BRUNER, J. S. 1984: “La intención en la estructura de la acción y de la interacción”, en LINAZA, J. (ed.) 1984: Acción, pensamiento y lenguaje. Madrid: Alianza, pp. 101115.

BUCCIARELLI, M., COLLE, L. y B. G. BARA 2003: "How children comprehend speech acts and communicative gestures”, en Journal of Pragmatics, 35, pp. 207-241.

BUCKLEY, B. 2003: Children's Communication Skills: From Birth to Five Years. London: Routledge.

BULNES JIMÉNEZ, J. M. 1993: Materiales Didácticos. Lengua Castellana y Literatura. Madrid: Ministerio de Educación y Ciencia.

BURTON-ROBERTS, N. 1984: "Modality and Implicature", en Linguistics and Philosophy, 7, pp. 181-206.

CABALLERO DÍAZ, C. 2005: "Pragmática e interculturalidad en la enseñanza del español como lengua extranjera. Las estrategias de cortesía en los manuales de ELE”, en RedELE, 4, [http://www.mepsyd.es/redele/biblioteca2005/caballerodiaz.shtml] (último acceso: diciembre 2014)

CAIN, K., OAKHILL, J. V., BARNES, M. A. y P. E. BRYANT 2001: “Comprehension skill, inference-making ability, and their relation to knowledge”, en Memory and Cognition, 29 (6), pp. 850-859.

CALSAMIGLIA, H., COTS, J. M., LORDA, C. U., NUSSBAUM, L., PAYRATÓ, L. y A. TUSÓN [Cercle d'Anàlisi del Discurs, C.A.D.] 1997: La parla com a espectacle. Estudi d'un debat televisiu. Bellaterra: Publicaciones de la Universidad Autónoma de Barcelona.

CAMACHO TABOADA, V. 2005: “Mentiras, relevancia y teoría de la mente”, en Pragmalingüística, 13, pp. 51-64.

CAMAIONI, L. y C. LAICARDI 1985: "Early social games and the acquisition of language”, en British Journal of Developmental Psychology, 3, pp. 31-39.

CAMPBELL, R. y R. WALES 1970: “The study of language acquisition”, en LYONS, J. (ed.) 1970: New Horizons in Linguistics. Harmondsworth: Penguin, pp. 242-260.

CAMPS, A. 2000: “Motivos para escribir”, en Textos de Didáctica de la Lengua y la Literatura, 23, pp. 69-78.

CANALE, M. 1983: "From communicative competence to communicative language pedagogy”, en RICHARDS, J. C. y R. W. SCHIMDT 1983: Language and communication. Harlow: Longman. ["De la competencia comunicativa a la pedagogía comunicativa del lenguaje”, en LLOBERA, M. (ed.) 1995: Competencia comunicativa. Documentos básicos en la enseñanza de lenguas extranjeras. Madrid: Edelsa, pp. 63-83].

CANALE, M. y M. SWAIN 1980: "Theoretical bases of communicative approaches to second language teaching and testing”, en Applied linguistics, 1, pp. 1-47. 
[“Fundamentos teóricos de los enfoques comunicativos”, en Revista Signos. Teoría y práctica de la educación, 17 (pp. 54-62) y 18 (pp. 78-89), 1996].

CAPELLI, C., NAKAGAWA, N. y C. MADDEN 1990: "How children understand sarcasm: the role of context and intonation”, en Child Development, 61, pp. 18241841.

CAPLAN, D. 1987: Neurolinguistics and linguistic aphasiology: An introduction. New York: Cambridge University Press.

CARDEBAT, D. 1999: “Cognitive Neuroanatomy of Language”, en ARGENTER, J. A. (ed.) 1999: Language, Brain and Behavior. Neurobiological Aspects of Linguistic Capacities and Language Processing. Barcelona: Instituts d'Estudis Catalans, pp. 25-34.

CARRELL, P. 1981: “Children's understanding of indirect request: Comparing child and adult comprehension”, en Journal of Child Language, 8, pp. 329-345.

CARSTON, R. 1988: "Implicature, explicature and truth-theoretic semantics", en KEMPSON, R. M. (ed.) 1988: Mental representation. Cambridge: Cambridge University Press, pp. 155-181.

CARSTON, R. 2002: Thoughts and Utterances. The pragmatics of explicit communication. Oxford: Blackwell.

CASSANY, D., LUNA, M. y G. SANZ 2002: Enseñar lengua. Barcelona: Grao.

CASTELlÀ, J. M. 1992: De la frase al text. Teories de l'ús lingüístic. Barcelona: Empúries.

CASTELLÀ, J. M. 1994a: “¿Qué gramática para la escuela? Sobre árboles, gramáticas y otras formas de andarse por las ramas”, en Textos de Didáctica de la Lengua y la Literatura, 4, pp. 15-23.

CASTELLÀ, J. M. 1994b: “Les tipologies textuals”, en CUENCA, M. J. (ed.) 1994: Lingüística i ensenyament de llengües. Valencia: Universidad de Valencia, pp. 109124.

CASTRO, A. 1922: “La enseñanza del español en España”, reeditado en 1987, en Cauce, 3, Universidad de Sevilla, pp. 209-237.

CELCE-MURCIA, M., DÖRNYEI, Z. y S. THURRELL 1995: “A pedagogically motivated model with content specifications”, en Issues in Applied Linguistics, 6, pp. 5-35.

CELCE-MURCIA, M. y E. OLSHTAIN 2000: Discourse and Context in Language Teaching. Cambridge: Cambridge University Press.

CENOZ, J. 1996: “La competencia comunicativa: su origen y componentes”, en CENOZ, J. y J. VALENCIA (eds.) 1996: La competencia pragmática: elementos lingüísticos y psicosociales. Bilbao: Universidad de País Vasco, pp. 95-114.

CENOZ, J. 2004: "El concepto de competencia comunicativa”, en SANCHEZ LOBATO, J. e I. SANTOS (dirs.) 2004: Vademécum para la formación de profesores. Enseñar 
español como segunda lengua (L2) / lengua extranjera (LE). Madrid: SGEL, pp. 449-466.

CENOZ, J. y J. VALENCIA (eds.) 1996: La competencia pragmática: elementos lingüísticos y psicosociales. Bilbao: Universidad del País Vasco.

CHAMPAGNE-LAVAU, M. y Y. JOANETTE 2009: "Pragmatics, theory of mind and executive functions after a right-hemisphere lesion: Different patterns of deficits”, en Journal of Neurolinguistics, 22 (5), pp. 413-426.

CHANDLER, M., FRITZ, A. S. y S. HALA 1989: "Small scale deceit: Deception as a marker of two, three and four-years old's early theories of mind", en Child Development, 60, pp. 1263-1277.

CHANTRAINE, Y., JOANETTE, Y. y B. SKA 1998: “Conversational abilities in patients with right hemisphere damage”, en PARADIS, M. (ed.) 1998: Pragmatics in neurogenic communication disorders. Tarryrown, NY: Pergamon Press, pp. 21-32.

CHARNEY, R. 1979: Speech roles and the development of personal pronouns. Chicago: University of Chicago Press.

CHAUDRON, C. 1988: Second language classrooms. Cambridge: Cambridge University Press.

CHERRY, E. 1957: On Human Communication. Cambridge, MA: MIT Press.

CHERRY-WILKINSON, L. y C. DOLLAGHAN 1979: "Peer communication in first grade reading groups”, en Theory Into Practice, 18, pp. 267-274.

CHOMSKY, N. 1957: Syntactic Structures. The Hague: Mouton.

CHOMSKY, N. 1959: “A review of B. F. Skinner Verbal Behavior”, en Language, 35, pp. 26-58.

CHOMSKY, N. 1965: Aspects of the Theory of Syntax. Cambridge, Massachusetts: The M.I.T. Press.

CHOMSKY, N. 1975: "Questions of Form and Interpretation”, en Linguistic Analysis, 1, pp. 75-109.

CHOMSKY, N. 1980: Rules and Representations. Oxford: Basil Blackwell.

CIFUENTES, J. L. 1989: Lengua y espacio. Introducción al problema de la deixis en español. Alicante: Universidad de Alicante.

CLARK, E. V. 2003: First Language Acquisition. Cambridge: Cambridge University Press.

CLARK, H. H. 1996: Using language. Cambridge: Cambridge University Press.

CLARK, H. H. y W. CHASE 1972: "On the process of comparing sentences against pictures”, en Cognitive Psychology, 3, pp. 472-517.

CLARK, H. H. y R. GERRIG 1984: "On the pretense theory of irony”, en Journal of Experimental Psychology: General, 113, pp. 121-126. 
CLEMENTE, R. A. 1989: "Medida del desarrollo morfosintáctico. Los problemas de la medición y utilización de la LME”, en Anuario de Psicología, 42, pp.103-115.

CLEMENTE, R. A. 1995: El desarrollo del lenguaje. Barcelona: Octaedro.

CLEMENTE, R. A. y C. BLASI 1996: Contextos de desarrollo psicológico y educación. Málaga: Aljibe.

CLYNE, M. 1977: "Intercultural communication breakdown and communication conflict: Towards a Linguistic Model and its exemplification”, en MOLONY, C., ZOBL, H. y W. STÖLTING (eds.) 1977: Deutsch im Kontakt mit anderen Sprachen/German in Contact with Other Languages. Kronberg: Scriptor-Verlag, pp. 129-146.

CODINA, V., FORTANET, I. y J. L. OTAL (eds.) 1996: Estudios de lingüística aplicada. Castellón de la Plana: Publicaciones de la Universidad Jaume I.

COHEN, G. 1989: Memory in Real World. Hove, UK: Lawrence Erlbaum Associates.

COLOMBO, J. 2001: “The development of visual attention”, en Annual Review of Psychology, 52, pp. 337-367.

CONSEJO DE EUROPA 2002: Marco común europeo de referencia para las lenguas: aprendizaje, enseñanza y evaluación. Madrid: Instituto de Cervantes- Ministerio de Educación, Cultura y Deporte.

CONTI-RAMSDEN, G. 2000: "The relevance of recent research on SLI to our understanding of normal language development”, en PERKINS, M. y S. HOWARD (eds.) 2000: New directions in language development and disorders. New York: Kluwer/Plenum, pp. 7-12.

CONTI-RAMSDEN, G. y M. MCTEAR 1989: “Assessment of Pragmatics”, en GRUNDY, K. 1989: Linguistics in Clinical Practice. London: Whurr Publ., pp. 206233.

CONTI-RAMSDEN, G., CRUTCHLEY, A. y N. BOTTING 1997: "The extent to which psychometric test differentiate subgroups of children with SLI”, en Journal of Speech, Language and Hearing Research, 40, pp. 765-777.

CONTI-RAMSDEN, G., BOTTING, N. y B. FARAGHER 2001: "Psycholinguistic markers for specific language impairment (SLI)", en Journal of Child Psychology and Psychiatry, 42, pp. 741-748.

COOK, V. 1992: “Evidence for multi-competence”, en Language Learning, 42, pp. 557591.

COOK, V. 1993: Linguistics and Second Language Acquisition. Londres: MacMillan.

COOK, V. 1995: "Multi-competence and the learning and many languages”, en Language, Culture and Curriculum, 8, pp. 93-98.

CORDER, S. P. 1981: Error Analysis and Interlanguage. Oxford: Oxford University Press. 
CORDER, S. P. 1983: “Strategies in Interlanguage Communication”, en FAERCH, C. y G. KASPER (eds.) 1983: Strategies in Interlanguage Communication. London: Longman, pp. 15-19.

COSERIU, E. 1967: “Determinación y entorno”, en COSERIU, E. 1967: Teoría del lenguaje y lingüística general. Madrid: Gredos, pp. 282-323.

COSERIU, E. 1988: Competencia lingüística: elementos de la teoría del hablar. Madrid: Gredos, 1992.

COTS, J. M., NUSSBAUM, L., PAYRATÓ, LL. y A. TUSÓN 1990: “Conversa(r)”, en Caplletra (Volum monogràfic sobre Anàlisi del Discurs), 7, pp. 51-72.

CRESPO, N., BENÍTEZ, R. y P. CÁCERAS 2007: “La compresión de las ironías orales”, en Estudios Filológicos, 42, pp. 79-94.

CREUSERE, M. 1999: "Theories of Adults. Understanding and Use of Irony and Sarcasm: Applications to and Evidence from Research with Children”, en Developmental Review, 19, pp. 213-262.

CROCKFORD, C. y R. LESSER 1994: “Assessing functional communication in aphasia: clinical utility and time demands of three methods", en European Journal of disorders of communication, 29, pp. 165-182.

CROWDER, R. G. 1982: Psicología de la lectura. Madrid: Alianza.

CUETOS VEGA, F. 1998: Evaluación y rehabilitación de las afasias. Aproximación cognitiva. Madrid: Editorial Médica Panamericana.

CUMMINGS, L. 2005: Pragmatics: a multidisciplinary perspective. Edinburg: Edinburg University Press.

CUMMINGS, L. (ed.) 2009a: The Pragmatics Encyclopedia. London: Routledge.

CUMMINGS, L. 2009b: Clinical Pragmatics. Cambridge: Cambridge University Press.

D’ODORICO, L. y F. FRANCO 1985: "The determinants in baby talk: Relationship to context”, in Journal of Child Language, 12, pp. 567-586.

DE LA IGLESIA, M. y J. OLIVAR 2008: Autismo y síndrome de Asperger: trastornos del espectro autista de alto funcionamiento. Guía para educadores y familias. Madrid: Cepe.

DELIS, D. C. y A. M. BIHRLE 1989: "Fraccionamiento de la cognición espacial como consecuencia del daño cerebral focal y difuso", en OSTROSKY-SOLIS, F. y A. ARDILA (eds.) 1989: Cerebro y lenguaje. Perspectivas en la organización cerebral del lenguaje y de los procesos cognoscitivos. México: Trillas, pp. 32-52.

DEMONTE, V. 1987: “El castellano: grandote, rico, pero enfermo”, en Cambio16, 832.

DENNIS, M., LAZENBY, A. L. y L. LOCKYER 2001: “Inferential language in highfunction children with autism", en Journal of Autism and Developmental Disorders, 31, pp. 47-54. 
DENNIS, M., PURVIS, K., BARNES, M., WILKINSON, M. y E. WINNER 2001: "Understanding of Literal Truth, Ironic Criticism, and Deceptive Praise Following Childhood Head Injury”, en Brain and Language, 78, pp. 1-16.

DÉPREZ, V. y A. PIERCE 1993: "Negation and Functional Projections in Early Grammar”, en Linguistic Inquiry, 24, pp. 25-67.

DEWART, H. y S. SUMMERS 1988: The Pragmatics Profile of Early Communication Skills. Windsor, UK: NFER-Nelson.

DEWART, H. y S. SUMMERS 1995: The Pragmatics Profile of Everyday Communication Skills in Children. Windsor, UK: NFER-Nelson.

DIK, S. C. 1989: The Theory of Functional Grammar. Dordrecht: Foris.

DIPPER, L. T., BRYAN, K. L. y J. TYSON 1997: "Bridging inference and relevance theory: An account of right hemisphere inference”, en Clinical Linguistics and Phonetics, 11 (3), pp. 213-28.

DOBBINSON, S., PERKINS, M. R. y J. BOUCHER 1998: "Structural patterns in conversations with a woman who has autism", en Journal of Communication Disorders, 31, pp. 113-134.

DONALDSON, M. 1992: Human Minds: An Exploration. London: Allen Lane.

DORE, J. 1974: “A pragmatic description of early language development”, en Journal of Psycholinguistic Research, 4, pp. 343-350.

DORE, J. 1975: “Holophrases, speech acts and language universals”, en Journal of Child Language, 2 (1), pp. 21-40.

DORE, J. 1978: “Conditions for the acquisition of speech acts”, en MARKOVA, I. (ed.) 1978: The social context of language. Chichester, England: Wiley, pp. 87-111.

DORE, J. y R. P. MCDERMOTT 1982: "Linguistic indeterminacy and social context in utterance interpretation”, en Language, 58, pp. 374-398.

DROMI, E. 1987: Early lexical development. New York: Cambridge University Press.

DROMI, E. y R. BERMAN 1982: “A morphemic measure of early language development from Modern Hebrew”, en Journal of Child Language, 9, pp. 403-424.

DROSTE, F. y J. E. JOSEPH (eds.) 1991: Linguistic Theory and Grammatical Descriptions. Amsterdam: John Benjamins.

DU BOIS, J. W. 1991: “Transcription design principles for spoken discourse research”, en Pragmatics, 1(1), pp. 71-103.

DUCROT, O. 1984: El decir y lo dicho. Barcelona: Paidós, 1986.

DUNN, K. y C. KENDRICK 1982: "The speech of two and three year olds to infant siblings: Baby talk and the context of communication”, en Journal of Child Language, 9, pp. 579-595. 
DURANTI, A. y C. GOODWIN 1992: Rethinking context: language as an interactive phenomenon. Cambridge: Cambridge University Press.

EDWARDS, J. 1994: Multilingualism. Londres: Routledge.

EGUREN, L. 1999: “Pronombres y adverbios demostrativos. Las relaciones deícticas”, en BOSQUE, I. y V. DEMONTE (eds.) 1999: Gramática descriptiva de la lengua española I. Madrid: Espasa-Calpe, pp. 929-972.

EGUREN, L. y O. FERNÁNDEZ SORIANO 2004: Introducción a una sintaxis minimista. Madrid: Gredos.

EISBACH, A. O. 2004: “Children's developing awareness of diversity in people's trains and thought”, en Child Development, 75, pp. 1694-1707.

ELIZONDO AZAGRA, M. 2008: "La comparación cultural. Una propuesta para el desarrollo de destrezas interculturales en el aula de español LE/L2”, en RedELE, 10, [http://www.educacion.es/redele/Biblioteca2009/ManuelElizondo/Memoria.pdf] (último acceso: febrero 2015)

ELLIS, R. 2004: Task-based Language Learning and Teaching. Oxford: Oxford University Press.

EMLER, N., OHANA, J. y J. DICKINSON 1990: “Children's representation of social relations”, en DUVEEN, G. y B. LLOYD (eds.) 1990: Social representations and the development of knowledge. Cambridge: Cambridge University Press, pp. 47-69.

EQUIPO PRISMA 2007a: Prisma: comienza nivel A1: método de español para extranjeros. Madrid: Edinumen, D. L.

EQUIPO PRISMA 2007b: Prisma: progresa nivel B1: método de español para extranjeros. Madrid: Edinumen, D. L.

ERVIN-TRIPP, S. M. 1977: "From conversation to syntax", en Papers and Reports in Child Language Development, 13, pp. 11-21.

ERVIN-TRIPP, S. M. 1979: “Children's verbal turn-taking”, en OCHS, E. y B. SCHEFFLIN (eds.) 1979: Developmental pragmatics. New York: Academic Press, pp. 391-414.

ERVIN-TRIPP, S. M. 1996: “Context in language”, en SLOBIN, D. I., GERHARDT, J., KYRATZIS, A. y J. GUO (eds.) 1996: Social Interaction, Social Context, and Language. Mahwah, NJ: Lawrence Erlbaum Associates, pp. 21-36.

ERVIN-TRIPP, S. M. 2000: “Studying conversation: How to get natural peer interaction”, en MENN, L. y N. B. RATNER (eds.) 2000: Methods for studying language production. Mahwah, NJ: Lawrance Erlbaum, pp. 271-288.

ESCANDELL VIDAL, M. V. 1996: "Los fenómenos de interferencia pragmática”, en Didáctica del español como lengua extranjera. Cuadernos del Tiempo Libre, 3. Colección Expolingua, pp. 95-109. 
ESCANDELL VIDAL, M. V. 1998: “Cortesía y Relevancia”, en HAVERKATE, H., MULDER, G. y C. FRAILE MALDONADO (eds.) 1998: La Pragmática lingüística del español: Recientes desarrollos. Amsterdam: Ropodi, pp. 131-146.

ESCANDELL VIDAL, M. V. 2004a: “Competencia comunicativa, arquitectura cognitiva y disciplinas lingüísticas”, en [http://www.uned.es/dpto-leng-esp-y-linggral/escandell/papers/Competencia,\%20arquitectura\%20y\%20disciplinas.pdf] (último acceso: febrero 2015).

ESCANDELL VIDAL, M. V. 2004b: “Aportaciones de la pragmática”, en SÁNCHEZ LOBATO, J. e I. SANTOS GARGALLO (dirs.) 2004: Vademécum para la formación de profesores. Enseñar español como segunda lengua (L2) / lengua extranjera (LE). Madrid: SGEL, pp. 179-197.

ESCANDELL VIDAL, M. V. 2005: La comunicación. Madrid: Gredos.

ESCANDELL VIDAL, M. V. 2006: Introducción a la pragmática (2 ${ }^{a}$ edición actualizada). Barcelona: Ariel.

ESLAMI-RASEKH, Z., ESLAMI-RASEKH, A. y A. FATAHI 2004: "The Effect of Explicit Metapragmatic Instruction on the Speech Act Awareness of Advanced EFL Students”, en Teaching English as a Second or Foreign Languag, 8 (2), pp. 1-12.

ESON, M. E. y A. S. SAPIRO 1982: “When 'don't' means ‘do': pragmatic and cognitive development in understanding an indirect imperative”, en First Language, 3, pp. 8391.

EURYDICE 2002: Las competencias clave. Un concepto en expansión dentro de la educación obligatoria. Madrid: Ministerio de Educación, Cultura y Deporte.

FAERCH, C. y G. KASPER (eds.) 1983: Strategies in Interlanguage Communication. London: Longman.

FARHADY, J. 1980: Justification, Development and Validation of Functional Language Test. PhD dissertation. Los Angeles: University of California.

FARMER, M. y A. OLIVER 2005: “Assessment of pragmatic difficulties and socioemotional adjustment in practice”, en International Journal of Language and Communication Disorders, 40 (4), pp. 403-429.

FEIDER, H. y M. SAINT-PIERRE 1987: "Étude psycholinguistique des capacités pragmatiques du langage chez les enfants de 5 et 6 ans”, en Revue Québequoise de Linguistique, 16, pp. 163-187.

FELSON, J. 1995: Supporting Language Learning in Everyday Life. San Diego: Singular Publishing Group, Inc.

FERNÁNDEZ CINTO, J. 1991: Actos de habla de la lengua española. Repertorio. Madrid: Edelsa.

FERNÁNDEZ PÉREZ, M. 1999: “El lingüista y las patologías del lenguaje”, en FERNÁNDEZ GONZÁLEZ, J., FERNÁNDEZ JUNCAL, C., MARCOS SÁNCHEZ, M., PRIETO DE LOS MOZOS, E. y L. SANTOS RÍO (eds.) 1999: 
Lingüística para el siglo XXI. Actas del III Congreso de Lingüística General. Vol. 1. Salamanca, pp. 633-639.

FERNÁNDEZ PÉREZ, M. 2000: "El enfoque pragmático en el diseño y proyección de pruebas de evaluación lingüística en edad infantil”, en Pragmalingüística, 8-9, pp. 113-122.

FERNÁNDEZ PÉREZ, M. 2001: "El enfoque pragmático en el diseño y proyección de pruebas de evaluación lingüística en edad infantil”, en DE LA CRUZ, I., SANTAMARÍA, C., TEJEDOR, C. y C. VALERO (eds.) 2001: La lingüística aplicada a finales del siglo XX. Ensayos y propuestas. Alcalá de Henares: Servicio de Publicaciones de la Universidad de Alcalá, pp. 649-654.

FERNÁNDEZ PÉREZ, M. 2006: “Lingüística clínica y lenguaje infantil”, en VILLAYANDRE LLAMAZARES, M. 2006: Actas del Simposio Internacional de la Sociedad Española de Lingüística. León: Universidad de León, pp. 586-601.

FERNÁNDEZ PÉREZ, M. 2011: “El corpus koiné de habla infantil. Líneas maestras”, en FERNÁNDEZ PÉREZ, M. (coord.) 2011: Lingüística de corpus y adquisición de la lengua. Madrid: Arco Libros, pp. 11-36.

FERNÁNDEZ SILVA, C. 2002: “La programación de cursos y el desarrollo de la competencia pragmática”, en IX Encuentro Práctico de Profesores ELE, Barcelona. [www.encuentro-practico.com/pdf/cfernandez2.pdf] (último acceso: enero 2015).

FERNÁNDEZ VALLEJO, J. 1998: “Teoría pragmática y análisis lingüístico en secundaria”, en CAUCE, Revista de Filología y su Didáctica, 20-21, pp. 557-591.

FERRIER, S. DUNHAM, P. y F. DUNHAM 2000: “The confused robot: Two robot: Two year olds' responses to break-down in conversation”, en Social Development, 9, pp. 337-347.

FEUILLET, J. 2006: Introduction à la typologie linguistique. Paris: Honoré Champion.

FEY, M. E. 1986: Language intervention with young children. Boston: College Hill.

FIDALGO, S., GARCÍA DOMÍNGUEZ, E., LOMAS, C., MARTÍNEZ, J. A. y A. OSORO 1990: “Apuntes para una lectura crítica del DCB de Lengua y Literatura”, en CEPs de Asturias, 4, pp. 33-40.

FILLMORE, C. J. 1977: “Scenes-and-frames semantics: Linguistic structures processing”, en ZAMPOLLI, A. (ed.) 1997: Fundamental Studies in Computer Science. Amsterdam: North Holland, pp. 55-81.

FLAVELL, J. H. 2004: “Theory-of-mind development: Retrospect and prospect”, en Merrill-Palmer Quarterly, 50, pp. 274-290.

FLAVELL, J. H., BOTKIN, P. T., FRY, C. L., WRIGHT, J. W. y P. E. JARVIS 1968: The development of role taking and communication skills in children. New York: Wiley.

FLAVELL, J. H. y P. H. MILLER 1998: “Social cognition”, en DAMON, W., KUHN, D. y R. S. SIEGLER (eds.) 1998: Handbook of child psychology: Vol.2. Cognition, perception, and language. New York: Wiley, pp. 851-989. 
FLAVELL, J. H., GREEN, F. L. y E. R. FLAVELL 2000: “Development of children's awareness of their own thoughts”, en Journal of Cognition and Development, 1, pp. 97-112.

FLAVELL, J. H., FLAVELL, E. R. y F. L. GREEN 2001: “Development of children’s Understanding of Connections between Thinking and Feeling”, en Psychological Science, 12 (5), pp. 430-432.

FODOR, J. 1983: The Modularity of Mind. Cambridge, MA: MIT Press.

FORRESTER, M. D. 1996: Psychology of language, A critical introduction. Londres: SAGE Publications.

FOSTER-COHEN, S. 2000: "Relevance theory and language acquisition: a productive paradigm shift?”, en Child Language Bulletin, 20, pp. 5-8.

FOSTER-COHEN, S. 2004: "Relevance theory, action theory and second language communication strategies”, en Second Language Research, 20, pp. 289-302.

FRANCESCATO, G. 1986: El lenguaje infantil: estructuración y aprendizaje. Barcelona: Peninsula, D. L.

FRANCK, D. 1981: "Seven Sins of Pragmatics: Thesis about Speech Act Theory, Conversational Analysis, Linguistics, and Rhetoric”, en PARRET, H., SBISÀ, M. y J. VERSCHUEREN (eds.) 1981: Possibilities and Limitations of Pragmatics. Amsterdam: John Benjamins, pp. 225-236.

FRANCH, B. y C. G. SIGNES 1999: "Pragmática intercultural: Emisiones del oyente en inglés británico y español peninsular”, en SÁNCHEZ MACARRO, A. 1999: Pragmática intercultural. Valencia: Universidad de Valencia, pp. 123-134.

FRASER, B. 2010: "Pragmatic competence: the case of hedging”, en KALTENBÖCK, G., MILHATSCH, W. y S. SCHNEIDER (eds.) 2010: New approaches to Hedging. Bingley: Emerald, pp. 15-34.

FREIRE, S., LLORENTE, M., GONZÁLEZ, A., MARTOS, J., MARTÍNEZ, C., AYUDA, R. y J. ARTIGAS 2004: Un acercamiento al síndrome de Asperger: una guía teórica práctica. España: Editorial Asperger.

FRIES, C. C. 1945: Teaching and Learning English as a Foreign Language. Ann Arbor, Michigan: University of Michigan Press.

FRITH, U. 1989: Autism: Explaining the enigma. Oxford, UK: Blackwell.

FRITH, U. 1991: Autism and Asperger's Syndrome. Cambridge: Cambridge University Press.

FRITH, U., MORTON, J. y A. M. LESLIE 1991: “The cognitive basis of a biological disorder: Autism”, en Trends in Neuroscience, 14, pp. 433-438.

GALEOTE MORENO, M. A. 2002: Adquisición del lenguaje: problemas, investigación y perspectivas. Madrid: Pirámide D.L. 
GALINDO MERINO, M. M. 2005: "La transferencia pragmática en el aprendizaje de ELE”, en Actas del XV Congreso ASELE. Oviedo: Universidad de Oviedo, Servicio de Publicaciones, 2006, pp. 289-298.

GALLAGHER, T. 1977: "Revision behaviours in the speech of normal children developing language”, en Journal of Speech and Hearing Research, 20, pp. 303-318.

GALLARDO PAÚLS, B. 1996: Análisis conversacional y pragmática del receptor. Valencia: Episteme.

GALLARDO PAÚLS, B. 2002a: “La investigación de los déficits pragmáticos”, en LUQUE, J. de D., PAMIES, A. y F. MANJÓN (eds.) 2002: Nuevas tendencias en la investigación lingüística. Granada: Método, pp. 525-538.

GALLARDO PAÚLS, B. 2002b: "Fronteras disciplinarias: pragmática y patología del lenguaje”, en HERNÁNDEZ SACRISTÁN, C. y E. SERRA ALEGRE (coords.) 2002: Estudios de lingüística clínica. Valencia: Nau Llibres, pp. 129-174.

GALLARDO PAÚLS, B. 2006: "Más allá de las palabras y la estructura: las categorías del componente pragmático”, en GARAYZÁBAL, E. (ed.) 2006: Lingüística clínica y logopedia. Madrid: A. Machado Libros, pp. 81-196.

GALLARDO PAÚlS, B. 2007: Pragmática para logopedas. Cádiz: Servicio de Publicaciones de la Universidad de Cádiz.

GALLARDO PAÚLS, B. y V. MORENO CAMPOS 2006: "Evolución de la pragmática en un caso de afasia de Broca severa”, en Revista de Logopedia, Foniatría y Audiología, 26 (4), pp. 188-203.

GARAYZÁBAL, E. 2004: "Lesionados del hemisferio derecho y dificultades de aprendizaje no verbal: similitudes lingüísticas”, en GALLARDO PAÚLS, B. y M. VEYAT (eds.) 2004: Estudios de lingüística clínica. Lingüística y patología. Valencia: Universitat AVaLCC, pp. 115-158.

GARAYZÁBAL, E. 2005: Síndrome de Williams. Materiales para su estudio. Valencia: Universitat AVaLCC.

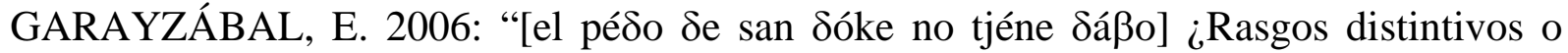
dislalia? La Lingüística y la Logopedia: fronteras disciplinarias y disciplinas complementarias”, en GARAYZÁBAL, E. (ed.) 2006: Lingüística Clínica y Logopedia. Madrid: A. Machado Libros S.A., pp. 21-80.

GARCÍA MATA, J. 2005: “Transferabilidad de la competencia pragmática. Implicaciones derivadas de la enseñanza de español como segunda lengua (E/SL) a niños inmigrantes”, en Actas del XV Congreso ASELE. Oviedo: Universidad de Oviedo, Servicio de Publicaciones, 2006, pp. 298-308.

GARCÍA MURGA, F. 1998: Las presuposiciones lingüísticas. Bilbao: Universidad del País Vasco.

GARFIELD, J. L., PETERSON C. y T. PERRY 2001: “Social Cognition, Language Acquisition and The Development of the Theory of Mind", en Mind and Language, 16, pp. 494-541. 
GARRIDO MEDINA, J. 1990: "Semántica flexible: límites de una teoría semántica del español”, en Actas del Congreso de la Sociedad Española de Lingüística. XX Aniversario, I. Madrid: Gredos, pp. 497-505.

GARRIDO RODRÍGUEZ, M. C. 2005: "Los conectores pragmáticos en la enseñanza de ELE: argumentación y relevancia”, en Actas del XV Congreso ASELE. Oviedo: Universidad de Oviedo, Servicio de Publicaciones, 2006, pp. 308-318.

GARVEY, C. 1975: “Requests and responses in children's speech”, en Journal of Child Language, 2, pp. 41-63.

GASS, S. y L. SELINKER (eds.) 1992: Language transfer in language learning. Rowley, MA: Newbury House.

GATHERCOLE, S. E. y A. D. BADDELEY 1993: Working Memory and Language. Hove, UK: Lawrence Erlbaum Associates.

GATHERCOLE, S. E. y G. J. HITCH 1993: "Developmental changes in short-term memory: A revised working memory perspective”, en COLLINS, A., GATHERCOLE, S. E., CONWAY, M. A. y P. E. MORRIS (eds.) 1993: Theories of memory. Hove, UK: Erlbaum, pp. 189-210.

GAZDAR, G. 1979: Pragmatics: Implicature, Presupposition and Logical Form. New York: Academic Press.

GENTNER, D. 1982: "Why nouns are learned before verbs: Linguistic relativity versus natural partitioning”, en KUCZAJ, S. (ed.) 1982: Language Development: vol. 2. Language, thought and culture. Hillsdale, NJ: Erlbaum, pp. 301-334.

GÉRARD, C. L. y V. BRUN 2003: Les dysphasies. Paris: Masson.

GESCHWIND, N. 1991: "Specializations of the human brain”, en WANG, W. (ed.) 1991: The Emergence of Language. New York: W. H. Freeman, pp. 72-87.

GIBBS, R. W. y J. O' BRIEN 1991: "Psychological aspects of irony understanding”, en Journal of Pragmatics, 16, pp. 523-530.

GILES, H. y N. COUPLAND 1991: Language: Contexts and consequences. Milton Keynes: Open University Press.

GILES, H., COUPLAND, J. y N. COUPLAND (eds.) 1991: Contexts of accommodation. Cambridge: Cambridge University Press.

GILLAM, R. B. y L. M. BEDORE 2000: "Language science", en GUILLAM, R. B., MARQUARDT, T. P. y F. N. MARTIN (eds.) 2000: Communication sciences and disorders- From science to clinical practice. San Diego, CA: Singular Publishing Club, pp. 385-408.

GIORA, R. 1995: “On Irony and Negation”, en Discourse Processes, 15, pp. 239-264.

GIORA, R. y O. FEIN 1999: "Irony: Context and Salience”, en Metaphor \& Symbol, 14 (4), pp. 241-257.

GIVÓN, T. 1995: Functionalism and grammar. Amsterdam: John Benjamins Publishing Company. 
GLÄSCHER, J. y R. ADOLPLAS 2003: "Processing of the arousal of subliminal and supraliminal emotional stimuli by the human amygdala", en Journal of Neurosciences, 23, pp. 10274-10282.

GLEASON, J. B. (ed.) 2001: The Development of Language. Boston: Pearson.

GOCHET, P. 1980: "Pragmatique formelle: Théorie des modèles et compétence pragmatique”, en PARRET, H. et al. (eds.) 1980: Le langage en contexte. Études philosophiques et linguistiques de pragmatique. Amsterdam: John Benjamins, pp. 317-388.

GOFFMAN, E. 1974: Frame Analysis. Cambridge: Harvard University Press.

GOIKOETXEA, E. y G. PASCUAL 2002: “Aprendizaje cooperativo: bases teóricas y hallazgos empíricos que explican su eficacia”, en Educación XXI, 5, pp. 227-247.

GOMBERT, J. 1992: Metalinguistic development. Chicago: University of Chicago Press.

GÓMEZ MORÓN, R. 2004: “La competencia pragmático-conversacional en los manuales de español como lengua extranjera: Breve revisión teórico-práctica desde la teoría pragmática de la cortesía lingüística”, en RUHSTALLER, S. y F. LORENZO BERGUILLOS (coords.) 2004: La competencia lingüística y comunicativa en el aprendizaje del español como lengua extranjera. Madrid: Edinumen, pp. 141-153.

GÓMEZ MORÓN, R., PADILLA CRUZ, M., FERNÁNDEZ AMAYA, L. y M. HERNÁNDEZ LÓPEZ 2009: Pragmatics Applied to language Teaching and Learning. Newcastle upon Tyne: Cambridge Scholars Publishing.

GÓMEZ, J. C., SARRIÀ, E., TAMARIT, J., BRIOSO, A. y E. LEÓN 1995: Los inicios de la comunicación: estudio comparado de niños y primates no humanos $e$ implicaciones para el autismo. Madrid: Ministerio de Educación y Ciencia-CIDE.

GÓMEZ, J. y M. NÚÑEZ 1998: “La mente social y la mente física: desarrollo y dominios del conocimiento”, en Infancia y Aprendizaje, 84, pp. 5-32.

GÓMEZ-PÉREZ, E., OSTROSKY-SOLÍS, F. y O. PÓSPERO-GARCÍA 2003: "Desarrollo de la atención, la memoria y los procesos inhibitorios: relación temporal con la maduración de la estructura y función cerebral”, en Revista de Neurología, 37 (6), pp. 561-567.

GONZÁLEZ NIETO, L. 1990: "Lengua y literatura en la educación secundaria (una fundamentación disciplinar)”, en Signos. Teoría y práctica de la educación, 1. [htpp://www.edebedigital.com/recursos/docs/recursos/594.pdf] (último acceso: marzo 2015).

GOODGLASS, H. 1993: Understanding aphasia. New York: Academic Press.

GOODGLASS, H. y E. KAPLAN 1983: Evaluación de la afasia y trastornos relacionados. Madrid: Editorial Médica Panamericana, 1996.

GOSWANI, U. y A. BROWN 1998: "Higher-order structure and relational reasoning: contrasting analogical and thematic relations”, en Cognition, 36, pp. 207-226. 
GOW, D. W. y P. C. GORDON 1993: “Coming to terms with stress: Effects of stress location in sentence processing”, en Journal of Psycholinguistic Research, 22, pp. 545-578.

GREEN, G. 1984: "Communication in aphasia therapy: some of the procedures and issues involved”, en British Journal of Disorders of Communication, 19, pp. 35-46.

GREENFIELD, P. M. y J. H. SMITH 1976: The structure of communication in early language development. New York: Academic Press.

GRICE, H. P. 1957: “Meaning”, en Philosophical Review, 66, pp. 377-388.

GRICE, H. P. 1969: “Utterer’s meaning and intentions”, en Philosophical Review, 78, pp. 147-177.

GRICE, H. P. 1975: “Logic and Conversation”, en COLE, P. y J. L. MORGAN (eds.) 1975: Syntax and Semantics, vol. 3: Speech Acts. New York: Academic Press, pp. 41-58.

GRICE, H. P. 1978: "Further notes on logic and conversation”, en COLE, P. (ed.) 1978: Syntax and Semantics, vol. 9: Pragmatics. New York: Academic Press, pp. 113-128.

GRICE, H. P. 1989: Studies in the Way of Words. Cambridge, MA: Harvard University Press.

GRIFFITHS, P. 1985: “The communicative functions of children's single-word speech”, en BARRET, M. 1985: Children's single-word speech. New York: Wiley, pp. 87112.

GROOT, P. J. M. 1975: “Testing communicative competence in listening comprehension”, en JONES, R. L. y B. SPOLSKY (eds.) 1975: Testing Language Proficiency. Arlington VA: Centre for Applied Linguistics, pp. 45-58.

GROSJEAN, F. 1989: "Neurolinguists, beware! The bilingual is not two monolinguals in one person”, en Brain and Language, 36, pp. 3-15.

GROSJEAN, F. 1992: “Another view of bilingualism”, en HARRIS, R. J. (ed.) 1992: Cognitive Processing in Bilinguals. Amsterdam: North Holland, pp. 51-62.

GROSSI, V. 2009: “Teaching Pragmatic Competence: Compliments and Compliment Responses in TSL classroom”, en Prospect, 24 (2), pp. 53-62.

GÜELL, M. y M. A. OLIVÉ 2001: “Rehabilitación de la afasia”, en PUYUELO, M. (ed.) 2001: Casos clínicos en logopedia, 3. Barcelona: Masson, pp. 145-208.

GUMPERZ, J. J. 1972: “Introduction”, en GUMPERZ, J. J. y D. H. HYMES (eds.) 1972: Directions in sociolinguistics. The ethnography of communication. New York: Basil Blackwell, pp. 1-25.

GUMPERZ, J. J. 1982a: Discourse strategies. Cambridge: Cambridge University Press.

GUMPERZ, J. J. 1982b: Language and social identity. Cambridge: Cambridge University Press. 
GUMPERZ, J. J. 1992: “Contextualization and understanding”, en DURANTI, A. y C. GOODWIN (eds.) 1992: Rethinking context. Cambridge: Cambridge University Press, pp. 229-252.

GUMPERZ, J. J. 1999: “On interactional sociolinguistics method”, en SARANGI, S. y C. ROBERTS (eds.) 1999: Talk, work and institutional order. Berlin: Mouton de Gruyter, pp. 453-471.

GUMPERZ, J. J. y N. BERENZ 1993: “Transcribing Conversational Exchanges”, en EDWARDS, J. A. y M. D. LAMPERT (eds.) 1993: Talking Data: Transcription and Coding in Discourse Research. Hillsdale, NJ: Lawrence Erlbaum Associates, pp. 91122.

GUPTA, R. y B. R. KAR 2009: "Development of attentional processes in ADHD and normal children”, en Progress Brain Research, 176, pp. 259-276.

GUTIÉRREZ CALVO, M. 2003: "Memoria operativa e inferencias en la comprensión del discurso”, en LEÓN, J. A. (ed.) 2003: Conocimiento y discurso. Claves para inferir y comprender. Madrid: Pirámide, pp. 123-138.

GUTIÉRREZ ORDÓNEZ, S. 2002: De pragmática y semántica. Madrid: Arco Libros.

GUTIÉRREZ ORDÓÑEZ, S. 2004: “La competencia pragmática”, en SÁNCHEZ LOBATO, J. e I. SANTOS GARGALLO (dirs.) 2004: Vademécum para la formación de profesores. Enseñar español como segunda lengua (L2) / lengua extranjera (LE). Madrid: SGEL, pp. 533-551.

GUTIÉRREZ ORDÓÑEZ, S. 2005: “Ejercitarás la competencia pragmática”, en Actas del $X V$ Congreso ASELE. Oviedo: Universidad de Oviedo, Servicio de Publicaciones, 2006, pp. 25-45.

GUTIÉRREZ-REXACH， J. 2002: “Demonstratives in Context”, en GUTIÉRREZREXACH, J. (ed.) 2002: From Words to Discourse. Trends in Spanish Semantics and Pragmatics. Oxford/New York: Elsevier Science, pp. 195-236.

HABERMAS, J. 1981: Teoría de la acción comunicativa. Madrid: Taurus, 1987.

HADWIN, J., BARON-COHEN, S., HOWLIN, P. y K. HILL 1997: "Does Teaching Theory of Mind Have an Effect on the Ability to Develop Conversation in Children with Autism?”, en Journal of Autism and Developmental Disorders, 27 (5), pp. 519537.

HAKES, D. 1982: “The development of metalinguistic abilities: What develops?”, en KUCZAJ, S. (ed.) 1982: Language Development: vol. 2. Language, thought and culture. Hillsdale, NJ: Erlbaum, pp. 163-202.

HALLIDAY, M. A. K. 1973: Explorations in the Functions of Language. London: Edward Arnold.

HALLIDAY, M. A. K. 1975: Learning how to mean: Explorations in the development of language. New York: Elsevier-North Holland Publishing.

HALLIDAY, M. A. K. 1978: Language as a social semiotic: The social interpretation of language and meaning. Baltimore: University Park Press. 
HALLIDAY, M. A. K. y R. HASSAN 1976: Cohesion in English. London: Longman.

HAMPSON, E. y D. KIMURA 1992: "Sex differences and hormonal influences on cognitive function in humans”, en BECKER, J. B., BREEDLOVE, S. M. y D. CREWS (eds.) 1992: Behavioral endocrinology. Cambridge: MIT Press, pp. 357398.

HAPPÉ, F. G. 1993: "Communicative competence and theory of mind in autism: A test of relevance theory”, en Cognition, 48, pp. 101-119.

HAPPÉ, F. G. 1994: Autism: An Introduction to Psychological Theory. Cambridge MA: Harvard University Press.

HAPPÉ, F. G. y E. LOTH 2002: “Theory of mind and tracking speakers’ intentions”, en Mind \& Language, 17, pp. 24-36.

HARLEY, T. 2001: The psychology of language: From data to theory ( $2^{\text {nd }}$ ed.). Hove: Psychology Press.

HARNISH, R. M. y A. K. FARMER 1984: "Pragmatics and the Modularity of the Linguistic System”, en Lingua, 63, pp. 255-277.

HAVERKATE, H. 1979: Impossible Sentences in Spanish: Theory and Description in Linguistic Pragmatics. Amsterdam: North Holland.

HAVERKATE, H. 1984: Speech Acts, Speakers and Hearers: References and Referential Strategies in Spanish. Amsterdam: John Benjamins.

HAVERKATE, H. 1996: “Estrategias de cortesía. Análisis intercultural”, en Actas del VII Congreso ASELE. Ciudad Real: Universidad de Castilla la Mancha, Ediciones de la Universidad de Castilla la Mancha, 1998, pp. 45-57.

HELM-ESTABROOKS, N. y L. A. MARTIN 1991: Manual de terapia de la afasia. Madrid: Editorial Médica Panamericana, 1994.

HERNÁNDEZ SACRISTÁN, C. 1999: Culturas y acción comunicativa. Introducción a la pragmática intercultural. Barcelona: Octaedro.

HERVÁS, F., PICÓ, E. y M. VILARRUBIAS 1990: “Elaboración de un test pragmático para ELE”, en Actas del II Congreso ASELE. Málaga: ASELE, 1994, pp. 185-197.

HEWITT, L. 2000: “Assessing communicative intents: A situated pragmatics approach”, en Seminars in Speech and Language, 21, pp. 257-266.

HIGASHIMORI, I. y D. WILSON 1996: “Questions on Relevance”, en UCL Working Papers in Linguistics, 8, pp. 111-124.

HILTON, L. M. 1990: “Identification et évaluation des differences pragmatiques du langage”, en Glossa, 18, pp. 14-20.

HOBSON, P. 1993: "Understanding persons: the role of affect", en BARON-COHEN, S., TAGER-FLUSBERG, H. y D. J. COHEN (eds.) 1993: Understanding other minds: Perspectives from autism. Oxford: Oxford University Press, pp. 204-227. 
HOLCK, P., NETTELBLADT, U. y A. SANDBERG 2009: “Children with cerebral palsy, spina bifida and pragmatic language impairment: Differences and similarities in pragmatic ability”, en Research in Developmental Disabilities, 30, pp. 942-951.

HOLLAND, A. L. 1980: Communicative Abilities in Daily Living. Baltimore: University Park Press.

HOLLAND, A. L. 1991: "Pragmatic aspect of intervention in aphasia”, en Journal of Neurolinguistics, 6, pp. 197-211.

HORN, L. R. 1988: “Teoría pragmática”, en NEWMEYER, F. J. (ed.) 1988: Panorama de la lingüística moderna de la Universidad de Cambridge I. Madrid: Visor, pp. 147181, 1990.

HORN, L. R. y G. WARD (eds.) 2004: The Handbook of Pragmatics. Oxford: Blackwell.

HORNBERGER, N. H. 1989: “Continua of biliteracy”, en Review of Educational Research, 59 (3), pp. 271-296.

HOUSE, J. 1996: "Developing pragmatic fluency in English as a foreign language: Routines and metapragmatic awareness", en Studies in Second Language Acquisition, 18, pp. 225-252.

HOUSE, J. y G. KASPER 1987: “Interlanguage pragmatics: Requesting in a foreign language”, en LÖRSCHER, W. y R. SCHULZE (eds.) 1987: Perspectives on language in performance. Festschrift for Werner Hüllen. Tübingen: Narr, pp. 12501288.

HUBER, W. 1990: “Text comprehension and production in aphasia: Analysis in terms of micro- and macroprocessing”, en JOANETTE, Y. y H. H. BROWNELL (eds.) 1990: Discourse ability and brain damage. Theoretical and empirical perspectives. New York: Springer-Verlag, pp. 154-179.

HUDSON, J. A. 1990: "The emergence of autobiographic memory in mother-child conversation”, en FIVUSH, R. y J. A. HUDSON (eds.) 1990: Knowing and remembering in young children. New York: Cambridge University Press, pp. 166196.

HUDSON, J. A. y K. NELSON 1986: "Repeated Encounters of Similar Kind: Effects of Familiarity on Children's Autobiographic Memory”, en Cognitive Development, 1, pp. 253-271.

HUDSON, J. A. y E. A. SLACKMAN 1990: “Children's use of scripts in inferential text processing”, en Discourse Processes, 13, pp. 375-386.

HULIT, L. M. y M. R. HOWARD 2002: Born to talk: an introduction to speech and language development. Boston: Allyn and Bacon.

HUTTENLOCHER, J., HAIGHT, W., BRYK, A., SELTER, M. y T. LYONS 1991: "Early vocabulary growth: Relation to language input gender", en Developmental Psychology, 27, pp. 236-248.

HYDE, J. S. y M. C. LINN 1988: “Gender differences in verbal ability: A meta-analysis”, en Psychologycal Bulletin, 104, pp. 53-69. 
HYMES, D. 1968: “The ethnography of speaking”, en FISHMAN, J. A. (comp.) 1968: Readings in the Sociology of Language. The Hague: Mouton, pp. 99-138.

HYMES, D. 1971: “Competence and performance in linguistic theory”, en HUXLEY, R. y E. INGRAMS (eds.) 1971: Language Acquisition: Models and Methods. London: Academic Press, pp. 3-28.

HYMES, D. 1972: “On Communicative Competence”, en PRIDE, J. B. y J. HOLMES (eds.) 1972: Sociolinguistics. Harmondsworth: Penguin, pp. 269-293.

IACONO, T. A., WARING, R. E. y J. B. CHAN 1996: "Sampling communicative behaviours in children with intellectual disability in structured and unstructured situations”, en European Journal of Disorders of Communication, 31, pp. 106-120.

IGOA, J. M., BELINCHÓN, M. y E. MARULANDA 2011: "Pragmática”, en CUETOS, F. (ed.) 2011: Neurociencia del lenguaje. Madrid: Editorial Médica Panamericana, pp. 111-135.

IM-BOLTER, N., JOHNSON, J. y J. PASCUAL-LEONE 2006: “Processing limitations in children with Specific Language Impairment: the role of Executive Function”, en Child Development, 77 (6), pp. 1822-1841.

INGRAM, D. 1989: First Language Acquisition. Cambridge: Cambridge University Press.

INOZEMTSEVA, O., MATUTE, E., GONZÁLEZ REYES, A. L., GUAJARDO CÁRDENAS, S., ROSSELLI. M. y E. A. RUIZ SÁNCHEZ 2010: "Influencia de la Edad en la Ejecución de Tareas Relacionadas con el Lenguaje en Escolares”, en Revista Neuropsicología, Neuropsiquiatría y Neurociencias, 10 (1), pp. 9-21.

INSTITUTO CERVANTES 2006/2007: Plan curricular del Instituto Cervantes: niveles de referencia para el español. Madrid: Biblioteca Nueva D.L.

INSTITUTO CERVANTES: Diccionario de términos clave de ELE del Instituto Cervantes [http://cvc.cervantes.es/ensenanza/biblioteca_ele/diccio_ele/default.htm] (último acceso: diciembre 2014).

JACKSON-MALDONADO, D., THAL, D., MARCHMAN, V., BATES, E. y V. GUTIÉRREZ-CLELLAN 1993: "Early lexical development in Spanish-speaking infants and toddlers”, en Journal of Child Language, 20, pp. 523-549.

JANNEY, R. W. y H. ARNDT 1992: “Intracultural Tact vs. Intercultural Tact”, en WATTS, S. I. y K. EHLICH (eds.) 1992: Politeness in Language. Studies in its History, Theory and Practice. Berlin: Mouton De Gruyter, pp. 21-41.

JASWAL, V. K. y E. M. MARKMAN 2001: "Learning proper and common names in inferential versus ostensive contexts”, en Child Development, 72, pp. 768-786.

JESSNER, U. 1996: "La transferencia en la adquisición de la segunda lengua”, en CENOZ, J. y J. F. VALENCIA (eds.) 1996: La competencia pragmática: elementos lingüísticos y psicosociales. Bilbao: Universidad de País Vasco, pp. 141-153.

JOANETTE, Y. y A. I. ANSALDO 1999: “Clinical Note: Acquired Pragmatics Impairments and Aphasia”, en STEMMER, B. (ed.) 1999: Pragmatics: Theoretical and Clinical Issues. Brain and Language, 68 (3), pp. 529-534. 
JOANETTE, Y., ANSALDO, A. I., KAHLAOUI, K., CÔTÈ, H., ABUSAMRA, V., FERRERES, A. y A. ROCH-LECOURS 2008: "Impacto de las lesiones del hemisferio derecho sobre las habilidades lingüísticas: perspectivas teórica y clínica”, en Revista de Neurología, 46, pp. 481-488.

JOHN, A. E., BOWE, M. L. y C. B. MERVIS 2009: "Referential communication skills of children with Williams syndrome: Understanding when messages are not adequate”, en American Journal on Intellectual and Developmental Disabilities, 114, pp. 85-99.

JOHNSON, C. J. y J. M. ANGLIN 1995: “Qualitative developments in the content and form of children's definitions”, en Journal of Speech and Hearing Research, 38, pp. 612-629.

JOHNSON, J. R. 1988: "Specific language disorders in the child", en LASS, N. J., MCREYNOLDS, L. V., NORTHERN, J. L. y D. E. YODER (eds.) 1988: Handbook of speech pathology and audiology. Toronto: B. C. Decker, Inc., pp. 685-715.

JOHNSON-LAIRD, P. N. 1983: Mental models: Towards a cognitive science of language, inference and consciousness. Cambridge: Cambridge University Press.

JOHNSTON, B., KASPER, G. y S. ROSS 1994: "Effect of rejoinders in production questionnaires”, en University of Hawaii Working Papers in ESL, 13 (1), pp. 121143.

JOHNSTON, J. R., MILLER, J. y P. TALLAL 2001: "Use of cognitive state predicates by language impaired children”, en International Journal of Language and Communication Disorders, 36, pp. 349-370.

JORGENSEN, J. 1996: “The functions of sarcastic irony in speech", en Journal of Pragmatics, 26, pp. 613-634.

JORGENSEN, J., MILLER, G. A. y D. SPERBER 1984: "Test of the mention theory of irony”, en Journal of Experimental Psychology: General, 113, pp. 112-120.

KANDEL, E., SCHWARTZ, J. H. y T. M. JESSELL 1997: Neurociencia y conducta. Madrid: Prentice Hall.

KAPLAN, D. 1989: "Demostratives. An essay on the Semantics, Logic, Metaphysics and Epistemology of Demostratives and Other Indexicals”, en ALMOG, J., PERRY, J. y H. WETTSTEIN (eds.) 1989: Themes from Kaplan. Oxford: Oxford University Press, pp. 481-563.

KARMILOFF-SMITH, A. 1979: A functional approach to child language: A study of determiners and reference. Cambridge: Cambridge University Press.

KARMILOFF-SMITH, A. 1983: “A note on the concept of 'metaprocedural processes' in linguistic and non-linguistic cognitive development”, en Archives de Psychologie, 51, pp. 35-40.

KARMILOFF-SMITH, A. 1985: "Language and cognitive processes from a development perspective”, en Language and Cognition Processes, 1, pp. 61-85.

KARMILOFF-SMITH, A. 1986: "Some fundamental aspect of language development after age 5”, en FLETCHER, P. y M. GARMAN (eds.) 1986: Language Acquisition: 
Studies in First Language Development (2 ${ }^{\text {nd }}$ ed.). Cambridge, UK: Cambridge University Press, pp. 455-474.

KARTTUNEN, L. y S. PETERS 1979: “Conventional implicature”, en OH, C. K. y D. A. DINNEN (eds.) 1979: Syntax and Semantics, 11: Presupposition. New York: Academic Press, pp. 1-56.

KASHER, A., BATORI, G., SOROKER, N., GRAVES, D. y E. ZAIDEL 1999: "Effects on Right- and Left-Hemisfere Damage on Understanding Conversational Implicatures”, en Brain and Language, 68, pp. 566-590.

KASPER, G. 1992: “Pragmatic Transfer”, en Second Language Research, 8, pp. 203-231.

KASPER, G. 1997: “Can pragmatic competence be taught?”, en NFLRC Net Work 6, Second Language Teaching and Curriculum Center. Manoa: University of Hawaii. [http://www.lll.hawaii.edu/nflrc/NetWorks/NW6/] (último acceso: febrero 2015).

KASPER, G. 2001: “Classroom research on interlanguage pragmatics”, en KASPER, G. y K. R. ROSE (eds.) 2001: Pragmatics in Language Teaching. Cambridge: Cambridge University Press, pp. 33-60.

KASPER, G. y E. KELLERMAN (eds.) 1997: Communication Strategies. Psycholinguistic and Sociolinguistic Perspectives. New York: Longman.

KASPER, G. y K. R. ROSE (eds.) 2001: Pragmatics in Language Teaching. Cambridge: Cambridge University Press.

KASPER, G. y K. R. ROSE 2002: Pragmatic development in a second language. Oxford: Blackwell.

KEENAN, E. 1977: “Making it last: repetition in children's discourse”, en ERVINTRIPP, S. y C. MITCHELL-KERNAN (eds.) 1977: Child discourse. New York: Academic Press, pp. 91-102.

KEENAN, T. y K. QUIGLEY 1999: “Do Young Children Use Echoic Information in Their Comprehension of Sarcastic Speech? A Test of Echoic Mention Theory”, en British Journal of Developmental Psychology, 1 (17), pp. 83-14.

KELLERMAN, E. y M. SHARWOOD SMITH 1986: Crosslinguistic influence in second language acquisition. New York: Oxford University Press.

KEMPSON, R. M. 1977: Semantic theory. Cambridge: Cambridge University Press.

KEMPSON, R. M. 1988: “Grammar and Conversational Principles”, en NEWMEYER, F. J. (ed.) 1988: Linguistics: the Cambridge Survey, vol. 2. Cambridge: Cambridge University Press, pp. 139-163.

KING, K. A. y R. E. SILVER 1993: "Sticking points: Effects of instruction on NNS refusal strategies”, en Working Papers in Educational Linguistics, 9, pp. 47-82.

KOIKE, D. A. y L. PEARSON 2005: "The effect of instruction and feedback in the development of pragmatic competence”, en System, 33, pp. 481-501. 
KORKMAN, M., KEMP, S. L. y U. KIRK 2001: "Effects of age on neurocognitive measures of children ages 5 to 12: A cross-sectional study of 800 children from the United States”, en Developmental Neuropsychology, 20 (1), pp. 331-334.

KOTTHOFF, H. 2003: "Responding to irony in different contexts: on cognition in conversation”, en Journal of Pragmatics, 35, pp. 1387-1411.

KRAMSCH, C. 1986: "From language proficiency to interactional competence”, en The Modern Language Journal, 70 (4), pp. 366-372.

KRASHEN, S. 1981: Second language acquisition and second language learning. Oxford: Pergamon Press.

KREUZ, R. J. y S. GLUCKSBERG 1989: "How to Be Sarcastic: The Echoic Reminder Theory of Verbal Irony”, en Journal of Experimental Psychology: General, 118 (4), pp. 374-386.

KUBOTA, M. 1995: "Teachability of conversational implicature to Japanese EFL learners”, en IRLT Bulletin, 9. Tokyo: The Institute for Research in Language Teaching, pp. 35-67.

KUCZAJ, S. A. 1982: “Language play and language acquisition”, en REESE, R. W. (ed.) 1982: Advances in child development and behavior, vol. 14. New York: Academic Press, pp. 197-232.

KUMON-NAKAMURA, S., GLUKSBERG, S. y M. BROWN 1995: "How about another Piece of Pie: The Allusional Pretense Theory of Discourse Irony”, en Journal of Experimental Psychology: General, 124, pp. 3-21.

KUNO, S. y K. TAKAMI 1993: Grammar and Discourse Principles. Chicago: Chicago University Press.

KURLAND, B. F. y C. E. SNOW 1997: "Longitudinal measurement of growth in definitional skill”, en Journal of Child Language, 24, pp. 603-625.

LABOV, W. 1972: Sociolinguistic Patterns. Philadelphia: University of Pennsylvania Press.

LACORTE, M. 2007: Lingüística aplicada al español. Madrid: Arco Libros.

LADO, R. 1957: Linguistics across Cultures. Ann Arbor, Michigan: University of Michigan Press.

LAGATTUTA, K. H., WELLMAN, H. M. y J. H. FLAVELL 1997: "Preschoolers' understanding of the link between thinking and feeling: Cognitive cuing and emotional change”, en Child Development, 68, pp. 1081-1104.

LAGATTUTA, K. H. y H. M. WELLMAN 2001: "Thinking about the past: Early knowledge about links between prior experience, thinking and emotion”, en Child Development, 72, pp. 82-102.

LAKOFF, G. 1972: "Hedges: A study in meaning criteria and the logic of fuzzy concepts", en Papers from the Eighth Regional Meeting of the Chicago Linguistic 
Society, pp. 183-228. Reprinted in Journal of Philosophical Logic, 1973, 2 (4), pp. 458-508.

LAKOFF, G. 1987: Women, fire and dangerous things. What categories reveal about the mind. Chicago: Chicago University Press.

LAMB, C. 2005: “Misunderstandings -a Sociolinguistic View on Meaning”, en Letras de Hoje, 40 (1), pp. 231-241.

LANDA, R. 2000: "Social language use in Asperger Syndrome, High-Functioning Autism”, en KLIN, A., VOLKMAR, F. R. y S. S. SPARROW (eds.) 2000: Asperger Syndrome. New York: The Guilford Press, pp. 125-155.

LANE, D. M. y D. A. PEARSON 1982: “The development of selective attention” en Merrill-Palmer Quarterly, 28, pp. 317-337.

LANGDON, R., DAVIES, M. y M. COLTHEART 2002: "Understanding minds and understanding communicated meanings in schizophrenia", en Mind and Language, 17, pp. 68-104.

LAVAL, V. y A. BERT-ERBOUL 2005: “French-speaking children's understanding of sarcasm: The role of intonation and context”, en Journal of Speech, Language and Hearing Research, 48, pp. 610-620.

LEECH, G. 1983: Principios de pragmática. Logroño: Universidad de la Rioja.

LEINONEN, E. y C. LETTS 1997: "Why pragmatic impairment? A case study in the comprehension of inferential meaning”, en European Journal of Disorders of Communication, 32, pp. 35-52.

LEINONEN, E. y D. KERBEL 1999: “Relevance theory and pragmatic impairment”, en International Journal of Language and Communication Disorders, 34, pp. 367-390.

LEINONEN, E., LETTS, C. y B. R. SMITH 2000: Children's Pragmatic Communication Difficulties. London: Whurr Publishers.

LEINONEN, E., RYDER, N., ELLIS, M. y C. HAMMOND 2003: “The use of context in pragmatic comprehension by specifically language-impaired and control children”, en Linguistics, 41(2), pp. 407-423.

LEINONEN, E. y N. RYDER 2008: "Relevance Theory and Communication Disorders”, en BALL, M. J., PERKINS, M. R. y S. HOWARD (eds.) 2008: The Handbook of Clinical Linguistics. United States: Blackwell, pp. 47-59.

LEÓN, J. A. e I. ESCUDERO 2010: "La comprensión del lenguaje: la producción de inferencias en la mente y en el cerebro”, en GALLARDO PAÚLS, B. y V. MORENO CAMPOS 2010: Estudios de Lingüística Clínica, V: Aplicaciones clínicas. Valencia: Universitat de Valencia, pp. 95-115.

LEONARD, L. 1998: Children with Specific Languaje Impairment. Cambridge: MacKeith Press.

LEONETTI, M. 1999: Los determinantes. Madrid: Arco Libros. 
LESLIE, A. 1991: "The theory of mind impairment in autism: Evidence for a modular mechanism of development?", en WHITEN, A. (ed.) 1991: Natural Theories of Mind: Evolution, Development and Simulation of Everyday Mindreading. Oxford: Blackwell, pp. 63-78.

LETTS, C. y E. LEINONEN 2001: "Comprehension of inferential meaning in languageimpaired and language normal children", en International Journal of Language and Communication Disorders, 36, pp. 307-328.

LEVINSON, S. 1983: Pragmática. Barcelona: Teide.

LEVINSON, S. 2004: “Deixis”, en HORN, L. R. y G. WARD (eds.) 2004: The Handbook of Pragmatics. Oxford: Blackwell, pp. 97-121.

LEWANDOWSKI, T. 1982: Diccionario de lingüística. Madrid: Cátedra.

LIDDICOAT, A. J. y C. CROZET 2001: "Acquiring French international norms though introduction”, en KASPER, G. y K. R. ROSE (eds.) 2001: Pragmatics in Language Teaching. Cambridge: Cambridge University Press, pp. 125-144.

LINSCOTT, R. J., KNIGHT, R. G. y H. P. D. GODFREY 1996: "The Profile of Functional Imparirment in Comunication (PFIC): a measure of communication impairment for clinical use”, en Brain Injury, 10, pp. 397-412.

LINTON, M. 1975: "Memory for real-world events", en NORMAN, D. A. y D. E. RUMELHART (eds.) 1975: Explorations in cognition. San Francisco: Freeman, pp. 376-404.

LINTON, M. 1982: “Transformations of memory in everyday life”, en NEISSER, U. (ed.) 1982: Memory observed. San Francisco: Freeman, pp. 77-91.

LOCASTRO, V. 2003: An Introduction to Pragmatics: Social Action for Language Teachers. Ann Arbor: University of Michigan Press.

LOCASTRO, V. 2006: An Introduction to Pragmatics. Oxford: Oxford University Press.

LOCK, A. 1980: The guided reinvention of language. London: Academic Press.

LLOYD, P., CAMAIONI, L. y P. ERCOLANI 1995: “Assessing referential communication skills in the primary school years: A comparative study", en British Journal of Developmental Psychology, 13, pp. 13-29.

LLOYD, P., PEERS, I. y C. FOSTER 2001: The Listening Skills Test. Hove: Psychological Corporation.

LOMAS, C. 1994: "La educación lingüística y literaria”, en Textos de Didáctica de la Lengua y la Literatura, 1, pp. 8-17.

LOMAS, C. 1997: “La educación Lingüística y el limbo de los justos”, en Signos. Teoría y práctica de la educación, 22, pp. 62-63.

LOMAS, C. y A. OSORO 1992: "Modelos teóricos y enfoques didácticos en el currículum de lengua”, en Cuadernos de Pedagogía, 203, pp. 64-67. 
LOMAS, C., OSORO, A. y A. TUSÓN 1993: Ciencias del Lenguaje, competencia comunicativa y enseñanza de la lengua. Barcelona: Paidós.

LOMAS, C. y A. OSORO 1996a: "Los objetivos de la educación lingüística y el currículo de Lengua Castellana y Literatura en la enseñanza secundaria”, en LOMAS, C. (coord.) 1996: La educación lingüística y literaria en la enseñanza secundaria. Horsori: Universitat de Barcelona, Instituto de Ciencias de la Educación, pp. 25-66.

LOMAS, C. y A. OSORO 1996b: "Enseñar lengua y literatura en la educación secundaria (Orientaciones para la elaboración de proyectos curriculares y programaciones de aula)”, en LOMAS, C. (coord.) 1996: La educación lingüística y literaria en la enseñanza secundaria. Horsori: Universitat de Barcelona, Instituto de Ciencias de la Educación, pp. 143-182.

LOMAS, J., PICKARD, L., BESTER, S., ELBARD, H., FINLAYSON, A. у C. ZOGHAIB 1989: "The Communicative Effectiveness Index: development and psychometric evaluation of a functional communication measure for adult aphasia”, en Journal of Speech and Hearing Disorders, 54, pp. 113-124.

LONG, M. H., ADAMS, L., MCLEAN, M. y F. CASTAÑOS 1976: “Doing things with words. Verbal interaction in lockstep and small group classroom situations”, en BROWN, H. D., YORIO, C. A. y R. H. CRYMES (eds.) 1976: Teaching and learning English as a second language: Trends in research and practice. Washington, DC: TESOL, pp. 137-153.

LÓPEZ GARCÍA, A. 1989: Fundamentos de lingüística perceptiva. Madrid: Gredos.

LÓPEZ GARCÍA, A. 2014: Los mecanismos neuronales del lenguaje. Valencia: Tirant Humanidades.

LÓPEZ-ORNAT, S., FERNÁNDEZ, A., GALLO, P. y S. MARISCAL (eds.) 1994: La adquisición de la lengua española. Madrid: Siglo XXI.

LOSH, M., BELLUGI, U., REILLY, J. y D. ANDERSON 2000: "Narrative as Social Engagement Tool: The Excessive Use of Evaluation in Narratives from Children with Williams Syndrome”, en Narrative Inquiry, 10 (2), pp. 265-290.

LOUKUSA, S. 2007: The use of context in pragmatic language comprehension in normally developing children and children with Asperger syndrome/highfunctioning autism: An application of relevance theory. Academic dissertation. Oulu: Oulu University Press.

LOUKUSA, S., LEINONEN, E. y N. RYDER 2007: "Development of pragmatic language comprehension in Finnish-speaking children”, en First Language, 27 (3), pp. 281-298.

LOUKUSA, S., LEINONEN, E., KUUSIKKO, S., JUSSILA, K., MATTILA, L., RYDER, N., EBELING, H. e I. MOILANEN 2007: "Use of context in pragmatic language comprehension by children with Asperger syndrome or high-functioning autism”, en Journal of Autism and Developmental Disorders, 37 (6), pp. 1049-1059. 
LOUKUSA, S., RYDER, N. y E. LEINONEN 2008: “Answering questions and explaining answers: A study of Finnish-speaking children”, en Journal of Psycholinguistic Research, 37 (3), pp. 219-241.

LOUKUSA, S. y I. MOILANEN 2009: "Pragmatic inference abilities in individuals with Asperger syndrome or high-functioning autism. A review”, en Research in Autism Spectrum Disorders, 3, pp. 890-904.

LOVE, R. J. y W. G. WEBB 1996: Neurología para los especialistas del habla y del lenguaje. Madrid: Editorial Médico Panamericana.

LYONS, J. (ed.) 1970: New Horizons in Linguistics. Harmondsworth: Penguin.

LYONS, J. 1983: Lenguaje, significado y contexto. Barcelona: Paidós.

MACWHINNEY, B. (ed.) 1999: The emergence of language. Mahwah, New Jersey: LEA.

MAINGUENEAU, D. 1990: Pragmatique pour le discourse littéraire. Paris: Bordas.

MANCHÓN RUIZ, R. M. 2001: “Un acercamiento psicolingüístico al fenómeno de la transferencia en el aprendizaje y uso de segundas lenguas”, en PASTOR CESTEROS, S. y V. SALAZAR GARCÍA (eds.) 2001: Estudios de lingüística. Anexo 1: Tendencias y líneas de investigación en la adquisición de segundas lenguas. Alicante: Universidad de Alicante, pp. 39-71.

MANES, J. y N. WOLFSON 1981: “The compliment formula”, en COULMAS, F. (ed.) 1981: Conversational routine: Explorations in standardized communication situations and prepatterned speech. The Hague: Mouton, pp. 115-132.

MANOCHIOPINING, S., SHEARD, C. y V. REED 1992: "Pragmatic assessment in adult aphasia: a clinical review”, en Aphasiology, 6 (6), pp. 519-533.

MARCHMAN, V. A. y E. BATES 1994: "Continuity in lexical and morphological development: A test of the critical mass hypothesis”, en Journal of Child Language, 21, pp. 339-366.

MARINAC, J. V. y A. E. OZANNE 1999: “Comprehension strategies: The bridge between literal and discourse understanding”, en Child Language Teaching and Therapy, 15, pp. 233-246.

MARRERO AGUIAR, V. 2009: “Lenguaje, mente y cerebro”, en ESCANDELL VIDAL, M. V., MARRERO AGUIAR, V., CASADO, C., GUTIÉRREZ RODRÍGUEZ, E. y P. RUIZ-VA (eds.) 2009: El lenguaje humano. Madrid: Editorial Universitaria Ramón Areces, pp. 305-337.

MARTÍN BORREGUERO, P. 2005: "Perfil lingüístico del individuo con síndrome de Asperger: Implicaciones para la Investigación y la Práctica Clínica”, en Revista de Neurología, 41 (Supl 1), pp. 115-122.

MARTÍN BORREGUERO, P. 2008: El síndrome de Asperger: ¿Excentricidad o discapacidad social? Madrid: Alianza Editorial.

MARTÍN PERIS, E. y N. SANS BAUDELAS 2004: Gente: curso de español basado en el enfoque por tareas 1. Barcelona: Difusión. 
MARTIN, I. y S. MCDONALD 2004: “An exploration of causes of non-literal language problems in individuals with Asperger syndrome”, en Journal of Autism and Developmental Disorders, 34, pp. 311-328.

MARTÍNEZ-FLOR, A. y Y. FUKUYA 2005: “The effect of instruction on learners' production of appropriate and accurate suggestions”, en System, 33 (3), pp. 463-480.

MARTOS, J. 2001: “Autismo: un trastorno penetrante del Desarrollo”, en MARTOS, J. y J. PÉREZ (comp.) 2001: Autismo. Un enfoque orientado a la formación en logopedia. Valencia: Nau Llibres, pp. 17-28.

MARTOS, J. y R. AYUDA 2002: “Comunicación y lenguaje en el espectro autista: el autismo y la disfasia”, en Revista de Neurología, 32 (supl. 1), pp. 58-63.

MATEER, C. 1983: "Motor and perceptual functions of the left hemisphere and their interaction”, en SEGALOWITZ, S. (ed.) 1983: Language functions and brain organization. New York: Academic Press, pp. 145-171.

MCBURNEY, D. H. y V. B. COLLINS 1977: Introduction to sensation/perception. Englewood Cliffs: Prentice Hall.

MCDONALD, S. 1999: "Exploring the process of inference generation in sarcasm: A review of normal and clinical studies”, en Brain and Language, 68, pp. 486-506.

MCLEAN, J. y L. SNYDER-MCLEAN 1978: A transactional approach to early language training. Columbus, OH: Merrill.

MCNEILL, D. 1966: “Developmental psycholinguistics”, en SMITH, F. y G. A. MILLER (eds.) 1966: The genesis of language. Cambridge, MA: MIT Press, pp. 15-84.

MCSHANE, J. 1980: Learning to talk. Cambridge: Cambridge University Press.

MCTEAR, M. y G. CONTI-RAMSDEN 1992: Pragmatic disability in children. San Diego, California: Singular Publishing Group.

MEIER, A. J. 1999: "Identifying and teaching underlying cultural themes of pragmatics", en BOUTON, L. y Y. KACHRU (eds.) 1999: Pragmatics and Language Learning, Monograph 9. Urbana-Champaign, IL: University of Illinois, Division of English as an International Language, pp. 113-127.

MENDOZA, A. y F. J. CANTERO 2003: “Didáctica de la Lengua y la Literatura: aspectos epistemológicos”, en MENDOZA, A. (coord.) 2003: Didáctica de la Lengua y la Literatura. Madrid: Pearson Educación, pp. 3-32.

MENDOZA, A., LÓPEZ, A. y E. MARTOS 1996: Didáctica de la Lengua para la enseñanza Primaria y Secundaria. Madrid: Akal.

MENDOZA LARA, E. (coord.) 2001: Trastorno específico del lenguaje. Madrid: Ediciones Pirámide.

MERVIS, C. B. y J. BERTRAND 1995: "Early lexical acquisition and the vocabulary spurt: A response to Goldfield and Reznick”, en Journal of Child Language, 22, pp. 461-468.

MESSER, D. J. 1994: The development of communication. New York: Wiley. 
MEY, J. L. 1993: Pragmatics. An Introduction. Oxford: Blackwell.

MEY, J. L. y M. TALBOT 1988: “Computation and the Soul”, en Journal of Pragmatics, 12, pp. 743-789.

MEYERS, J. E. y K. R. MEYERS 2000: “Oddesa Suplemental norms for children and adolescents”, en Psychological Assessment Resources (ed.) 2000: Rey complex figure test and recognition trial. Florida: Lutz, pp. 1-4.

MILIÁN, M. 1993: “Las actividades de escritura en las áreas curriculares no lingüísticas”, en Aula de Innovación Educativa, 14, pp. 34-39.

MILOSKY, L. M. 1992: "Children listening: The role of world knowledge in language comprehension”, en CHAPMAN, R. S. (ed.) 1992: Processes in language Acquisition and Disorders. St Louis, MO: Mosby-Year Book, pp. 20-44.

MILLS, D. L., COFFEY-CORINA, S. A. y H. J. NEVILLE 1993: "Language acquisition and cerebral specialization in 20-month-old infants", en Journal of Cognitive Neuroscience, 5 (3), pp. 317-334.

MILLS, D. L., COFFEY-CORINA, S. A. y H. J. NEVILLE 1997: "Language comprehension and cerebral specialization from 13 to 20 months", en Developmental Neuropsychology, 13 (3), pp. 397-445.

MILLS, D. L., PLUNKETT, K., PRAT, C. y G. SCHAFER 2005: "Watching the infant brain learn words: effects of vocabulary size and experience”, en Cognitive Development, 20, pp. 19-31.

MINISTERIO DE EDUCACIÓN Y CIENCIA 1989: Diseño Curricular Base. Educación Primaria, Educación Secundaria Obligatoria. Madrid: MEC.

MINISTERIO DE EDUCACIÓN Y CIENCIA 1991a: Real Decreto 1006/1991, de 14 de junio, por el que se establecen las enseñanzas primarias correspondientes a la Educación Primaria. Real Decreto 1007/1991 que define las enseñanzas mínimas correspondientes a la Educación Secundaria Obligatoria. BOE, 26 de junio de 1991. Madrid.

MINISTERIO DE EDUACIÓN Y CIENCIA 1991b: Real Decreto1344/1991, de 6 de septiembre, por el que se establece el currículo de Educación Primaria. Real Decreto1345/1991, de 6 de septiembre, por el que se establece el currículo de la Educación Secundaria Obligatoria. BOE, 13 de septiembre de 1991. Madrid.

MINISTERIO DE EDUCACIÓN Y CIENCIA 1992: Real Decreto 1178/1992 de dos de octubre por el que se establecen las enseñanzas mínimas del Bachillerato. BOE, 21 de octubre de 1992. Real Decreto 1179/1992 de dos de octubre por el que se establece el Currículo de Bachillerato. BOE, 21 de octubre de 1992. Madrid.

MINISTERIO DE EDUCACIÓN Y CIENCIA 2007: Real Decreto 1467/2007, de 2 de noviembre, por el que se establece la estructura del bachillerato y se fijan sus enseñanzas mínimas. BOE, 6 de noviembre de 2007. Madrid.

MINISTERIO DE EDUCACIÓN Y CIENCIA 2011: Real Decreto 1146/2011, de 29 de julio, por el que se modifica el Real Decreto 1631/2006, de 29 de diciembre, por el que se establecen las enseñanzas mínimas correspondientes a la Educación 
Secundaria Obligatoria, así como los Reales Decretos 1834/2008, de 8 de noviembre, y 860/2010, de 2 de julio, afectados por estas modificaciones.BOE, 30 de julio de 2011. Madrid.

MINISTERIO DE EDUCACIÓN Y CIENCIA 2012: Real Decreto 1190/2012, de 3 de agosto, por el que se modifican el Real Decreto 1513/2006, de 7 de diciembre, por el que se establecen las enseñanzas mínimas de la Educación Primaria, y el Real Decreto 1631/2006, de 29 de diciembre, por el que se establecen las enseñanzas mínimas correspondientes a la Educación Secundaria Obligatoria. BOE, 4 de agosto de 2012. Madrid.

MINSKY, M. A. 1975: “A framework for representing knowledge”, en WINSTON, P. H. (ed.) 1975: The psychology of computer vision. Nueva York: McGraw-Hill, pp. 211277.

MINSKY, M. A. 1977: "Frame System Theory”, en JOHNSON-LAIRD, P. N. y P. C. WASON 1977: Thinking Readings in Cognitive Science. Cambridge: Cambridge University Press, pp. 355-376.

MITCHELL, P. 1997: Introduction to theory of mind: Children, autism and apes. London: Arnold.

MOLLOY, R., BROWNELL, H. H. y H. GARDNER 1990: "Discourse Comprehension by Right-Hemisphere Stroke Patients: Deficits of Prediction and Revision", en JOANETTE, Y. y H. H BROWNELL (eds.) 1990: Discourse Ability and Brain Damage. New York: Springer-Verlag, pp. 113-130.

MONFORT, M. y I. MONFORT JUÁREZ 2001: En la mente. Madrid: Entha Ediciones.

MONFORT, M., JUÁREZ SÁNCHEZ, A. e I. MONFORT JUÁREZ 2004: Niños con Trastornos pragmáticos del lenguaje y de la comunicación. Madrid: Entha.

MONSALVE, C. 2001: “Comunicación y lenguaje en autismo: claves para el buen trabajo de un logopeda”, en MARTOS, J. y J. PÉREZ (comp.) 2001: Autismo. Un enfoque orientado a la formación en logopedia. Valencia: Nau Llibres, pp. 65-84.

MORENO CAMPOS, V. 2010: “Pragmática clínica y análisis cuantitativo”, en GALLARDO PAÚLS, B. y V. CAMPOS MORENO 2010: Estudios de Lingüística Clínica, V: Aplicaciones clínicas. Valencia: Universitat de Valencia, pp. 163-177.

MORENO CAMPOS, V. 2011: Pragmática en afasia. Tesis doctoral. Valencia: Universitat de Valencia (http://www.tdx.cat/bitstream/handle/10803/63176/moreno.pdf?sequence=1) (último acceso: enero 2015).

MORENO GARCÍA, C., MORENO, V. y P. ZURITA 2007a: Avance: curso de español: nivel básico-intermedio. Alcobendas, Madrid: Sociedad General Española de Librería.

MORENO GARCÍA, C., MORENO, V. y P. ZURITA 2007b: Avance: curso de español: nivel intermedio-avanzado. Alcobendas, Madrid: Sociedad General Española de Librería. 
MORGAN, J. L. 1975: “Some Interactions of Syntax and Pragmatics”, en COLE, P. y J. L. MORGAN 1975: Syntax and Semantics, vol.3: Speech Acts. New York: Academic Press, pp. 289-303.

MORISSET, C. E., BARNARD, K. E. y C. L. BOOTH 1995: “Toddlers' language development: Sex differences within social risk”, en Developmental Psychology, 31, pp. 851-865.

MORRIS, C. W. 1938: "Foundation of the Theory of Signs", en NEURATH, O., CARNAP, R. y C. MORRIS (comps.) 1938: International Encyclopaedia of Unified Science. Chicago: University of Chicago Press, pp. 77-138.

MUNDY, P., SIGMAN, M. y C. KASARI 1993: "Theory of mind and joint attention déficits in autism”, en BARON-COHEN, S., TAGER-FLUSBERG, H. y D. COHEN (eds.) 1993: Understanding other minds: Perspectives from autism. Oxford: Oxford University Press, pp. 181-203.

MYERS-SCOTTON, C. y J. BERNSTEIN 1988: "Natural conversation as a model for textbook dialogue”, en Applied Linguistics, 9, pp. 372-384.

NAKASSIS, C. y J. SNEDEKER 2002 "Beyond Sarcasm: Intonation and Context as Relational Cues in Childrens's Reconigtion of Irony”, en GREENHYLL, A., HUGHS, M., LITTLE FIED, H. y H. WALSH (eds.) 2002: Procedings of the Tweenty-sixth Boston University Conference on Language Development. Summerville, MA: Cascadilla Press, pp. 429-440.

NATHAN, L. 2002: "Functional communication skills of children with speech difficulties: Performance on Bishop's Communication Checklist”, en Child Language Teaching and Therapy, 18 (3), pp. 213-231.

NAUGHTON, D. 2006: "Cooperative strategy training and oral interaction: Enhancing small group communication in the language classroom”, en The Modern Language Journal, 90, pp. 169-184.

NELSON, K. 1978: "How children represent knowledge of their world in and out of language: A preliminary report”, en SIEGLER, R. S. (ed.) 1978: Children's Thinking. Hillsdale, NJ: Lawrence Erlbaum Associates, pp. 255-273.

NELSON, K. (ed.) 1986: Event knowledge: Structure function in development. Hillsdale, NJ: Erlbaum.

NELSON, K. 1996: Language in cognitive development. The emergence of the mediated mind. Cambridge, UK: Cambridge University Press.

NELSON, L. M. y H. R. BAUER 1991: "Speech and language production at age 2: Evidence for tradeoffs between linguistic and phonetic processing”, en Journal of Speech and Hearing Research, 34, pp. 879-892.

NEWMEYER, F. 1983: Grammatical Theory. Its Limits and Possibilities. Chicago: Chicago University Press.

NIEZGODA, K. y C. RÖVER 2001: "Pragmatic and grammatical awareness: A function of the learning environment?”, en KASPER, G. y K. R. ROSE (eds.) 2001: 
Pragmatics in Language Teaching. Cambridge: Cambridge University Press, pp. 6379.

NINIO, A. 1986: “The illocutionary aspect of utterances”, en Discourse Processes, 9, pp. 127-147.

NINIO, A. y J. BRUNER 1978: “The achievement and antecedents of labelling”, en Journal of Child Language, 5, pp. 1-15.

NINIO, A., SNOW, C. E., PAN, B. A. y P. ROLLINS 1994: "Classifying communicative acts in children's interactions”, en Journal of Communication Disorders, 27, pp. 157-188.

NINIO, A. y C. E. SNOW 1996: Pragmatic Development. Colorado: Westview Press.

NIPPOLD, M. 1998: Later Language Development. The School Age and Adolescent Years. Austin: Proed.

NOGUEROL, A. 1995: Bases psicolingüístiques y lingüístiques per a l'ensenyament $i$ l'aprenentatge de la llengua de Catalunya. Tesis de doctorado. Universidad de Barcelona.

NORBURY, C. F. y D. V. M. BISHOP 2002: "Inferential processing and story recall in children with communication problems: a comparison of specific language impairment, pragmatic language impairment and high-functioning autism”, en International Journal of Language \& Communication Disorders, 37 (3), pp. 227251.

NORRIS, J. y L. ORTEGA 2000: "Effectiveness of L2 instruction: A research synthesis and quantitative meta-analysis”, en Language Learning, 50, pp. 417-528.

NOVECK, I. y D. SPERBER 2007: "The why and how of experimental pragmatics. The case of scalar inferences", en BURTON-ROBERTS, N. (ed.) 2007: Advances in Pragmatics. Basingstoke: Palgrave, pp. 184-212.

NUNAN, D. 1993: Designing Tasks for the Communicative Classroom. Cambridge, UK: Cambridge University Press.

NUSSBAUM, L. 1996: "La didáctica de la lengua: temas y líneas de investigación e innovación”, en LOMAS, C. (coord.) 1996: La educación lingüística y literaria en la enseñanza secundaria. Horsori: Universitat de Barcelona, Instituto de Ciencias de la Educación, pp. 109-122.

O’NEILL, D. 1996: "Pragmatics and the development of communicative ability", en GREEN, D. W., COOPER, R., JOHNSTON, A., HOWELL, P., MORTON, J., VAN DE KOOT, H., O’NELILL, D. y P. BURGESS (eds.) 1996: Cognitive Science: An introduction. Oxford, UK: Blackwell publishers, pp. 244-275.

O’NEILL, J. 1988-89: “Relevance and Pragmatic Inference”, en Theoretical Linguistics, 15, pp. 241-261.

OAKHILL, J. 1984: “Inferential and memory skills in children's comprehension of stories”, en British Journal of Education Psychology, 54, pp. 31-39. 
OAKHILL, J. y N. YUILL 1986: "Pronoun resolution in skilled and less-skilled comprehenders: Effects of memory load and inferential complexity”, en Language and Speech, 29, pp. 25-37.

OBLER, L. K. y K. GJERLOW 2001: El lenguaje y el cerebro. Madrid: Akal.

OCHS, E. y B. B. SCHIEFFELIN 1979: Developmental Pragmatics. New York: Academic Press.

OCHS, E. y B. B. SCHIEFFELIN 1984: "Language acquisition and socialization: Three developmental stories and their implications”, en SCHWEDER, R. y R. LEVINE (eds.) 1984: Culture Theory: Essays on Mind, Self and Emotion. Cambridge: Cambridge University Press, pp. 276-320.

ODLIN, T. 1989: Language Transfer: Cross-linguistic influence in language learning. Cambridge: Cambridge University Press.

OLIVERAS, A. 2000: Hacia la competencia intercultural en el aprendizaje de una lengua extranjera: estudio del choque cultural y los malentendidos. Madrid: Edinumen S. A.

OLSHTAIN, E. y A. D. COHEN 1990: “The learning of complex speech act behaviour”, en TESL Canada Journal, 7, pp. 45-65.

OLLER, J. W. 1979: Language Test at School. London: Longman.

OSORO, A. 1996: “Los lenguajes del cómic”, en Textos de Didáctica de la Lengua y la Literatura, 7, pp. 31-42.

OWENS, R. E. 2003: Desarrollo del Lenguaje (5 $5^{a}$ edición). Madrid: Pearson Prentice Hall.

PADILLA CRUZ, M. 2010: "Teaching interjection in the ESL/EFL class: a pragmatic approach”, en PÉREZ RUIZ, L., PARRADO ROMÁN, I. y P. TABARÉS PÉREZ (eds.) 2010: Estudios de metodología de la lengua inglesa. Vol. V. Valladolid: Universidad de Valladolid, pp. 23-33.

PADILLA, X. A. 2005a: Pragmática del orden de palabras. Alicante: Servicio de publicaciones de la Universidad de Alicante.

PADILLA, X. A. 2005b: “Enunciados irónicos en español: Estudio fonopragmático”, en Español Actual, 81, pp. 85-94.

PALACIOS, J., HIDALGO, M. V. y M. C. MORENO 1998: "Familia y vida cotidiana”, en RODRIGO, M. J. y J. PALACIOS (coords.) 1998: Familia y desarrollo humano. Madrid: Alianza, pp. 71-89.

PAPAFRAGOU, A. y N. TANTALOU 2004: “Children’s Computation of Implicatures”, en Language Acquisition, 12 (1), pp. 71-82.

PAPP, S. 2006: “A relevance-theoretic account of the development and deficits of theory of mind in normally developing children and individuals with autism”, en Theory \& Psychology, 16, pp. 141-161. 
PARIS, S. y L. UPTON 1976: “Children's memory for inferential relationships in prose”, en Child Development, 47, pp. 660-668.

PAYRATÓ, L. 1995: “Transcripción del discurso coloquial” en CORTÉS RODRÍGUEZ, L. (ed.) 1995: El español coloquial. Actas del I Simposio sobre análisis del discurso oral. Almería: Universidad de Almería, pp. 45-70.

PEIRCE, B. N. 1995: “Social identity, investment, and language learning”, en TESOL Quarterly, 29, pp. 9-31.

PENN, C. 1985: “The Profile of Communicative Appropiateness: A clinical tool for the assessment of pragmatics", en The South African Journal of Communication Disorders, 32, pp. 18-23.

PENN, C. 1999: "Pragmatic Assessment and Therapy for Persons with Brain Damage: What have Clinicians Gleaned in Two decades?”, en STEMMER, B. (ed.) 1999: Pragmatics: Theoretical and Clinical Issues. Brain and Language, 68 (3), pp. 535552.

PEÑA-CASANOVA, J., DIÉGUEZ-VIDE, F. y M. PÉREZ PAMIES 1995: “Tipos clínicos de afasias y alteraciones asociadas”, en PEÑA-CASANOVA, J. y M. PÉREZ PAMIES (eds.) 1995: Rehabilitación de la afasia y trastornos asociados. Barcelona: Masson, pp. 67-90.

PERAITA, H. 1989: Adquisición del lenguaje. Madrid: Universidad Nacional de Educación a Distancia.

PERALTA, M. 2000: “Adquisición y desarrollo del lenguaje y la comunicación: una visión pragmática constructivista centrada en los contextos”, en Límite, 7, pp. 54-66.

PÉREZ ESTEVE, P. 2007: “La competencia de las competencias: la comunicación lingüística. Su presencia en el currículo de Educación infantil y Primaria”, en ÁLVAREZ ANGULO, T. (dir.) 2007: La competencia en comunicación lingüística en las áreas del currículo. Madrid: Ministerio de Educación y Ciencia, pp. 9-38.

PÉREZ ESTEVE, P. y F. ZAYAS 2007: Competencia en comunicación lingüística. Madrid: Alianza.

PÉREZ GARCÍA, E. 2007: "La deixis social como concepto pragmático en la interpretación sociolingüística: Delimitación de estudios”, en Interlingüística, 17, pp. 807-816.

PÉREZ PAMIES, M., MANERO, R. M. e I. BERTRÁN SERRA 1988: “Afasias”, en PEÑA CASANOVA, J. (ed.) 2004: Manual de logopedia. Barcelona: Masson, pp. 369-408.

PÉREZ-LEROUX. A. T. y J. M. LICERAS 2002: The Acquisition of Spanish Morphosyntax: The L1/L2 Connection. Dordrecht: Kluwer.

PÉREZ-PEREIRA, M. 1989: "The acquisition of morphemes: Some evidence from Spanish”, en Journal of Psycholinguistic Research, 18, pp. 289-312. 
PERKINS, L., CRISP, J. y D. WALSHAW 1999: "Exploring conversation analysis as an assessment tool in aphasia: The issue of reliability”, en Aphasiology, 13, pp. 259281.

PERNER, J. 1991: Understanding the representation of mind. Cambridge, MA: The MIT Press.

PERNER, J., FRITH, U., LESLIE, A. M. y S. R. LEEKAM 1989: "Exploration of the autistic child's theory of mind: Knowledge, belief and communication”, en Child Development, 60, pp. 689-700.

PEXMAN, P. y M. GLENWRIGHT 2007: "How do typically developing children grasp the meaning of verbal irony?”, en Journal of Neurolinguistics, 20, pp. 178-196.

PHELPS-TERASAKI, D. y T. PHELPS-GUNN 1992: Test of pragmatic language. Hove: Psychological Corporation.

PIAGET, J. 1923: Le langage et la pensée chez l'enfant, Neuchâtel, Paris : Delachaux y Niestlè.

PIJNACKER, J., HAGOORT, P., BUITELAAR, J., TEUNISSE, J. P. y B. GEURTS 2009: "Pragmatic inferences in high-functioning adults with autism and Asperger syndrome”, en Journal of Autism and Developmental Disorders, 39, pp. 607-618.

PINE, J. 1995: "Variation in vocabulary development as a function of birth order", en Child Development, 66 (1), pp. 272-282.

PINKER, S. 1982: “A theory of the acquisition of lexical interpretive grammars”, en BRESNAN, J. (ed.) 1982: The Mental of Grammatical Relations. Cambridge, MA: MIT Press, pp. 655-726.

PINKER, S. 1995: El instinto de lenguaje: cómo crea el lenguaje la mente. Madrid: Alianza Editorial.

PINKER, S. 1997: Cómo funciona la mente. Barcelona: Destino.

PLUNKETT, T. K. 1995: “Connectionist approaches to language acquisition”, en FLECHTER, P. y B. MACWHINNEY (eds.) 1995: The handbook of child language. Oxford: Blackwell, pp. 36-72.

PONS BORDERÍA, S. 2004: Conceptos y aplicaciones de la Teoría de la Relevancia. Madrid: Arco Libros.

PONS BORDERÍA, S. 2005a: "El significado y la pragmática: desde Grice hasta la Teoría de la Relevancia”, en MOYA CORRAL, J. A. (ed.) 2005: Pragmática y Enseñanza de la Lengua Española. Actas de las X Jornadas sobre Enseñanza de la Lengua Española. Granada: Universidad de Granada, pp. 55-68.

PONS BORDERÍA, S. 2005b: La enseñanza pragmática en clase de E/LE. Madrid: Arco Libros.

PORTILLO MAYORGA, M. R. 2003: Aprendizaje y uso del español como lengua materna. León: Universidad de León.

PORTOLÉS, J. 2004: Pragmática para hispanistas. Madrid: Síntesis, D.L. 
POYATOS, F. 1980: "Interactive functions and limitations of verbal and non verbal behaviors in natural conversation”, en Semiótica, 30 (3-4), pp. 211-244.

POYATOS, F. 1994: La comunicación no verbal. Madrid: Istmo.

PRADO, J. 2001: “La competencia comunicativa en el entorno tecnológico: desafío para la enseñanza”, en Comunicar, 17, pp. 21-30.

PRADO, J. 2011: Didáctica de la lengua y la literatura para educar en el siglo XXI (2a edición). Madrid: La Muralla.

PREGO VÁZQUEZ, G. 2004: "Las narrativas en niños de tres/cuatro años: un puente entre la sintaxis y la pragmática”, en VEYRAT, M. y B. GALLARDO PAÚLS (eds.) 2004: Estudios de Lingüística Clínica. Aspectos evolutivos. Valencia: Universitat de Valencia, pp. 99-126.

PREGO VÁZQUEZ, G., SOUTO GÓMEZ, M. y B. DIESTE QUIROGA 2011: “El desarrollo pragmático: intenciones y acción comunicativa en edad temprana”, en FERNÁNDEZ PÉREZ, M. 2011: Lingüística de corpus y adquisición de la lengua. Madrid: Arco Libros, pp. 149-203.

PREMACK, D. 1990: “On the coevolution of language and social competence”, en The Behavioral and Brain Sciences, 13, pp. 754-756.

PREMACK, D. y G. WOODRUFF 1978: “Does the chimpanzee have a theory of mind?”, en The Behavioural and Brain Sciences, 7, pp. 515-526.

PRIDE, J. B. y J. HOLMES (eds.) 1972: Sociolinguistics. Harmondsworth: Penguin.

PRIETO DE LOS MOZOS, E. 1998: “Gramáticas de base pragmática y comunicativa: justificaciones”, en GALLARDO PAÚLS, B. (ed.) 1998: Temas de lingüística y gramática, Vol. I. Valencia: Publicaciones de la Universitat de Valencia, pp. 146162.

PRIETO NAVARRO, L. 2007: El aprendizaje cooperativo. Madrid: PPC.

PRINZ, P. y F. WEINER 1987: The Pragmatic Screening Test. OH: The Psychological Corporation.

PRIZANT, B. M. 1983: "Echolalia in autism: assessment and intervention”, en Seminars in Speech and Language, 4 (1), pp. 63-77.

PRUTTING, C. A. y D. M. KIRCHNER 1983: “Applied pragmatics”, en GALLAGHER, T. M. y C. A. PRUTTING 1983: Pragmatic assessment and intervention issues in language. San Diego: California College-Hill Press, pp. 29-64.

PRUTTING, C. A. y D. M. KIRCHNER 1987: “A clinical appraisal of the pragmatic aspect of language”, en Journal of Speech and Hearing Disorders, 52, pp. 105-119.

PUYUELO, M., WIIG, E. H., RENOM, J. y A. SOLANAS 1997: BLOC: Batería de Lenguaje Objetiva y Criterial. Barcelona: Masson.

RADFORD, J. y C. TARPLEE 2000: “The management of conversation topic by a ten year old child with pragmatic difficulties”, en Clinical Linguistics and Phonetics, 14, pp. 387-403. 
RAMBERG, C., EHLERS, S., NYDEN, A., JOHANSSON, M. y C. GILLBERG 1996: "Language and pragmatic functions in school-age children on the autism spectrum", en European Journal of Disorders of Communication, 31, pp. 387-414.

RAPIN, I. 1996: "Developmental language disorders: A clinical update”, en Journal of Child Psychology and Psychiatry, 37, pp. 643-655.

RAPIN, I. y D. A. ALLEN 1983: "Developmental language disorders: nosological considerations”, en KIRK, U. (ed.) 1983: Neuropsychology of language, reading and spelling. New York: Academic Press, pp. 155-184.

RAPIN, I. y M. DUNN 2003: "Update on the language disorders of individuals on the autistic spectrum”, en Brain \& Development, 25, pp. 166-172.

RATTAZZI, A. 2009: "Consideraciones diagnósticas en relación al síndrome de Asperger”, en [http://www.neurologiacognitiva.org/material/1240352230S.pdf] (último acceso: febrero 2015).

REA, P. M. 1985: "Language testing and the communicative language curriculum”, en LEE, Y., FOK, A., LORD, R. y G. LOW (eds.) 1985: New Directions in Language Testing. Oxford: Pergamon Press, pp. 15-32.

RÉCANATI, F. 1993: Direct Reference. From Language to Thought. Oxford: Blackwell.

RÉCANATI, F. 2001: “What is said”, en Synthese, 128, pp. 75-91.

RÉCANATI, F. 2002: “Unarticulated constituents”, en Linguistics and Philosophy, 25, pp. 299-345.

REDDY, V. 1999: “Prelinguistic communication”, en BARRET, M. (ed.) 1999: The development of language. Hove, UK: Psychology Press, pp. 25-50.

REPACHOLI, B. y V. SLAUGHTER (eds.) 2003: Individual differences in Theory of Mind: Implications for typical and atypical development. New York: Psychology Press.

REYES, G. 1990: La pragmática lingüística. El estudio del lenguaje. Barcelona: Montesinos.

REYES, G. 1995: El abecé de la pragmática. Madrid: Arco Libros.

REYES, G. 2002: Metapragmática. Lenguaje sobre lenguaje, ficciones, figuras. Valladolid: Editorial de la Universidad de Valladolid.

RICE, M. L. 1984: “Cognitive aspects of communicative development”, en SCHIEFELBUSCH, R. y J. PICKAR (eds.) 1984: The acquisition of communicative competence. Baltimore: University Park Press, pp. 23-67.

RICE, M., SELL, M. y P. HADLEY 1990: “The Social Interactive Coding System: An online, clinically relevant descriptive tool”, en Language, Speech and Hearing Services in Schools, 21, pp. 2-14.

RICHARDS, J. C., J. PLATT y H. WEBER 1985: Longman Dictionary of Applied Linguistic. Harlow: Longman. 
RINALDI, W. 1996: Understanding ambiguity: An assessment of pragmatic meaning comprehension. Windsor: NFER-Nelson.

RINALDI, W. 2001: Social Use of Language Programme (SULP)-revised. Windsor: NFER-Nelson.

RINTELL, E. y C. J. MITCHELL 1989: "Studying requests and apologies: An inquiry into method”, en BLUM-KULKA, S., HOUSE, J. y G. KASPER (eds.) 1989: CrossCultural Pragmatics: Requests and Apologies. Norwood, New Jersey: Ablex, pp. 248-272.

RIPICH, D. y P. GRIFFIN 1988: "Narrative abilities of children with learning disabilities and non-disabled children”, en Journal of Learning Disabilities, 21, pp. 165-173.

RIVIÈRE, A. 1996: “Actividad y sentido del autismo”, en La esperanza no es un sueño: Actas del V Congreso Internacional Autismo-Europa. Madrid: ESCUELA Libre Editorial, pp. 553-562.

RIVIÈRE, A. 1997: “Curso de desarrollo normal y autismo”, celebrado en el Casino Taoro, Santa Cruz de Tenerife (septiembre).

RIVIÈRE, A. y M. NUÑEZ 2001: La mirada mental. Bueno Aires: Aique.

ROBINSON, E. J. 1994: "What people say, what they think, and what is really the case: Children's understanding of utterances as sources of knowledge”, en LEWIS, C. y P. MITCHELL (eds.) 1994: Children's Early Understanding of Mind: Origins and Development. Hove, UK: Lawrence Erlbaum Associates, pp. 355-381.

RODRÍGUEZ, S. 2005: “Actividades para la enseñanza de pragmática en español como L2: el caso de los actos de habla”, en [http://www.iupui.edu/ flac/Rodriguez-01.pdf] (último acceso: diciembre 2014).

ROEVER, C. 2001: “Assesment of Second Language Pragmatics” en [http://www2.hawaii.edu/ roever/ilp-test.htm] (último acceso: diciembre 2014).

RONDAL, J. A. 1995: Exceptional language development in Down syndrome. Implications for the cognition-language relationship. New York: Cambridge University Press.

RONDAL, J. A. y J. SERÓN 1995: Trastornos del lenguaje. Barcelona: Paidós.

ROODENRYS, S., HULME, C. y G. BROWN 1993: "The development of short-term memory span: separable effects of speech rate and long-term memory”, en Journal of Experimental Child Psychology, 6 (3), pp. 431-442.

ROSE, K. R. 1997: "Pragmatics in the classroom: theoretical concerns and practical possibilities”, en Pragmatics and Language Learning. Monograph Series, 8, pp. 267-295.

ROSE, K. R. 2005: “On the effects of instruction in second language pragmatics”, en System, 33, pp. 385-399. 
ROSE, K. R. y C. KWAI-FUN 2001: "Inductive and deductive teaching of compliments and compliment responses”, en ROSE, K. R. y G. KASPER (eds.) 2001: Pragmatic Language Teaching. Cambridge: Cambridge University Press, pp.145-170.

ROSSElli, M., ARDILlA, A., BATEMAN, J. R. y M. GUZMÁN 2001: "Developmental norms in the neuropsychological evaluation of Spanish speaking children” en Developmental Neuropsychology, 20 (1), pp. 355-374.

ROSSElli, M., MATUTE, E., ARDELA, A., BOTERO, V. E., TANGARIFE, G. A., ECHEVERRÍA, S. E. et al. 2004: "Evaluación Neuropsicológica Infantil (ENI): Una batería para la evaluación de niños entre 5 y 16 años de edad. Estudio normativo colombiano”, en Revista de Neurología, 38 (8), pp. 720-731.

RUEDA, Y. T. 2006: “Developing pragmatic competence in a foreign language”, en Colombian Applied Linguistic Journal, 8, pp. 172-182.

RUIZ DE MENDOZA, F. J. 1996: “Aspectos pragmáticos de la negociación del significado”, en CENOZ, J. y J. F. VALENCIA (eds.) 1996: La competencia pragmática: elementos lingüísticos y psicosociales. Bilbao: Universidad de País Vasco, pp. 47-70.

RUIZ GURILLO, L. 2006: Hechos pragmáticos del español. Alicante: Publicaciones de la Universidad de Alicante.

RUIZ GURILlO, L., MARIMÓN, C., PADILLA, X. A. y L. TIMOFEEVA 2004: “El proyecto GRIALE para la ironía en español: Conceptos previos”, en Revista de Lengua Española y Lingüística General, 18, pp. 231-242.

RUIZ-CONTRERAS, A. y S. CANSINO 2005: "Neuropsicología de la interacción entre la atención y la memoria episódica: revisión de estudios de modalidad visual”, en Revista de Neurología, 41 (12), 733-743.

RUMERLHART, D. E., MCCLELLAND, J. L. y el grupo de investigación PDP 1986: Exploration in the microstructure of cognition, vol. 2. Cambridge, MA: MIT Press.

RYDER, N. y E. LEINONEN 2003: "Use of context in question answering by 3-, 4- and 5-year-old children”, en Journal of Psycholinguistic Research, 32, pp. 397-415.

SAARNI, C. 1999: The Development of emotional competence. New York: Guilford.

SACKS, H., SCHEGLOFF, E. E. y G. JEFFERSON 1974: "A simplest systematic for the organization of turn-taking for conversation”, en Language, 50 (4), pp. 696-735.

SÁNCHEZ LOBATO, J. e I. SANTOS GARGALLO (dirs.) 2004: Vademécum para la formación de profesores. Enseñar español como segunda lengua (L2) / lengua extranjera (LE). Madrid: SGEL.

SÁNCHEZ MIGUEL, E. 1998: Comprensión y redacción de textos. Barcelona: Edebé.

SANFORD, A. J. y S. C. GARROD 1981: Understanding written language. Chichester, New York: Wiley.

SANTAMARÍA, C. 1995: Introducción al razonamiento humano. Madrid: Alianza. 
SAUSSURE, F. 1916: Cours de linguistique générale, publicado por BALLY, C. y A. SECHEHAYE, con la colaboración de A. RIEDLINGERR. Lausana-París: Payot. [Traducción al español de Amado Alonso 1980: Curso de Lingüística General, Buenos Aires: Losada].

SAVIGNON, S. J. 1983: Communicative Competence: Theory and Classroom Practice. Reading, Mass: Adison-Wesley Publishing Company.

SAVILLE-TROIKE, M. 1989: The Ethnography of Communication: An Introduction. Londres: Blackwell.

SCARCELLA, R., ANDERSEN, E. S. y L. S. KRASHEN (eds.) 1990: Developing Communicative Competence in a Second Language. New York: Newbury House.

SCHANK, R. C. y R. P. ABELSON 1977: Scripts, plans, goals, and understanding. Hillsdale NJ: Lawrence Erlbaum.

SCHMIDT, R. 1993: “Conciousness, learning and interlanguage pragmatics", en KASPER, G. y S. BLUM-KULKA (eds.) 1993: Interlanguage pragmatics. New York: Oxford University press, pp. 21-42.

SEARLE, J. R. 1969: Speech acts: An Essay in the Philosophy of Language. Cambridge: Cambridge University Press.

SEARLE, J. R. 1975: “Indirect speech acts”, en COLE, P. y J. L. MORGAN (eds.) 1975: Syntax and Semantics, Volume 3: Speech Acts. New York: Academic Press, pp. 5982.

SEARLE, J. R. 1979: Expression and Meaning: Studies in the Theory of Speech Acts. Cambridge: Cambridge University Press.

SEBASTIÁN, E. y D. SLOBIN 1994: “Development of linguistic forms: Spanish”, en BERNMAN, R. y D. SLOBIN (eds.) 1994: Relating Events in Narrative: A Crosslinguistic Developmental Study. Hillsdale, NJ: LEA, pp. 239-284.

SEMEL, E., WIIG, E. H. y W. SECORD 2000: Clinical evaluation of language fundamentals-third edition. Hove: Psychological Corporation.

SERON, X. y P. FEYEREISEN 1982: “Neurolingüística”, en RONDAL, J. A. y X. SERON (eds.) 1982: Trastornos del lenguaje, 1. Lenguaje oral, lenguaje escrito, neurolingüística. Barcelona: Paidós 1991, pp. 193-241.

SERRA, M., SOLÉ, M. R., SERRAT, E., BEL, A. y M. APARICI 2000: La adquisición del lenguaje. Barcelona: Ariel.

SERRAT, E. y M. CAPDEVILA 2001: "La adquisición de la interrogación: las interrogativas parciales”, en Infancia y Aprendizaje, 24, pp. 3-17.

SHAMAY-TSOORY, S. G., TOMER, R. y J. AHARON-PERETZ 2005: "The Neuroanatomical Basis of Understanding Sarcasm and Its Relationship to Social Cognition”, en Neuropsychology, 19 (3), pp. 288-300. 
SHAND, N. y Y. KOSAWA 1985: "Japanese and American behavior types at three months: Infants and infant-mother dyads”, en Infant Behavior and Development, 8, pp. 225-240.

SHANTZ, C. 1982: “Children's understanding of social rules and social context”, en SERAFICA, C. (ed.) 1982: Social-cognitive development in context. New York: Guilford, pp. 167-198.

SHAPIRO, B. y M. DANLEY 1985: "The role of the right hemisphere in the control of speech prosody in propositional and affective contexts”, en Brain and Language, 25, pp. 19-36.

SHATZ, M. 1982: "On mechanisms of language acquisition: Can features of the communicative environment account for development?”, en WANNER, E. y L. R. GLEITMAN (eds.) 1982: Language acquisition : The stage of the art. Cambridge: Cambridge University Press, pp. 102-127.

SHATZ, M. y R. GELMAN 1973: "The development of communication skills: Modification in the speech of young children as a function of listener”, en Monographs of the Society for Research in Child Development, 38 (5), pp. 1-37.

SHIELDS, J. 1991: “Semantic-pragmatic disorder: A right hemisphere syndrome?”, en British Journal of Disorders of Communication, 26, pp. 383-392.

SHIELDS, J., VARLEY, R., BROKS, P. y A. SIMPSON 1996: "Social cognition in developmental language disorders and high-level autism”, en Developmental Medicine and Child Neurology, 38, pp. 487-495.

SHULMAN, B. 1985: Test of pragmatic skills. Tucson: Communication Skill Builders.

SIEGAL, M. 1996: "The role of learner subjectivity in second language sociolinguistic competency: Western women learning Japanese”, en Applied Linguistics, 17, pp. 356-382.

SIEGAL, M. y K. BEATTIE 1991: "Where to look first for children's understanding of false beliefs”, en Cognition, 38, pp. 1-12.

SIEGEL, L. S. 1994: "Working memory and reading: A lifespan perspective", en International Journal of Behavioral Development, 17 (1), pp. 109-124.

SIGMAN, M. y C. KASARI 1995: “Joint Attention across contexts in normal and autistic children”, en MOORE, C. y P. DUNHAM (eds.) 1995: Joint Attention: Its Origins and Role in Development. Hillsdale, New York: Lawrence Erlbaum, pp. 189-203.

SIGUÁN, M. 1995: La enseñanza de la lengua por tareas. Barcelona: ICE-Horsori.

SILVA, A. J. B. 2003: "The effects of instruction on pragmatic development: teaching polite refusals”, en English in Second Language Studies, 22 (1), pp. 55-106.

SINCLAIR, H. 1967: Acquisition du langage et dévelopment de la pensée. Paris: Dunod.

SKINNER, B. F. 1957: Verbal Behavior. Englewood Clifts, New Jersey: Prentice-Hall.

SLOBIN, D. I. 1985: The crosslinguistic study of language acquisition. Hillsdale, New Jersey: LEA. 
SLOBIN, D. I. 1997: “The Universal, the Typological, and the Particular in Acquisition”, en SLOBIN, D. I. (ed.) 1997: The Crosslinguistic Study of Language Acquisition, vol. 5 (Expanding the Contexts). Hillsdale: Lawrence Erlbaum, pp.1-39.

SMITH, B. R. y E. LEINONEN 1992: Clinical Pragmatics. Unravelling the complexities of communicative failure. London: Chapman and Hall.

SNOW, C. E. 1991: "The theoretical basis for relationships between language and literacy”, en Journal of Research in Childhood Education, 6, pp. 5-10.

SNOW, C. E., SMITH, N. y M. HOEFNAGEL-HÖLE 1980: "The acquisition of some Dutch morphological rules”, en Journal of Child Language, 7, pp. 539-553.

SNOW, C. E. y D. K. DICKINSON 1991: "Skills that aren't basic in a new conception of literacy”, en PURVES, A. y E. JENNINGS (eds.) 1991: Literate systems and individual lives. Perspectives on literacy and schooling. Albany, New York: Suny Press, pp. 175-213.

SPANOUDIS, G., NATSOPOULOS, D. y G. PANAYIOTOU 2007: "Mental verbs and pragmatic language difficulties", en International Journal of Language and Communication Disorders, 42 (4), pp. 487-504.

SPECTOR, C. 1996: “Children's comprehension of idioms in the contexts of humour”, en Language, Speech and Hearing Services in Schools, 27, pp. 307-313.

SPERBER, D. 1994: “Understanding verbal understanding”, en KHALFA, J. (ed.) 1994: What is Intelligence?. Cambridge: Cambridge University Press, pp. 179-198.

SPERBER, D. y D. WILSON 1981: "Irony and the use-mention distinction”, en COLE, P. (ed.) 1981: Radical Pragmatics. New York: Academic Press, pp. 295-318.

SPERBER, D. y D. WILSON 1982: "Manual knowledge and relevance in theories of comprehension”, en SMITH, N. V. (ed.) 1982: Mutual Knowledge. London: Academic Press, pp. 61-85.

SPERBER, D. y D. WILSON 1986/1995: Relevance: Communication and Cognition (2 ${ }^{\text {nd }}$ expanded edition). Oxford, UK: Blackwell.

SPERBER, D. y D. WILSON 1990: “Retórica y pertinencia”, en Revista de Occidente, 115, pp. 5-26.

SPERBER, D. y D. WILSON 1997: "Remarks on relevance theory and social sciences”, en Multilingua, 16, pp. 145-151.

SPERBER, D. y D. WILSON 1998: "Irony and relevance: A reply to Seto, Hamamoto and Yamanashi”, en CARSTON, R. y S. UCHIDA (eds.) 1998: Relevance Theory: Applications and Implications. Amsterdam: John Benjamins, pp. 283-293.

SPERBER, D. y D. WILSON 2002: "Pragmatics, Modularity and Mind-reading”, en Mind and Language, 17, pp. 3-23.

SPOLSKY, B. (ed.) 1978: Approaches to Language Testing. Advances in Language Testing Series, 2. Arlington: Va. Center for Applied Linguistics. 
STEMMER, B. (ed.) 1999: "Pragmatics: Theoretical and Clinical Issues”, en Brain and Language, 68 (3), pp. 393-401.

STEMMER, B., GIROUX, F. y Y. JOANETTE 1994: "Production and evaluation of request by right hemisphere brain-damaged individuals”, en Brain and Language, 47, pp. 1-31.

STERN, C. y W. STERN 1907: Die Kindersprache, Eine Psychologische und Sprachteoritische Undersuchung. Leipzig: Barth.

STROHNER, H. y K. E. NELSON 1974: “The young child's development of sentence comprehension: Influence of event probability, nonverbal context, syntactic form, and strategies”, en Child Development, 45, pp. 567-576.

SULLIVAN, K., ZAITCHIK, D. y H. TAGER-FLUSBERG 1994: "Preschoolers can attribute second-order beliefs”, en Developmental Psychology, 30, pp. 395-402.

SULLIVAN, K., WINNER, E. y N. HOPFIELD 1995: "How Children Tell a Lie from a Joke: The Role of Second-Order Mental State Attributions”, en British Journal of Developmental Psychology, 13, pp. 191-204.

SURIAN, L., BARON-COHEN, S. y H. VAN DER LELY 1996: “Are children with autism deaf to Gricean Maxims?”, en Cognitive Neuropsychiatry, 1, pp. 55-71.

SURIAN, L. y M. SIEGAL 2001: "Sources of Performance on Theory of Mind Tasks in Right Hemisphere-Damaged Patients”, en Brain and Language, 78, pp. 224-232.

TAGA, G., ASAKAWA, K., MAKI, A., KONISHI, Y. y H. HOIZUMI 2003: "Brain imaging in awake infants by near-infrared optical topography", en Proceedings of the National Academy of Science U. S. A., 100 (19), pp. 10722-10727.

TAGER-FLUSBERG, H. 1981: "On the nature of linguistic functioning in early infantile autism”, en Journal of Autism and Developmental Disorders, 11, pp. 45-56.

TAKAHASHI, S. 2001: "The role of input enhancement in developing pragmatic competence”, en ROSE, K. R. y G. KASPER (eds.) 2001: Pragmatic Language Teaching. Cambridge: Cambridge University Press, pp. 125-144.

TAMARIT, J. 1990: “Comunicación y autismo: Claves para un logopeda aventurero” ponencia de las Jornadas de Renovación Logopédica "Ciudad de Plasencia”, en [www.asociacionalanda.org/pdf/articulos/autismo_logopeda.pdf] (último acceso febrero 2015).

TAMARIT, J. 1992: "El autismo y las alteraciones de la comunicación en la infancia y adolescencia. Intervención educativa”, en Páginas Autismo España: [http://aut.ts.es/] (último acceso: febrero 2015).

TANNEN, D. y C. WALLAT 1987: "Interactive frames and knowledge schemas in interaction: examples from medical examination/interview”, en JAWORSKI, A. y A. N. COUPLAND (eds.) 1999: The Discourse Reader. Londres: Routledge, pp. 332348. 
TATEMAYA, Y. 2001: "Explicit instruction and JFL learner's use of international discourse markers”, en ROSE, K. R. y G. KASPER (eds.) 2001: Pragmatics in language teaching. Cambridge: Cambridge University Press, pp. 200-222.

TATEYAMA, Y., KASPER, G., MUI, L., TAY, H. y O. THANANART 1997: “Explicit and implicit teaching of Japanese pragmatics routines”, en BOUTON, L. (ed.) 1997: Pragmatics and language learning, 8. Urbana, IL: University of Illinois at UrbanaChampaign, pp. 163-177.

TAYLOR, D. S. 1988: "The meaning and use of the term competence in linguistics and applied linguistics”, en Applied Linguistics, 9, pp. 148-168.

THIERRY, G., VIHMAN, C. A. M. y M. ROBERTS 2003: "Familiar words capture the attention of 11-month-olds in less than 250ms”, en NeuroReport, 14 (18-19), pp. 2307-2310.

THOMAS, J. 1983: “Cross-Cultural Pragmatic Failure”, en Applied Linguistics, 4, pp. 91112.

THOMAS, J. 1995: Meaning in interaction: an introduction to pragmatics. London: Longman.

TOMASELLO, M. 1992: First verbs. Cambridge, MA: Cambridge University Press.

TOMASELLO, M., KRUGER, A. y H. RATNER 1993: “Cultural learning”, en Behavioral and Brain Sciences, 16, pp. 495-552.

TOMASELLO, M. y P. BROOKS 1999: "Early syntactic development: A construction grammar approach”, en BARRET, M. (ed.) 1999: The development of language. Hove: Psychology Press, pp. 161- 190.

TORDERA, J. C. 2007: “Trastorno de espectro autista: Delimitación lingüística”, en ELUA, 21, pp. 301-314.

TORDERA, J. C. 2014: "La evaluación de la competencia pragmática en el nivel B2 del Instituto Cervantes”, en Foro de Profesores de E/LE, 10, pp. 271-281.

TUSÓN VALLS, A. 1997: Análisis de la conversación. Barcelona: Ariel.

UDWIN, O. y W. JULE 1990: "Expressive language of children with Williams Syndrome”, en American. Journal of Med. Genetics, 6, pp. 108-114.

UDWIN, O., YULE, W. y N. MARTIN 1987: "Cognitive abilities and behavioral characteristics of children with idiopathic infantile hypercalcaemia”, en Journal of Child Psychology and Psychiatry, 28, pp. 297-309.

UMSTEAD, R. S. y L. B. LEONARD 1983: “Children's resolution of pronominal reference in text”, en First Language, 4, pp. 73-84.

UTSUMI, A. 2000: "Verbal irony as implicit display of ironic environment: Distinguishing ironic utterances from non irony”, en Journal of Pragmatics, 32, pp. 1777-1806. 
VAN DER HENST, J. B., SPERBER, D. y G. POLITZER 2002: "When is a conclusion worth deriving? A relevance-based analysis of indeterminate relational problems”, en Thinking and Reasoning, 8, pp. 1-20.

VAN DER HENST, J. B. y D. SPERBER 2004: “Testing cognitive and communicative principle of relevance”, en NORVECK, I. A. y D. SPERBER (eds.) 2004: Experimental Pragmatics. Basindstoke, UK: Palgrave Macmillan, pp. 141-171.

VAN DER MEER, A., VAN DER WEEL, F. R. y D. N. LEE 1995: “The functional significance of arm movements in neonatos”, en Science, 267, pp. 693-695.

VAN DIJK, T. A. 1977: Text and Context. Explorations in the semantics and pragmatics of discourse. London: Longman.

VAN DIJK, T. A. 1995: “Discourse semantics and ideology”, en Discourse and society, 6 (2), pp. 243-289.

VAN DIJK, T. A. 2001: “Algunos principios de una teoría del contexto”, en ALED. Revista latinoamericana de estudios del discurso, 1(1), pp. 69-81.

VAN DIJK, T. A. y W. KINTSCH 1983: Strategies of discourse comprehension. New York: Academic Press.

VAN EK, J. A. 1986: Objectives for Foreign Language Learning (Vol I.). Estrasburgo: Council of Europe.

VAN EK, J. A. y J. L. M. TRIM 1991: Threshold 1990. Cambridge: Cambridge University Press.

VAN HOUT, A. 2001: “Afasia del niño”, en NARBONA, J. y C. CHEVRIE-MULLER (eds.) 2001: El lenguaje del niño (2 ${ }^{a}$ edición). Barcelona: Mason, pp. 277-285.

VANHALLE, C., LEMIEUX, S., SKA, B. y Y. JOANETTE 2000: “The evaluation of the Ability of Right-Hemisphere-Damage Patients to Process Speech Acts: An Ecological Approach”, en Brain and Language, 74: Academy of Aphasia Meeting, pp. 483-486.

VARÓN LÓPEZ, A. 2008: “El contexto en la teoría de la relevancia”, en [http://human.kanagawa-u.ac.jp] (último acceso: enero 2015).

VELLENGA, H. 2004: "Learning pragmatics form ESL and EFL text books: How likely?”, en TESL Electronic Journal, 8 (2), pp. 1-18.

VENDRELL, J. M. 2001: “Las afasias: semiología y tipos clínicos”, en Revista Neurología, 32 (10), pp. 980-986.

VERA LUJÁN, A. y M. BLANCO RODRÍGUEZ 2014: Cuestiones de Pragmática en la enseñanza del español como 2/L. Madrid: Arco Libros.

VERDE RUIZ, S. 2010: La competencia pragmática: componentes, desarrollo y aplicación. Trabajo de Grado. Salamanca: Universidad de Salamanca.

VERSCHUEREN, J. 1999: Understanding Pragmatics. Londres: Arnold. 
VERSCHUEREN, J. 2000: “Notes on the role of metapragmatic awareness”, en Language use, Pragmatics, 10 (4), pp. 439-456.

VERSCHUEREN, J. y J. O. ÖSTMAN (eds.) 2006: Handbook of pragmatics: 2006 installment. Amsterdam: John Benjamin.

VERTÉ, S., GEURTS, H. M., ROEYERS, H., ROSSEEL, Y., OOSTERLAAN, J. y J. A. SERGEANT 2006: "Can the children's communication checklist differentiate autism spectrum subtypes?”, en Autism, 10 (3), pp. 266-287.

VICENTE MATEU, J. A. 1994: La deixis. Egocentrismo y subjetividad en el lenguaje. Murcia: Universidad de Murcia.

VIEIRO, P. y J. A. GARCÍA-MADRUGA 1997: “An analysis of story comprehension through spoken and written summaries in school-age children”, en Reading and Writing: An Interdisciplinary Journal, 9, pp. 41-53.

VILÀ, M. 2005: "El discurso explicativo oral: estrategias comunicativas”, en VILÀ, M. (coord.) 2005: El discurso oral formal: contenidos de aprendizaje y secuencias didácticas. Barcelona: Grao, pp. 37-56.

VYGOTSKY, L. S. 1934/1986: Thinking and Language. Cambridge, MA: MIT Press, [Original ruso de 1934].

WAKUSAWA, K., SUGIURA, M., SASSA, Y., JEONG, H., HORIE, K., SATO, S., YOKOYAMA, H., TSUCHIYA, S., INUMA, K. y R. KAWASHIMA 2007: "Comprehension of implicit meanings in social situations involving irony: A functional MRI study”, en Neuroimage, 37 (4), pp. 1417-1426.

WALKER, R. C. S. 1989: “Review of Relevance”, en Mind and Language, 4, pp. 151159.

WARREN, A. R. y L. A. MCCLOSKEY 1997: "Language in social contexts", en GLEASON, J. B. (ed.) 1997: The development of language. Boston: Allyn and Bacon, pp. 210-258.

WATSON, T. J. 1925: Behaviorism. New York: Norton.

WEINREICH, U. 1996: “On the semantic structure of English”, en GREENBERG, J. H. (ed.) 1996: Universals of language, $2^{\text {nd }}$ Edition. Cambridge, MA: MIT Press, pp. 142-217.

WEIR, C. J. 1988: Communicative language testing with special reference to English as a FL. Exeter: University of Exeter.

WEISMER, S. y J. EVANS 2002: “The role of processing limitations in early identification of specific language impairment”, en Topics in Language Disorders, 22, pp. 15-29.

WELLMAN, H. M., CROSS, D. y J. WATSON 2001: "Meta-analysis of theory-of-mind development: The truth about false belief”, en Child Development, 72, pp. 665-584.

WELLS, G. 1985: Language development in the pre-school years. Cambridge: Cambridge University Press. 
WEXLER, K. y P. CULLICOVER 1980: Formal Principles of Language Acquisition. Cambridge, MA: MIT Press.

WHITEHURST, G. J., SMITH, M., FISCHEL, J. E., ARNOLD, D. S. y C. J. LONIGAN 1991: "The continuity of babble and speech in children with specific expressive language delay”, en Journal of Speech, Language, and Hearing Research, 34, pp. 1121-1129.

WIDDOWSON, H. G. 1989: "Knowledge of language and ability for use”, en Applied Linguistics, 10, pp. 128-137.

WIEMANN, J. y P. BLACKLUND 1980: "Current Theory and Research in Communicative Competence” en Review of Educational Research, 50 (1), pp. 185199.

WIIG, E. H. 1990: Wiig Criterion Referenced Inventory of Language. San Antonio, TX: The Psychological Coorporation.

WIIG, E. H. y W. SECORD 1989: Test of Language Competence- expanded edition. Hove: Psychological Corporation.

WILDNER-BASSETT, M. 1984: Improving pragmatic aspects of learners' interlanguage. Tübingen: Narr.

WILKINSON, L. C., WILKINSON, A. C., SPINELLI, F. y C. P. CHIANG 1984: "Metalinguistic knowledge of pragmatic rules in school age children", en Child Development, 55, pp. 2130-2140.

WILSON, D. 1975: Presupposition and Non-Truth Conditional Semantics. New York: Academic Press.

WILSON, D. 2000: “Metarepresentation in linguistic communication”, en SPERBER, D. (ed.) 2000: Metarepresentations: A Multidisciplinary Perspective. Oxford: Oxford University Press, pp. 411-448.

WILSON, D. 2003: “New Direction for Research on Pragmatics and Modularity”, en UCL Working Papers in Linguistics, 15, pp. 105-127.

WILSON, D. 2006: “The pragmatics of verbal irony: Echo or pretence?”, en Lingua, 116, pp. 1722-1743.

WILSON, D. y D. SPERBER 1988: "Representation and relevance”, en KEMPSON, R. M. (ed.) 1988: Mental Representations: The Interface between Language and Reality. Cambridge: Cambridge University Press, pp. 133-153.

WILSON, D. y D. SPERBER 1993: “Linguistic form and relevance”, en Lingua, 90, pp. $1-25$.

WILSON, D. y D. SPERBER 2002a: “Relevance Theory”, en UCL Working Papers in Linguistics, 14, pp. 249-287.

WILSON, D. y D. SPERBER 2002b: “Truthfulness and relevance”, en Mind, 11, pp. 583632. 
WILSON, D. y D. SPERBER 2004: "Relevance Theory”, en HORN, L. y G. WARD (eds.) 2004: Handbook of Pragmatics. Oxford, UK: Blackwell, pp. 607-632.

WIMMER, H. y J. PERNER 1983: "Beliefs about beliefs: Representation and constraining function of wrong beliefs in young children? Understanding of deception”, en Cognition, 13, pp. 103-128.

WISHNOFF, J. 2000: “Hedging your bets: L2 learners' acquisition of pragmatic devices in academic writing and computer-mediated discourse", en Working Papers of the Department of ESL, 19 (1), pp. 119-157.

WITELSON, S. 1987: “Neurobiological aspects of language in children”, en Child Development, 58, pp. 653-688.

WOLF, A. J. E. 1999: “Context and relevance theory in language teaching”, en IRAL, 37, pp. 95-109.

XIAO-LE, G. 2011: "The effect of Explicit and Implicit Instructions of Request Strategies”, en Intercultural Communication Studies XX, 1, pp 104-123.

YONT, K., HEWITT, L. y A. MICCIO 2000: “A coding system for describing conversational breakdowns in pre-school children”, en American Journal of Speech Language Pathology, 9, pp. 300-309.

YOSHIMI, D. R. 2001: "Explicit instruction and JFL learners' use of interactional discourse markers”, en ROSE, K. R. y G. KASPER (eds.) 2001: Pragmatic in Language teaching. Cambridge: Cambrigde University Press, pp. 223-247.

YOUNG, E. C., DIEHL, J. J., MORRIS, D., HYMAN, S. L. y L. BENNETTO 2005: “The use of two language test to identify pragmatic language problems in children with autism spectrum disorders”, en Language, Speech, and Hearing Services in Schools, 36 (1), pp. 62-72.

YULE, G. 2007: El Lenguaje. Madrid: Akal.

ZAIDEL, E., KASHER, A., SOROKER, N. y G. BATORI 2002: "Effects of Right and Left Hemisphere Damage on Performance of the Right Hemisphere Communication Battery”, en Brain and Language, 80, pp. 510-535.

ZEGARAC, V. 2004: "Relevance theory and the in second language acquisition", en Second Language Research, 20, pp. 193-211.

ZORRIQUETA, M. E. 1996: "Desarrollo de las convenciones pragmáticas en la adquisición de las oraciones de relativo en castellano”, en Actas del I Encuentro Internacional sobre Adquisición de las Lenguas del Estado. Santiago de Compostela: Universidad de Santiago de Compostela, pp. 329-334. 


\section{ANEXO 1.}

\section{Muestra de ítems (TEST PRAGMÁTICO PARA ELE)}

\section{2.- Estás en un grupo de la clase que está organizando una salida a un concierto. Quieres invitar a un profesor que también es amigo tuyo. ¿Qué le dices?}

A. Oye, queremos ir a un concierto con un grupo de la clase. ¿Quieres acompañarnos?

B. Oiga un pregunta. ¿Podría venir un amigo mi con nosotros al concierto?

C. Me gustaría invitarle a un concierto mañana por la noche. Espero que acepte mi invitación.

D. Sábado con la clase iremos a un concierto. ¿Qué te parece de venir con nosotros?

4. Estás haciendo un ejercicio de deberes. Piensas que lo has hecho bien pero no estás seguro. Quieres pedirle a un profesor que mire si tus respuestas son correctas. ¿Qué le dices?
A. Ya podrías mirarme esto un rato. ¿No?
B. ¿Puede conectar mi ejercicio, por favor?
C. ¿Puede mirarme este ejercicio para ver si mis respuestas son correctas, por favor?
D. Oiga, por favor. ¿Esto es bien?

15. Normalmente vas a la escuela con un profesor que también es amigo tuyo. Una mañana estáis llegando tarde y quieres sugerirle que toméis el autobús. ¿Qué le dices?
A. Oye. Yo me voy porque tengo prisa.
B. Oye, ¿porqué no cogemos el autobús que ya es muy tarde?
C. ¿Qué te parece si iremos en autobús? Es muy tarde.
D. Si usted quiere podríamos coger el autobús porque es un poco tarde.

17. Estás comiendo con un compañero en el bar de la escuela. Él dice que la comida es siempre más cara en la escuela que fuera de la escuela; estás seguro que no. ¿Qué le dices para sacarle de su error?
A. Pero, ¿qué dices? Al contrario. En la escuela la comida y las bebidas son más baratas que fuera.
B. La comida está bien y comer en la escuela es divertido.
C. Como digas tonterías te rompo la cara. Este sitio es más barato
D. Que no. La comida del bar de la escuela es más barato que en otro sitio

Fuente: Hervás, Picó y Vilarrubias (1990: 195-196). 
ANEXO 2.

Listas de habilidades pragmáticas

CATEGORÍAS DE FALTA DE PROPIEDAD (INAPROPIACY) (Bishop y Adams, 1989)

Problemas expresivos de tipo semántico o sintáctico

Fallo en la comprensión del significado del enunciado adulto

Problemas pragmáticos I: Violación de la estructura del intercambio

Ausencia de respuesta

No toma en consideración una sugerencia

Problemas pragmáticos II: Fallo en el uso del contexto en la comprensión del enunciado adulto

Problemas pragmáticos III: Demasiada poca información

Presuposición inadecuada

Referente no establecido

Omisión de un elemento lógico en un argumento o secuencia

Problemas pragmáticos IV: Demasiada información

Afirmación innecesaria

Elaboración excesiva

Repetición innecesaria

Falta de uso de elipsis

Contenido o estilo inusual o socialmente inapropiado

Inestabilidad en el mantenimiento del tema

Cambio de tema sin señalar

Formulación estereotipada

Pregunta inadecuada (a la que el adulto no puede contestar, o cuya respuesta conoce el niño)

Enunciado socialmente inapropiado (demasiado familiar, o lo contrario)

\section{Otro}

Carece de conocimiento o experiencia

Sin clasificar

Fuente: Monfort et al. (2004: 31) 
LISTA DE CONTROL DEL LENGUAJE PRAGMÁTICO DE TATTERSHALL (Hilton, 1990)

\section{Introducción al tema}

A. ¿Introduce los temas?

B. ¿Es capaz de llamar la atención del receptor?

C. ¿Son suficientes las informaciones que proporciona?

D. ¿Varía los temas?

E. ¿Encuentra las palabras exactas sin utilizar demasiado muletillas como “eso”, “cosa”...?

F. ¿Son sus palabras coherentes y fáciles de seguir?

G. ¿Se adapta a situaciones diferentes (varía el estilo, la selección de vocabulario...)

H. ¿Subraya los elementos más importantes sin dejar que el receptor se las arregle como pueda?

\section{Mantenimiento del tema}

A. ¿Contesta a las preguntas?

B. ¿Reconoce y mantiene el tema del otro?

C. ¿Pide las informaciones que necesita?

D. ¿Da informaciones respecto al tema?

E. Si le resulta confuso, ¿pide aclaraciones?

F. ¿Expresa su desacuerdo?

G. ¿Espera su turno y puede introducir adecuadamente un tema?

H. ¿Mantiene el turno de palabra bastante tiempo?

I. ¿Se da cuenta de que el receptor se aburre?

J. ¿Se da cuenta de que el receptor no le sigue?

\section{Objetivos diversos}

A. ¿Hace peticiones sin ser demasiado brusco?

B. ¿Puede dar instrucciones claras a los receptores?

C. ¿Se comporta de forma inapropiada con los demás?

D. ¿Sabe dar las gracias, pedir disculpas...?

E. ¿Interpreta y utiliza las señales no verbales con el fin de hacer o decir lo apropiado?

F. Cuando el receptor no le sigue, ¿revisa sus mensajes?

G. ¿Tienen relación sus respuestas con las preguntas realizadas?

H. ¿Expresa sus sentimientos?

I. ¿Explica sus sentimientos?

J. ¿Se defiende en un conflicto?

K. ¿Expresa sus opiniones?

L. ¿Es capaz de defender sus puntos de vista?

M. ¿Hace prueba de imaginación (no solo en temas propuestos, sino por sí solo)?

N. ¿Pregunta para aprender o por curiosidad?

O. ¿Hace preguntas a los adultos?

P. ¿Sabe pedir las cosas con tacto?

IV. Manifestaciones no verbales

A. ¿ ¿Habla suficientemente rápido y fuerte?

B. ¿Es adecuado su contacto visual con el receptor?

Fuente: Monfort et al. (2004: 32-33) 


\section{ANEXO 3.}

\section{Children's Communication Checklist: ítems}

\begin{tabular}{|c|}
\hline Items (Pragmatics in the Children's Communication Checklist ) \\
\hline 1. People understand virtually everything he says \\
\hline 2. People have trouble in understanding much of what he says \\
\hline 3. Seldom makes errors in producing speech sounds \\
\hline 4. Mispronounces one or two speech sounds but is not difficult to understand \\
\hline 5. Production of speech sounds immature, like that of a younger child \\
\hline 6. He seems unable to produce several sounds \\
\hline 7. Leaves off beginning or ends of words, or omits entire syllables \\
\hline $\begin{array}{l}\text { 8. It is much harder to understand him when he is talking in sentences, rather than just } \\
\text { producing single words }\end{array}$ \\
\hline 9. Speech is extremely rapid \\
\hline $\begin{array}{l}\text { 10. Seems to have difficulty in constructing the whole of what he wants to say, makes false } \\
\text { starts, and repeats whole words and phrases }\end{array}$ \\
\hline 11. Speech is clearly articulated and fluent \\
\hline 12. Speech is mostly two or three words phrases \\
\hline 13. Can produce long and complicated sentences \\
\hline 14. Tends to leave out words and grammatical endings, producing sentences \\
\hline 15. Sometimes makes errors in pronouns \\
\hline 16. Talks to anyone and everyone \\
\hline 17. Talks too much \\
\hline 18. Keeps telling people things that they know already \\
\hline 19. Talks to himself \\
\hline ely about things that $n$ \\
\hline 21. Asks questions although he knows already the answer \\
\hline $\begin{array}{l}\text { 22. It is sometimes hard to make sense of what he is saying because it seems illogical or } \\
\text { disconnected }\end{array}$ \\
\hline 23. Conversation with him can be enjoyable and interesting \\
\hline 24. Can give an easy-to-follow account of a past event \\
\hline 25. Can talk clearly about what he plans to do in the future \\
\hline 26. Would have difficulty in explaining a younger child how to play a game such as ‘snap’ \\
\hline $\begin{array}{l}\text { 27. Would have difficulty in telling a story, or describing what he has done, in an orderly } \\
\text { sequence of events }\end{array}$ \\
\hline 28. Uses terms like ‘he’ or ‘it’ without making clear what he is talking about \\
\hline $\begin{array}{l}\text { 29. Does not seem to realize the need to explain what he is talking about to someone who does } \\
\text { not share his experiences }\end{array}$ \\
\hline $\begin{array}{l}\text { 30. Pronounces words in an over-precise manner: accent may sound rather affected or 'put on', } \\
\text { as if the child is mimicking a television personality rather than talking like those around him }\end{array}$ \\
\hline 31. Makes frequent use of expressions \\
\hline 32. Will suddenly change the topic of conversation \\
\hline $\begin{array}{l}\text { 33. Often turns the conversation to a favourite theme, rather than following what the other } \\
\text { persons wants to talk about }\end{array}$ \\
\hline 34. Conversation with him tends to go off in unexpected directions \\
\hline 35. Includes over-precise information in his talk \\
\hline $\begin{array}{l}\text { 36. Has favourite phrases, sentences or longer sequences which he will use a great deal, } \\
\text { sometimes in inappropriate situations }\end{array}$ \\
\hline 37. Sometimes seems to say things that he does not fully understand \\
\hline 38. Tends to repeat back what others have just said \\
\hline 39. His ability to communicate clearly seems to vary a great deal from one situation to another \\
\hline 40. Takes in just one or two words in a sentence, and so often misinterprets what has been said \\
\hline
\end{tabular}


42. Tends to be over-literal, sometime with (unintentionally) humorous results.

43. Gets into trouble because he does not always understand the rules for polite behaviour, and is regarded by others as rude or strange

44. May say things which are tactless or socially inappropriate

45. Treats everyone the same way, regardless of social status

46. Ignores conversational overtures from others

47. Seldom or never starts a conversation does not volunteer information about what has happened

48. Does not seem to read facial expressions or tone of voice adequately and may not realize when other people are upset or angry

49. Poor at using facial expression or gestures to convey his feelings; he may look blank when angry, or smile when anxious

50. Makes good use of gestures to get his meaning across

51. Seldom or never looks at the person he is talking to: seems to actively avoid eye contact

52. Tends to look away from the person he is talking to: seems inattentive or preoccupied

53. Smiles appropriately when talking to people

54. Is popular with other children

55. Has one or two good friends

56. Tends to be babied, teased or bullied by other children

57. Is deliberately aggressive to other children

58. May hurt or upset other children unintentionally

59. A loner: neglected by other children, but not disliked

60 . Perceived as odd by other children and actively avoided

61. Has difficulty making relations with others because of anxiety

62. With familiar adults, he seems inattentive, distant or preoccupied

63. Overly keen to interact with adults, lacking inhibition that most children show with strangers

64. Uses sophisticated or unusual words

65. Has a large store of factual information

66. Has one or more over-riding specific interests, and will prefer doing activities involving this to anything else

67. Enjoys watching television programs intended for children of his age

68. Seems to have no interests: prefers to do nothing

69. Prefers to do things with other children rather than on his own

70. Prefers to be with adults rather than other children

Fuente: Bishop (1998: 879-891) 
ANEXO 4.

Protocolo Pragmático de Prutting y Kirchner (1983)

\begin{tabular}{|c|c|c|c|c|}
\hline ACTO COMUNICATIVO & $\begin{array}{l}\text { USO } \\
\text { APROPIADO }\end{array}$ & $\begin{array}{l}\text { USO } \\
\text { INAPROPIADO }\end{array}$ & $\begin{array}{l}\text { SIN } \\
\text { OBSERVACIÓN }\end{array}$ & $\begin{array}{l}\text { EJEMPLOS Y } \\
\text { COMENTARIOS }\end{array}$ \\
\hline \multicolumn{5}{|l|}{ Aspectos verbales } \\
\hline \multicolumn{5}{|l|}{ A. Actos de habla } \\
\hline \multicolumn{5}{|l|}{ 1. Par adyacente } \\
\hline \multicolumn{5}{|l|}{ 2. Tipo de Acto de habla } \\
\hline \multicolumn{5}{|l|}{ B. Temas de conversación } \\
\hline \multicolumn{5}{|l|}{ 3. Selección } \\
\hline \multicolumn{5}{|l|}{ 4. Introducción } \\
\hline \multicolumn{5}{|l|}{ 5. Mantenimiento } \\
\hline \multicolumn{5}{|l|}{ 6. Cambio } \\
\hline \multicolumn{5}{|l|}{ C. Toma de turno } \\
\hline \multicolumn{5}{|l|}{ 7. Inicio } \\
\hline \multicolumn{5}{|l|}{ 8. Respuesta } \\
\hline \multicolumn{5}{|l|}{ 9. Rectificación- revisión } \\
\hline \multicolumn{5}{|l|}{ 10. Tiempo de pausa } \\
\hline \multicolumn{5}{|l|}{$\begin{array}{l}\text { 11. Interrupción- } \\
\text { solapamiento }\end{array}$} \\
\hline \multicolumn{5}{|l|}{ 12. Retroalimentación } \\
\hline \multicolumn{5}{|l|}{ 13. Adyacencia } \\
\hline \multicolumn{5}{|l|}{ 14. Contingencia } \\
\hline \multicolumn{5}{|l|}{ 15. Cantidad- concisión } \\
\hline \multicolumn{5}{|c|}{ D. Selección léxica/ uso en los actos de habla } \\
\hline \multicolumn{5}{|c|}{ 16. Especificidad/propiedad } \\
\hline \multicolumn{5}{|l|}{ 17. Cohesión } \\
\hline \multicolumn{5}{|l|}{ E. Variaciones estilísticas } \\
\hline \multirow{2}{*}{\multicolumn{5}{|c|}{$\begin{array}{l}\text { 18. Cambios de estilo } \\
\text { comunicativo } \\
\text { F. Inteligibilidad v prosodia }\end{array}$}} \\
\hline & & & & \\
\hline \multicolumn{5}{|l|}{ 19. Inteligibilidad } \\
\hline \multicolumn{5}{|l|}{ 20. Intensidad vocálica } \\
\hline \multicolumn{5}{|l|}{ 21. Cualidad vocálica } \\
\hline 22. Prosodia & & & & \\
\hline 23. Fluidez & & & & \\
\hline Aspectos no verbales & & & & \\
\hline G. Kinésica y proxémica & & & & \\
\hline 24. Proxémica física & & & & \\
\hline 25. Contacto físico & & & & \\
\hline 26. Postura corporal & & & & \\
\hline $\begin{array}{l}\text { 27. Movimientos de pies, } \\
\text { piernas, brazos y manos }\end{array}$ & & & & \\
\hline 28. Gestos & & & & \\
\hline 29. Expresión facial & & & & \\
\hline 30. Mirada & & & & \\
\hline
\end{tabular}

Fuente: Gallardo Paúls (2006: 176) 


\section{ANEXO 5.}

Pragmatics Profile of Early Communication Skills de Dewart y Summers (1988)

\section{A. INTENCIONES COMUNICATIVAS}

\section{DIRECCIÓN DE LA ATENCIÓN}

Ejemplos: Llorando. Haciéndole gestos de queja. Vocalizando. Llamándola (v. gr. “¡Mami!”)

\section{A) Hacia sí mismo}

¿Cómo capta [nombre del niño] su atención?

\section{B) Hacia los hechos}

Si usted y [nombre del niño] van por la calle o están en un parque y él/ella ve algo que le interesa, ¿qué querría hacer?

Ejemplos: Señalar. Señalar y vocalizar. Señalar y mirarle a Ud. Decir alguna palabra, v. gr. “¡mira!”, “avión”.

Empezar a hablar de ello

\section{(...)}

\section{B. RESPUESTA A LA COMUNICACIÓN}

\section{LOGRAR LA ATENCIÓN DEL NIÑO}

hace?

Si Ud. Quiere captar la atención de [nombre del niño] ¿Cómo lo

Ejemplos: Moviéndome la cabeza cerca de su cara. Tocándolo/la. Diciendo su nombre.

\section{INTERÉS EN LA INTERACCIÓN} responde normalmente?

Si Ud. está sentado junto a [nombre del niño] y le habla, ¿cómo

Ejemplos: Muestra poco interés. Mira con atención y asegura el contacto visual. Mueve su cuerpo o su cara. Participa en la "conversación” mediante sonidos o palabras.

\section{(...)}

\section{INTERACCIÓN Y CONVERSACIÓN}

bien?

¿En qué ocasiones siente Ud. y [nombre del niño] se comunican

¿Puede describir una ocasión reciente en que Ud. y [nombre del niño] _ se comunicaron entre sí? 


\section{INICIAR LA INTERACCIÓN}

¿Cómo empieza típicamente una interacción entre Ud. y [nombre del niño]_ ?

¿Siempre empieza Ud. o a veces lo hace él/ella? ¿Cómo lo hace?

Ejemplos: Haciendo algún sonido. Hablándole a Ud. (v. gr. Preguntándole algo o señalando algo). Diciendo su nombre.

\section{(...)}

\section{VARIACIÓN CONTEXTUAL}

\section{PERSONA}

o hablar?

¿Hay gente con la que a [nombre del niño] le guste más estar

Ejemplos: Su madre. Otros familiares. Cuidadores, maestros, ... Amigos de la familia. Otros niños. Extraños.

Fuente: Gallardo Paúls (2006: 181) 
ANEXO 6.

Consentimiento informado para los padres de los niños participantes en el estudio

\section{Consentimiento Informado para Padres}

El propósito de esta carta de consentimiento es informar a los padres de un estudio que ha sido planteado al Centro desde la Universidad de Salamanca (facultad de Filología) con una clara explicación de la naturaleza del mismo, así como del rol de sus hijos en él como participantes.

La presente investigación es conducida por Susana Verde Ruiz, estudiante de doctorado de la Universidad de Salamanca. Este proyecto forma parte de otro de carácter internacional que ya ha sido llevado a cabo en Reino Unido y Finlandia. La meta de este estudio es conocer cómo los niños procesan el lenguaje, es decir, cómo desarrollan la habilidad para responder a preguntas y explicar sus respuestas usando el contexto y su conocimiento del mundo. Para ello, se llevarán a cabo entrevistas individuales a los alumnos en las que se les mostrará una serie de dibujos y se les dará información acerca del contexto. A continuación se les pedirá que respondan a preguntas relacionadas con los dibujos. La duración será aproximadamente 15 minutos por alumno. Las respuestas serán grabadas con una grabadora de voz, de modo que la investigadora pueda transcribir después las ideas que el/la niño/a haya expresado.

La participación en este estudio es estrictamente voluntaria, de forma que si el/la niño/a no quiere contestar no se procederá con su cuestionario. La información que se recoja no se usará para ningún otro propósito fuera de los de esta investigación. Sus respuestas al cuestionario serán codificadas usando un número de identificación y, por lo tanto, serán anónimas. Solo se sabrá la edad y el sexo, pero en ningún momento el/la niño/a será identificado/a con su nombre ni ningún otro dato.

Desde ya le agradecemos su participación.

D/ Dña consentimiento a mi hijo/a en él. he sido informado/a de la meta de este estudio y doy para participar voluntariamente

Salamanca, a

Fdo: 


\section{ANEXO 7.}

Ejemplos de apoyo visual de las preguntas del test
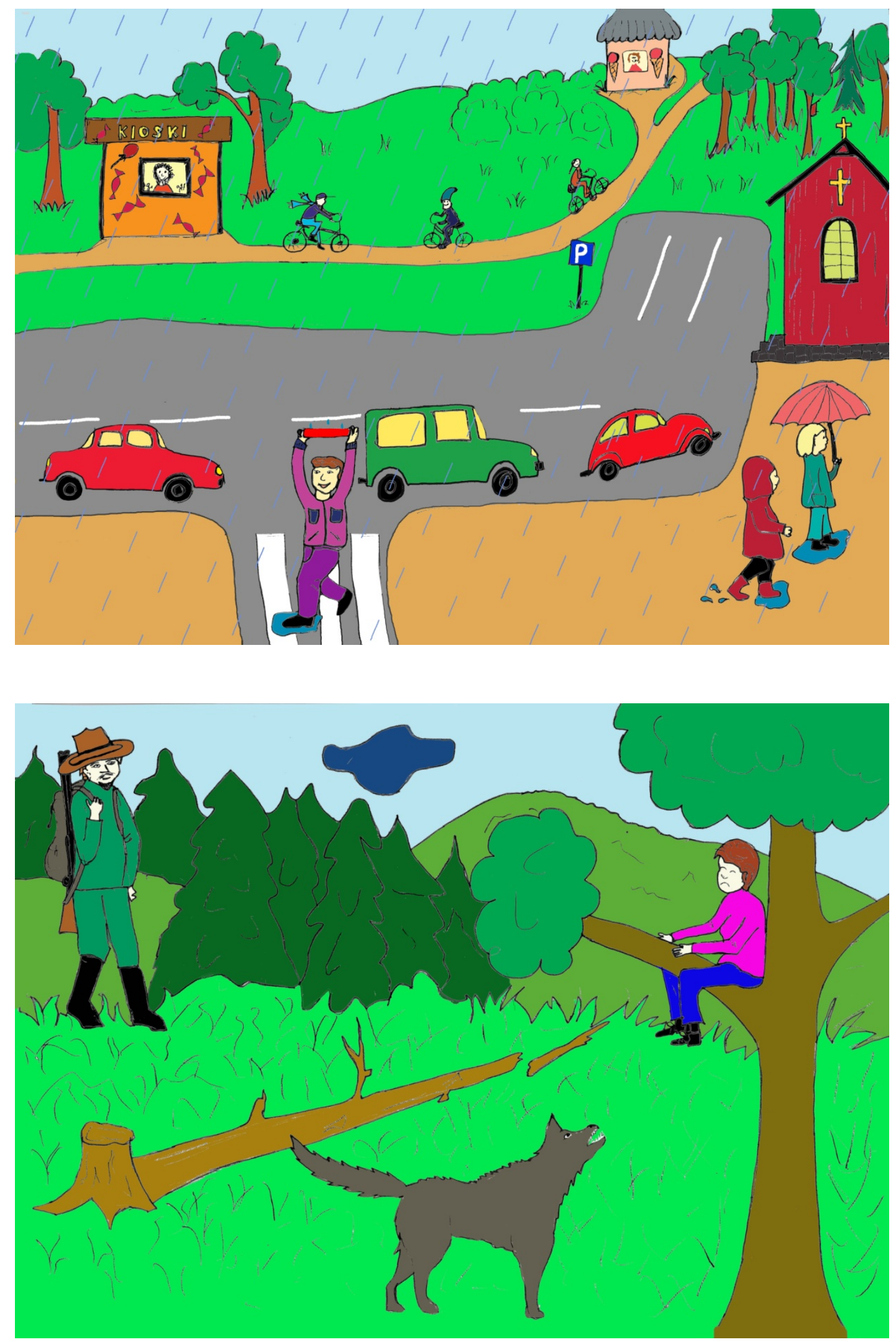

Fuente: Loukusa (2007) 


\section{ANEXO 8.}

Análisis estadístico por ciclos educativos. Aplicación de las pruebas no paramétricas de Kruskal-Wallis y Mann-Whitney por tipo de pregunta.

-Preguntas de implicaturas

-Respuestas válidas

\begin{tabular}{|r|r|r|r|}
\hline \multicolumn{1}{c}{ Prueba de Kruskal Wallis } & \multicolumn{2}{c|}{ Rangos } \\
\hline \multirow{3}{*}{ Respcorr } & Ciclos_educativos & N & Rango promedio \\
\cline { 2 - 4 } & Educación infantil & 61 & 40,37 \\
& Educación primaria 1ciclo & 43 & 81,17 \\
& Educación primaria 2ciclo & 36 & 108,81 \\
& Total & 140 & \\
\hline
\end{tabular}

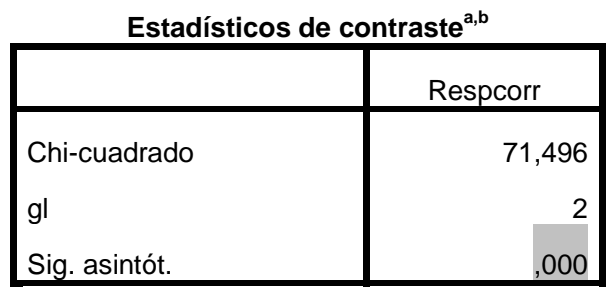

a. Prueba de Kruskal-Wallis

b. Variable de agrupación: Ciclos_educativos

\section{Estadísticos de contraste ${ }^{a}$}

\begin{tabular}{|l|r|}
\hline & \multicolumn{1}{|c|}{ Respcorr } \\
\hline U de Mann-Whitney & 454,500 \\
W de Wilcoxon & 2345,500 \\
Z & $-5,725$ \\
Sig. asintót. (bilateral) &, 000 \\
\hline
\end{tabular}

a. Variable de agrupación:

Ciclos_educativos

Rangos

\begin{tabular}{|l|r|r|c|}
\hline Ciclos_educativos & $\mathrm{N}$ & \multicolumn{1}{|c|}{$\begin{array}{c}\text { Rango } \\
\text { promedio }\end{array}$} & $\begin{array}{c}\text { Suma de } \\
\text { rangos }\end{array}$ \\
\hline $\begin{array}{l}\text { Educación primaria } \\
\text { 1ciclo }\end{array}$ & 43 & 30,74 & 1322,00 \\
Respcorr Educación primaria & 36 & 51,06 & 1838,00 \\
2ciclo & 79 & & \\
Total & & & \\
\hline
\end{tabular}

Estadísticos de contraste ${ }^{\mathrm{a}}$

\begin{tabular}{|l|r|}
\hline & Respcorr \\
\hline U de Mann-Whitney & 376,000 \\
W de Wilcoxon & 1322,000 \\
Z & $-4,217$ \\
Sig. asintót. (bilateral) &, 000 \\
\hline
\end{tabular}

a. Variable de agrupación:

Ciclos_educativos 
-Explicaciones válidas

\begin{tabular}{|r|r|r|r|}
\hline \multicolumn{1}{|c|}{ Prueba de Kruskal Wallis } & \multicolumn{2}{c|}{ Rangos } \\
\hline \multirow{3}{*}{ Explcorr } & Ciclos_educativos & $\mathrm{N}$ & \multicolumn{1}{c|}{$\begin{array}{c}\text { Rango } \\
\text { promedio }\end{array}$} \\
\cline { 2 - 3 } & Educación infantil & 61 & 32,98 \\
& Educación primaria 1ciclo & 43 & 93,24 \\
& Educación primaria 2ciclo & 36 & 106,92 \\
& Total & 140 & \\
\hline
\end{tabular}

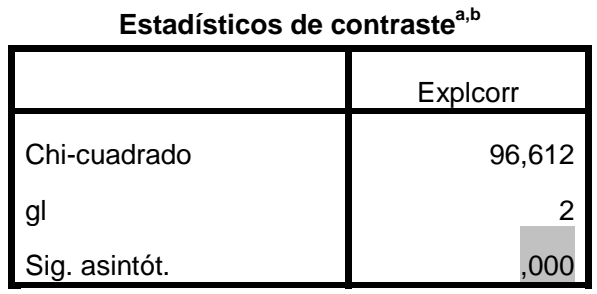

a. Prueba de Kruskal-Wallis

b. Variable de agrupación: Ciclos_educativos

\begin{tabular}{|l|r|r|r|c|}
\hline \multicolumn{1}{|c|}{ Prueba de Mann-Whitney } & \multicolumn{2}{c|}{ Rangos } \\
\hline Ciclos_educativos & $\mathrm{N}$ & \multicolumn{1}{c|}{$\begin{array}{c}\text { Rango } \\
\text { promedio }\end{array}$} & $\begin{array}{c}\text { Suma de } \\
\text { rangos }\end{array}$ \\
\hline Educación infantil & 61 & 32,57 & 1986,50 \\
Explcorr & $\begin{array}{l}\text { Educación primaria } \\
\text { 1ciclo }\end{array}$ & 43 & 80,78 & 3473,50 \\
Total & 104 & & \\
\hline
\end{tabular}

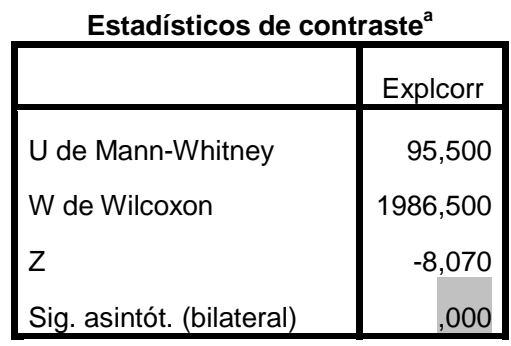

a. Variable de agrupación:

Ciclos_educativos

\section{Estadísticos de contraste ${ }^{\mathrm{a}}$}

\begin{tabular}{|l|r|}
\hline & Explcorr \\
\hline U de Mann-Whitney & 536,000 \\
W de Wilcoxon & 1482,000 \\
$Z$ & $-2,448$ \\
Sig. asintót. (bilateral) &, 014 \\
\hline
\end{tabular}

a. Variable de agrupación:

Ciclos_educativos 
-Preguntas de rutina

-Respuestas válidas

\begin{tabular}{|r|r|r|r|}
\hline & \multicolumn{2}{c}{ Prueba de Kruskal-Wallis } & \multicolumn{2}{c|}{ Rangos } \\
\hline & Ciclos_educativos & $\mathrm{N}$ & \multicolumn{1}{c|}{$\begin{array}{c}\text { Rango } \\
\text { promedio }\end{array}$} \\
\hline \multirow{3}{*}{ Respcorr } & Educaciín infantil & 61 & 49,85 \\
& Educación primaria 1ciclo & 43 & 76,59 \\
& Educación primaria 2ciclo & 36 & 98,21 \\
& Total & 140 & \\
\hline
\end{tabular}

\begin{tabular}{|l|r|}
\hline \multicolumn{2}{|c|}{ Estadísticos de contraste ${ }^{\mathrm{a}, \mathrm{b}}$} \\
\hline & \multicolumn{1}{|c|}{ Respcorr } \\
\hline Chi-cuadrado & 38,895 \\
gl & 2 \\
Sig. asintót. &, 000 \\
\hline
\end{tabular}

a. Prueba de Kruskal-Wallis

b. Variable de agrupación:

Ciclos_educativos

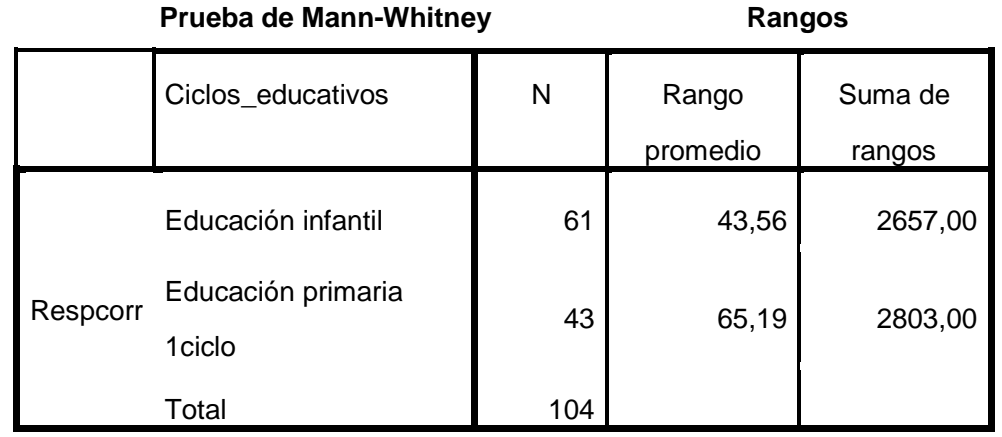

\begin{tabular}{|l|r|}
\hline \multicolumn{2}{|c|}{ Estadísticos de contraste $^{\mathrm{a}}$} \\
\hline U de Mann-Whitney & Respcorr \\
W de Wilcoxon & 766,000 \\
Z & 2657,000 \\
Sig. asintót. (bilateral) & $-3,883$ \\
\hline
\end{tabular}

a. Variable de agrupación:

Ciclos_educativos

Rangos

\begin{tabular}{|c|c|c|c|c|}
\hline & Ciclos_educativos & $\mathrm{N}$ & $\begin{array}{c}\text { Rango } \\
\text { promedio }\end{array}$ & $\begin{array}{c}\text { Suma de } \\
\text { rangos }\end{array}$ \\
\hline Respcorr & $\begin{array}{l}\text { Educación primaria } \\
1 \text { ciclo } \\
\text { Educación primaria } \\
2 \text { ciclo } \\
\text { Total }\end{array}$ & $\begin{array}{l}36 \\
79\end{array}$ & 33,41 & 1436,50 \\
\hline
\end{tabular}

Estadísticos de contraste ${ }^{\mathrm{a}}$

\begin{tabular}{|l|r|}
\hline & Respcorr \\
\hline U de Mann-Whitney & 490,500 \\
W de Wilcoxon & 1436,500 \\
Z & $-3,176$ \\
Sig. asintót. (bilateral) &, 001 \\
\hline
\end{tabular}

a. Variable de agrupación:

Ciclos_educativos 
-Explicaciones válidas

\begin{tabular}{|l|l|r|r|}
\multicolumn{1}{c}{ Prueba de Kruskal-Wallis } & \multicolumn{2}{c|}{ Rangos } \\
\hline \multirow{2}{*}{ Ciclos_educativos } & $\mathrm{N}$ & \multicolumn{1}{c|}{$\begin{array}{c}\text { Rango } \\
\text { promedio }\end{array}$} \\
\hline \multirow{2}{*}{ Explcorr } & Educaciín infantil & 61 & 35,89 \\
& Educación primaria 1ciclo & 43 & 85,35 \\
& Educación primaria 2ciclo & 36 & 111,42 \\
& Total & 140 & \\
\hline
\end{tabular}

\begin{tabular}{|l|r|}
\hline \multicolumn{2}{|c|}{ Estadísticos de contraste ${ }^{\mathrm{a}, \mathrm{b}}$} \\
\hline \multicolumn{1}{|c|}{ Explcorr $^{\text {Chi-cuadrado }}$} & 89,740 \\
$\mathrm{gl}$ & 2 \\
Sig. asintót. &, 000 \\
\hline
\end{tabular}

a. Prueba de Kruskal-Wallis

b. Variable de agrupación:

Ciclos_educativos

Prueba de Mann-Whitney

\begin{tabular}{|l|r|r|r|r|}
\hline & Ciclos_educativos & $\mathrm{N}$ & \multicolumn{1}{|c|}{$\begin{array}{c}\text { Rango } \\
\text { promedio }\end{array}$} & $\begin{array}{c}\text { Suma de } \\
\text { rangos }\end{array}$ \\
\hline & $\begin{array}{l}\text { Educaciín infantil } \\
\text { Explcorr } \begin{array}{l}\text { Educación primaria } \\
\text { 1ciclo }\end{array}\end{array}$ & 35,31 & 2154,00 \\
Total & 104 & 76,88 & 3306,00 \\
\hline
\end{tabular}

Prueba de Mann-Whitney

\begin{tabular}{|l|r|r|r|}
\hline Ciclos_educativos & $\mathrm{N}$ & \multicolumn{1}{|c|}{$\begin{array}{c}\text { Rango } \\
\text { promedio }\end{array}$} & $\begin{array}{c}\text { Suma de } \\
\text { rangos }\end{array}$ \\
\hline $\begin{array}{l}\text { Educación primaria } \\
\text { 1ciclo }\end{array}$ & 43 & 30,47 & 1310,00 \\
Explcorr Educación primaria \\
$\begin{array}{l}\text { 2ciclo } \\
\text { Total }\end{array}$ & 36 & 51,39 & 1850,00 \\
\hline
\end{tabular}

Estadísticos de contraste ${ }^{\mathrm{a}}$

\begin{tabular}{|l|r|}
\hline \multicolumn{2}{|c|}{ Estadísticos de contraste } \\
\hline U de Mann-Whitney & \multicolumn{1}{c|}{ Explcorr } \\
\hline W de Wilcoxon & 2154,000 \\
Z & $-7,022$ \\
Sig. asintót. (bilateral) &, 000 \\
\hline
\end{tabular}

a. Variable de agrupación:

Ciclos_educativos

Estadísticos de contraste ${ }^{\mathrm{a}}$

\begin{tabular}{|l|r|}
\hline & Explcorr \\
\hline U de Mann-Whitney & 364,000 \\
W de Wilcoxon & 1310,000 \\
Z & $-4,286$ \\
Sig. asintót. (bilateral) &, 000 \\
\hline
\end{tabular}

a. Variable de agrupación:

Ciclos_educativos 
-Preguntas de sentimiento

-Respuestas válidas

\begin{tabular}{|r|r|r|r|}
\hline \multicolumn{1}{|c}{ Prueba de Kruskal-Wallis } & \multicolumn{2}{c|}{ Rangos } \\
\hline \multirow{3}{*}{ Ciclos_educativos } & $\mathrm{N}$ & \multicolumn{1}{c|}{$\begin{array}{c}\text { Rango } \\
\text { promedio }\end{array}$} \\
\hline \multirow{2}{*}{ Respcorr } & Educación infantil & 61 & 57,75 \\
& Educación primaria 1ciclo & 43 & 78,95 \\
& Educación primaria 2ciclo & 36 & 82,00 \\
& Total & 140 & \\
\hline
\end{tabular}

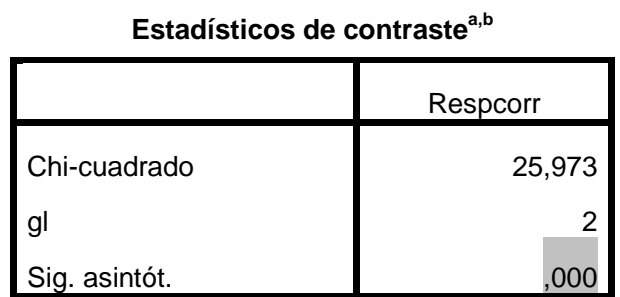

a. Prueba de Kruskal-Wallis

b. Variable de agrupación: Ciclos_educativos

\begin{tabular}{|l|l|r|r|r|}
\multicolumn{2}{c}{ Prueba Mann-Whitney } & \multicolumn{3}{c|}{ Rangos } \\
\hline & Ciclos_educativos & $\mathrm{N}$ & \multicolumn{1}{c|}{$\begin{array}{c}\text { Rango } \\
\text { promedio }\end{array}$} & $\begin{array}{c}\text { Suma de } \\
\text { rangos }\end{array}$ \\
\hline & $\begin{array}{l}\text { Educación infantil } \\
\text { Respcorr }\end{array}$ & $\begin{array}{l}\text { Educación primaria } \\
\text { 1ciclo }\end{array}$ & 45,95 & 2803,00 \\
Total & 104 & 61,79 & 2657,00 \\
\hline
\end{tabular}

\begin{tabular}{|c|c|}
\hline \multicolumn{2}{|c|}{ Estadísticos de contraste ${ }^{\mathrm{a}}$} \\
\hline & Respcorr \\
\hline U de Mann-Whitney & 912,000 \\
\hline W de Wilcoxon & 2803,000 \\
\hline Z & $-3,639$ \\
\hline Sig. asintót. (bilateral) &, 000 \\
\hline
\end{tabular}

a. Variable de agrupación:

Ciclos_educativos

Prueba Mann-Whitney

\begin{tabular}{|l|r|r|r|r|}
\hline & Ciclos_educativos & $\mathrm{N}$ & \multicolumn{1}{|c|}{$\begin{array}{c}\text { Rango } \\
\text { promedio }\end{array}$} & $\begin{array}{c}\text { Suma de } \\
\text { rangos }\end{array}$ \\
\hline $\begin{array}{l}\text { Educación primaria } \\
\text { 1ciclo }\end{array}$ & 43 & 39,16 & 1684,00 \\
Respcorr Educación primaria & 36 & 41,00 & 1476,00 \\
2ciclo & 79 & & \\
Total & & & \\
\hline
\end{tabular}

Estadísticos de contraste ${ }^{a}$

\begin{tabular}{|l|r|}
\hline & Respcorr \\
\hline U de Mann-Whitney & 738,000 \\
W de Wilcoxon & 1684,000 \\
$Z$ & $-1,302$ \\
Sig. asintót. &, 193 \\
(bilateral) & \\
\hline
\end{tabular}

a. Variable de agrupación:

Ciclos_educativos 
-Explicaciones válidas

\begin{tabular}{|l|l|r|r|}
\hline \multicolumn{1}{|l}{ Prueba de Kruskal-Wallis } & \multicolumn{2}{c|}{ Rangos } \\
& Ciclos_educativos & $\mathrm{N}$ & \multicolumn{1}{c|}{$\begin{array}{c}\text { Rango } \\
\text { promedio }\end{array}$} \\
\hline \multirow{4}{*}{ Explcorr } & Educación infantil & 61 & 38,39 \\
& Educación primaria 1ciclo & 43 & 91,55 \\
& Educación primaria 2ciclo & 36 & 99,78 \\
& Total & 140 & \\
\hline
\end{tabular}

\begin{tabular}{|l|r|}
\hline \multicolumn{2}{|c|}{ Estadísticos de contraste ${ }^{\mathrm{a}, \mathrm{b}}$} \\
\hline \multicolumn{1}{|c|}{ Explcorr } \\
\hline Chi-cuadrado & 76,510 \\
gl & 2 \\
Sig. asintót. &, 000 \\
\hline
\end{tabular}

a. Prueba de Kruskal-Wallis

b. Variable de agrupación:

Ciclos_educativos

Prueba Mann-Whitney

\begin{tabular}{|l|r|r|r|}
\hline Ciclos_educativos & N & \multicolumn{1}{|c|}{$\begin{array}{c}\text { Rango } \\
\text { promedio }\end{array}$} & $\begin{array}{c}\text { Suma de } \\
\text { rangos }\end{array}$ \\
\hline Educación infantil & 61 & 35,70 & 2177,50 \\
Explcorr $\begin{array}{l}\text { Educación primaria } \\
\text { 1ciclo }\end{array}$ & 43 & 76,34 & 3282,50 \\
Total & 104 & & \\
\hline
\end{tabular}

Prueba de Mann-Whitney

\begin{tabular}{|l|r|r|r|}
\hline Ciclos_educativos & $\mathrm{N}$ & \multicolumn{1}{|c|}{$\begin{array}{c}\text { Rango } \\
\text { promedio }\end{array}$} & $\begin{array}{c}\text { Suma de } \\
\text { rangos }\end{array}$ \\
\hline \multicolumn{1}{|l|}{$\begin{array}{l}\text { Educación primaria } \\
\text { 1ciclo }\end{array}$} & 43 & 37,21 & 1600,00 \\
Explcorr Educación primaria & 36 & 43,33 & 1560,00 \\
2ciclo & 79 & & \\
Total & & & \\
\hline
\end{tabular}

Estadísticos de contraste $^{\mathrm{a}}$

\begin{tabular}{|l|r|}
\hline & \multicolumn{1}{|c|}{ Explcorr } \\
\hline U de Mann-Whitney & 286,500 \\
W de Wilcoxon & 2177,500 \\
Z & $-7,000$ \\
Sig. asintót. (bilateral) &, 000 \\
\hline
\end{tabular}

a. Variable de agrupación:

Ciclos_educativos

\section{Estadísticos de contraste ${ }^{\mathrm{a}}$}

\begin{tabular}{|l|r|}
\hline & Explcorr \\
\hline U de Mann-Whitney & 654,000 \\
W de Wilcoxon & 1600,000 \\
$Z$ & $-1,479$ \\
Sig. asintót. (bilateral) &, 139 \\
\hline
\end{tabular}

a. Variable de agrupación:

Ciclos_educativos 
-Preguntas de ironía

\section{-Respuestas válidas}

Prueba de Kruska-Wallis

\begin{tabular}{|r|r|r|r|}
\hline & Ciclos_educativos & $\mathrm{N}$ & \multicolumn{1}{|c|}{$\begin{array}{c}\text { Rango } \\
\text { promedio }\end{array}$} \\
\hline Educación infantil & 61 & 35,46 \\
Respcorr & Educación primaria 1ciclo & 43 & 89,49 \\
& Educación primaria 2ciclo & 36 & 107,19 \\
& 140 & \\
\hline
\end{tabular}

Estadísticos de contraste $\mathrm{e}^{\mathrm{a}, \mathrm{b}}$

\begin{tabular}{|l|r|}
\hline & \multicolumn{1}{|c|}{ Respcorr } \\
\hline Chi-cuadrado & 90,865 \\
GI & 2 \\
Sig. asintót. &, 000 \\
\hline
\end{tabular}
a. Prueba de Kruskal-Wallis
b. Variable de agrupación

Ciclos_educativos
Prueba de Mann-Whitney

Rangos

\begin{tabular}{|l|r|r|r|r|}
\hline & Ciclos_educativos & $\mathrm{N}$ & \multicolumn{1}{c|}{$\begin{array}{c}\text { Rango } \\
\text { promedio }\end{array}$} & \multicolumn{1}{c|}{$\begin{array}{c}\text { Suma de } \\
\text { rangos }\end{array}$} \\
\hline & Educación infantil & 61 & 35,06 & 2138,50 \\
Respcorr & $\begin{array}{l}\text { Educación primaria } \\
\text { 1ciclo }\end{array}$ & 43 & 77,24 & 3321,50 \\
Total & 104 & & \\
\hline
\end{tabular}

Prueba de Mann-Whitney

\begin{tabular}{|l|l|r|r|r|}
\hline & Ciclos_educativos & $\mathrm{N}$ & $\begin{array}{r}\text { Rango } \\
\text { promedio }\end{array}$ & $\begin{array}{r}\text { Suma de } \\
\text { rangos }\end{array}$ \\
\hline Educación primaria & 43 & 34,24 & 1472,50 \\
1ciclo & 36 & 46,88 & 1687,50 \\
Respcorr & Educación primaria & & \\
2ciclo & 79 & & \\
Total & & & \\
\hline
\end{tabular}

Estadísticos de contraste ${ }^{\mathrm{a}}$

\begin{tabular}{|l|r|}
\hline \multicolumn{2}{|c|}{ Estadísticos de contraste } \\
\hline U de Mann-Whitney & Respcorr \\
W de Wilcoxon & 247,500 \\
Z & 2138,500 \\
Sig. asintót. (bilateral) & $-7,141$ \\
\hline
\end{tabular}

a. Variable de agrupación:

Ciclos_educativos

Estadísticos de contraste

\begin{tabular}{|l|r|}
\hline & Respcorr \\
\hline U de Mann-Whitney & 526,500 \\
W de Wilcoxon & 1472,500 \\
Z & $-3,009$ \\
Sig. asintót. (bilateral) &, 003 \\
\hline
\end{tabular}

a. Variable de agrupación:

Ciclos_educativos 
-Explicaciones válidas

\begin{tabular}{|r|r|r|r|}
\hline \multicolumn{1}{|c|}{ Kruskal-Wallis } & \multicolumn{1}{c|}{ Rangos } \\
\hline & Ciclos_educativos & $\mathrm{N}$ & \multicolumn{1}{c|}{$\begin{array}{c}\text { Rango } \\
\text { promedio }\end{array}$} \\
\hline \multirow{5}{*}{ Explcorr } & Educación infantil & 61 & 41,92 \\
& Educación primaria 1ciclo & 43 & 81,20 \\
& Educación primaria 2ciclo & 36 & 106,15 \\
& Total & 140 & \\
\hline
\end{tabular}

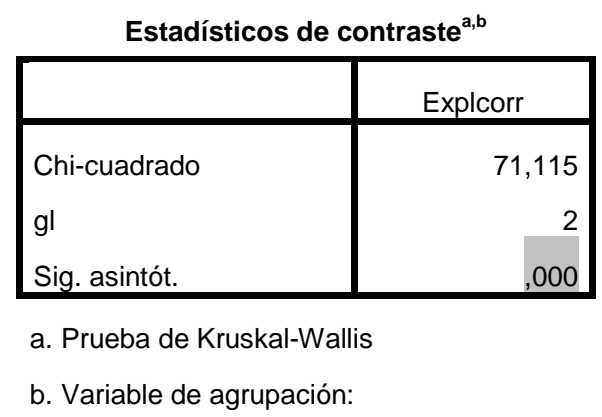

Ciclos_educativos

Prueba Mann-Whitney

\begin{tabular}{|l|r|r|c|}
\hline Ciclos_educativos & N & \multicolumn{1}{|c|}{$\begin{array}{c}\text { Rango } \\
\text { promedio }\end{array}$} & $\begin{array}{c}\text { Suma de } \\
\text { rangos }\end{array}$ \\
\hline & 61 & 40,39 & 2464,00 \\
Educación infantil & 43 & 69,67 & 2996,00 \\
$\begin{array}{l}\text { Explcorr Educación primaria } \\
\text { 1ciclo }\end{array}$ & 104 & & \\
Total & & & \\
\hline
\end{tabular}

Prueba Mann-Whitney

\begin{tabular}{|l|r|r|r|}
\hline Ciclos_educativos & $\mathrm{N}$ & \multicolumn{1}{|c|}{$\begin{array}{c}\text { Rango } \\
\text { promedio }\end{array}$} & $\begin{array}{c}\text { Suma de } \\
\text { rangos }\end{array}$ \\
\hline \multicolumn{1}{|l|}{$\begin{array}{l}\text { Educación primaria } \\
\text { 1ciclo }\end{array}$} & 33 & 33,52 & 1441,50 \\
Explcorr Educación primaria & 36 & 47,74 & 1718,50 \\
2ciclo & 79 & & \\
Total & & & \\
\hline
\end{tabular}

Estadísticos de contraste ${ }^{\mathrm{a}}$

\begin{tabular}{|l|r|}
\hline & \multicolumn{1}{|c|}{ Explcorr } \\
\hline U de Mann-Whitney & 573,000 \\
W de Wilcoxon & 2464,000 \\
Z & $-5,855$ \\
Sig. asintót. (bilateral) &, 000 \\
\hline
\end{tabular}

a. Variable de agrupación:

Ciclos_educativos 
-Preguntas de referencia

\section{-Respuestas válidas}

\begin{tabular}{|r|r|r|r|}
\hline \multicolumn{1}{|c}{} & Prueba Kruskal-Wallis & \multicolumn{2}{c|}{ Rangos } \\
& Ciclos_educativos & $\mathrm{N}$ & \multicolumn{1}{c|}{$\begin{array}{c}\text { Rango } \\
\text { promedio }\end{array}$} \\
\hline & Educación infantil & 61 & 43,84 \\
& Educación primaria 1ciclo & 43 & 80,90 \\
Respcorr & 36 & 103,25 \\
& Educación primaria 2ciclo & 140 & \\
\hline & Total &
\end{tabular}

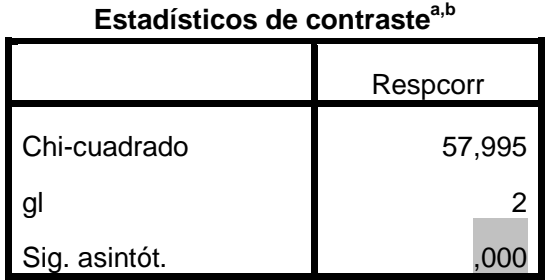

a. Prueba de Kruskal-Wallis

b. Variable de agrupación:

Ciclos_educativos

\begin{tabular}{|l|l|r|r|c|}
\multicolumn{2}{l}{ Prueba Mann-Whitney } & \multicolumn{2}{c|}{ Rangos } \\
\hline & Ciclos_educativos & $\mathrm{N}$ & \multicolumn{1}{c|}{$\begin{array}{c}\text { Rango } \\
\text { promedio }\end{array}$} & $\begin{array}{c}\text { Suma de } \\
\text { rangos }\end{array}$ \\
\hline & $\begin{array}{l}\text { Educación infantil } \\
\text { Respcorr } \begin{array}{l}\text { Educación primaria } \\
\text { 1ciclo }\end{array}\end{array}$ & 40,10 & 2446,00 \\
Total & 104 & 70,09 & 3014,00 \\
\hline
\end{tabular}

Estadísticos de contraste ${ }^{\mathrm{a}}$

\begin{tabular}{|l|r|}
\hline & Respcorr \\
\hline U de Mann-Whitney & 555,000 \\
W de Wilcoxon & 2446,000 \\
Z & $-5,150$ \\
Sig. asintót. (bilateral) &, 000 \\
\hline
\end{tabular}

a. Variable de agrupación:

Ciclos_educativos

Estadísticos de contraste

\begin{tabular}{|l|r|}
\hline & Respcorr \\
\hline U de Mann-Whitney & 464,500 \\
W de Wilcoxon & 1410,500 \\
Z & $-3,550$ \\
Sig. asintót. (bilateral) &, 000 \\
\hline
\end{tabular}

a. Variable de agrupación:

Ciclos_educativos 


\begin{abstract}
ANEXO 9.
Ejemplos de transcripciones de niños de 3, 4, 5, 6, 7, 8 y 9 años
\end{abstract}

B17. Entrevista realizada el 08/02/2011

\title{
NIÑO 3 AÑOS (27/06/2007)
}

S: ¿¿uántos años tienes?

O: $\{$ el niño enseña tres dedos $\}$

S: ¿cuántos?// ¿tres?/ tres/ mira/ este es el dibujo de un pueblo/ en un día de lluvia/ hay coches/ circulando por la carretera/ y un niño cruzando por el paso de cebra/ ¿por qué está sujetando el niño un libro/ por encima de la cabeza?

O: porque lo va a leer en el cole

S: va:le/ mira aquí los niños se acaban de despertar/ ¿qué hora debe ser?

O: // no lo sé

S: va:le/ ¿qué van a hacer ahora los niños?

O: (vestirse)

S: y ¿cómo lo sabes?

O: porque me viste mi madre

S: muy bien// mira están los niños jugando en el patio/ y hay un niño llorando delante del columpio/ ¿qué crees que ha pasado?

O: que le/ que le ha dado un niño en la pierna

S: y ¿cómo lo sabes?

O: porque estaba ahí tumbado

S: vale/ ¿quién podría ayudar al niño?

O: $\{$ el niño señala a la profesora $\}$

S: ¿quién?

O: esa \{señala de nuevo a la profesora\}

S: $y$ ¿por qué lo sabes?

O: // porque lo aprendo todo

S: va:le/ y ¿cómo se siente el niño?

O: mal

S: ¿por qué/ crees eso?

O: porque le ha dado el columpio

S: va:le/ mira/ aquí la familia va a empezar a cenar/ y hay una niña cerca del horno/ la madre le dice/ "ten cuidado"/¿qué quiere decir la madre?

O: que/ que no le salte

S: y ¿cómo lo sabes?

O: porque/ me cocina mi madre

S: va:le/ aquí están los niños jugando en el jardín/ el niño tiene un balón en las manos/ ¿de qué color es?

O: azul

S: muy bien/ la madre llama a los niños/ "la cena está lista”/ ¿qué quiere decir la madre?

$\mathrm{O}$ : que hay que ir a/ comer

S: y ¿cómo lo sabes?

O: porque mi madre me hace comida

S: va:le// aquí está un niño subido en un árbol/y debajo hay un lobo//¿por qué está el niño subido en la rama del árbol?

O: pa que no le coma el lobo 
S: y ¿cómo sabes eso?

O: y se rompió el palo/ ese \{el niño señala la rama del suelo\}

S: ¿cómo se siente el niño?

O: bien

S: ¿quién podría ayudar al niño?

S: // el lobo

S: va:le// ahora te voy a contar una historia:/ que no tiene dibujos/ y te voy a hacer preguntas/ ¿vale?

O: $\{$ el niño asiente con la cabeza $\}$

S: una mujer llega a casa después del trabajo/ su perro la está esperando en casa/ ha estado todo el día solo/ y necesita salir a hacer pipí/ la mujer saca al perro a la calle/ ¿quién ha estado solo todo el día?

O: el perro

S: muy bien/ y ¿por qué salen la mujer y el perro de casa?

O: /// porque iba a hacer pis

S: muy bien/ y ¿cómo lo sabes?

$\mathrm{O}: / / /$ porque mi madre hace pis

S: $\{r i s a\} /$ vale/ el/ la mujer y el perro van caminando por un lado la calle/ un gato sale de los arbustos/ corriendo muy rápido/ el perro tira de la correa/y la mujer se cae al suelo/ y el perro comienza a correr detrás del gato/ ¿quién sale del arbusto?

$\mathrm{O}:$ // el gato

S: muy bien/ y ¿por qué se cae la mujer?

O: porque/ tiró: el perro

S: ¿¿ómo lo sabes?

O: /// porque me (cuenta) mucho mi padre y me lo ha dicho

S: vale/ el perro/ persigue al gato/ y el gato se sube a un árbol/ el perro empieza a ladrar debajo del árbol/ el gato se sienta en la rama del árbol/ ¿quién se sienta en la rama del árbol?

O: /// el perro

S: ${ }^{\circ}$ (vale) ${ }^{\circ}$ / es el gato/ pero ¿por qué el gato se sienta en la rama del árbol?

O: // pa que no le coma el lobo

S: muy bien/ y ¿ ¿ómo sabes eso?

O: porque lo sé todo

S: vale/ la mujer corre/ y llama al perro para que vuelva/ sin embargo el perro no obedece a la mujer/ dos niños están cerca del perro mirándolo/ la mujer grita/ "iayuda!”/ a los niños y/ “iven aquí!”/ al perro/ ¿qué quiere decir la mujer cuando le grita/ “iven aquí!”/ al perro?

O: pues/ que venga

S: vale/ y ¿qué quiere decir la mujer cuando grita/ "iayuda!”/ a los chicos?

O: // pues// pues que le/ pues que le metan al perro a casa

$\mathrm{S}$ : vale/ y ¿qué crees que va a pasar después en esta historia?

O: // no lo sé

S: bue:no/ volvemos a los dibujos/ mira/ una niña/ que lleva su vestido nuevo/ está corriendo por un camino lleno de charcos/ ¿quién va corriendo por el camino?

O: la niña

S: vale/ la madre le grita/ “irecuerda que llevas tu vestido nuevo!”/ ¿qué quiere decir la madre?

O: que no se lo salpique

S: y ¿cómo lo sabes?

$\mathrm{O}$ : // porque/ solo/ las/ sé las cosas que me las dicen todas mi madre y mi padre 
S: vale/ mira aquí un grupo de niños están jugando en el salón/ la niña se acerca a los niños y les pregunta/ “¿puedo jugar?”/ los niños le responden/ “es que ya somos el mismo número de jugadores en cada equipo/ ¿consigue jugar la niña?

O: sí:

S: ${ }^{\circ}(\text { vale })^{\circ} / /$ un hombre está cortando el césped con un cortadora de césped/ ¿qué corta el hombre?

O: // el céspe(d)

S: va:le/ la mujer le dice al hombre/ "hay flores creciendo en el centro/ así que recuerda tener cuidado”/ ¿por qué le dice eso la mujer?

O: pa que no las corte

S: y ¿cómo lo sabes?

O: porque lo/ porque lo sé todo lo que me lo dicen

S: vale/ mira/ la madre:/ acompaña a sus hijos hasta el jardín de casa/ ¿adónde van los niños?

O: a casa

$\mathrm{S}$ : vale/ los niños tienen que cru[zar]>

O: $<$ [como] yo cuando voy al parque/ y: cuando me dice mi padre/ que voy a casa/ pues voy con él

S: vale /los niños tienen que cruzar una carretera con muchos coches/ la madre les dice que recuerden mirar a los dos lados/ ¿qué quiere decir la madre?

O: que no se pillen

S: ¿quién?

O: esta y este \{el niño señala a los niños del dibujo\}

S: va:le/ el padre y el hijo están sentados en la mesa/ pero la hija está mirando por la ventana/ el padre le dice a la niña/ "tu comida se va a enfriar"/ ¿por qué le dice eso el padre?

O: pa que la coma:/ enseguida

S: y ¿cómo lo sabes?

O: porque lo/ e(s) lo mismo

S: vale/ ahora te voy a hacer preguntas sin dibujos/ ¿vale?/ mira/ un profesor ha puesto un examen a sus alumnos/ y se pasea por las mesas mientras lo hacen/ se detiene en la mesa de un niño que no ha escrito ninguna respuesta/ y le dice muy serio/ "ya veo que has estudiado mucho"/ ¿qué quiere decir el profesor?

O: pues que:/ ya no lo hace

S: un niño está en una tienda de juguetes/ en frente de una estantería donde hay una muñeca/ un balón/ y un perro/ el chico señala al perro/ y dice que quiere comprarlo/ ¿qué quiere comprar el niño?

O: el perro

S: muy bien/ unos niños han visitado a Papá Noel en el centro comercial/ y al día siguiente/ le cuentan a su profesora/ que había muchos otros niños/ ¿dónde había muchos otros niños?

O: no lo sé

S: va:le/ un niño se/ ¡uy! los niños regresan de una excursión en el parque de atracciones/ su padre los ve muy contentos/ y les dice/ "parece que os lo habéis pasado muy mal en el parque de atracciones ¿eh?”/ ¿qué quiere decir?

O: pues que se porten otro día bien

S: va:le/ un niño se cae de la bicicleta/ y la bicicleta se rompe/ ¿cómo se siente el niño?

O: mal

S: ¿por qué piensas eso?

O: // porque/ los niños se caen/ y se parte/ la bicicleta/ y nos hacemos daño 
S: vale/ un niño se ha puesto la camiseta del revés por error/ y sus compañeros de clase se ríen de él/ ¿cómo se siente el niño?

O: mal

S: ¿por qué piensas eso?

O: // porque/ todos/ cuando se ponen la camiseta al revés y vamos al cole/ se ríen

S: vale/ una madre entra en la habitación de su hija/ y ve/ los juguetes por el suelo:/ la ropa tirada encima de la cama:/ migas de galleta por encima de todo:/ y le dice en tono de enfado/ "pues sí que tienes limpia esta habitación”/ ¿qué quiere decir?

O: pues que// pues que no la limpie

S: va:le/ una mujer ha ganado la lotería/ y va conduciendo su coche nuevo/ ¿cómo se siente la mujer?

O: bien

S: y ¿cómo lo sabes?/ ¿por qué piensas eso?

O: porque/ lo pienso todo

S: vale/ Juan ha suspendido todo/ y su padre enfadado le dice/ "eres un genio”/ ¿qué quiere decir?

O: pues/ pues que se porte bien

S: vale/ volvemos a los dibujos/ mira/ un niño tiene/ patatas/ cena-/ zanahorias y albóndigas en el plato/ su madre le dice/ "tienes patatas y zanahorias en el plato/ ¿qué más?/ ¿qué responde el niño?

$\mathrm{O}$ : pos que se lo va a comer todo

S: vale// una niña y un niño están en el quiosco/ le piden a la dependienta/ una bolsa de gusanitos y dos chupachús/ la dependienta les pregunta/ “¿algo más?”/ ¿qué les está preguntando la dependienta?

$\mathrm{O}$ : pues que si queréis un helado

S: vale/ es hora de irse a la cama/ pero los niños no están durmiendo sino que están jugando a las cartas/ el padre entra en la habitación y les dice/ "meteos en la cama”/ ¿qué quiere decir el padre?

$\mathrm{O}$ : pues que se duerman

S: ${ }^{\circ}(v a l e)^{\circ} /$ es hora de ir al colegio/ y los niños deberían estar de camino/ sin embargo están sentados en el salón/ viendo los dibujos/ la madre entra y les dice/ “daos prisa”/ ¿qué quiere decir la madre?”

O: pues que se vayan al cole

S: vale/ y la última/ mira/ está lloviendo fuera/ y la madre mira por la ventana/ y dice de forma sarcástica/ “iqué día tan bonito!”/ ¿qué quiere decir la madre?

O: pues que cojan estos juguetes \{el niño señala los juguetes olvidados en el jardín\}

S: va:le/ muchas gracias 
CII5. Entrevista realizada el 17/02/2011

\section{NIÑA 4 AÑOS (01/12/2006)}

S: ¿cuántos años tienes?

A: cuatro

S: ¿¿cuándo es tu cumpleaños?

A: ya ha pasado

S: vale/ mira

A: ha si-/ es en el/ en el uno/ el uno de diciembre/ ya ha pasao/ y lo he celebrao en el parque de bolas

S: muy bien/ mira este es el dibujo de un pueblo un día de lluvia/ hay coches circulando por la carretera:/ y un niño cruzando por el paso de cebra:/ ¿por qué está el niño sujetando un libro/ por encima de la cabeza?/ ¿por qué?

A: con las/ por-/ que lo va a llevar a la biblioteca

S: vale/ los niños se acaban de despertar/ ¿qué hora debe ser?

A: // no sé

S: ¿qué van a hacer ahora los niños?

A: a desayunar

S: ¿cómo lo sabes?

A: porque yo siempre que me levanto desayuno

S: va:le/ aquí están los niños jugando en el patio/ y hay un niño delante del columpio llorando/ ¿qué crees que ha pasado?

A: que s’ha caído

S: ¿cómo lo sabes?

A: porque yo siempre/ algunas veces/ veo a algunos niños/ que no se agarran/ y se caen

S: ¿quién podría ayudar al niño?

A: la profesora

S: ¿cómo sabes eso?

A: porque mi profesora/ cuando me caigo me/ me levanta

S: ¿cómo se siente el niño?

A: mal

S: ¿por qué?

A: porque está llorando

S: vale/ mira la familia va a empezar a cenar/ la niña está cerca del horno/ y la madre le dice a la niña/ "ten cuidado"/ ¿qué quiere decir la madre?

A: que se va a quemar

S: ¿cómo lo sabes?

A: porque/ porque/ alguna ve:z/ cuando/ en la casa de una/ de un/ de una madre que se llama Begoña:

S: $\mathrm{mm}$

A: ve a un-/ a la niña Laura que es su niña:/ y tiene dos niños/ que uno se llama Álvaro y otro se llama Lau-/ y Laura algunas veces se acerca

S: y ¿qué le dice su madre?

A: que no se acerque

S: ¿por qué?

A: porque se puede quemar

S: va:le/ los niños están jugando en el jardín/ el niño tiene un balón en las manos/ ¿de qué color es?

A: azul 
S: vale/ la madre/ llama a los niños/ "la cena está lista”/ ¿qué quiere decir la madre?

A: que cuando está/ cuando: ha-/ hayan cenao/ se van a la cama

S: va:le// aquí hay un niño subido a un árbol/ y debajo hay un lobo/ ¿por qué está el niño subido en el árbol?

A: porque ese lobo le va a comer

S: ¿cómo lo sabes?

A: porque/ porque/ porque yo de pequeña tenía un lobito/ de juguete:/ y/ y estaba jugando:/ y yo me subía a la cama para que no me comiera

S: ¿cómo se siente el niño?

A: mal

S: ¿por qué?

A: porque el lobo le va a comer

S: ${ }^{\circ}(\text { vale })^{\circ} /$ ¿quién podría ayudar al niño?

A: el cazador

S: ¿cómo lo sabes?

A: porque sí

S: va:le/ ahora te voy a contar una historia sin dibujos/ y te voy haciendo preguntas/ una mujer llega a casa después del trabajo/ su perro la está esperando en casa/ ha estado solo todo el día/ y necesita salir a hacer pipí/ la mujer saca al perro a la calle/ ¿quién ha estado solo todo el día?

A: el perro

S: y ¿por qué salen la mujer y el perro de casa?

A: porque el perro se hace pis

S: ¿cómo lo sabes?

A: porque sí:/ porque yo algunas veces/ cuando salgo de casa haciendo/ sin/ sin hacer pipí/ hago pipí en un sitio/ para que no me vean

S: la mujer/ y el perro van caminando por un lado de la calle/ un gato/ sale de los arbustos corriendo muy rápido/ el perro tira de la correa/ y la mujer se cae al suelo/ y el perro comienza a correr detrás del gato/ ¿quién sale del arbusto?

A: el gato

S: y ¿por qué se cae la mujer?

A: porque el perro/ va muy rápido

S: ¿cómo lo sabes?

A: es que/ es que yo sé todo porque soy muy lista

S: el perro persigue al gato/ y el gato se sube a un árbol/ el perro empieza a ladrar debajo del árbol/ el gato se sienta en la rama del árbol/ ¿quién se sienta en la rama del árbol?

A: el gato

S: y ¿por qué el gato se sienta en la rama del árbol?

A: porque el perro le está persiguiendo

S: ¿cómo lo sabes?

A: porque sí:

S: vale/ la mujer corre/ y llama al perro para que vuelva/ sin embargo el perro no obedece a la mujer/ dos niños están cerca del perro mirándolo/ la mujer grita/ “¡ayuda!”/ a los niños y/ “iven aquí!”/ al perro/ ¿qué quiere decir la mujer cuando le grita/ “iven aquí!”/ al perro?

A: que vaya

S: ¿qué quiere decir la mujer cuando grita/ “¡ayuda!”/ a los niños?

A: que la ayuden

S: ¿qué crees que va a pasar después en esta historia?

A: no lo sé 
S: bue:no/ volvemos a los dibujos/ una niña/ que lleva su vestido nuevo/ está corriendo por un camino lleno de charcos/ ¿quién va corriendo por el camino?

A: la niña

S: la madre le grita/ “¡recuerda que llevas tu vestido nuevo!”/ ¿qué quiere decir la madre?

A: que si se mete en un/ char-/ si se cae en un charco se mancha el vestido

S: ¿cómo lo sabes?

A: porque yo algunas veces que me caigo en un charco/ de agua/ me empapo la/ la ro:pa

S: ${ }^{\circ}(\text { bueno })^{\circ} /$ los niños están jugando en el salón/ la niña se acerca a los niños que están jugando y les pregunta/ “¿puedo jugar?/ los niños le responden/ “es que ya somos el mismo número de jugadores en cada equipo”/ ¿consigue jugar la niña?

A: no:

S: ¿por qué?

A: porque solo ha-/ porque solo puede haber cuatro niños porque/ porque hay estos dos equipos/ y estos dos equipos \{la niña señala los niños que están jugando en equipos\}

S: el hombre está cortando el césped con un/ con una cortadora de césped/ ¿qué corta el hombre?

A: la hierba

S: la mujer le dice al hombre/ "hay flores creciendo en el centro/ así que recuerda tener cuidado"/¿por qué le dice eso la mujer?

A: porque si/ las/ porque si las/ porque si/ lo hace como la hierba/ se estrope:an

S: ¿cómo lo sabes?

A: porque yo algunas veces/ que/ que de pequeña mi papá cortaba/ cor-/ taba/ la hierba

S: $\mathrm{mm}$

A: pues/ como había unas margaritas y unos tulipanes/ le dije que no me los cortara/ porque si porque quería que estara adornando// [el ce-]>

S: $<$ [el jar]dín

A: el jardín

S: la madre/ acompaña a los niños hasta el jardín de casa/ ¿adónde van los niños?

A: a jugar

S: vale/ los niños tienen que cruzar una carretera con muchos coches/ la madre les dice que recuerden mirar/ a los dos lados/ ¿qué quiere decir la madre?

A: que si/ miran a/ que si no miran a los dos laos/ pues/ sin darse cuenta/ pasan y y le atropella un coche

S: el padre y el hijo están sentados en la mesa/ pero la niña está mirando por la ventana/ el padre le dice a la niña/ "tu comida se va a enfriar"/ ¿por qué le dice eso el padre?

A: por-/ que si no/ no le gusta y no la puede comer

S: va:le/ ahora te voy a hacer unas preguntas sin dibujos/ el profesor ha puesto un examen a sus alumnos/ y se pasea por las mesas mientras lo hacen/ se detiene en la mesa de un niño que no ha escrito ninguna respuesta/ y le dice muy serio/ "ya veo que has estudiado mucho”/ ¿qué quiere decir el profesor?

A: que le va a castigar

S: ¿cómo lo sabes?

A: porque algunas veces Gloria me castiga

S: y ¿por qué le ha dicho/ "ya veo que has estudiado mucho”?

A: porque no ha estudiao

S: un niño está en una tienda de juguetes/ en frente de una estantería donde hay una muñeca/ un balón y un perro/ el chico señala al perro/ y dice que quiere comprarlo/ ¿qué quiere comprar el niño?

A: el perro 
S: unos niños han visitado a Papá Noel en el centro comercial/ al día siguiente le cuentan a su profesora/ que había muchos otros niños/ ¿dónde había muchos otros niños?

A: no lo sé

S: los niños regresan de una excursión en el parque de atracciones/ su padre los ve muy contentos/ y les dice/ "parece que os lo habéis pasado muy mal en el parque de atracciones ¿eh?”/ ¿qué quiere decir?

A: pues que l'han empujao unos niños y l' han pegao

S: un niño se cae de la bicicleta/ y la bicicleta se rompe/ ¿cómo se siente el niño?

A: mal

S: ¿¿por qué?

A: porque se:/ porque se hace una pupita

S: un chico se ha puesto la camiseta del revés por error/ y sus compañeros de clase se ríen de él/ ¿cómo se siente el niño?

A: mal

S: ¿por qué?

A: porque/ porque se están riendo de él

S: una madre entra en la habitación de su hija y ve/ los juguetes por el suelo:/ la ropa tirada encima de la cama:/ migas de galleta por encima de todo:/ y le dice en tono de enfado/ "pues sí que tienes limpia esta habitación”/¿qué quiere decir?

A: que la tiene en(su)ciada

S: y ¿cómo lo sabes?

A: porque yo siempre que tengo/ la ropa tira-/ la/ la habitación tirada/mi madre dice que lo recoja

S: va:le/ y ¿̇por qué le ha dicho que la tiene limpia?

A: porque/ le va a castigar

S: ${ }^{\circ}$ (bueno $)^{\circ} /$ una mujer ha ganado la lotería/ y ahora va conduciendo su coche nuevo/ ¿cómo se siente la mujer?

A: bien

S: ¿cómo lo sabes?

A: porque mamá siempre/ que va a unos sitios se siente bien

S: '(vale) \% Juan/ ha suspendido todo/ y su padre enfadado le dice/ "eres un genio"/ ¿qué quiere decir?

A: que los ge-//

S: ¿qué?

A: ///

$\mathrm{S}:$ ¿qué quiere decir?

A: es que no lo sé

S: va:le/ volvemos a los dibujos/ un niño tiene/ patatas/ zanahorias y albóndigas en el plato/ su madre le dice/ "tienes patatas/ y zanahorias en el plato/ ¿qué más?”/ ¿qué responde el niño?

A: que// que// que lo va a cortar

S: vale/ una niña y un niño están en el quiosco/ le piden a la dependienta/ una bolsa de gusanitos y un chupachús/ la dependienta les pregunta/ “¿algo más?”/ ¿qué les está preguntando la dependienta?”

A: que le den un chupachús y una bolsita

S: es hora de dormir/ y los niños deberían estar en la cama/ pero están jugando a las cartas/ el padre entra y les dice/ "meteos en la cama”/ ¿qué quiere decir el padre?

A: que se/ que se tienen que ir a dormir porque si no/ por la mañana no pueden ir al cole porque tienen sueño 
S: vale/ es hora de ir al colegio/ y los niños deberían estar de camino/ sin embargo están sentados en el salón viendo los dibujos/ la madre entra y les dice/ "meteos en la ca-/ e: “daos prisa”/ ¿qué quiere decir la madre?”

A: que tienen que ir al colegio

S: vale/ está lloviendo fuera/ la madre mira por la ventana/ y dice/ “iqué día tan bonito!”/ ¿qué quiere decir la madre?

A: que está lloviendo

S: ¿cómo lo sabes?

A: porque siempre que mamá dice/ “iqué bonito!”/ es/ yo digo que está lloviendo

S: entonces/ ¿no es bonito o sí?

A: no:

S: ¿por qué?

A: porque está lloviendo

S: va:le/ muchas gracias 


\section{C1-2. Entrevista realizada el 11/02/2011}

\section{NIÑA 5 AÑOS (19/04/2005)}

S: ¿cuántos años tienes?

A: cinco

S: y ¿cuándo es tu cumpleaños?

A: en abril

S: vale/ mira este es el dibujo de un pueblo/ un día de lluvia/ hay coches circulando por la carretera:/ y un niño cruzando por el paso de cebra/ ¿por qué está el niño sujetando un libro/ por encima de la cabeza?

A: porque está lloviendo para no moja:rse

S: ¿cómo sabes eso?

A: po-/ porque:/ porque:// mm/ está lloviendo

S: los niños se acaban de despertar/ ¿qué hora debe ser?

A: e:: las nueve de la mañana

S: y ¿qué van a hacer ahora los niños?

A: desayunar/ ponerse la ropa// lavarse la cara:/ cepillarse los die:ntes

S: y ¿cómo lo sabes?

A: porque se acaban de despertar de la cama/ y van a desayunar/ y::

S: va:le/ aquí están los niños jugando en el patio/ hay un niño delante del columpio llorando/ ¿qué crees que ha pasado?

A: que se ha caído del columpio/ y se ha hecho una heri:da

S: y ¿cómo lo sabes?

A: porque el columpio/ está/ está columpiando

$\mathrm{S}:$ ¿quién podría ayudar al niño?

A: la mamá

S: y ¿cómo lo sabes?

A: porque está: al lado del niño

S: y ¿cómo se siente el niño?

A: mal

S: ¿por qué?

A: porque se ha hecho una herida/ y le duele

S: va:le/ aquí la familia va a empezar a cenar/ la niña está cerca del horno/ y la madre le dice a la niña/ "ten cuidado"/ ¿qué quiere decir la madre?

A: que tenga cuidado/ de no quemarse

S: y ¿cómo lo sabes?

A: porque está el horno encendí:do

S: muy bie:n/ los niños están jugando en el jardín/ el niño tiene un balón en las manos/ ¿de qué color es?

A: azul

S: la madre llama a los niños/ "la cena está lista”/ ¿qué quiere decir la madre?

A: que tienen que cenar/ y luego irse a la ca:ma

S: y ¿cómo sabes eso?

A: porque: la m-/ porque// e: los niños// tienen que ir al colegio

S: mira aquí hay un niño subido en un árbol/ y hay lobo debajo/ ¿por qué está el chico subido en el árbol?

A: porque le da miedo el lobo

S: y ¿cómo sabes eso?

A: $\mathrm{mm} /$ porque:/ el lobo le puede morder 
S: ¿cómo se siente el niño?

A: mal

S: ¿por qué?

A: porque el lo-/ porque le da miedo el lobo de que lo pueda morder

$\mathrm{S}:$ ¿quién podría ayudar al niño?

A: el cazador

S: y ¿cómo lo sabes?

A: porque el cazador/ puede matar a un lobo

S: muy bien/ ahora te voy a contar una historia sin dibujos/ y te hago preguntas/ ¿vale?/ una mujer llega a casa después del trabajo/ su perro la está esperando en casa/ ha estado solo todo el día/ y necesita salir a hacer pipí/ la mujer saca al perro a la calle/ ¿quién ha estado solo todo el día?

A: el perro

S: y ¿por qué salen la mujer y el perro de casa?

A: porque el perro necesita hacer pipí

S: y ¿cómo sabes eso?

A: porque:/ ha estado solo

S: vale/ la mujer y el perro van caminando por un lado de la calle/ un gato sale de los arbustos corriendo muy rápido/ el perro tira de la correa/ y la mujer se cae al suelo/ el perro comienza a correr detrás del gato/ ¿quién sale del arbusto?

A: un gato

S: y ¿por qué se cae la mujer?

A: porque el perro tira de la correa

S: y ¿cómo sabes eso?

A: porque:/ a los perros les da miedo los gatos y a los gatos los perros

S: vale/ el perro persigue al gato/ y el gato se sube a un árbol/ el perro empieza a ladrar debajo del árbol/ el gato se sienta/ en la rama del árbol/ ¿quién se sienta en la rama del árbol?

A: el gato

S: vale/ y ¿por qué se sienta el gato en la rama del árbol?

A: porque::/ al/ al gato le da miedo el perro/ y al perro el gato

$\mathrm{S}:$ ¿cómo sabes eso?

A: porque: el gato se estaba subido en un á:rbol/ y el perro está ladrando/ debajo

S: una/ la mujer corre/ y llama al perro para que vuelva/ sin embargo el perro no obedece a la mujer/ dos niños están cerca del perro mirándolo/ la mujer grita/ “jayuda!”/ a los niños y/ “iven aquí!”/ al perro/ ¿qué quiere decir la mujer cuando le grita/ “iven aquí!”/ al perro?

A: que venga:// para: que/ para que le ayude a levanta:rse

S: y ¿qué quiere decir la mujer cuando grita/ “iayuda!”/ a los chicos?

A: porque:/ que ayude a los niños

$\mathrm{S}:$ ¿qué crees que va a pasar después en esta historia?

A: que::::// e:/// después// el gato:// e:// se va a ir

S: va:le/ mira/ volvemos con los dibujos/ una niña/ que lleva su vestido nuevo/ está corriendo por un camino lleno de charcos/ ¿quién va corriendo por el camino?

A: la niña

S: la madre le dice \{carraspeo\}/ “recuerda que llevas tu vestido nuevo"/ ¿qué quiere decir la madre?

A: // que: no se ensucie el vestido porque es nuevo

S: y ¿cómo sabes eso?

A: porque la madre se lo ha dicho

406 
S: va:le/ un grupo de niños está jugando en el salón/ la niña/ se acerca a los niños que están jugando/ y les pregunta/ “¿puedo jugar?”/ los niños le responden/ "es que ya somos el mismo número de jugadores en cada equipo”/ ¿consigue jugar la niña?

A: e: sí

S: vale/ un hombre está cortando el césped/ con una cortadora de césped/ ¿qué corta el hombre?

A: el césped

S: vale/ la mujer le dice al hombre/ "hay flores creciendo en el centro/ así que recuerda tener cuidado"/ ¿por qué le dice eso la mujer?

A: porque las/ las puede corta:r/ y son muy bonitas

S: ¿cómo lo sabes?

A: porque se lo ha dicho al señor ${ }^{\circ}\left(\right.$ la señora ${ }^{\circ}$

S: la madre acompaña a los hijos/ hasta el jardín de casa/ ¿adónde van los niños?

A: al cole

S: y ¿cómo lo sabes?

A: porque:: van con las mochilas

S: vale/ los niños tienen que co-/ que cruzar una carretera con muchos coches/ la madre les dice que recuerden mirar/ a los dos lados/ ¿qué quiere decir la madre?

A: para que: tengan cuidado con los coches/ porque les pueden pillar

S: va:le/ el padre y el hijo están sentados en la mesa/ pero la niña está mirando por la ventana/ el padre le dice a la niña/ "tu comida se va a enfriar"/ ¿por qué le dice eso el padre?

A: porque: la comida se le va a enfriar/ y luego no le va a gustar

S: ¿cómo lo sabes?

A: porque el padre se lo ha dicho a la niña

S: vale/ ahora te voy a hacer unas preguntas sin dibujos/ ¿vale?/ un profesor ha puesto un examen a sus alumnos/ y se pasea por las mesas mientras lo hacen/ se detiene en la mesa de un niño que no ha escrito ninguna respuesta/ y le dice muy serio/ "ya veo que has estudiado mucho"/ ¿qué quiere decir el profesor?

A: que no ha estudiado nada

S: y ¿cómo sabes eso?

A: porque se lo acaba de decir

S: que no ha estu-/ le ha dicho/ que "has estudiado mucho"/ ¿por qué le dice que ha estudiado mucho?

A: porque no ha estudiado nada

S: va:le/ un niño está en una tienda de juguetes/ en frente de una estantería donde hay una muñeca/ un balón y un perro/ el niño señala al perro/ y dice que quiere comprarlo/ ¿qué quiere comprar el niño?

A: un perro

S: vale/ los/ unos niños han visitado a Papá Noel \{entra una profesora\}

S: unos niños han visitado a Papá Noel en el centro comercial/ al día siguiente le cuentan a su profesora/ que había muchos otros niños/ ¿dónde había muchos otros niños?

A: en el centro comercial

S: vale/ los niños regresan de una excursión en el parque de atracciones/ su padre los ve muy contentos/ y les dice/ "parece que os lo habéis pasado muy mal en el parque de atracciones ¿eh?”/ ¿qué quiere decir?

A: que: se lo han pasado muy bien

S: ¿cómo lo sabes? 
A: porque: se lo ha dicho/ el padre

S: pero el padre les ha dicho que/ e:/ parecía que se lo habían pasado muy mal

A: muy bien

S: pero se lo han pasado bien entonces?

A: $\{$ la niña asiente con la cabeza $\}$

S: vale/ un niño se cae de la bicicleta/ y la bicicleta se rompe/ ¿cómo se siente el niño?

A: mal

S: ¿por qué piensas eso?

A: porque se ha hecho una herida

S: vale/ un chico se ha puesto la camiseta del revés por error/ y sus compañeros de clase se ríen de él/ ¿cómo se siente el niño?

A: mal

S: ¿por qué/ piensas eso?

A: porque se están riendo de él

S: va:le/ una madre entra en la habitación de su hija/ y ve los juguetes por el suelo:/ la ropa tirada encima de la cama:/ libros tirados en un rincón:/ migas de galleta por encima de todo:/ y le dice en tono de enfado/ "pues sí que tienes esta habitación limpia”/ ¿qué quiere decir?

A: que la tiene sucia

S: y ¿cómo lo sabes?

A: porque:/ la madre le ha dicho co-/ con/ co:n/ cara de enfadada

S: va:le/ una mujer ha ganado la lotería/ y ahora va conduciendo su coche nuevo/ ¿cómo se siente la mujer?

A: bien

S: ¿por qué piensas eso?

A: porque ha ganado la lotería

S: vale/ Juan ha suspendido todo/ y su padre enfadado le dice/ "eres un genio"/ ¿qué quiere decir?

A: que:/ que:/ que:::// que lo ha hecho/ que ha suspendido los exámenes

S: vale/ y ¿cómo lo sabes?

A: porque::/ cuan-/ porque cuando/ le/ el padre le dijo/ que era un genio/ era para decirle que ha suspendido los exámenes

S: vale/ mira te voy a enseñar dibujos/ un niño tiene patatas/ zanahorias y albóndigas en el plato/ la madre le dice/ “tienes patatas y zanahorias en el plato/ ¿qué más?” ¿qué responde el niño?

A: albóndigas

S: muy bien/ una niña y un niño están en el quiosco/ le piden a la dependienta/ una bolsa de gusanitos y dos chupachús/ la dependienta les pregunta/ “¿algo más?”/ ¿qué les está preguntando la dependienta?”

A: que si quieren algo más

S: es hora de irse a la cama/ pero los niños no están durmiendo/ sino que están jugando a las cartas/ el padre/ entra en la habitación y les dice/ "meteos en la cama”/ ¿qué quiere decir el padre?

A: que ya es hora de ir a dormir

S: vale/ es hora de ir al colegio/ y los niños deberían estar de camino/ sin embargo/ están sentados en el salón viendo los dibujos/ la madre entra y les dice/ "daos prisa”/ ¿qué quiere decir la madre?”

A: que:/ se vayan al colegio/ porque van a llegar tarde

S: va:le/ está lloviendo fuera/ la madre mira por la ventana/ y dice/ “iqué día tan bonito!”/ ¿qué quiere decir la madre? 
A: que: está lloviendo

S: entonces ¿es un día bonito o no?

A: no

S: y ¿por qué dice/ “iqué día tan bonito!”?

A: porque:::// porque/ está mojando las cosas

S: va:le/ muchas gracias 
B34. Entrevista realizada el 10/02/2011

\section{NIÑO 6 AÑOS (19/04/2004)}
S: ¿cuántos años tienes?
$\mathrm{O}$ : seis
S: ¿cuándo es tu cumpleaños?
O: diecinueve de abril

S: muy bien/ mira este es el dibujo de un pueblo/ un día de lluvia/ hay coches circulando por la carretera:/ y un niño cruzando por el paso de cebra/ ¿por qué está sujetando el niño un libro/ por encima de la cabeza?

O: porque está lloviendo

S: y ¿para qué lo sujeta?

O: pa que no le caiga la lluvia

S: y ¿cómo lo sabes?

$\mathrm{O}$ : porque si no se moja

S: los niños se acaban de despertar/ ¿qué hora debe ser?

O: // las ocho?

S: ¿qué van a hacer ahora los niños?

O: desayunar

S: y ¿cómo sabes eso?

O: porque yo siempre/ cuando me levanto desayuno

S: aquí los niños están en el patio/ y hay un niño delante del columpio llorando/ ¿qué crees que ha pasado?

O: que se ha caído

S: y ¿cómo sabes eso?

O: porque se ha hecho daño

S: ¿quién podría ayudar al niño?

O: la maestra?

S: ¿cómo lo sabes?

O: porque es más mayor y lo sabe

S: ¿cómo se siente el niño?

O: mal

S: ¿por qué crees eso?

O: porque se ha hecho daño

S: va:le/ aquí la familia va a empezar a cenar/ la niña está cerca del horno/ y la madre le dice a la niña/ "ten cuidado”/¿qué quiere decir la madre?

$\mathrm{O}$ : que no se queme

S. y ¿cómo lo sabes?

O: porque la niña se-/ mm/ casi no saben cocinar

S: va:le/ los niños están jugando en el jardín/ el niño tiene un balón en las manos/ ¿de qué color es?

O: azul

S: la madre llama a los niños/ "la cena está lista”/ ¿qué quiere decir la madre?

$\mathrm{O}$ : que tienen que ir a cenar

S: y ¿cómo sabes eso?

$\mathrm{O}$ : porque es la hora de cenar

S: va:le/ el niño está subido en un árbol/ y hay debajo un lobo/ ¿por qué está el niño subido en el árbol?

O: porque le da miedo el lobo 


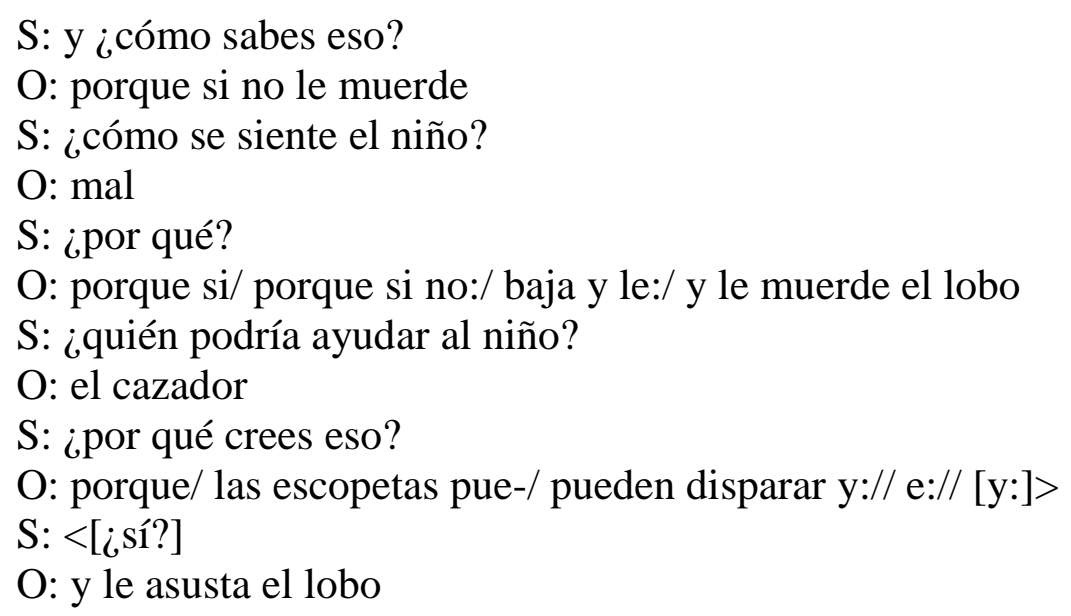

S: va:le/ ahora te voy a contar una historia sin dibujos/ y te voy a hacer preguntas/ una mujer llega a casa después del trabajo/ su perro la está esperando en casa/ ha estado todo el día solo/ y necesita salir a hacer pipí/ la mujer saca al perro a la calle/ ¿quién ha estado solo todo el día?

O: el perro

S: ¿por qué salen la mujer y el perro de casa?

O: // no sé

S: la mujer y el perro van caminando por un lado de la calle/ un gato/ sale de los arbustos corriendo muy rápido/ el perro tira de la correa/ y la mujer se cae al suelo/ el perro comienza a correr detrás del gato/ ¿quién sale del arbusto?

$\mathrm{O}$ : el gato

S: y ¿por qué se cae la mujer?

O: porque:/ se va el perro corriendo

S: y ¿cómo sabes eso?

O: porque el/ porque la mujer/ a/ a lo mejor es/ porque: el perro/ e/ tiraba con todas sus fuerzas

S: el perro persigue al gato/ y el gato se sube a un árbol/ el perro empieza a ladrar debajo del árbol/ el gato se sienta en la rama del árbol/ ¿quién se sienta en la rama del árbol?

O: el gato

S: y ¿por qué se sienta el gato en la rama del árbol?

O: porque está a gusto

S: la mujer corre/ y llama al perro para que vuelva/ sin embargo/ el perro no obedece a la mujer/ dos niños están cerca del perro mirándolo/ la mujer grita/ “jayuda!”/ a los chicos y/ “¡ven aquí!”/ al perro/ ¿qué quiere decir la mujer cuando grita/ “¡ven aquí!”/ al perro?

O: que vaya

S: ¿qué quiere decir la mujer cuando grita/ “¡ayuda!”/ a los chicos?

O: que le ayu-/ que le: ayuden a: llevárselo

$\mathrm{S}:$ ¿qué crees que va a pasar después?

$\mathrm{O}$ : que se van a casa?

S: va:le/ volvemos a los dibujos/ una niña/ que lleva su vestido nuevo/ está corriendo por un camino lleno de charcos/ ¿quién va corriendo por el camino?

O: la niña

S: la madre le grita/ “irecuerda que llevas tu vestido nuevo!”/ ¿qué quiere decir la madre?

$\mathrm{O}$ : que no se lo manche

S: ¿Cómo sabes eso?

O: porque: los charcos están sucios y: es nuevo/ y no se lo tiene que manchar 
S: los niños están jugando en el salón/ la niña se acerca a los niños que están jugando y les pregunta/ “¿puedo jugar?/ los niños le responden/ "es que ya somos el mismo número de jugadores en cada equipo”/ ¿consigue jugar la niña?

O: $\mathrm{mm} / / / \mathrm{no}$ ?

S: ¿por qué?

$\mathrm{O}$ : porque ya tienen el mismo:/ ju-/ número de jugadores?

S: va:le/ el hombre está cortando el césped/ con una cortadora de césped/ ¿qué corta el hombre?

O: la hierba

S: vale/ la mujer le dice al hombre/ "hay flores creciendo en el centro/ así que recuerda tener cuidado"/¿por qué le dice eso la mujer?

O: por-/ pa que no las corte

S: ¿cómo lo sabes?

O: porque le gustan a las mujeres

S: va:le/ la madre acompaña a los hijos hasta el jardín de casa/ ¿adónde van los niños?

O: al cole?

S: ¿cómo lo sabes?

O: porque tienen las mochilas?

S: vale/ los niños tienen que/ pasar/ por una carretera con muchos coches/ la madre les dice que recuerden mirar/ a los dos lados/ ¿qué quiere decir la madre?

O: // que miren a los dos lados/ porque si no le pilla un coche

S: vale/ el padre y el hijo están sentados en la mesa/ pero la hija está mirando por la ventana/ el padre le dice a la niña/ "tu comida se va a enfriar”/ ¿por qué le dice eso el/ padre?

O: porque:/ porque:// si no está frí-/ si está fría es que casi no tiene sabor y no le va a gustar

S: va:le/ ahora te voy a hacer unas preguntas sin dibujos/ un profesor/ ha hecho un e-/ ha puesto un examen a sus alumnos/ y se pasea por las mesas mientras lo hacen/ se detiene en la mesa de un niño que no ha escrito ninguna respuesta/ y le dice muy serio/ "ya veo que has estudiado mucho”/ ¿qué quiere decir el profesor?

O: que no ha estudiado nada

S: y ¿cómo sabes eso?

O: por-/ que:/ porque es muy vago

S: vale/ y ¿por qué le dice: que ha estudiado mucho?

O: de broma

S: un niño/ está en una tienda de juguetes/ en frente de una estantería donde hay una muñeca/ un balón y un perro/ el niño señala al perro/ y le dice que quiere comprarlo/ ¿qué quiere comprar el niño?

O: el perro

S: unos niños han visitado a Papá Noel en el centro comercial/ al día siguiente le cuentan a su profesora/ que había muchos otros niños/ ¿dónde había muchos otros niños?

O: en el cen-/ tro comercial

S: los niños regresan de una excursión en el parque de atracciones/ su padre los ve muy contentos/ y les dice/ "parece que os lo habéis pasado muy mal en el parque de atracciones ¿eh?”/ ¿qué quiere decir?

O: de broma que:/ que se lo han pasado muy bien

S: vale/ un niño se cae de la bicicleta/ y la bicicleta se rompe/ ¿cómo se siente el niño?

O: mal

S: ¿por qué piensas eso?

O: porque: a lo mejor la bi-/ la bicicleta le gustaba/ y:/// y se l’ha roto 
S: un chico se ha puesto una camiseta del revés por error/ y sus compañeros de clase se ríen de él/ ¿cómo se siente el niño?

O: mal

S: ¿por qué piensas eso?

$\mathrm{O}$ : porque no le gusta que se ría de él

S: una madre entra en la habitación de su hija/ y ve/ los juguetes por el suelo:/ la ropa tirada encima de la cama:/ e:/ migas de galleta por encima de todo:/ y le dice en tono de enfado/ "pues sí que tienes limpia esta habitación”/ ¿qué quiere decir?

O: que está muy sucia

S: y ¿cómo lo sabes?

O: porque es de broma

S: va:le/ una mujer ha ganado la lotería/ y ahora va conduciendo su nuevo coche/ ¿cómo se siente la mujer?

O: muy bien

S: y ¿por qué crees eso?

$\mathrm{O}$ : porque ha ganado un coche

S: Juan/ ha suspendido todo/ y su padre enfadado le dice/ "eres un genio"/ ¿qué quiere decir?

O: de broma/ que está todo mal

S: va:le/ volvemos a los dibujos/ un niño tiene/ patatas/ zanahorias/ y albóndigas en el plato/ la madre le dice/ “tienes patatas y zanahorias en el plato/ ¿qué más?”/ ¿qué responde el niño?

S: y albóndigas

S: una niña y un niño están en un quiosco/ le piden a la dependienta/ una bolsa de gusanitos y dos chupachús/ la dependienta les pregunta/ “¿algo más?”/ ¿qué les está preguntando la dependienta?”

O: que si quieren algo más

S: es hora de irse a dormir/ pero los niños no están en la cama/ sino que están jugando a las cartas/ el padre entra y les dice/ "meteos en la cama”/ ¿qué quiere decir el padre?

O: que se vayan a dormir

S: muy bien/ es hora de ir al colegio/ y los niños deberían estar de camino/ sin embargo están sentados en el salón viendo los dibujos/ la madre entra y les dice/ "daos prisa”/ ¿qué quiere decir la madre?

O: que vayan al colegio

S: vale// está lloviendo fuera/ la madre mira por la ventana y dice/ “iqué día tan bonito!”/ ¿qué quiere decir la madre?

O: de broma/ que: es un día muy mal

S: va:le/ muchas gracias 
C41. Entrevista realizada el 15/02/2011

NIÑA 7 AÑOS (01/04/2003)

S: ¿cuántos años tienes?

A: siete

S: ¿cuándo es tu cumpleaños?

A: el uno de abril

S: muy bien/ mira este es el dibujo de un pueblo:/ un día de lluvia/ hay coches circulando por la carretera:/ y un chico cruzando por el paso de cebra/ ¿por qué está el niño sujetando un libro/ por encima de la cabeza?

A: para que no: se moje de la lluvia

S: ¿cómo lo sabes?

A: pue:s// porque llueve \{la niña hace un gesto de seguir pensando\}

S: vale/ y ¿qué más?

A: y esos niños/tienen el paraguas/ y: ese/ y el otro/ tiene un gorro/ pues también para que no se mojen de la lluvia

S: vale/ aquí los niños se acaban de despertar/ ¿qué hora debe ser?

A: pue:s/ mm/ las nu-/ las ocho:/ de: la mañana

S: vale/ ¿qué van a hacer ahora los niños?

A: desayunar

S: ¿cómo lo sabes?

A: pues/ porque:// se están levantando

S: vale/ y entonces ¿después de levantarse?// ¿qué van a hacer?/ ¿desayunar?

A: sí

S: vale/ los niños están jugando en el patio/ y hay un niño delante del columpio llorando/ ¿qué crees que ha pasado?

A: pues que se ha caído del columpio

S: ¿cómo lo sabes?

A: pues porque está el columpio/ balanceando y está cerca del columpio

S: ¿quién podría ayudar al niño?

A: esa señora $\{$ la niña señala a la profesora $\}$

S: ¿cómo lo sabes?

A: pues porque está:/ al camino de él

S: va:le/ ¿cómo se siente el niño?

A: mal

S: ¿por qué?

A: porque: tiene/ un/ tiene/ una herida

S: va:le/ aquí la familia va a empezar a cenar/ la niña está cerca del horno/ y la madre le dice a la niña/ "ten cuidado"/¿qué quiere decir la madre?

A: pues que no se acerque mucho/ porque le puede quemar

S: ¿cómo lo sabes?

A: pue:s porque/ e:l horno está caliente/ y si lo tocas/ pues te puedes quemar

S: vale/ aquí están los niños jugando en el jardín/ el niño tiene un balón en las manos/ ¿de qué color es?

A: $\mathrm{mm} /$ azul

S: vale/ la madre/ llama a los niños/ "la cena está lista”/ ¿qué quiere decir la madre?

A: pues que:/ vayan a: cenar

S: ¿cómo lo sabes?

A: pues porque se lo dice la madre 
S: va:le/ aquí hay un niño/ subido en un/ árbol/ y hay un lobo debajo/ ¿por qué está el niño subido en la rama del árbol?

A: para que:/ no le coja el/ el lobo

S: ¿cómo sabes eso?

A: pues porque los lobos/ son carnívoros/ y se pueden comer a las personas

S: ¿Cómo se siente el niño?

A: mal

S: ¿̇por qué?

A: porque tiene miedo/ de que le coma

S: vale/ ¿quién podría ayudar al niño?

A: el cazador

S: ¿por qué?

A: porque tiene una escopeta/ y le mata al lobo/ y después/ le ayuda a bajarse/ y: ya está

S: va:le/ ahora te voy a contar una historia sin dibujos/ y te hago preguntas/ una mujer llega a casa después del trabajo/ su perro la está esperando en casa/ ha estado solo todo el día/ y necesita salir a hacer pis/ la mujer saca al perro a la calle/ ¿quién ha estado solo todo el día?

A: el perro

S: ¿por qué salen la mujer y el perro de casa?

A: porque el perro necesita hacer pis

S: y ¿cómo sabes eso?

A: pues/ porque:/ lo cuenta en la historia

S: vale/ la mujer y el perro van caminando por un lado de la calle/ un gato sale de/ de los arbustos corriendo muy rápido/ el perro tira de la correa/ y la mujer/ se cae al suelo/ el perro comienza a correr detrás del gato/ ¿quién sale del arbusto?

A: el gato

S: ¿por qué se cae la mujer?

A: porque:/ al correr el perro/ pues le tira

S: ¿cómo lo sabes?

A: pues porque los perros pueden tirar/ a las personas corriendo

S: el perro persigue al gato/ el gato se sube a un árbol/ y el perro empieza a ladrar debajo del árbol/ el gato se sienta en la rama del árbol/ ¿quién se sienta en la rama del árbol?

A: el gato

S: y ¿por qué el gato se sienta en la rama del árbol?

A: pue:s/ para: que no: le coja

S: ¿cómo lo sabes?

A: pues que:/ porque lo:s gatos tienen miedo a los perros

S: la mujer corre/ y llama al perro para que vuelva/ sin embargo el perro no obedece a la mujer/ dos niños están cerca del perro mirándolo/ la mujer grita/ “iayuda!”/ a los niños y/ “¡ven aquí!”/ al perro/ ¿qué quiere decir la mujer cuando le grita/ “¡ven aquí!”/ al perro?

A: pue:s/// para que venga a ella

S: ¿qué quiere decir la mujer cuando grita/ “¡ayuda!”/ a los niños?

A: pues para que le ayuden a: los niños

S: y ¿qué crees que va a pasar después en esta historia?

A: mm/ que a los niños le ayudan/ y: el perro va con la madre/ y: vienen uno:s/ unos/ unos para salvar a los niños/ y cogen al gato/ llaman a su dueño/ le: co-/ le llevan a su dueño el gato/ y: y se van/ y ya está

S: vale/ volvemos a los dibujos/ una niña que lleva su vestido nuevo/ está corriendo por un camino lleno de charcos/ ¿quién va corriendo por el camino?

A: la niña 
S: vale/ la madre le grita/ “irecuerda que llevas tu vestido nuevo!”/ ¿qué quiere decir la madre?

A: pues que no se caiga/ y no: se/ moje:/ y no se manche el vestido

S: ¿cómo lo sabes?

A: pues porque la niña/ está por charcos/y se puede caer/y se puede manchar

S: ${ }^{\circ}\left(\right.$ vale $^{\circ}$ / los niños están jugando en el salón/ la niña/ les pregunta a los niños que están jugando/ “¿puedo jugar?”/ los niños le responden/ "es que ya somos el mismo número de jugadores en cada equipo”/ ¿consigue jugar la niña?

A: $\mathrm{mm} / / / \mathrm{mm}$ no

S: ¿por qué?

A: porque si ya son/ l-/ ya son suficientes jugadores/ pues no puede jugar

S: vale/ el hombre está cortando el césped/ con una cortadora de césped/ ¿qué corta el hombre?

A: el césped

S: vale/ la mujer le dice al hombre/ "hay flores creciendo en el centro/ así que recuerda tener cuidado"/ ¿por qué le dice eso la mujer?

A: porque las puede cortar/ y: se pueden morir

S: ¿cómo lo sabes?

A: pues porque está cerca de ellas/ y: no se puede dar cuenta/ y las puede matar

S: vale/ la madre acompaña a los niños hasta el jardín de casa/ ¿adónde van los niños?

A: $\mathrm{mm} /$ al autobús

S: ¿cómo lo sabes?

A: porque tienen las mochilas

S: va:le/ los niños tienen que cruzar por una carretera con muchos coches/ la madre les dice/ que recuerden mirar/ a los dos lados/ ¿qué quiere decir la madre?

A: pues que:/ miren a los dos lados porque puede venir un coche

S: vale/ el padre y el hijo están sentados en la mesa/ pero la niña está mirando por la ventana/ el padre le dice a la niña/ "tu comida se va a enfriar"/ ¿por qué le dice eso el padre?

A: porque está mirando por la ventana/ y si tarda mucho/ pues se enfría su comida

S: ¿cómo lo sabes?

A: pues/ porque: las comidas se enfrían/ si tardas mucho

S: vale/ ahora te voy a hacer preguntas/ sin dibujos/ el profesor ha puesto un examen a sus alumnos/y se pasea por las mesas mientras lo hacen/ se detiene en la mesa de un niño que no ha escrito ninguna respuesta/ y le dice muy serio/ "ya veo que has estudiado mucho"/ ¿qué quiere decir el profesor?

A: pues/ que:/ que le dice que:/ no ha estudiao nada

S: ¿cómo lo sabes?

A: pue:s/ porque/ al verle que no ha escrito ninguna pregunta/ le/ le dice eso/ y:/ y: le dice que no ha hecho ninguna pregunta

S: vale/ pero ¿por qué le dice que ha estudiado mucho?

A: es/ es como un decir

S: ${ }^{\circ}(\text { vale })^{\circ} /$ un niño está en una tienda de juguetes/ en frente de una estantería/ donde hay una muñeca/ un balón y un perro/ el chico señala al perro/ y dice que quiere comprarlo/ ¿qué quiere comprar el niño?

A: e:/// un/ el perro

S: vale/ unos niños han visitado a Papá Noel en el centro comercial/ al día siguiente le cuentan a su profesora/ que había muchos otros niños/ ¿dónde había muchos otros niños?

A: en/ en el centro comercial 
S: los niños regresan de una excursión en el parque de atracciones/ su padre los ve muy contentos/ y les dice/ "parece que os lo habéis pasado muy mal en el parque de atracciones ¿eh?”/ ¿qué quiere decir?

A: pues que se/ que se lo han pasao muy bien

S: ¿cómo lo sabes?

A: porque es un decir

S: un niño se cae de la bicicleta/ y la bicicleta se rompe/ ¿cómo se siente el niño?

A: mal

S: ¿por qué?

A: porque/ se cae y se hace una herida

S: un chico se ha puesto la camiseta del revés por error/ y sus compañeros de clase se ríen de él/ ¿cómo se siente el niño?

A: mal

S: ¿por qué?

A: porque la tiene de al revés/ y: los niños/ se ríen

S: una madre entra en la habitación de su hija y ve/ los juguetes por el suelo/ la ropa tirada encima de la cama/ migas de galleta por encima de todo/ y le dice en tono de enfado/ "pues sí que tienes limpia esta habitación”/ ¿qué quiere decir?

A: pues que la tiene muy sucia

S: ¿por qué?

A: porque es un decir

S: vale/ una mujer ha ganado la lotería/ y ahora va conduciendo su coche nuevo/ ¿cómo se siente la mujer?

A: bien

S: ¿por qué?

A: porque/ ha:/ ganao un/ la lotería/ y:/ y:/ y va conduciendo

S: vale/ Juan/ ha suspendido todo/ y su padre enfadado le dice "eres un genio"/ ¿qué quiere decir?

A: pues que es un genio de no trabajar

S: vale/ volvemos a los dibujos/ un niño tiene patatas/ zanahorias y albóndigas en el plato/ su madre le dice/ "tienes patatas y zanahorias en el plato ¿qué más?”/ ¿qué responde el niño?

A: y también albóndigas

S: un niño y una niña están en el quiosco/ le piden a la dependienta/ una bolsa de gusanitos y dos chupachús/ la dependienta les pregunta/ “¿algo más?”/ ¿qué les está preguntando la dependienta?

A: que: si quieren algo más

S: es hora de irse a la cama/ pero los niños no están durmiendo/ sino que están jugando a las cartas/ el padre entra y les dice/ "meteos en la cama”/ ¿qué quiere decir el padre?

A: pues que: vayan a la cama

S: es hora de ir al colegio/ los niños deberían estar de camino/ y sin embargo están ju-/ sentados en el salón viendo los dibujos/ la madre entra y les dice/ “daos prisa”/ ¿qué quiere decir la madre?

A: pues/ que se den prisa/// para:// $\mathrm{mm} / /$ para:/// para irse

S: vale/ está lloviendo fuera/ la madre mira por la ventana y dice/ “iqué día tan bonito!”/ ¿qué quiere decir?

A: que es un día feo

S: ¿cómo lo sabes?

A: porque llueve/ y está oscuro/ el cielo

S: vale/ y ¿por qué ha dicho que era bonito? 
A: pues porque es un decir

S: va:le/ muchas gracias 
C47. Entrevista realizada el 15/02/2011

\section{NIÑO 8 AÑOS (19/02/2002)}

S: ¿cuántos años tienes?

O: ocho

S: ¿cuándo es tu cumpleaños?

O: e:/ dentro de cuatro días

S: y eso es el?

O: diecinueve de febrero

S: vale/ mira/ este es el dibujo/ de un pueblo un día de lluvia/ hay coches circulando por la carretera:/ y un niño cruzando por el paso de cebra/ ¿por qué está el niño sujetando un libro/ por encima de la cabeza?

O: por/ para que no le dé la lluvia en la cabeza

S: ¿cómo lo sabes?

O: porque está lloviendo y a nadie le gusta la lluvia

S: va:le// los niños se acaban de despertar/ ¿qué hora debe ser?

O: pues las ocho:/ las ocho y cuarto:

S: [¿qué]>

O: $<$ [de] ocho a nueve

$\mathrm{S}:$ ¿qué van a hacer ahora los niños?

O: desayunar

S: ¿cómo lo sabes?

O: porque siempre que nos levantamos desayunamos

S: vale/ mira aquí están los niños jugando en el patio/ y hay un niño delante del columpio llorando/ ¿qué crees que ha pasado?

O: que se ha caído del columpio

S: ¿cómo lo sabes?

O: porque hombre si está llorando al lao del columpio:

S: vale/ ¿quién podría ayudarle?

O: la: señora

S: ¿por qué crees eso?

O: porque: es mayor y: es adulta

S: vale/ ¿cómo se siente el niño?

O: mal

S: ¿por qué?

O: porque está llorando

S: vale/ aquí la familia va a empezar a cenar/ la niña está cerca del horno/ y la madre le dice a la niña/ "ten cuidado"/ ¿qué quiere decir la madre?

O: que no se queme

S: ¿cómo lo sabes?

O: porque:/ e: normalmente cuando estás cerca de un horno/ lo peor que puede pasar es que te quemes

S: aquí están los niños jugando en el jardín/ el niño tiene un balón en las manos/ ¿de qué color es?

O: azul

S: vale/ la madre/ llama a los niños/ "la cena está lista”/ ¿qué quiere decir la madre?

O: que vayan a cenar

S: ¿cómo lo sabes?

O: porque:/ no sé 
S: la madre les ha dicho/ "la cena está lista"

O: pues/ pa que: vayan a comer/ y:/ porque es lo más normal al decir/ mm/ eso

S: va:le/ mira aquí hay un niño subido en un árbol/ y debajo del árbol hay un lobo/ ¿por qué está el niño subido en la rama del árbol?

O: para que no le coma el (lobo)/ el lobo

S: ¿cómo lo sabes?

O: porque es lo más normal

S: vale/ ¿cómo se siente el niño?

O: e:/ muy sus-/ asustado

$\mathrm{S}:$ ¿por qué crees eso?

O: porque hombre/ que te vaya a comer un lobo no es/ de buen gusto

S: vale/ ¿quién podría ayudar al niño?

O: e:l cazador

S: ¿por qué crees eso?

O: porque mata a la:/ a los animales/ pa: comérselos

S: va:le

O: y pa hacer otras cosas

S: ahora te voy a contar una historia sin dibujos y te hago preguntas

O: [vale]>

S: < [una] mujer llega a casa después del trabajo/ su perro la está esperando en casa/ ha estado solo todo el día/ y necesita salir a hacer pis/ la mujer saca al perro a la calle/ ¿quién ha estado solo todo el día?

O: el perro

S: ¿por qué salen la mujer y el perro de casa?

$\mathrm{O}:\{$ el niño hace un gesto de no haber oído bien $\}$

S: ¿por qué salen la mujer y el perro de casa?

O: para que el perro haga su:s/ necesidades

S: ¿cómo lo sabes?

O: porque los perros hacen las (nece)sidades fuera/ no van al baño

S: vale/ la mujer y el perro van caminando por un lado de la calle/ un gato sale de los arbustos corriendo muy rápido/ el perro tira de la correa/ y la mujer se cae al suelo/ el perro comienza a correr detrás del gato/ ¿quién sale del arbusto?

O: el gato

S: ¿por qué se cae la mujer?

O: porque el perro empieza a tirar

S: y ¿cómo lo sabes?

$\mathrm{O}$ : porque me lo acabas de decir

S: ${ }^{\circ}(\text { vale })^{\circ}$ / el perro persigue al gato/ y el gato se sube a un árbol/ el perro empieza a ladrar debajo del árbol/ el gato se sienta en la rama del árbol/ ¿quién se sienta en la rama del árbol?

O: el gato

S: y ¿por qué se sienta el gato en la rama del árbol?

O: para que no le co:-/ para que no:/ lo muerda el perro o:/ lo mate

S: y ¿cómo lo sabes?

O: es lo más normal

S: ¿por qué?

O: porque:/ suele ser así/ suele ser/ el perro come al gato

S: vale/ la mujer corre/ y llama al perro para que venga/ sin embargo el perro no obedece a la mujer/ dos niños están cerca del perro mirándolo/ la mujer grita/ “¡ayuda!”/ a los niños 
y/ “iven aquí!”/ al perro/ ¿qué quiere decir la mujer cuando le grita/ “iven aquí!”/ al perro?

O: que vaya

S: ¿qué quiere decir la mujer cuando grita/ “iayuda!”/ a los niños

O: para que: le ayuden a levantarla

S: y ¿qué crees que va a pasar después en esta historia?

O: pues/ que cogerá al perro/ y se lo llevará a casa

S: va:le/ volvemos a los dibujos/ una niña/ que lleva su vestido nuevo/ va corriendo por un camino lleno de charcos/ ¿quién va corriendo por el camino?

O: la niña

S: vale/ la madre le grita/ “irecuerda que llevas tu vestido nuevo!”/ ¿qué quiere decir la madre?

O: que no se lo manche

S: ¿cómo lo sabes?

O: porque:/ lleva un vestido nuevo lo:/ e:/ lo mejor es no mancharlo/ de barro

S: va:le/ aquí los niños están jugando en el salón/ la niña se acerca a los niños que están jugando/ y les pregunta /“¿puedo jugar?”/ los niños le responden/ "es que ya somos el mismo número de jugadores en cada equipo"/ ¿consigue jugar la niña?

O: $\mathrm{mm} /$ no creo

S: ¿por qué?

O: porque:/ los niños/ pues querrán jugar solos/ entre los dos/ dos y dos

S: vale

O: yo como siempre me pasa lo mismo:

S: vaya/ el hombre está cortando el césped/ con una cortadora de césped/ ¿qué corta el hombre?

O: el césped

S: vale/ la mujer le dice al hombre/ "hay flores creciendo en el centro/ así que recuerda tener cuidado"/ ¿por qué le dice eso la mujer?

$\mathrm{O}$ : porque son bonitas y no quiere que se las estropee

S: ¿cómo lo sabes?

O: porque las flores son bonitas/y son de adornos/ y cuesta mucho:/ que broten

S: vale/ la madre acompaña a sus hijos hasta el jardín de casa/ ¿adónde van los niños?

O: a casa/ ¡ah! al jardín

S. vale

O: a ver repite

S: la madre/ acompaña a los niños hasta el jardín de casa

O: [al jardín]>

$\mathrm{S}:<[$ ¿ adónde] van los niños?

O: al jardín

S: vale/ los niños tienen que cruzar/ una carretera:/ con muchos coches/ la madre les dice que recuerden mirar/ a los dos lados/ ¿qué quiere decir la madre?

O: que: miren a los dos lados/ por si algún coche viene muy rápido y:/ los pilla

S: ${ }^{\circ}(\text { vale })^{\circ} /$ el padre y el hijo están sentados en la mesa/ pero la niña está mirando por la ventana/ el padre le dice a la niña/ "tu comida se va a enfriar"/ipor qué le dice eso el padre?

O: para que luego la comi-/ pa que la comida sepa mejor y:// y jay!/ y la comida sepa mejor $\mathrm{y}: /$ que:/ se:/ mm/ no la tengan que volver a calentar

$\mathrm{S}$ : va:le/ vale ahora te voy a hacer unas preguntas/ sin dibujos

O: vale 
S: un profesor/ ha puesto un examen a sus alumnos/ y se pasea por las mesas mientras lo hacen/ se detiene en la mesa de un niño que no ha escrito ninguna respuesta/y le dice muy serio/ "ya veo que has estudiado mucho"/ ¿qué quiere decir el profesor?

O: que: no ha escrito nada/ que no está trabajando nada

S: ¿cómo lo sabes?

O: e:/ porque pasó en mi clase

S: ¿qué pasó?

O: que un/ un niño estuvimos una hora/ y solo escribió el nombre

S: vale/ [y entonces?] $>$

$\mathrm{O}:<$ [bueno ni] el nombre/ escribió dos palabras

S: ¿por qué le dice/ "ya veo que has estudiado mucho"?

O: porque no ha trabajado nada/ en todo/ ese tiempo

S: entonces ¿ha estudiado mucho?

O: no

S: vale/ un niño está en una tienda de juguetes/ en frente de una estantería donde hay una muñeca/ un balón y un perro/ el chico señala al perro/ y dice que quiere comprarlo/ ¿qué quiere comprar el niño?

O: el perro

S: vale/ unos niños han visitado a Papá Noel en el centro comercial/ al día siguiente/ le cuentan a su profesora/ que había muchos otros niños/ ¿dónde había muchos otros niños?

O: en el centro comercial

S: los niños regresan de una excursión en el parque de atracciones/ su padre los ve muy contentos/y les dice/ "parece que os lo habéis pasado muy mal en el parque de atracciones ¿eh?”/ ¿qué quiere decir?

O: que se lo han pasado muy bien

S: ¿cómo lo sabes?

O: porque es una:/ frase hecha

S: un niño se cae de la bicicleta/ y la bicicleta se rompe/ ¿cómo se siente el niño?

O: mal

S: ¿por qué?

O: porque está/ porque se habrá hecho daño

S: un chico se ha puesto la camiseta del revés por error/ y sus compañeros de clase se ríen de él/ ¿cómo se siente el niño?

O: mal

S: ¿por qué?

O: porque: no es de buen gusto que alguien se ría de ti

S: una madre entra en la habitación de su hija/ y ve/ los juguetes por el suelo:/ la ropa tirada encima de la cama:/ migas de galleta por encima de todo:/ y le dice en tono de enfado/ "pues sí que tienes limpia esta habitación”/ ¿qué quiere decir?

$\mathrm{O}$ : pues que la tiene muy muy sucia

S: ¿cómo lo sabes?

O: una frase hecha

S: una mujer ha ganado la lotería/ y ahora va conduciendo su coche nuevo/ ¿cómo se siente la mujer?

O: perfecta/ como mejor que nunca

S: \{la entrevistadora se ríe\} ¿por qué?

O: porque la lotería es/ es/ es de alegría/ es/ te da mucho dinero

S: vale/ Juan ha suspendido todo/ y su padre enfadado le dice/ "eres un genio"/ ¿qué quiere decir?

O: que:/ no sabe nada/ nada de nada 
S: ¿por qué?/ ¿cómo lo sabes?

$\mathrm{O}$ : porque si suspende ya todo pues/ [¿qué]>

$\mathrm{S}:<[$ ¿por qué $]$

O: va a saber?

S: ¿por qué le ha dicho que es un genio?

$\mathrm{O}$ : e: una frase hecha que se dice muchas veces

S: vale/ mira/ volvemos a los dibujos

O: vale

S: un niño tiene patatas/ zanahorias y albóndigas en el plato/ su madre le dice/ "tienes patatas y zanahorias en el plato/ ¿qué más?”/ ¿qué responde el niño?

O: almóndigas

S: un niño y una niña están en el quiosco/ le piden a la dependienta/ una bolsa de gusanitos y dos chupachús/ la dependienta les pregunta/ “¿algo más?”/ ¿qué les está preguntando la dependienta?”

O: que si quieren/ coger algo más/ que si quieren pedir algo más

S: es hora de ir a dormir/ pero los niños no están en la cama/ sino que están jugando a las cartas/ el padre entra y les dice/ "meteos en la cama”/ ¿qué quiere decir el padre?

O: que se duerman/ en la cama

S: ${ }^{\circ}(\text { vale })^{\circ} /{ }^{\circ}(\text { sí })^{\circ} /$ es hora de ir al colegio/ y los niños deberían estar de camino/ sin embargo están sentados en el salón viendo los dibujos/ la madre entra y les dice/ "daos prisa”/ ¿qué quiere decir la madre?”

O: que vayan rápido al colegio/ que: van a llegar tarde

S: está lloviendo fuera/ la madre mira por la ventana y dice/ “iqué día tan bonito!”/ ¿qué quiere decir la madre?

O: que: es un/ que: no: es un día que le guste mucho

S: ¿por qué?

O: porque está lloviendo

S: y ¿por qué ha dicho que era bonito?

O: $\mathrm{mm} /$ una frase hecha

S: va:le/ muchas gracias 
CII17. Entrevista realizada el 17/02/2011

\section{NIÑA 9 AÑOS (25/03/2001)}

$\mathrm{S}:$ ¿cuántos años tienes?

A: $\mathrm{mm} /$ pues nueve pero::

S: ¿cuándo es tu cumpleaños?

A: el veinticinco de marzo

S: vale/ mira este es el dibujo de un pueblo un día de lluvia/ hay coches circulando por la carretera:/ y un niño cruzando por el paso de cebra/ ¿por qué está sujetando el ni-/ño un libro/ por encima de la cabeza?

A: // pues para:/ que:/ para no mojarse?

S: ¿cómo lo sabes?

A: pues porque está lloviendo/ y: están cayendo las gotas en el libro

S: vale/ los niños se acaban de despertar/ ¿qué hora debe ser?

A: // pue:s/ la:s ocho y media

S: ¿qué van a hacer ahora los niños?

A: desayunar/ bueno/ es que depende/ yo me visto a-/ primero y luego desayuno

S: ¿cómo lo sabes?

A: // pue:s no sé// ¡ah! porque: la ventana:/ se ve: que: todavía no ha amanecido

S: va:[le] $>$

A: $<$ [que] está oscuro

S: tú has dicho que ahora van a desayunar/ por ejemplo

A: sí

S: ¿cómo sabes que ahora van a desayunar?

A: porque se están levantando

S: vale

A: de pie

S: los niños están jugando en el patio/ hay un niño delante del columpio/ llorando/ ¿qué crees que ha pasado?

A: que: se ha caído

S: ¿cómo lo sabes?

A: porque: el columpio todavía se está moviendo/ y: el niño está en el suelo

S: vale/ ¿quién podría ayudar al niño?

A: la persona adulta que está ahí \{la niña señala a la profesora

S: y ¿cómo sabes eso?

A: porque se dirige hacia ese lado

S: ¿cómo se siente el niño?

A: mal/ porque se ha caído y está triste y:/ y:/ le duele/ la herida

S: la ma-/ la familia va a empezar a cenar/ la niña está cerca del horno/ y la madre le dice a la niña/ "ten cuidado"/ ¿qué quiere decir la madre?

A: que:/ tenga cuidado para que no se queme y:

S: ¿cómo lo sabes?

A: porque está en el horno la cazuela

S: y ¿qué pasa?// ¿qué puede pasar?

A: pues que:/ se queme la niña/ y suelte y se caiga todo

S: los niños están jugando en el jardín/ el niño tiene un balón en las manos/ ¿de qué color?

A: azul

S: vale/ la madre llama a los niños/ "la cena está lista”/ ¿qué quiere decir la madre? 
A: que vayan hacia allá/ aunque esto es un poco raro porque/ ¿cómo va a estar la cena si el cielo es azul/ y no ha oscurecido?

$\mathrm{S}$ : vamos a imaginar que es en Inglaterra/ que cenan a las siete

A: vale $\{$ la niña se ríe $\}$

S: y es un día de verano/ entonces la madre/ les dice/ "la cena está lista”

A: pues ten-/ e:/ que tienen que ir hacia allá/ para ce[nar]>

S: $<$ [y ] ¿cómo lo sabes?

A: porque ya:/ ya no se están pasando el balón/ y ya está diciéndole la niña a este \{la niña señala al niño\} que: le/ que ya recojan

S: vale/ aquí hay un lobo debajo del árbol/ y hay un chico subido en el árbol/ ¿por qué está el chico subido en el árbol?

A: porque tiene miedo de que le coma

S: ¿cómo lo sabes?

A: porque el/ e:l lobo tiene las fauces abiertas/ y:/ y/ y claro

S: ¿cómo se siente el niño?

A: mi-/ e que tiene/ tiene miedo

S: ¿cómo lo sabes?

A: porque tiene la cara así \{la niña hace una mueca imitando la cara del niño\}

S: $\{$ risa $\}$ vale/ ¿quién podría ayudar al niño?

A: ese $\{$ la niña señala al cazador $\}$

S: ¿quién?

A: el cazador

S: ¿por qué?

A: porque puede matar al lobo

S: vale/ ahora te voy a contar una historia/ y te hago preguntas/ sin dibujos/ una mujer llega a casa después del trabajo/ su perro la está esperando en casa/ ha estado solo todo el día/ y necesita salir a hacer pis/ la mujer saca al perro a la calle/ ¿quién ha estado solo todo el día?

A: el perro

S: ¿por qué salen la mujer y el perro de casa?

A: porque: el perro ha estado solo todo el día y necesita salir

S: ¿cómo lo sabes?

A: porque/ tiene necesidad de ir a hacer pis y caca o lo que quiera

S: vale

A: [y si:]>

S: $<$ [la mujer] y el perro van caminando por un lado de la calle/ un gato sale de los arbustos corriendo muy rápido/ el perro tira de la correa/ y la mujer se cae al suelo/ el perro comienza a correr detrás del gato/ ¿quién sale del arbusto?

A: el gato

S: y ¿por qué se cae la mujer?

A: porque le ha tirado muy fuerte el perro de la correa

S: ¿cómo lo sabes?

A: porque lo llevaba agarrado

S: y ¿entonces?

A: pues/ si ha salido corriendo/ y ella lo tenía agarrado y no podía sujetarlo/ pues se ha caído

S: el perro persigue al gato/ y el gato se sube al árbol y el perro empieza a ladrar debajo del árbol/ el gato se sienta en la rama del árbol/ ¿quién se sienta en la rama del árbol?

A: el gato

S: y ¿por qué se sienta el gato en la rama del árbol? 
A: porque: le está persiguiendo e:I perro

S: ¿cómo lo sabes?

A: porque: los perros $\{$ risa $\}$ no/ no están bien con los gatos

S: la mujer corre/ y llama al perro para que vuelva/ sin embargo el perro no obedece a la mujer/ dos niños están cerca del perro mirándolo/ la mujer grita/ “iayuda!”/ a los niños y/ “¡ven aquí!”/ al perro/ ¿qué quiere decir la mujer cuando grita/ “¡ven aquí!”/ al perro?

A: que vaya hacia ella para que ya no moleste más a la gente/ ni al gato

S: ¿qué quiere decir la mujer cuando grita/ “iayuda!”/ a los niños?

A: que vengan a ayudarla para que:/ cojan el perro

$\mathrm{S}$ : ¿qué crees que va a pasar después en esta historia?

A: pues/ que:/ el perro ya consigue venir aquí/ y los a-/ los niños ayudan a la mujer y ya

S: vale/ volvemos a los dibujos/ una niña que lleva su vestido nuevo/ está corriendo por un camino lleno de charcos/ ¿quién va corriendo por el camino?

A: la niña

S: vale/ la madre le grita/ "recuerda que llevas tu vestido nuevo"/ ¿qué quiere decir la madre?

A: que no se lo manche con los charcos

S: ¿cómo lo sabes?

A: porque:/ porque:/ se le ve que está salpicando todo y:/ están ahí las gotas

S: vale/ los niños están jugando en el salón/ la niña se acerca a los niños que están jugando y les pregunta/ “¿puedo jugar?”/ los niños le responden/ “es que ya somos el mismo número de jugadores en cada equipo”/ ¿consigue jugar la niña?

A: // pues sí/ porque cuando acabaran la partida se turnarían

S: va:le/ un hombre está cortando el césped/ con una cortadora de césped/ ¿qué corta el hombre?

A: el césped

S: la mujer le dice al hombre/ "hay flores creciendo en el centro/ así que recuerda tener cuidado”/ ¿por qué le dice eso la mujer?

A: para que no se estropeen las plantas

S: ¿cómo lo sabes?

A: porque: si pasas por encima una cosa de las flores/ se: se salen los pétalos y todo

S: la madre acompaña a los hijos \{entra una profesora $\}$

P: hola

S: hasta el jardín de casa/ ¿adónde van los niños?

A: al colegio

S: ¿cómo lo sabes?

A: porque llevan mochilas

S: va:le/ los niños tienen que cruzar una carretera con muchos coches/ \{la profesora se va \} la madre les dice que recuerden mirar/ a los dos lados/ ¿qué quiere decir la madre?

A: que miren para que no se le atro-/ no se le/ no/ miren para:/ a ver/ \{la niña toma aire por si viene un coche/ y les/ y les atropella

S: vale/ el padre y el hijo están sentados en la mesa/ pero la niña está mirando por la ventana/ el padre le dice a la niña/ "tu comida se va a enfriar”/ ¿por qué le dice eso el padre?

A: porque como está para allá/ e: va a tardar mucho:/ y se enfría/ mientras

S: ¿cómo lo sabes?

A: // pues e: porque en ese rato/ se puede enfriar

S: va:le/ ahora te voy a hacer unas preguntas sin dibujos/ un profesor/ ha puesto un examen a sus alumnos/ y se pasea por las mesas mientras lo hacen/ se detiene en la mesa 
de un niño que no ha escrito ninguna respuesta/ y le dice muy serio/ "ya veo que has estudiado mucho"/ ¿qué quiere decir el profesor?

A: pues que como los tenía en blanco/ que no ha estudiado y: no se las sabe

S: ¿cómo lo sabes?

A: porque si lo-/ e si lo ha puesto en blanco/ será porque no se lo [sabía]>

$\mathrm{S}:<$ [pero] ¿por qué le ha dicho/ "ya veo que has estudiado mucho"?

A: porque es una ironía:/ y: quería decir lo contrario

S: vale/ un niño está en una tienda de juguetes/ en frente de una estantería donde hay una muñeca/ un balón y un perro/ el chico señala al perro y dice que quiere comprarlo/ ¿qué quiere comprar el niño?

A: el perro

S: unos niños han visitado a Papá Noel en el centro comercial/ al día siguiente le cuentan a su profesora/ que había muchos otros niños/ ¿dónde había muchos otros niños?

A: en el centro comercial

S: los niños regresan de una excursión en el parque de atracciones/ su padre los ve muy contentos/ y les dice/ "parece que os lo habéis pasado muy mal en el parque de atracciones ¿eh?”/ ¿qué quiere decir?

A: es u-/ es una ironía/ y/ ha-/ han dicho que se/ ha dicho/ que si se lo han pasado muy bien

S: un niño se cae de la bicicleta/ y la bicicleta se rompe/ ¿cómo se siente el niño?

A: // mal y ade-/ y ade[más]>

$\mathrm{S}:<\left[^{\circ}\right.$ (¿por $]$ qué? ${ }^{\circ}$

A: a lo mejor/ está triste y: preocupado por la/ la bronca que le van a echar sus padres/ ${ }^{\circ}$ (puede ser) ${ }^{\circ}$

S: un niño se ha puesto la camiseta del/ del revés por error/ y sus compañeros de clase se ríen de él/ ¿cómo se siente el niño?

A: // pue:s/ triste y a-/ y:/ y: mal porque/ se ríen de él ${ }^{\circ}$ (sus compañeros) ${ }^{\circ}$

S: una madre entra en la habitación de su hija y ve/ los juguetes por el suelo:/ la ropa tirada encima de la cama:/ migas de galleta por encima de todo:/ y le dice en tono de enfado/ "pues sí que tienes limpia esta habitación”/¿qué quiere decir?

A: que la tiene muy sucia

S: ¿cómo lo sabes?

A: porque: es una ironía/ y lo ha dicho con tono de enfado

S: una mujer ha ganado la lotería/ y ahora va conduciendo su coche nuevo/ ¿cómo se siente la mujer?

A: pue:s bien

S: ¿por qué crees eso?

A: porque: ha i-/ va con su coche nuevo

S: Juan/ ha suspendido todo/ y su padre enfadado le dice/ "eres un genio"// ¿qué quiere decir?

A: que lo ha hecho fatal

S: ¿cómo lo sabes?

A: porque es una ironía

S: un niño tiene patatas/ zanahorias y albóndigas en el plato/ su madre le dice/ "tienes patatas y zanahorias en el plato ¿qué más?”/ ¿qué responde el niño?

A: y:: albóndigas

S: una niña y un niño están en el quiosco/ le piden a la dependienta/ una bolsa de gusanitos y dos chupachús/ la dependienta les/ les pregunta/ “¿algo más?”/ ¿qué les está preguntando la dependienta?

A: que si quieren algo más/ de comer 
S: es hora de irse a la cama/ pero los niños no están dormidos/ sino que están jugando a las cartas/ el padre entra y les dice/ "meteos en la cama”/ ¿qué quiere decir el padre?

A: pue:s/ que se metan/ que vayan a/ a dormir a la cama

S: es hora de ir al colegio/ y los niños deberían estar de camino/ sin embargo están sentados en el salón viendo los dibujos/ la madre entra y les dice/ "daos prisa”/ ¿qué quiere decir la madre?

A: que se va-/ yan e al colegio

S: está lloviendo fuera/ la madre mira por la ventana y dice/ “iqué día tan bonito!”/ ¿qué quiere decir?

A: es una ironía/ y quiere decir que está fatal el día

S: ¿por qué?

A: porque está lloviendo

$\mathrm{S}$ : vale/ muchas gracias

*Las grabaciones originales de estas transcripciones se encuentran en CD adjunto 